\title{
Eliminación de pesticidas organofosforados mediante fotoelectrocatálisis con fotoánodos de $\mathrm{WO}_{3}$.
}

Instituto Universitario de Seguridad Industrial, Radiofísica y Medioambiental Departamento de Ingeniería Química y Nuclear

\section{Tesis doctoral}

Gemma Roselló Márquez

Dirigida por: José García Antón y

Ramón M. Fernández Domene

Valencia, 2021

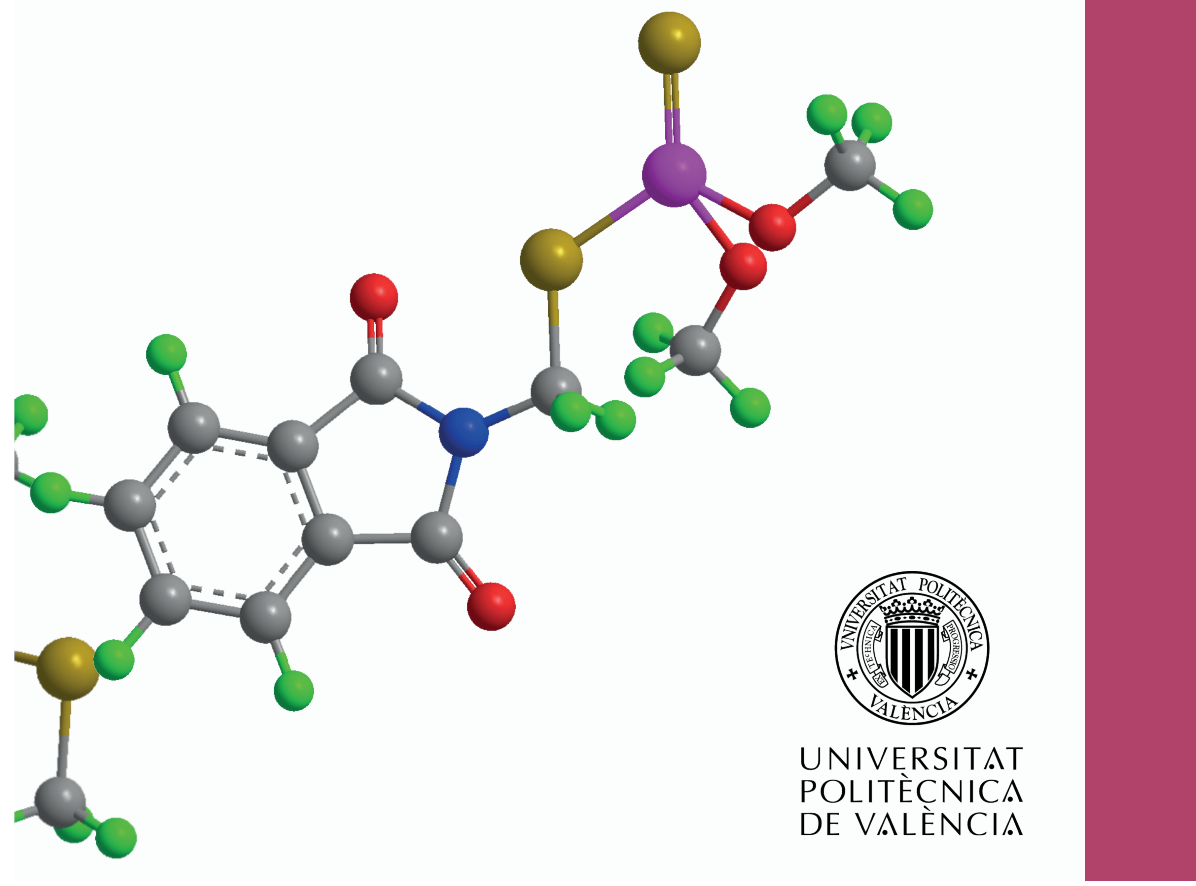



Universitat Politècnica de València

Instituto Universitario de Seguridad Industrial, Radiofísica y Medioambiental

Departamento de Ingeniería Química y Nuclear

Eliminación de pesticidas organofosforados mediante fotoelectrocatálisis con fotoánodos de $\mathrm{WO}_{3}$.

Programa de Doctorado en Ingeniería y Producción Industrial

\section{Tesis Doctoral}

\section{Gemma Roselló Márquez}

Dirigida por:

Dr. José García Antón

Dr. Ramón M. Fernández Domene 



\section{AGRADECIMIENTOS}

En primer lugar, quiero agradecer a mis directores José García Antón y Ramón Fernández Domene, por haberme dado la oportunidad de realizar esta Tesis Doctoral con ellos, y por la dedicación y apoyo que me han brindado en cada momento. Sobre todo, por guiarme en cada paso y transmitirme los valores de rigor, humildad y sencillez en el trabajo.

Agradezco a la Generalitat Valenciana y al Fondo Social Europeo por la ayuda predoctoral recibida para la realización de la presente Tesis Doctoral (ACIF 1592018) así como para la realización de una estancia predoctoral en la Universidad de Lisboa. También quiero agradecer al Ministerio de Economía, Industria y Competitividad, por la concesión de los proyectos CTQ2016-79203-R (2016) y PID2019-105844RB-I00 (2019) en los cuales he podido participar durante la Tesis Doctoral.

I would like to thank to the Department of Chemical Engineering of the Instituto Superior Tecnico (University of Lisbon). Particularly I would like to express my gratitude to Professor Joao Salvador Fernandes for all his support and consideration during my research stay.

También quisiera agradecer al grupo de Ingeniería Electroquímica y Corrosión (IEC) y a mis compañeros de barracón los buenos momentos que he pasado con ellos! Julia, Jordi, César, gracias por hacerme sentir como una más de vosotros nada más llegar a esta aventura. Dioni, gracias por esa "pequeña" orientación en el momento oportuno que aporta luz en los momentos difíciles. Ramón, otra vez tú, gracias por no ser solo mi director de tesis, sino por haber sido a lo largo de este viaje, el apoyo incondicional tanto a nivel profesional como personal y con el que espero contar durante mucho tiempo más. Patri, Bianca, Ramiro, a pesar de acabar sin vosotros por aquí, no puedo olvidarme de cada uno de los momentos a vuestro lado. Y bueno, Pedro y Mireia, qué deciros a vosotros, solo puedo deciros que mil gracias. Gracias por cada una de las risas que hemos compartido, por estar ahí en los momentos de bajón y animarme en la recta final, que es cuando 
más lo necesitaba, y sobre todo, por haber formado esta pequeña "familia" que espero que dure siempre.

Ha llegado el momento de agradecer a dos personitas que han marcado mi vida desde el 2012. Lorena y Álex. El grado cruzó nuestros caminos y a partir de ahí os habéis convertido en dos personas imprescindibles en mi vida. Gracias por esas visitas al barracón que alegraban la tarde y esas charlas que hacían ver todo de otro color.

Y como no, a mi gente de Gandía! Anabel, Kaira, Pisi, Sara, Sabina, Marc. Gracias por hacer que los fines de semana fueran el momento perfecto para recargar pilas y por comprender esos "hoy no puedo, voy muy agobiada" que tuvisteis que aguantar más de una vez. Prometo recompensar cada uno de ellos.

Y por supuesto, a Jonatan. Gracias por ser mi compañero de vida, por apoyarme siempre en cada paso que doy, por aportarme la calma que en algunos momentos he perdido, y por hacerme ver siempre algo positivo en toda esta aventura. Mil gràcies per tot!

Por último, solo me queda agradecer a toda mi familia, pero en especial a vosotros, papá y mamá, por vuestro amor y apoyo incondicional en todas las decisiones que he tomado a lo largo de mi vida. Gracias por animarme a seguir en cada paso que he dado, con el cariño que os caracteriza y por todos vuestros consejos que han conseguido que hoy sea la persona que soy. Este trabajo es gracias a vosotros. 
D. JOSÉ GARCÍA ANTÓN Y D. RAMÓN M. FERNÁNDEZ DOMENE, Catedrático de Universidad en el Departamento de Ingeniería Química y Nuclear de la Universitat Politècnica de València y Profesor Ayudante Doctor en el Departamento de Ingeniería Química de la Universitat de València.

\section{CERTIFICAN:}

Que la Ingeniera Química Dña. GEMMA ROSELLÓ MÁRQUEZ ha realizado en los laboratorios del Departamento de Ingeniería Química y Nuclear de la Universitat Politècnica de València y bajo nuestra dirección el siguiente trabajo para optar al Grado de Doctor en Ingeniería y Producción Industrial: "Eliminación de pesticidas organofosforados mediante fotoelectrocatálisis con fotoánodos de $\mathrm{WO}_{3}{ }^{\prime \prime}$.

Y para que así conste firman la presente en Valencia a 11 de Marzo de 2021.

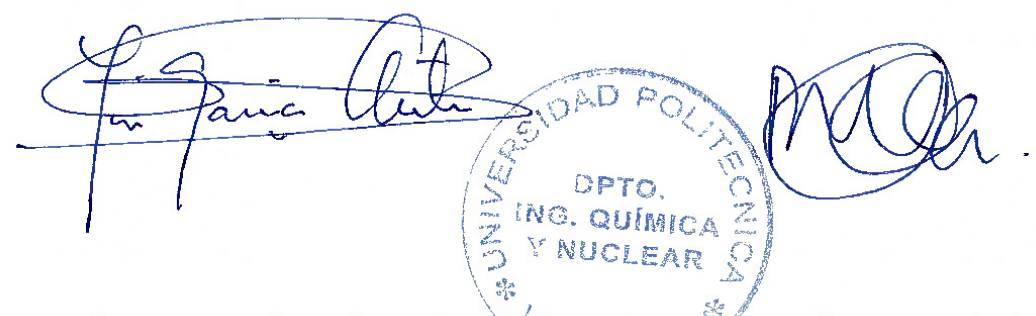

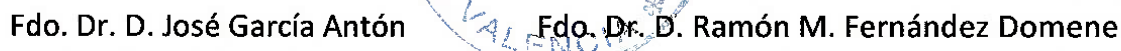





\section{RESUMEN}

La presente Tesis Doctoral tiene dos objetivos claramente diferenciados, siendo el primero de ellos la realización de un estudio de optimización de la síntesis de nanoestructuras de óxido de wolframio $\left(\mathrm{WO}_{3}\right)$ mediante el uso de un diseño de experimentos, mientras que el segundo de ellos es el uso de estas nanoestructuras en la degradación fotoelectrocatalítica de 4 pesticidas organofosforados de diferentes subfamilias (diazinon, fosmet, clorfenvinfos $y$ fenamifos). El uso del óxido de wolframio como fotocatalizador en el proceso fotoelectrocatalítico (FEC) despierta un gran interés, ya que se trata de un semiconductor con gran fotoestabilidad en electrolitos acuosos ácidos, excelente conductividad eléctrica, tiene la capacidad de absorber la parte azul del espectro visible además de la luz ultravioleta, y el borde superior de la banda de valencia es mayor que el potencial de oxidación de $\mathrm{H}_{2} \mathrm{O} / \mathrm{O}_{2}$. Todo ello hace que el $\mathrm{WO}_{3}$ sea capaz de fotooxidar eficazmente una amplia gama de compuestos orgánicos. Las nanoestructuras estudiadas en la Tesis Doctoral se sintetizaron mediante anodizado electroquímico, ya que se trata de una técnica sencilla que permite un control de sus parámetros de manera fácil y efectiva, permitiendo obtener las nanoestructuras directamente sobre el propio sustrato metálico. Además, la necesidad de controlar y eliminar los contaminantes emergentes en el medio ambiente se ha vuelto cada vez más crucial durante las últimas décadas. Así, en esta Tesis se han degradado 4 pesticidas tóxicos y persistentes en el medioambiente mediante la técnica de fotoelectrocatálisis (FEC) utilizando las nanoestructuras de $\mathrm{WO}_{3}$. En esta técnica, los fenómenos electrolíticos y fotocatalíticos actúan juntos para mineralizar el contaminante orgánico. Además, la FEC está atrayendo la atención de los investigadores por su capacidad para degradar contaminantes orgánicos y transformarlos en compuestos inocuos con condiciones de trabajo no extremas.

Por tanto, en el diseño de experimentos realizado en la Tesis Doctoral se modificaron 3 variables con tres niveles cada una, por tanto se escogió un diseño $3^{3}$. Las variables que se modificaron fueron el electrolito utilizado durante el anodizado, la temperatura y atmosfera en el proceso de post-anodizado (tratamiento térmico), obteniendo de esta manera nanoestructuras con diferentes propiedades tanto estructurales como fotoelectroquímicas. 
Los resultados obtenidos mostraron que las nanoestructuras que presentan mejores propiedades morfológicas y fotoelectroquímicas, y con una estructura cristalina más adecuada fueron las obtenidas con el ácido metanosulfónico $\left(\mathrm{CH}_{4} \mathrm{O}_{3} \mathrm{~S}\right)$ como electrolito y calentadas en el proceso de post-anodizado a $600{ }^{\circ} \mathrm{C}$ y en atmósfera de aire.

Con estas nanoestructuras optimizadas, se realizó el proceso de degradación de los 4 pesticidas seleccionados mediante fotoelectrocatálisis. En este proceso, se partió de una concentración inicial de $20 \mathrm{ppm}$ en todos los pesticidas, haciéndose un seguimiento del pesticida mediante UV-Visible y cromatografía líquida de ultra alto rendimiento acoplada a la espectrometría de masas (UHPLC-MS/Q-TOF).

Tras 24 horas de ensayo se consiguió degradar el diazinon hasta 2 ppm (consiguiendo un $90 \%$ de degradación), el clorfenvinfos se degradó hasta 1 ppm (consiguiendo un $95 \%$ de degradación) y el fosmet y fenamifos se degradaron al $100 \%$. Para cada uno de los pesticidas se ha propuesto una ruta de degradación según los compuestos intermedios identificados mediante el UHPLC-MS/Q-TOF, dando como resultado final moléculas más pequeñas y más inocuas para los seres humanos y para el medioambiente. 


\section{ABSTRACT}

This Doctoral Thesis has two clearly differentiated objectives. The first objective is to carry out an optimization study of the synthesis of tungsten oxide nanostructures $\left(\mathrm{WO}_{3}\right)$ using a design of experiments. The second objective is to use of these nanostructures in the photoelectrocatalytic degradation of 4 organophosphate pesticides of different subfamilies (diazinon, phosmet, chlorfenvinphos and fenamiphos). The use of tungsten oxide as a photocatalyst in the photoelectrocatalytic (PEC) process arouses great interest, since it is a semiconductor with great photostability in acidic aqueous electrolytes, excellent electrical conductivity, it has the ability to absorb the blue part of the visible spectrum in addition to ultraviolet light, and the upper edge of the valence band is greater than the oxidation potential of $\mathrm{H}_{2} \mathrm{O} / \mathrm{O}_{2}$. All this makes $\mathrm{WO}_{3}$ capable of efficiently photo-oxidizing a wide range of organic compounds. The nanostructures studied in the Doctoral Thesis were synthesized using electrochemical anodization, since it is a simple technique that permits the control their parameters easily and effectively, allowing the nanostructures to be obtained directly on the metal substrate itself. Furthermore, the need to control and eliminate emerging pollutants in the environment has become increasingly crucial over the past decades. Thus, in this Thesis, 4 toxic and persistent pesticides in the environment have been degraded by the photoelectrocatalysis (PEC) technique using the $\mathrm{WO}_{3}$ nanostructures. In this technique, the electrolytic and photocatalytic phenomena act together to mineralize the organic contaminant. PEC is attracting the attention of researchers for its ability to degrade organic pollutants and transform them into harmless compounds under non-extreme working conditions.

Therefore, in the design of experiments carried out in the Doctoral Thesis, 3 variables were modified with three levels each one, therefore a $3^{3}$ design was chosen. The variables that were modified were the electrolyte used during the anodization, the temperature and the atmosphere in the post-anodization process (annealing treatment), thus obtaining nanostructures with different structural and photoelectrochemical properties.

The results obtained showed that the nanostructures with the best morphological and photoelectrochemical properties, and with adequate crystalline structure 
were those obtained with methanesulfonic acid $\left(\mathrm{CH}_{4} \mathrm{O}_{3} \mathrm{~S}\right)$ as electrolyte and annealed in the post-anodization process at $600{ }^{\circ} \mathrm{C}$ and in an air atmosphere.

With these optimized nanostructures, the degradation process of the 4 selected pesticides was carried out by photoelectrocatalysis. This process started from an initial concentration of $20 \mathrm{ppm}$ in all pesticides, using UV-Visible and Ultra-High Performance Liquid Chromatography coupled to Mass Spectrophotometry (UHPLC-MS / Q-TOF) to monitoring the process.

After 24 hours of experiment, the diazinon was degraded to 2 ppm (achieving 90\% degradation), chlorfenvinphos was degraded to $1 \mathrm{ppm}$ (achieving 95\% degradation) and phosmet and fenamiphos were 100\% degraded. For each of the pesticides, a degradation route has been proposed according to the intermediate compounds identified by UHPLC-MS/Q-TOF, resulting in smaller and more innocuous molecules for humans and the environment. 


\section{RESUM}

La present tesi doctoral té dos objectius clarament diferenciats, sent el primer la realització d'un estudi d'optimització de la síntesi de nanoestructures d'òxid de wolframi $\left(\mathrm{WO}_{3}\right)$ mitjançant l'ús d'un disseny d'experiments, mentre que el segon és l'ús d'aquestes nanoestructures en la degradació fotoelectrocatalítica de quatre pesticides organofosforats de diferents subfamílies (diazinon, fosmet, clorfenvinfòs i fenamifòs). L'ús de l'òxid de wolframi com a fotocatalitzador en el procés fotoelectrocatalític (FEC) desperta un gran interès, ja que es tracta d'un semiconductor amb gran fotoestabilitat en electròlits aquosos àcids; amb una excel-lent conductivitat elèctrica; té la capacitat d'absorbir la part blava de l'espectre visible, a més de la llum ultraviolada, i la vora superior de la banda de valència és major que el potencial d'oxidació d' $\mathrm{H}_{2} \mathrm{O} / \mathrm{O}_{2}$. Tot això fa que el $\mathrm{WO}_{3}$ siga capaç de fotooxidar eficaçment una àmplia gamma de compostos orgànics. Les nanoestructures estudiades en la tesi doctoral es van sintetitzar mitjançant anodització electroquímica, ja que es tracta d'una tècnica senzilla que permet un control dels seus paràmetres de manera fàcil i efectiva, i permet obtenir les nanoestructures directament sobre el mateix substrat metàl-lic. A més, la necessitat de controlar i eliminar els contaminants emergents en el medi ambient s'ha tornat cada vegada més crucial durant les últimes dècades. Així, en aquesta tesi s'han degradat quatre pesticides tòxics i persistents en el medi ambient mitjançant la tècnica de la fotoelectrocatàlisi (FEC) utilitzant les nanoestructures de $\mathrm{WO}_{3}$. En aquesta tècnica, els fenòmens electrolítics i fotocatalítics actuen junts per a mineralitzar el contaminant orgànic. La FEC està atraient l'atenció del personal investigador per la seua capacitat per a degradar contaminants orgànics $i$ transformar-los en compostos innocus amb condicions de treball no extremes.

Per tant, en el disseny d'experiments realitzat en la tesi doctoral es van modificar tres variables amb tres nivells cadascuna, per tant, es va triar un disseny $3^{3}$. Les variables que es van modificar van ser: l'electròlit utilitzat durant l'anodització, la temperatura i l'atmosfera en el procés de postanodització (tractament tèrmic), i es van obtenir d'aquesta manera nanoestructures amb diferents propietats, tant estructurals com fotoelectroquímiques.

Els resultats obtinguts van mostrar que les nanoestructures que presenten millors propietats morfològiques i fotoelectroquímiques, i amb una estructura cristal-lina 
més adequada, van ser les obtingudes amb l'àcid metanosulfònic $\left(\mathrm{CH}_{4} \mathrm{O}_{3} \mathrm{~S}\right)$ com a electròlit, i calfades en el procés de postanodització a $600^{\circ} \mathrm{C}$ i en atmosfera d'aire.

Amb aquestes nanoestructures optimitzades, es va realitzar el procés de degradació dels quatre pesticides seleccionats mitjançant fotoelectrocatàlisi. En aquest procés, es va partir d'una concentració inicial de $20 \mathrm{ppm}$ en tots els pesticides, i es va fer un seguiment del pesticida mitjançant UV visible i cromatografia líquida d'ultraalt rendiment acoblada a l'espectrometria de masses (UHPLC-MS/Q-TOF).

Després de 24 hores d'assaig, es va aconseguir degradar el diazinon fins a 2 ppm (es va assolir un $90 \%$ de degradació), el clorfenvinfòs es va degradar fins a 1 ppm (es va assolir un $95 \%$ de degradació) i el fosmet i el fenamifòs es van degradar al $100 \%$. Per a cadascun dels pesticides s'ha proposat una ruta de degradació segons els compostos intermedis identificats mitjançant I'UHPLC-MS/Q-TOF, que dona com a resultat final molècules més xicotetes i més innòcues per als éssers humans i per al medi ambient. 


\section{LISTA DE PUBLICACIONES DERIVADAS DE LA TESIS DOCTORAL}

1. R.M. Fernández-Domene, R. Sánchez-Tovar, B. Lucas-Granados, G. Roselló-Márquez, J. García-Antón. "A simple method to fabricate highperformance nanostructured $\mathrm{WO}_{3}$ photocatalysts with adjusted morphology in the presence of complexing agents". Materials \& Design 116 (2017) 160-170. DOI: 10.1016/j.matdes.2016.12.016

2. R.M. Fernández-Domene, G. Roselló-Márquez, R. Sánchez-Tovar, B. Lucas-Granados, J. García-Antón. "Photoelectrochemical removal of chlorfenvinphos by using $\mathrm{WO}_{3}$ nanorods: Influence of annealing temperature and operation $\mathrm{pH}^{\prime \prime}$. Separation and Purification Technology 212 (2019) 458-464. DOI: 10.1016/j.seppur.2018.11.049

3. G. Roselló-Márquez, R.M. Fernández-Domene, R. Sánchez-Tovar, S. García-Carrión, B. Lucas-Granados, J. García-Antón. "Photoelectrocatalyzed degradation of a pesticides mixture solution (chlorfenvinphos and bromacil) by $\mathrm{WO}_{3}$ nanosheets". Science of The Total Environment 674 (2019) 88-95. DOI: 10.1016/j.scitotenv.2019.04.150

4. G. Roselló-Márquez, R.M. Fernández-Domene, R. Sánchez-Tovar, J. García-Antón. "Influence of annealing conditions on the photoelectrocatalytic performance of $\mathrm{WO}_{3}$ nanostructures". Separation and Purification Technology 238 (2020) 116417. DOI: 10.1016/j.seppur.2019.116417

5. G. Roselló-Márquez, R.M. Fernández-Domene, R. Sánchez-Tovar, J. García-Antón. "Photoelectrocatalyzed degradation of organophosphorus pesticide fenamiphos using $\mathrm{WO}_{3}$ nanorods as photoanode". Chemosphere 246 (2020) 125677. DOI: 10.1016/j.chemosphere.2019.125677

6. G. Roselló-Márquez, R.M. Fernández-Domene, R. Sánchez-Tovar, M. CifreHerrando, J. García-Antón. "Degradation of Diazinon based on 
photoelectrocatalytic technique using enhanced $\mathrm{WO}_{3}$ nanostructures: mechanism and pathway". Journal of Environmental Chemical Engineering. 9 (2021) 105371 DOI: 10.1016/j.jece.2021.105371

7. R. Sánchez-Tovar, E. Blasco-Tamarit, L.I bañez-Arlandis, R.M. FernándezDomene, G. Roselló-Márquez, J. García-Antón. "Novel $\mathrm{TiO}_{2}-\mathrm{WO}_{3}$ selfordered nanotubes used as photoanodes: Influence of $\mathrm{Na}_{2} \mathrm{WO}_{4}$ and $\mathrm{H}_{2} \mathrm{O}_{2}$ concentration during electrodeposition". Surface and Coatings Technology 415 (2021) 127124 DOI: 10.1016/j.surfcoat.2021.127124

8. G. Roselló-Márquez, R.M. Fernández-Domene, J. García-Antón. "Organophosphorus pesticides (chlorfenvinphos, phosmet and fenamiphos) photoelectrodegradation by using $\mathrm{WO}_{3}$ nanostructures as photoanode". Journal of Electroanalytical Chemistry. (2021) DOI: 10.1016/j.jelechem.2021.115366 


\section{PRÓLOGO}

En la presente Tesis Doctoral se estudia la síntesis de nanoestructuras de $\mathrm{WO}_{3}$ mediante anodizado electroquímico y su aplicación medioambiental, como es la degradación de pesticidas organofosforados. Esta Tesis se divide en cinco capítulos diferentes cuyo contenido se detalla a continuación:

El Capítulo 1 presenta la problemática de la exposición prolongada a pesticidas tanto para el medio ambiente como para las personas y el interés en desarrollar técnicas eficientes con las que conseguir eliminarlos, como es la fotoelectrocatálisis. Se describen cuatro tipos de pesticidas organofosforados que posteriormente se estudiará su eliminación mediante FEC.

Una vez realizada la introducción a la Tesis y se ha evaluado el estado del arte tanto de dicha problemática como de la técnica FEC, en el Capítulo 2 se presentan los objetivos principales de la Tesis, así como el plan de trabajo.

El Capítulo 3 describe y detalla los procedimientos y técnicas experimentales empleadas durante la Tesis con el fin de alcanzar los objetivos propuestos. En él se ve explicado el proceso de anodizado empleado para obtener las nanoestructuras, así como todas las técnicas de caracterización tanto morfológica como fotoelectroquímica. Además, también se explican los fundamentos teóricos de la técnica FEC utilizada para degradar los pesticidas.

Los resultados experimentales se presentan y discuten en el Capítulo 4, que se divide en tres subcapítulos diferentes.

El Capítulo 4.1 se centra en el estudio de las características de las diferentes nanoestructuras de $\mathrm{WO}_{3}$ obtenidas al variar el ácido empleado en el electrolito y la temperatura y atmósfera en el proceso de post-anodizado. Se realizan los ensayos detallados anteriormente con el fin de evaluar y optimizar las propiedades fotoelectroquímicas de las nanoestructuras de $\mathrm{WO}_{3}$ que posteriormente actuarán como fotocatalizadores en el proceso de degradación de pesticidas.

En el Capítulo 4.2 los principales resultados obtenidos del Capítulo 4.1 se contrastan y corroboran mediante la realización de un diseño de experimentos 
factorial $3^{3}$ y un estudio de superficie de respuesta empleando el modelo de BoxBehnken y así definir finalmente las condiciones óptimas de la síntesis.

El Capítulo 4.3 tiene como objetivo degradar 4 pesticidas organofosforados ya que son compuestos orgánicos muy tóxicos tanto para el medioambiente como para la salud humana y que se utilizan con gran frecuencia en la agricultura mundial. Este objetivo se lleva a cabo al aplicar la técnica FEC a la disolución problema. Para que esta técnica sea efectiva se emplean las nanoestructuras de $\mathrm{WO}_{3}$ optimizadas en la primera parte de la Tesis. Los procesos de degradación se monitorizaron mediante espectroscopía Ultravioleta-Visible y UHPLC-MS/MS-QTOF, con el fin de ver el transcurso de la degradación y posteriormente analizar los productos de degradación obtenidos.

Finalmente, el Capítulo 5 resume las principales conclusiones de la presente Tesis. 


\section{ÍNDICE}

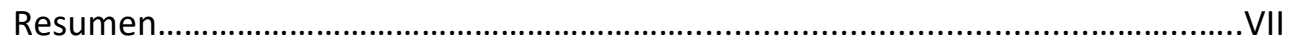

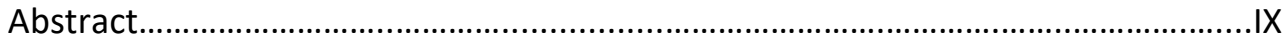

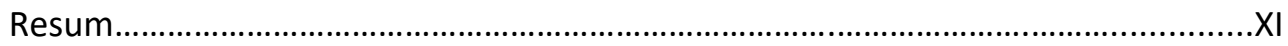

Lista de publicaciones derivadas de la Tesis Doctoral.............................................III

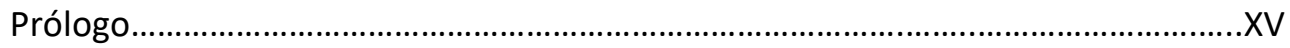

Índice de figuras.................................................................................................XXI

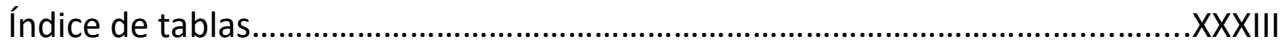

Capítulo 1. Introducción.....................................................1

1. Pesticidas. Clasificación, propiedades y usos.........................................................3

1.1. Visión general de los pesticidas y clasificación...........................................3

1.2. Problemática y usos de los pesticidas.....................................................11

2. Pesticidas organofosforados. Clasificación, propiedades y legislación.................14

2.1. Clasificación de los pesticidas organofosforados...................................15

2.2. Propiedades de los pesticidas organofosforados..................................16

2.3. Legislación de pesticidas organofosforados............................................21

3. Pesticidas organofosforados elegidos a degradar .................................................24

3.1. Presentación del primer pesticida, fenamifos.........................................24

3.2. Presentación del segundo pesticida, fosmet............................................29

3.3. Presentación del tercer pesticida, diazinón.............................................33

3.4. Presentación del cuarto pesticida, clorfenvinfos....................................38

4. Procesos de degradación de pesticidas.................................................................41

4.1. Fenton y electro-Fenton.....................................................................43

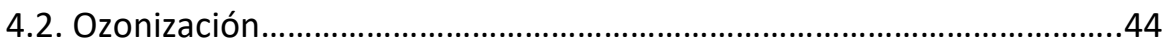

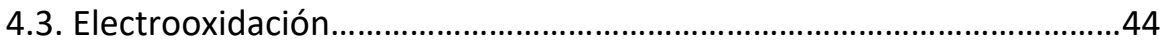

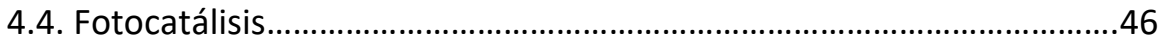




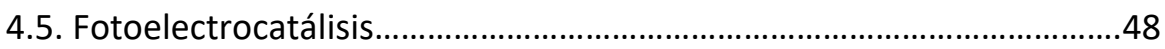

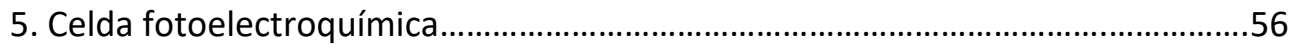

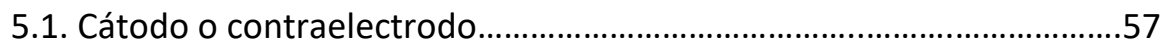

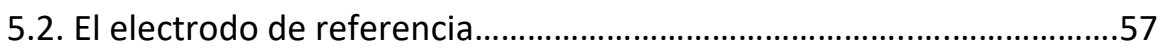

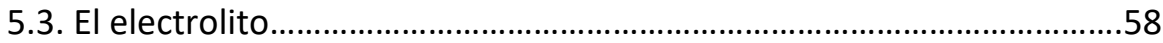

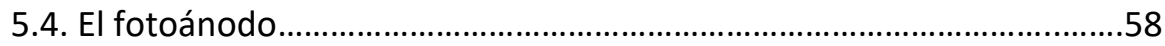

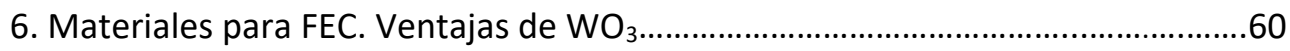

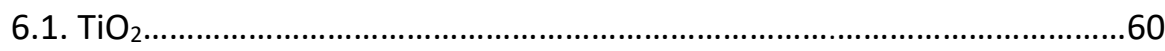

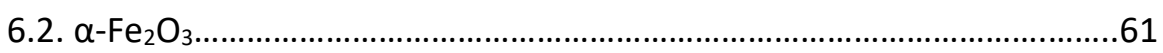

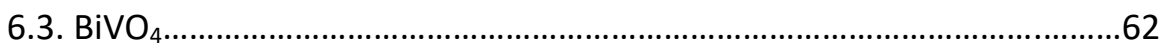

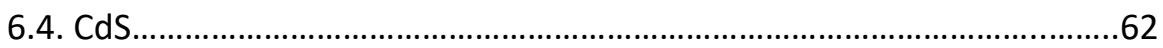

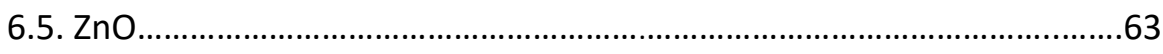

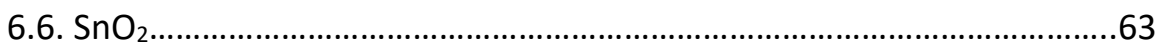

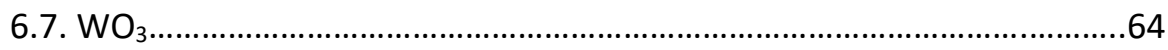

7. Interés en la investigación del $\mathrm{WO}_{3}$ como fotoelectrodo.....................................67

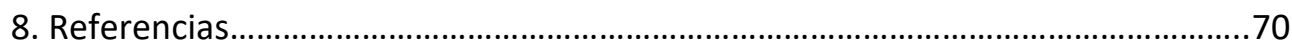

Capítulo 2. Objetivos y plan de trabajo...................................81

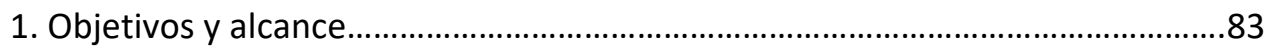

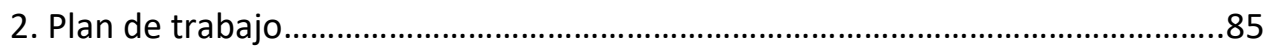

Capítulo 3. Metodología experimental...................................87

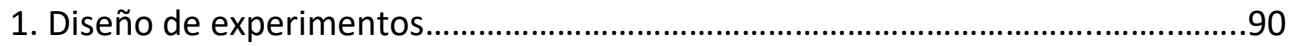

2. Síntesis de las nanoestructuras de $\mathrm{WO}_{3}$ mediante anodizado

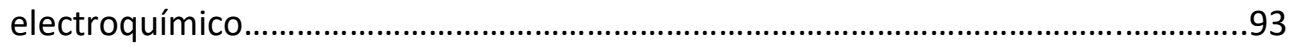

2.1. Preparación de los electrodos..............................................................94

2.2. Proceso de anodizado electroquímico.....................................................95

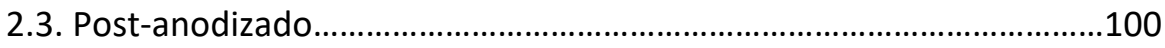

3. Proceso de caracterización de la muestra anodizada..........................................101

3.1. Técnica de Microscopía Laser Confocal Raman....................................101 
3.2. Microscopia Electrónica de Barrido de Emisión de Campo (FESEM)

3.3. Caracterización superficial de las nanoestructuras mediante Espectroscopía Fotoelectrónica de rayos X (XPS). .106

3.4 Caracterización electroquímica mediante espectroscopia de impedancias fotoelectroquímica (PEIS)......................................................110

3.5. Análisis de Mott-Schottky................................................................120

3.6. Microscopía de Fuerza Atómica (AFM).................................................121

4. Procedimiento de degradación de los pesticidas................................................126

4.1. Técnicas de seguimiento de la degradación........................................126

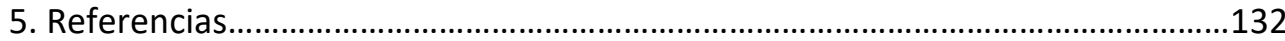

Capítulo 4. Análisis y discusión de resultados......................139

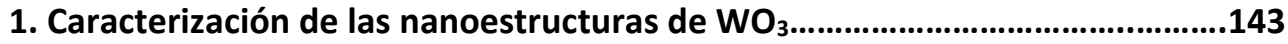

1.1. Transitorio de densidad de corriente..................................................146

1.2. Caracterización morfológica de la superficie mediante microscopia FESEM

1.3. Caracterización de la estructura cristalina de las nanoestructuras mediante Microscopía Laser Confocal Raman

1.4. Caracterización topográfica mediante Microscopía de fuerza atómica (AFM)

1.5. Caracterización superficial de las nanoestructuras mediante Espectroscopía Fotoelectrónica de Rayos X (XPS)

1.6. Caracterización fotoelectroquímica de las nanoestructuras mediante espectroscopia de impedancia electroquímica (PEIS) 188

1.7. Análisis de Mott-Schottky.....

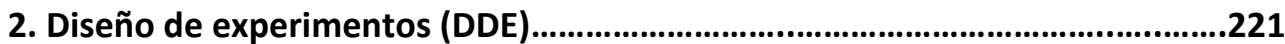

2.1. Diseño factorial $3^{3}$ 221

2.2. Estudio de superficie de respuesta (RSM) mediante Box-Behnken (BBD)

3. Degradación fotoelectrocatalítica de pesticidas organofosforados .235

3.1. Diazinon 
3.1.1. Espectroscopía UV-Vis........................................................237

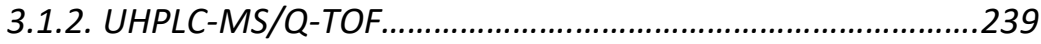

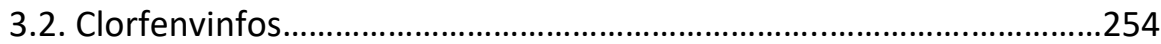

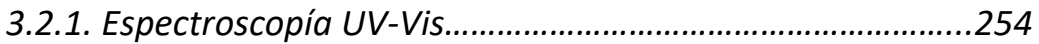

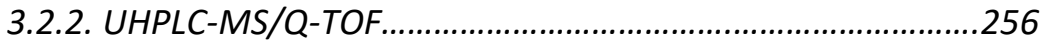

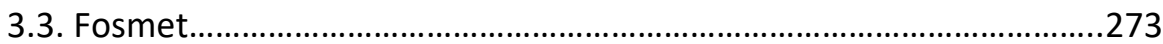

3.3.1. Espectroscopía UV-Vis.......................................................274

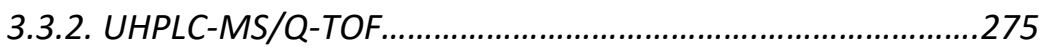

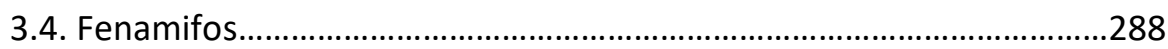

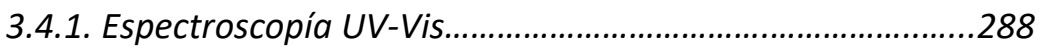

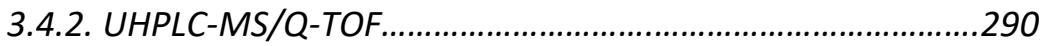

4. Referencias............................................................................................................304

\section{Capítulo 5. Conclusiones finales/Final conclusions...............319}

1. Conclusiones finales de la caracterización de las nanoestructuras de $\mathrm{WO}_{3} \ldots . . .321$

2. Conclusiones finales de la degradación fotoelectrocatalítica................................325

3. Final conclusions of $\mathrm{WO}_{3}$ nanostructures characterization ..................................327

4. Final conclusions of the photoelectrocatalytic degradation................................331 


\section{ÍNDICE DE FIGURAS}

Capítulo 1. Introducción.................................................................1

Figura 1.1. Población mundial del 1950 al 2050 según Naciones Unidas..................4

Figura 1.2. Principales vías de entrada del pesticida al organismo..........................8

Figura 1.3. a) Uso de pesticidas mundial entre 1990 y 2016, b) Porcentaje de ventas en el 2016 comparado con el porcentaje en 2011 .......................................14

Figura 1.4. Estructura química en común de los pesticidas organofosforados.......15

Figura 1.5. Clasificación de los pesticidas organofosforados según Holmstedt......16

Figura 1.6. a) Mecanismo de acción de las colinesterasas, b) Inhibición de las colinesterasas en presencia de pesticidas organofosforados.

Figura 1.7. a) Estructura química del fenamifos, b) estructura de fenamifos sulfóxido y $\mathrm{c}$ ) estructura del fenamifos sulfona...............................................26

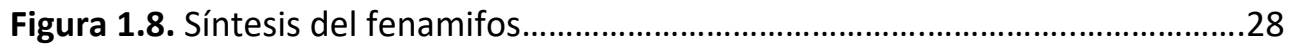

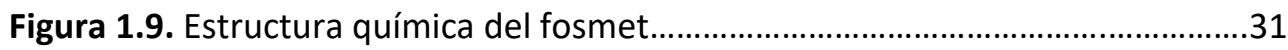

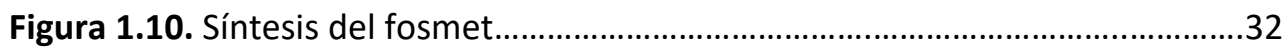

Figura 1.11. a) Estructura química del diazinón y b) estructura química del

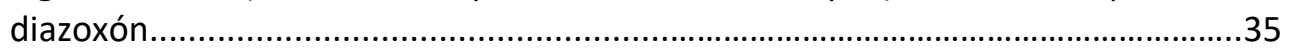

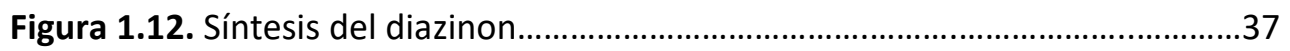

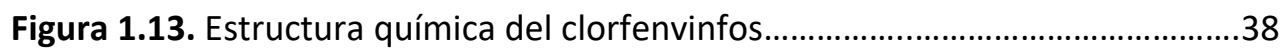

Figura 1.14. Síntesis del clorfenvinfos.............................................................4

Figura 1.15. Principales técnicas utilizadas para la eliminación de

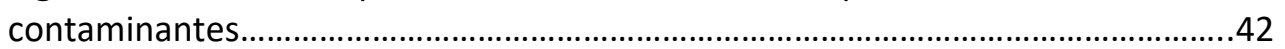

Figura 1.16. Esquema de funcionamiento del proceso de electro-Fenton.............43

Figura 1.17. Esquema del proceso de $\mathrm{FC}$ empleando $\mathrm{WO}_{3}$ como semiconductor catalítico 
Figura 1.18. Esquema de funcionamiento de un semiconductor a) tipo $n$ y b) tipo

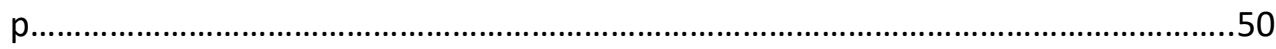

Figura 1.19. Las bandas energéticas en la interfase de un semiconductor tipo $\mathrm{n}$ y el electrolito mostrando la relación entre la pareja redox $\left(\mathrm{H}_{2} \mathrm{O} / \mathrm{O}_{2}\right.$ y $\left.\mathrm{H}_{2} / \mathrm{H}^{+}\right)$, la caída de potencial en la capa de Helmholtz $\left(\mathrm{V}_{\mathrm{H}}\right)$, la función de trabajo del semiconductor $\left(\Phi_{S}\right)$, la función de trabajo del electrolito $\left(\Phi_{R}\right)$ y el cuasi-nivel de Fermi referido al electrón $\left(E_{F, n}\right)$ y el cuasi-nivel de Fermi referido al hueco $\left(E_{F, p}\right)$ en tres casos: a) entes del equilibrio entre las dos fases, $b$ ) después del equilibrio bajo condiciones de oscuridad y c) en equilibrio cuasi-estático bajo condiciones de iluminación.....51

Figura 1.20. Esquema de funcionamiento de un sistema de FEC..............................55

Figura 1.21. Esquema celda fotoelectroquímica...................................................56

Figura 1.22. Anchura y posiciones de banda de los semiconductores típicos de tipo $\mathrm{n}$ y tipo $\mathrm{p}$ utilizados actualmente en $\mathrm{FEC}$ a $\mathrm{pH}=0$.

Figura 1.23. a) Celdas unitarias de las diferentes fases de $\mathrm{WO}_{3}$ y sus se muestran en b) correspondientes estructuras de banda y c) El diagrama de energía libre de las facetas

Figura 1.24. La distribución de trabajos de investigación sobre el $\mathrm{WO}_{3}$ por año de publicación entre 2009 y 2017 .68

Figura 1.25. Aplicaciones de los fotocatalizadores basados en $\mathrm{WO}_{3}$ .70

\section{Capítulo 2. Objetivos y plan de trabajo}

Figura 2.1. Esquema de la estructura de la Tesis Doctoral dividida en diferentes capítulos

Capítulo 3. Metodología experimental

Figura 3.1. Barra de wolframio teflonada. .94

Figura 3.2. Montaje de anodizado electroquímico completo. . .96

Figura 3.3. Esquema del horno tubular utilizado. 100 
Figura 3.4. Microscopio Laser Raman Confocal WITec Alpha. 102

Figura 3.5. Diagramas de dispersión de la luz al incidir sobre la materia .103

Figura 3.6. Microscopio electrónico de barrido de emisión de campo ZEISS ULTRA55 104

Figura 3.7. Interacción de electrones de alta energía con muestras sólidas........105

Figura 3.8. Sistema de lentes de un microscopio FE-SEM..................................106

Figura 3.9. Fundamento físico-químico del análisis XPS.........................................108

Figura 3.10. Esquema del equipo utilizado en el análisis XPS...............................109

Figura 3.11. Funciones sinusoidales del potencial y la intensidad registrada......111

Figura 3.12. Diagrama de Nyquist.....................................................................113

Figura 3.13. a) Diagrama de Bode-módulo, b) Diagrama de Bode-fase................115

Figura 3.14. Equipo utilizado para medir las impedancias......................................116

Figura 3.15. Diagrama simplificado del funcionamiento del potenciostato..........117

Figura 3.16. Esquema del simulador solar utilizado............................................118

Figura 3.17. Representación en función si el semiconductor es tipo n o tipo p...120

Figura 3.18. Configuración básica de AFM .122

Figura 3.19. Detalles del equipo de AFM. …………...............................................123

Figura 3.20. Equipo UHPLC-MS/MS. ................................................................120

Capítulo 4. Análisis y discusión de resultados..............................137

Figura 4.1. a) Película compacta, b) Película porosa.................................................145

Figura 4.2. Registros de la densidad de corriente frente al tiempo, durante el anodizado electroquímico del wolframio a $20 \mathrm{~V}$ durante 4 horas con los 3 ácidos diferentes 146

Figura 4.3. Imágenes FE-SEM de las nanoestructuras de óxido de wolframio tras el anodizado electroquímico con $\mathrm{H}_{2} \mathrm{SO}_{4}$ y su posterior calentamiento a $400{ }^{\circ} \mathrm{C}$ en a) 
aire a 1000 aumentos, b) aire a 20000 aumentos, c) $N_{2}$ a 1000 aumentos, d) $N_{2}$ a 20000 aumentos, e) Ar a 1000 aumentos, f) Ar a 20000 aumentos. 150

Figura 4.4. Imágenes FE-SEM de las nanoestructuras de óxido de wolframio tras el anodizado electroquímico con $\mathrm{H}_{2} \mathrm{SO}_{4}$ y su posterior calentamiento a $500{ }^{\circ} \mathrm{C}$ en a) aire a 1000 aumentos, b) aire a 20000 aumentos, c) $\mathrm{N}_{2}$ a 1000 aumentos, d) $\mathrm{N}_{2}$ a 20000 aumentos, e) Ar a 1000 aumentos, f) Ar a 20000 aumentos. 151

Figura 4.5. Imágenes FE-SEM de las nanoestructuras de óxido de wolframio tras el anodizado electroquímico con $\mathrm{H}_{2} \mathrm{SO}_{4}$ y su posterior calentamiento a $600{ }^{\circ} \mathrm{C}$ en a) aire a 1000 aumentos, b) aire a 20000 aumentos, c) $\mathrm{N}_{2}$ a 1000 aumentos, d) $\mathrm{N}_{2}$ a 20000 aumentos, e) Ar a 1000 aumentos, f) Ar a 20000 aumentos. 152

Figura 4.6. Imágenes FE-SEM de las nanoestructuras de óxido de wolframio tras el anodizado electroquímico con $\mathrm{CH}_{4} \mathrm{O}_{3} \mathrm{~S}$ y su posterior calentamiento a $400{ }^{\circ} \mathrm{C}$ en a) aire a 1000 aumentos, b) aire a 20000 aumentos, c) $\mathrm{N}_{2}$ a 1000 aumentos, d) $\mathrm{N}_{2}$ a 20000 aumentos, e) $\operatorname{Ar}$ a 1000 aumentos, f) Ar a 20000 aumentos. 154

Figura 4.7. Imágenes FE-SEM de las nanoestructuras de óxido de wolframio tras el anodizado electroquímico con $\mathrm{CH}_{4} \mathrm{O}_{3} \mathrm{~S}$ y su posterior calentamiento a $500{ }^{\circ} \mathrm{C}$ en a) aire a 1000 aumentos, b) aire a 20000 aumentos, c) $\mathrm{N}_{2}$ a 1000 aumentos, d) $\mathrm{N}_{2}$ a 20000 aumentos, e) Ar a 1000 aumentos, f) Ar a 20000 aumentos. 155

Figura 4.8. Imágenes FE-SEM de las nanoestructuras de óxido de wolframio tras el anodizado electroquímico con $\mathrm{CH}_{4} \mathrm{O}_{3} \mathrm{~S}$ y su posterior calentamiento a $600{ }^{\circ} \mathrm{C}$ en a) aire a 1000 aumentos, b) aire a 20000 aumentos, c) $\mathrm{N}_{2}$ a 1000 aumentos, d) $\mathrm{N}_{2}$ a 20000 aumentos, e) Ar a 1000 aumentos, f) Ar a 20000 aumentos. 156

Figura 4.9. Imágenes FE-SEM de las nanoestructuras de óxido de wolframio tras el anodizado electroquímico con $\mathrm{HNO}_{3}$ y su posterior calentamiento a $400{ }^{\circ} \mathrm{C}$ en a) aire a 1000 aumentos, b) aire a 20000 aumentos, c) $\mathrm{N}_{2}$ a 1000 aumentos, d) $\mathrm{N}_{2}$ a 20000 aumentos, e) Ar a 1000 aumentos, f) Ar a 20000 aumentos. 158

Figura 4.10. Imágenes FE-SEM de las nanoestructuras de óxido de wolframio tras el anodizado electroquímico con $\mathrm{HNO}_{3}$ y su posterior calentamiento a $500{ }^{\circ} \mathrm{C}$ en a) aire a 1000 aumentos, b) aire a 20000 aumentos, c) $\mathrm{N}_{2}$ a 1000 aumentos, d) $\mathrm{N}_{2}$ a 20000 aumentos, e) Ar a 1000 aumentos, f) Ar a 20000 aumentos. 159

Figura 4.11. Imágenes FE-SEM de las nanoestructuras de óxido de wolframio tras el anodizado electroquímico con $\mathrm{HNO}_{3}$ y su posterior calentamiento a $600{ }^{\circ} \mathrm{C}$ en a) 
aire a 1000 aumentos, b) aire a 20000 aumentos, c) $\mathrm{N}_{2}$ a 1000 aumentos, d) $\mathrm{N}_{2}$ a 20000 aumentos, e) $\operatorname{Ar}$ a 1000 aumentos, f) Ar a 20000 aumentos. 160

Figura 4.12. Espectro Raman de las nanoestructuras de óxido de wolframio tras el anodizado electroquímico con $\mathrm{H}_{2} \mathrm{SO}_{4}$

Figura 4.13. Espectros Raman obtenidos para las muestras sintetizadas por anodizado electroquímico en medio $\mathrm{H}_{2} \mathrm{SO}_{4}$, y calentadas a diferentes temperaturas y en atmósfera de aire. 164

Figura 4.14. Espectros Raman obtenidos para las muestras sintetizadas por anodizado electroquímico en medio $\mathrm{H}_{2} \mathrm{SO}_{4}$, y calentadas a diferentes temperaturas y en atmósfera de nitrógeno. 164

Figura 4.15. Espectros Raman obtenidos para las muestras sintetizadas por anodizado electroquímico en medio $\mathrm{H}_{2} \mathrm{SO}_{4}$, y calentadas a diferentes temperaturas y en atmósfera de argón. 165

Figura 4.16. Espectros Raman obtenidos para las nanoestructuras de $\mathrm{WO}_{3}$ sintetizadas por anodizado electroquímico en medio $\mathrm{H}_{2} \mathrm{SO}_{4}$, calentadas a diferentes atmósferas y a $600{ }^{\circ} \mathrm{C}$

Figura 4.17. Espectros Raman obtenidos para las muestras sintetizadas por anodizado electroquímico con $\mathrm{CH}_{4} \mathrm{O}_{3} \mathrm{~S}$, calentadas a diferentes temperaturas...168

Figura 4.18. Espectros Raman obtenidos para las muestras sintetizadas por anodizado electroquímico con $\mathrm{HNO}_{3}$, calentadas a diferentes temperaturas......168

Figura 4.19. Espectros Raman obtenidos para las muestras sintetizadas por anodizado electroquímico con los diferentes ácidos, calentadas a $600{ }^{\circ} \mathrm{C}$ en aire .169

Figura 4.20. Imágenes AFM en dos y tres dimensiones de las nanoestructuras obtenidas con $\mathrm{H}_{2} \mathrm{SO}_{4}$ y calentadas en aire a a) $400{ }^{\circ} \mathrm{C}$, b) $500{ }^{\circ} \mathrm{C}$ y c) $600{ }^{\circ} \mathrm{C}$

Figura 4.21. Imágenes AFM en dos y tres dimensiones de las nanoestructuras obtenidas con $\mathrm{CH}_{4} \mathrm{O}_{3} \mathrm{~S}$ y calentadas en aire a a) $400{ }^{\circ} \mathrm{C}$, b) $500{ }^{\circ} \mathrm{C}$ y c) $600{ }^{\circ} \mathrm{C} . \ldots . .173$

Figura 4.22. Imágenes AFM en dos y tres dimensiones de las nanoestructuras obtenidas con $\mathrm{HNO}_{3}$ y calentadas en aire a a) $400{ }^{\circ} \mathrm{C}$, b) $500{ }^{\circ} \mathrm{C}$ y c) $600{ }^{\circ} \mathrm{C}$ .174 
Figura 4.23. Espectro XPS de las muestras sintetizadas con $\mathrm{H}_{2} \mathrm{SO}_{4}, \mathrm{CH}_{4} \mathrm{O}_{3} \mathrm{~S}$ y $\mathrm{HNO}_{3}$ 175

Figura 4.24. Espectros XPS de alta resolución de pico W4f de las muestras sintetizadas con $\mathrm{H}_{2} \mathrm{SO}_{4}$. 177

Figura 4.25. Espectros XPS de alta resolución de pico W4f de las muestras sintetizadas con $\mathrm{CH}_{4} \mathrm{O}_{3} \mathrm{~S}$. .178

Figura 4.26. Espectros XPS de alta resolución de pico W4f de las muestras sintetizadas con $\mathrm{HNO}_{3}$. 178

Figura 4.27. Espectros XPS de alta resolución de pico 01 s de las muestras sintetizadas con $\mathrm{H}_{2} \mathrm{SO}_{4}$. 181

Figura 4.28. Espectros XPS de alta resolución de pico O1s de las muestras sintetizadas con $\mathrm{CH}_{4} \mathrm{O}_{3} \mathrm{~S}$. 181

Figura 4.29. Espectros XPS de alta resolución de pico O1s de las muestras sintetizadas con $\mathrm{HNO}_{3}$.

Figura 4.30. Espectros XPS de alta resolución de pico N1s de las muestras sintetizadas con $\mathrm{CH}_{4} \mathrm{O}_{3} \mathrm{~S}$. 184

Figura 4.31. Espectros XPS de alta resolución de pico N1s de las muestras sintetizadas con $\mathrm{HNO}_{3}$. .184

Figura 4.32. Densidad de corriente registrada durante $30 \mathrm{~min}$ con las nanoestructuras obtenidas mediante anodizado electroquímico en medio $\mathrm{H}_{2} \mathrm{SO}_{4}$ y calentadas en a) aire, b) $\mathrm{N}_{2}$, c) Ar y d) resumen de todos los casos.

Figura 4.33. Diagramas experimentales de Nyquist de las nanoestructuras formadas tras el anodizado electroquímico en $\mathrm{H}_{2} \mathrm{SO}_{4}$ como electrolito y calentadas a diferentes temperaturas en atmosferas de a) aire, b) $\mathrm{N}_{2}$, c) $\mathrm{Ar}$. .188

Figura 4.34. Diagramas experimentales de Bode-fase de las nanoestructuras formadas tras el anodizado electroquímico en $\mathrm{H}_{2} \mathrm{SO}_{4}$ como electrolito y calentadas a diferentes temperaturas en atmosferas de a) aire, b) $\mathrm{N}_{2}$, c) $\mathrm{Ar}$. 190

Figura 4.35. Diagramas experimentales de Bode-módulo de las nanoestructuras formadas tras el anodizado electroquímico en $\mathrm{H}_{2} \mathrm{SO}_{4}$ como electrolito y calentadas a diferentes temperaturas en atmosferas de a) aire, b) $\mathrm{N}_{2}$, c) $\mathrm{Ar}$. 191 
Figura 4.36. Circuito eléctrico equivalente utilizado para ajustar los datos experimentales de PEIS al modelo teórico propuesto. .193

Figura 4.37. Densidad de corriente registrada durante $30 \mathrm{~min}$ con las nanoestructuras obtenidas con $\mathrm{CH}_{4} \mathrm{O}_{3} \mathrm{~S}$ y calentadas en a) aire, b) $\mathrm{N}_{2}$, c) Ar y d) resumen de todos los casos.

Figura 4.38. Diagramas experimentales de Nyquist de las nanoestructuras formadas tras el anodizado electroquímico en $\mathrm{CH}_{4} \mathrm{O}_{3} \mathrm{~S}$ como electrolito y calentadas a diferentes temperaturas en atmosferas de a) aire, b) $\mathrm{N}_{2}$, c) $\mathrm{Ar}$........196

Figura 4.39. Diagramas experimentales de Bode-fase de las nanoestructuras formadas tras el anodizado electroquímico en $\mathrm{CH}_{4} \mathrm{O}_{3} \mathrm{~S}$ como electrolito y calentadas a diferentes temperaturas en atmosferas de a) aire, b) $\mathrm{N}_{2}$, c) Ar.......197

Figura 4.40. Diagramas experimentales de Bode-módulo de las nanoestructuras formadas tras el anodizado electroquímico en $\mathrm{CH}_{4} \mathrm{O}_{3} \mathrm{~S}$ como electrolito y calentadas a diferentes temperaturas en atmosferas de a) aire, b) $\mathrm{N}_{2}$, c) $\operatorname{Ar}$.......198

Figura 4.41. Densidad de corriente registrada durante $30 \mathrm{~min}$ con las nanoestructuras obtenidas con $\mathrm{HNO}_{3}$ y calentadas en a) aire, b) $\mathrm{N}_{2}$, c) Ar y d) resumen de todos los casos 201

Figura 4.42. Diagramas experimentales de Nyquist de las nanoestructuras formadas tras el anodizado electroquímico en $\mathrm{HNO}_{3}$ como electrolito y calentadas a diferentes temperaturas en atmosferas de a) aire, b) $\mathrm{N}_{2}$, c) $\mathrm{Ar}$ .202

Figura 4.43. Diagramas experimentales de Bode-fase de las nanoestructuras formadas tras el anodizado electroquímico en $\mathrm{HNO}_{3}$ como electrolito y calentadas a diferentes temperaturas en atmosferas de a) aire, b) $\mathrm{N}_{2}$, c) $\mathrm{Ar}$. .204

Figura 4.44. Diagramas experimentales de Bode-módulo de las nanoestructuras formadas tras el anodizado electroquímico en $\mathrm{HNO}_{3}$ como electrolito y calentadas a diferentes temperaturas en atmosferas de a) aire, b) $\mathrm{N}_{2}$, c) $\mathrm{Ar}$. .205

Figura 4.45. Gráficos Mott-Schottky realizados bajo iluminación solar simulada, de las nanoestructuras sintetizadas por anodizado electroquímico en medio $\mathrm{H}_{2} \mathrm{SO}_{4}$ como electrolito y calentadas en a) aire a diferentes temperaturas, b) $\mathrm{N}_{2}$ a diferentes temperaturas y c) Ar a diferentes temperaturas .209 
Figura 4.46. Gráficos Mott-Schottky realizados bajo iluminación solar simulada, de las nanoestructuras sintetizadas por anodizado electroquímico en medio $\mathrm{CH}_{4} \mathrm{O}_{3} \mathrm{~S}$ como electrolito y calentadas en a) aire a diferentes temperaturas, b) $\mathrm{N}_{2}$ a diferentes temperaturas y c) Ar a diferentes temperaturas. 212

Figura 4.47. Gráficos Mott-Schottky realizados bajo iluminación solar simulada, de las nanoestructuras sintetizadas por anodizado electroquímico en medio $\mathrm{HNO}_{3}$ como electrolito y calentadas en a) aire a diferentes temperaturas, b) $\mathrm{N}_{2}$ a diferentes temperaturas y c) Ar a diferentes temperaturas. .215

Figura 4.48. a) Diagrama de Pareto, b) gráfico de efectos principales y c) gráfico de interacción entre los factores .223

Figura. 4.49. a) La representación para BBD consiste en el punto central y el punto medio de los bordes; b) Tres diseños factoriales entrelazados $2^{2}$ y un punto central.

Figura 4.50. Gráficos de superficie de respuesta tridimensional en donde los factores variables son a) ácido electrolito y atmósfera, b) atmósfera y temperatura y c) ácido electrolito y temperatura.

Figura 4.51. Espectro UV-vis de los patrones de diazinon .236

Figura 4.52. Espectros UV-Vis de diazinón cuando se utiliza la técnica PEC durante $6 \mathrm{~h}$

Figura 4.53. a) Cromatograma TIC de los patrones de diazinón. Ampliación del pico, b) espectro de masas asociado a ese pico. 239

Figura 4.54. Hidrólisis del diazinón en condiciones ácidas .240

Figura 4.55. Vías de protonación del diazinón. 240

Figura 4.56. a) Cromatograma del diazinón con y $\sin \mathrm{H}_{2} \mathrm{SO}_{4}$ y b) espectro de masas del cromatograma .242

Figura 4.57. Cromatograma TIC de todas las muestras degradadas. El recuadro muestra una ampliación del pico principal. .243

Figura 4.58. Ajuste cinética pseudo-primer orden .245

Figura 4.59. a) Cromatograma de ion exacto (EIC) de 2-isopropanol-6metilpirimidin-4-ol y b) espectro de masas del compuesto. .246 
Figura 4.60. a) Cromatograma EIC de 1-hidroxiisopropil diazoxon y b) espectro de masas del compuesto.

Figura 4.61. a) Cromatograma EIC del producto de degradación número 5 y b) espectro de masas del compuesto 248

Figura 4.62. a) Cromatograma EIC del producto de degradación número 7 y b) espectro de masas del compuesto

Figura 4.63. a) Cromatograma EIC de los patrones de diazinón y b) Cromatograma EIC de diazinón para las muestras degradadas.. .250

Figura 4.64. Ruta de degradación propuesta del diazinon mediante PEC. .251

Figura 4.65. Espectro UV-vis de los patrones de clorfenvinfos. 253

Figura 4.66. Espectros UV-Vis de clorfenvinfos cuando se utiliza la técnica PEC durante $6 \mathrm{~h}$. .254

Figura 4.67. a) Cromatograma EIC de los patrones de diazinon y b) espectro de masas del compuesto .255

Figura 4.68. Cromatograma TIC de todas las muestras degradadas. El recuadro muestra una ampliación del pico principal. 256

Figura 4.69. Ajuste cinética pseudo-primer orden .258

Figura 4.70. Ajuste cinética pseudo-primer orden segundo pico. 259

Figura 4.71. a) Cromatograma EIC del producto de degradación número 1 y b) espectro de masas del compuesto 260

Figura 4.72. a) Cromatograma EIC del producto de degradación número 2 y b) espectro de masas del compuesto 261

Figura 4.73. a) Cromatograma EIC del producto de degradación número 3 y b) espectro de masas del compuesto 262

Figura 4.74. a) Cromatograma EIC del producto de degradación número 4 y b) espectro de masas del compuesto .263

Figura 4.75. a) Cromatograma EIC del producto de degradación número 5 y b) espectro de masas del compuesto 264 
Figura 4.76. a) Cromatograma EIC del producto de degradación número 6 y b) espectro de masas del compuesto .265

Figura 4.77. a) Cromatograma EIC del producto de degradación número 7 y b) espectro de masas del compuesto 267

Figura 4.78. a) Cromatograma EIC del producto de degradación número 8 y b) espectro de masas del compuesto 268

Figura 4.79. a) Cromatograma EIC del producto de degradación número 9 y b) espectro de masas del compuesto. 269

Figura 4.80. Ruta de degradación propuesta del clorfenvinfos mediante PEC.....270

Figura 4.81. Espectro UV-Vis de los patrones de fosmet. .272

Figura 4.82. Espectros UV-Vis de fosmet cuando se utiliza la técnica PEC durante 6 h.

Figura 4.83. a) Cromatograma EIC de los patrones de fosmet y b) espectro de masas del compuesto. .274

Figura 4.84. Recta de calibrado de los patrones de fosmet mediante UHPLCMS. .275

Figura 4.85. a) Cromatograma EIC de todas las muestras degradadas de fosmet y b) espectro de masas del compuesto. .276

Figura 4.86. Ajuste cinética pseudo-primer orden .277

Figura 4.87. a) Cromatograma EIC del producto de degradación número 1 y b) espectro de masas del compuesto..... 279

Figura 4.88. a) Cromatograma EIC del producto de degradación número 2 y b) espectro de masas del compuesto. 280

Figura 4.89. a) Cromatograma EIC del producto de degradación número 3 y b) espectro de masas del compuesto. 281

Figura 4.90. a) Cromatograma EIC del producto de degradación número 4 y b) espectro de masas del compuesto .282 
Figura 4.91. a) Cromatograma EIC del producto de degradación número 5 y b) espectro de masas del compuesto

Figura 4.92. a) Cromatograma EIC del producto de degradación número 6 y b) espectro de masas del compuesto .284

Figura 4.93. Ruta de degradación propuesta del fosmet mediante PEC 285

Figura 4.94. Espectro UV-Vis de los patrones de fenamifos .287

Figura 4.95. Espectros UV-Vis de fenamifos cuando se utiliza la técnica PEC durante $6 \mathrm{~h}$ .288

Figura 4.96. a) Cromatograma EIC de los patrones de fenamifos y b) espectro de masas del compuesto 289

Figura 4.97. Recta de calibrado de los patrones de fenamifos mediante HPLCMS. .290

Figura 4.98. a) Cromatograma EIC de todas las muestras degradadas de fenamifos y b) espectro de masas del compuesto .291

Figura 4.99. Ajuste cinética pseudo-primer orden .292

Figura 4.100. a) Cromatograma EIC del producto de degradación número 1 y b) espectro de masas del compuesto 294

Figura 4.101. a) Cromatograma EIC del producto de degradación número 2 y b) espectro de masas del compuesto .295

Figura 4.102. a) Cromatograma EIC del producto de degradación número 3 y b) espectro de masas del compuesto 296

Figura 4.103. a) Cromatograma EIC del producto de degradación número 4 y b) espectro de masas del compuesto

Figura 4.104. a) Cromatograma EIC del producto de degradación número 5 y b) espectro de masas del compuesto .298

Figura 4.105. a) Cromatograma EIC del producto de degradación número 6 y b) espectro de masas del compuesto 299 
Figura 4.106. Ruta de degradación propuesta del fenamifos mediante

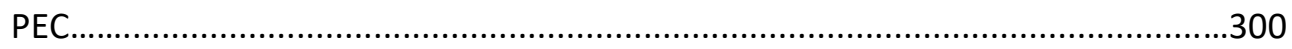




\section{ÍNDICE DE TABLAS}

Capítulo 1. Introducción............................................................1

Tabla 1.1. Comportamiento medioambiental de los pesticidas en función de los parámetros físico-químicos

Tabla 1.2. Clasificación de los pesticidas en función de la estructura química del pesticida.

Tabla 1.3. Clasificación del riesgo toxicológico de los plaguicidas según la OMS.

Tabla 1.4. Clasificación de pesticidas según la $\mathrm{DT}_{50}$

Tabla 1.5. Principales disposiciones en España que regulan los pesticidas organofosforados.

Tabla 1.6. Propiedades físico-químicas del fenamifos .25

Tabla 1.7. Propiedades físico-químicas del fosmet 29

Tabla 1.8. Propiedades físico-químicas del diazinón. 34

Tabla 1.9. Propiedades físico-químicas del clorfenvinfos .39

Tabla 1.10. Materiales para ánodos en la mineralizacion de compuestos orgánicos

Capítulo 3. Metodología experimental

Tabla 3.1. Tabla ANOVA para un diseño de experimentos

Tabla 3.2. Rango de longitudes de onda con su correspondiente color absorbido y transmitido. 
Tabla 4.1. Experimentos realizados variando: tipo de ácido, temperatura y atmósfera de calentamiento.

Tabla 4.2. Área del pico de $\mathrm{W}_{4} \mathrm{f}_{7 / 2}$ en el espectro XPS de alta resolucion en las tres muestras.

Tabla 4.3. Área del pico de oxígeno en el espectro XPS de alta resolucion en las tres

muestras.

182

Tabla 4.4. Área del pico de nitrógeno en el espectro XPS de alta resolucion en las tres muestras

Tabla 4.5. Valores medios de las resistencias, obtenidos tras el ajuste de los datos experimentales de EIS al circuito eléctrico equivalente, de las nanoestructuras sintetizadas con $\mathrm{H}_{2} \mathrm{SO}_{4}$ como electrolito. .194

Tabla 4.6. Valores medios de las resistencias, obtenidos tras el ajuste de los datos experimentales de EIS al circuito eléctrico equivalente, de las nanoestructuras sintetizadas con $\mathrm{CH}_{4} \mathrm{O}_{3} \mathrm{~S}$ como electrolito.

Tabla 4.7. Valores medios de las resistencias, obtenidos tras el ajuste de los datos experimentales de EIS al circuito eléctrico equivalente, de las nanoestructuras sintetizadas con $\mathrm{HNO}_{3}$ como electrolito.

Tabla 4.8. Valores medios de $N_{D}$ y $E_{F B}$, de las nanoestructuras sintetizadas por anodizado electroquímico en medio $\mathrm{H}_{2} \mathrm{SO}_{4}$ y calentadas a diferentes temperaturas y atmosferas.

Tabla 4.9. Valores medios de $N_{D}$ y $E_{F B}$, de las nanoestructuras sintetizadas por anodizado electroquímico en medio $\mathrm{CH}_{4} \mathrm{O}_{3} \mathrm{~S}$ y calentadas a diferentes temperaturas y atmosferas.

Tabla 4.10. Valores medios de $N_{D}$ y $E_{F B}$, de las nanoestructuras sintetizadas por anodizado electroquímico en medio $\mathrm{HNO}_{3}$ y calentadas a diferentes temperaturas y atmosferas.

.216

Tabla 4.11. Rango de variables y niveles del diseño de experimentos .221

Tabla 4.12. Diseño factorial completo utilizado para la optimización de las nanoestructuras de $\mathrm{WO}_{3}$. 
Tabla 4.13. Experimentos realizados en el diseño Box-Behnken 226

Tabla 4.14. Tabla ANOVA para el modelo cuadrático de superficie de respuesta en la optimización de las nanoestructuras $\mathrm{WO}_{3}$ .228

Tabla 4.15. Valores característicos del análisis ANOVA..........................................229

Tabla 4.16. Valores óptimos de los tres factores..................................................232

Tabla 4.17. Concentración de IMP en cada muestra degradada.............................243

Tabla 4.18. Tabla resumen de los compuestos intermedios identificados con su $\mathrm{m} / \mathrm{z}$ y tiempo de retención

Tabla 4.19. Concentración de clorfenvinfos en cada muestra degradada 257

Tabla 4.20. Tabla resumen de los compuestos intermedios identificados con su $\mathrm{m} / \mathrm{z}$ y tiempo de retención. 271

Tabla 4.21. Concentración de fosmet en cada muestra degradada .277

Tabla 4.22. Tabla resumen de los compuestos intermedios identificados con su $\mathrm{m} / \mathrm{z}$ y tiempo de retención. 286

Tabla 4.23. Concentración de fenamifos en cada muestra degradada 292

Tabla 4.24. Tabla resumen de los compuestos intermedios identificados con su $\mathrm{m} / \mathrm{z}$ y tiempo de retención .301 



\section{Capítulo 1}

Introducción 



\section{Capítulo 1. \\ Introducción}

1. Pesticidas. Clasificación, propiedades y usos.

1.1. Visión general de los pesticidas y clasificación.

La cifra de población mundial aumenta cada año marcando una tendencia al alza que seguirá en las próximas décadas. Si en el 1950 la población mundial contaba con 2529 millones de personas, en el año 2018 esta cifra aumentó hasta 7500 millones. Esta tendencia se calcula que se mantendrá como mínimo hasta el año 
2050 [1]. Según la Figura 1.1, en ese año, el dato de población que se espera es de 9150 millones de personas.

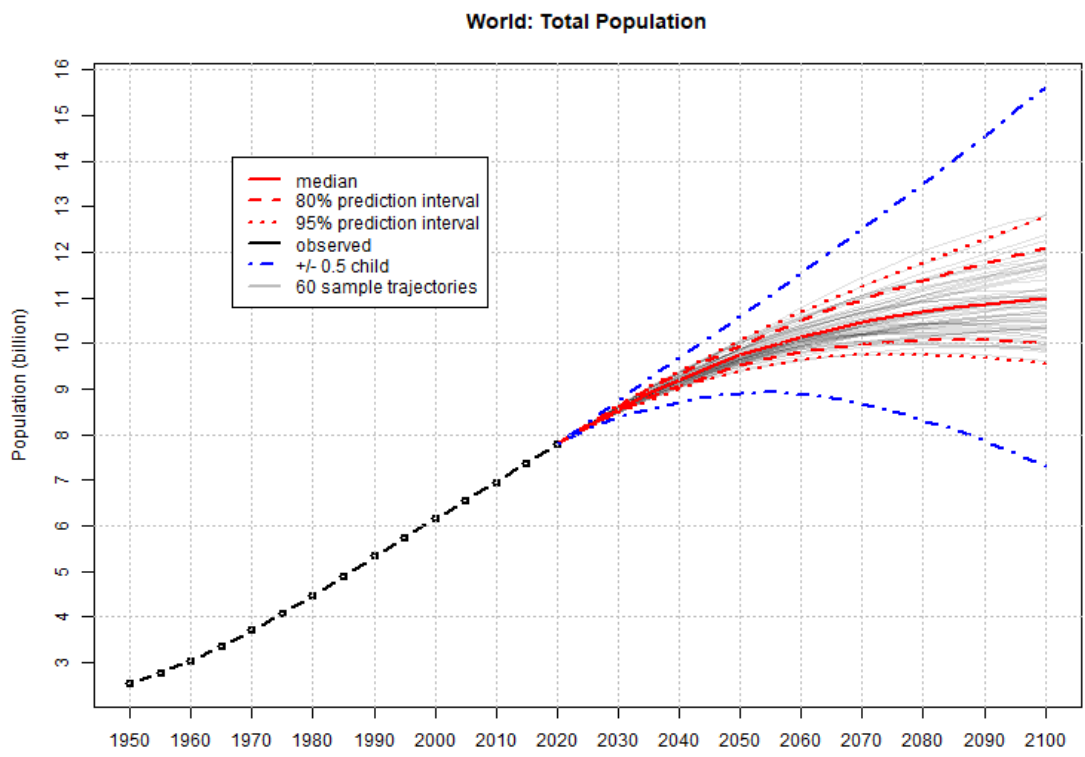

Figura 1.1 Población mundial del 1950 al 2050 según Naciones Unidas [1].

Con estas expectativas, la necesidad de incrementar la producción de alimentos cada vez es mayor, además de obtenerlos en un plazo de tiempo mucho menor. Todo esto lleva a la búsqueda de soluciones que den como resultado un mayor rendimiento de las cosechas y minimicen las posibles pérdidas.

Actualmente, con el fin de satisfacer la demanda de productos agrícolas, los agricultores se ven con la obligación de llevar a cabo medidas de emergencia contra las plagas que afecten a sus cosechas, siendo una de ellas el uso de pesticidas. Pero no son todo ventajas lo que aporta esta solución, ya que debido a la falta de información de los agricultores, éstos usan de manera desproporcionada estas sustancias, ocasionando graves problemas medioambientales, posteriormente.

Los pesticidas se desarrollaron ya que se necesitaban sustancias que combatiesen posibles plagas principalmente en la agricultura, aunque también en zonas verdes como pueden ser parques, jardines, etc. El propósito de los pesticidas es luchar contra las plagas objetivo absorbiéndose por éstas hasta acabar con ellas. Estas 
sustancias tienen la capacidad de llegar a todas las células vivas, atravesándolas y provocando una alta toxicidad en ellas hasta incluso provocar su muerte. Por tanto, si estos pesticidas entran en contacto con seres vivos que no son objetivo, pueden provocar graves efectos secundarios e incluso extinción de especies.

De acuerdo a la Directiva de la Unión Europea 91/414/CEE [2], se considera producto fitosanitario o plaguicida todo aquel que contenga principios activos cuya finalidad es:

- Preservar las cosechas impidiendo que elementos dañinos les afecten.

- Mejorar la subsistencia de los productos agrícolas.

- Eliminar los seres vivos no deseados como son las malas hierbas o plagas de insectos.

Para conseguir una máxima eficiencia, los pesticidas presentan una formulación concreta que contiene los siguientes ingredientes comunes:

1. Materia o ingrediente activo: este ingrediente es el componente mayoritario del pesticida y el encargado de intervenir contra la plaga. Pueden existir varios ingredientes activos en un pesticida con el fin de ampliar su rango de aplicación o maximizar la acción contra cierta plaga.

2. Materias o ingredientes inertes: su principal función es dar cuerpo al producto fitosanitario consiguiéndose una buena manipulación y perfecto acabado.

3. Coadyuvantes: se utilizan para mejorar las características físicas y químicas del ingrediente activo. Entre ellos destacan los mojantes que sirven para aumentar la viscosidad, los dispersantes para aumentar la homogeneidad y los estabilizadores que evitan la rápida degradación de la materia activa.

4. Aditivos: no aumentan la eficacia del pesticida pero se utilizan principalmente como medidas de seguridad para los seres vivos y para llevar a cabo el cumplimiento de la legislación vigente en cada momento.

No obstante, cada pesticida experimenta un comportamiento en función de los valores de las características físico-químicas propias. En la siguiente tabla se observa el comportamiento esperado en función del intervalo de valores que presenten en cada característica. 
Tabla 1.1. Comportamiento medioambiental de los pesticidas en función de los parámetros físicoquímicos [3].

\begin{tabular}{|c|c|c|}
\hline PARÁMETRO & VALORES & COMPORTAMIENTO \\
\hline \multirow{2}{*}{ Presión de vapor } & $<1 \cdot 10^{-8} \mathrm{~Pa}$ & Bajo potencial para volatilizarse \\
\hline & $>1 \cdot 10^{-3} \mathrm{~Pa}$ & Alto potenical para volatilizarse \\
\hline \multirow{2}{*}{ Solubilidad en agua } & \multirow{2}{*}{$1-\left.10^{5} \mathrm{mg} \cdot\right|^{-1}$} & $\begin{array}{l}\text { Baja solubilidad: mayor afinidad por el } \\
\text { suelo }\end{array}$ \\
\hline & & $\begin{array}{c}\text { Alta solubilidad: mayor afinidad por el } \\
\text { agua }\end{array}$ \\
\hline \multirow{2}{*}{ Constante de Henry } & $<1 \cdot 10^{-5} \mathrm{~atm} \mathrm{m^{3 }} \mathrm{mol}^{-1}$ & Afinidad por el medio hídríco \\
\hline & $>1 \cdot 10^{-5} \mathrm{~atm} \mathrm{~m} \mathrm{~mol}^{-1}$ & Alto potencial para volatilizarse \\
\hline \multirow{2}{*}{$\begin{array}{l}\text { Coeficiente de } \\
\text { partición octanol- } \\
\text { agua }\end{array}$} & $10-10^{2}$ & Afinidad por el medio hídrico \\
\hline & $10^{3}-10^{5}$ & $\begin{array}{c}\text { Afinidad por la materia orgánica, suelo, } \\
\text { sedimento o biota }\end{array}$ \\
\hline \multirow{2}{*}{$\begin{array}{l}\text { Coeficiente de } \\
\text { adsorción al carbono } \\
\text { orgánico }\end{array}$} & $10-10^{3} \mathrm{ml} \cdot \mathrm{g}^{-1} \mathrm{C} . \mathrm{O}$. & Afinidad por el agua y el aire \\
\hline & $10^{3}-10^{6} \mathrm{ml} \cdot \mathrm{g}^{-1} \mathrm{C} . \mathrm{O}$ & $\begin{array}{c}\text { Afinidad por la materia orgánica, suelo, } \\
\text { sedimento o biota }\end{array}$ \\
\hline \multirow{3}{*}{ Índice GUS } & $>2.8$ & Elevado potenical de lixiviación \\
\hline & $2.8-1.8$ & Medio potenical de lixiviación \\
\hline & $<1.8$ & Bajo potenical de lixiviación \\
\hline
\end{tabular}

En la mayoría de los casos los pesticidas acaban llegando a ríos, mares y acuíferos, pero la concentración de éstos en el agua puede estar influenciada por los siguientes parámetros:

1. La velocidad de degradación que presenta cada pesticida tanto en agua como en suelo.

2. Flujo del río y parámetros fisicoquímicos del agua (por ejemplo, temperatura del agua y pH) que afectan a la dilución y a la degradación. 
3. Reservorios presentes en el río, mar o acuífero que afectan al tiempo que el agua está retenida junto con los pesticidas disueltos en ella.

4. La temporada del año en la que se encuentre ya que está directamente relacionada con el tipo de cultivo que se lleva a cabo y las condiciones meteorológicas. En el caso de España, y más concretamente la Comunidad Valenciana, se produce la siembra de los cultivos a principio de la primavera y se recolectan en verano, mientras que en menor cantidad existen los que se cultivan durante todo el año. Por tanto, los herbicidas, insecticidas y fungicidas se encontrarán en mayor cantidad durante la temporada de primavera y verano ya que es cuando se aplican principalmente.

Como se ha mencionado anteriormente, los pesticidas son sustancias químicas que pueden provocar graves efectos secundarios a seres vivos que no son objetivo y por tanto hay que tratarlos con cautela. Los principales riesgos que presentan son los siguientes:

- Riesgos para la agricultura. El uso de pesticidas en el campo no está exento de riesgos para la propia agricultura ya que puede conllevar peligros importantes para los vegetales. Entre los efectos secundarios perjudiciales más importantes se encuentran: la eliminación de depredadores naturales de plagas, la creación de resistencias en los vegetales hacia estos productos químicos y una variación en el equilibrio ecológico que hace que puedan surgir nuevas plagas.

- Riesgos para el medioambiente. Se trata de uno de los principales riesgos que ocasionan los pesticidas ya que éstos acaban directamente en él bien sea en plantas, suelo, bacterias o aguas, pero los posibles efectos adversos dependen de las características del ecosistema en el que se haya aplicado, de las propiedades tóxicas del compuesto, la cantidad de pesticida aplicada en los procedimientos fitosanitarios y de la movilidad y la persistencia del mismo en las diferentes partes del terreno.

- Riesgos para la salud humana. Los pesticidas pueden ocasionar importantes problemas en la salud de los seres humanos al provocar daños en el organismo como por ejemplo carcinogenicidad, mutagenicidad, alteraciones hormonales, etc. En la Figura 1.2 se puede observar las principales vías de entrada al organismo $[3,4]$. 


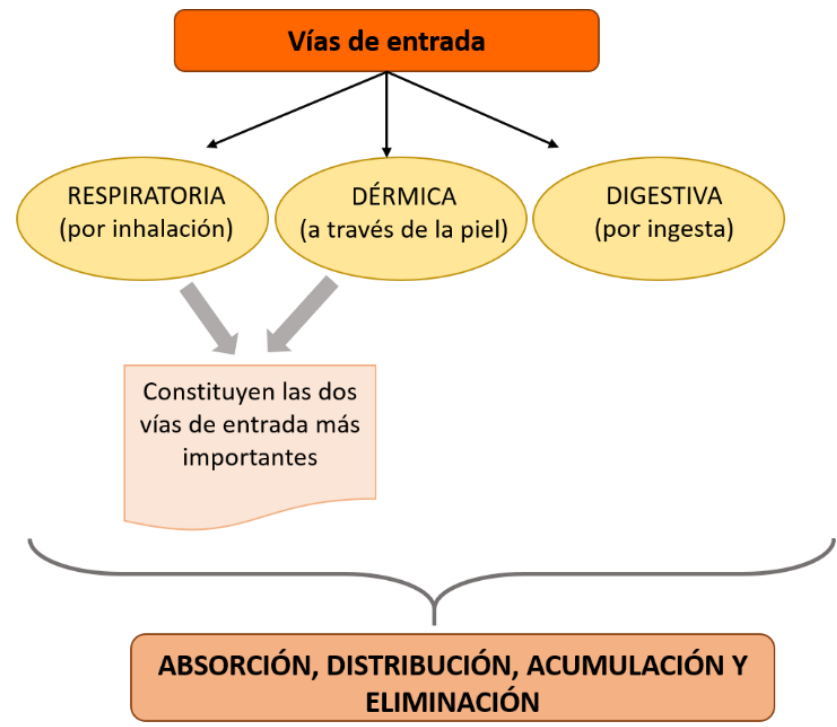

Figura 1.2. Principales vías de entrada del pesticida al organismo.

Una vez comentadas las principales características de los pesticidas, se van a clasificar de manera detallada. Esta clasificación se puede realizar en base a diferentes criterios:

1. Por tipo de plaga a la que atacan los pesticidas. Entre los grupos más comunes se encuentran para controlar las malezas, los insectos, los ácaros y los hongos.

2. Por estructura química del pesticida. La principal ventaja que ofrece este criterio es permitir identificar pesticidas con efectos parecidos sobre las plagas y el medioambiente. Dentro de la clasificación por estructura química se encuentra la clasificación de sustancias químicas combinando el grupo químico principal con mecanismo de ataque a las plagas. En la Tabla 1.2 se muestra esta clasificación [5]. 
Tabla 1.2. Clasificación de los pesticidas en función de la estructura química del pesticida.

\begin{tabular}{|c|c|c|}
\hline $\begin{array}{l}\text { Tipo de } \\
\text { producto }\end{array}$ & Modo o sitio de acción & Grupo químico \\
\hline \multirow{8}{*}{ Insecticidas } & \multirow{4}{*}{ Interferencia del sistema nervioso } & $\begin{array}{l}\text { Organoclorados, organofosforados, } \\
\text { carbamatos }\end{array}$ \\
\hline & & Reguladores del crecimiento \\
\hline & & $\begin{array}{l}\text { Avermectinas, nicotinoides- } \\
\text { nitrometilenos }\end{array}$ \\
\hline & & Nicotina \\
\hline & Reguladores del crecimiento & $\begin{array}{l}\text { Benzoil-fenilureas, benzamidas, } \\
\text { benzoil-hidrazinas }\end{array}$ \\
\hline & Toxinas alimentarias & Bacillus thuringiensis \\
\hline & Sistema respiratorio & Fosfuros, bromuros, etc \\
\hline & Tóxicos físicos & $\begin{array}{c}\text { Aceites minerales, tierra de diatomeas, } \\
\text { geles de sílice }\end{array}$ \\
\hline \multirow{10}{*}{ Fungicidas } & \multirow{2}{*}{$\begin{array}{l}\text { Inhibición de la síntesis de ácidos } \\
\text { nucleicos }\end{array}$} & $\begin{array}{l}\text { Fenilamidas, pirimidinas, derivados de } \\
\text { hidrocaruros aromáticos }\end{array}$ \\
\hline & & Derivados de benzimidazol \\
\hline & \multirow{2}{*}{ Mitosis y división celular } & Ditiocarbamatos, benzimidazoles \\
\hline & & Fenilureas, benzamidas \\
\hline & $\begin{array}{c}\text { Respiración: inhibición de la } \\
\text { producción de ATP en los procesos } \\
\text { enzimáticos del metabolismo } \\
\text { energético }\end{array}$ & $\begin{array}{l}\text { Carboximidas, quinonas, cúprico, } \\
\text { arsenicales, derivados del estaño, } \\
\text { disulfuros }\end{array}$ \\
\hline & Síntesis de aminoácidos y proteínas & Anilinopirimidinas \\
\hline & Transducción de señales & $\begin{array}{l}\text { Quinolinas, fenilpirroles, } \\
\text { dicarboximidas }\end{array}$ \\
\hline & \multirow{2}{*}{ Síntesis de lípidos y membrana } & $\begin{array}{l}\text { Dicarboximidas, hidrocarburos } \\
\text { aromáticos }\end{array}$ \\
\hline & & $\begin{array}{l}\text { Clorofenoles, nitroanilinas, } \\
\text { ditiocarbamatos, amidas }\end{array}$ \\
\hline & $\begin{array}{c}\text { Biosíntesis de esterol en las } \\
\text { membranas }\end{array}$ & Morfolinas, triazoles \\
\hline
\end{tabular}


Tabla 1.2. Clasificación de los pesticidas en función de la estructura química del pesticida. (Continuación)

\begin{tabular}{|c|c|c|}
\hline \multirow{3}{*}{ Fungicidas } & Alteración de la estructura celular & Dodecilguanidina \\
\hline & Acción múltiple & $\begin{array}{l}\text { Cúpricos, sulfúricos, ditiocarbamatos, } \\
\text { sulfamidas }\end{array}$ \\
\hline & $\begin{array}{c}\text { Inhibición de la acetil coenzima A } \\
\text { carboxilasa }\end{array}$ & Ariloxi-fenoxi, ciclohexanodionas \\
\hline \multirow{14}{*}{ Herbicidas } & $\begin{array}{l}\text { Inhibición de la aceto lactato } \\
\text { sintetasa }\end{array}$ & $\begin{array}{l}\text { Imidazolinonas, sulfonilureas, } \\
\text { sulfonamidas }\end{array}$ \\
\hline & $\begin{array}{l}\text { Inhibición de la formación de } \\
\text { microtúbulos }\end{array}$ & Dinitroanilinas \\
\hline & \multirow{2}{*}{ Auxinas sintéticas } & $\begin{array}{l}\text { Clorofenóxidos, derivados del ácido } \\
\text { benzoico }\end{array}$ \\
\hline & & $\begin{array}{c}\text { Ácidos piridin carboxílicos, ácidos } \\
\text { quinolín carboxílicos }\end{array}$ \\
\hline & $\begin{array}{l}\text { Inhibición de la fotosíntesis en el } \\
\text { fotosistema II }\end{array}$ & $\begin{array}{l}\text { Tirazinas, triazinonas, uracilos, ureas } \\
\text { sustituidas, carbamatos, amidas }\end{array}$ \\
\hline & $\begin{array}{l}\text { Inhibición de la fotosíntesis en el } \\
\text { fotosistema II y respiración }\end{array}$ & Benzonitrilos \\
\hline & \multirow{2}{*}{$\begin{array}{c}\text { Inhibición de la protoporfirinógeno } \\
\text { oxidasa }\end{array}$} & Difeniléteres, oxadiazoles \\
\hline & & Triazolinonas \\
\hline & Inhibición de la síntesis de lípidos & Tiocarbamatos \\
\hline & $\begin{array}{l}\text { Desviación del flujo electrónico en } \\
\text { el fotosistema I }\end{array}$ & Bipiridilos \\
\hline & $\begin{array}{l}\text { Inhibición de la síntesis de } \\
\text { carotenoides }\end{array}$ & Isoxasoles, nicotinanilidas \\
\hline & $\begin{array}{l}\text { Inhibición de la síntesis de } \\
\text { proteínas, metabolismo de lípidos y } \\
\text { división celular }\end{array}$ & Acetanilidas \\
\hline & $\begin{array}{l}\text { Interferencia en la actividad } \\
\text { enzimática y precipitación de } \\
\text { proteínas }\end{array}$ & Carboxílicos aromáticos \\
\hline & $\begin{array}{l}\text { Interferencia en el metabolismo del } \\
\text { fósforo }\end{array}$ & Arsenicales \\
\hline
\end{tabular}




\subsection{Problemática y usos de los pesticidas.}

El uso masivo de pesticidas puede provocar graves efectos al medioambiente llegando a contaminar gran parte de los ríos y acuíferos del planeta ya que presentan propiedades muy tóxicas, por tanto, ya se ha reconocido como un problema importante en muchos países. Desde la ONU (Organización de las Naciones Unidas) se pretende aclarar que el uso de pesticidas no tiene porqué implicar un mayor crecimiento de los alimentos animando a iniciar un proceso de cambio a nivel mundial con el fin de obtener una producción agrícola más sana [6].

En cuanto a la toxicidad que presentan los pesticidas hay diversos indicadores para medir y clasificar cada fitosanitario, entendiéndose toxicidad por la capacidad que tienen los plaguicidas para producir daños celulares o incluso muertes a seres vivos tanto objetivo como no objetivo. Los factores que más influyen en el nivel de toxicidad de un pesticida son la dosis y el tiempo de exposición. Como una primera clasificación de toxicidad se encuentran los pesticidas con toxicidad aguda y los pesticidas con toxicidad no aguda. La primera de ellas ocurre cuando los efectos producidos por la sustancia química se manifiestan a las horas o minutos después de haberse expuesto una única vez al pesticida. En cambio, los pesticidas con toxicidad no aguda manifiestan los efectos cuando han trascurrido periodos medianos o largos y sus daños pueden ser reversibles, pero en ambos tipos de toxicidad los efectos se pueden producir en sistemas reproductivos, endocrinos, oftalmológicos, cutáneos, neurológicos, cancerígenos y mutagénicos.

Entre los indicadores principales que clasifican los pesticidas según su toxicidad destacan los siguientes:

- DL50: este indicador hace referencia a la dosis letal media, es decir la cantidad de sustancia química que provoca la muerte en el $50 \%$ de la población de animales analizada (mayoritariamente ratas y conejos) cuando el pesticida entra en contacto mediante la vía oral o dérmica. La $\mathrm{DL}_{50}$ se mide en miligramos de sustancia activa por kilogramos de peso del animal (mg sustancia activa/kg animal). En la Tabla $1.3 \mathrm{se}$ muestra la clasificación que hace la OMS respecto a la toxicidad para los pesticidas en función de la $\mathrm{DL}_{50}[5]$. 
Se ha comprobado que el $15 \%$ de los pesticidas se encuentran dentro de las categorías con más riesgo (la y lb), el 38\% se encuentran dentro de la categoría considerada como moderadamente peligrosa (II), el $18 \%$ dentro de poco peligroso (III) y el $29 \%$ restante no ofrece peligro (IV).

- $\quad \mathrm{CL}_{50}$ : En el caso de que el contacto sea por inhalación se utiliza este indicador expresándose en miligramos de la sustancia por litro de agua o aire (ppm). Esta forma se utiliza para animales acuáticos o en el caso de ambientes cerrados.

- $\quad$ NOEL: este indicador se utiliza cuando el contacto no se ha producido una única vez, sino que se han producido exposiciones continuas debido principalmente a los alimentos, agua potable o aires. Hace referencia a la cantidad de pesticida que puede ser ingerida durante la vida sin ocasionar riesgos notorios a la salud, conociéndose también como ingesta diaria admisible. Se expresa en miligramos diarios de producto por kilogramo de peso corporal y ya viene tabulado para una gran cantidad de alimentos y pesticidas [7].

Tabla 1.3. Clasificación del riesgo toxicológico de los plaguicidas según la OMS [5].

\begin{tabular}{|c|c|c|c|c|}
\hline \multirow{2}{*}{$\begin{array}{c}\text { Clasificación de los } \\
\text { riesgos de los } \\
\text { plaguicidas }\end{array}$} & \multicolumn{4}{|c|}{$\begin{array}{c}\text { Dosis letal media del ingrediente activo (mg/kg vivo) que } \\
\text { causa la muerte del } 50 \% \text { de los animales experimentales } \\
\text { (DL }\end{array}$} \\
\cline { 2 - 5 } & \multicolumn{2}{|c|}{ Forma líquida } & \multicolumn{2}{c|}{ Forma sólida } \\
\cline { 2 - 5 } Oral & Dermal & Oral & Dermal \\
\hline $\begin{array}{c}\text { Clase I.a. Producto } \\
\text { sumamente peligroso }\end{array}$ & 20 o menos & 40 o menos & 5 o menos & 10 o menos \\
\hline $\begin{array}{c}\text { Clase I.b. Producto muy } \\
\text { peligroso }\end{array}$ & 20 a 200 & 40 a 400 & 5 a 50 & 10 a 100 \\
\hline $\begin{array}{c}\text { Clase II. Producto } \\
\text { moderadamente } \\
\text { peligroso }\end{array}$ & 200 a 2000 & 400 a 4000 & 50 a 500 & 100 a 1000 \\
\hline $\begin{array}{c}\text { Clase III. Producto poco } \\
\text { peligroso }\end{array}$ & 2000 a 3000 & mayor de & 500 a 2000 & Mayor de \\
\hline $\begin{array}{c}\text { Clse IV. Producto que } \\
\text { normalmente no ofrece } \\
\text { peligro }\end{array}$ & Mayor de 3000 & - & Mayor de & \\
\hline
\end{tabular}


Además de la toxicidad de un pesticida, también es importante tener en cuenta la persistencia en el suelo y en el agua que poseen. Esto quiere decir el tiempo que la sustancia química subsiste en el ambiente en el que se encuentra. Por tanto, cuanto mayor sea la permanencia en el medio, mayor persistencia tendrá ese pesticida. Para clasificar los plaguicidas en función de este parámetro se utiliza la DT $_{50}$ (vida media de la sustancia) y se define como el tiempo que ha de transcurrir para poder transformar o degradar la sustancia química tanto en aire, agua como suelo. Finalmente, los pesticidas quedan clasificados según este parámetro de la siguiente manera [8].

Tabla 1.4. Clasificación de pesticidas según la $\mathrm{DT}_{50}$.

\begin{tabular}{|c|c|}
\hline Clase & DT $_{\mathbf{5 0}}$ (días) \\
\hline Extrema & $>120$ \\
Alta & $120-60$ \\
Mediana & $60-30$ \\
Ligera & $30-15$ \\
No persistente & $<15$ \\
\hline
\end{tabular}

Otro problema que conlleva el uso masivo y descontrolado de pesticidas es que muchos organismos crean resistencia hacia esas sustancias químicas, haciéndose menos vulnerables. Esta nueva característica de resistencia lo transmiten a su descendencia formando así nuevas poblaciones con una gran resistencia a esos pesticidas por lo que dejan de ser efectivos y llegando a necesitarse hasta mil veces la cantidad que se aplicó por primera vez. Por tanto, los pesticidas pierden eficacia cuando se utilizan dosis altas y con ello se produce una mayor acumulación del ingrediente activo tanto en aire, agua, suelo y alimentos aumentando el riesgo de toxicidad tanto en el medioambiente como en los seres humanos además de suponer un mayor coste el tratamiento de plagas.

En cuanto al uso de pesticidas según la FAOSTAT desde el 1990 hasta el 2016 se ha incrementado considerablemente como se muestra en la Figura 1.3. 


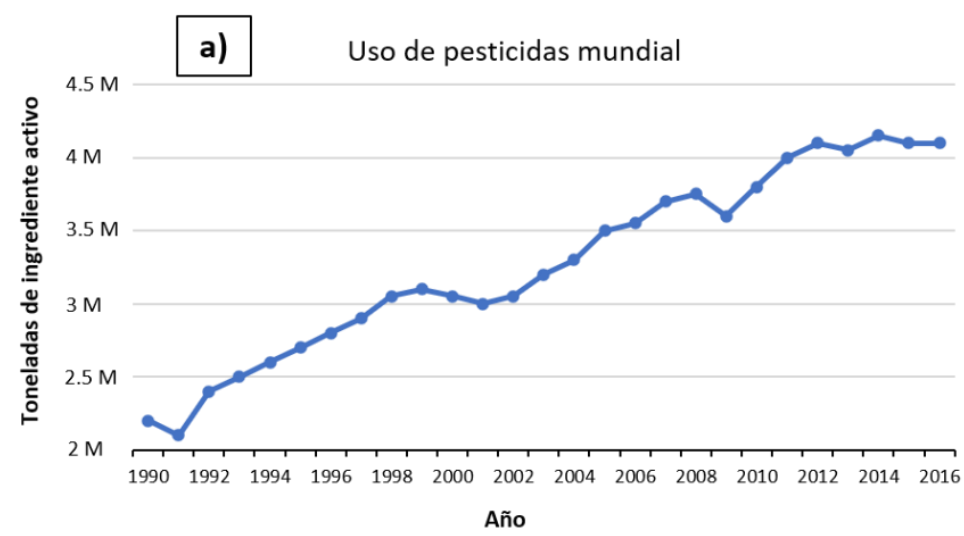

Venta de pesticidas. Comparación del año 2016 con 2011

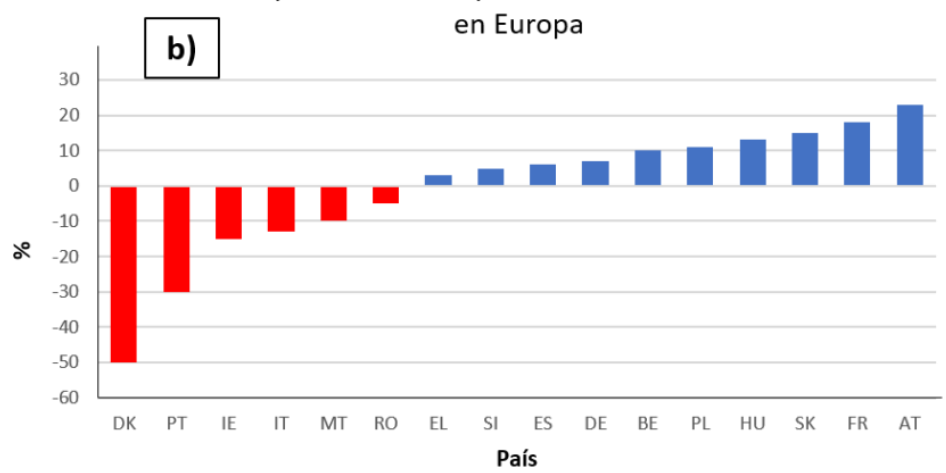

Figura 1.3. a) Uso de pesticidas mundial entre 1990 y 2016, b) porcentaje de ventas en el 2016 comparado con el porcentaje en 2011 [9].

\section{Pesticidas organofosforados. Clasificación, propiedades y legislación.}

Los pesticidas organofosforados (OP) son los más utilizados en la agricultura mundial, superando ya a los pesticidas organoclorados debido a su mayor efectividad. El primer pesticida organofosforado que se creó fue el tetraetilpirofosfato (TEPP) en 1854 por Clemont. Se usó principalemte durante la II Guerra Mundial con los conocidos "gases nerviosos" ya que cuenta con propiedades muy tóxicas tanto en insectos como en humanos. Desde 1945 se han sintetizado más 
de 40.000 compuestos, de los cuales alrededor de 50 son los más empleados habitualmente [10].

La estructura química de estos pesticidas cuenta con ésteres de ácido fosfórico y se usan tanto en la industria como en situaciones domésticas. En la Figura 1.4 se muestra esquematizada su estructura química.

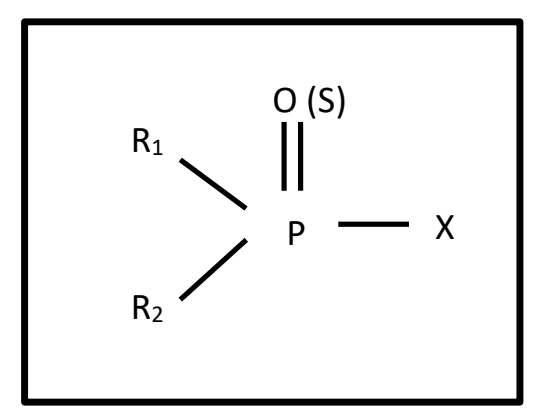

Figura 1.4. Estructura química en común de los pesticidas organofosforados.

Esta fórmula fue descrita por Schrader en 1937 en la que $R_{1}$ y $R_{2}$ pueden ser diferentes compuestos (por ejemplo grupos alquil, amida, alcoxi, tiol), la $\mathrm{X}$ un halógeno, tiocianato, cianuro, tiofenoxi, fosfato, carboxilo, etc $[4,11]$ y el oxígeno unido por el doble enlace al fósforo puede ser substituido por azufre.

\subsection{Clasificación de los pesticidas organofosforados.}

En base a los compuestos que aparecen como $R_{1}, R_{2}$ y $X$ se proponen varias clasificaciones de los pesticidas organofosforados pero la más utilizada es la realizada por Holmstedt. En la Figura 1.5 se muestra esta clasificación. 


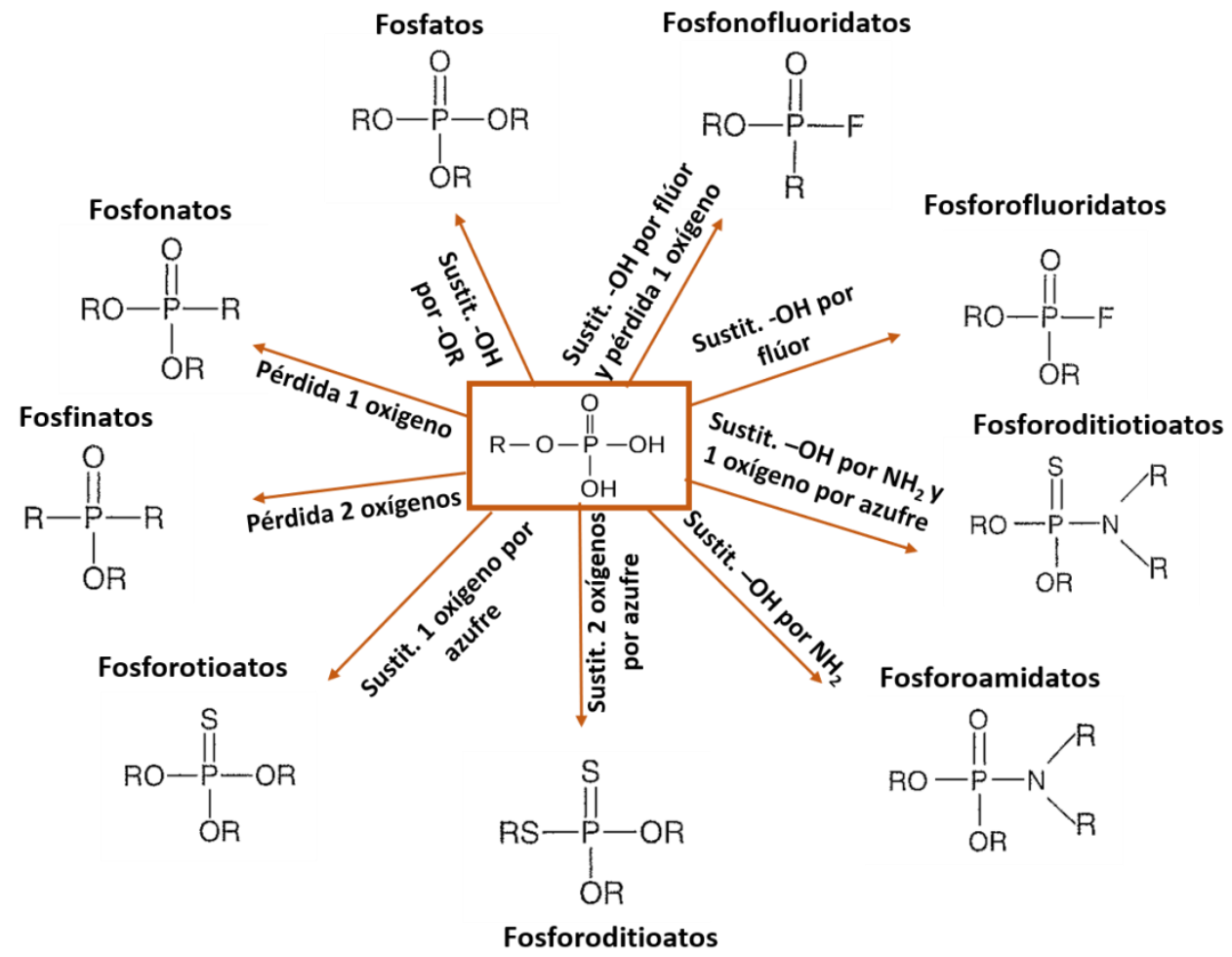

Figura 1.5. Clasificación de los pesticidas organofosforados según Holmstedt [11].

Tienen un amplio abanico de aplicaciones, pero entre las más comunes destacan la agricultura, en aplicaciones domésticas, en aplicaciones veterinarias y en zonas verdes como son jardines y parques.

\subsection{Propiedades de los pesticidas organofosforados.}

Aunque dentro de los pesticidas organofosforados hay una gran variedad de subclasificaciones, las propiedades físico-químicas y biológicas que en general cumplen todos ellos son las siguientes [12,13]:

- Presión de vapor mediana, dando lugar a pesticidas volátiles y facilitando la inhalación por parte del ser vivo.

- Cuentan con una alta solubilidad en medio acuoso además de ser liposolubles. 
- Se degradan parcialmente ya que pueden sufrir hidrolisis, pero su persistencia en el ambiente es elevada.

- Poseen una alta toxicidad.

En cuanto a la toxicidad de los pesticidas organofosforados, se ha demostrado que tanto las plagas objetivo como cualquier ser vivo son envenenados al entrar en contacto con este pesticida ya que se produce la fosforilación de la enzima acetilcolinesterasa (ACE). Este enzima es la responsable de producir la hidrolisis y su posterior cese de la actividad biológica de la acetilcolina, un neurotransmisor, en tan solo un segundo. Una vez se ha producido la inhibición de la ACE (alrededor del 70\%), la acetilcolina se acumula dando lugar a una alta toxicidad en las terminaciones nerviosas y provocando una estimulación extra de la actividad eléctrica y de los sistemas simpático y parasimpático. Además, se produce una muerte de las células a causa de los inhibidores de ACE al suceder reacciones intracelulares que dan lugar a una acumulación de iones de calcio y producción de radicales libres. Esta producción de radicales libres afecta principalmente al cerebro al ocasionar estrés oxidativo y a los lípidos dando lugar a especies de peroxidación como son el F2-isoprostano y el F4-neuroprostano. Estas especies se utilizan como biomarcadores de la presencia de un deterioro oxidativo de las neuronas. Otro efecto que tiene el contacto con este tipo de pesticidas es la activación de la proteína quinasa $\mathrm{C}$ favoreciendo la aparición de tumores o la inhibición de la síntesis de ADN y replicación de las células neuronales. A continuación, en la Figura 1.6, se esquematiza este proceso [10,14]. 
a)

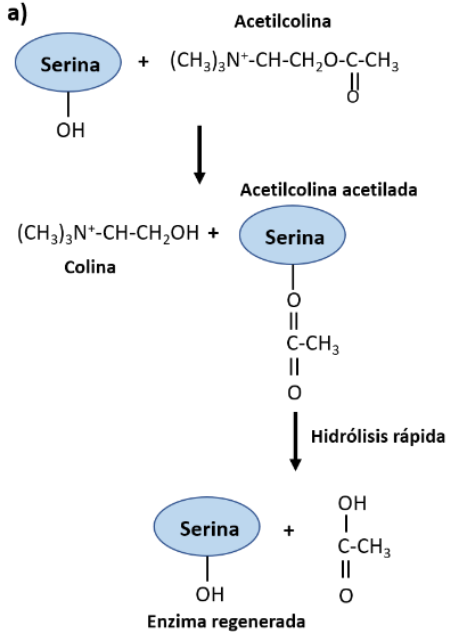

Mecanismo de acción de las colinesterasas b)

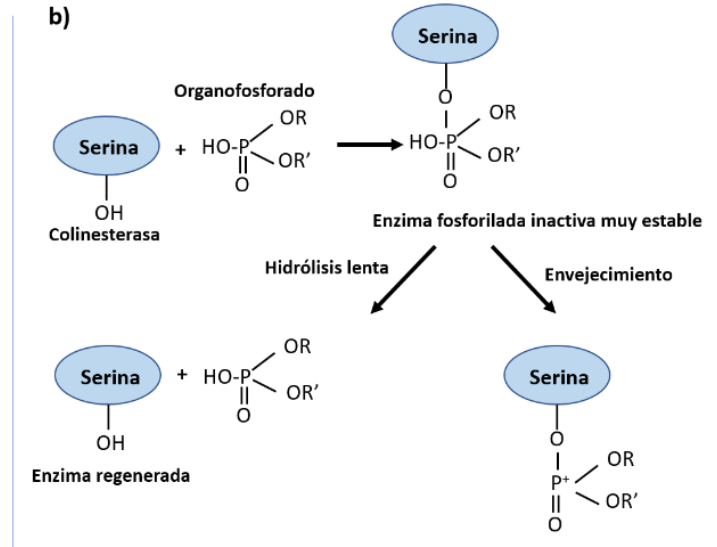

Complejo fosforilado extremadamente estable

Inhibición de las colinesterasas en presencia de pesticidas organofosforados

Figura 1.6. a) Mecanismo de acción de las colinesterasas, b) Inhibición de las colinesterasas en presencia de pesticidas organofosforados.

Entre los síntomas más destacados de envenenamiento a causa de los pesticidas organofosforados se encuentran dolor de cabeza, vértigo, problemas para conciliar el sueño, espasmos, coma y parálisis respiratoria. Además, se pueden manifestar otros síntomas menos agudos al tiempo de haber sufrido una exposición como son una debilidad muscular y problemas para respirar.

Por tanto, el gran uso de los pesticidas organofosforados en todo el mundo y la falta de información a nivel general sobre sus efectos produce un alto riesgo para la salud y el medioambiente ya que pueden ocasionar desde un simple mareo o malestar hasta incluso la muerte [15].

También se han estudiado las propiedades que presentan estos pesticidas cuando entran en contacto con el medioambiente. Los resultados del uso de estos compuestos como agentes de control de plagas en cultivos y animales, así como la eliminación de plagas en ganado vacuno y ovino hacen que se hayan encontrado en el suelo, agua de río, aguas subterráneas, sedimentos fluviales y en la atmósfera. Aunque se sabe que la persistencia de los insecticidas organofosforados (OP) se ve afectada por los procesos de transporte y por procesos de degradación química y biológica, la presencia de residuos de OP en 
zonas lejanas a las zonas donde se produjo la aplicación demuestran que estos pesticidas pueden ser transportados largas distancias por aire y agua. A continuación se describen los principales procesos de transporte de los pesticidas OP.

\section{Sorción}

La sorción influye en el comportamiento y el destino de los pesticidas en el medio ambiente. La sorción ocurre cuando una molécula de pesticida entra en contacto con el suelo en donde los constituyentes del pesticida y el mismo suelo establecen en cuestión de horas, un pseudo equilibrio. El término de sorción se define como la transferencia de un soluto entre un fluido y una fase sólida. La sorción depende de tres factores, que a menudo interactúan de manera compleja: las propiedades moleculares del soluto, la constitución del suelo y las reacciones que se lleven a cabo entre ambos medios [16].

La absorción de OP a los sólidos del suelo se produce gracias a superficies minerales que tienen una carga superficial dependiente del $\mathrm{pH}$ en soluciones acuosas. Dado que la sorción tiene lugar en un medio acuoso, las interacciones entre el agua y los OP son de particular importancia. Por ejemplo, los OP que son menos solubles en agua $y$, por lo tanto, son más hidrófobos, a menudo se adsorben más fuertemente al suelo. Por tanto, el comportamiento de un pesticida en el suelo se verá afectado por la naturaleza física de la sustancia química y la presencia de aditivos como agentes humectantes, emulsionantes y tensioactivos. Desafortunadamente, hay poca información disponible sobre los efectos de los componentes de los OP en el suelo, pero se sabe que las arcillas y los óxidos de hierro se encuentran entre las fracciones minerales más importantes que afectan a la adsorción [17].

La materia orgánica del suelo aún no está tan bien caracterizada como para permitir su relación entre la estructura y propiedades. Sin embargo, se ha observado que la adsorción de los pesticidas no iónicos (por ejemplo, los herbicidas diuron y linurón) varía mucho según la naturaleza de la materia orgánica con la que entran en contacto. La materia orgánica del suelo no es un solo material sino una mezcla de materiales sólidos y semisólidos que tienen una gama de propiedades que dependen de la historia de la muestra y su edad. La materia orgánica del suelo es la entidad principal responsable de la sorción de pesticidas, especialmente no iónicos. Cada vez está más claro que la cantidad de carbono orgánico no es el único parámetro que tiene gran influencia en las tasas 
de sorción de pesticidas, sino que dependen de varios factores. Además de la naturaleza del adsorbente y pesticidas, los factores que más influyen son la temperatura, composición iónica de la solución y relaciones suelo-agua [18].

\section{Volatilización}

La volatilización es un proceso importante en la disipación de algunos compuestos organofosforados de la superficie del suelo húmedo, el follaje o el agua. Los factores que influyen en este proceso son la presión de vapor $\left(v_{p}\right)$, la solubilidad del pesticida, el comportamiento de adsorción y la persistencia del compuesto, así como características ambientales como la temperatura, humedad y movimiento del aire. La $v_{p}$ varía según el OP utilizado; por ejemplo, el diclorvos tiene una $v_{p}$ de $1 \cdot 10^{-2} \mathrm{mmHg}$ y se volatiliza rápidamente bajo condiciones ambientales; esa es la razón de la alta acción fumigante del diclorvos y el control efectivo de insectos resultante. En contraste, el EPN (etil p-nitrofenilo tiobenceno) tiene una $v_{p}$ muy baja y es prácticamente no volátil. Además, las tasas de volatilización en hojas de árboles $u$ otros sustratos que no sean el suelo generalmente son más altas que las del suelo. Por ejemplo, la tasa de volatilización del metil paratión $\left(v_{p} 2 \cdot 10^{-5}\right.$ $\mathrm{mmHg}$ ) en una hoja y en el suelo húmedo fue de $0.44 \mathrm{\mu g} / \mathrm{cm}^{2} /$ ha y 0,03 $\mu \mathrm{g} / \mathrm{cm}^{2} /$ ha, respectivamente [17].

\section{Lixiviación}

El término lixiviación se refiere al movimiento de residuos de pesticidas en el perfil del suelo, y en las aguas subterráneas a través del agua de filtración. La exposición de los organismos acuáticos a los pesticidas en el agua subterránea puede ser preocupante, dependiendo de la toxicidad y concentración de los productos químicos. Los factores que influyen en el potencial de lixiviación incluyen propiedades químicas, comportamiento de sorción y persistencia, además de variables ambientales como la lluvia y la porosidad del suelo.

Algunos compuestos organofosforados, como el clorpirifos [19], son relativamente no móviles en el perfil del suelo, porque se unen fuertemente a la materia orgánica. Un estudio realizado por McCall en 1985 [20] mostraron que el clorpirifos estaba confinado a $5 \mathrm{~cm}$ desde la superficie terrestre después de su aplicación. Esas observaciones también fueron confirmadas por M. Oliver [21], en donde los residuos de los pesticidas fueron encontrados como máximo a $9 \mathrm{~cm}$ desde el suelo[19]. 


\section{Escorrentía}

El transporte de pesticidas sobre la superficie de los campos tratados a través de agua o sedimentos en movimiento es una ruta importante de disipación de pesticidas. La escorrentía es preocupante, porque los organismos acuáticos no objetivo podrían verse afectados por los pesticidas que se mueven a las vías fluviales desde los sitios de aplicación. Generalmente, los pesticidas con una solubilidad mayor a $10 \mathrm{mg} / \mathrm{L}$ se moverán principalmente debido a la escorrentía, y los pesticidas menos solubles se moverán principalmente por sorción y erosión de las partículas del suelo. El movimiento de compuestos muy solubles depende principalmente del grado de solubilidad y de factores del medio ambiente como la Iluvia y la conductividad hidráulica del suelo. El movimiento de productos químicos altamente adsorbidos al suelo ocurre principalmente debido a un proceso ligado a la erosión. La cantidad de clorpirifos transportados por escorrentía a un estanque, después de tres aplicaciones continuas, en un estudio de EE. UU. alcanzó solo el $0.03 \%$. Del mismo modo, aproximadamente el $0.1 \%$ del diazinón aplicado estuvo presente en la escorrentía de los campos de maíz. Sin embargo, otros compuestos OP altamente solubles en agua como el fenamifos (400 mg/L) pueden migrar más fácilmente a otras aguas superficiales debido a la baja unión con la matriz del suelo [22].

\subsection{Legislación de pesticidas organofosforados.}

En cuanto a la legislación mundial de pesticidas organofosforados todavía no existe un consenso por el cual quede regulado el uso o prohibición de los pesticidas, y por tanto cada país es responsable de esta decisión, como ejemplo está el caso del paratión, cuya comercialización y uso están prohibidos en muchos países, incluyendo España, pero en cambio en Colombia se sigue usando. A nivel europeo sí que existen reglamentos y directivas que regulan el uso de estas sustancias. Por ahora las 4 directivas que hay para regular el uso de estos productos químicos son:

- Directiva 67/548/CEE del Consejo sobre aproximación de las disposiciones legales, reglamentarias y administrativas de los Estados Miembros relativas a la clasificación, envasado y etiquetado de las sustancias peligrosas. 
- Directiva 1999/45/CE del Consejo, sobre la aproximación de las disposiciones legales, reglamentarias y administrativas de los Estados Miembros relativas a la clasificación, envasado y etiquetado de preparados peligrosos.

- Reglamento (CEE) no 793/93 del Consejo, sobre evaluación y control del riesgo de sustancias existentes.

- Directiva 76/769/CEE relativa a la aproximación de las disposiciones legales, reglamentarias y administrativas de los Estados Miembros que limitan la comercialización y el uso de determinadas sustancias y preparados peligrosos [10].

Además, España también cuenta con más legislación para regular su uso. Existe una Ley General de Sanidad por la que diferentes departamentos trabajan conjuntamente para elaborar protocolos y ejecutan la legislación de sustancias tóxicas y peligrosas. Particularmente, es la Subdirección General de Salud ambiental y laboral del Ministerio de Sanidad la unidad competente para la aplicación y la transposición de la legislación europea sobre el control de productos químicos en todos los aspectos relacionados con la salud. Además, es la responsable, entre otras funciones, del registro de plaguicidas de usos en salud pública, del sistema de notificación de sustancias nuevas, de la evaluación del riesgo de sustancias existentes, de la directiva de limitaciones, de la exportación e importación de sustancias y productos químicos peligrosos, de la clasificación y etiquetado de sustancias y preparados químicos peligrosos, de la evaluación de la peligrosidad toxicidad de los productos fitosanitarios, zoosanitarios y fertilizantes, y de la homologación de productos para el tratamiento de piscinas. La legislación española que regula los biocidas se fundamenta en las directivas europeas y su transposición para nuestro país. A continuación, en la Tabla 1.5 aparecen resumidas las principales disposiciones que se han aprobado en nuestro país desde el 1983 [23-25]: 
Tabla 1.5. Principales disposiciones en España que regulan los pesticidas organofosforados.

\begin{tabular}{|c|c|}
\hline ÁMBITO & LEGISLACIÓN \\
\hline $\begin{array}{c}\text { Reglamentación Técnico-Sanitaria para la fabricación, } \\
\text { comercialización y utilización de plaguicidas. }\end{array}$ & $\begin{array}{c}\text { Real Decreto } 3349 / 1983 \text {, de } 30 \text { de } \\
\text { noviembre }\end{array}$ \\
\hline $\begin{array}{c}\text { Se modifica la Reglamentación Técnico-Sanitaria para } \\
\text { la fabricación, comercialización y utilización de los } \\
\text { plaguicidas. }\end{array}$ & $\begin{array}{l}\text { Real Decreto } 162 / 1991 \text {, de } 8 \text { de } \\
\text { febrero }\end{array}$ \\
\hline $\begin{array}{l}\text { Se normalizan la inscripción y funcionamiento del } \\
\text { Registro de Establecimientos y Servicios Plaguicidas. }\end{array}$ & Orden de 24 de febrero de 1993 \\
\hline $\begin{array}{l}\text { Se prohíbe la comercialización y utilización de } \\
\text { plaguicidas de uso ambiental que contiene } \\
\text { determinados ingredientes activos peligrosos. }\end{array}$ & Orden de 4 de febrero de 1994 \\
\hline $\begin{array}{c}\text { Se establece la normativa reguladora de la } \\
\text { homologación de cursos de capacitación para realizar } \\
\text { tratamientos con plaguicidas. }\end{array}$ & Orden de 8 de marzo de 1994 \\
\hline $\begin{array}{c}\text { Se modifica la Reglamentación Técnico-Sanitaria para } \\
\text { la fabricación, comercialización y utilización de los } \\
\text { plaguicidas. }\end{array}$ & $\begin{array}{l}\text { Real Decreto } 443 / 1994 \text {, de } 11 \text { de } \\
\text { marzo }\end{array}$ \\
\hline $\begin{array}{c}\text { Comercialización de Biocidas en el ámbito europeo, } \\
\text { estableciendo principios comunes de evaluación y } \\
\text { autorización de biocidas evitando, de esta forma } \\
\text { barreras económicas/administrativas. }\end{array}$ & $\begin{array}{l}\text { Directiva 98/8/CE del Parlamento } \\
\text { Europeo y del Consejo de } 16 \text { de } \\
\text { febrero de } 1998\end{array}$ \\
\hline $\begin{array}{c}\text { Relativo a la primera fase del programa contemplado } \\
\text { en el apartado } 2 \text { del artículo } 16 \text { de la Directiva } \\
\text { 98/8/CE del Parlamento Europeo y del Consejo sobre } \\
\text { Biocidas. }\end{array}$ & $\begin{array}{l}\text { Reglamento CE № } 1896 / 2000 \text { de la } \\
\text { Comisión de } 7 \text { de septiembre de } 2000\end{array}$ \\
\hline $\begin{array}{c}\text { Transposición de la Directiva 98/8/CE a nuestro } \\
\text { ordenamiento jurídico, por el que se regula el } \\
\text { proceso de evaluación para el registro, autorización y } \\
\text { comercialización de biocidas. }\end{array}$ & $\begin{array}{c}\text { Real Decreto } 1054 / 2002 \text { de } 11 \text { de } \\
\text { octubre }\end{array}$ \\
\hline $\begin{array}{l}\text { Relativo a la segunda fase del programa de trabajo } \\
\text { de diez años contemplado en el apartado } 2 \text { del } \\
\text { artículo } 16 \text { de la Directiva 98/8/CE del Parlamento } \\
\text { Europeo y del Consejo relativa a la comercialización } \\
\text { de biocidas y por el que se modifica el Reglamento } \\
\text { (CE) no } 1896 / 2000 \text {. }\end{array}$ & $\begin{array}{l}\text { Reglamento Ce № 2032/2003 de la } \\
\text { Comisión de } 4 \text { de noviembre de } 2003\end{array}$ \\
\hline $\begin{array}{c}\text { Relativo a la comercialización de productos } \\
\text { fitosanitarios y por el que se derogan las Directivas } \\
\text { 79/117/CEE y } 91 / 414 / \text { CEE del Consejo. }\end{array}$ & $\begin{array}{l}\text { Reglamento (CE) no } 1107 / 2009 \text { del } \\
\text { Parlamento Europeo y del Consejo, de } \\
21 \text { de octubre de } 2009\end{array}$ \\
\hline
\end{tabular}


Tabla 1.5. Principales disposiciones en España que regulan los pesticidas organofosforados. (Continuación)

\begin{tabular}{|c|c|}
\hline $\begin{array}{l}\text { Este Reglamento se modifica cada vez que una nueva } \\
\text { sustancia activa se aprueba o se renueva. Se puede } \\
\text { encontrar una base de datos actualizada de la } \\
\text { situación de las sustancias activas fitosanitarias aquí. } \\
\text { Las sustancias activas que se han incluido en la lista, } \\
\text { están siendo sometidas a un programa de revisión. }\end{array}$ & $\begin{array}{l}\text { Reglamento de Ejecución (UE) no } \\
540 / 2011 \text { de la Comisión, de } 25 \text { de } \\
\text { mayo de } 2011 \text {, por el que se aplica el } \\
\text { Reglamento (CE) no } 1107 / 2009 \text { del } \\
\text { Parlamento Europeo y del Consejo en } \\
\text { lo que respecta a la lista de sustancias } \\
\text { activas autorizadas. }\end{array}$ \\
\hline $\begin{array}{l}\text { Tabla 1.5. Principales disposiciones en España } \\
\text { que regulan los pesticidas organofosforados. } \\
\text { (Continuación) }\end{array}$ & $\begin{array}{l}\text { Tabla 1.5. Principales } \\
\text { disposiciones en España que } \\
\text { regulan los pesticidas } \\
\text { organofosforados. (Continuación) }\end{array}$ \\
\hline $\begin{array}{l}\text { Tabla 1.5. Principales disposiciones en España } \\
\text { que regulan los pesticidas organofosforados. } \\
\text { (Continuación) }\end{array}$ & $\begin{array}{l}\text { Tabla 1.5. Principales } \\
\text { disposiciones en España que } \\
\text { regulan los pesticidas } \\
\text { organofosforados. (Continuación) }\end{array}$ \\
\hline $\begin{array}{l}\text { Tabla 1.5. Principales disposiciones en España } \\
\text { que regulan los pesticidas organofosforados. } \\
\text { (Continuación) }\end{array}$ & $\begin{array}{c}\text { Tabla 1.5. Principales } \\
\text { disposiciones en España que } \\
\text { regulan los pesticidas } \\
\text { organofosforados. (Continuación) }\end{array}$ \\
\hline
\end{tabular}

\section{Pesticidas organofosforados elegidos a degradar.}

Una vez presentadas las diferentes subfamilias que existen dentro de los pesticidas organofosforados, se eligen 4 pesticidas, cada uno de una subfamilia diferente, con el fin de estudiar el proceso de degradación de subfamilias de pesticidas diferentes.

\subsection{Presentación del primer pesticida, fenamifos.}

El primero de ellos es el fenamifos (cuyo nombre según la IUPAC es etil 4-metiltiom-tolilisopropilfosforamidato) que pertenece a la subfamilia de los fosforoamidatos, según la Figura 1.5. Su principal función es controlar los 
nematodos presentes durante la producción agrícola en el momento de siembra o incluso antes de ella. Se trata de un pesticida muy tóxico para los mamíferos ya que cuenta con una $\mathrm{DL}_{50}$ oral de $8 \mathrm{mg} / \mathrm{kg}$ de ratas. Por tanto, se sitúa según la Tabla 1.3 dentro de la categoría lb), producto peligroso. En cuanto a su persistencia en el suelo, al presentar una vida media entre 20 y 87 días, según la Tabla 1.4 se clasifica como moderadamente persistente. Además, en la siguiente tabla se muestran las propiedades físico-químicas más importantes del pesticida.

Tabla 1.6. Propiedades físico-químicas del fenamifos [26,27].

\begin{tabular}{|c|c|c|}
\hline Propiedad fisico-química & Valor & Temperatura $\left({ }^{\circ} \mathrm{C}\right)$ \\
\hline Solubilidad en agua & $400 \mathrm{mg} / \mathrm{L}$ & 20 \\
Solubilidad en hexano & $10-20 \mathrm{~g} / \mathrm{L}$ & 20 \\
Peso molecular & $303.4 \mathrm{~g} / \mathrm{mol}$ & \\
Temperatura de fusión & $49{ }^{\circ} \mathrm{C}$ & \\
Constante de disociación pKa & 10.5 & \\
Log P (octanol-agua) & 3.23 & 20 \\
Densidad & $1.191 \mathrm{~g} / \mathrm{cm}^{3}$ & 23 \\
Presión de vapor & $0.12 \mathrm{mPa}$ & 20 \\
Constante de Henry & $9.1 \cdot 10^{-5} \mathrm{~Pa} \mathrm{~m} / \mathrm{mol}$ & 20 \\
Índice GUS & 0.49 & \\
\hline
\end{tabular}

Cuando se produce la oxidación de este pesticida se obtiene fenamifos sulfóxido (el nombre según la IUPAC es ácido $\mathrm{N}$-isopropilamidofosfórico etílico 4(metilsulfinil) -3-metilfenil éster), el cual también puede oxidarse, aunque en este caso más lentamente para dar fenamifos sulfona (cuyo nombre según la IPAC es (metilsulfonil) -m-tolil éster). Ambos metabolitos presentan valores de toxicidad parecidos a los del fenamifos aunque tienen una movilidad y persistencia en los medios más alta.

Al presentar una alta solubilidad en el agua (como se muestra en la Tabla 1.6), tanto el fenamifos como sus metabolitos tienen una gran capacidad para lixiviar por el suelo por lo que se encuentran con frecuencia residuos de estos compuestos tanto en aguas superficiales como en subterráneas. La estructura molecular del fenamifos se muestra en la Figura 1.7a) $[28,29]$. 


\subsubsection{Toxicidad del fenamifos}

La toxicidad del fenamifos se ha estudiado en organismos acuáticos y terrestres. Recientemente, Tanya Cáceres [30] determinó la toxicidad del fenamifos y sus metabolitos en el alga acuática Pseudokirchneriella subcapitata y el alga terrestre Chlorococcum. La toxicidad que mostró el fenamifos y sus metabolitos siguió el siguiente orden: fenamifos fenol> fenamifosulfona fenol> fenamifos sulfóxido fenol> fenamifos, aunque la toxicidad del pesticida puede variar entre especies, $y$ por lo tanto también es importante realizar pruebas de toxicidad a diferentes especies.

Entre los invertebrados terrestres, E. foetida ha sido reconocido como un organismo representante para evaluar la toxicidad de los xenobióticos, principalmente porque el crecimiento y la reproducción de esta especie está bien documentada. El LC 50 de fenamifos para este organismo correspondió a 795 $\mathrm{mg} / \mathrm{kg}$ en el suelo.

Sin embargo, la información sobre el efecto nocivo en estos invertebrados, después de una larga exposición en el suelo junto al fenamifos es poco conocida y, por lo tanto, se requiere una mayor investigación en esta área [31].

\subsubsection{Movilidad del fenamifos.}

Como se ha comentado anteriormente, según los datos de sorción y lixiviación documentados, el fenamifos se puede clasificar como un pesticida con una persistencia en el suelo moderada. Sin embargo, debido a sus características químicas, el fenamifos y sus principales productos de degradación (fenamifos sulfóxido (FSO) cuya estructura química está representada en la Figura 1.7b) y fenamifos sulfona cuya estructura química está representada en la Figura 1.7c)) tienen un gran potencial de lixiviación hasta llegar a aguas subterráneas. 

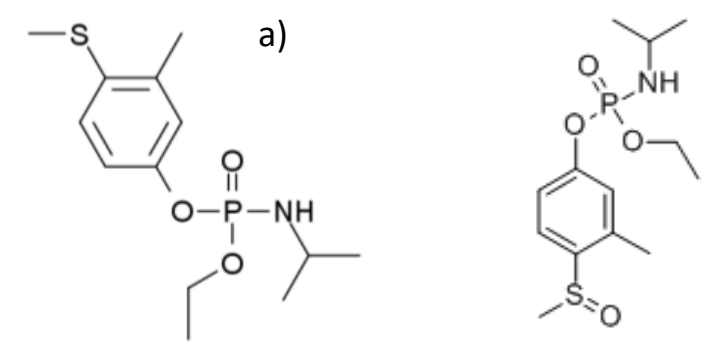

b)

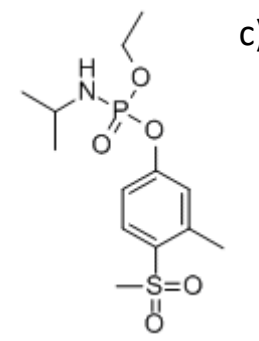

c)

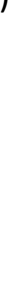

Figura 1.7. a) Estructura química del fenamifos, b) estructura de fenamifos sulfóxido y c) estructura del fenamifos sulfona.

Rai Kookana [32] estudió la transformación y degradación del fenamifos y sus metabolitos en suelos arenosos de Australia. En este estudio, el pesticida exhibió una vida media de 50 días en suelos superficiales y 140 días en suelos subterráneos, desapareciendo más rápido en suelos húmedos que en suelos secos. El compuesto original fue rápidamente oxidado a FSO y luego, aunque con tasas de degradación muy bajas, a fenamifosulfona. Existen estudios sobre la influencia de las propiedades del suelo en la degradación de fenamifos en 16 suelos de todo el mundo. En ellos se concluye que la vida media en suelos con un clima templado (alrededor de $16{ }^{\circ} \mathrm{C}$ ), variaron de 29.2 a 166.7 días, mientras que la vida media del compuesto en suelos de regiones tropicales (alrededor de $30{ }^{\circ} \mathrm{C}$ ) varió de 14.1 a 52.6 días.

La profundidad media a la que se lixivió el fenamifos y sus metabolitos, cuando se estudió en suelos arenosos en Australia, fue de $28 \mathrm{~cm}$. Unos estudios de lixiviación realizados en columnas bajo condiciones controladas, usando fenamifos, demostraron que el pesticida era relativamente móvil, encontrándose entre un 16.2-63.8\% de residuos en el lixiviado. Los principales metabolitos encontrados en el lixiviado fueron $\mathrm{FSO}_{\text {y }} \mathrm{FSO}_{2}$, que eran más móviles que el compuesto original. Se ha demostrado que la eliminación inadecuada de los residuos de fenamifos causaron contaminación en aguas subterráneas ya que la vida media del pesticida en condiciones anaerobias podría llegar hasta los 1000 años [33,34]. 


\subsubsection{Síntesis fenamifos}

En cuanto a la síntesis del pesticida, el fenamifos se obtiene gracias a la reacción entre el éster de cloro de fosfato y una amina. El éster de cloro de fosfato se obtiene al reaccionar oxicloruro de fósforo con un alcohol. La secuencia de reacciones completa se presenta a continuación [35]:<smiles></smiles><smiles>CCOP(=O)(NC(C)C)Oc1ccc(SC[C@H](C)NC(C)C)c(C)c1</smiles>

Fenamifos

Isopropil amina

Figura 1.8. Síntesis del fenamifos.

\subsubsection{Legislación que regula el uso del fenamifos.}

De acuerdo con la normativa europea, solo se podrán autorizar los usos como nematicida aplicado mediante riego por goteo en invernaderos con estructura permanente según el artículo 29, apartado 6, del Reglamento (CE) no 1107/2009. Además, se tendrán en cuenta las conclusiones del informe de revisión del fenamifos y, sobre todo, sus apéndices I y II, tal y como fue adoptado por el Comité Permanente de la Cadena Alimentaria y de Sanidad Animal el 14 de julio de 2006. Los Estados miembros deberán prestar especial atención a la protección de los organismos acuáticos, los organismos no diana del suelo y las aguas subterráneas en situaciones vulnerables. En su caso, las condiciones de 
autorización deberán incluir medidas de reducción del riesgo, y deberán iniciarse programas de vigilancia en las zonas vulnerables para controlar la posibilidad de contaminación de las aguas subterráneas [36].

Como conclusión general, cabe esperar que los productos fitosanitarios que contienen fenamifos cumplan los requisitos de seguridad establecidos en el artículo 5, apartado 1, letras a) y b), de la Directiva 91/414 / CEE. Sin embargo, esta conclusión está sujeta al cumplimiento de los requisitos particulares en las secciones 4, 5, 6 y 7 de este informe, así como a la implementación de las disposiciones del Artículo 4 (1) y los principios uniformes establecidos en el Anexo VI de la Directiva 91/414 / CEE, por cada producto fitosanitario que contiene fenamifos para el que los estados miembros otorgarán o revisarán la autorización.

Con respecto a los residuos en particular, la revisión ha establecido que los residuos derivados de los usos propuestos, como consecuencia de la aplicación consistente con las buenas prácticas de protección del medioambiente, no tienen efectos nocivos para la salud humana o animal. La ingesta diaria máxima teórica (TMDI; excluyendo el agua y los productos de origen animal) para un adulto de 60 $\mathrm{kg}$ es el $2,9 \%$ de la ingesta diaria admisible (IDA), basada en la dieta europea FAO / OMS (agosto de 1994).

No se espera que la ingesta adicional de agua y productos de origen animal genere problemas de ingesta [37].

\subsection{Presentación del segundo pesticida, fosmet.}

El siguiente pesticida seleccionado ha sido el fosmet (cuyo nombre segun la IUPAC es $\mathrm{O}, \mathrm{O}$-dimetil S-ftalimidometil fosforoditioato), que pertence a la subfamilia de los fosforodioatos. Se trata de un insecticida organofosforado que se aplica tanto en animales como en plantas, siendo su principal objetivo el control de la palomilla, pulgones, ácaros y moscas de la fruta. En la Tabla 1.7 se muestran las principales propiedades físico-químicas del pesticida [38]. 
Tabla 1.7. Propiedades físico-químicas del fosmet.

\begin{tabular}{|c|c|c|}
\hline Propiedad físico-química & Valor & Temperatura $\left({ }^{\circ} \mathrm{C}\right)$ \\
\hline Solubilidad en agua & $24.4 \mathrm{mg} / \mathrm{L}$ & 20 \\
Solubilidad en acetona & $650 \mathrm{~g} / \mathrm{L}$ & 25 \\
Peso molecular & $317.321 \mathrm{~g} / \mathrm{mol}$ & \\
Temperatura de fusión & $72.5^{\circ} \mathrm{C}$ & \\
Log P (octanol-agua) & 2.84 & 20 \\
Densidad & $1.5 \mathrm{~g} / \mathrm{cm}^{3}$ & 23 \\
Presión de vapor & Despreciable & 20 \\
Constante de Henry & $8.38 \cdot 10^{-9} \mathrm{~atm} \cdot \mathrm{m}^{3} / \mathrm{mol}$ & 20 \\
Índice GUS & 0.48 & \\
\hline
\end{tabular}

\subsubsection{Toxicidad del fosmet.}

El fosmet se caracteriza por tener una toxicidad moderada por ingesta, moderadaalta a través de la piel y muy alta cuando se trata de toxicidad por inhalación. Posee una $\mathrm{DL}_{50}$ oral entre 113 y $369 \mathrm{mg} / \mathrm{kg}$ en ratas de ambos sexos mientras que la $\mathrm{DL}_{50}$ dérmica para el fosmet en el conejo varía de 1560 a $4640 \mathrm{mg} / \mathrm{kg}$, por tanto según la Tabla 1.3 este pesticida se encuentra dentro de la clase II siendo moderadamente peligroso. En suelos arenosos y arcillosos, la mitad de la cantidad inicial del compuesto se descompone entre 3 y 19 días. Además, el compuesto persiste por más tiempo en el suelo seco que en el suelo húmedo y su solubilidad en agua a $25^{\circ} \mathrm{C}$ se encuentra alrededor de $26 \mathrm{ppm}[39,40]$.

Para evaluar la toxicidad oral del pesticida se llevaron a cabo estudios en ratas con fosmet. En estos estudios se obtuvo que el fosmet presenta una $\mathrm{DL}_{50}$ de 230 $\mathrm{mg} / \mathrm{kg}$ para ratas de ambos sexos. Este resultado ha sido probado en un estudio reciente realizado en la Facultad de Farmacia de la Universidad de Barcelona y fue auditado por la Unidad de Garantía de Calidad de esta Universidad [41]. En la declaración de garantía de calidad, se informa que el estudio se realizó de conformidad con los principios de BPL (OCDE) (Directiva 87/18 / CEE incluida en la legalización española con RD 822/1993).

Para evaluar la toxicidad cutánea se realizó un estudio con ratas y se determinó que la $\mathrm{DL}_{50}$ era mayor de $1000 \mathrm{mg} / \mathrm{kg}$ de peso corporal y en el segundo estudio 
(McCabe, 1978) se encontró que la $\mathrm{DL}_{50}$ dérmica era mayor de $5000 \mathrm{mg} / \mathrm{kg}$ de peso corporal en conejos, por tanto, los datos disponibles indican que el fosmet no garantiza la clasificación de toxicidad cutánea aguda $[42,43]$.

\subsubsection{Movilidad del fosmet.}

El fosmet es estable a la fotólisis en el suelo y parece ser estable a la fotólisis acuosa, en cambio es susceptible a una hidrólisis en condiciones alcalinas y neutras y, en un grado mucho menor, en condiciones ácidas siendo la degradación microbiana su ruta principal de disipación. En suelos donde la actividad microbiana es mínima, la lixiviación puede ser una ruta importante de disipación para este compuesto. Este pesticida se degrada rápidamente en condiciones aeróbicas en el suelo (3 días) y más lentamente en condiciones anaeróbicas (19 días). El fosmet oxon es el único metabolito de degradación conocido que presenta una alta toxicidad, identificada en varios estudios realizados sobre movilidad en el medioambiente. Los estudios han indicado que el fosmet oxon es menos móvil que el fosmet porque no se detectó en el lixiviado de los estudios de movilidad. Además, el fosmet oxón solo se detectó en la capa superior del suelo en los estudios de campo, mientras que el fosmet se detectó a una mayor profundidad, aproximadamente de $26,67 \mathrm{~cm}$. Según estudios de laboratorio y estudios de campo, el fosmet y fosmet oxon son una amenaza para las aguas subterráneas ya que también pueden contaminar las aguas superficiales, principalmente como resultado de la escorrentía debida a las tormentas poco después de las aplicaciones en el campo [44]. En la Figura 1.9 a) se muestra la estructura molecular del fosmet y en la 1.9 b) del fosmet oxon.<smiles>COP(=S)(OC)SCN1C(=O)c2ccccc2C1=O</smiles>

b)<smiles>COP(=O)(OC)SCN1C(=O)c2ccccc2C1=O</smiles>

Figura 1.9. a) Estructura química del fosmet y b) Estructura química del fosmet oxon. 


\subsubsection{Síntesis del fosmet}

La síntesis del fosmet se lleva a cabo a partir del ácido dialquil fosforo dithioico el cual reacciona con una especie clorada. La secuencia completa de reacciones se detalla a continuación [35]:<smiles>O=C1NC(=O)c2ccccc21</smiles>

Ftalimida<smiles>O=C[C@H](O)C(Cl)Cl</smiles><smiles>COP(=S)(S)OC</smiles><smiles>COP(=S)(OC)SCN1C(=O)c2ccccc2C1=O</smiles>

Fosmet

Figura 1.10. Síntesis del fosmet.

\subsubsection{Legislación que regula el uso del fosmet.}

Solo se podrán autorizar los usos como insecticida y acaricida. Para la aplicación de los principios uniformes a los que se refiere el artículo 29, apartado 6, del Reglamento (CE) no 1107/2009, se tendrán en cuenta las conclusiones del informe de revisión sobre el fosmet y, en particular, sus apéndices I y II, tal como fue adoptado por el Comité Permanente de la Cadena Alimentaria y de Sanidad Animal el 24 de noviembre de 2006. En esta evaluación general, los Estados miembros: - deberán atender especialmente a la protección de las aves, los mamíferos, los organismos acuáticos, las abejas y otros artrópodos no diana; cuando sea pertinente, las condiciones de autorización deberán incluir medidas de reducción del riesgo, como zonas tampón, y la reducción de la aportación de 
escorrentías y vertidos a las aguas de superficie; - prestarán especial atención a la seguridad de los operarios y velarán por que en las condiciones de uso se exija la utilización de equipos de protección individual y respiratoria adecuados. Los Estados miembros interesados solicitarán que se presenten estudios adicionales a fin de confirmar la evaluación del riesgo para las aves (riesgo grave) y los mamíferos herbívoros (riesgo a largo plazo). Velarán por que el notificante a instancias del cual se ha incluido el fosmet en el presente anexo facilite dichos estudios a la Comisión en el plazo de dos años a partir de la autorización [36].

Los productos fitosanitarios que contienen fosmet deben cumplir los requisitos de seguridad establecidos en el artículo 5, apartado 1, letras a) y b), de la Directiva 91/414 / CEE. Sin embargo, esta conclusión está sujeta al cumplimiento de los requisitos particulares en las secciones 4, 5, 6 y 7 de este informe, así como a la implementación de las disposiciones del Artículo 4 (1) y los principios uniformes establecidos en el Anexo VI de la Directiva 91/414 / CEE, por cada producto fitosanitario que contenga fosmet para el cual los estados miembros otorgarán o revisarán la autorización.

Con respecto a los residuos en particular, la revisión ha establecido que los residuos derivados de los usos propuestos, como consecuencia de la aplicación consistente con las buenas prácticas de protección del medioambiente, no tienen efectos nocivos para la salud humana o animal. La ingesta diaria máxima teórica (TMDI; excluyendo el agua y los productos de origen animal) para un adulto de 60 $\mathrm{kg}$ es el $12 \%$ de la ingesta diaria admisible (IDA), basada en la dieta europea FAO / OMS (agosto de 1994) con una IDA de 0.003 mg / kg / día [45].

\subsection{Presentación del tercer pesticida, diazinón.}

El tercer pesticida elegido ha sido el diazinón (cuyo nombre según la IUPAC es 0,0-dietil 0-2-isopropil-6-metilpirimidin-4-il fosforotioato), el cual pertenece a la subfamilia de los fosforotioatos. Se trata de un insecticida utilizado en la agricultura para controlar insectos en plantas, frutas y hortalizas. Se puede encontrar en forma de polvo, gránulos o solución emulsionable. En la Tabla 1.8 se muestran las principales propiedades físico-químicas del pesticida $[46,47]$. 
Tabla 1.8. Propiedades físico-químicas del diazinón

\begin{tabular}{|c|c|c|}
\hline Propiedad físico-química & Valor & Temperatura $\left({ }^{\circ} \mathrm{C}\right)$ \\
\hline Solubilidad en agua & $60 \mathrm{mg} / \mathrm{L}$ & 20 \\
Solubilidad en hexano & $250000 \mathrm{mg} / \mathrm{L}$ & 20 \\
Peso molecular & $304.35 \mathrm{~g} / \mathrm{mol}$ & \\
Temperatura de fusión & - & \\
Constante de disociación pKa & 2.6 & 25 \\
Log P (octanol-agua) & 3.69 & 20 \\
Densidad & $1.1 \mathrm{~g} / \mathrm{cm}^{3}$ & 20 \\
Presión de vapor & $11.97 \mathrm{mPa}$ & 20 \\
Constante de Henry & $6.09 \cdot 10^{-2} \mathrm{~Pa} \cdot \mathrm{m}^{3} \cdot \mathrm{mol}^{-1}$ & 25 \\
Índice GUS & 1.51 & \\
\hline
\end{tabular}

Según la OMS, este pesticida está clasificado como moderadamente peligroso (Clase II) ya que posee una $\mathrm{DL}_{50}$ oral para ratas es de $1250 \mathrm{mg} / \mathrm{kg}$ y la $\mathrm{DL}_{50}$ dérmica es de $540-650 \mathrm{mg} / \mathrm{kg}$. La persistencia en el suelo es de 90 días por tanto se caracteriza por tener una persistencia media en el medio ambiente. Cuenta con una solubilidad en el agua a $25{ }^{\circ} \mathrm{C}$ de $40 \mathrm{ppm}$, se considera que es moderadamente móvil y por tanto, causa una gran preocupación por la calidad del agua subterránea y de consumo.

El diazinón fue uno de los insecticidas más utilizados para el control de plagas domésticas y agrícolas en la década de los 90 en los EE.UU. En el 2000, la Agencia de Protección Ambiental de los Estados Unidos anunció un acuerdo con los solicitantes de registro de diazinón para cancelar todos los usos residenciales del diazinón. Los usos en zonas interiores se cancelaron en 2002 y los usos en zonas exteriores en 2004 , dejando solo los usos agrícolas para el diazinón $[48,49]$.

Los usos agrícolas actuales del diazinón se limitan a cultivos seleccionados, y los productos de diazinón están regulados como pesticidas de uso restringido.

El diazinón se degrada en el agua como resultado de la hidrólisis, especialmente en condiciones ácidas. En agua estéril, se determinó que el diazinón tenía una vida media de solo 12 días en agua ácida $(\mathrm{pH}=5)$ y 138 días en agua neutra $(\mathrm{pH}=7)$.

La descomposición del diazinón es más rápida a temperaturas de agua más cálidas, degradando de 2 a 4 veces más rápido en agua a $21^{\circ} \mathrm{C}$ que en agua a 10 
${ }^{\circ} \mathrm{C}$, siendo su principal metabolito el diazoxón. La estructura química tanto del diazinón como del diazoxón se muestran en la Figura 1.11.

a)

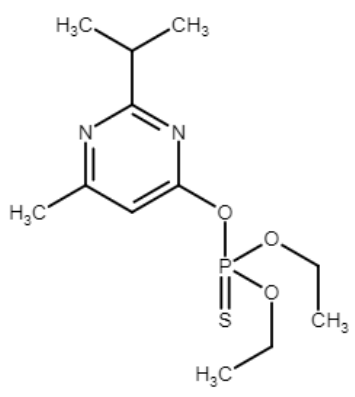

b)

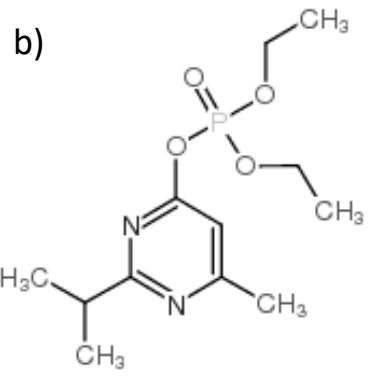

Figura 1.11.a) Estructura química del diazinón y b) estructura química del diazoxón.

No se espera que el diazinón se volatilice fácilmente del agua debido a su presión de vapor y la constante de Henry. Sin embargo, en algunos estudios, hasta el 50\% del diazinón aplicado se volatilizó del agua. El diazinón se ha detectado en lluvia a concentraciones de hasta $2 \mu \mathrm{g} / \mathrm{L}$ y en niebla a concentraciones de hasta $76 \mu \mathrm{g} / \mathrm{L}$ $[50,51]$.

\subsubsection{Toxicidad del diazinón.}

El diazinón se absorbe fácilmente cuando la exposición es oral. Se observó una absorción rápida y extensa después de la ingesta de una dosis de $0.011 \mathrm{mg} / \mathrm{kg}$ de diazinón ( $94 \%$ de pureza) por un grupo de cinco voluntarios, produciéndose la excreción de aproximadamente el $60 \%$ de la dosis administrada como metabolitos de dialquil fosfato en la orina, la mayoría (90\%) de los cuales se recuperaron dentro de las 14 horas posteriores a la administración. Se detectó un $10 \%$ de diazinón en varios tejidos de una mujer que había ingerido una cantidad letal, lo que sugiere una rápida absorción del tracto gastrointestinal. Los estudios en animales también demuestran una rápida absorción de diazinón después de la administración oral.

La absorción de diazinón después de la exposición dérmica se ha demostrado en humanos. Los voluntarios estuvieron expuestos durante 24 horas a diazinón aplicado en el antebrazo o el abdomen con acetona. Mediante un análisis de 
orina, se determinó que la absorción es del 3 al $4 \%$ de la dosis aplicada, sin diferencias relacionadas con el área aplicada [52].

\subsubsection{Movilidad del diazinón.}

Según su presión de vapor, si se libera diazinón a la atmósfera, se espera que exista tanto en fase vapor como en partículas. La conversión de diazinón a diazoxón en el aire se dará con bastante rapidez y la posibilidad de transporte atmosférico significa que este pesticida puede moverse a cierta distancia de las áreas agrícolas a las no agrícolas. El diazinón liberado al agua desde fuentes puntuales y no puntuales puede emitirse a la atmósfera por volatilización, absorberse en suelos y sedimentos, o acumularse en organismos acuáticos. Si bien no se puede esperar que la volatilización del diazinón sea significativa según la constante de Henry, puede ser un proceso de transporte importante. Sanders y Seiber (1983) [53] informaron que el $17 \%$ del diazinón aplicado a un estanque se volatilizó en 24 horas. El diazinón liberado al agua también puede ser absorbido moderadamente por los suelos y sedimentos en función de sus valores de coeficiente de partición de carbono orgánico $\left(\mathrm{K}_{\mathrm{oc}}\right)$ medidos en el suelo. Debido a que este plaguicida solo es moderadamente adsorbido por algunos suelos, puede ocurrir lixiviación en el agua subterránea. Dado que algunos de los metabolitos del diazinón son tóxicos en sí mismos, puede ser necesario tener precaución en los casos en que haya razones para creer que los peces han tenido una exposición reciente al diazinón. El diazinón liberado en el suelo pasa a la atmósfera a través de la volatilización, al agua superficial a través de la escorrentía y al agua subterránea como resultado de la lixiviación [54,55]. 


\subsubsection{Síntesis del diazinón.}

La síntesis del diazinón se produce gracias a la reacción entre el etil acetoacetate y amidinas, para posteriormente reaccionar con DEPCT y dar el diazinón. A continuación se detalla la secuencia complete de reacciones [35]:

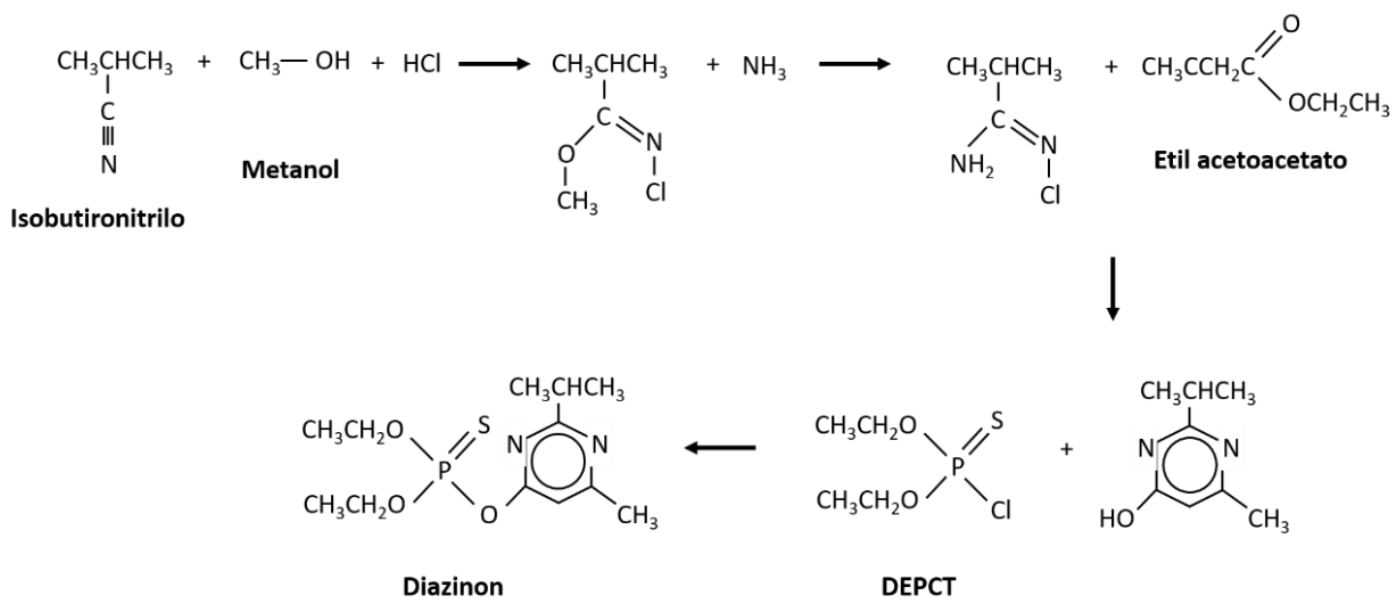

Figura 1.12. Síntesis del diazinon.

\subsubsection{Legislación de uso del diazinón.}

La legislación vigente concluye que:

- La información disponible es insuficiente para satisfacer los requisitos establecidos en el Anexo II y en la Directiva 91/414 / CEE del Anexo III, en particular con respecto a:

- La presencia de impurezas muy tóxicas que no han sido analizadas en las evaluaciones de riesgos toxicológicos o ecotoxicológicos.

- El destino y el comportamiento de la sustancia en el medio ambiente y sus propiedades ecotoxicológicas.

- Se identificaron preocupaciones con respecto a:

- La exposición del operador, aunque se utiliza un alto grado de equipo de protección personal.

- Trabajadores y transeúntes. 
- Exposición del consumidor

- El riesgo agudo para las aves insectívoras

- El riesgo a largo plazo para los mamíferos insectívoros

- La alta toxicidad para los organismos acuáticos

En conclusión, a partir de las evaluaciones realizadas sobre la base de la información presentada, no se espera que ningún producto fitosanitario que contenga la sustancia activa en cuestión cumpla en general los requisitos establecidos en el artículo 5, apartado 1, letras a) y b), de la Directiva 91 del Consejo / 414 / CEE.

Por lo tanto, el diazinón no debe incluirse en el anexo I de la Directiva 91/414 / CEE, en donde se encuentran los productos aceptados [56]. No obstante, se ha elegido este pesticida para degradar ya que se han encontrado trazas del compuesto en acuíferos y aguas subterráneas.

\subsection{Presentación del cuarto pesticida, clorfenvinfos.}

Por último, el cuarto pesticida elegido es el clorfenvinfos (cuyo nombre según la IUPAC es (EZ)-2-cloro-1-(2,4-diclorofenil) vinil dietil fosfato). Se trata de un insecticida organofosforado de la subfamilia de los fosfatos, utilizado para controlar insectos y plagas en el ganado. También se ha usado para controlar plagas domésticas como moscas, pulgas y ácaros. En la Figura 1.13 se muestra su estructura química.

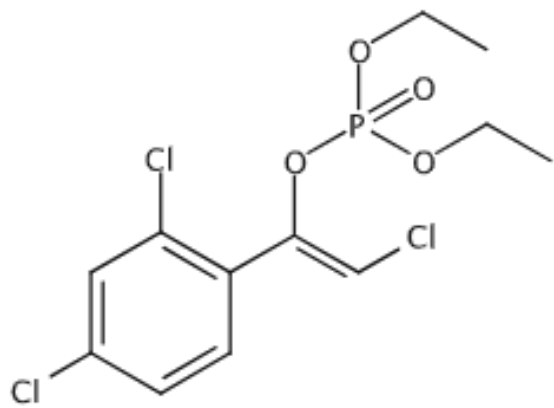

Figura 1.13. Estructura química del clorfenvinfos. 
El producto químico puro ( $100 \%$ clorfenvinfos) se trata de un líquido incoloro con un olor suave que se mezcla fácilmente con acetona, etanol y propilenglicol, se descompone lentamente por el agua y es corrosivo en metales.

Las propiedades físico-químicas más importantes son las que se detallan en la siguiente tabla [57]:

Tabla 1.9. Propiedades físico-químicas del clorfenvinfos.

\begin{tabular}{|c|c|c|}
\hline Propiedad físico-química & Valor & Temperatura $\left({ }^{\circ} \mathrm{C}\right)$ \\
\hline Solubilidad en agua & $125 \mathrm{mg} / \mathrm{L}$ & 25 \\
Peso molecular & $359.6 \mathrm{~g} / \mathrm{mol}$ & \\
Temperatura de fusión & Entre $-19 \mathrm{y}-23^{\circ} \mathrm{C}$ & \\
Constante de disociación pKa & - & \\
Log P (octanol-agua) & 3.8 & 20 \\
Densidad & $1.52 \mathrm{~g} / \mathrm{mL}$ & 25 \\
Presión de vapor & $0.001 \mathrm{~Pa}$ & 20 \\
Constante de Henry & $2.1 \cdot 10^{-9} \mathrm{~atm} \cdot \mathrm{m}^{3} / \mathrm{mol}$ & 25 \\
Índice GUS & 1.72 & \\
\hline
\end{tabular}

Para el caso del clorfenvinfos, mediante los ensayos llevados a cabo con ratas, se determinó que la $\mathrm{DL}_{50}$ oral vale $10 \mathrm{mg} / \mathrm{kg}$, por tanto, pertenece a la clase la considerándose un producto sumamente peligroso. Además, se ha determinado que la $\mathrm{DT}_{50}$ tiene un valor de 40 días, por tanto, según la Tabla 1.4, tiene una persistencia en el suelo mediana [58].

\subsubsection{Toxicidad del clorfenvinfos.}

El clorfenvinfos es extremadamente tóxico para los animales, especialmente para los roedores y los perros, por vía oral. Los valores de $\mathrm{DL}_{50}$ por vía oral para ratas, conejos y perros se han estimado en $9.7,300$ y $50.5 \mathrm{mg} / \mathrm{kg}$, respectivamente. Se calculó una $\mathrm{DL}_{50}$ oral aguda de $23 \mathrm{mg} / \mathrm{kg}$ a partir de los datos de mortalidad de un número no especificado de ratas Wistar que recibieron dosis variables de clorfenvinfos en aceite de oliva. 
Un estudio [59] concluyó que la alteración de las actividades cerebrales y hepáticas pueden deberse al efecto inhibidor del clorfenvinfos sobre la actividad de la noradrenalina. En otros estudios [57], se demostró que el clorfenvinfos inhibe independientemente la actividad de noradrenalina en ratas rápidamente (3 horas) con dosis tan bajas como $4 \mathrm{mg} / \mathrm{kg}$. Sobre esta base, se ha postulado que el clorfenvinfos también puede actuar a través de mecanismos noradrenérgicos centrales, perturbando el equilibrio entre la tasa de formación y la utilización de noradrenalina. Además, esta acción puede ser responsable de los cambios en la presión arterial observados en otros estudios a través de mecanismos centrales noradrenérgicos al subministrar clorfenvinfos [60].

\subsubsection{Movilidad del clorfenvinfos}

El clorfenvinfos entra en contacto con el medio ambiente por escorrentía después de la lluvia y la lixiviación de los sitios de desechos peligrosos. Después de que se haya lixiviado, puede estar presente en el suelo, en el agua subterránea (pozos) y en las aguas superficiales (ríos y estanques). Desde el suelo, también puede ser arrastrado a las aguas superficiales por la lluvia. Además, puede pasar del suelo al aire por evaporación o al ser absorbido por las plantas. No obstante, se ha demostrado que el clorfenvinfos se volatiliza lentamente del agua debido a los valores que presenta de presión de vapor y constante de Henry, clasificándose como un pesticida no volátil. Por tanto, los procesos de transporte que pueden mover el clorfenvinfos del suelo a otros medios son la lixiviación, la escorrentía, la absorción por las plantas, y en menor medida la volatilización.

El valor de $\mathrm{K}_{\text {oc }}$ reportado sugiere que la adsorción de clorfenvinfos al suelo es moderadamente fuerte, por lo tanto, las tasas de lixiviación y escorrentía serán procesos relativamente menores en la mayoría de los suelos. Se observó muy poca lixiviación de clorfenvnfos y ninguna lixiviación de sus productos de degradación en varios estudios de campo [61,62].

El clorfenvinfos también se transporta desde el suelo de un área a otra o desde el suelo al agua superficial a través de la escorrentía. Los pesticidas con una solubilidad en agua $>10 \mathrm{mg} / \mathrm{L}$ se mueven principalmente mediante este proceso, y por tanto, el clorfenvinfos con una solubilidad alrededor de 145 ppm se moverá mayoritariamente por escorrentía [60]. 


\subsubsection{Síntesis de clorfenvinfos.}

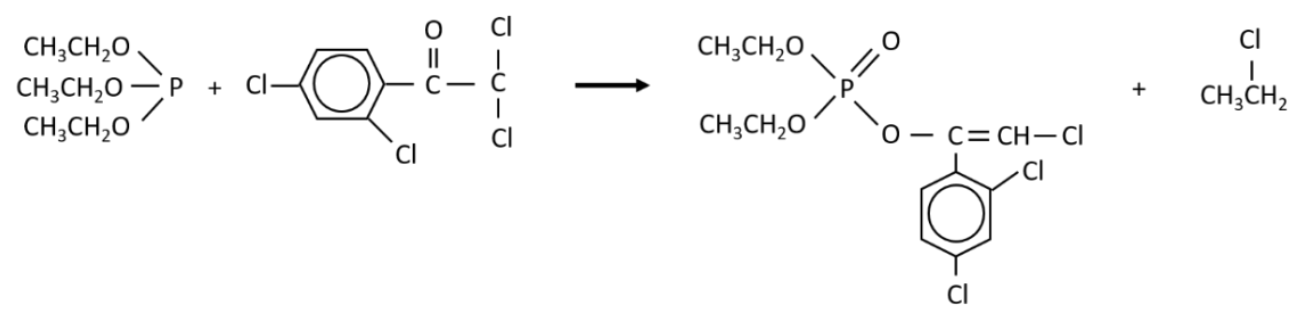

Clorfenvinfos

La síntesis del clorfenvinfos se detalla a continuación [35]:

Figura 1.14. Síntesis del clorfenvinfos.

\subsubsection{Legislación del uso del clorfenvinfos.}

Según la legislación vigente en la Unión Europea este pesticida tiene prohibida tanto la comercialización como su uso debido a la entrada en vigor del reglamento (CE) No 2076/2002 DE LA COMISIÓN de 20 de noviembre de 2002 por el que se prolonga el período contemplado en el apartado 2 del artículo 8 de la Directiva 91/414/CEE del Consejo y relativo a la no inclusión de determinadas sustancias activas en el anexo I de dicha Directiva, así como a la retirada de autorizaciones de productos fitosanitarios que contengan estas sustancias [63]. No obstante, la elección de este pesticida se debe a su presencia en acuíferos y aguas subterráneas.

\section{Procesos de degradación de pesticidas.}

En los últimos años, los procesos destinados al cuidado y protección del medioambiente han cobrado un especial interés. En la Figura 1.15 se resume las principales técnicas utilizadas para la eliminación de contaminantes. Diversos autores han publicado una extensa bibliografía que informa sobre las características y aplicaciones de las técnicas más importantes desarrolladas para este propósito, incluidos métodos fisicoquímicos y químicos, procesos de 
oxidación avanzados (AOP), tratamientos microbiológicos y descomposición enzimática $[64,65]$.

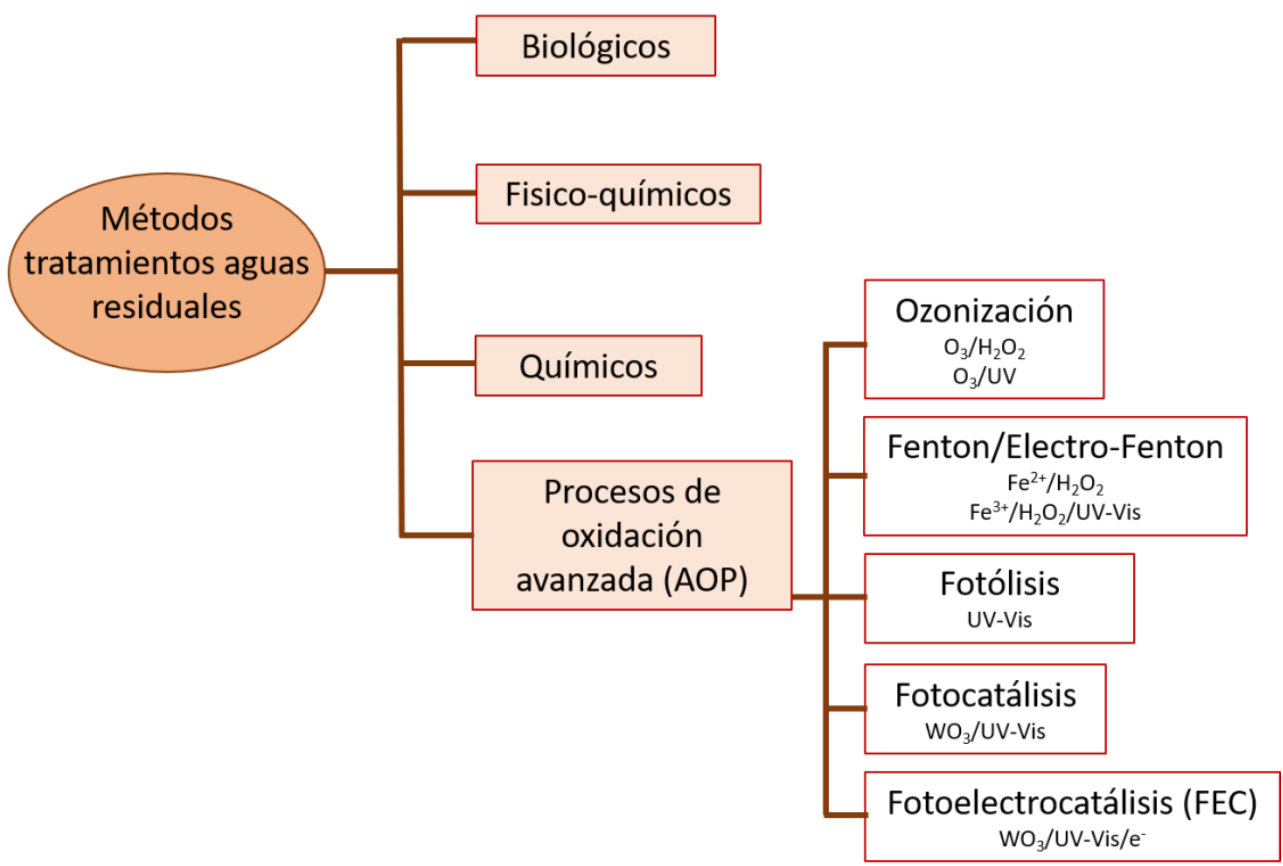

Figura 1.15. Principales técnicas utilizadas para la eliminación de contaminantes.

Hay veces que las técnicas convencionales como son los tratamientos microbiológicos resultan ineficientes para llegar a las concentraciones de pesticidas presentes en el agua exigidas por la ley, ya que las bacterias utilizadas pueden llegar a morirse por la acción de los compuestos orgánicos objeto de eliminación como son los pesticidas. Por este motivo es necesario implementar otras técnicas que consigan llegar a ese objetivo. Estas técnicas son las que se encuentran dentro de los procesos de oxidación avanzada (AOP) [66,67].

Estas técnicas son más eficientes ya que los procesos que tienen lugar son termodinámicamente más favorables además de tener una velocidad de oxidación muy alta debido a la presencia de radicales hidroxilo $(\bullet \mathrm{OH})$. Estos radicales tienen un potencial redox estándar $\left(\mathrm{E}_{0}\right)$ de $2.8 \mathrm{~V}$ que les otorga una velocidad de reacción con los compuestos orgánicos entre 106-1012 veces más rápido que otros oxidantes convencionales $[68,69]$. 


\subsection{Fenton y electro-Fenton}

El proceso Fenton (F) consiste en una mezcla de $\mathrm{H}_{2} \mathrm{O}_{2}$ y $\mathrm{Fe}^{2+}$, que según la reacción 1.1, da como resultado la generación de radicales hidroxilo. Esta reacción se lleva a cabo en medio ácido, a pH 3 ya que el valor del pH influye en la generación de radicales $\bullet \mathrm{HO}$ y en la eficiencia de la oxidación. Cuando se utiliza un $\mathrm{pH}$ cercano a 4 la degradación disminuye y las sales de hierro precipitan como hidróxidos reduciendo así la viabilidad de la reacción [70].

$$
\mathrm{Fe}^{2+}+\mathrm{H}_{2} \mathrm{O}_{2} \rightarrow \mathrm{Fe}^{3+}+\mathrm{OH}^{-}+\cdot \mathrm{OH}
$$

El proceso de electro-Fenton (EF) es una variante del proceso Fenton basado en la electrogeneración del reactivo de Fenton. En este proceso, el $\mathrm{H}_{2} \mathrm{O}_{2}$ se forma por la reducción de $\mathrm{O}_{2}$ según la reacción 1.2 , en un cátodo de material carbonoso conductor como puede ser el grafito, carbón vítreo reticulado o tela de carbón. Una ventaja del proceso de EF en comparación con el proceso de Fenton clásico es que el $\mathrm{Fe}^{2+}$ se regenera en el cátodo por la reducción del Fe ${ }^{3+}$ (reacción 1.3), mejorando así la reacción de Fenton y, por lo tanto, la oxidación de compuestos orgánicos con el exceso de $\bullet \mathrm{OH}$ producido [71,72]. En la Figura 1.16 se muestra el esquema de funcionamiento a escala laboratorio del proceso de EF [73].

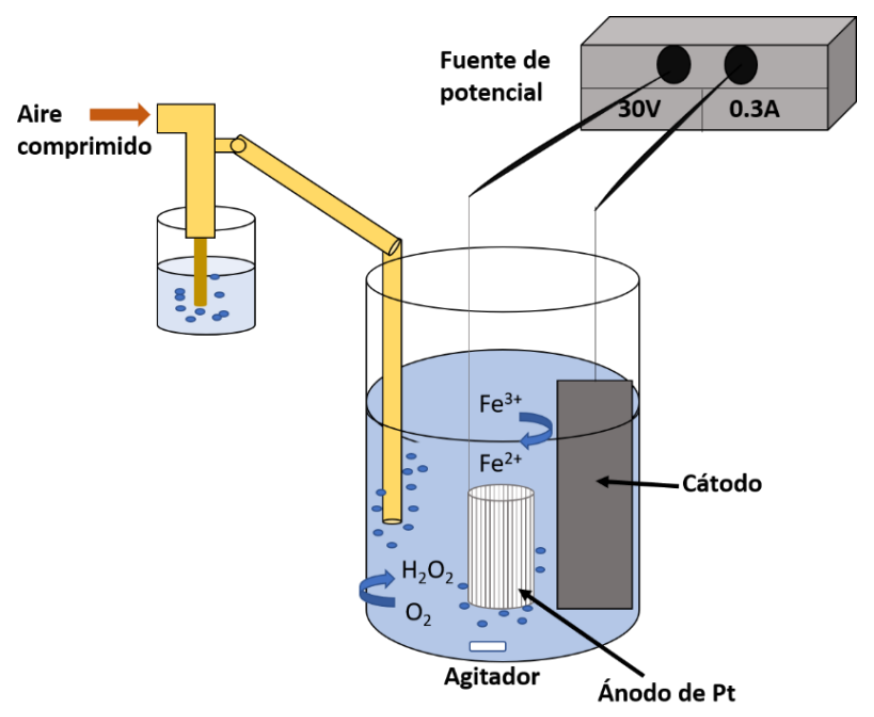

Figura 1.16. Esquema de funcionamiento del proceso de electro-Fenton. 


$$
\begin{gathered}
\mathrm{O}_{2}+2 \mathrm{H}^{+}+2 e^{-} \rightarrow \mathrm{H}_{2} \mathrm{O}_{2} \\
\mathrm{Fe}^{3+}+e^{-} \rightarrow \mathrm{Fe}^{2+}
\end{gathered}
$$

Tanto la reacción de Fenton como la de EF pueden ser mejoradas utilizando radiación UV $(\approx 300 \mathrm{~nm})$ proveniente de lámparas especiales o bien, de la radiación solar. A estos procesos se les conoce como foto-Fenton (FF) o foto electro-Fenton (FEF). Debido a la acción catalítica de la radiación, se producen radicales hidroxilo mediante la foto-reducción del $\mathrm{Fe}^{3+}$ de la especie $\mathrm{Fe}(\mathrm{OH})^{2+}$ que es predominante a pH cercano a 3 (reacción 1.4).

$$
\mathrm{Fe}(\mathrm{OH})^{2+}+h v \rightarrow \mathrm{Fe}^{2+}+\cdot \mathrm{OH}
$$

\subsection{Ozonización}

En cuanto a la ozonización, en el tratamiento de aguas, el ozono es utilizado por su poder oxidante, que le confiere una importante reactividad frente a un gran número de compuestos orgánicos e inorgánicos. Se han demostrado dos vías principales de reacción del ozono, la vía molecular, donde el ozono reacciona directamente con la materia orgánica o inorgánica, siendo este un proceso lento y selectivo, y la vía indirecta, donde el ozono molecular se descompone en el agua produciendo radicales hidroxilo, que poseen una reactividad no selectiva mucho más potente que la del propio ozono. El mecanismo completo de la ozonización es complejo debido a que parámetros como el $\mathrm{pH}$ o la naturaleza de las moléculas a destruir se deben tener en cuenta $[74,75]$.

\subsection{Electrooxidación}

Otra de las técnicas de degradación de contaminantes orgánicos dentro de las técnicas de oxidación avanzada es la electrooxidación. Está indicada para efluentes con una baja concentración de contaminantes (DQO $<5 \mathrm{~g} \mathrm{~L}^{-1}$ ) y la principal ventaja de este proceso es que no se requiere añadir reactivos químicos, ya que únicamente con la aplicación de corriente eléctrica se consigue la mineralización. En esta técnica se utiliza un ánodo con una alta sobretensión de 
oxígeno con el que se pueden degradar contaminantes orgánicos directamente en su superficie mediante la oxidación de radicales hidroxilo $(\mathrm{M}(\bullet \mathrm{OH}))$.

Mediante un ánodo convencional de platino se mineraliza débilmente ya que éste genera una pequeña cantidad del reactivo $\mathrm{Pt}(\bullet \mathrm{OH})$ en su superficie a partir de la reacción 1.5, y por tanto no puede eliminar totalmente los productos finales [76].

$$
\mathrm{Pt}+\mathrm{H}_{2} \mathrm{O} \rightarrow \mathrm{Pt}(\cdot \mathrm{OH})+\mathrm{H}^{+}+e^{-}
$$

Pero con el uso reciente de ánodos de diamante dopados con boro (BDD) en electrooxidación se ha demostrado que puede mineralizar completamente muchos compuestos aromáticos y ácidos carboxílicos. Este electrodo es preferible para esta técnica ya que permite que exista una interacción muy débil entre el electrodo y radicales hidroxilo resultando más efectiva la eliminación de estos compuestos orgánicos (reacción 1.6) que con el uso de electrodos de platino.

$$
B D D+H_{2} O \rightarrow B D D(\cdot O H)+H^{+}+e^{-}
$$

En la siguiente tabla (1.10) se muestra la comparación de distintos materiales usados como ánodos en la mineralización electroquímica de compuestos orgánicos en medio ácido.

\begin{tabular}{|c|c|c|c|c|}
\hline Electrodo & $\begin{array}{l}\text { Potencial de } \\
\text { oxidación (V) }\end{array}$ & $\begin{array}{l}\text { Sobrepotencial } \\
\text { de } \mathrm{O}_{2} \text { (V) }\end{array}$ & $\begin{array}{c}\text { Entalpía de } \\
\text { adsorción } \mathrm{M}-\mathrm{OH}\end{array}$ & $\begin{array}{l}\text { Poder de } \\
\text { oxidación } \\
\text { del ánodo }\end{array}$ \\
\hline $\mathrm{RuO}_{2}-\mathrm{TiO}_{2}$ & $1.4-1.7$ & 0.18 & $\begin{array}{c}\text { Quimisorción de } \\
\text { radicales } \mathrm{OH}\end{array}$ & \\
\hline $\mathrm{IrO}_{2}-\mathrm{Ta}_{2} \mathrm{O}_{5}$ & $1.5-1.8$ & 0.25 & & \\
\hline $\mathrm{Ti} / \mathrm{Pt}$ & $1.7-1.9$ & 0.3 & & \\
\hline $\mathrm{Ti} / \mathrm{PbO}_{2}$ & $1.8-2$ & 0.5 & & \\
\hline $\mathrm{Ti} / \mathrm{SnO}_{2}-\mathrm{Sb}_{2} \mathrm{O}_{5}$ & $1.9-2.2$ & 0.7 & & \\
\hline p-Si/BDD & $2.2-2.6$ & 1.3 & $\begin{array}{c}\text { Fisisorción de } \\
\text { radicales } \mathrm{OH}\end{array}$ & \\
\hline
\end{tabular}

Tabla 1.10. Materiales para ánodos en la mineralizacion de compuestos orgánicos. 
Una variante de la electrooxidacion es la oxidación anódica con electrogeneración de $\mathrm{H}_{2} \mathrm{O}_{2}$ en la que un cátodo de carbono-politetrafluoroetileno (PTFE) con difusión de $\mathrm{O}^{2-}$ suministra continuamente peróxido de hidrógeno a la disolución contaminada contenida en una celda a partir de la reducción de gas $\mathrm{O}_{2}$ mediante dos electrones (reacción 1.7). Además, una fracción de esta especie $\left(\mathrm{H}_{2} \mathrm{O}_{2}\right)$ se oxida en el ánodo para formar el radical hidroperoxil débilmente oxidante $\left(\mathrm{HO}_{2} \cdot\right)$ como intermedio (reacción 1.8) [76,77].

$$
\begin{gathered}
\mathrm{O}_{2}(g)+2 \mathrm{H}^{+}+2 e^{-} \rightarrow \mathrm{H}_{2} \mathrm{O}_{2} \\
\mathrm{H}_{2} \mathrm{O}_{2} \rightarrow \mathrm{HO}_{2} \cdot+H^{+}+e^{-}
\end{gathered}
$$

\subsection{Fotocatálisis.}

El proceso de fotocatálisis ( $\mathbf{F C}$ ) se basa en la trasferencia de carga a través de la interfase formada entre un semiconductor que actúa como catalizador y una solución acuosa que contenga al contaminante. La fotocatálisis utiliza un catalizador que es sensible a la radiación, por tanto, se trata de una transformación fotoquímica. La mayoría de los catalizadores utilizados son óxidos de metales semiconductores, que se caracterizan por tener una anchura de banda prohibida que se extiende desde la banda de valencia (VB), hasta la banda de conducción (CB). Cuando el catalizador recibe la energía de un fotón (hv) se produce la excitación de un electrón en el catalizador y éste gana la suficiente energía para cambiar de nivel, como se muestra en la Figura 1.17. Al mismo tiempo se forma un hueco, cada vez que un electrón abandona la banda de valencia [78].

Estas dos especies (electrón-hueco) forman un par en la superficie del catalizador, donde se pueden recombinar o participar en reacciones redox con las sustancias adsorbidas en la superficie del catalizador. Si esta interacción se realiza en un ambiente acuoso se producirán radicales $\bullet \mathbf{O H}$. Las propiedades químicas de adsorción del sustrato y las condiciones de la reacción química determinarán en gran medida el mecanismo de reacción que predominará. 


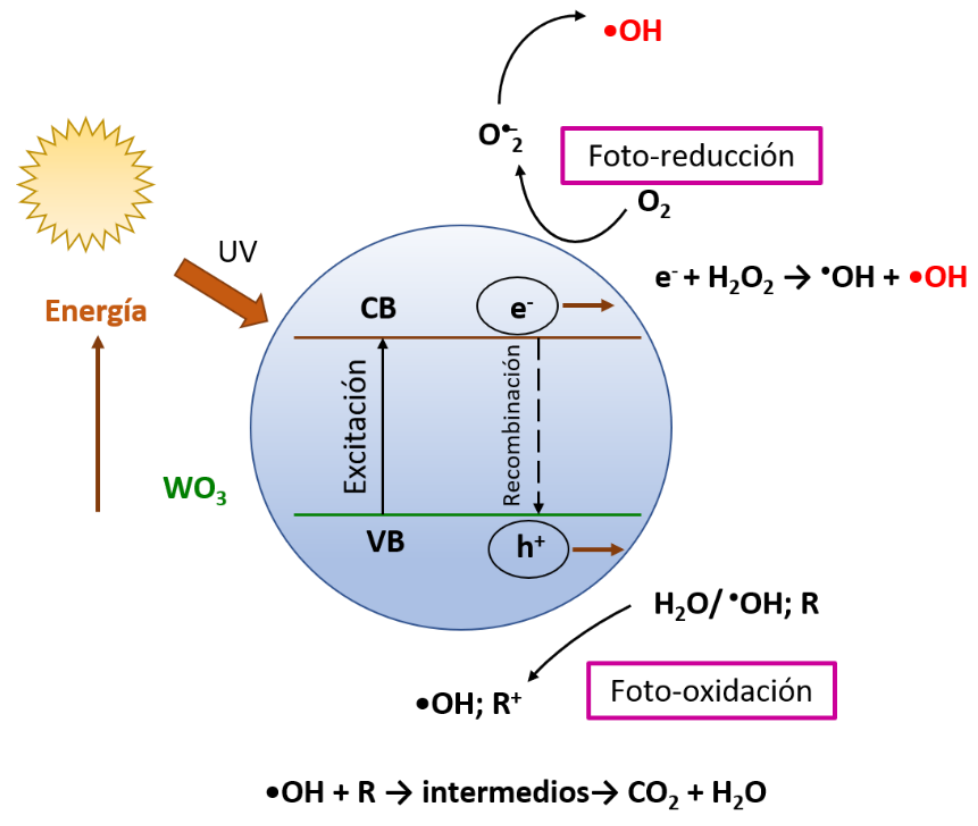

Figura 1.17. Esquema del proceso de $\mathrm{FC}$ empleando $\mathrm{WO}_{3}$ como semiconductor catalítico.

La reacción fotocatalítica puede ser representada en varios pasos, como se describe a continuación [78,79].

$$
\text { Semiconductor }+h v \rightarrow e_{C B}^{-}+h_{V B}^{+}
$$

En el hueco $\left(\mathrm{h}^{+}\right)$ocurre la reacción de oxidación del contaminante adsorbido ( $\mathrm{RX}$ ad) mientras que la formación de radicales hidroxilo se da a partir de las moléculas de agua:

$$
\begin{gathered}
h^{+}+R X_{a d} \rightarrow R X_{a d}^{+} \\
h^{+}+H_{2} O \rightarrow O H^{-}+H^{+} \\
h^{+}+O H^{-} \rightarrow \cdot O H_{a d}
\end{gathered}
$$

El oxígeno molecular actúa como aceptor de electrones en la banda de conducción formando aniones superóxido (1.13) que reaccionan en el medio 
formando peróxido de hidrógeno (1.14 y 1.15 ) el cual reacciona a su vez con la radiación formando más radicales hidroxilo.

$$
\begin{aligned}
e^{-}+\mathrm{O}_{2} & \rightarrow \mathrm{O}_{2}^{-} \\
\mathrm{H}^{+}+\mathrm{O}_{2}^{-} & \rightarrow \cdot \mathrm{O}_{2} \mathrm{H} \\
\mathrm{H}^{+}+\mathrm{O}_{2}^{-}+\mathrm{O}_{2} \mathrm{H} & \rightarrow \mathrm{H}_{2} \mathrm{O}_{2}+\mathrm{O}_{2} \\
\mathrm{H}_{2} \mathrm{O}_{2}+h v & \rightarrow 2(\cdot \mathrm{OH})
\end{aligned}
$$

Finalmente, los radicales hidroxilo reaccionan con el contaminante orgánico adsorbido en la superficie del catalizador, formando especies más simples.

$$
R X_{a d}^{+}+\cdot O_{a d} \rightarrow \text { Intermedios }
$$

\subsection{Fotoelectrocatálisis.}

Y finalmente, el proceso que se va a emplear en esta Tesis Doctoral, y que resulta muy interesante por sus múltiples ventajas es la fotoelectrocatálisis (FEC).

La fotoelectrocatálisis (FEC) combina procesos electrolíticos y fotocatalíticos. Recientemente, el proceso de tratamiento fotoelectrocatalítico ha recibido considerable atención en el campo ambiental debido a su capacidad para retrasar la recombinación de pares de electrones-hueco $\left(\mathrm{e}_{\mathrm{cB}}^{-} / \mathrm{h}^{+}{ }_{\mathrm{vB}}\right)$ y la posibilidad de aumentar la vida útil de este último dando como resultado una mayor eficiencia en los procesos de degradación de compuestos orgánicos. El potencial externo aplicado al semiconductor en el proceso FEC es un factor clave en la técnica fotoelectrocatalítica ya que acelera la reacción fotocatalítica. Este semiconductor actúa como fotocatalizador de las reacciones químicas absorbiendo la radiación solar y transformando los compuestos contaminantes en otros menos dañinos $[80,81]$.

Existen dos tipos de óxidos metálicos semiconductores, como son los semiconductores de tipo $\mathrm{n}$ y lo semiconductores de tipo $\mathrm{p}$. Los semiconductores de tipo $\mathrm{n}$ son los resultantes de procesos de dopado en los que se añaden 
materiales donantes de electrones al semiconductor con el fin de aumentar el número de electrones. En cambio, los semiconductores tipo $\mathrm{p}$ son también el resultado de procesos de dopado pero en este caso se añaden materiales aceptores de electrones para aumentar el número de huecos del semiconductor.

Para un electrodo semiconductor tipo $\mathrm{n}$, el nivel de Fermi es mayor que el potencial redox del electrolito, por lo tanto, los electrones se transferirán desde el electrodo hacia la disolución hasta que se neutralice la diferencia inicial entre ambos potenciales electroquímicos. En el momento en el que la carga del semiconductor es positiva con respecto a la carga del electrolito, las bandas de energía se doblan hacia arriba, llamándose ese fenómeno como condiciones de agotamiento. En el caso del semiconductor de tipo $p$, el nivel de Fermi es inferior al potencial redox del electrolito y, por tanto, los electrones se transferirán desde el electrolito hacia el electrodo hasta alcanzar el equilibrio. Esto causa el doblamiento hacia abajo de los bordes de las bandas de energía, produciendo el fenómeno mencionado anteriormente de condiciones de agotamiento. A continuación, se muestra un esquema resumen del funcionamiento de ambos semiconductores [80]. 

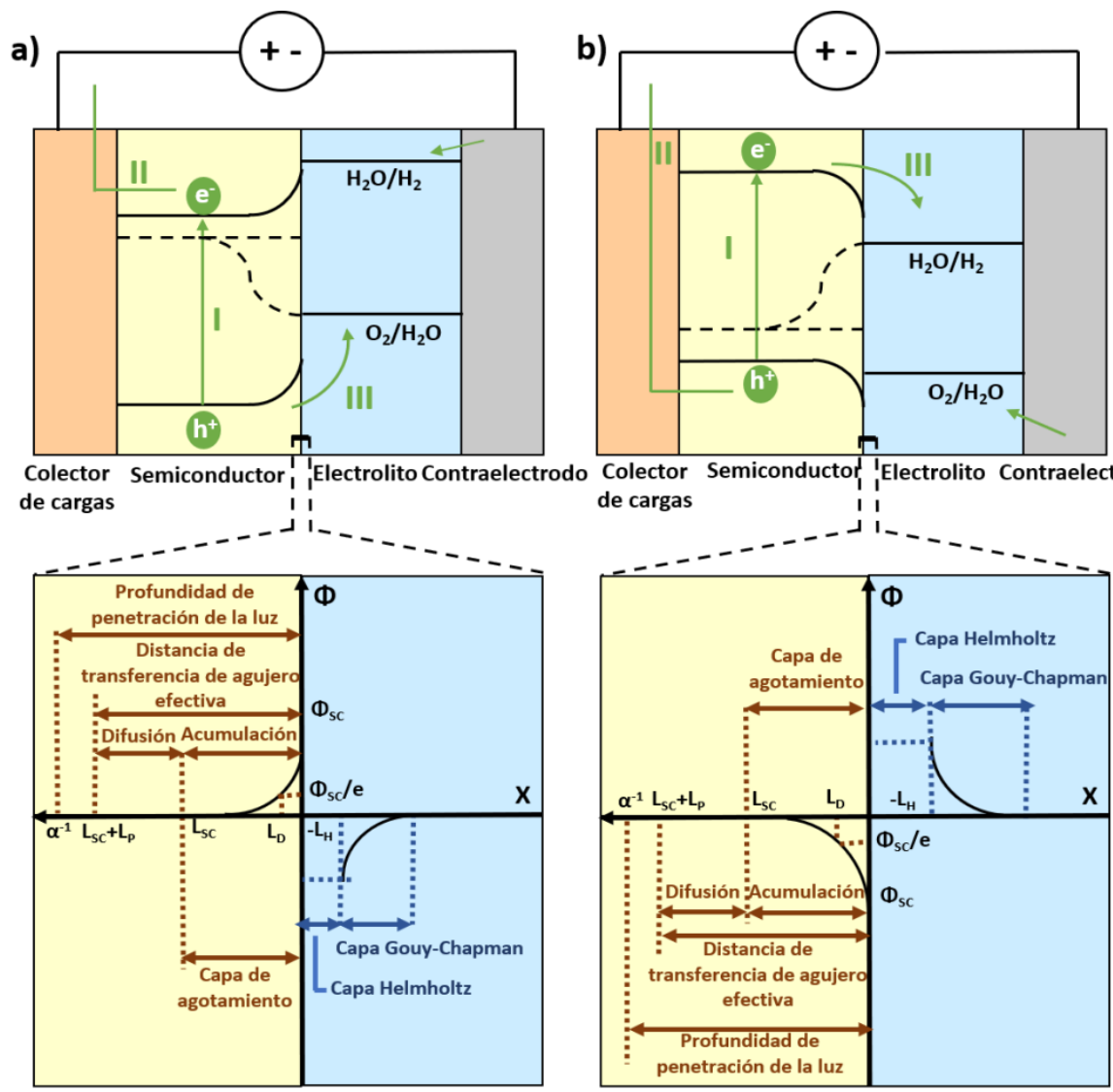

Figura 1.18. Esquema de funcionamiento de un semiconductor a) tipo $n$ y b) tipo $p$.

En general, la reacción completa en el proceso de FEC comprende tres pasos principales: 1) absorción de luz; 2) separación de cargas y 3) reacciones químicas superficiales [82].

En el proceso de absorción de luz, la migración de cargas y las reacciones químicas en la superficie se pueden expresar utilizando la siguiente ecuación:

$$
\eta=\frac{J_{m p}\left(E_{r e x}^{0}\left|E_{\text {means }} E_{a o c}\right|\right)}{P_{\text {in }}}=\frac{J_{m p}\left(1.23-V_{a p p}\right)}{P_{\text {in }}}
$$

donde $\mathrm{E}_{\text {rex }}^{0}$ es el potencial de reducción del agua (1.23 V), $\mathrm{E}_{\text {means }}$ es el potencial del electrodo de trabajo bajo irradiación de luz, $\mathrm{E}_{\mathrm{oc}}$ es el potencial de circuito abierto del electrodo de trabajo bajo la misma irradiación, la $\mathrm{V}_{\text {app }}$ es el potencial aplicado 
entre el fotoelectrodo y el contraelectrodo, $\mathrm{J}_{\mathrm{mp}}$ es la densidad de corriente, y $\mathrm{P}_{\text {in }}$ es la potencia de la iluminación.

Los procesos que se dan entre el semiconductor y el electrolito son complejos. La unión semiconductor-electrolito comprende tres capas: una capa de carga espacial, una capa de Helmholtz y una capa de Gouy. La Figura 1.19 representa la unión entre el semiconductor y el electrolito para un semiconductor de tipo n. En particular, el espesor de la capa Helmholtz es alrededor de 0.3-0.5 nm, que es independiente del fotoelectrodo. En cambio, el grosor de la capa de carga espacial y la capa de Gouy disminuyen al aumentar la concentración de portadores de carga dentro de la interfaz entre el fotoelectrodo y electrolito[82,83].

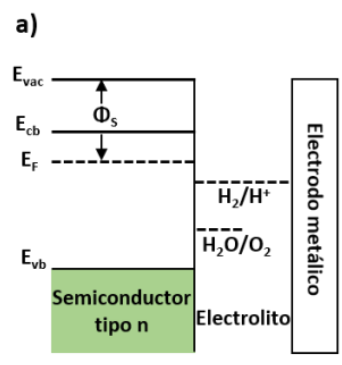

Antes del equilibrio

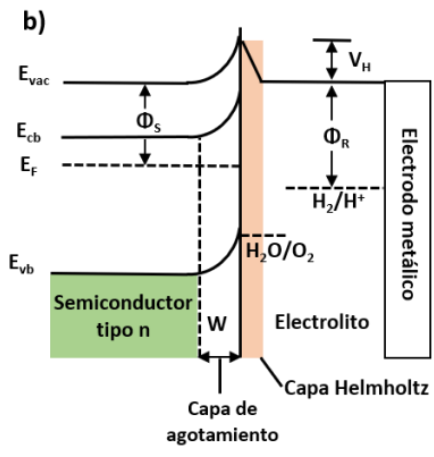

Equilibrio en condiciones oscuras

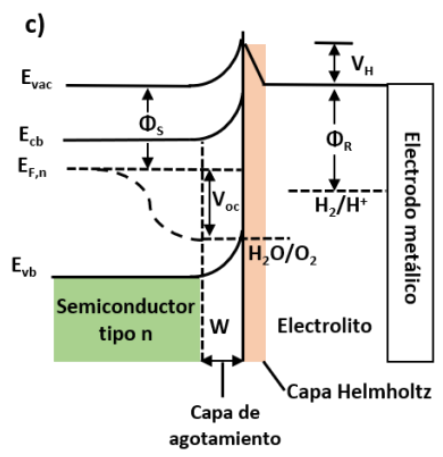

Equilibrio bajo iluminación

Figura 1.19. Las bandas energéticas en la interfase de un semiconductor tipo $\mathrm{n}$ y el electrolito mostrando la relación entre la pareja redox $\left(\mathrm{H}_{2} \mathrm{O} / \mathrm{O}_{2}\right.$ y $\left.\mathrm{H}_{2} / \mathrm{H}^{+}\right)$, la caída de potencial en la capa de Helmholtz $\left(V_{H}\right)$, la función de trabajo del semiconductor $\left(\Phi_{S}\right)$, la función de trabajo del electrolito $\left(\Phi_{R}\right)$ y el cuasi-nivel de Fermi referido al electrón $\left(E_{F, n}\right)$ y el cuasi-nivel de Fermi referido al hueco $\left(\mathrm{E}_{\mathrm{F}, \mathrm{p}}\right)$ en tres casos: a) entes del equilibrio entre las dos fases, $\mathrm{b}$ ) después del equilibrio bajo condiciones de oscuridad y c) en equilibrio cuasi-estático bajo condiciones de iluminación.

La capa de carga espacial de un semiconductor de tipo n puede ser además dividida en tres capas: 1) la capa de acumulación, donde se acumulan los electrones móviles, 2) la capa de agotamiento y 3) la capa de inversión, donde están los huecos acumulados. El grosor de la capa de carga espacial ( $\left.L_{s c}\right)$ se puede estimar de la siguiente manera:

$$
\begin{gathered}
L_{S C}=L_{D}\left[2 q\left|\Phi_{S C}\right| / k T\right]^{1 / 2}=L_{D}\left[2 q\left(V-V_{f b}\right) / k T\right]^{1 / 2} \\
L_{D}=\left[\varepsilon_{0} \varepsilon k T / q^{2}\left(n_{0}+p_{0}\right)\right]^{1 / 2}
\end{gathered}
$$


donde $L_{D}$ está estrechamente relacionado con la concentración del portador de carga de un fotoelectrodo, $\varepsilon_{0}$ es la constante dieléctrica en el vacío, $\varepsilon$ es la constante dieléctrica, $k$ es la constante de Boltzmann, $T$ es la temperatura absoluta en Kelvin, $q$ es la carga electrónica, $V$ es el potencial aplicado, $V_{\mathrm{fb}}$ es el potencial plano del fotoelectrodo, $\mathrm{y}_{0}$ y $\mathrm{p}_{0}$ hacen referencia a las concentraciones de electrones y huecos del fotoelectrodo, respectivamente. Las cargas fotogeneradas se someten a un proceso de difusión cuando salen de la capa de agotamiento. La longitud de difusión del portador minoritario $\left(L_{p}\right)$, que hace referencia a la distancia que un hueco puede recorrer antes de recombinarse con un electrón, se define como:

$$
\begin{gathered}
L_{p}=(D \tau)^{1 / 2}=\left[\left(\mu k_{b} T / q\right) \tau\right]^{1 / 2} \\
\mu=q \tau / m^{*}
\end{gathered}
$$

donde $D$ es el coeficiente de difusión del portador minoritario y $\tau$ es la vida útil. El coeficiente de difusión está estrechamente relacionado con la movilidad del portador minoritario, $\mu\left(\mathrm{m}^{2} \mathrm{~V}^{-1} \mathrm{~s}^{-1}\right)$, que se puede determinar de acuerdo con la ecuación 1.22, donde $\mathrm{m}^{*}$ es la masa efectiva del portador minoritario. Observando las ecuaciones 1.23 y 1.24, se puede afirmar que una disminución de $m$ * provoca un aumento en $L_{p}$.

Se debe resaltar que todas las condiciones mencionadas son para una celda FEC que utiliza un electrodo semiconductor de tipo $n$. Cuando se usa un semiconductor de tipo $\mathrm{p}$ como fotoelectrodo, todos los procesos bajo iluminación son análogos (como se muestra en la Figura 1.18 b), excepto que los dopantes ionizados están cargados negativamente y la disolución cerca del fotoelectrodo está cargada positivamente. Por tanto, los electrones tienden a desplazarse hacia las especies aceptoras cargadas positivamente adsorbidas en la interfaz semiconductor-electrolito para semiconductores de tipo $p[82,84]$.

El rendimiento de los fotoelectrodos puede evaluarse mediante la eficiencia de conversión del fotón incidente (IPCE), que está influenciada por la absorción óptica, el ancho de la capa de carga espacial y la longitud de difusión del portador minoritario. La IPCE de un fotoelectrodo a una longitud de onda $\lambda$ puede calcularse mediante la siguiente ecuación:

$$
\operatorname{IPCE}(\lambda)=1240 \cdot \frac{J_{P}(\lambda)}{p \cdot \lambda} \cdot 100 \%
$$


donde $p$ es la intensidad de la luz ( $\left.\mathrm{mW} \mathrm{cm}{ }^{-2}\right), \lambda$ es la longitud de onda de la luz incidente $(\mathrm{nm})$ y $\mathrm{J}_{\mathrm{p}}(\lambda)$ es la densidad de la fotocorriente $\left(\mathrm{mA} \mathrm{cm}{ }^{-2}\right)$ bajo irradiación a una sola longitud de onda ( $\lambda)$. La eficiencia de la fotoconversión IPCE $(\lambda)$ de un fotoelectrodo es otro parámetro importante para revelar el rendimiento de FEC bajo la irradiación de luz. Se ha demostrado que los factores como son la configuración de la celda (dos o tres electrodos), la fuente de luz, el contraelectrodo, la resistencia de contacto y la estructura de banda del semiconductor, influirán en la $\eta$ de un fotoelectrodo.

La eficiencia de una celda fotoelectrocatalítica está influenciada principalmente por la absorción óptica, el ancho de la capa de carga espacial, la difusión de portadores de carga minoritarios y la cinética de reacción superficial, que son responsables de la absorción de luz, la separación/migración de carga y las reacciones químicas superficiales. Sin embargo, se debe tener en cuenta que un control morfológico durante la elaboración de los semiconductores ofrece la oportunidad de optimizar de forma independiente cada paso mencionado anteriormente. Por esta razón, los fotoelectrodos basados en nanoestructuras han recibido una gran atención debido a sus altas relaciones superficie-volumen y vías de transporte directo para los portadores de carga fotogenerados [84].

Después de describir los fenómenos de la flexión de la banda de semiconductores y la región de carga espacial, se puede explicar la energía de la banda de la interfaz de semiconductor/electrolito antes del equilibrio entre las dos fases, después del equilibrio (en condiciones oscuras) y en equilibrio cuasiestático en condiciones de iluminación. Como se muestra en la Figura 1.19, cuando un fotoánodo semiconductor de tipo $\mathrm{n}$ se sumerge en un electrolito que contiene un par redox (por ejemplo, $\mathrm{H}_{2} \mathrm{O} / \mathrm{O}_{2}$ ), se produce una transferencia de electrones entre el semiconductor y la disolución hasta que se establece el equilibrio. Después del equilibrio, el electrodo tendrá un exceso de carga positiva, que surge de los átomos dopantes en el semiconductor, y la disolución tendrá un exceso de carga negativa. La carga positiva se extiende sobre la capa de agotamiento con un ancho "W" y la carga negativa se extiende sobre una región mucho más estrecha (la capa de Helmholtz) entre el electrodo y el electrolito (Fig. 19a y b). En la Figura 1.19c, la iluminación produce electrones y huecos que no están en equilibrio, por tanto, las propiedades electrónicas del sistema no se regirán por los niveles de Fermi sino por los llamados cuasi-nivel de Fermi. El cuasi-nivel de Fermi es una medida directa de la concentración de electrones y huecos en un punto determinado del semiconductor. Aunque el cuasi nivel de Fermi se entiende como 
una fuerza impulsora termodinámica, este concepto se ha determinado a partir de demostraciones cinéticas que dan como resultado explicaciones cuasitermodinámicas, ya que se encuentran muchas limitaciones en su aplicación, y por tanto limitan el valor predictivo del cuasi-nivel de Fermi $[83,85]$.

Por tanto, el proceso básico de la fotoelectrocatálisis consiste en excitar un electrón de la banda de valencia (VB) a la banda de conducción (CB) del semiconductor, creando así un hueco $\left(\mathrm{h}^{+}\right)$en la banda de valencia. Esto se debe a la irradiación UV con una energía igual o superior a la anchura de banda prohibida. Estos portadores de carga $\left(\mathrm{e}^{-} / \mathrm{h}^{+}\right)$migran hasta la superficie del fotocatalizador, como se muestra en la ecuación 1.24 para un semiconductor de tipo $n$, como es el óxido de wolframio $[81,85]$.

$$
W O_{3}+h v \rightarrow e_{C B}^{-}+h_{V B}^{+}
$$

A esto le sigue la formación de radicales extremadamente reactivos (como $\bullet \mathrm{OH}$ ) en la superficie del semiconductor y una oxidación directa de las especies contaminantes. Por lo tanto, los contaminantes en las aguas residuales pueden degradarse directamente en la superficie del semiconductor o indirectamente al reaccionar con radicales hidroxilo. El hueco fotogenerado en la banda de valencia puede reaccionar con una molécula de agua adsorbida para formar especies oxidantes que posteriormente atacan al contaminante. No obstante se ha demostrado que, en ausencia de moléculas de agua, los radicales hidroxilo no podían formarse e impedían la fotodegradación de los compuestos orgánicos en fase líquida.

Los electrones excitados a la banda de conducción pueden reaccionar con aceptores de electrones como el oxígeno adsorbido $\left(\mathrm{O}_{2}\right)$ para formar radicales superóxido o reaccionar con la molécula de agua adsorbida $\left(\mathrm{H}_{2} \mathrm{O}\right)$ para formar especies oxidativas como los radicales hidroxilo. Las ecuaciones que explican estos procesos son las ecuaciones 1.11-1.15 expresadas en capítulo 4.4.

La recombinación de los pares electrones-hueco fotogenerados reduce la eficiencia cuántica y limita la aplicación de la fotoelectrocatálisis en el campo del tratamiento de aguas contaminadas. Cada recombinación significa una pérdida de un hueco que de otro modo podría haber promovido la reacción de degradación. Para lograr una buena eficiencia fotoelectrocatalítica, se debe evitar esta recombinación. La Figura 1.20 muestra el mecanismo general del proceso 
fotoelectrocatalítico y la reacción principal que ocurre en la superficie del $\mathrm{WO}_{3}$. Según bibliografía, el potencial aplicado es un factor clave que mejora la eficiencia fotoelectrocatalítica. De hecho, cuando se aplica un sesgo positivo al fotoánodo, los electrones generados de este modo pueden transferirse al circuito externo en lugar de a la molécula de oxígeno. Como resultado, el hueco fotogenerado o el radical $\bullet \mathrm{OH}$ quedará en la superficie del electrodo de $\mathrm{WO}_{3}$. Por lo tanto, la tasa de recombinación fotoelectrocatalítica entre electrones y huecos es menor. Pero en el proceso fotoelectrocatalítico, la velocidad de conversión no depende directamente del potencial aplicado, sino que depende de varios factores: (i) las propiedades de los semiconductores, (ii) luz de difusión, (iii) adsorción y desorción del reactivo y productos y (iv) la intensidad del campo eléctrico en la región de carga espacial [86].

El esquema de funcionamiento de la técnica FEC con un semiconductor tipo $n$ queda reflejado en la siguiente Figura.

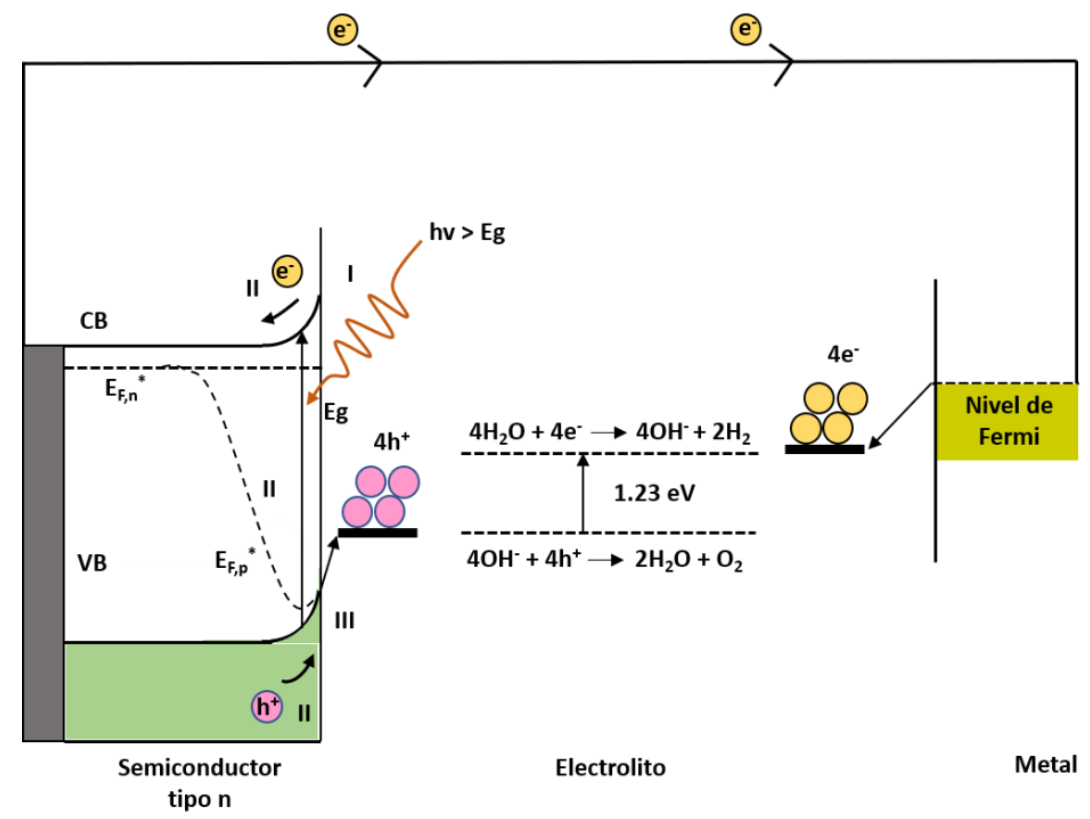

Figura 1.20. Esquema de funcionamiento de un sistema de FEC.

\section{Celda fotoelectroquímica.}


Una celda fotoelectroquímica es un reactor en el cual se lleva a cabo procesos fotoelectrocatalíticos con el fin de tratar aguas contaminadas o producir energía mediante la fotólisis del agua. Como mínimo, una celda fotoelectrocatalítica consiste en un recipiente donde contener el electrolito, un ánodo (normalmente un óxido semiconductor), un cátodo, una ventana transparente que permita que el fotoelectrodo (semiconductor) se ilumine e instalaciones para conectar eléctricamente ambos electrodos a un potenciostato con los que aplicar el potencial. Otros componentes que a menudo están presentes son un electrodo de referencia, y una o más entradas y salidas para un sistema de circulación de gas y/o purga de gas del electrolito. Además, la celda fotoelectroquímica puede contener un agitador magnético y una membrana que separa los compartimentos anódico y catódico para evitar la mezcla de los gases de oxígeno e hidrógeno desprendidos en el caso de la fotólisis del agua [87].

En la Figura 1.21 se muestra un esquema de una celda fotoelectroquímica típica.

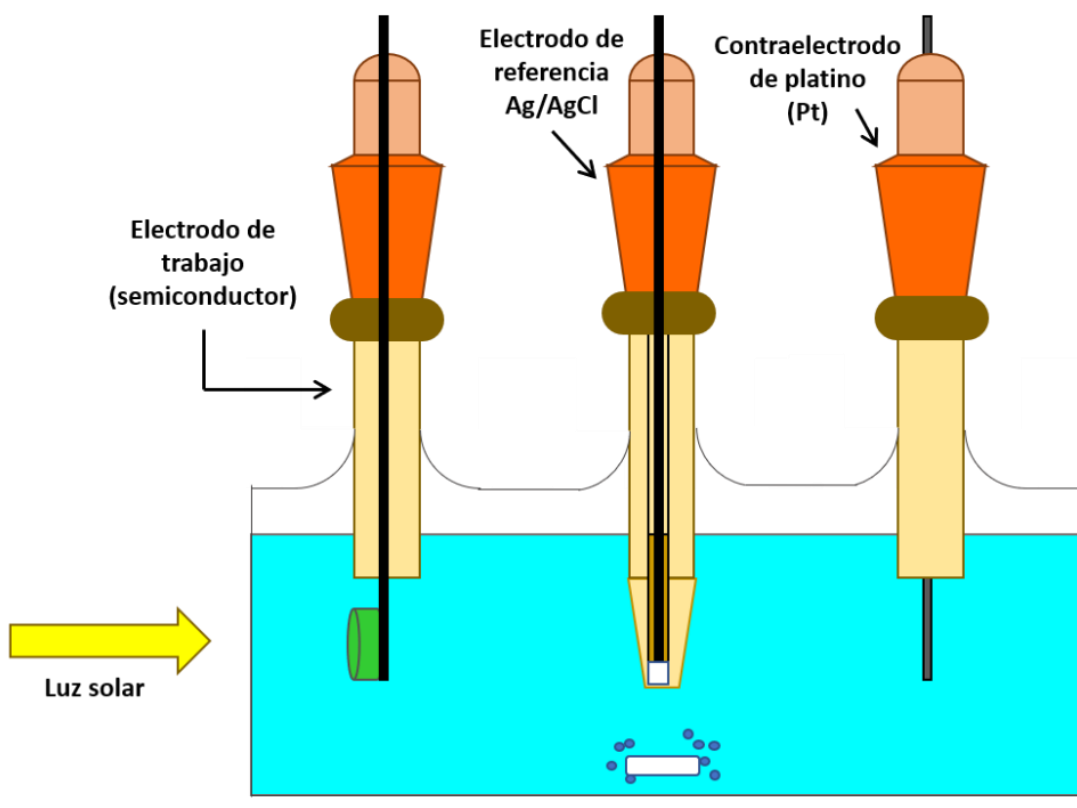

Agitador magnético

Figura 1.21. Esquema celda fotoelectroquímica.

A continuación, se describen los principales componentes de esta celda. 


\subsection{Cátodo o contraelectrodo}

Para evitar limitaciones de rendimiento, la reacción en el contraelectrodo (cátodo) debe ser rápida y el electrodo en sí debe tener una alta actividad catalítica. El platino (Pt) es el material más utilizado como contraelectrodo, que combina una buena estabilidad química con un sobrepotencial muy pequeño para la evolución de hidrógeno (aproximadamente $0.1 \mathrm{~V}$ ). Idealmente, el área de la superficie debe ser al menos dos veces mayor que el área del fotoelectrodo (ánodo), y ambos electrodos deben estar enfrentados simétricamente para evitar densidades de corriente no homogéneas en éste último. Para altas concentraciones de electrolitos (típicamente>0.5 M), el último requisito es menos estricto debido a la pequeña caída de potencial a través del electrolito. Una configuración común es una punta de platino o una malla de Pt, siendo necesario un orificio circular en la malla para evitar que bloquee la luz $[87,88]$.

\subsection{El electrodo de referencia}

El potencial aplicado es un parámetro clave en los procesos fotoelectrocatalíticos. Este potencial debe medirse con respecto a un potencial de referencia fijo, de modo que cualquier cambio en el potencial aplicado refleje un cambio solo en el fotoelectrodo. El contraelectrodo o cátodo no se puede usar para esto, ya que el sobrepotencial en la interfaz contraelectrodo/electrolito es generalmente desconocido y varía con la cantidad de corriente que fluye a través de la celda. Para evitar esta dependencia de la corriente, se agrega un tercer electrodo a la celda fotoelectroquímica: este es el electrodo de referencia. El potencial del fotoelectrodo ahora se puede medir con respecto al potencial (fijo) del electrodo de referencia con un flujo de corriente insignificante a través de este último. Los potenciales se indican actualmente utilizando la escala RHE (electrodo reversible de hidrógeno). El potencial cero en la escala RHE refleja el potencial redox $\mathrm{H}^{+} / \mathrm{H}_{2}$ en la solución real, independientemente del pH. Esto hace que sea más conveniente usarlo que la escala NHE (electrodo normal de hidrógeno). Los electrodos de plata/cloruro de plata son los más usados como electrodos de referencia, y han reemplazado en gran medida a los electrodos de calomelanos (SCE) tradicionales y menos respetuosos con el medio ambiente ya que se basan en $\mathrm{Hg}_{2} \mathrm{Cl}_{2} / \mathrm{Hg}$. Un criterio de selección importante para un electrodo de referencia es su estabilidad en el electrolito [87]. 


\subsection{El electrolito}

El electrolito en una celda fotoelectroquímica consiste en una disolución en la que se disuelven las especies activas a reducir u oxidar para producir especies más simples y en donde están sumergidos todos los electrodos.

\subsection{El fotoánodo.}

Pero el componente clave para los sistemas fotoelectrocatalíticos es el fotoelectrodo o fotoánodo, que convierte los fotones incidentes en pares electrón-hueco.

Un fotoánodo ideal requiere materiales semiconductores que posean las siguientes características: (i) Anchura de banda prohibida y posiciones de banda adecuadas. La luz solar natural consiste en 5\% de UV (300-400 nm), 43\% visible $(400-700 \mathrm{~nm})$ y $52 \%$ de radiación infrarroja $(700-2500 \mathrm{~nm})$. Por lo tanto, se requiere la absorción de luz de la región visible para aumentar la eficiencia, y esto a su vez depende del intervalo de banda del semiconductor. Como el potencial de reducción de protones se encuentra a $0 \mathrm{~V}$ frente a NHE y el potencial de $\mathrm{O}_{2} / \mathrm{H}_{2} \mathrm{O}$ a $1.23 \mathrm{~V}$ frente a $\mathrm{NHE}(\mathrm{pH}=0)$, la anchura de banda mínima teórica de un semiconductor adecuado debe ser alrededor de $1.23 \mathrm{eV}$. Sin embargo, al considerar las pérdidas de energía termodinámicas $(0.3-0.4 \mathrm{eV})$ que ocurren durante el transporte del portador de carga y el requisito de aplicar un potencial en exceso para una cinética de reacción superficial aceptable $(0.4-0.6 \mathrm{eV})$, se requiere un intervalo de bandas entre $1.9 \mathrm{eV}$ y $3.2 \mathrm{eV}$ para obtener fotovoltajes considerables. Teóricamente, es preferible una anchura de banda prohibida de 2.0 eV para un uso óptimo de la luz solar. La Figura 1.22 ilustra la anchura y posiciones de banda de los semiconductores típicos de tipo $n$ y tipo $p$ utilizados actualmente en $\mathrm{FEC}$ a $\mathrm{pH}=0$. Esta representación se ha realizado en orden creciente del eje $y$, es decir, el potencial más negativo está representado en la parte inferior y el más positivo en la parte superior, y por tanto, se ha invertido la posición de la banda de valencia y conducción respecto a la posición convencional. Este cambio se ha hecho con el fin de realizar una explicación más clara de las posiciones de banda de los semiconductores. Cabe señalar que las 
posiciones de banda de los semiconductores varían según el pH del electrolito, ya que $V_{H}$ (caída de potencial a través de la capa de Helmohltz) (como se ilustra en la Figura 1.19) depende de $\mathrm{pH}$ de la disolución (en $0.059 \mathrm{~V}$ por unidad de $\mathrm{pH}$ ) con respecto al potencial redox del electrolito [89].

En general, las posiciones de banda de la mayoría de los semiconductores, en particular los óxidos, muestran la misma dependencia con el $\mathrm{pH}$ que la representada por la ecuación de Nernst.

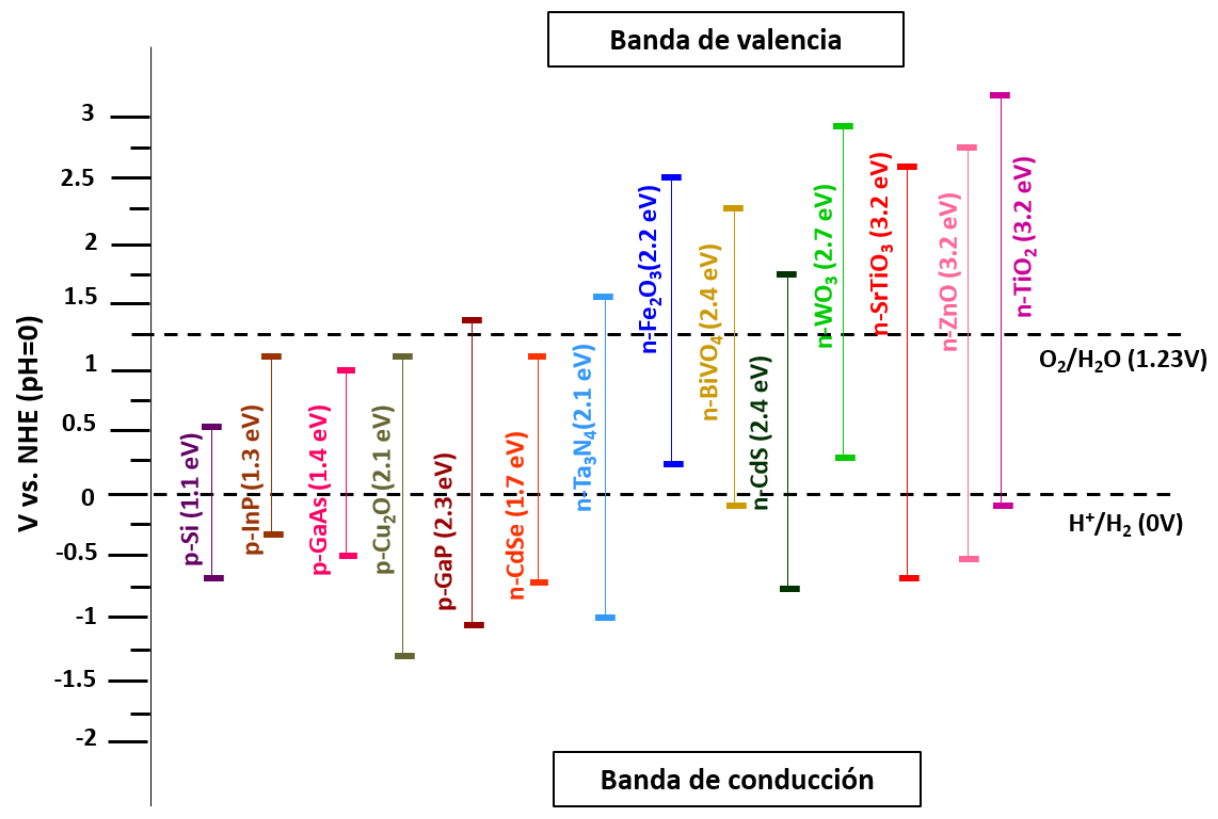

Figura 1.22. Anchura y posiciones de banda de los semiconductores típicos de tipo $n$ y tipo $p$ utilizados actualmente en $\mathrm{FEC} \mathrm{a} \mathrm{pH}=0$.

(ii) Separación y transporte eficientes del portador de carga en el semiconductor. La recombinación de carga es un factor importante que contribuye a las eficiencias bajas en los procesos de degradación y, por lo tanto, se requieren técnicas para promover la separación y transporte eficientes del portador de carga, que depende tanto de las propiedades intrínsecas (movilidad de huecos y electrones) como de las propiedades extrínsecas (cristalinidad y morfología de las nanoestructuras) del material. (iii) Fuerte actividad catalítica y estabilidad. Una cinética de reacción adecuada y rápida puede evitar la acumulación de carga superficial, que de otro modo conduciría a una recombinación de electroneshuecos. La fotocorrosión es un problema importante para muchos 
semiconductores, en particular sulfuros metálicos, y ocurre cuando los pares electrón-hueco fotogenerados no oxidan ni reducen el medio, sino que descomponen el fotocatalizador. Estas reacciones de fotocorrosión dependen de las posiciones relativas de los bordes de la banda de semiconductores. La fotocorrosión anódica puede ocurrir si el potencial de descomposición anódico $\left(E_{p d}\right)$ está por encima de la banda de valencia del semiconductor [89]. Por el contrario, la fotocorrosión catódica puede ocurrir si el potencial de descomposición catódico $\left(F_{\text {in }}\right)$ está por debajo de la banda de conducción del semiconductor. Los óxidos metálicos, como $\mathrm{BiVO}_{4}$ y $\mathrm{ZnO}$, o los sulfuros metálicos, como $\mathrm{MoS}_{2}$ y CdS, pueden sufrir fácilmente fotocorrosión anódica dependiendo del $\mathrm{pH}$ del electrolito, ya que los valores reales de los potenciales de descomposición dependen del valor del pH. Sin embargo, los materiales comunes como $\mathrm{TiO}_{2}$ y $\mathrm{Fe}_{2} \mathrm{O}_{3}$, a pesar de que su potencial de descomposición anódico está por encima del potencial de la banda de valencia, son termodinámicamente estables debido a que su cinética de reacción de descomposición es muy lenta.

En los últimos 10 años se han investigado numerosos materiales que actúan como fotoánodo en aplicaciones fotoelectrocatalíticas. A continuación, se resumen los fotoánodos más empleados hasta ahora, así como sus principales propiedades [88].

\section{Materiales para FEC. Ventajas de $\mathrm{WO}_{3}$.}

Como se ha mencionado anteriormente, uno de los aspectos más importantes en el proceso FEC es la elección de un material adecuado para los fotoánodos. A continuación se detallan los materiales más utilizados en esta técnica.

\section{1. $\mathrm{TiO}_{2}$}

Los fotoelectrodos basados en $\mathrm{TiO}_{2}$ se han investigado en profundidad desde 1972, debido a sus interesantes propiedades, como estar compuesto de elementos no tóxicos, abundantes en la tierra, ser fotoquímicamente estables en condiciones fuertemente ácidas o muy básicas y tener una adecuada anchura de banda prohibida ( $3.2 \mathrm{eV}$ para anatasa y $3.0 \mathrm{eV}$ para la fase rutilo), aunque solo el $5 \%$ del espectro solar (predominantemente luz UV) puede ser absorbido. Durante la última década, se han hecho muchos intentos para dopar $\mathrm{TiO}_{2}$ con aniones o 
cationes para extender su rango de trabajo en la región visible con el fin de mejorar la absorción, manteniendo su buena estabilidad y bajo coste. La banda de valencia de $\mathrm{TiO}_{2}$ se puede modificar mediante la introducción de especies no metálicas, como el carbono o el nitrógeno, a través de la formación de estados intermedios, y la banda de conducción se puede modificar formando estados donantes debajo de ella al doparse con iones de metales de transición $3 \mathrm{~d}$. Sin embargo, en la mayoría de estos ejemplos, debido a que no hay un cambio fundamental en la anchura de banda, no se ha registrado una mejora sustancial en la actividad de estos materiales. Aunque el dopaje puede extender su absorción de luz hacia lo visible, la absorción óptica aún es muy moderada por encima de $450 \mathrm{~nm}[88]$.

\section{2. $\alpha-\mathrm{Fe}_{2} \mathrm{O}_{3}$}

$\mathrm{El} \alpha-\mathrm{Fe}_{2} \mathrm{O}_{3}$ (hematita) es un material con buena estabilidad química, baja toxicidad y bajo coste, debido a su alta abundancia natural. Además, tiene anchura de banda prohibida entre 1.9 y $2.32 \mathrm{eV}$, lo que permite una absorción de luz visible que se traduce en una eficiencia de degradación buena. Sin embargo, la hematita posee una posición de banda de conducción significativamente más positiva que el potencial de reducción de protones y, por lo tanto, solo puede ser utilizado en presencia de un potencial externo. Además, la hematita tiene otros inconvenientes, que incluyen: (1) una corta vida útil del portador de carga del orden de los picosegundos, debido a la recombinación rápida del portador de carga; (2) una movilidad lenta del portador de carga minoritaria (hueco), lo que resulta en una longitud de difusión muy corta de 2-4 nm para los huecos; y (3) mala cinética de oxidación del agua, lo que conduce a una alta tasa de recombinación en la superficie debido a la acumulación de huecos [90]. Para superar estas limitaciones, se han aplicado varias estrategias para mejorar la actividad de los fotoelectrodos basados en hematita. En primer lugar, se ha demostrado que el dopaje por diferentes elementos, como $\mathrm{Si}$, $\mathrm{Ti}$ y $\mathrm{P}$, mejora la conductividad de los electrones en la hematita. En segundo lugar, se ha observado que la morfología del semiconductor de tipo nanorods ramificados mejora la corta longitud de difusión de los huecos fotogenerados y facilita el transporte eficiente del hueco a la superficie [91]. Además, este material ha sido optimizado utilizando el anodizado electroquímico como método de síntesis, en el que se han variado 
parámetros como la velocidad de rotación del electrodo, el electrolito utilizado, y las condiciones de calentamiento en el proceso de post-anodizado [92,93].

\section{3. $\mathrm{BiVO}_{4}$}

$\mathrm{BiVO}_{4}$ es un semiconductor de tipo $\mathrm{n}$ compuesto de elementos relativamente abundantes en la superficie terrestre. Tiene una anchura de banda de $2.4 \mathrm{eV}$, con una posición de banda de conducción cercana a $0 \mathrm{~V}$ frente a NHE $(\mathrm{pH}=0)$ y una posición de banda de valencia en $2.4 \mathrm{eV}$ vs. $\operatorname{NHE}(\mathrm{pH}=0)$. No obstante, la eficiencia de $\mathrm{BiVO}_{4}$ está limitada por varios factores. La recombinación del portador de carga es un problema debido a su corta longitud de difusión de electrones (solo $10 \mathrm{~nm}$ ) así como la cinética de oxidación de agua tan pobre que experimenta. La longitud de difusión de electrones puede incrementarse significativamente al doparse con elementos como Mo y W. La cinética de reacción pobre puede mejorarse mediante la adición de co-catalizadores de evolución de oxígeno tales como $\mathrm{CoPO}_{4}$ (fosfato de cobalto) [94,95].

\subsection{CdS}

En teoría, la evolución fotocatalítica de $\mathrm{H}_{2}$ y $\mathrm{O}_{2}$ bajo irradiación de luz visible se puede lograr sobre CdS puro, debido a su anchura de banda prohibida relativamente estrecha de $2.4 \mathrm{eV}$, una posición de banda de conducción adecuada de $0.7 \mathrm{~V}$ y una posición de banda de valencia de $1.7 \mathrm{~V}$ vs. NHE $(\mathrm{pH}=0)$. Aunque el material posee una larga longitud de difusión del portador de carga en el rango de micrómetros, su cinética de oxidación del agua pobre conduce a la acumulación de huecos fotogenerados en la superficie, lo que resulta en una seria fotocorrosión anódica. Para evitar esto, los eliminadores de huecos, como $\mathrm{S}^{2-}$, se emplean comúnmente cuando se utiliza CdS para la reducción fotocatalítica del agua. Las capas de pasivación de superficie se han usado ampliamente para reducir la recombinación de carga en la superficie, aumentar la cinética de reacción y proteger al semiconductor de la corrosión química. Sin embargo, se necesita una mayor investigación para mejorar el rendimiento y la estabilidad de los fotoelectrodos basados en sulfuro [96].

\section{5. $\mathrm{ZnO}$}


El ZnO es un tipo de semiconductor con una anchura de banda prohibida de 3.2 eV similar a la del $\mathrm{TiO}_{2}$ y se esperaría que tenga una actividad fotocatalítica similar. Sin embargo, esta propiedad no solo depende de la anchura de banda prohibida, sino también de la posición de la banda de conducción (BC) y la banda de valencia (BV). La mayor ventaja del $\mathrm{ZnO}$ es que absorbe gran parte del espectro solar y más cuantos de luz que el $\mathrm{TiO}_{2}$. Algunas investigaciones han puesto en relieve el rendimiento del $\mathrm{ZnO}$ en la degradación de compuestos orgánicos. Sin embargo, el principal inconveniente del $\mathrm{ZnO}$ en medio acuoso es su inestabilidad química, produciendo $\mathrm{Zn}(\mathrm{OH})_{2}$ sobre la superficie de las partículas de $\mathrm{ZnO}$, llevando así a la desactivación del catalizador con el tiempo.

$$
\begin{aligned}
\mathrm{ZnO}+2 \mathrm{H}_{a q}^{+} & \rightarrow \mathrm{Zn}_{a q}^{2+}+\mathrm{H}_{2} \mathrm{O} \\
\mathrm{ZnO}+\mathrm{H}_{2} \mathrm{O} & \rightarrow \mathrm{Zn}(\mathrm{OH})_{2} \downarrow
\end{aligned}
$$

El intervalo de $\mathrm{pH}$ en el que el $\mathrm{ZnO}$ es estable es muy limitado, dado que las reacciones 25 y 26 dependen en gran medida de este. Otra desventaja que posee el $\mathrm{ZnO}$ es la fotodescomposición que sufre durante una radiación prolongada. Esto se atribuye principalmente a la oxidación del $\mathrm{ZnO}$ por los huecos $\left(\mathrm{h}^{+}\right)$de acuerdo a la reacción (1.27), por lo tanto, su aplicación como fotocatalizador es muy limitada [97].

$$
\mathrm{ZnO}+2 h^{+} \rightarrow \mathrm{Zn}^{2+}+\frac{1}{2} \mathrm{O}_{2}
$$

\section{6. $\mathrm{SnO}_{2}$}

$\mathrm{El} \mathrm{SnO}_{2}$ es un semiconductor de tipo $\mathrm{n}$ con una energía de banda prohibida de 3.8 eV, que corresponde a un borde de adsorción óptica por debajo de $330 \mathrm{~nm}$. Sin embargo, presenta un gran inconveniente ya que debido a la posición de la banda de conducción es incapaz de reducir moléculas de agua. Por tanto, los semiconductores de este tipo no han sido considerados como fotocatalizadores adecuados que puedan ser utilizados individualmente. Por otro lado, estos materiales pueden tener una ventaja en cuanto a su estructura de bandas, $y$, posiblemente, se puedan utilizar cuando se combina con otros semiconductores con la anchura de banda adecuada [98]. 


\section{7. $\mathrm{WO}_{3}$}

Finalmente, el $\mathrm{WO}_{3}$ es un semiconductor con una anchura de banda prohibida de $2.6 \mathrm{eV}, 0.6 \mathrm{eV}$ más estrecha que el $\mathrm{TiO}_{2}$, por lo tanto, la luz visible puede ser aprovechada mejor con el $\mathrm{WO}_{3}$. La Figura 1.22 muestra que el borde superior de la banda de valencia del $\mathrm{WO}_{3}$ supera el potencial de oxidación del $\mathrm{H}_{2} \mathrm{O} / \mathrm{O}_{2}$, por lo tanto, los huecos fotogenerados en el $\mathrm{WO}_{3}$ son capaces de oxidar una amplia gama de compuestos orgánicos. Otra de las virtudes del $\mathrm{WO}_{3}$ es su notable fotoestabilidad en soluciones acuosas ácidas, por lo que es un fotocatalizador de gran alcance, por ejemplo, para el tratamiento de aguas residuales contaminadas por compuestos orgánicos.

Debido a sus buenas propiedades en comparación con los semiconductores descritos anteriormente, se va a centrar la atención en los fotoánodos basados en $\mathrm{WO}_{3}[99]$.

El $\mathrm{WO}_{3}$ está compuesto por unidades de perovskita, un tipo de estructura cristalina con el oxígeno dispuesto en los centros de las caras, y es uno de los candidatos más atractivos para la fotoelectrocatálisis, ya que exhibe una absorción de aproximadamente el $12 \%$ del espectro solar, una longitud moderada de difusión del hueco ( $150 \mathrm{~nm}$ ) en comparación con $\alpha-\mathrm{Fe}_{2} \mathrm{O}_{3}(2-4 \mathrm{~nm})$ y exhiben fotocorrientes de estado estacionario más grandes debido a la mayor eficiencia de conversión del fotón incidente (IPCE) si se compara también con el $\alpha-\mathrm{Fe}_{2} \mathrm{O}_{3}$. Además, presenta un mejor transporte de electrones $\left(12 \mathrm{~cm}^{2} \mathrm{~V}^{-1} \mathrm{~s}^{-1}\right)$ que $\mathrm{TiO}_{2}(0.3$ $\left.\mathrm{cm}^{2} \mathrm{~V}^{-1} \mathrm{~s}^{-1}\right)$. Según el requisito para la fotólisis del agua, el nivel de la CB del semiconductor tiene que ser más negativo que el potencial redox de $\mathrm{H}^{+} / \mathrm{H}_{2}[0 \mathrm{~V}$ vs. electrodo de hidrógeno normal (NHE)], mientras que la banda de valencia del semiconductor tiene que ser más positivo que el potencial redox de $\mathrm{O}_{2} / \mathrm{H}_{2} \mathrm{O}(1.23$ V) [100].

$\mathrm{El} \mathrm{WO}_{3}$ posee una posición del borde de la banda de valencia lo suficientemente positiva para la oxidación del agua. Por lo tanto, durante la fotólisis del agua, se puede producir oxígeno, pero no $\mathrm{H}_{2}$ ya que el nivel de la $\mathrm{CB}$ del $\mathrm{WO}_{3}$ no es lo suficientemente negativo para la reducción espontánea del $\mathrm{H}^{+}$. Por lo tanto, se puede acoplar con un fotocátodo (es decir, un semiconductor tipo $\mathrm{p}$ adecuado para producción de $\mathrm{H}_{2}$ solar) en forma de tándem o aplicando un potencial de polarización para lograr la fotólisis del agua completa produciendo tanto $\mathrm{H}_{2}$ como $\mathrm{O}_{2}[99,100]$. 
El $\mathrm{WO}_{3}$ es un material de tipo $\mathrm{n} y$, por lo tanto, sus bandas en la interfaz electrodo-electrolito favorece su uso como fotoánodo. Además, es altamente estable a $\mathrm{pH}$ bajo donde la evolución de $\mathrm{H}_{2}$ a menudo es más eficiente. Por lo tanto, el $\mathrm{WO}_{3}$ se considera un material más adecuado que $\mathrm{TiO}_{2}$ y $\alpha-\mathrm{Fe}_{2} \mathrm{O}_{3}$ para aplicaciones como fotoelectrólisis del agua y degradación de compuestos orgánicos. Sin embargo, la alta recombinación de electrones y huecos fotogenerados en $\mathrm{WO}_{3}$ hace que sea un desafío cumplir con los requisitos de la aplicación práctica.

A principios de 1976, ya demostraron [101] que el $W_{3}$ era un excelente fotocatalizador para la oxidación del agua. Posteriormente, se demostró que solo la fase monoclínica I $\left(\boldsymbol{\gamma}-\mathrm{WO}_{3}\right)$ es la fase más estable a temperatura ambiente $\mathrm{y}$ siempre muestra una gran actividad fotocatalítica.

La estructura cristalina del $\mathrm{WO}_{3}$ consiste en una estructura similar a la perovskita $\mathrm{ABO}_{3}$ basada en las redes tridimensionales de octaedros de $\mathrm{WO}_{6}$ que comparten esquinas. Sin embargo, debido a las distorsiones correspondientes a los desplazamientos antiferroeléctricos de los átomos de $\mathrm{W}$ y a las rotaciones mutuas de los octaedros de oxígeno, la estructura del $\mathrm{WO}_{3}$ muestra cinco fases estables (en el rango de temperatura de 900 a $180^{\circ} \mathrm{C}$ ) que corresponden con las fases tetragonal $\left(\alpha-W_{3}\right)$, ortorrómbico $\left(\beta-W_{3}\right)$, monoclínico I $\left(\gamma-W_{3}\right)$, triclínico $(\delta$ $\mathrm{WO}_{3}$ ) y monoclínico II $\left(\varepsilon-\mathrm{WO}_{3}\right)$. Las celdas unitarias de las diferentes fases de $\mathrm{WO}_{3}$ y sus correspondientes estructuras de banda se muestran en las Figura 1.23a y b. La separación de banda electrónica de $\mathrm{WO}_{3}$ aumenta significativamente con la distorsión del octaedro original que conduce a un fuerte aumento en la compresión y la separación de banda. Es decir, la disposición cristalográfica determina la anchura de banda de los semiconductores, y aumenta de $1.6 \mathrm{eV}$ en la estructura cúbica similar a perovskita a $2.4 \mathrm{eV}$ en la estructura distorsionada monoclínica completa. Dicha modificación en la estructura cristalina tiene una fuerte influencia en los estados de defectos y la anchura de banda del $\mathrm{WO}_{3}$.

Observando todas las estructuras cristalinas, la estructura monoclínica es altamente estable siendo la más eficiente en aplicaciones fotoelectrocatalíticas. La cristalinidad también afecta a la actividad fotoelectrocatalítica del $\mathrm{WO}_{3}$ ya que el potencial requerido para la fotooxidación del agua en la superficie de $\mathrm{WO}_{3}$ depende principalmente de la orientación de los cristales. Por ejemplo, se ha demostrado [102] que el potencial requerido para la fotooxidación es 1.04, 1.10 y $1.05 \mathrm{~V}$ para las orientaciones (200), (020) y (002) del $\mathrm{WO}_{3}$, respectivamente. De 
hecho, se ha demostrado [103] que la orientación de cristal (002) muestra una evolución fotocatalítica de $\mathrm{O}_{2}$ mejorada y una eficiente reducción de $\mathrm{CO}_{2}$ a $\mathrm{CH}_{4}$ bajo iluminación. Además, la orientación cristalina (002) del $\mathrm{WO}_{3}$ es más favorable para la adsorción y degradación de contaminantes orgánicos. Se ha mostrado [104] que los fotoánodos de $\mathrm{WO}_{3}$ con estructura (002) facilitan la separación del portador de carga fotoinducido conduciendo a una mayor fotocorriente y una mejor fotoestabilidad. El diagrama de energía libre de las facetas se muestra en la Figura 1.23c. Las esferas grises representan los átomos de wolframio, las esferas rojas representan los átomos de oxígeno y las esferas blancas los protones. El oxígeno en forma de gas no se muestra en los modelos. La orientación (200) necesita superar todo el cambio de energía de $1.62 \mathrm{eV}$ para impulsar la reacción de oxidación del agua, mientras que la orientación (002) solo necesita superar el cambio de energía de $1.49 \mathrm{eV}$. Además, la conversión a las especies en $\mathrm{O}_{2}{ }^{\circ-}$, encargadas de producir radicales hidroxilo, en la orientación (200) es más difícil que en la orientación (002). Por lo tanto, se acumularán más electrones en la orientación (200) durante las reacciones de oxidación y reducción, lo que produce una mayor recombinación de pares electrón-hueco reduciendo la actividad fotoelectrocatalítica y la estabilidad de los fotoánodos [105]. 
(a)

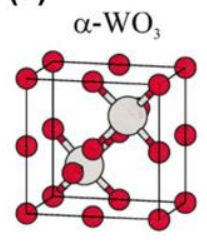

$\delta-\mathrm{WO}_{3}$
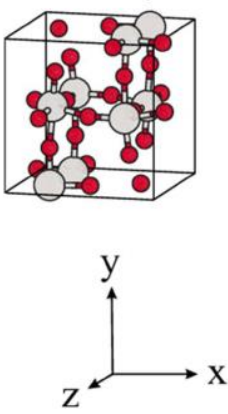

$\beta-\mathrm{WO}_{3}$

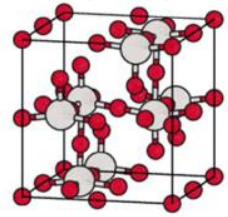

$\varepsilon-\mathrm{WO}_{3}$

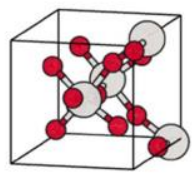

$\gamma-\mathrm{WO}_{3}$

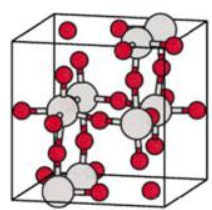

orth- $\mathrm{WO}_{3}$

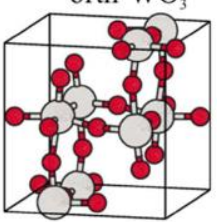

(b)
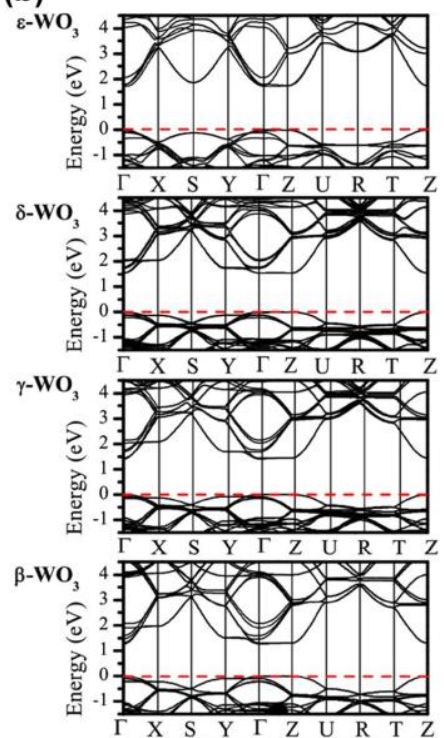

orth-WO

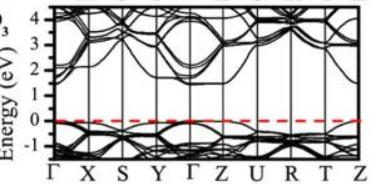

$\alpha-\mathrm{WO}_{3}$

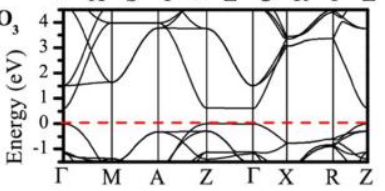

hex-Wo

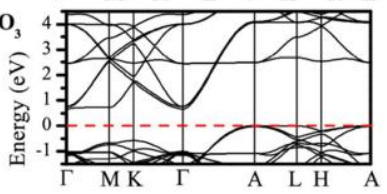

Figura 1.23. a) Celdas unitarias de las diferentes fases de $\mathbf{W O}_{3}$ y sus energías que se muestran en b) correspondientes estructuras de banda y c) El diagrama de energía libre de las facetas [105].

\section{Interés en la investigación del $\mathrm{WO}_{3}$ como fotoelectrodo.}

La distribución de trabajos de investigación sobre el $\mathrm{WO}_{3}$ por año de publicación entre 2009 y 2017 se muestra en la Figura 1.24. En ella se puede observer que hay un total de 338 trabajos de investigación sobre $\mathrm{WO}_{3}$ publicados durante los últimos diez años. Es evidente que las publicaciones relacionadas con el fotocatalizador $\mathrm{WO}_{3}$ aumentaron considerablemente a partir del 2012. En 
general, la figura muestra una tendencia al alza, lo que indica que el fotocatalizador de $\mathrm{WO}_{3}$ ha despertado un gran interés en el campo de la FEC [105].

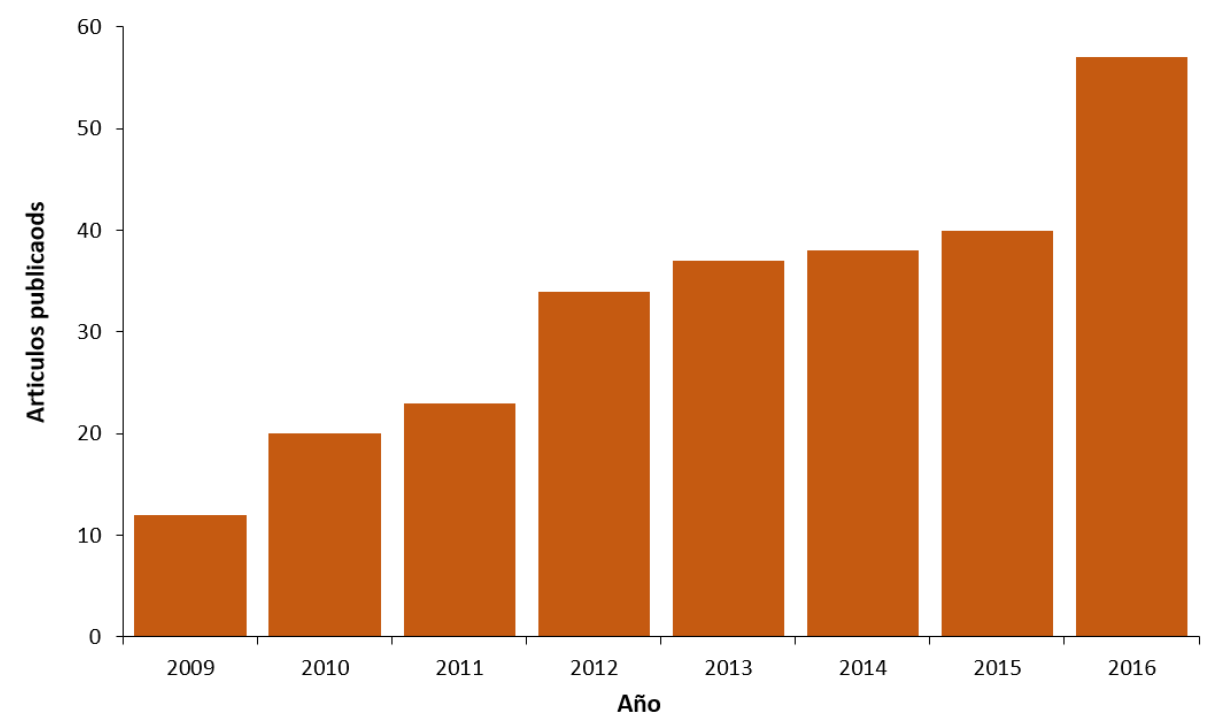

Figura 1.24. La distribución de trabajos de investigación sobre el $\mathrm{WO}_{3}$ por año de publicación entre 2009 y 2017.

El control de la morfología de un fotocatalizador se ha considerado como una de las vías más prometedoras para mejorar la actividad fotocatalítica. Esto se debe a que las reacciones fotocatalíticas suelen ser procesos que ocurren en la superficie $y$, por lo tanto, la eficiencia fotocatalítica está estrechamente relacionada con la morfología y la microestructura de un fotocatalizador.

$\mathrm{El} \mathrm{WO}_{3}$ en forma nanoestructurada está despertando un gran interés debido a las buenas propiedades que presenta. En general, las estrategias para la síntesis de nanopartículas $\mathrm{WO}_{3}$ se pueden dividir en enfoques directos e indirectos. Dentro de los enfoques directos se encuentran los métodos hidrotermales, solvotérmico, anodizado y descarga de arco de fase sólido-líquido (SLPAD). Entre estos métodos, los métodos hidrotermales, solvotérmicos y anodizado son muy eficaces para la síntesis controlable de nanoestructuras de $\mathrm{WO}_{3}$. Este control se puede llevar a cabo fácilmente variando los factores, como tipo de precursores, solventes, agentes de protección y temperatura, así como valores de pH. Además, el $\mathrm{WO}_{3}$ se 
puede fabricar a través de métodos indirectos con precursores en forma de láminas preparadas (como $\mathrm{WO}_{3} \cdot 2 \mathrm{H}_{2} \mathrm{O}, \mathrm{H}_{2} \mathrm{WO}_{4}$ y $\mathrm{Bi}_{2} \mathrm{WO}_{2} \mathrm{O}_{9}$ ) y la posterior deshidratación de los precursores obtenidos, tales como calcinación, exfoliación y tratamiento con plasma [106].

La eficiencia de recolección de carga de las nanoestructuras de $\mathrm{WO}_{3}$ se puede mejorar significativamente mediante la introducción de una morfología porosa y nanocristalina que consiste en una red de partículas $\mathrm{WO}_{3}$ con tamaños en el rango de decenas de nanómetros, es decir, más pequeña que la longitud de difusión del orificio. Por tanto, el anodizado es probablemente la mejor ruta para fabricar los fotoánodos de $\mathrm{WO}_{3}$ porosos para aplicaciones fotoelectrocatalíticas. De hecho, los fotoánodos de $\mathrm{WO}_{3}$ han exhibido una de las fotocorrientes más altas mostradas hasta ahora. Como esta técnica conduce a la formación de $\mathrm{WO}_{3}$ fuertemente interconectados y fuertemente unidos a la base del metal, puede producir altas eficiencias debido a un mejor transporte de carga. El control morfológico o la morfología específica tienen una influencia significativa en el rendimiento cuántico interno de los fotoánodos de $\mathrm{WO}_{3}$. Además, se ha demostrado [107] que la recombinación de electrones y huecos en el $\mathrm{WO}_{3}$ poroso se reduce debido al aumento en las longitudes efectivas de difusión de portadores minoritarios que mejoran el rendimiento cuántico interno en comparación con los electrodos compactos. Como resultado, los electrodos de $\mathrm{WO}_{3}$ porosos muestran un aumento de seis veces en la densidad de la fotocorriente, de 0.12 a $0.55 \mathrm{~mA} \cdot \mathrm{cm}^{-2}$ (bajo iluminación AM 1.5G) [108,109].

La composición y la temperatura del electrolito utilizado en el anodizado juegan un papel crucial en la obtención de una capa razonable de nanoestructuras de $\mathrm{WO}_{3}$ y resultados reproducibles.

Además, se observa que la preparación de los fotoelectrodos de $\mathrm{WO}_{3}$ es lenta a temperatura ambiente $\left(20^{\circ} \mathrm{C}\right)$, y se aceleró enormemente $(\times 10)$ llevando a cabo el anodizado a $40-50{ }^{\circ} \mathrm{C}$. Esto proporciona un enfoque rápido y conveniente para la fabricación de fotoelectrodos de $\mathrm{WO}_{3}$ eficientes. También se ha observado que el potencial aplicado y el tiempo de anodizado desempeñan un papel importante en la morfología de las nanoestructuras de $\mathrm{WO}_{3}[105]$.

En los últimos años, los fotocatalizadores basados en $\mathrm{WO}_{3}$ se han utilizado en muchos campos, como la fotodegradación de compuestos orgánicos, purificación del aire, autolimpieza, fotorreducción de $\mathrm{CO}_{2}$, tratamiento de iones de metales pesados, desprendimiento de hidrógeno a partir de la fotoelectrólisis del agua y 
desinfección de campos bacterianos [99]. En la Figura 1.25 se ilustra un resumen de las aplicaciones de los fotocatalizadores basados en $\mathrm{WO}_{3}$.

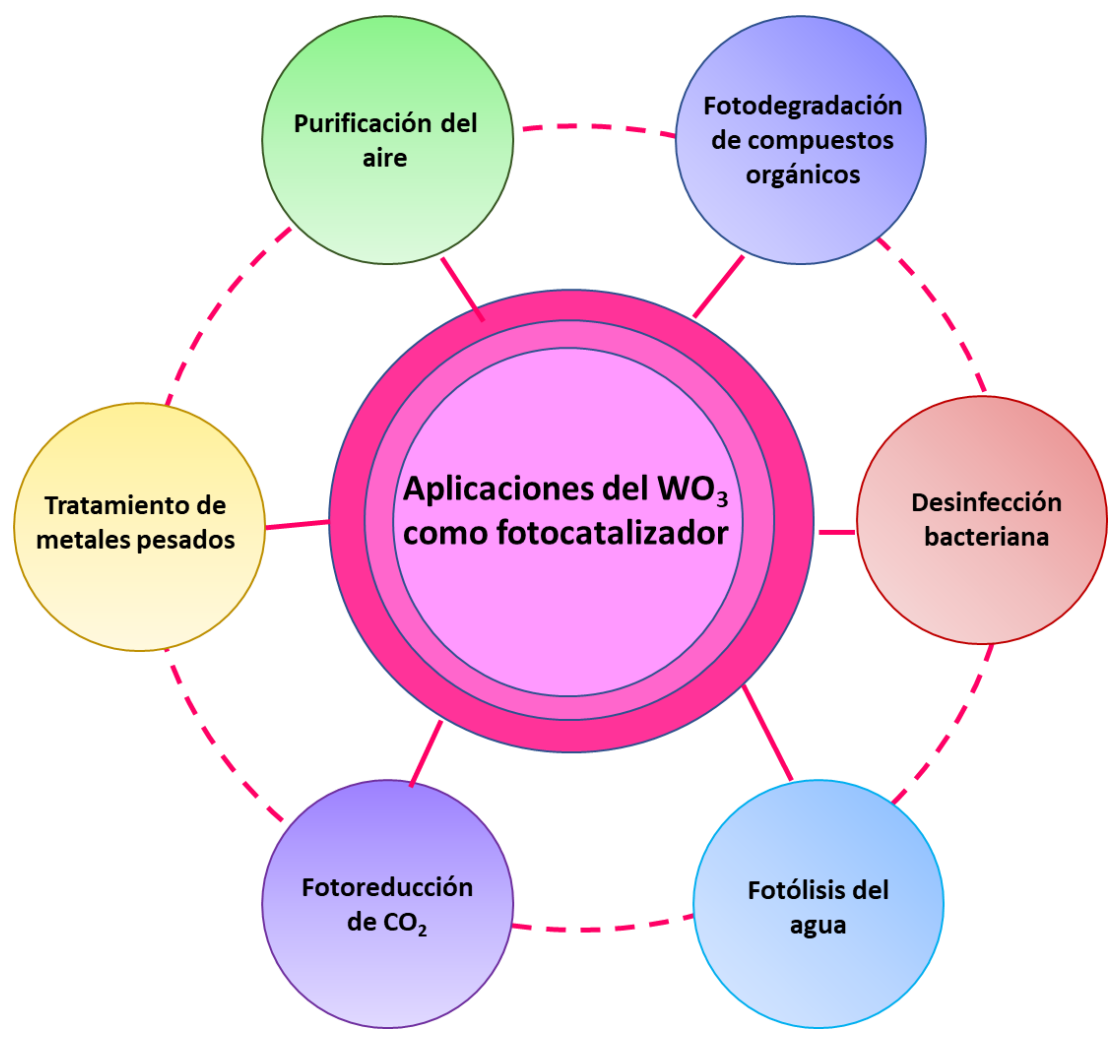

Figura 1.25. Aplicaciones de los fotocatalizadores basados en $\mathrm{WO}_{3}$.

\section{Referencias.}

1. Naciones Unidas World Population Pospects Available online: https://population.un.org/wpp/Graphs/Probabilistic/POP/TOT/900 (accessed on Mar 20, 2020).

2. Directiva 91/414/CEE DIRECTIVA DEL CONSEJO de 15 de julio de 1991 relativa a la comercialización de productos fitosanitarios. 1-3.

3. Escudero García, J. Regeneración de aguas contaminadas por plaguicidas (sustancias prioritarias y preferentes), con elevado potencial de lixivación, 
mediante fotocatálisis solar heterogénea. TDR (Tesis Dr. en Red) 2015.

4. Morifusa Eto Organophosphorus Pesticides. Organic and Biological Chemestry; CRC Press, 2018; ISBN 9781315896205.

5. Bedmar, F. Informe especial plaguicidas agrícolas. J. Agric. Sci. 2006, 21, 144, pp 31-43.

6. Ecoosfera ONU habla sobre pesticidas: "Catastróficos para el ambiente, salud humana y la sociedad" Available online: https://ecoosfera.com/2017/03/onupesticidas-negativos-para-salud-y-medio-ambiente/ (accessed on Mar 25, 2020).

7. Pacheco Pérez, M. Recambio sanguíneo en una intoxicación por organofosforado (Pyrinex) Reporte de un caso. Rev. Toxicol. 2009, 76, 172-173, doi:http://www.redalyc.org/articulo.oa?id=91913002011 Cómo.

8. FAO Parámetros de los plaguicidas que influyen en los procesos que tienen lugar en el suelo Available online: https://ecoosfera.com/2017/03/onu-pesticidasnegativos-para-salud-y-medio-ambiente/ (accessed on Apr 1, 2020).

9. FAOSTAT Usos pesticidas Available online: http://www.fao.org/statistics/es/ (accessed on Apr 3, 2020).

10. Gallardo, M. Aplicación de sistemas de extracción sin disolventes para la determinación de pesticidas organofosforados en material de interés médicolegal, Facultad de Medicina e Odontoloxia, 2005.

11. Agencia de Protección Ambiental de Estados Unidos (EPA). Insecticidas organofosforados. Reconoc. y manejo envenenamientos por Pestic. II Insecticidas 2015, 113, 1003.

12. Montuori, P.; Aurino, S.; Nardone, A.; Cirillo, T.; Triassi, M. Spatial distribution and partitioning of organophosphates pesticide in water and sediment from Sarno River and Estuary, Southern Italy. Environ. Sci. Pollut. Res. 2015, 22, 8629-8642, doi:10.1007/s11356-014-4016-z.

13. Eddleston, M.; Buckley, N.A.; Eyer, P.; Dawson, A.H. Management of acute organophosphorus pesticide poisoning. Lancet 2008, 371, 597-607, doi:10.1016/S0140-6736(07)61202-1.

14. Jokanović, M. Neurotoxic effects of organophosphorus pesticides and possible association with neurodegenerative diseases in man: A review. Toxicology 2018, 410, 125-131, doi:10.1016/j.tox.2018.09.009.

15. Sud, D.; Kaur, P. Heterogeneous photocatalytic degradation of selected organophosphate pesticides: A review. Crit. Rev. Environ. Sci. Technol. 2012, 42, 2365-2407, doi:10.1080/10643389.2011.574184. 
16. Garelick, H.; Jones, H.; Dybowska, A.; Valsami-Jones, E. Reviews of Environmental Contamination and Toxicology. Rev. Environ. Contam. Toxicol. 2008, 197, 17-60, doi:10.1007/978-0-387-79284-2_2.

17. Chawla, P.; Kaushik, R.; Shiva Swaraj, V.J.; Kumar, N. Organophosphorus pesticides residues in food and their colorimetric detection. Environ. Nanotechnology, Monit. Manag. 2018, 10, 292-307, doi:10.1016/j.enmm.2018.07.013.

18. Wauchope, R.D.; Yeh, S.; Linders, J.B.H.J.; Kloskowski, R.; Tanaka, K.; Rubin, B.; Katayama, A.; Kördel, W.; Gerstl, Z.; Lane, M. Pesticide soil sorption parameters: Theory, measurement, uses, limitations and reliability. Pest Manag. Sci. 2002, 58, 419-445, doi:10.1002/ps.489.

19. Gilden, R.C.; Huffling, K.; Sattler, B. Pesticides and health risks. JOGNN - J. Obstet. Gynecol. Neonatal Nurs. 2010, 39, 103-110, doi:10.1111/j.15526909.2009.01092.x.

20. Kale, S.P.; Carvalho, F.P.; Raghu, K.; Sherkhane, P.D.; Pandit, G.G.; Rao, A.M.; Mukherjee, P.K.; Murthy, N.B.K. Studies on degradation of 14C-chlorpyrifos in the marine environment. Chemosphere 1999, 39, 969-976, doi:10.1016/S00456535(99)00028-4.

21. Oliver, M.R.; Williams, R.L.; Ries, S.B.; Krieger, R.I. Transferable chlorpyrifos residue from turf grass and an empirical transfer coefficient for human exposure assessments. Bull. Environ. Contam. Toxicol. 2003, 70, 644-651, doi:10.1007/s00128-003-0033-1.

22. Kamanyire, R.; Karalliedde, L. Organophosphate toxicity and occupational exposure. Occup. Med. (Chic. III). 2004, 54, 69-75, doi:10.1093/occmed/kqh018.

23. Ministerio de Salud Consumo y Bienestar Social Funciones Dirección General de Salud Pública, Calidad e Innovación Available online: https://www.mscbs.gob.es/organizacion/ministerio/organizacion/sgralsanidad/dg spciF.htm (accessed on Apr 15, 2020).

24. J. Moreno Marí Situación actual en España de los aerosoles insecticidas registrados en sanidad ambiental para uso doméstico. Rev. Española Salud Pública 2003, 383391.

25. Ministerio de Salud Consumo y Bienestar Social Legislacion de aplicación a los productos fitosanitarios Available online:

https://www.mscbs.gob.es/ciudadanos/saludAmbLaboral/fitosan/prodfitosan/legi slafitos.htm (accessed on Apr 23, 2020).

26. Instituto Nacional de Seguridad e Higiene en el Trabajo Documentación toxicológica para el establecimiento del límite de exposición profesional del Fenamifos. Doc. limites Expo. Prof. 2011, 153, 307-313, doi:10.1111/j.1749- 
6632.1968.tb11745.x.

27. Abu Ghalwa, N.M.; B Farhat, N. Adsorption of Fenamiphos Pesticide from Aqueous Solutions by Electrocoagulation Using Sacrificial Anodes. J. Environ. Anal. Toxicol. 2016, 06, 2-9, doi:10.4172/2161-0525.1000357.

28. Fenoll, J.; Hellín, P.; Martínez, C.M.; Flores, P.; Navarro, S. Semiconductor oxidessensitized photodegradation of fenamiphos in leaching water under natural sunlight. Appl. Catal. B Environ. 2012, 115-116, 31-37, doi:10.1016/j.apcatb.2011.12.023.

29. Kumar, S.; Kaushik, G.; Dar, M.A.; Nimesh, S.; López-Chuken, U.J.; Villarreal-Chiu, J.F. Microbial Degradation of Organophosphate Pesticides: A Review. Pedosphere 2018, 28, 190-208, doi:10.1016/S1002-0160(18)60017-7.

30. Cáceres, T.; Megharaj, M.; Naidu, R. Toxicity and transformation of fenamiphos and its metabolites by two micro algae Pseudokirchneriella subcapitata and Chlorococcum sp. Sci. Total Environ. 2008, 398, 53-59, doi:10.1016/j.scitotenv.2008.03.022.

31. David M. Whitacre Reviews of environmental contamination and toxicology; CRC Press LLC, 2010; ISBN 9781441956224.

32. Rai S. Kookana; C. Phang; and L. A. G. Aylmore Transformation and degradation of fenamiphos nematicide and its metabolites in soils. Aust. J. Soil Res. 1997, 35, 227-239, doi:10.1071/SR96105 0004-9573/97/040753\$05.00.

33. Yadini, A. El; Marouane, B.; Ahmido, A.; Dunlop, P.; Byrne, J.A.; Azzouzi, M. El; Hajjaji, S. El Photolysis and photodegradation of fenamiphos insecticide by using slurry and supported TiO2. J. Mater. Environ. Sci. 2013, 4, 973-980.

34. El Yadini, A.; Saufi, H.; Dunlop, P.S.M.; Byrne, J.A.; El Azzouzi, M.; El Hajjaji, S. Supported TiO 2 on Borosilicate Glass Plates for Efficient Photocatalytic Degradation of Fenamiphos . J. Catal. 2014, 2014, 1-8, doi:10.1155/2014/413693.

35. Thomas A. Unger Pesticide Synthesis Handbook; William Andrew, 2000;

36. Unión Europea Reglamento de ejecución (UE) n540/2011 por el que se aplica el Reglamento (CE) $n^{\circ} 1107 / 2009$ del parlamento europeo y del Consejo en lo que respecta a la lista de sustancias activas autorizadas. 2011, L 153, 1-186.

37. European Commission Health \& Consumer Protection Fenamiphos /10017/2006 rev. 314 July 2006. 2006.

38. ChemSrc Phosmet properties Available online:

https://www.chemsrc.com/en/cas/732-11-6_509792.html (accessed on Apr 24, 2020). 
39. European Commission Commision Regulation (EU) 2018/1480. Off. J. Eur. Union 2018, 251, 48-119.

40. Agarwal, V.; Srivastav, J.; Gupta, A.; Gulabani, A. Photo-assisted Degradation of Imidan Insecticide in Aqueous Solution of $\mathrm{TiO}_{2}$. J. Energy Res. Environ. Technol. 2015, 2, 19-21, doi:2394-157X.

41. Dorneles, A.L.; de Souza Rosa, A.; Blochtein, B. Toxicity of organophosphorus pesticides to the stingless bees Scaptotrigona bipunctata and Tetragonisca fiebrigi. Apidologie 2017, 48, 612-620, doi:10.1007/s13592-017-0502-x.

42. Kanan, S.M.; Yousef, I.A.A.; Abdo, N.M. The photodecomposition of phosmet over UV irradiated silver nanoclusters doped in mordenite zeolite. Appl. Catal. B Environ. 2007, 74, 130-136, doi:10.1016/j.apcatb.2007.02.004.

43. Srivastava, S. Degradation Studies of Insecticide Imidacloprid Using Fluidized Bed Photocatalytic Reactor, School of energy and environment, Thapar University, Patiala, 2013.

44. US Environmental Protection Agency US Environmental Protection Agency, Office of Pesticide ProgramInterim Reregistration Eligibility Decision for Phosmet. 2006, 5-13.

45. European Commission Health \& Consumer Protection Conclusion on the peer review of the pesticide risk assessment of the active substance phosmet. EFSA J. 2011, 9, doi:10.2903/j.efsa.2011.2162.

46. Rasoulifard, M.H.; Akrami, M.; Eskandarian, M.R. Degradation of organophosphorus pesticide diazinon using activated persulfate: Optimization of operational parameters and comparative study by Taguchi's method. J. Taiwan Inst. Chem. Eng. 2015, 57, 77-90, doi:10.1016/j.jtice.2015.05.014.

47. Gar Alalm, M.; Tawfik, A.; Ookawara, S. Comparison of solar $\mathrm{TiO}_{2}$ photocatalysis and solar photo-Fenton for treatment of pesticides industry wastewater: Operational conditions, kinetics, and costs. J. Water Process Eng. 2015, 8, 55-63, doi:10.1016/j.jwpe.2015.09.007.

48. Wang, C.; Shih, Y. Degradation and detoxification of diazinon by sono-Fenton and sono-Fenton-like processes. Sep. Purif. Technol. 2015, 140, 6-12, doi:10.1016/j.seppur.2014.11.005.

49. Salarian, A.A.; Hami, Z.; Mirzaie, N.; Mohseni, S.M.; Asadi, A.; Bahrami, H.; Vosoughi, M.; Alinejad, A.; Zare, M.R. N-doped $\mathrm{TiO}_{2}$ nanosheets for photocatalytic degradation and mineralization of diazinon under simulated solar irradiation: Optimization and modeling using a response surface methodology. J. Mol. Liq. 2016, 220, 183-191, doi:10.1016/j.molliq.2016.04.060. 
50. Mirmasoomi, S.R.; Mehdipour Ghazi, M.; Galedari, M. Photocatalytic degradation of diazinon under visible light using TiO2/Fe2O3nanocomposite synthesized by ultrasonic-assisted impregnation method. Sep. Purif. Technol. 2017, 175, 418-427, doi:10.1016/j.seppur.2016.11.021.

51. Aly, M.M.; Al-aidaroos, B.A.; Alfassi, F.A. Pesticides Characters, Importance and Microbial Degradation. IOSR J. Pharm. Biol. Sci. 2017, 12, 20-28, doi:10.9790/3008-1202022028.

52. Čolović, M.; Krstić, D.; Petrović, S.; Leskovac, A.; Joksić, G.; Savić, J.; Franko, M.; Trebše, P.; Vasić, V. Toxic effects of diazinon and its photodegradation products. Toxicol. Lett. 2010, 193, 9-18, doi:10.1016/j.toxlet.2009.11.022.

53. Sanders, P.F.; Seiber, J.N. A chamber for measuring volatilization of pesticides from model soil and water disposal systems. Chemosphere 1983, 12, 999-1012, doi:10.1016/0045-6535(83)90252-7.

54. Shemer, H.; Linden, K.G. Degradation and by-product formation of diazinon in water during UV and UV/H2O2 treatment. J. Hazard. Mater. 2006, 136, 553-559, doi:10.1016/j.jhazmat.2005.12.028.

55. U.S. Department of Health and Human Services Toxicological Profile for Diazinon. ATSDR's Toxicol. Profiles 2002, doi:10.1201/9781420061888_ch72.

56. European Commission Health \& Consumer Protection Chemicals, contaminants, pesticides. Diazinon. Opin. Sci. Comm. Food 2006, 2001-2003.

57. U.S. Department of Health and Human Services Toxicological Profile for Chlorfenvinphos. ATSDR's Toxicol. Profiles 2002, doi:10.1201/9781420061888_ch54.

58. University of Hertfordshire Pesticide Properties DataBase Available online: http://sitem.herts.ac.uk/aeru/footprint/es/Reports/138.htm (accessed on Apr 20, 2020).

59. Bozena Szatkowska, Marta Kwiatkowska, Jaromir Michałowicz, Paulina Sicinska, Bogumiła Huras, B.B. Impact of chlorfenvinphos, an organophosphate 22 insecticide on human blood mononuclear cells (in vitro). Pestic. Biochem. Physiol. 2012, 102, 175-181, doi:10.1016/j.pestbp.2012.01.001.

60. Alister, C.; Araya, M.; Kogan, M. Effects of physicochemical soil properties of five agricultural soils on herbicide soil adsorption and leaching. Cienc. e Investig. Agrar. 2011, 38, 243-251, doi:10.4067/s0718-16202011000200010.

61. Kuzmanović, M.; Ginebreda, A.; Petrović, M.; Barceló, D. Risk assessment based prioritization of 200 organic micropollutants in 4 Iberian rivers. Sci. Total Environ. 2015, 503-504, 289-299, doi:10.1016/j.scitotenv.2014.06.056. 
62. Calatayud-Vernich, P.; Calatayud, F.; Simó, E.; Picó, Y. Occurrence of pesticide residues in Spanish beeswax. Sci. Total Environ. 2017, 605-606, 745-754, doi:10.1016/j.scitotenv.2017.06.174.

63. Parlamento Europeo y del consejo Reglamento (CE) $n^{\circ} 1107 / 2009$ del Parlamento Europeo y del Consejo, de 21 de octubre de 2009, relativo a la comercialización de productos fitosanitarios y por el que se derogan las Directivas 79/117/CEE y 91/414/CEE del Consejo. 2009, 1-50.

64. Zarei, E.; Ojani, R. Fundamentals and some applications of photoelectrocatalysis and effective factors on its efficiency: a review. J. Solid State Electrochem. 2017, 21, 305-336, doi:10.1007/s10008-016-3385-2.

65. Dos Santos, A.B.; Cervantes, F.J.; van Lier, J.B. Review paper on current technologies for decolourisation of textile wastewaters: Perspectives for anaerobic biotechnology. Bioresour. Technol. 2007, 98, 2369-2385, doi:10.1016/j.biortech.2006.11.013.

66. Reddy, P.V.L.; Kim, K.H. A review of photochemical approaches for the treatment of a wide range of pesticides. J. Hazard. Mater. 2015, 285, 325-335, doi:10.1016/j.jhazmat.2014.11.036.

67. Herrmann, J.M.; Guillard, C. Photocatalytic degradation of pesticides in agricultural used waters. Comptes Rendus I'Academie des Sci. - Ser. Ilc Chem. 2000, 3, 417422, doi:10.1016/S1387-1609(00)01137-3.

68. Longobucco, G.; Pasti, L.; Molinari, A.; Marchetti, N.; Caramori, S.; Cristino, V.; Boaretto, R.; Bignozzi, C.A. Photoelectrochemical mineralization of emerging contaminants at porous $\mathrm{WO}_{3}$ interfaces. Appl. Catal. B Environ. 2017, 204, 273282, doi:10.1016/j.apcatb.2016.11.007.

69. Baranda, A.B.; Fundazuri, O.; Martínez De Marañón, I. Photodegradation of several triazidic and organophosphorus pesticides in water by pulsed light technology. J. Photochem. Photobiol. A Chem. 2014, 286, 29-39, doi:10.1016/j.jphotochem.2014.03.015.

70. Oliveira, C.; Alves, A.; Madeira, L.M. Treatment of water networks (waters and deposits) contaminated with chlorfenvinphos by oxidation with Fenton's reagent. Chem. Eng. J. 2014, 241, 190-199, doi:10.1016/j.cej.2013.12.026.

71. Nikolaus Klamerth, Wolfgang Gernjak, Sixto Malatob, Ana Aguera, B.L. PhotoFenton decomposition of chlorfenvinphos: Determination of reaction pathway. Water Res. 2009, 43, 441-449, doi:10.1016/j.watres.2008.10.013water research 43 (2009) 441-449.

72. Oturan, N.; Oturan, M.A. Electro-Fenton Process: Background, New Developments, and Applications; Elsevier Inc., 2018; ISBN 9780128131602. 
73. M.I. Maldonado Rubio, W. Gernjak, I. Oller Alberola, J. Blanco Gálvez, P. Fernández Ibáñez, S.M.R. Photo-fenton degradation of alachlor, atrazine, chlorfenvinphos, diuron, isoproturon and pentachlorophenol at solar pilot plant. Environ. Pollut. 2006, 27, 135-146, doi:10.1504/IJEP.2006.010459.

74. Acero, J.L.; Real, F.J.; Javier Benitez, F.; González, A. Oxidation of chlorfenvinphos in ultrapure and natural waters by ozonation and photochemical processes. Water Res. 2008, 42, 3198-3206, doi:10.1016/j.watres.2008.03.016.

75. Maldonado, M.I.; Malato, S.; Pérez-Estrada, L.A.; Gernjak, W.; Oller, I.; Doménech, X.; Peral, J. Partial degradation of five pesticides and an industrial pollutant by ozonation in a pilot-plant scale reactor. J. Hazard. Mater. 2006, 138, 363-369, doi:10.1016/j.jhazmat.2006.05.058.

76. Guinea, E.; Garrido, J.A.; Rodríguez, R.M.; Cabot, P.L.; Arias, C.; Centellas, F.; Brillas, E. Degradation of the fluoroquinolone enrofloxacin by electrochemical advanced oxidation processes based on hydrogen peroxide electrogeneration. Electrochim. Acta 2010, 55, 2101-2115, doi:10.1016/j.electacta.2009.11.040.

77. Madsen, H.T.; Søgaard, E.G.; Muff, J. Study of degradation intermediates formed during electrochemical oxidation of pesticide residue 2,6-dichlorobenzamide (BAM) at boron doped diamond (BDD) and platinum-iridium anodes. Chemosphere 2014, 109, 84-91, doi:10.1016/j.chemosphere.2014.03.020.

78. Gutierrez-Mata, A.G.; Velazquez-Martínez, S.; Álvarez-Gallegos, A.; Ahmadi, M.; Hernández-Pérez, J.A.; Ghanbari, F.; Silva-Martínez, S. Recent Overview of Solar Photocatalysis and Solar Photo-Fenton Processes for Wastewater Treatment. Int. J. Photoenergy 2017, 2017, doi:10.1155/2017/8528063.

79. Paul, B.; Martens, W.N.; Frost, R.L. Immobilised anatase on clay mineral particles as a photocatalyst for herbicides degradation. Appl. Clay Sci. 2012, 57, 49-54, doi:10.1016/j.clay.2011.12.009.

80. Peleyeju, M.G.; Arotiba, O.A. Recent trend in visible-light photoelectrocatalytic systems for degradation of organic contaminants in water/wastewater. Environ. Sci. Water Res. Technol. 2018, 4, 1389-1411, doi:10.1039/c8ew00276b.

81. Jiang, C.; Moniz, S.J.A.; Wang, A.; Zhang, T.; Tang, J. Photoelectrochemical devices for solar water splitting-materials and challenges. Chem. Soc. Rev. 2017, 46, 46454660, doi:10.1039/c6cs00306k.

82. Xiao, F.X.; Miao, J.; Tao, H.B.; Hung, S.F.; Wang, H.Y.; Yang, H. Bin; Chen, J.; Chen, R.; Liu, B. One-dimensional hybrid nanostructures for heterogeneous photocatalysis and photoelectrocatalysis. Mater. View 2015, 11, 2115-2131, doi:10.1002/smll.201402420.

83. Daghrir, R.; Drogui, P.; Robert, D. Photoelectrocatalytic technologies for 
environmental applications. J. Photochem. Photobiol. A Chem. 2012, 238, 41-52, doi:10.1016/j.jphotochem.2012.04.009.

84. Shi, Z.; Wen, X.; Guan, Z.; Cao, D.; Luo, W.; Zou, Z. Recent progress in photoelectrochemical water splitting for solar hydrogen production. Ann. Phys. (N. Y). 2015, 358, 236-247, doi:10.1016/j.aop.2015.04.005.

85. Garcia-Segura, S.; Brillas, E. Applied photoelectrocatalysis on the degradation of organic pollutants in wastewaters. J. Photochem. Photobiol. C Photochem. Rev. 2017, 31, 1-35, doi:10.1016/j.jphotochemrev.2017.01.005.

86. Li, J.; Wu, N. Semiconductor-based photocatalysts and photoelectrochemical cells for solar fuel generation: A review. Catal. Sci. Technol. 2015, 5, 1360-1384, doi:10.1039/c4cy00974f.

87. Krol, R. va de; Grätzel, M. Photoelectrochemical Hydrogen Production; Electronic Materials: Science \& Technology, 2012; ISBN 9781461413790.

88. Wang, Z.; Wang, L. Photoelectrode for water splitting: Materials, fabrication and characterization. Sci. China Mater. 2018, 61, 806-821, doi:10.1007/s40843-0189240-y.

89. Wang, S.C.; Tang, F.Q.; Wang, L.Z. Visible Light Responsive Metal Oxide Photoanodes for Photoelectrochemical Water Splitting: a Comprehensive Review on Rational Materials Design. J. Inorg. Mater. 2018, 33, 173-197, doi:10.15541/jim20170352.

90. Young, K.M.H.; Klahr, B.M.; Zandi, O.; Hamann, T.W. Photocatalytic water oxidation with hematite electrodes. Catal. Sci. Technol. 2013, 3, 1660-1671, doi:10.1039/c3cy00310h.

91. Kim, J.Y.; Magesh, G.; Youn, D.H.; Jang, J.W.; Kubota, J.; Domen, K.; Lee, J.S. Singlecrystalline, wormlike hematite photoanodes for efficient solar water splitting. Sci. Rep. 2013, 3, 1-8, doi:10.1038/srep02681.

92. Lucas-Granados, B.; Sánchez-Tovar, R.; Fernández-Domene, R.M.; García-Antón, J. Influence of electrolyte temperature on the synthesis of iron oxide nanostructures by electrochemical anodization for water splitting. Int. J. Hydrogen Energy 2018, 43, 7923-7937, doi:10.1016/j.ijhydene.2018.03.046.

93. Lucas-Granados, B.; Sánchez-Tovar, R.; Fernández-Domene, R.M.; García-Antón, J. Iron oxide nanostructures for photoelectrochemical applications: Effect of applied potential during Fe anodization. J. Ind. Eng. Chem. 2019, 70, 234-242, doi:10.1016/j.jiec.2018.10.020.

94. Park, Y.; McDonald, K.J.; Choi, K.S. Progress in bismuth vanadate photoanodes for use in solar water oxidation. Chem. Soc. Rev. 2013, 42, 2321-2337, 
doi:10.1039/c2cs35260e.

95. Seabold, J.A.; Zhu, K.; Neale, N.R. Efficient solar photoelectrolysis by nanoporous Mo:BiVO4 through controlled electron transport. Phys. Chem. Chem. Phys. 2014, 16, 1121-1131, doi:10.1039/c3cp54356k.

96. Bao, N.; Shen, L.; Takata, T.; Domen, K. Self-templated synthesis of nanoporous CdS nanostructures for highly efficient photocatalytic hydrogen production under visible light. Chem. Mater. 2008, 20, 110-117, doi:10.1021/cm7029344.

97. Chaudhary, D.; Singh, S.; Vankar, V.D.; Khare, N. ZnO nanoparticles decorated multi-walled carbon nanotubes for enhanced photocatalytic and photoelectrochemical water splitting. J. Photochem. Photobiol. A Chem. 2018, 351, 154-161, doi:10.1016/j.jphotochem.2017.10.018.

98. Wang, Z.; Li, X.; Tan, C.K.; Qian, C.; Grimsdale, A.C.; Tok, A.I.Y. Highly porous $\mathrm{SnO}_{2}$ nanosheet arrays sandwiched within $\mathrm{TiO}_{2}$ and $\mathrm{CdS}$ quantum dots for efficient photoelectrochemical water splitting. Appl. Surf. Sci. 2019, 470, 800-806, doi:10.1016/j.apsusc.2018.11.182.

99. Tahir, M.B.; Nabi, G.; Rafique, M.; Khalid, N.R. Nanostructured-based $\mathrm{WO}_{3}$ photocatalysts: recent development, activity enhancement, perspectives and applications for wastewater treatment. Int. J. Environ. Sci. Technol. 2017, 14, 2519-2542, doi:10.1007/s13762-017-1394-z.

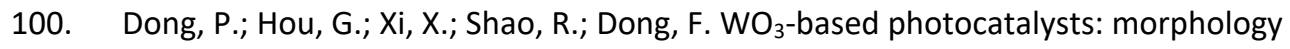
control, activity enhancement and multifunctional applications. Environ. Sci. Nano 2017, 4, 539-557, doi:10.1039/c6en00478d.

101. Butler, M.A.; Nasby, R.D.; Quinn, R.K. Tungsten trioxide as an electrode for photoelectrolysis of water. Solid State Commun. 1976, 19, 1011-1014, doi:10.1016/0038-1098(76)90642-6.

102. Xie, Y.P.; Liu, G.; Yin, L.; Cheng, H.M. Crystal facet-dependent photocatalytic oxidation and reduction reactivity of monoclinic $\mathrm{WO}_{3}$ for solar energy conversion. J. Mater. Chem. 2012, 22, 6746-6751, doi:10.1039/c2jm16178h.

103. Guo, Y.; Quan, X.; Lu, N.; Zhao, H.; Chen, S. High photocatalytic capability of selfassembled nanoporous $\mathrm{WO}_{3}$ with preferential orientation of (002) planes. Environ. Sci. Technol. 2007, 41, 4422-4427, doi:10.1021/es062546c.

104. Wang, S.; Chen, H.; Gao, G.; Butburee, T.; Lyu, M.; Thaweesak, S.; Yun, J.H.; Du, A.; Liu, G.; Wang, L. Synergistic crystal facet engineering and structural control of $\mathrm{WO}_{3}$ films exhibiting unprecedented photoelectrochemical performance. Nano Energy 2016, 24, 94-102, doi:10.1016/j.nanoen.2016.04.010.

105. Kalanur, S.S.; Duy, L.T.; Seo, H. Recent Progress in Photoelectrochemical Water 
Splitting Activity of $\mathrm{WO}_{3}$ Photoanodes; Springer US, 2018; Vol. 61; ISBN 1124401809501.

106. Karatutlu, A.; Barhoum, A.; Sapelkin, A. Liquid-phase synthesis of nanoparticles and nanostructured materials; Elsevier Inc., 2018; ISBN 9780128135167.

107. Reyes-Gil, K.R.; Wiggenhorn, C.; Brunschwig, B.S.; Lewis, N.S. Comparison between the quantum yields of compact and porous $\mathrm{WO}_{3}$ photoanodes. J. Phys. Chem. $\mathrm{C}$ 2013, 117, 14947-14957, doi:10.1021/jp4025624.

108. Thummavichai, K.; Wang, N.; Xu, F.; Rance, G.; Xia, Y.; Zhu, Y. In situ investigations of the phase change behaviour of tungsten oxide nanostructures. R. Soc. Open Sci. 2018, 5, doi:10.1098/rsos.171932.

109. Fernández-Domene, R.M.; Sánchez-Tovar, R.; Segura-Sanchís, E.; García-Antón, J. Novel tree-like $\mathrm{WO}_{3}$ nanoplatelets with very high surface area synthesized by anodization under controlled hydrodynamic conditions. Chem. Eng. J. 2016, 286, 59-67, doi:10.1016/j.cej.2015.10.069. 


\section{Capítulo 2}

Objetivos y plan de trabajo 



\section{Capítulo 2. \\ Objetivos y plan de trabajo}

\section{Objetivos y alcance}

Debido a las grandes preocupaciones sobre los efectos nocivos de pesticidas en el medio ambiente y la salud humana, el uso de tecnologías capaces de eliminarlos han cobrado un gran interés en la sociedad. Entre estas tecnologías destaca la fotoelectrocatálisis (FEC) debido a su alta eficacia respecto a otras técnicas y su fácil puesta en marcha.

Sin embargo, la fotoelectrocatálisis presenta ciertas limitaciones ya que encontrar el fotoándo adecuado que presente mejores propiedades fotolectroquímicas no es fácil. Existen varios materiales semiconductores aptos para actuar como fotoánodos, pero el $\mathrm{WO}_{3}$ se presenta como un candidato prometedor. Entre los principales parámetros a evaluar se encuentran la resistencia a la transferencia de 
carga, la resistencia a la recombinación de pares electrón-hueco, la respuesta registrada del fotoándo al ser iluminado, etc. Por lo tanto, al optimizar estos parámetros la fotoelectrocatálisis se convierte en una tecnología competitiva para el tratamiento de efluentes que contienen contaminantes emergentes, como son los pesticidas. En consecuencia, el primer objetivo de la presente Tesis es:

"Optimizar, mediante un diseño de experimentos, la síntesis de nanoestructuras de $\mathrm{WO}_{3}$, que posteriormente actuarán como fotocatalizadores en la técnica conocida como fotoelectrocatálisis (FEC)".

El primer objetivo de la Tesis se logrará mediante la realización de varios ensayos experimentales en los que se estudiaran diferentes propiedades de las nanoestructuras. Estos son los siguientes:

- Estudio de la formación de las nanoestructuras de $\mathrm{WO}_{3}$ mediante el anodizado electroquímico.

- Caracterización mediante Microscopía Raman de la composición y estructura cristalina de las diferentes nanoestructuras obtenidas.

- Estudio superficial de las nanoestructuras mediante Espectroscopía Fotoelectrónica de rayos X (XPS).

- Caracterización morfológica de la superficie de las nanoestructuras mediante Microscopía Electrónica de Barrido de Emission de Campo (FESEM).

- Determinación de la topografía de las nanoestructuras de $\mathrm{WO}_{3}$ mediante AFM.

- Evaluar las características fotoelectroquímicas de las nanoestructuras mediante ensayos de espectroscopía de impedancias fotoelectroquímica (PEIS) y Mott-Schottky.

Una vez optimizadas las nanoestructuras de $\mathrm{WO}_{3}$ surge el segundo objetivo de la Tesis. Este objetivo está relacionado con la aplicación de la técnica FEC para eliminar contaminantes emergentes. Por tanto, el segundo objetivo es:

"Conseguir la degradación de cuatro pesticidas organofosforados mediante la técnica FEC con el fin de obtener compuestos más sencillos y menos nocivos tanto para la salud humana como para el medioambiente". Estos 4 pesticidas son el diazinon, clorfenvinfos, fosmet y fenamifos. Se tratan de 4 pesticidas organofosforados de diferentes subfamilias para poder ver las diferencias en su comportamiento durante la degradación fotoelectrocatalítica. 


\section{Plan de trabajo.}

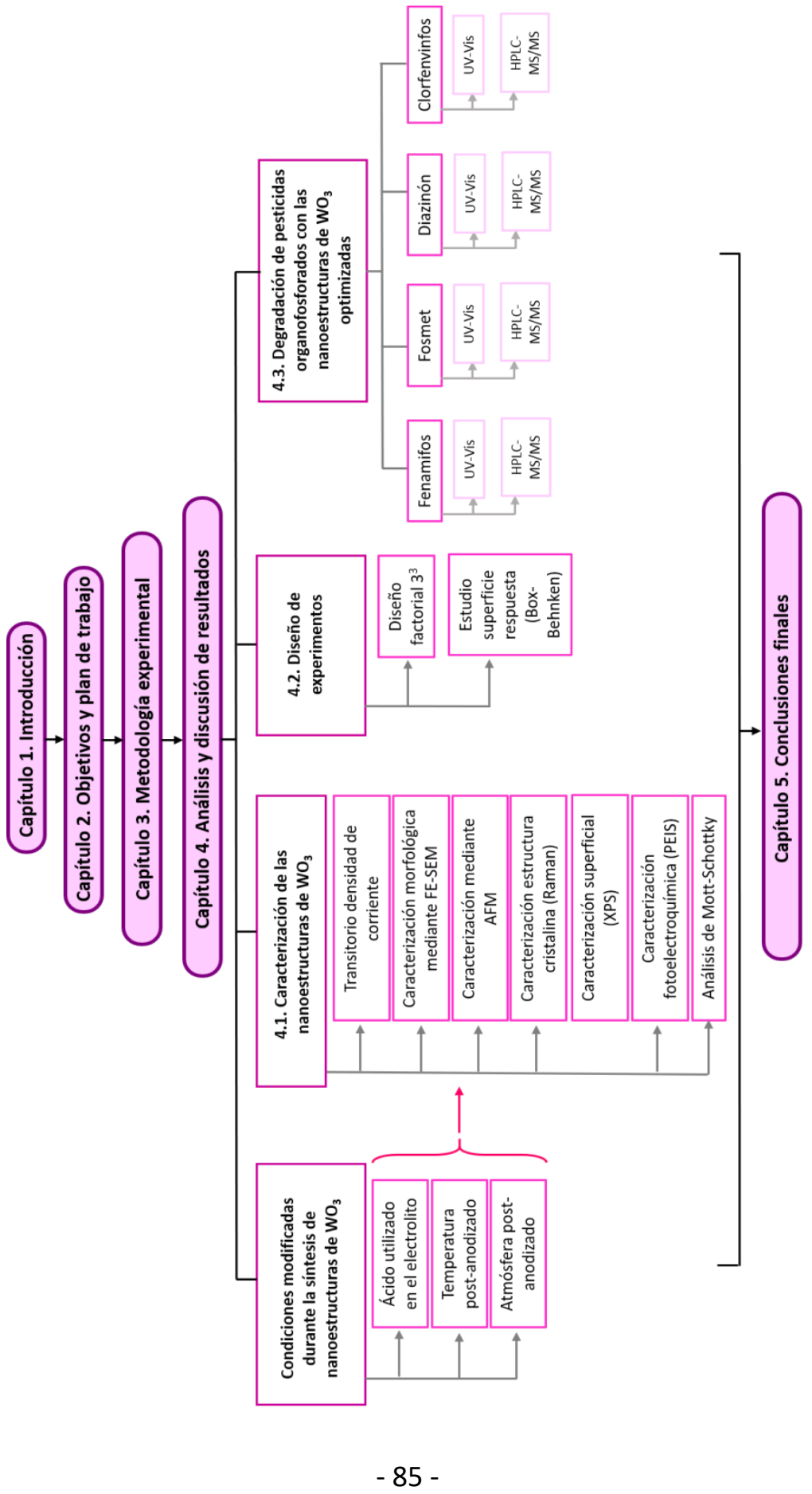

을 



\section{Capítulo 3}

Metodología experimental 



\section{Capítulo 3. \\ Metodología experimental}

El procedimiento experimental que se ha llevado a cabo durante la realización de esta Tesis consta de tres partes bien diferenciadas. En primer lugar, se realizó un estudio de optimización de la síntesis de nanoestructuras de $\mathrm{WO}_{3}$ mediante un diseño de experimentos en el que se variaron los parámetros que se explicarán a continuación. En la segunda parte se llevó a cabo la síntesis de las nanoestructuras mediante la técnica conocida como anodizado electroquímico y su posterior caracterización. Y finalmente, la tercera parte de esta tesis consistió en la degradación de cuatro contaminantes emergentes, como es el caso de los pesticidas organofosforados, mediante el uso de las nanoestructuras obtenidas en la segunda parte de la Tesis. 


\section{Diseño de experimentos}

En primer lugar, se ha realizado un diseño de experimentos con el fin de hallar las condiciones óptimas en la síntesis de nanoestructuras de $\mathrm{WO}_{3}$. Para ello se ha utilizado un diseño factorial $3^{3}$ en el que variando tres factores característicos del proceso de síntesis a tres niveles cada uno se halla el máximo valor de la densidad de fotocorriente con un número reducido de experimentos.

La forma más eficiente de realizar pruebas es mediante el uso de un diseño estadístico de experimentos. Esta técnica se basa en establecer las pruebas o experimentos que se han de llevar a cabo y la manera en la que se tiene que proceder, para así conseguir datos que se puedan tratar estadísticamente y además faciliten conclusiones imparciales para resolver los problemas planteados u obtener mejoras en ellos. Los problemas más comunes que se pueden tratar y solucionar con el diseño de experimentos son los que se exponen a continuación [1]:

1. Contrastar varios materiales con el objetivo de seleccionar el más adecuado.

2. Cotejar diversos equipos de medida con el fin de comprobar que todos poseen la misma precisión.

3. Establecer qué factores tienen más efecto dentro de un proceso productivo en las propiedades de un producto determinado.

4. Optimizar las condiciones de operación como pueden ser la velocidad, la temperatura o la humedad para conseguir que se disminuyan los desperfectos o se alcance una mejora en el proceso.

5. Conseguir una disminución de tiempo total del proceso productivo.

6. Lograr un proceso que sea robusto frente a factores ambientales $u$ oscilaciones de factores considerados como ruido.

El diseño factorial tiene como objetivo examinar diversos factores y los efectos que ocasionan en una o varias variables respuesta, en el caso en el que todos los factores tienen la misma importancia. Los factores que se analizan en el diseño de experimentos pueden ser de tipo cualitativo como por ejemplo tipos de materiales y máquinas o de tipo cuantitativo como son la temperatura, la presión o la cantidad de un material. Se necesita elegir al menos dos niveles para cada factor con el fin de realizar un estudio en el que se revele la influencia que tiene cada factor en la variable respuesta. Con el uso de un diseño factorial completo se 
llevan a cabo todas las combinaciones posibles con los niveles de los factores elegidos para estudiar [2].

El diseño factorial presenta varias ventajas como son las que se muestra a continuación:

- Se puede estudiar tanto el efecto individual como la interacción entre todos los factores

- Con estos diseños es posible componer diseños compuestos cuando se necesite realizar un estudio más exhaustivo. Estos diseños compuestos son útiles en el caso de que la respuesta de los factores estudiados no sea lineal.

- En las primeras etapas de un estudio que conlleva muchos factores es útil usar diseños factoriales fraccionados en el momento en el que para descartar los factores menos importantes se utiliza el criterio económico.

- En los casos en los que no puede llevarse a cabo un diseño factorial al completo en condiciones idénticas estos diseños pueden utilizarse junto con diseños en bloques, como ocurre en las ocasiones en las que con el material disponible solo se puede realizar la mitad del experimento, por tanto, las pruebas se dividen en bloques repartiendo en cada bloque los experimentos de la forma más equitativa posible.

El modelo estadístico viene representado por la siguiente ecuación para este tipo de diseños:

$$
Y_{i j k}=\mu+\alpha_{i}+\beta_{j}+(\alpha \beta)_{i j}+\varepsilon_{i j k}
$$

en donde $\mu$ representa la media general, $\alpha$ se asocia al efecto debido al $i$-ésimo nivel del factor $A, \beta$ representa el efecto del $j$-ésimo nivel del factor $B,(\alpha \beta)$ se asocia al efecto que tiene la interacción de los efectos $i j$, y $\varepsilon$ simula el error aleatorio (el cual sigue una distribución normal de media cero y desviación típica constante). Las restricciones que se detallan a continuación son introducidas para que la estimación de los parámetros sea única [3]: 


$$
\sum_{i=1}^{a} \alpha_{i}=0, \sum_{j=1}^{b} \beta_{j}=0 \text { y } \sum_{i=1}^{a} \sum_{j=1}^{b}(\alpha \beta)_{i j}=0
$$

Las hipótesis que se toman en el modelo anteriormente descrito son:

$$
\begin{aligned}
& H_{0}: \text { Efecto de factor } A=0 \\
& H_{A}: \text { Efecto de factor } A \neq 0 \\
& H_{0}: \text { Efecto de factor } B=0 \\
& H_{A}: \text { Efecto de factor } B \neq 0
\end{aligned}
$$

Estas hipótesis quedan contrastadas haciendo uso de un análisis de varianza, que en el caso de un diseño factorial de $n$ repeticiones da lugar a la descomposición de la variación total como:

$$
S C_{T}=S C_{A}+S C_{B}+S C_{A B}+S C_{E}
$$

en donde los grados de libertad respectivamente son:

$$
n a b-1=(a-1)+(b-1)+(a-1)(b-1)+a b(n-1)
$$

La componente $(n-1)$ representado en los grados de libertad de la suma de cuadrados del error $\left(\mathrm{SC}_{\mathrm{E}}\right)$ indica que existe la necesidad de realizar al menos dos repeticiones de cada experimento para poder construir una tabla de ANOVA. En esta tabla aparecen los cuadrados medios (CM) que representan la suma de cuadrados divididos por sus grados de libertad. Al dividir los cuadrados medios entre el cuadrado medio del error (CME) se calculan los estadísticos de prueba con la distribución F. Todo esto está detallado en la Tabla 3.1 [2]. 
Tabla 3.1. Tabla ANOVA para un diseño de experimentos.

\begin{tabular}{c|c|c|c|c|c|}
$\begin{array}{c}\text { Fuente de } \\
\text { variabilidad }\end{array}$ & $\begin{array}{c}\text { Suma de } \\
\text { cuadrados }\end{array}$ & $\begin{array}{c}\text { Grados de } \\
\text { libertad }\end{array}$ & $\begin{array}{c}\text { Cuadrado } \\
\text { medio }\end{array}$ & $F_{0}$ & Valor-p \\
\hline Efecto A & $\mathrm{SC}_{\mathrm{A}}$ & $a-1$ & $\mathrm{CM}_{\mathrm{A}}$ & $\mathrm{CM}_{\mathrm{A}} / \mathrm{CM}_{\mathrm{E}}$ & $\mathrm{P}\left(\mathrm{F}>\mathrm{F}_{0}{ }^{\mathrm{A}}\right)$ \\
Efecto B & $\mathrm{SC}_{\mathrm{B}}$ & $\mathrm{b}-1$ & $\mathrm{CM}_{\mathrm{B}}$ & $\mathrm{CM}_{\mathrm{B}} / \mathrm{CM}_{\mathrm{E}}$ & $\mathrm{P}\left(\mathrm{F}>\mathrm{F}_{0}{ }^{\mathrm{B}}\right)$ \\
Efecto AB & $\mathrm{SC}_{\mathrm{AB}}$ & $(\mathrm{a}-1)(\mathrm{b}-1)$ & $\mathrm{CM}_{\mathrm{AB}}$ & $\mathrm{CM}_{\mathrm{AB}} / \mathrm{CM}_{\mathrm{E}}$ & $\mathrm{P}\left(\mathrm{F}>\mathrm{F}_{0}{ }^{\mathrm{AB}}\right)$ \\
Error & $\mathrm{SC}_{\mathrm{E}}$ & $\mathrm{ab}(\mathrm{n}-1)$ & $\mathrm{CM}_{\mathrm{E}}$ & & \\
Total & $\mathrm{SC}_{\mathrm{T}}$ & $\mathrm{abn-1}$ & & & \\
\hline
\end{tabular}

Si el valor- $p$ es menor que el nivel de significancia prefijado (normalmente corresponde a un valor de 0.05 ), se rechaza la hipótesis nula y se concluye que el correspondiente efecto es muy influyente en la variable de respuesta.

Como ya se ha comentado, la finalidad del experimento es maximizar la densidad de fotocorriente registrada en los minutos previos a los ensayos de espectroscopía de impedancia electroquímica, variando el ácido usado en el electrolito y la temperatura y atmósfera a la cual se han deshidratado las nanoestructuras en el proceso de post-anodizado.

Dentro de estos factores se ha decidido seleccionar para el caso del tipo de ácido del electrolito los siguientes ácidos: ácido sulfúrico $\left(\mathrm{H}_{2} \mathrm{SO}_{4}\right)$, ácido metanosulfónico $\left(\mathrm{CH}_{4} \mathrm{O}_{3} \mathrm{~S}\right)$ y ácido nítrico $\left(\mathrm{HNO}_{3}\right)$, para la temperatura de deshidratación se han seleccionado los valores de $400{ }^{\circ} \mathrm{C}, 500{ }^{\circ} \mathrm{C}$ y $600{ }^{\circ} \mathrm{C}$, y finalmente, en el caso de la atmósfera se ha probado con nitrógeno $\left(\mathrm{N}_{2}\right)$, argón (Ar) y aire.

Finalmente, los datos recopilados a partir de los experimentos se han analizado con el software Statgraphics Centurion, para obtener los valores estadísticos que revelen las condiciones óptimas de síntesis de nanoestructuras de $\mathrm{WO}_{3}$.

\section{Síntesis de las nanoestructuras de $\mathrm{WO}_{3}$ mediante anodizado electroquímico.}

Gracias al uso del anodizado electroquímico se obtienen nanoestructuras con una elevada área superficial haciendo que sus propiedades fotoelectroquímicas se 
vean mejoradas y puedan utilizarse como fotocatalizadores en muchas aplicaciones. Además, mediante esta técnica se puede modificar la morfología de estas nanoestructuras con relativa facilidad variando los parámetros de operación como son el potencial aplicado, la temperatura del electrolito utilizado, la velocidad de rotación del electrodo, etc.

\subsection{Preparación de los electrodos}

Los electrodos a tratar son pequeñas barras de wolframio con unas medidas determinadas: $8 \mathrm{~mm}$ de diámetro y $0.5 \mathrm{~cm}^{2}$ de área transversal. Estas barras son las que se han sometido a un anodizado electroquímico para obtener sobre ellas las nanoestructuras de $\mathbf{W O}_{3}$. En la Figura 3.1 se muestra la barra de wolframio utilizada, en donde se detallan sus diferentes partes. Cabe destacar que la parte superior se trata de una pieza de latón que sirve para enroscar el electrodo de wolframio al RDE, ya que realizar la rosca directamente en el wolframio es muy difícil por su dureza.

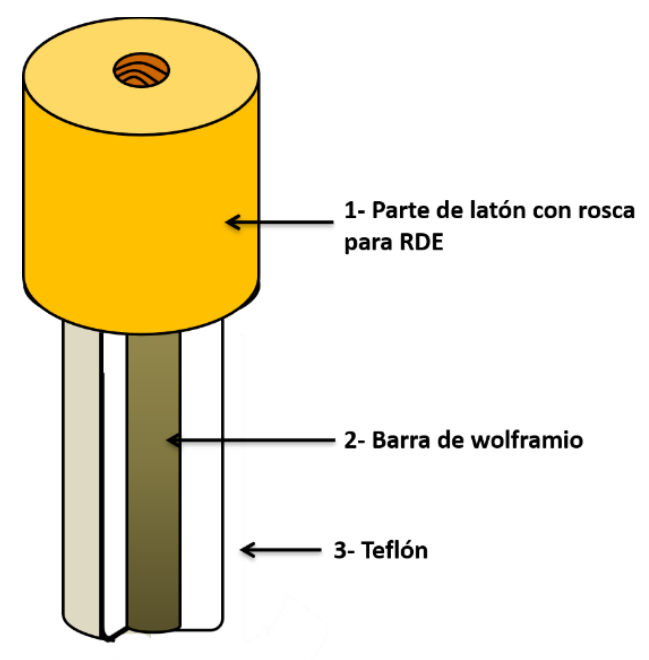

Figura 3.1. Barra de wolframio teflonada

Las barras de wolframio se han sometido en primer lugar a un proceso de pulido utilizando una pulidora Struers Labopol-21 hasta llegar a obtener una superficie tipo espejo. Para ello, se han utilizado 3 lijas de carburo de silicio con diferente tamaño de grano que va desde 220 hasta 4000 mesh. La lija de 220 se ha utilizado 
para desbastar la superficie de la barra de wolframio, la de 500 para perfeccionar el acabado obtenido anteriormente y finalmente, la de 4000 para conseguir el acabado tipo espejo.

Una vez pulida la superficie de los electrodos, se ha limpiado la superficie con agua destilada y se ha secado con aire comprimido para eliminar cualquier traza del proceso de pulido. A continuación, se ha sonicado la muestra con ultrasonidos para mejorar la limpieza de la superficie. Para ello, se ha introducido la muestra en un vaso de precipitados con etanol durante 2 minutos.

\subsection{Proceso de anodizado electroquímico.}

Una vez se consiguió una superficie de electrodo completamente acondicionada, se sometió al proceso de anodizado electroquímico con el fin de obtener las nanoestructuras de $\mathrm{WO}_{3}$ que posteriormente se utilizarán como fotocatalizadores en el proceso de degradación de los pesticidas. El proceso de anodizado se caracteriza por tratarse de un proceso electroquímico encargado de crear una capa de óxido sobre la superficie del electrodo de forma controlada y con características mejoradas.

En primer lugar, una vez acondicionada la muestra, se teflonó toda la barra de wolframio a excepción de la superficie frontal de $0.5 \mathrm{~cm}^{2}$ para obtener las nanoestructuras solo en la superficie tratada. Una vez teflonada, se unió a un electrodo rotatorio ( $\mathrm{RDE}$, Rotating Disk Electrode) (Autolab) mediante el cual la muestra a anodizar giraba a una velocidad fijada. Este electrodo se sumergió en una celda de teflón en la que se encontraba el electrolito el cual fue calentado hasta $50{ }^{\circ} \mathrm{C}$ por la acción de un circuito externo de recirculación de agua y etilenglicol. Además, se utilizó una malla de platino como cátodo y un multímetro en serie con la fuente de tensión con la que se aplicaba el potencial requerido. Este montaje permitía enviar vía online los valores de densidad de corriente registrados al ordenador para posteriormente analizarlos. Este montaje se observa en la Figura 3.2. 


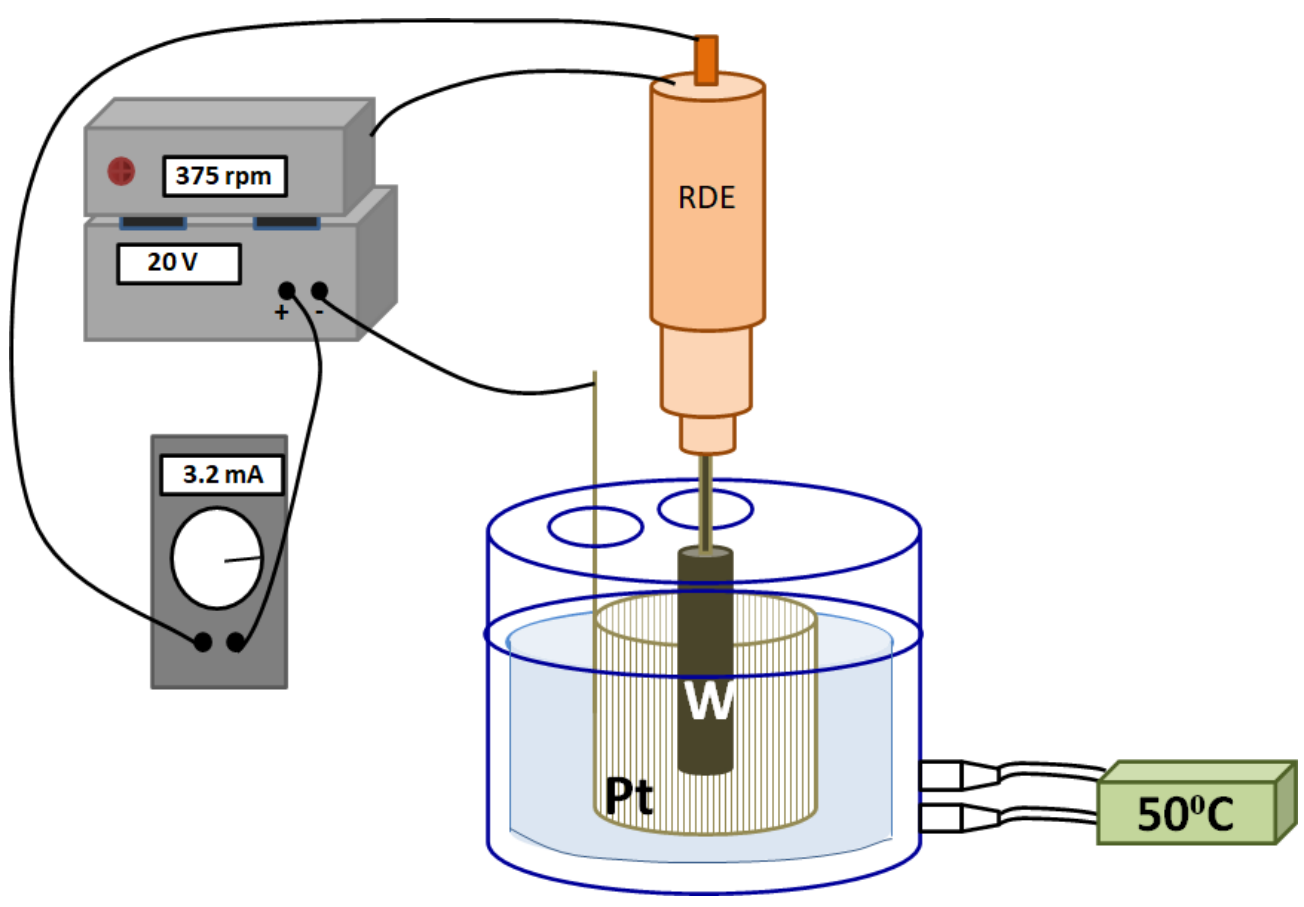

Figura 3.2. Montaje de anodizado electroquímico completo.

De todos los parámetros que se pueden modificar en este proceso, solo se varió el electrolito utilizado ya que todos los demás parámetros ya estaban fijados por estudios realizados con anterioridad.

- La temperatura del electrolito utilizado fue de $50{ }^{\circ} \mathrm{C}$. Mendes [4] ha investigado el efecto de la temperatura del proceso de anodizado en las propiedades de las nanoestructuras obtenidas. En su estudio se utilizó un rango de temperatura de $25{ }^{\circ} \mathrm{C}$ a $65^{\circ} \mathrm{C}$ y se realizaron curvas de corrientevoltaje y mediciones de impedancia electroquímica. Se demostró que la fotocorriente de los fotoánodos de $\mathrm{WO}_{3}$ (independientemente del sustrato o la morfología) aumentó con el aumento de la temperatura de funcionamiento. Además, se observó un cambio catódico en el potencial de inicio con el aumento de la temperatura, lo que indica una barrera de energía cinética más pequeña para la transferencia de carga a través de la 
interfase $\mathrm{WO}_{3}$ /electrolito. Las temperaturas de funcionamiento óptimas se asignaron entre 45 y $55{ }^{\circ} \mathrm{C}$ ya que el aumento en la temperatura de funcionamiento por encima de $55{ }^{\circ} \mathrm{C}$ causó una disminución en la actividad de fotoelectrocatalítica de las nanoestructuras debido a la mayor tasa de recombinación de los electrones con los huecos fotogenerados. Además, se realizó una prueba de estabilidad a largo plazo de los fotoánodos de $\mathrm{WO}_{3}$ y las muestras sintetizadas a una temperatura más alta mostraron una baja estabilidad al experimentar una disminución drástica en la fotocorriente $[5,6]$.

- El potencial aplicado fue de $20 \mathrm{~V}$ entre el electrodo de trabajo (W) y el contraelectrodo (malla de Pt) mediante una fuente de tensión. Esta elección se realizó ya que en estudios anteriores se demostró que con un potencial menor de $20 \mathrm{~V}$ solo se observaban pequeños hoyos en una capa compacta de óxido en vez de formarse una estructura porosa. Además, si el potencial era superior a $30 \mathrm{~V}$, se producía un colapso de la nanoestructura porosa dando lugar de nuevo a capas compactas de óxido de wolframio [7].

- La velocidad de rotación del electrodo fue de $375 \mathrm{rpm}$. Las condiciones hidrodinámicas influyen en el crecimiento de las nanoestructuras de dos maneras opuestas. Por un lado, las condiciones hidrodinámicas mejoran la transferencia de masa hacia la superficie del electrodo, favoreciendo así la formación de especies solubles responsables de la formación de nanoestructuras, mientras que por otro lado, la convección mecánica reduce la concentración de especies solubles cerca de la superficie del electrodo, por lo tanto, disminuye la tasa de crecimiento de las nanoestructuras por precipitación. El primer factor (aumento de la transferencia de masa, formación de especies solubles y la posterior precipitación) tuvo más influencia a velocidades de rotación bajas (hasta $375 \mathrm{rpm}$ ), mientras que a velocidades de rotación superiores a $375 \mathrm{rpm}$ fue el segundo factor (disminución de la concentración de especies solubles cerca de la superficie) que predominó sobre la primera para determinar la formación y el crecimiento de nanoestructuras, ya que el grosor de la capa de nanoestructuras disminuyó a altas rpm. Por tanto, las capas de nanoestructuras más gruesas se obtuvieron a 375 rpm, ya que 
esta velocidad de rotación era lo suficientemente alta como para mejorar la transferencia de masa hacia la superficie del electrodo y, por lo tanto, para aumentar la formación de especies solubles y su posterior precipitación en forma de $\mathrm{WO}_{3}$ hidratado, pero no era demasiado alta para facilitar la eliminación de estas especies solubles del área circundante del electrodo [8].

- El tiempo de anodizado fue de $\mathbf{4}$ horas. Este fue el tiempo elegido ya que en estudios previos se demostró que se necesitaban 4 horas para que ocurrieran las 3 etapas características de la formación de nanoestructuras de $\mathrm{WO}_{3}$ con las características y propiedades óptimas para su uso como fotocatalizador [9].

- La concentración de agente complejante $\left(\mathrm{H}_{2} \mathrm{O}_{2}\right)$ en el electrolito fue de $0.05 \mathrm{M}$. Con el uso de $\mathrm{H}_{2} \mathrm{O}_{2}$ se obtuvieron nanoestructuras de $\mathrm{WO}_{3}$ muy pequeñas. Esta forma particular y tan pequeña de las nanoestructuras agregadas condujeron a mejorar la transferencia y separación de carga. Sin embargo, un exceso de $\mathrm{H}_{2} \mathrm{O}_{2}$, condujo a una reducción en la fotoactividad de las nanoestructuras. Por tanto, la concentración óptima para las aplicaciones fotoelectroquímicas fue de $0.05 \mathrm{M} \mathrm{H}_{2} \mathrm{O}_{2}$, ya que dio un aumento de la densidad de la fotocorriente en comparación con las nanoestructuras convencionales [10].

Una vez definidos todos los parámetros que permanecieron constantes durante el anodizado, solo queda definir el parámetro variable, como es el ácido utilizado en el electrolito. Se decidió variar este parámetro utilizando tres ácidos diferentes, ya que el ácido utilizado juega un papel fundamental en la obtención de las nanoestructuras $y$, por tanto, era un parámetro importante que optimizar en el diseño de experimentos.

Es muy importante estudiar el efecto del electrolito y su composición sobre la actividad fotocatalítica ya que las especies iónicas y las moléculas orgánicas presentes en el electrolito dictan la cinética de reacción, la termodinámica y su influencia en el transporte de carga en la celda electroquimica. Es decir, el conocimiento sobre el $\mathrm{pH}$, el oxígeno disuelto, la conductividad de los electrolitos 
y la composición de los electrolitos es crucial para evaluar las propiedades fotoelectrocatalíticas de las nanoestructuras obtenidas ya que se ha demostrado que el electrolito usado durante el anodizado tiene un gran efecto en los huecos fotogenerados en la banda de valencia del electrodo de $\mathrm{WO}_{3}$. Una cinética pobre en la superficie del $\mathrm{WO}_{3}$ puede conducir a una oxidación incompleta del agua y competir con la formación de especies de peróxido y la fotooxidación de aniones o moléculas orgánicas[11,12].

Se ha investigado [5] la eficiencia de las nanoestructuras de $\mathrm{WO}_{3}$ en presencia de varios electrolitos de diferentes aniones, tales como acetato, cloruro, fosfato, perclorato y sulfato. Las pruebas se llevaron a cabo midiendo simultáneamente la fotocorriente y la evolución de $\mathrm{O}_{2}$ bajo iluminación. Se detectó una fotocorriente significativa en presencia de todos los electrolitos empleados, sin embargo, no todos los electrolitos dieron como resultado una evolución eficiente de $\mathrm{O}_{2}$. En presencia de iones acetato y cloruro, se genera una fotocorriente considerable, pero no se detectó evolución de $\mathrm{O}_{2}$ debido a que la fotooxidación de los iones acetato y cloruro suprime completamente la evolución de $\mathrm{O}_{2}$ en la superficie de $\mathrm{WO}_{3}$.

La presencia y la fotooxidación de moléculas orgánicas en el electrolito también competirán con la fotooxidación del agua a $\mathrm{O}_{2}$ en la superficie del $\mathrm{WO}_{3}$. La presencia de estas moléculas orgánicas suprime fuertemente la reacción de oxidación del agua en el fotoánodo de $\mathrm{WO}_{3}$ pero aumenta la densidad de la fotocorriente obtenida $[13,14]$.

Por tanto, con todos estos datos se decidió probar tres electrolitos diferentes, como son el ácido sulfúrico $\left(\mathrm{H}_{2} \mathrm{SO}_{4}\right)$, el ácido nítrico $\left(\mathrm{HNO}_{3}\right)$ y el ácido metanosulfónico $\left(\mathrm{CH}_{4} \mathrm{O}_{3} \mathrm{~S}\right)$ con una concentración $1.5 \mathrm{M}$ en cada caso. Se decidió probar los dos primeros ácidos para ver el efecto que tenía utilizar diferentes aniones en el anodizado. El uso del $\mathrm{CH}_{4} \mathrm{O}_{3} \mathrm{~S}$ se fundamenta en estudiar el efecto que tiene usar un ácido con una parte orgánica como electrolito en la síntesis de las nanoestructuras.

Una vez se obtuvo la muestra anodizada, se cortó con una cortadora Buehler Isomet 4000 y se guardó en el desecador para posteriormente someterla al tratamiento de post-anodizado. Este paso es necesario ya que las muestras deben medir una altura alrededor de $0.5 \mathrm{~cm}$ para poder analizarlas en el FE-SEM y por disminuir el gasto de wolframio. 


\subsection{Post-anodizado.}

Al obtener las nanoestructuras por el método de anodizado electroquímico, el resultado obtenido fueron nanoestructuras de $\mathrm{WO}_{3}$ hidratadas y amorfas, y por tanto, para eliminar el agua de su estructura y convertirla en cristalina, se requiere un proceso de calentamiento a partir del cual ocurran esos cambios $[15,16]$.

El tratamiento de post-anodizado consistió en introducir las muestras anodizadas en un horno tubular Carbolite TVS 12/600 de cuarzo. Este tratamiento térmico se caracteriza por tener tres parámetros que modificar con el fin de obtener las nanoestructuras más cristalinas y deshidratadas sin perder sus propiedades fotoelectroquímicas. Estos parámetros son el tiempo que permanecen en el horno, la temperatura y la atmósfera inerte en la que se encuentran las nanoestructuras. En la Figura 3.3 se encuentra el esquema del horno tubular utilizado.

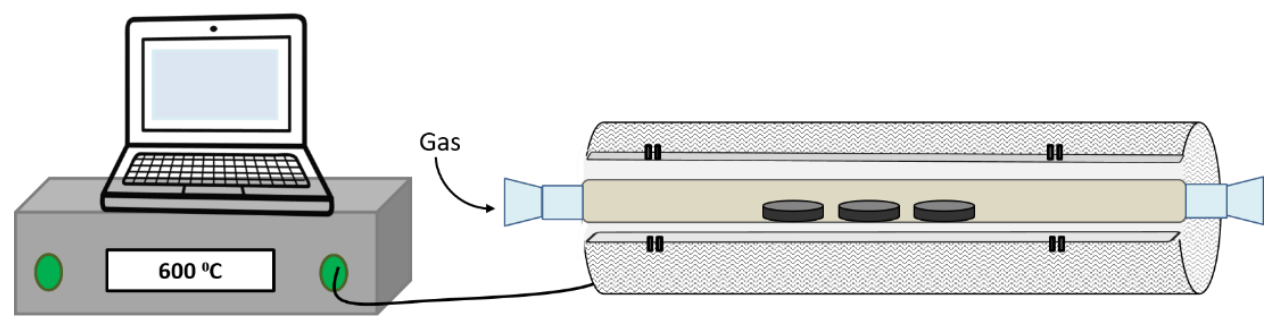

Figura 3.3. Esquema del horno tubular utilizado.

El único parámetro que permaneció constante fue el tiempo de calentamiento de las nanoestructuras que fue de $\mathbf{4}$ horas, sin contar el tiempo de calentamiento y de enfriamiento por convección natural del horno. Se aplicó este tiempo ya que fue el utilizado en otros estudios por ser el tiempo óptimo en el que las nanoestructuras se deshidrataban y convertían su estructura a cristalina [10].

En cuanto a la temperatura de calentamiento fue de $400{ }^{\circ} \mathrm{C}, 500{ }^{\circ} \mathrm{C}$ y $600^{\circ} \mathrm{C}$ con el fin de optimizar las propiedades de las nanoestructuras obtenidas. Se decidió variar el parámetro temperatura ya que es un factor crítico para la obtención de nanoestructuras cristalinas con buenas propiedades fotoelectroquímicas. En algunos casos, debido al procedimiento de síntesis utilizado, tienen que eliminarse mediante tratamientos térmicos algunas impurezas o moléculas de 
agua que hacen que las nanoestructuras no presenten una gran eficiencia fotoelectrocatalítica [17]. Además, el proceso de calentamiento puede causar una transformación en la estructura del $\mathrm{WO}_{3}$, en la que la fase en la que se encontraban las nanoestructuras hidratadas cambia a otra fase más estable, formándose nuevos enlaces. El aumento de la temperatura de calentamiento aumenta la cristalinidad de las nanoestructuras, pero se debe establecer un límite superior de temperatura dependiendo del sustrato. Por lo tanto, la temperatura de calentamiento juega un papel importante cuando se emplea un método de síntesis basado en disoluciones acuosas [18-20].

Finalmente, el tercer parámetro crítico en el proceso de post-anodizado es la atmósfera inerte utilizada. En este caso se varió entre una atmósfera de argón (atmósfera no oxidante), nitrógeno $\left(\mathrm{N}_{2}\right)$ y aire (oxidante, por su contenido en $\mathrm{O}_{2}$ ). La atmosfera empleada es también un parámetro fundamental en el control de la fase y la morfología ya que podrían verse afectadas las transiciones de la estructura a través de la distorsión de la red, relajación de la unión W-O y las vacantes de oxígeno dentro de las nanoestructuras [21-23]. Estos impactos, por lo tanto, influirían en el rendimiento final de los nanomateriales en aplicaciones fotoelectrocatalíticas.

\section{Proceso de caracterización de la muestra anodizada.}

Una vez sintetizadas las muestras, se caracterizaron con diferentes técnicas con el fin de hallar las condiciones de síntesis óptimas.

\subsection{Técnica de Microscopía Laser Confocal Raman.}

Mediante la técnica de Microscopía Laser Confocal Raman se caracterizaron superficialmente las muestras obtenidas mediante un Microscopio Laser Raman Confocal Witec empleando un láser de neón de $632 \mathrm{~nm}$ con una potencia de 750 $\mu \mathrm{W}$. El equipo utilizado es el que se muestra en la Figura 3.4. Se trata de una técnica no destructiva y que no requiere un pretratamiento de las muestras y gracias a la cual se analizan dos variables importantes, como son la composición y la estructura cristalina de las nanoestructuras de $\mathrm{WO}_{3}$. 


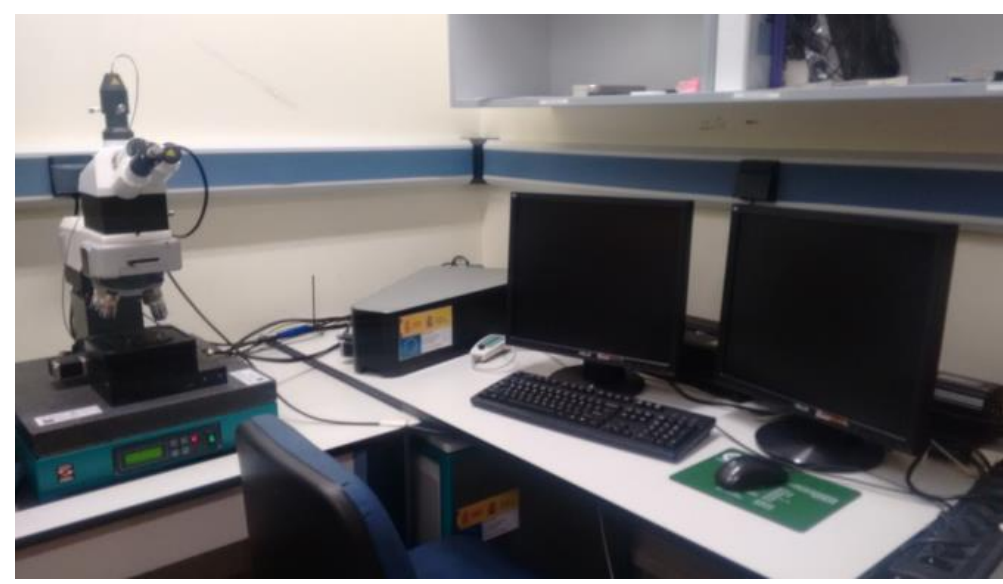

Figura 3.4. Microscopio Laser Raman Confocal WITec Alpha.

Esta caracterización se realizó en dos momentos diferentes del proceso, antes y después del tratamiento térmico, con el fin de estudiar cómo afecta la temperatura a su composición y estructura cristalina de las nanoestructuras formadas.

El fundamento de la técnica de espectroscopia Raman se basa en la incidencia de un haz de luz monocromática a un conjunto de moléculas el cual provoca la aparición de un momento dipolar eléctrico oscilante inducido debido a una oscilación de la densidad electrónica. Este momento dipolar actúa como fuente de radiación dando lugar a dos casos diferentes. El primero de ellos se trata de la dispersión Rayleigh, que consiste en obtener como resultado de la interacción fotón-molécula un fotón dispersado con la misma frecuencia que el fotón incidente, dando lugar a un choque elástico en donde ni el fotón ni la molécula sufren variaciones en su estado energético. El segundo de ellos se trata de la dispersión Raman en donde el fotón es dispersado a una frecuencia distinta a la incidente (choque inelástico) $[24,25]$.

La dispersión Raman se divide a su vez en dos subfenómenos: la dispersión Raman Stokes, en donde la frecuencia del fotón dispersado es menor a la del incidente, produciéndose una transferencia de energía del fotón a la molécula para pasar de un estado de energía no permitido a uno permitido mayor al que tenía inicialmente (el fotón es dispersado con una frecuencia $v_{0}+v_{r}$ ); y la dispersión antiStokes, en donde la frecuencia del fotón dispersado es mayor a la del incidente, produciéndose en este caso la transferencia de energía de la molécula al fotón 
para pasar de un estado de energía superior al fundamental a su estado vibracional fundamental después del choque $[26,27]$. En la Figura 3.5 se muestran los diagramas de las diferentes formas de dispersión de la luz al incidir sobre la
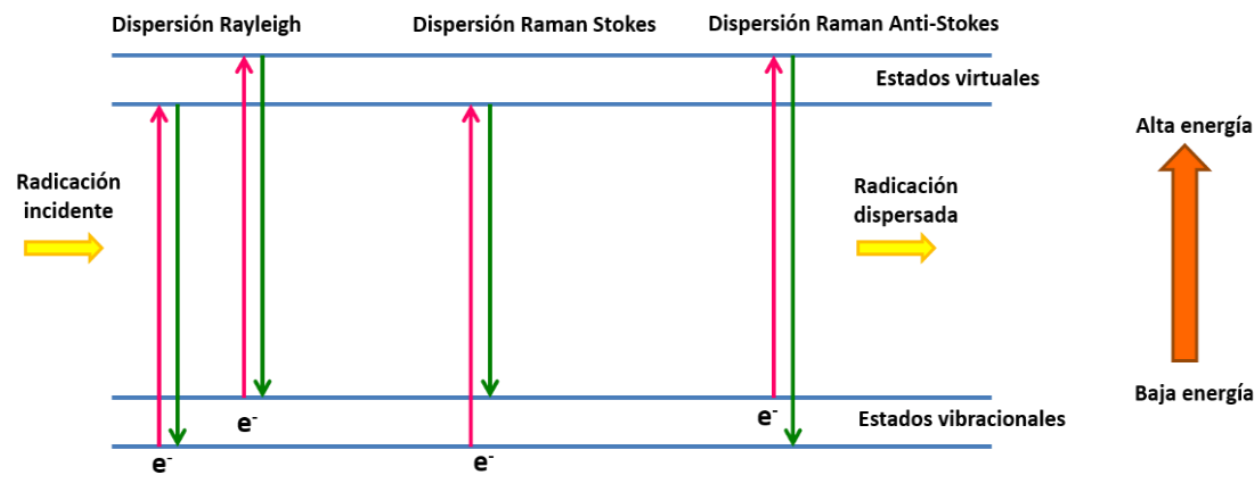

materia.

Figura 3.5. Diagramas de dispersión de la luz al incidir sobre la materia.

Cada tipo de material poseerá un conjunto de valores $v_{r}$ intrínsecos a su estructura cristalina y al tipo de enlaces químicos que contiene. En el espectro Raman se representan estos fenómenos mediante la intensidad óptica dispersada frente al número de onda normalizado al que se produce. Este último concepto se define como una magnitud proporcional a la frecuencia e inversamente proporcional a la longitud de onda.

A temperatura ambiente, la mayoría de las moléculas están en su estado vibracional de menor energía dando lugar a una mayor probabilidad de que ocurran transferencias de energía del tipo Raman Stokes que las del tipo Raman anti-Stokes. Esta diferencia provoca que habitualmente se trabaje solo utilizando la dispersión Raman Stokes. Solo en el caso en que se produzca un efecto de fluorescencia unido a una naturaleza química del material particular podrían enmascarar las bandas Raman, siendo entonces interesante medir la dispersión anti-Stokes $[24,28]$.

Por tanto, una vez realizadas las medidas con el Microscopio Laser Raman Confocal, se obtuvieron los correspondientes espectros Raman para cada muestra en el que se grafican la intensidad Raman en función del desplazamiento Raman 
(hace referencia a la diferencia entre la frecuencia de la radiación incidente y la dispersada).

\subsection{Microscopia Electrónica de Barrido de Emisión de Campo (FE-SEM).}

Mediante otra técnica de caracterización como es la Microscopía FE-SEM (Microscopio Electrónico de Barrido ZEISS ULTRA55), se caracterizó nuevamente la superficie de la muestra para comprobar la morfología de las nanoestructuras formada sobre el sustrato. Las imágenes se adquirieron a 1.000, 10.000 y 20.000 aumentos, utilizando un voltaje de aceleración de 3 kV. En la Figura 3.6 se muestra el microscopio utilizado.

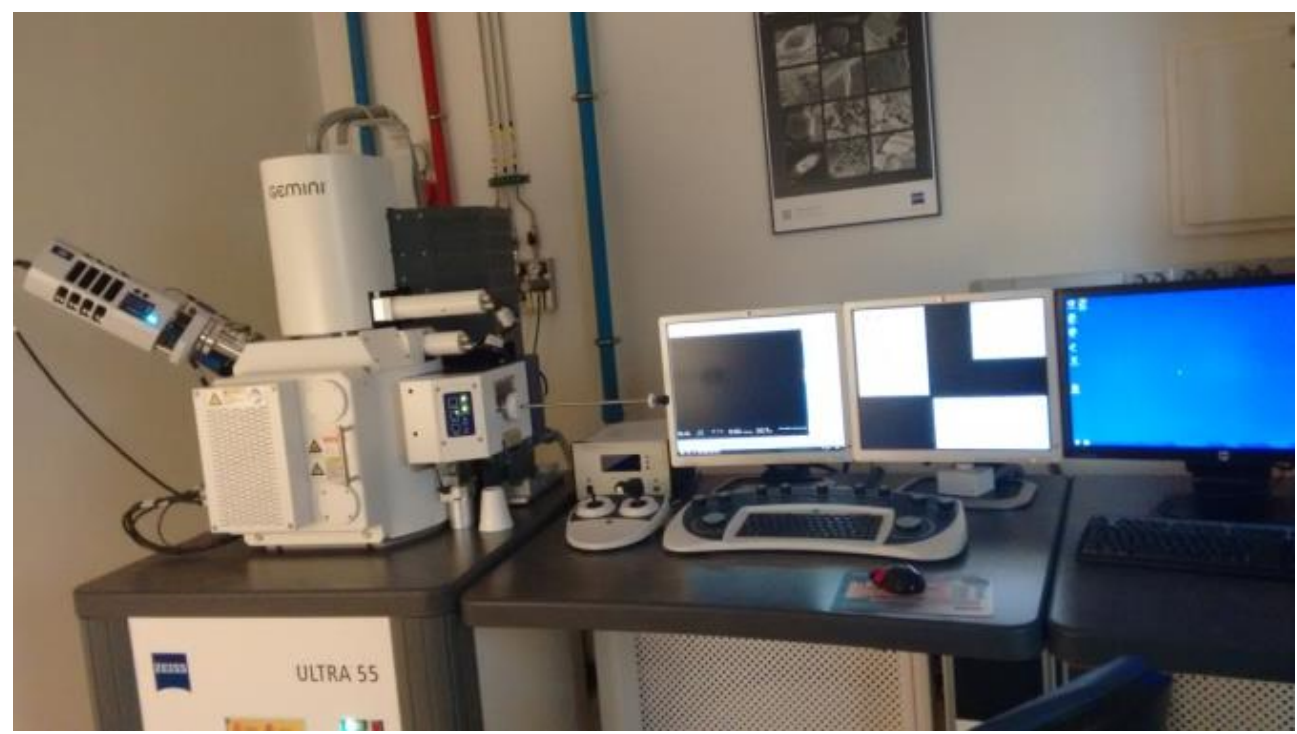

Figura 3.6. Microscopio electrónico de barrido de emisión de campo ZEISS ULTRA55.

El microscopio electrónico de barrido de emisión de campo (FE-SEM) es un equipo capaz de proporcionar una información variada y completa de la superficie de la muestra con una gran resolución. Para ello, se barre con un haz de electrones sobre la superficie de la muestra visualizando en un monitor la información que interesa dependiendo de los detectores utilizados [29].

En cuanto a la fuente de electrones se trata de un cañón de emisión de campo que proporciona haces de electrones de alta y baja energía muy focalizados, permitiendo utilizar potenciales bajos $(0.02-5 \mathrm{kV})$ y ofreciendo una gran 
resolución espacial. Gracias a esto se minimiza el efecto de carga en muestras no conductoras y se evita daños en muestras sensibles al haz electrónico [30,31].

Las imágenes obtenidas por el microscopio electrónico de barrido se producen debido a electrones secundarios o electrones retrodispersados generados por la interacción con la superficie del material de un haz de electrones incidentes. En el momento en que el haz de electrones incide en una muestra sólida, se puede producir una desviación de éstos o que los electrones puedan atravesarla, dado lugar a electrones absorbidos, trasmitidos, reflejados y dispersados. Solo en el caso en el que el material es significativamente delgado se transmite una parte importante del haz. Estas interacciones se pueden observar en la Figura 3.7.

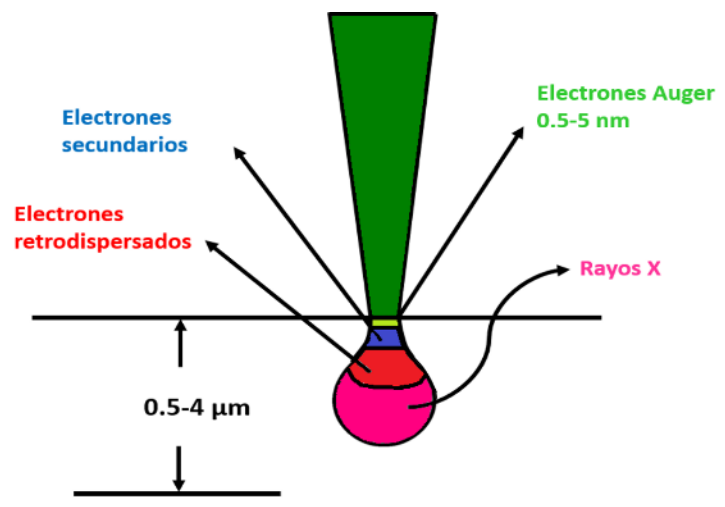

Figura 3.7. Interacción de electrones de alta energía con muestras sólidas.

Además, el FE-SEM utiliza detectores dentro de la lente, (in lens). Estos detectores se caracterizan por estar optimizados para trabajar a alta resolución y muy bajo potencial de aceleración dotando al equipo de la posibilidad de ofrecer su máximo rendimiento [32].

Todos los detectores disponibles en este equipo son los siguientes:

- Detector de electrones secundarios $\mathrm{SE}_{2}$

- Detector de electrones secundarios in lens

- Detector de electrones retrodispersados AsB

- Detector de electrones retrodispersados in lens EsB

- Detector de energía dispersiva de Rayos X, EDS

En la Figura 3.8 se muestra un esquema del sistema de lentes de un microscopio FE-SEM. 


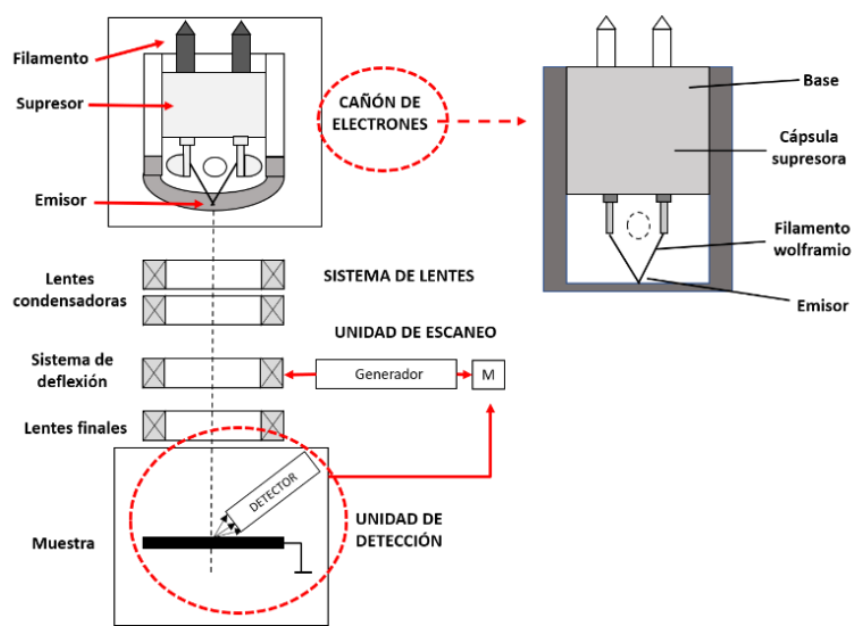

Figura 3.8. Sistema de lentes de un microscopio FE-SEM.

\subsection{Caracterización superficial de las nanoestructuras mediante Espectroscopía Fotoelectrónica de rayos X (XPS).}

Otra técnica utilizada en la caracterización de las muestras ha sido la conocida como espectroscopía fotoelectrónica de rayos $X$ (XPS). Se trata de una técnica para analizar la química en la superficie de un material. Esta técnica mide la composición elemental, fórmula empírica, estado químico y estado electrónico de los elementos dentro de un material. La información que proporciona el XPS sobre las capas superficiales es importante para muchas aplicaciones industriales y de investigación donde la composición de la superficie juega un papel fundamental. Los campos donde más se utiliza son en nanomateriales, energía fotovoltaica, catálisis, corrosión, adhesión, dispositivos electrónicos, tratamientos de superficies y recubrimientos de película fina utilizados para numerosas aplicaciones.

Los espectros XPS se obtienen irradiando una superficie sólida con un haz de rayos $\mathrm{X}$ monoenergéticos (los rayos $\mathrm{Al}$ k $\alpha$ o los rayos $\mathrm{Mg} \mathrm{K} \alpha$ son los más utilizados) que provocan la emisión de fotoelectrones desde la superficie de la muestra. Simultáneamente, se utiliza un analizador de energía de electrones para medir la energía de los fotoelectrones emitidos. A partir de la energía de enlace y la 
intensidad del pico del fotoelectrón, se puede determinar la identidad, cantidad y estado químico del elemento [33].

El fundamento físico-químico del proceso de fotoemisión es el siguiente:

Cuando un átomo o molécula absorbe un fotón de rayos $X$, puede expulsar un electrón. La energía cinética (KE) del electrón depende de la energía del fotón (hv) y la energía de enlace (BE) del electrón, es decir, la energía requerida para eliminar el electrón de la superficie.

Midiendo la energía cinética de los electrones emitidos, es posible determinar qué elementos están cerca de la superficie de un material y la energía de enlace del electrón. Esta energía depende de varios factores [34]:

- Elemento a partir del cual se emite el electrón.

- El orbital desde el que se expulsa el electrón

- El entorno químico del átomo desde el que se emitió el electrón.

Por otra parte, la energía cinética de los electrones emitidos es proporcional a la frecuencia de los fotones excitantes. Si se utiliza fotones de energía muy superior a la umbral, el exceso de ésta es transmitido al electrón que se emite.

El proceso de fotoemisión es extremadamente rápido, alrededor de $10^{-16} \mathrm{~s}$, y su comportamiento se rige mediante la ecuación de Einstein:

$$
E_{B}=h v-K E
$$

donde $E_{B}$ es la energía de enlace del electrón en el átomo, hv es la energía de la fuente de rayos $X, y$ KE es la energía cinética del electrón detectado que es medida por el espectrómetro del XPS.

Cuando un sólido es irradiado por rayos $X$, también se puede producir la emisión de electrones Auger. Estos electrones se producen al ionizar un electrón interno (cercano al núcleo), el cual deja una vacante, para que un electrón de un nivel de energía superior caiga en ella y libere energía. La energía liberada se transfiere a otro electrón, que es expulsado del átomo. Este segundo electrón expulsado es un electrón Auger [35].

Las interacciones débiles entre átomos, como fuerzas de cristalización o puente de hidrógeno, no alteran suficientemente la distribución electrónica como para 
que se pueda observar un cambio en la energía de enlace medible. Por tanto, la energía de enlace que se mide por XPS se asocia siempre a enlaces de tipo iónico o covalente entre átomos. En la Figura 3.9 se muestra el fundamento del análisis XPS.

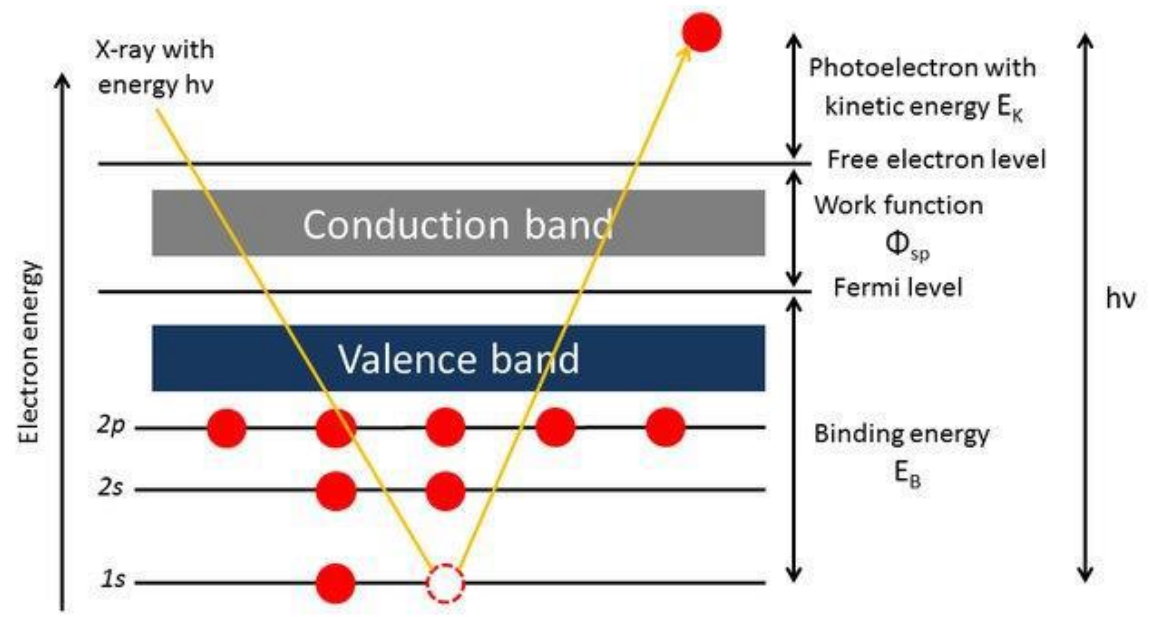

Figura 3.9. Fundamento físico-químico del análisis XPS.

A continuación, se detalla los componentes básicos del equipo utilizado en el análisis XPS.

Los componentes primarios de un equipo XPS son:

- el sistema de vacío

- la fuente de rayos X

- un analizador de energía del electrón

- un sistema de datos.

La parte central del equipo lo constituye la cámara principal de vacío en la que la muestra es analizada. La realización del experimento en condiciones de vacío se debe a los siguientes motivos:

- Los fotoelectrones han de viajar desde la muestra hasta el detector sin colisionar con ninguna partícula de fase gaseosa.

- Algunos componentes tales como la fuente de rayos $X$ requieren condiciones de vacío para mantener la operatividad. 
- La composición superficial de la muestra ha de permanecer invariable durante el experimento.

Las muestras son introducidas en una primera cámara donde se vacía la atmósfera existente y se consigue un vacío de $10^{-6}$ torr. Alcanzar el ultra-alto vacío es una operación lenta, cuya duración oscila entre varios minutos y horas. La colocación de la muestra en el interior de la cámara se realiza mediante una barra unida a un portamuestras. Dentro de la cámara principal, la muestra puede ser orientada en distintas posiciones y se puede elegir la zona de la superficie a trabajar. Todo esto es controlado mediante una cámara de vídeo. Las fuentes de rayos $\mathrm{X}$ más utilizada son las de Al o $\mathrm{Mg}$. La radiación X es monocromatizada antes de llegar a la muestra mediante un cristal de cuarzo. Esto permite aprovechar el rango de energía en que la intensidad de la radiación $\mathrm{X}$ es máxima (1-2 eV), evitar los picos satélites de fluorescencia de rayos $\mathrm{X}$, e impedir que electrones de alta energía provoquen golpes de calor a la muestra y la degraden. El área de muestra que puede ser irradiada por los rayos $\mathrm{X}$ varía entre zonas circulares de unos pocos centímetros de diámetro hasta unas 50 micras. Esta focalización depende de la geometría de la fuente y del tipo de cañón de electrones utilizado para estimular la emisión de rayos X. En la Figura 3.10 está representado el esquema del equipo utilizado en el análisis XPS [36].

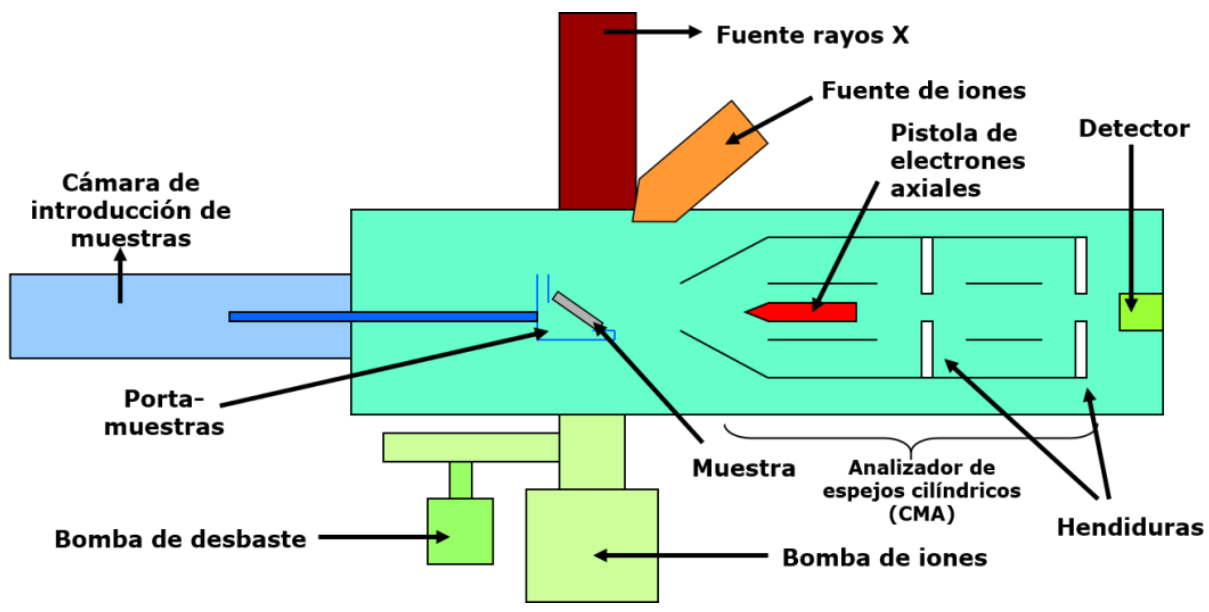

Figura 3.10. Esquema del equipo utilizado en el análisis XPS.

Finalmente, las condiciones que se han aplicado para realizar el análisis XPS de las muestras estudiadas son las siguientes: 
- Todos los espectros se obtuvieron usando radiación Al-Ka (1486.6 eV) monocromatizada, produciendo un punto de rayos $X$ enfocado (en forma elíptica con una longitud de eje mayor de $400 \mu \mathrm{m}$ ) a $3 \mathrm{~mA} \times 12 \mathrm{kV}$.

- El analizador alfa hemisférico operó en el modo de energía constante con energías de paso de exploración de 200 eV para medir toda la banda de energía y $50 \mathrm{eV}$ para medir selectivamente los elementos particulares.

- Los datos de XPS se analizaron con el software Avantage. Se utilizó una función de fondo inteligente para aproximar los fondos experimentales y se calculó la composición elemental de la superficie a partir de las áreas de los picos sustraídas al fondo. La compensación de carga se logró con la pistola axial de electrones que proporciona electrones de baja energía e iones de argón de baja energía de una sola Fuente.

- Además, las condiciones de vacío para realizar los experimentos son de Ultra-alto vacío. Es decir, sólo se empiezan a obtener los espectros si el vacío es igual o menor a $5 \cdot 10^{-8} \mathrm{mBar}$.

\subsection{Caracterización electroquímica mediante espectroscopia de impedancias fotoelectroquímica (PEIS).}

La técnica de caracterización mediante PEIS es una técnica no destructiva y muy sensible a posibles perturbaciones pequeñas generadas en el sistema. Gracias a ello, se puede caracterizar las propiedades tanto de materiales como de sistemas electroquímicos [37].

Con el fin de explicar el funcionamiento y fundamento de esta técnica es necesario definir previamente el concepto de resistencia eléctrica. Esta es la capacidad de un elemento de un circuito para resistir el flujo de corriente eléctrica. La ley de Ohm (ecuación 3.10) define la resistencia en términos de la relación entre el voltaje $\mathrm{E}$ y la corriente $\mathrm{I}$.

$$
R=\frac{E}{I}
$$

Aunque se trata de una relación bien conocida, su uso se limita a un solo elemento del circuito: la resistencia ideal. Una resistencia ideal tiene varias propiedades simplificadoras [38]:

- Sigue la Ley de Ohm en todos los niveles de corriente y voltaje.

- Su valor de resistencia es independiente de la frecuencia. 
- Las señales de corriente y voltaje a través de una resistencia están en fase entre sí.

No obstante, en el mundo real existen elementos de circuito que exhiben un comportamiento mucho más complejo. Estos elementos nos obligan a abandonar el simple concepto de resistencia. En su lugar utilizamos el concepto de impedancia, que es un parámetro de circuito más general.

Al igual que la resistencia, la impedancia es una medida de la capacidad de un circuito para resistir el flujo de corriente eléctrica. Pero, a diferencia de la resistencia, la impedancia no está limitada por las propiedades simplificadoras mencionadas anteriormente.

La impedancia electroquímica generalmente se mide aplicando un potencial sinusoidal de corriente alterna a una celda electroquímica y midiendo la corriente a través de la celda. Si se aplica una excitación potencial sinusoidal, la respuesta que se registra será una función sinusoidal a la misma frecuencia, pero desplazada en fase, como se observa en la Figura $3.11[39,40]$.

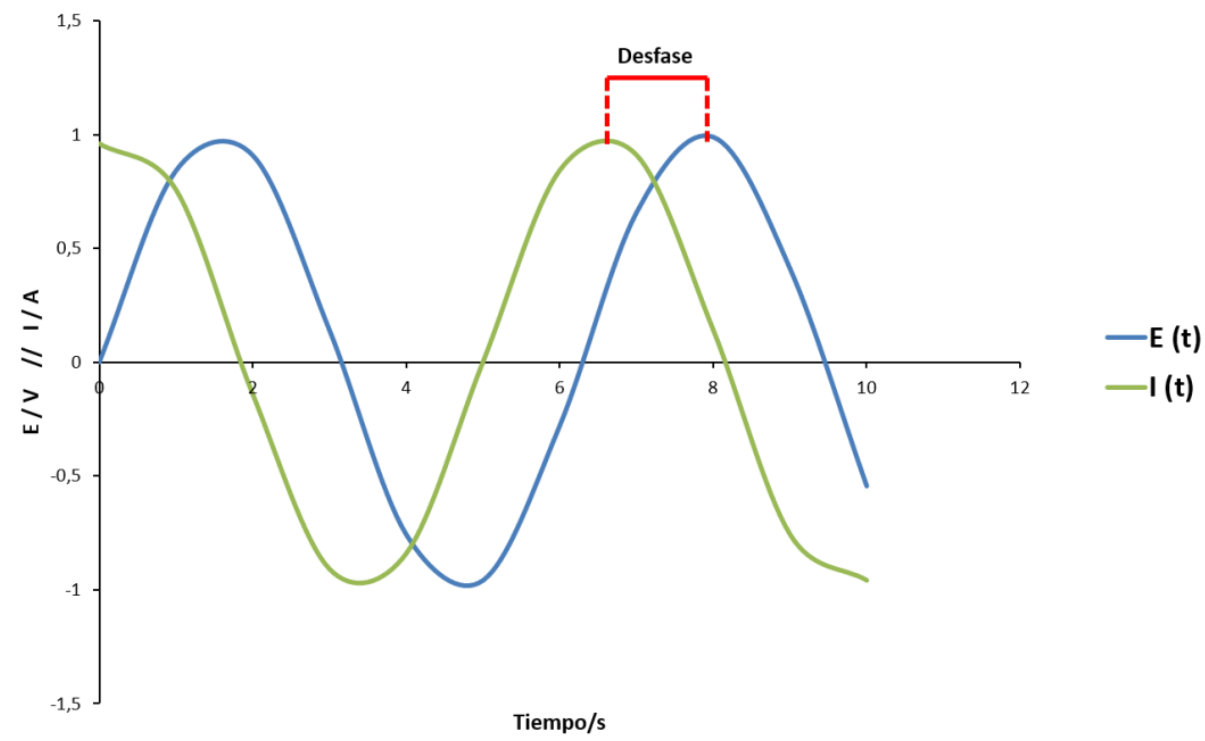

Figura 3.11. Funciones sinusoidales del potencial y la intensidad registrada. 
El potencial aplicado, expresado en función del tiempo, se expresa de la siguiente forma:

$$
E_{t}=E_{0} \cdot \sin (\omega t)
$$

$E_{t}$ es el potencial en el tiempo t, $E_{0}$ es la amplitud de la señal y $\omega$ es la frecuencia radial. La relación entre la frecuencia radial $\omega$ (expresada en radianes / segundo) y la frecuencia $f$ (expresada en hercios) es:

$$
\omega=2 \pi f
$$

En un sistema lineal, la señal de respuesta, $I_{t}$, se desplaza en la fase $(\phi)$ y tiene una amplitud diferente, $I_{0}$, como se muestra en la ecuación 3.13 .

$$
I_{t}=I_{0} \cdot \sin (\omega t+\emptyset)
$$

Finalmente, una expresión análoga a la Ley de Ohm nos permite calcular la impedancia del sistema como:

$$
Z=\frac{E_{t}}{I_{t}}=\frac{E_{0} \cdot \sin (\omega t)}{I_{0} \cdot \sin (\omega t+\emptyset)}=Z_{0} \cdot \frac{\sin (\omega t)}{\sin (\omega t+\emptyset)}
$$

Por lo tanto, la impedancia se expresa en términos de magnitud, $Z_{0}$, y un cambio de fase, $\phi$.

Además, si se aplica la relación de Euler expresada en la ecuación 3.15, se obtiene la expresión de la impedancia como una función compleja [38] (ecuación 3.16).

$$
\begin{gathered}
\exp (j \emptyset)=\cos \emptyset+j \sin \emptyset \\
Z(\omega)=\frac{E}{I}=Z_{0} \cdot \exp (j \emptyset)=Z_{0} \cdot(\cos \emptyset+j \sin \emptyset)
\end{gathered}
$$

Como se observa en la ecuación 3.16, la expresión que hace referencia a la impedancia $Z(\omega)$ se compone de una parte real (término resistivo) y una parte imaginaria (término capacitivo o inductivo). Si la parte real se traza en el eje $X$ y la parte imaginaria se traza en el eje $Y$ de un gráfico, obtenemos el gráfico más sencillo y más utilizado conocido como "Gráfico de Nyquist" representado en la Figura 3.12. En esta gráfica el eje $Y$ es negativo y cada punto del diagrama de Nyquist corresponde a la impedancia a una determinada frecuencia. Los datos de baja frecuencia están en el lado derecho del gráfico y los correspondientes a las frecuencias más altas están a la izquierda. Normalmente se obtiene un 
semicírculo, pero dependiendo de los procesos electroquímicos que ocurran habrá un semicírculo, dos o incluso un semicírculo abierto [41].

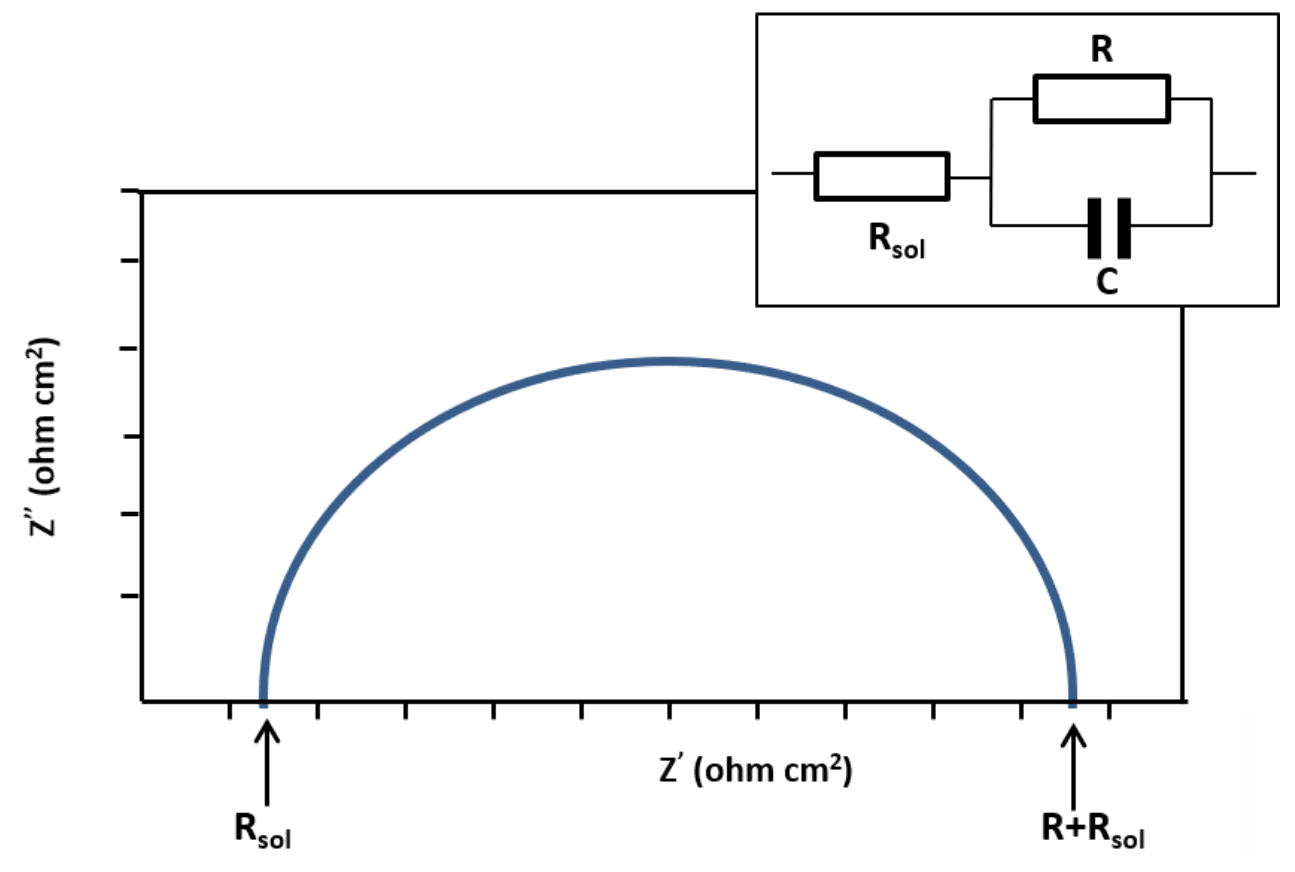

Figura 3.12. Diagrama de Nyquist.

De este gráfico se pueden sacar valores de resistencias de los sistemas electroquímicos como pueden ser la resistencia del electrolito $\left(R_{s}\right)$, la resistencia a la transferencia de carga, etc. La resistencia del electrolito queda representada con la primera intersección del semicírculo con el eje $\mathrm{X}$, mientras que la resistencia de transferencia de carga queda representada con la amplitud del semicírculo. Además, para realizar una buena interpretación de los datos obtenidos a partir de las impedancias es necesario seleccionar un modelo eléctrico que se ajuste experimentalmente a los datos. Este modelo eléctrico se denomina circuito eléctrico equivalente y hace referencia a una combinación de elementos pasivos a partir de los cuales se obtiene valores de los diferentes parámetros eléctricos, dando información sobre las resistencias que presentan los diferentes sistemas electroquímicos. A través del circuito eléctrico seleccionado se obtienen unas medidas que facilitan información relevante relacionada con las resistencias tanto de polarización como de la disolución y la capacitancia de la 
doble capa de Helmholtz [42]. Los datos proporcionados a altas frecuencias dan información sobre la resistencia de la disolución mientras que los adquiridos a bajas frecuencias proporcionan información sobre la cinética de la reacción. Según el modelo propuesto y la forma que éste adopte se obtendrá una información u otra de los parámetros característicos.

Para obtener el modelo eléctrico al cual se van a ajustar los datos experimentales existen dos formas diferentes que se exponen a continuación:

1. Proponiendo una hipótesis de lo que está teniendo lugar mediante un planteamiento teórico. Una vez planteada esta hipótesis se plantea un modelo teórico obteniendo los parámetros de este modelo a partir de los datos experimentales para finalmente relacionarlos con las propiedades tanto físicas como químicas del sistema.

2. Considerando el sistema electroquímico como una caja negra a partir de la cual se predice su comportamiento en el futuro, es decir, mediante un modelo experimental. Normalmente se trata de modelos que se representan mediante circuitos eléctricos en donde su respuesta es equiparable al comportamiento de los datos experimentales.

El circuito eléctrico equivalente correspondiente a la representación de la Figura 3.12 está representado en la misma Figura.

En el diagrama de Nyquist, la impedancia se puede representar como un vector de longitud $|Z|$. El ángulo entre este vector y el eje $X$, comúnmente llamado "ángulo de fase", es $\Phi(=\arg (Z))$. Sin embargo, el diagrama de Nyquist tiene como inconveniente que no se puede saber qué frecuencia se usó para registrar cada dato representado en el gráfico $[43,44]$.

Por tanto, otro método de presentación popular es el diagrama de Bode. A diferencia del diagrama de Nyquist, el gráfico de Bode muestra información de la frecuencia. En este caso se representa en el eje $X$ el logaritmo de la frecuencia mientras que en el eje $Y$ se pueden encontrar dos casos. Si se representa el logaritmo del módulo de la impedancia, entonces se obtendría el gráfico conocido como Bode-módulo, mientras que, si se representa el ángulo de fase, entonces se encontraría el gráfico conocido como Bode-Fase. En la Figura 3.13 se muestra un ejemplo de esta representación. En el caso del gráfico de Bode-módulo se puede sacar la resistencia del electrolito a partir del valor a máxima frecuencia y el valor 
de la resistencia de transferencia de carga a partir del valor obtenido a mínima frecuencia $[43,45]$.
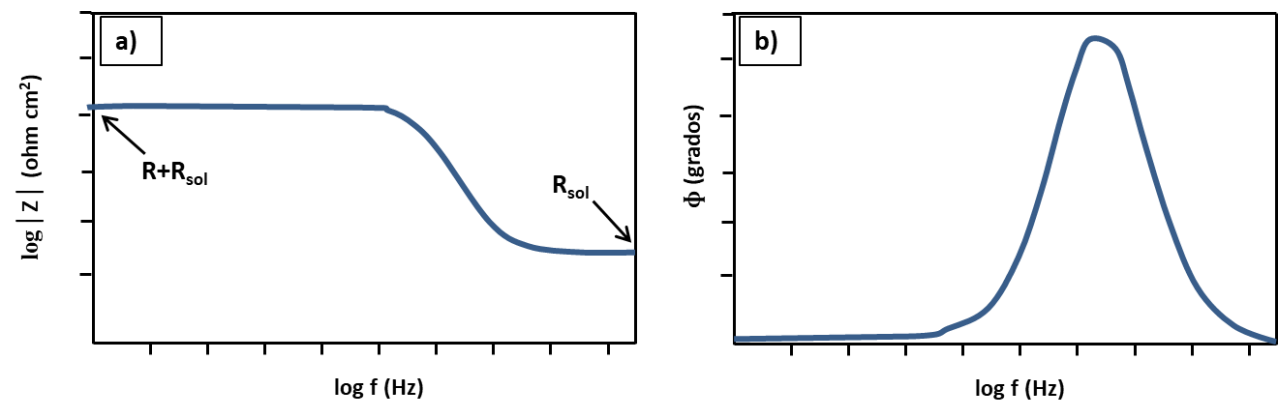

Figura 3.13. a) Diagrama de Bode-módulo, b) Diagrama de Bode-fase.

Con el fin de evaluar la calidad de los datos obtenidos mediante esta técnica, se puede utilizar el análisis de Kramers-Kronig. Las relaciones K-K exigen que los datos espectrales del plano complejo causal muestren dependencia entre magnitud y fase. La parte real de un espectro se puede obtener mediante la integración de la parte imaginaria y viceversa.

Las relaciones K-K siempre se cumplirán para los datos PEIS que son lineales, causales y estables. Si los datos espectrales reales e imaginarios medidos no cumplen con las relaciones $\mathrm{K}-\mathrm{K}$, es porque no cumplen con algunas de las condiciones descritas anteriormente.

Desafortunadamente, la transformación K-K requiere integración en un rango de frecuencia de cero a infinito. Dado que nadie puede medir los datos espectrales en ese rango, evaluar las relaciones $\mathrm{K}-\mathrm{K}$ a través de la integración siempre implica suposiciones sobre el comportamiento de un espectro fuera de la frecuencia sobre la cual se midió [37].

Para realizar esta caracterización de las nanoestructuras se dispuso del montaje experimental mostrado en la Figura 3.14. La Figura 3.14 muestra una descripción general de los componentes principales para una configuración con luz solar simulada. Se usa un potenciostato para controlar el potencial de la muestra y medir la corriente. Además, se utiliza una célula solar o fotodiodo calibrado para verificar que la intensidad del simulador solar en la posición de la muestra corresponde al valor deseado, generalmente $1000 \mathrm{~W} / \mathrm{m}^{2}$, que corresponde a $1 \mathrm{sol}$ 
a AM 1.5. A continuación se proporciona una descripción más detallada de los componentes individuales [46].

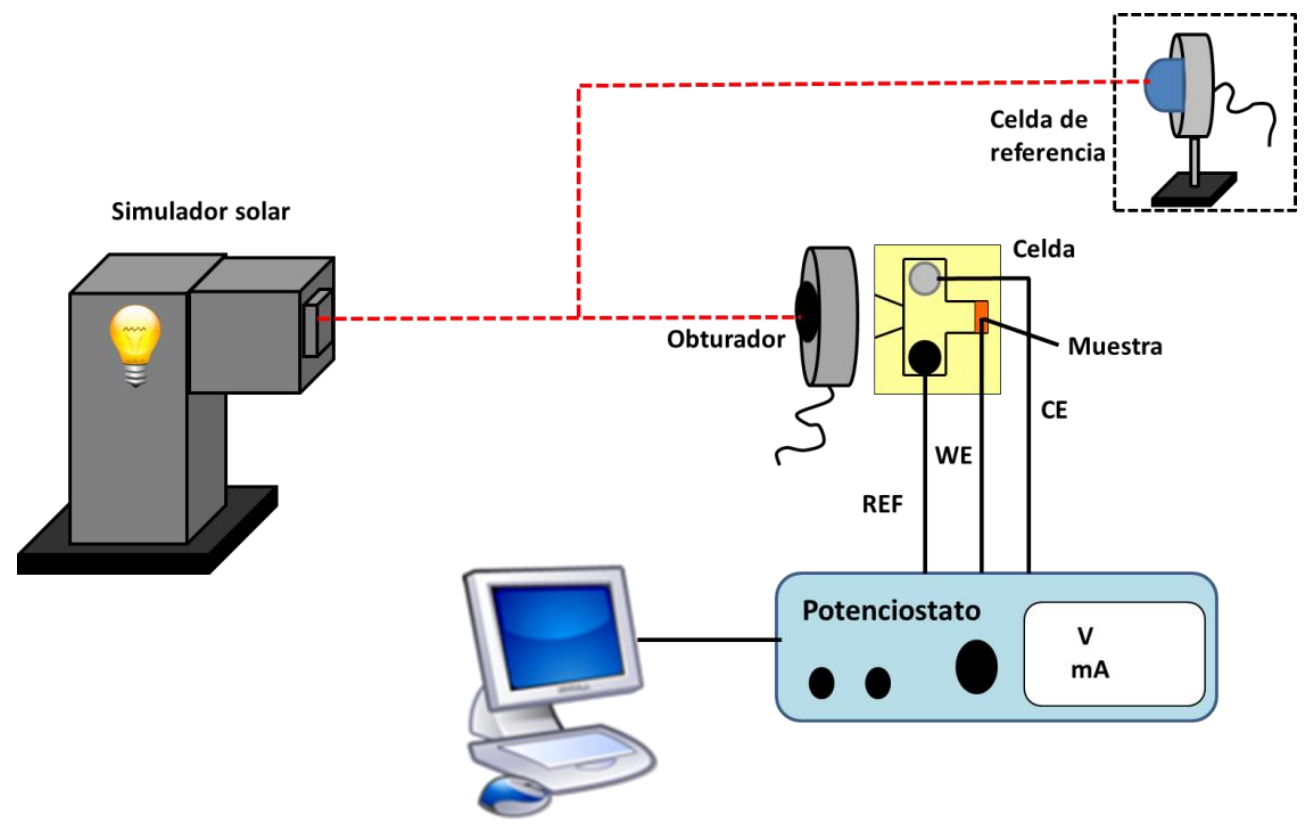

Figura 3.14. Equipo utilizado para medir las impedancias.

\subsubsection{El potenciostato}

El componente central en cada configuración fotoelectroquímica es el potenciostato. Una comprensión básica de su funcionamiento interno es muy útil para evitar errores comunes y aprovechar al máximo las mediciones. Un diagrama simplificado de un potenciostato se muestra en la Figura 3.15. La mayoría de los potenciostatos tienen tres o cuatro cables de prueba que se conectan a la célula o dispositivo bajo prueba. Los tres cables que siempre están presentes son los de los electrodos de trabajo (WE), contraelectrodo (CE) y de referencia (REF). El cuarto opcional es básicamente un segundo electrodo de referencia que "detecta" el potencial del electrodo de trabajo. Si no hay un cuarto cable de prueba, significa que está conectado internamente a la conexión del electrodo de trabajo. El objetivo del potenciostato es medir la diferencia de potencial entre las entradas, y asegura que se mantenga igual a la diferencia de potencial deseada ajustando el potencial en la salida. La diferencia de potencial deseada es la suma 
del potencial establecido por el usuario y el potencial presente en la entrada de modulación. Por lo tanto, para una simple medición de dos electrodos en un dispositivo fotoelectrocatalítico, los cables REF y CE deben estar unidos para medir la diferencia de potencial entre WE y CE. Para una medición de tres electrodos, se desconoce el potencial del contraelectrodo. En la mayoría de los casos esto no es un problema, ya que solo interesan los procesos que tienen lugar en el electrodo de trabajo. El contraelectrodo solo sirve para suministrar el voltaje y la corriente necesarios. Las entradas REF y SENSE consumen una corriente insignificante, por lo que toda la corriente a través de la celda pasa a través de la resistencia de rango de intensidad, $\mathrm{R}_{\mathrm{i}}$, que convierte la corriente en voltaje. Paralelo a esta resistencia hay un condensador, $C_{\text {filtro, }}$ cuyo valor a menudo puede ser seleccionado (o completamente desconectado) por el usuario. Junto con $R_{i}$, esto forma un conjunto resistencia-condensador $(\mathrm{R}-\mathrm{C})$ que reduce el ruido y proporciona mediciones más estables. La mayoría de los fabricantes especifican los valores de $R_{i}$ y $C_{\text {filtro }}$ porque sus valores afectan la velocidad del potenciostato [46].

Figura 3.15. Diagrama simplificado del funcionamiento del potenciostato.

\subsubsection{El simulador solar}

La luz solar real no tiene la misma intensidad y distribución espectral en todo el

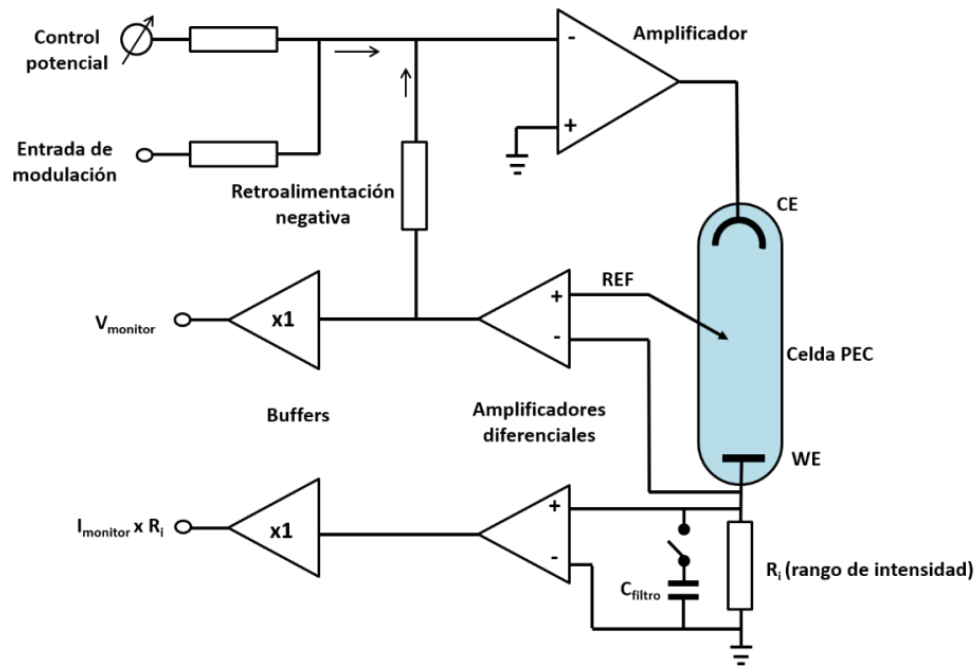

mundo, por tanto, para facilitar comparaciones significativas del rendimiento de 
los dispositivos, las características de rendimiento generalmente se citan para las llamadas condiciones AM 1.5G. Esto significa "masa de aire 1.5 global", y se refiere a la distribución espectral y la intensidad de la luz solar en una superficie inclinada orientada hacia el sur después de que haya recorrido 1.5 veces el grosor de la atmósfera terrestre. El espectro AM 1.5G incluye las contribuciones directas y difusas de la luz solar incidente, y tiene una intensidad total integrada de 100 $\mathrm{mW} \cdot \mathrm{cm}^{-2}$. Dado que la luz solar real AM $1.5 \mathrm{G}$ no está disponible en todo momento y en todos los lugares, se utilizan simuladores solares. Las lámparas de xenón son ampliamente aceptadas para brindar la mejor combinación con el espectro solar. Los filtros ópticos se utilizan para optimizar la forma espectral general y para eliminar (hasta cierto punto) las líneas afiladas en el espectro de emisión de xenón. Algunas veces se usa un filtro de agua para eliminar el exceso de intensidad espectral en la región IR. Al elegir un simulador solar para la investigación, se debe considerar cuidadosamente la orientación del puerto de salida de luz. La mayoría de los simuladores solares tienen su puerto de salida orientado verticalmente, es decir, brillando "hacia abajo". Esto es conveniente para las células solares de estado sólido, pero es un poco complicado para las celdas FEC que contienen un electrolito líquido: se tendría que usar un espejo ya que el fotoelectrodo está montado verticalmente en la mayoría de las celdas FEC. Afortunadamente, varios fabricantes ofrecen la posibilidad de que la luz salga de lado. En la Figura 3.16 se muestra un esquema del simulador solar utilizado [46]. 


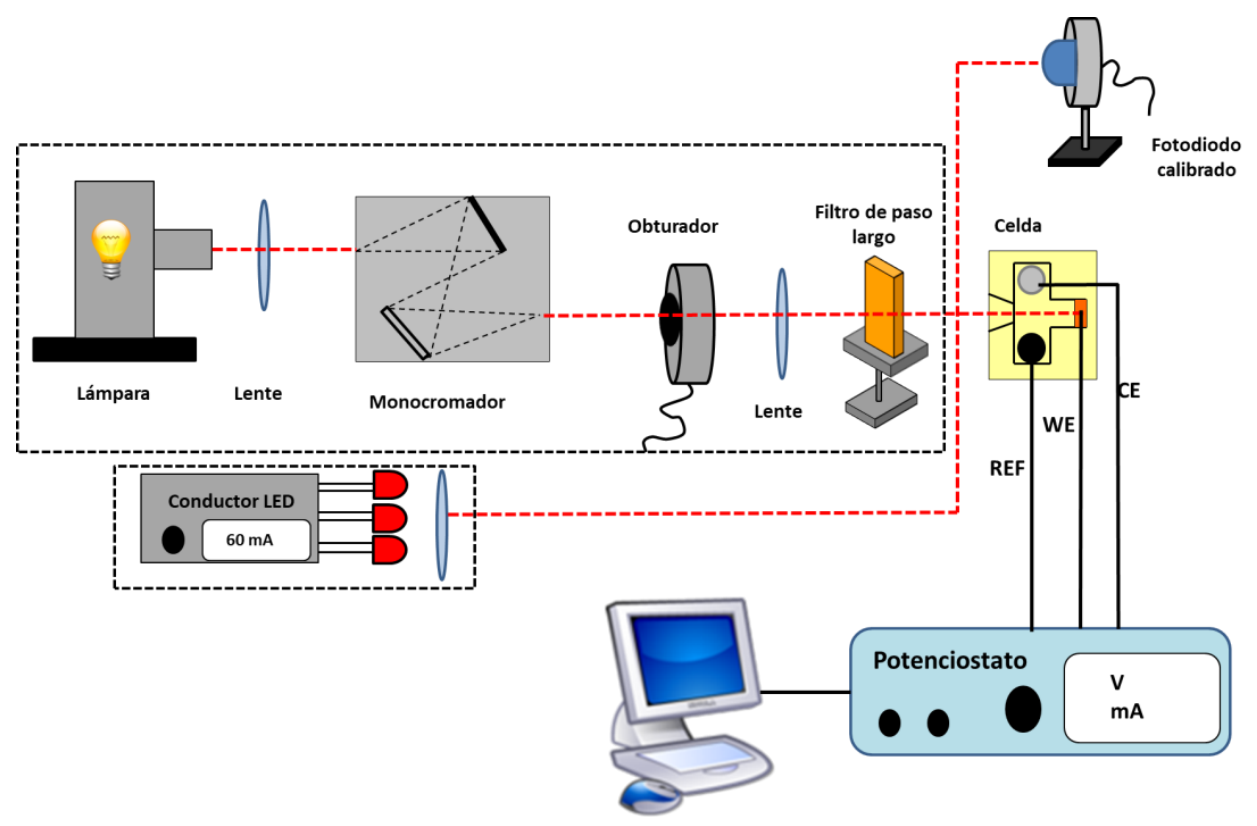

Figura 3.16. Esquema del simulador solar utilizado.

Finalmente, en una cubeta de cuarzo, que actuó como reactor, se introdujo la disolución de trabajo para la realización de estas medidas. En esa cubeta se sumergieron también el electrodo de trabajo (las nanoestructuras obtenidas), el contraelectrodo (una punta de platino), el electrodo de referencia de plata/cloruro de plata $(\mathrm{Ag} / \mathrm{AgCl})(3 \mathrm{M} \mathrm{KCl})$ y un agitador magnético. El reactor electroquímico se situó dentro de una caja metálica con el fin de evitar la exposición a la luz ambiental y ruido electromagnético exterior. Los valores de los parámetros característicos fueron los siguientes:

- Potencial: $1 \mathrm{~V}$.

- Los ensayos se realizaron en condiciones de iluminación solar simulada AM $1.5\left(100 \mathrm{~mW} \cdot \mathrm{cm}^{-2}\right)$ utilizando un simulador solar (LOT, LSE340/850.27B).

- Tiempo hasta alcanzar un estado estacionario: $30 \mathrm{~min}$.

- Frecuencia: desde $10 \mathrm{KHz}$ hasta $10 \mathrm{mHz}$.

- $10 \mathrm{mV}$ de amplitud de la señal. 


\subsection{Análisis de Mott-Schottky}

Finalmente, todas las muestras se analizaron empleando la teoría de MottSchottky para describir la naturaleza semiconductora del recubrimiento. Esta teoría permite la determinación de la densidad portadora $\left(N_{b}\right)$ a partir de la representación de la capacitancia de la región de carga espacial $\left(C_{s c}\right)$ en función del potencial aplicado como se muestra en la ecuación (3.17) referida a un semiconductor de tipo $\mathrm{n}$ [47].

$$
\frac{1}{C_{S C}^{2}}=\frac{2 N_{A}}{N_{b} F} \cdot\left(\left(E-E_{f b}\right)-\frac{R T}{F}\right.
$$

donde $\mathrm{N}_{\mathrm{A}}$ es el número de Avogadro, $\mathrm{F}$ es la constante de Faraday, $\mathrm{R}$ la constante de Boltzmann, $\mathrm{T}$ la temperatura absoluta y $\mathrm{E}_{\mathrm{fb}}$ el potencial de banda plana. Además, según la ecuación (3.18) se establece una relación para la capacitancia $C$ obtenida del circuito eléctrico equivalente para el recubrimiento, con capacitancia $\mathrm{C}_{\mathrm{sc}}$ y $\mathrm{C}_{\mathrm{H}}$ (capacitancia de la capa de Helmholtz). Pero la capacitancia de la región de carga espacial es mucho menor que la de la capa de Helmholtz, por tanto, el término $1 / C_{H}$ es despreciable frente al término $1 / C_{s c}$.

$$
\frac{1}{C^{2}}=\frac{1}{C_{S C}^{2}}+\frac{1}{C_{H}^{2}}
$$

Por lo tanto, una gráfica de $1 / \mathrm{C}_{\mathrm{sc}}{ }^{2}$ frente a $\mathrm{E}_{\mathrm{fb}}$ muestra una línea recta a partir de la cual se puede determinar $\mathrm{E}_{\mathrm{fb}}$ a partir de la ordenada en el origen nombrada como b. El valor de $\mathrm{N}_{\mathrm{b}}$ también se puede calcular a partir de la pendiente, llamada $m$. Esta relación permite establecer el $N_{b}$ y el $E_{f b}$ como se muestra en las ecuaciones (3.19) y (3.20), respectivamente $[48,49]$.

$$
\begin{gathered}
m=\frac{2 N_{A}}{N_{b} F \varepsilon_{r} \varepsilon_{0}} \rightarrow N_{b}=\frac{2 N_{A}}{m F \varepsilon_{r} \varepsilon_{0}} \\
b=\frac{2 N_{A}}{N_{b} F \varepsilon_{r} \varepsilon_{0}} \cdot E_{f b} \rightarrow E_{f b}=\frac{N_{b} F \varepsilon_{r} \varepsilon_{0} b}{2 N_{A}}
\end{gathered}
$$

donde $\varepsilon_{\mathrm{r}}$ la constante dieléctrica relativa del recubrimiento y $\varepsilon_{0}$ la permitividad al vacío. 
En la Figura 3.17 se muestra esta representación en función de si el semiconductor que se está analizando es de tipo $\mathrm{n}$ o tipo $\mathrm{p}$. En el caso de obtener una pendiente positiva, estaría indicando que se trata de un semiconductor de tipo $n$, mientras que, si es negativa, indicaría que es un semiconductor de tipo $p$ $[50,51]$.

Semiconductor tipo $\mathrm{n}$

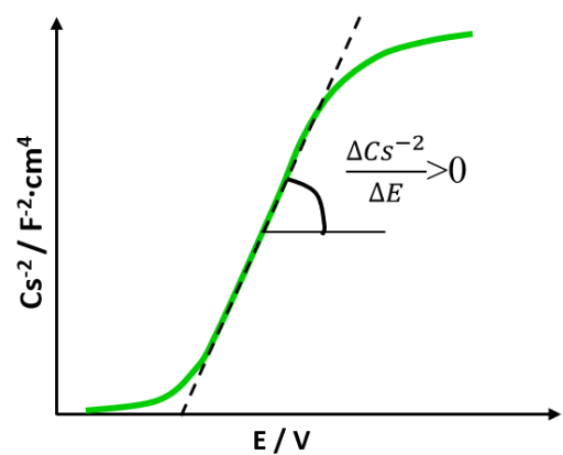

Semiconductor tipo $p$

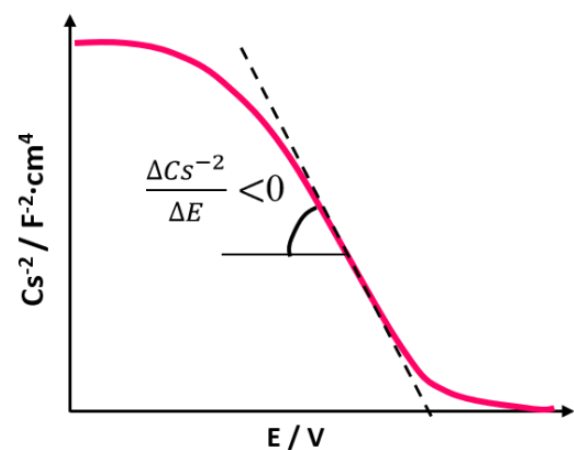

Figura 3.17. Representación en función si el semiconductor es tipo n o tipo p.

Una vez explicados los fundamentos de esta técnica, a continuación, se indican las condiciones experimentales usadas. Los ensayos de Mott-Schottky se realizaron en una celda electroquímica con una configuración de tres electrodos, donde las nanoestructuras de $\mathrm{WO}_{3}$ eran el electrodo de trabajo, el contraelectrodo usado fue una punta de platino, el electrodo de referencia fue un electrodo de $\mathrm{Ag} / \mathrm{AgCl}$ ( $3 \mathrm{M} \mathrm{KCl}$ ) y el electrolito utilizado fue $0.1 \mathrm{M} \mathrm{H}_{2} \mathrm{SO}_{4}$. Con el uso de un potenciostato se pudieron realizar las medidas aplicando un barrido de potencial que iba desde $0.7 \mathrm{~V}$ hasta $0.1 \mathrm{~V}$ con una velocidad de $50 \mathrm{mV} \cdot \mathrm{s}^{-1} \mathrm{y}$ una amplitud de $10 \mathrm{mV}$. El equipo utilizado es el mismo que se usó para llevar a cabo la técnica de PEIS, mostrado en la Figura 3.14.

\subsection{Microscopía de Fuerza Atómica (AFM).}

Se trata de una técnica de caracterización superficial que obtiene las imágenes de la superficie gracias a la interacción de una punta con la superficie de la muestra. Esta técnica puede realizar medidas en escala nanométrica o incluso atómica. Para realizar las medidas no requiere de ningún tratamiento previo de la muestra ni realizar vacío. Además, es capaz de mapear tridimensionalmente la superficie. 
Con la microscopía de fuerza atómica se obtienen imágenes con resoluciones atómicas de $10^{-10} \mathrm{~m}$ o una décima parte de nanómetro. Este método el instrumento posee una punta, integrada en el extremo de un cantilever en donde los potenciales interatómicos se desarrollan entre los átomos de la punta y los átomos de la superficie $[52,53]$.

A medida que la punta se mueve a través de la superficie, los potenciales interatómicos obligan al cantilever a saltar hacia arriba y hacia abajo conforme encuentra cambios en los contornos de la superficie. Por lo tanto, midiendo la desviación del cantilever, se pueden trazar las características topográficas de la superficie. En la Figura 3.18 se muestra una configuración básica de AFM. La fuerza atómica entre una muestra y la punta se mide con un láser y un detector para controlar el movimiento del cantilever. El soporte de la muestra mueve la muestra hacia arriba y hacia abajo a través de un tubo de exploración piezoeléctrico para mantener la fuerza de interacción a un nivel preseleccionado. Finalmente, se puede construir una imagen tridimensional registrando el movimiento del cantilever en la dirección $Z$ en función de la posición $X$ e $Y$ de la muestra. Teóricamente para cualquier material que tenga cierta rigidez, dicho instrumento siempre es capaz de producir imágenes de superficie con resoluciones atómicas.

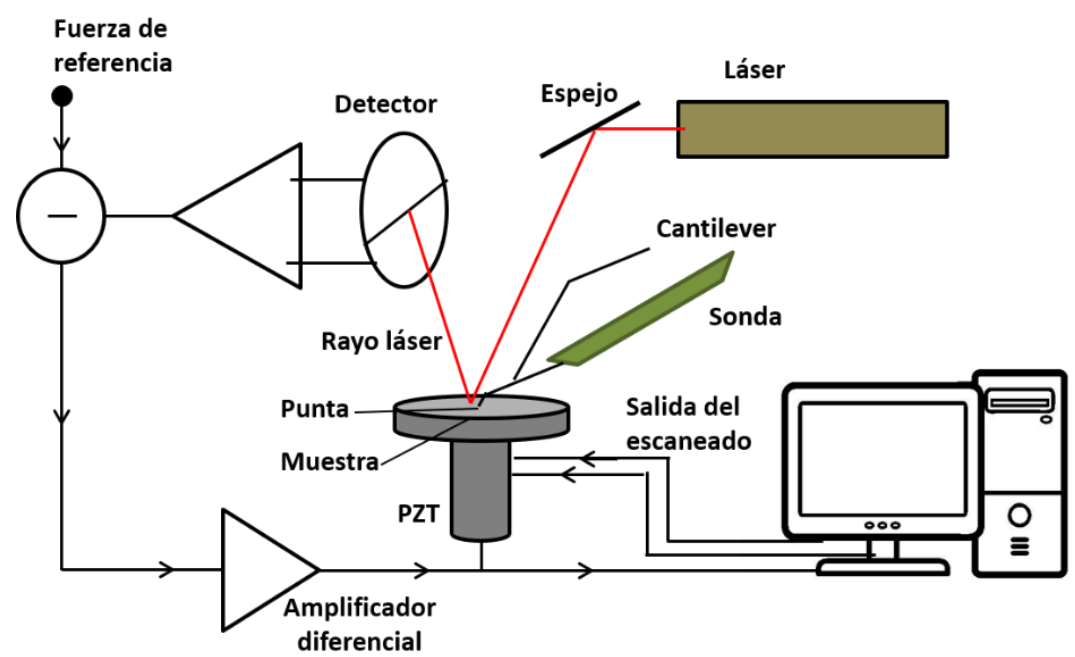

Figura 3.18. Configuración básica de AFM. 
El diodo láser del cabezal AFM se reemplaza por el láser He-Ne conectado al cabezal AFM con una fibra óptica monomodo. Esto reduce el ruido que afecta a la estabilidad del diodo láser. El chip en el cantilever está pegado al soporte de media luna que se sujeta a los imanes en el cabezal AFM (Figura 3.19).

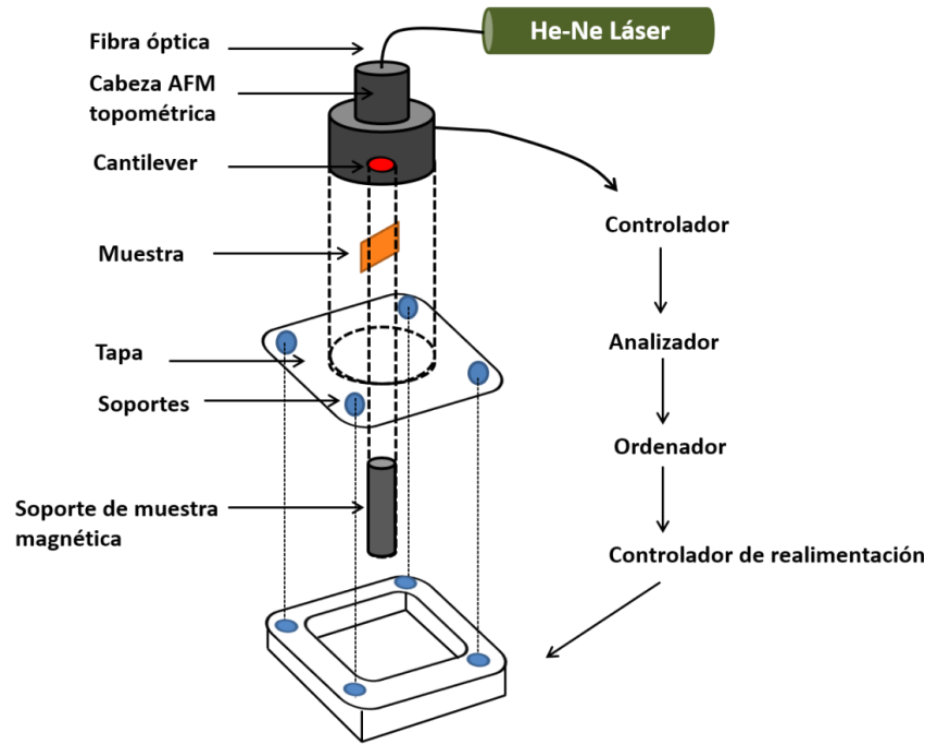

Figura 3.19. Detalles del equipo de AFM.

El AFM puede operar en tres modos [54]:

\subsubsection{Modo de contacto (AFM Contact)}

En este modo, la sonda se arrastra por la superficie. Durante el escaneo, se mantiene una curva constante en el cantilever. La curva en el cantilever corresponde a un desplazamiento de la punta de la sonda (zt) en relación con un cantilever no flexionado en su posición inicial.

La fuerza normal aplicada es $p=k z t$, donde $k$ es la constante de resorte en cantilever. A medida que cambia la topografía de la muestra, el escáner z mueve la posición relativa de la punta o la muestra para mantener una desviación constante. El movimiento del escáner $z$ es directamente proporcional a la topografía de la muestra. Usando este mecanismo de retroalimentación, la topografía de la muestra se mapea durante el escaneo asumiendo que el 
movimiento del cantilever corresponde directamente a la topografía de la muestra [55]. Existen ciertos inconvenientes asociados con este modo de operación, tales como:

(i) Existe la posibilidad de contaminación de la superficie. El daño y la deformación de las muestras pueden ocurrir durante la formación de imágenes en modo de contacto en el aire porque se debe aplicar una fuerza significativa para superar los efectos de la contaminación de la superficie (humedad de la superficie).

(ii) La combinación de la fuerza normal y la fuerza lateral creada al arrastrar la punta de la sonda a través de la muestra generan tensiones de contacto elevadas que pueden dañar la muestra, la punta o ambas.

\subsubsection{Modo sin contacto (AFM AC)}

El cantilever vibra cerca de su frecuencia de resonancia (aproximadamente 100 $\mathrm{kHz}$ ). La separación entre la muestra y la punta es del orden de 1-10 nm. La punta oscila justo por encima de la capa de contaminación superficial. La frecuencia de resonancia y la amplitud del cantilever oscilante cambian a medida que se acerca a la superficie debido a las interacciones con fuerzas débiles de largo alcance. La amplitud o la frecuencia de resonancia se mantienen constantes a través del circuito de retroalimentación y el escáner. El movimiento del escáner se utiliza para generar la imagen topográfica. La constante del resorte " $\mathrm{k}$ " es mayor que en el modo de contacto para reducir la tendencia de la punta a ser empujada hacia la superficie por fuerzas atractivas [56]. Los inconvenientes asociados con este modo son:

(i) La combinación de fuerzas débiles interactivas de Van der Waal y grandes constantes de resorte hace que la señal sea pequeña, lo que provoca una retroalimentación inestable y velocidades de exploración más lentas.

(ii) La resolución lateral es menor que la del modo de contacto debido a la separación entre la punta y la muestra. 


\subsubsection{Modo de fuerza pulsada (DPFM)}

Este modo es adecuado para obtener imágenes de muestras blandas. Aunque la resolución es similar al modo de contacto, las fuerzas aplicadas son más bajas. El cantilever oscila cerca de su frecuencia de resonancia, pero la amplitud de oscilación es mucho mayor que en el modo sin contacto. La punta hace contacto con la superficie durante muy poco tiempo en cada ciclo de oscilación. La interacción punta-muestra altera la amplitud, la frecuencia de resonancia y el ángulo de fase de la palanca oscilante. La amplitud del cantilever es tal que la sonda mantiene suficiente energía para que la punta golpee y salga de la capa de contaminación de la superficie [52,57].

Por tanto, una vez sintetizadas todas las muestras, se analizaron mediante AFM. Las condiciones experimentales que se aplicaron para poder obtener las imágenes AFM de cada una de las muestras fueron las siguientes:

- Las medidas de AFM se realizaron utilizando el equipo Witec en modo AC.

- El tamaño de grano y la rugosidad de la superficie de las películas depositadas se determinan en un área de escaneo de $5 \mu \mathrm{m} \times 5 \mu \mathrm{m}$.

- SetPoint de $0.5 \mathrm{~V}$.

- Ganancias i-Gain y p-Gain son del $5 \%$.

- La Amplitud que se fija es de $0.55 \mathrm{Vpp}$.

- Líneas obtenidas por imagen: 256.

- Velocidad de escaneo: $0.5 \mathrm{~s} /$ línea.

\section{Procedimiento de degradación de los pesticidas.}

El proceso de degradación consistió en aplicar la técnica de fotoelectrocatálisis con el fin de degradar los pesticidas organofosforados elegidos (diazinon, clorfenvinfos, fosmet y fenamifos) que son tóxicos y nocivos para el medioambiente y el ser humano. Con el fundamento de esta técnica descrito en el capítulo 1.4.5, se explican a continuación los pasos seguidos para llevar a cabo la degradación.

En primer lugar, se preparó la disolución a degradar con una concentración de pesticida de $20 \mathrm{ppm}$ y una concentración de $\mathrm{H}_{2} \mathrm{SO}_{4}$ de $0,1 \mathrm{M}$. Una vez preparada la 
disolución se introdujeron $14 \mathrm{~mL}$ en una cubeta de cuarzo que actuó como reactor. En esa cubeta se sumergieron también el electrodo de trabajo (las nanoestructuras obtenidas), el contraelectrodo (la punta de platino), el electrodo de referencia y un agitador magnético. Esta cubeta se situó a $30 \mathrm{~cm}$ del simulador solar para conseguir una intensidad total de $100 \mathrm{~mW} \cdot \mathrm{cm}^{-2}$ y simular las llamadas condiciones AM 1.5G.

Este electrodo de trabajo se preparó uniendo a la base de la muestra donde estaban las nanoestructuras un cable de cobre mediante cinta adhesiva de cobre. Una vez unidos, se teflonó todo para que solo quedase en contacto con la disolución la superficie con las nanoestructuras de óxido de wolframio.

Una vez todo listo, se encendió el simulador solar y se conectaron los cables del potenciostato a los electrodos para aplicar $1 \mathrm{~V}$ y comenzar así la degradación. El montaje experimental es el mismo que el utilizado para el análisis de PEIS y de Mott-Schottky, mostrado en la Figura 3.14.

\subsection{Técnicas de seguimiento de la degradación.}

Durante la degradación, así como después de ella se han utilizado dos técnicas analíticas con el fin de explicar los procesos que se estaban produciendo y caracterizar posteriormente los nuevos productos de degradación obtenidos.

\subsubsection{Espectroscopía Ultravioleta-Visible.}

Para controlar el proceso de degradación descrito anteriormente se utilizó la técnica de espectroscopia Visible y Ultravioleta (UV-Vis). Cada media hora se tomaba muestra para medir en el espectrofotómetro Ultravioleta-Visible Unicam UV4 UV/Vis el espectro asociado a esa concentración y seguir el proceso de degradación. El tiempo total de degradación fue de 6 horas.

El fundamento de la espectroscopía se debe a la capacidad de las moléculas para absorber radiaciones, entre ellas las radiaciones dentro del espectro UV-Visible. Las longitudes de onda de las radiaciones que una molécula puede absorber y la eficiencia con la que se absorben dependen de la estructura atómica y de las condiciones del medio ( $\mathrm{pH}$, temperatura, fuerza iónica, constante dieléctrica), por lo que dicha técnica constituye un valioso instrumento para la determinación y caracterización de moléculas [58]. Para ello, se utiliza la ley de Beer-Lambert (ec. 
3.21) que relaciona de forma empírica la absorción de luz con las propiedades del material o compuesto analizado.

$$
A=\varepsilon \cdot l \cdot c
$$

donde $\varepsilon$ es el coeficiente de absorción molar, c la concentración y I la distancia recorrida por la radiación, es decir longitud de la celda. Esta ley determina que para el caso de un mismo compuesto la absorbancia (A) es directamente proporcional a la concentración. En la Tabla 3.2 se indican las longitudes de onda con el color absorbido y transmitido correspondiente.

Tabla 3.2. Rango de longitudes de onda con su correspondiente color absorbido y transmitido.

\begin{tabular}{|c|c|c|}
\hline $\begin{array}{c}\text { Rango de longitudes de } \\
\text { Onda }(\mathbf{n m})\end{array}$ & Color absorbido & $\begin{array}{c}\text { Color transmitido } \\
\text { (observado) }\end{array}$ \\
\hline $100-190$ & Ultravioleta del vacío & Ninguno \\
$190-380$ & Ultravioleta Cercano & Ninguno \\
$380-435$ & Violeta & Amarillo-Verde \\
$435-480$ & Azul & Amarillo \\
$480-500$ & Verde-Azul & Naranja-Rojo \\
$500-560$ & Verde & Púrpura \\
$560-580$ & Amarillo-Verde & Violeta \\
$580-595$ & Amarillo & Azul \\
$595-650$ & Naranja & Verde-Azul \\
$650-780$ & Rojo & Azul-Verde \\
\hline
\end{tabular}

La base principal de la espectroscopía UV y Visible se corresponde con las transiciones electrónicas entre los diferentes niveles energéticos de un átomo.

Se llaman grupos cromóforos a los grupos de átomos que producen la absorción en el UV próximo. La mayoría de los cromóforos potenciales son grupos insaturados y heteroatómicos que poseen pares de electrones sin compartir.

Al formar un enlace químico dos átomos, se combinan los orbitales atómicos de cada átomo con el fin de formar dos orbitales moleculares, el orbital enlazante de baja energía y el antienlazante de energía superior. Entre los orbitales de los átomos se originan enlaces covalentes de dos tipos: enlaces sigma $(\sigma)$ que hace 
referencia al enlace simple de las moléculas orgánicas y resulta del solapamiento frontal de dos orbitales atómicos, y enlaces pi $(\pi)$ que corresponde con el doble enlace en las moléculas orgánicas y son el resultado del solapamiento lateral de orbitales atómicos $\pi[59]$.

Cuando se forma el enlace covalente $(\sigma \circ \pi)$ se efectúan simultáneamente orbitales antienlazantes: $\sigma^{*}$ cuando se trata de orbitales moleculares enlazantes $\sigma$ y $\pi^{*}$ en el momento que se forma un orbital molecular enlazante $\pi$. Existen otro tipo de electrones que no son participes de la formación de enlaces covalentes en una molécula y son conocidos como electrones $n$ o no enlazantes. Al producirse la excitación de los electrones $n, \sigma$ ó $\pi$ se realiza la absorción de energía radiante en el UV o Visible, en donde estos electrones ocupan algunos orbitales antienlazantes.

Cuanto mayor es la energía necesaria para realizar una transición específica, la longitud de onda de la radicación que se tiene que aportar para conseguir esta transición es menor. Se debe tener en cuenta que existen cambios rotacionales y vibracionales en una molécula dando lugar a un espectro de bandas en vez de un espectro de líneas discretas como en el caso de un átomo $[59,60]$.

El procedimiento que se siguió para controlar la degradación de los pesticidas consistió en primer lugar en realizar unos patrones que contenían la sustancia a degradar a diferentes concentraciones con el fin de obtener el espectro para cada concentración al analizarlos con el espectrofotómetro UV-Vis.

A cada patrón preparado se le añadió la cantidad necesaria de $\mathrm{H}_{2} \mathrm{SO}_{4}$ para así obtener una concentración de $0.1 \mathrm{M}$. Una vez obtenida la absorbancia correspondiente a los patrones en el espectrofotómetro, se pasaron las muestras tomadas cada media hora durante los ensayos de degradación de cada pesticida para seguir el proceso de degradación y tener la variación de la concentración con el tiempo.

\subsubsection{Cromatografía de líquidos de alto rendimiento acoplado a un espectrómetro de masas de alta resolución y masa exacta (UHPLC-MS/MS-Q- TOF).}

La cromatografía líquida acoplada a la espectrometría de masas de tiempo de vuelo cuadrupolo es una técnica sensible y eficiente para la detección y 
confirmación de residuos de pesticidas en el agua, en frutas y verduras, en productos farmacéuticos, etc.

Por tanto, la espectrometría de masas por cromatografía líquida de alto rendimiento es una técnica instrumental extremadamente versátil. Como su nombre indica, la instrumentación comprende un cromatógrafo de líquidos de alto rendimiento (UHPLC) conectado, a través de una interfaz adecuada, a un espectrómetro de masas (MS). La principal ventaja que tiene UHPLC/MS es que es capaz de analizar una gama muy amplia de componentes. Las soluciones derivadas de muestras de interés se inyectan en una columna de UHPLC que comprende un tubo estrecho de acero inoxidable (generalmente de $150 \mathrm{~mm}$ de longitud y $2 \mathrm{~mm}$ de diámetro interno, o más pequeño) lleno de finas partículas de sílice modificadas químicamente. Los compuestos se separan en función de su interacción relativa con el recubrimiento químico de estas partículas (fase estacionaria) y el disolvente que se eluye a través de la columna (fase móvil) $[61,62]$. Los componentes que eluyen de la columna cromatográfica se introducen luego en el espectrómetro de masas a través de una interfaz especializada. Las dos interfaces más comunes utilizadas para UHPLC/MS son las interfaces de ionización por electropulverización y de ionización química a presión atmosférica.

La espectrometría de masas (MS) es una técnica analítica que mide la relación masa-carga $(\mathrm{m} / \mathrm{z})$ de partículas cargadas (iones). Aunque hay muchos tipos diferentes de espectrómetros de masas, todos utilizan campos eléctricos o magnéticos para manipular el movimiento de iones producidos a partir de un analito de interés y determinar su $\mathrm{m} / \mathrm{z}$. Los componentes básicos de un espectrómetro de masas son la fuente de iones, el analizador de masas y el detector. En la fuente de iones es donde los componentes de una muestra introducida en un sistema de MS se ionizan mediante haces de electrones, haces de fotones (luces UV), rayos láser o descarga de corona. En el caso de la ionización por electropulverización, la fuente de iones pasa los iones que existen en la solución líquida a la fase gaseosa $[63,64]$. La fuente de iones convierte y fragmenta las moléculas de la muestra neutras en iones en fase gaseosa que se envían al analizador de masas. Mientras que el analizador de masas aplica los campos eléctricos y magnéticos para clasificar los iones por sus masas, el detector mide y amplifica la corriente de iones para calcular la abundancia de cada ion resuelto en masa. El sistema de datos registra, procesa, almacena y muestra datos 
en un ordenador en donde se podrán procesar posteriormente. El esquema del montaje se muestra en la Figura 3.20.

El espectro de masas se puede usar para determinar la masa de los analitos, su composición elemental e isotópica, o para dilucidar la estructura química de la muestra. Entre los muchos tipos diferentes de analizadores de masas, los que encuentran aplicación en los sistemas LC-MS son los analizadores de cuadrupolo, tiempo de vuelo (TOF), trampas de iones y cuadrupolo híbrido-TOF (QTOF) $[62,65]$.

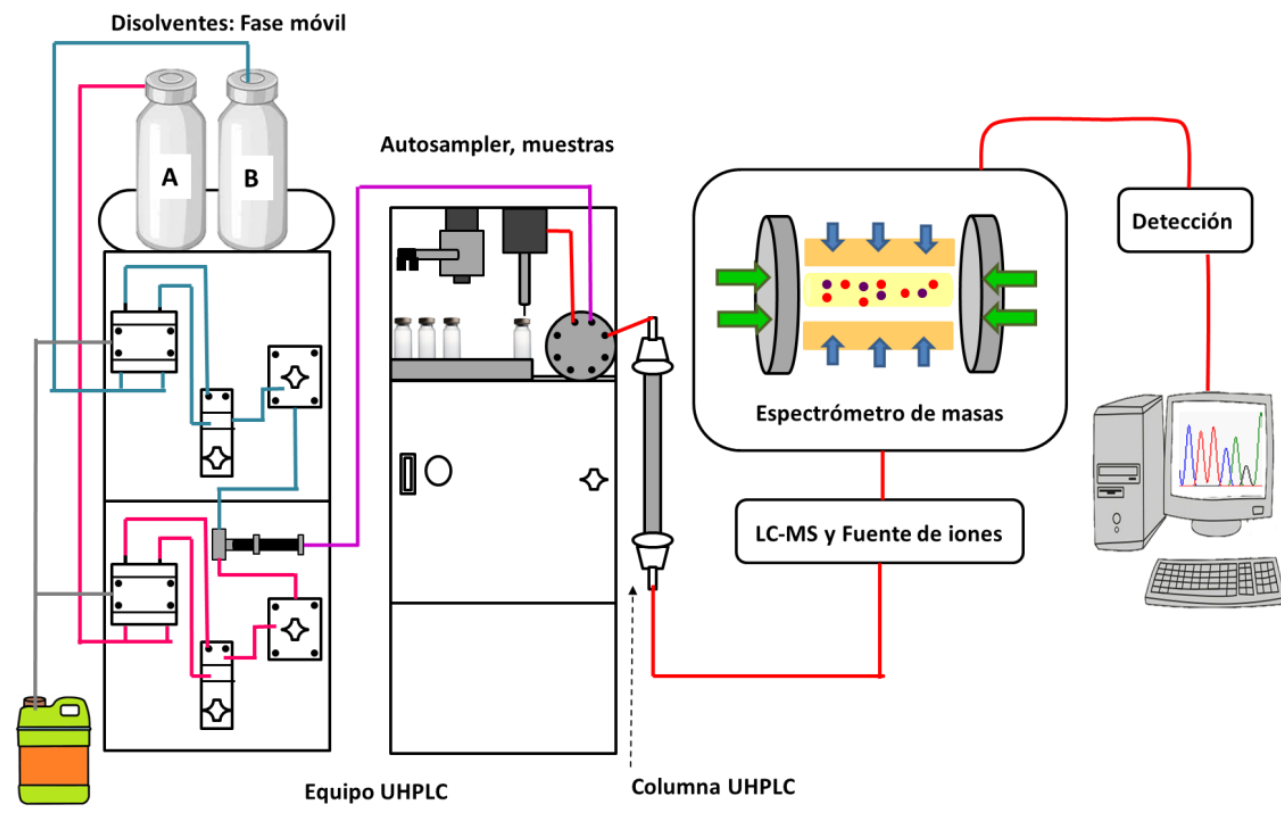

Figura 3.20. Equipo UHPLC-MS/MS.

Las condiciones experimentales que se utilizaron para analizar cada pesticida degradado fueron las siguientes:

- El análisis se realizó con el equipo Agilent 1290 Infinity equipado con una columna analítica C-18 (Agilent ZORBAX Eclipse Plus) de $50 \mathrm{~mm} \times 2.1 \mathrm{~mm}$ y con $1.8 \mu \mathrm{m}$ de tamaño de partícula.

- Se inyectaban $20 \mu \mathrm{L}$ de cada muestra.

- Las fases móviles utilizadas eran agua ultrapura (A) y acetonitrilo (B) ambos con $0.1 \%(\mathrm{v} / \mathrm{v})$ de ácido acético. Se usó una composición inicial de las fases móviles de $95 \%$ de A y $5 \%$ de B durante 3 min. Luego, esta 
composición cambio a $90 \%$ de A y $10 \%$ de B y finalmente, en 25 minutos y mediante un gradiente lineal, la composición final alcanzó un 100\% de B. Una vez alcanzó esta composición se mantuvo durante 3 minutos.

- La velocidad de flujo fue de $0.5 \mathrm{ml} \cdot \mathrm{min}^{-1}$.

- El UHPLC estaba conectado a un espectrómetro de masas de tiempo de vuelo (TOF) que operaba en modo de ionización positiva, utilizando los siguientes parámetros de operación:

- Voltaje capilar $4000 \mathrm{~V}$

- Presión del nebulizador 40 psi

- Caudal de gas de secado $9 \mathrm{~L} \mathrm{~min}^{-1}$

- Temperatura del gas $325^{\circ} \mathrm{C}$

- Voltaje del skimmer $65 \mathrm{~V}$

- Octopolar rf $250 \mathrm{~V}$

- Voltaje del fragmento $190 \mathrm{~V}$

- Se registraron espectros de masas precisos en el rango de 70 a $1200 \mathrm{~m} / \mathrm{z}$

\section{Referencias}

1. Montgomery, D.C. Design and Analysis of Experiments Eighth Edition; 2012; Vol. 2; ISBN 9781118146927.

2. Gutiérrez Pulido, Humberto; de la Vara Salazar, R. Análisis y diseño de experimentos; McGrawHill, 2008; ISBN 9789701065266.

3. Kuehl, R.O. Design of Experiments: Statistical Principles of Research Design and Analysis; 2001; Vol. 43; ISBN 0534368344.

4. Mendes, A.; Andrade, L.; Lopes, T. Dynamic phenomenological modeling of PEC cells for water splitting under outdoor conditions. Energy Procedia 2012, 22, 23 34, doi:10.1016/j.egypro.2012.05.227.

5. Kalanur, S.S.; Duy, L.T.; Seo, H. Recent Progress in Photoelectrochemical Water Splitting Activity of WO3 Photoanodes; Springer US, 2018; Vol. 61; ISBN 1124401809501.

6. $\mathrm{Ng}, \mathrm{C} . ; \mathrm{Ng}, \mathrm{Y} . \mathrm{H} . ;$ Iwase, A.; Amal, R. Influence of Annealing Temperature of $\mathrm{WO}_{3}$ in Photoelectrochemical Conversion and Energy Storage for Water Splitting. Appl. Mater. interfaces 2013, 5, 5269-5275, doi:dx.doi.org/10.1021/am401112q.

7. Sánchez Martínez, D.; Torres Guerra, L.; Zarazúa Morín, M.; Gómez Solís, C. 
Influencia del método de síntesis sobre la morfología y propiedades fotocatalíticas del $\mathrm{WO}_{3}$. Cienc. UANL 2015, 18, 40-47.

8. Fernández-Domene, R.M.; Sánchez-Tovar, R.; Lucas-Granados, B.; García-Antón, J. Improvement in photocatalytic activity of stable $\mathrm{WO}_{3}$ nanoplatelet globular clusters arranged in a tree-like fashion: Influence of rotation velocity during anodization. Appl. Catal. B Environ. 2016, 189, 266-282, doi:10.1016/j.apcatb.2016.02.065.

9. Fernández-Domene, R.M.; Sánchez-Tovar, R.; Segura-Sanchís, E.; García-Antón, J. Novel tree-like $\mathrm{WO}_{3}$ nanoplatelets with very high surface area synthesized by anodization under controlled hydrodynamic conditions. Chem. Eng. J. 2016, 286, 59-67, doi:10.1016/j.cej.2015.10.069.

10. Fernández-Domene, R.M.; Sánchez-Tovar, R.; Lucas-Granados, B.; RosellóMárquez, G.; García-Antón, J. A simple method to fabricate high-performance nanostructured $\mathrm{WO}_{3}$ photocatalysts with adjusted morphology in the presence of complexing agents. Mater. Des. 2017, 116, 160-170, doi:10.1016/j.matdes.2016.12.016.

11. Caramori, S.; Cristino, V.; Meda, L.; Tacca, A.; Argazzi, R.; Bignozzi, C.A. Efficient anodically grown $\mathrm{WO}_{3}$ for photoelectrochemical water splitting. Energy Procedia 2012, 22, 127-136, doi:10.1016/j.egypro.2012.05.214.

12. Memar, A.; Phan, C.M.; Tade, M.O. Controlling particle size and photoelectrochemical properties of nanostructured $\mathrm{WO}_{3}$ with surfactants. Appl. Surf. Sci. 2014, 305, 760-767, doi:10.1016/j.apsusc.2014.03.194.

13. Zhang, X.; Chandra, D.; Kajita, M.; Takahashi, H.; Dong, L.; Shoji, A.; Saito, K.; Yui, T.; Yagi, M. Facile and simple fabrication of an efficient nanoporous $\mathrm{WO}_{3}$ photoanode for visible-light-driven water splitting. Int. J. Hydrogen Energy 2014, 39, 20736-20743, doi:10.1016/j.ijhydene.2014.06.062.

14. Zhang, J.; Salles, I.; Pering, S.; Cameron, P.J.; Mattia, D.; Eslava, S. Nanostructured $\mathrm{WO}_{3}$ photoanodes for efficient water splitting: Via anodisation in citric acid. RSC Adv. 2017, 7, 35221-35227, doi:10.1039/c7ra05342h.

15. Afify, H.H.; Hassan, S.A.; Obaida, M.; Moussa, I.; Abouelsayed, A. Preparation, characterization, and optical spectroscopic studies of nanocrystalline tungsten oxide $\mathrm{WO}_{3}$. Opt. Laser Technol. 2019, 111, 604-611, doi:10.1016/j.optlastec.2018.10.036.

16. Zhou, J.; Lin, S.; Chen, Y.; Gaskov, A.M. Facile morphology control of $\mathrm{WO}_{3}$ nanostructure arrays with enhanced photoelectrochemical performance. Appl. Surf. Sci. 2017, 403, 274-281, doi:10.1016/j.apsusc.2017.01.209.

17. Huirache Acuña, R.; Lara Romero, J.; Rivera Muñoz, E.M.; Reyes Francis, E.; Franco 
Casanova, K.M.; García Martínez, I.P.; Castro Cedeño, B.; Paraguay Delgado, F. Síntesis hidrotérmica de nanoestructuras de óxido de wolframio $\left(\mathrm{WO}_{3}\right)$ monoclínico. Memorias del XXXIV encuentro Nac. y II Congr. Int. la AMIDIQ 2013, 2076-21079.

18. Zhu, T.; Nan, M.; Wen, Y.; Chan, E. Electrochemically synthesized tungsten trioxide nanostructures for photoelectrochemical water splitting : Influence of heat treatment on physicochemical properties, photocurrent densities. Colloids Surfaces A Physicochem. Eng. Asp. 2015, 484, 297-303, doi:10.1016/j.colsurfa.2015.08.016.

19. Chai, Y.; Tam, C.W.; Beh, K.P.; Yam, F.K.; Hassan, Z. Effects of thermal treatment on the anodic growth of tungsten oxide films. Thin Solid Films 2015, 588, 44-49, doi:10.1016/j.tsf.2015.04.033.

20. Ahmadi, E.; Yan, C.; Abdul, K.; Lockman, Z. Preparation of anodic nanoporous $\mathrm{WO}_{3}$ film using oxalic acid as electrolyte. J. Alloys Compd. 2017, 704, 518-527, doi:10.1016/j.jallcom.2017.02.123.

21. Naseri, N. Photoresponse enhancing in nanostructured $\mathrm{WO}_{3}$ films by slight change in heating ambient. J. Alloys Compd. 2017, 693, 871-875, doi:10.1016/j.jallcom.2016.09.275.

22. Marsen, B.; Miller, E.L.; Paluselli, D.; Rocheleau, R.E. Progress in sputtered tungsten trioxide for photoelectrode applications. Int. J. Hydrogen Energy 2007, 32, 1310-1315, doi:10.1016/j.ijhydene.2006.01.022.

23. Ma, Z.; Linnenberg, O.; Rokicinska, A.; Kustrowski, P.; Slabon, A. Augmenting the photocurrent of $\mathrm{CuWO}_{4}$ photoanodes by heat treatment in the nitrogen atmosphere. J. Phys. Chem. C 2018, 122, 19281-19288, doi:10.1021/acs.jpcc.8b02828.

24. H.J. Bowley; D.L. Gerrard; J.D. Louden; G. Turrel Practical Raman Spectroscopy. Springer 2012.

25. Qu, M.A.G.S.F. Raman Spectroscopy for Nanomaterials Characterization; Springer, 2012;

26. Edwards, H.G.M. Modern Raman Spectroscopy-a practical approach.Ewen Smith and Geoffrey Dent. John Wiley and Sons Ltd, Chichester, 2005. Pp. 210. ISBN 0471 496685 (cloth, hb); 0471497940 (pbk). J. Raman Spectrosc. 2005, 36, 835-835, doi:10.1002/jrs.1320.

27. Wu, N.; Wyart, Y.; Siozade, L.; Georges, G.; Moulin, P. Characterization of ultrafiltration membranes fouled by quantum dots by confocal laser scanning microscopy. J. Memb. Sci. 2014, 470, 40-51, doi:10.1016/j.memsci.2014.07.001. 
28. Govindarajan, M.; Karabacak, M.; Udayakumar, V.; Periandy, S. FT-IR, FT-Raman and UV spectral investigation: Computed frequency estimation analysis and electronic structure calculations on chlorobenzene using HF and DFT. Spectrochim. Acta - Part A Mol. Biomol. Spectrosc. 2012, 88, 37-48, doi:10.1016/j.saa.2011.11.052.

29. CSIC Principios Generales de la Microscopía Electrónica de Barrido (Scanning Electron Microscope, SEM). Inst. Cienc. Mater. Madrid Lab. Microsc. 2010, 3.

30. Singh, A.K. Experimental methodologies for the characterization of nanoparticles; Eng. Nanoparticles Struct. Prop. Mech. Toxic, 2016;

31. Webb, J; Holgate, J.H. Scanning Electron Microscopy; Encycl. Food Sci. Nutr, 2003;

32. Joseph I. Goldstein, Dale E. Newbury, Joseph R. Michael, Nicholas W.M. Ritchie, John Henry J. Scott, D.C.J. Scanning Electron Microscopy and X-Ray Microanalysis; Springer, 2017;

33. Corcoran, C.J.; Tavassol, H.; Rigsby, M.A.; Bagus, P.S.; Wieckowski, A. Application of XPS to study electrocatalysts for fuel cells. J. Power Sources 2010, 195, 78567879, doi:10.1016/j.jpowsour.2010.06.018.

34. Hantsche, H. Comparison of basic principles of the surface-specific analytical methods: AES/SAM, ESCA (XPS), SIMS, and ISS with X-ray microanalysis, and some applications in research and industry. Scanning 1989, 11, 257-280, doi:10.1002/sca.4950110602.

35. Andrade, J.D. X-ray Photoelectron Spectroscopy (XPS). Surf. Interfacial Asp. Biomed. Polym. 1985.

36. McArthur, S.L. Applications of XPS in bioengineering Sally. Surf. Interface Anal. 2006, 38, 1380-1385, doi:10.1002/sia.

37. Florian J. Günter, Jan Bernd Habedank, David Schreiner, Tobias Neuwirth, R.G. and G.R. Introduction to Electrochemical Impedance Spectroscopy as a Measurement Method for the Wetting Degree of Lithium-Ion Cells. J. Electrochem. Soc 2018, 165, A3249-A3256.

38. Flores, J.M.; Romero, R.D.; Llongueras, J.G. Espectroscopía de impedancia electroquímica en corrosión. J. Chem. Inf. Model. 2014, 41, 3-5, doi:10.3989/collectbot.1989.v17.143.

39. Bond, A.M.; Compton, R.G.; Fiedler, D.A.; Inzelt, G.; Kahlert, H.; Lohse, H.; Lovric, M.; Lovric, S.K.; Marken, F.; Neudeck, A.; et al. Electroanalytical Methods Guide to Experiments and Applications 2nd, revised and extended edition; 2009; ISBN 9783642029141.

40. Kashyap, D.; Dwivedi, P.K.; Pandey, J.K.; Kim, Y.H.; Kim, G.M.; Sharma, A.; Goel, S. 
Application of electrochemical impedance spectroscopy in bio-fuel cell characterization: A review. Int. J. Hydrogen Energy 2014, 39, 20159-20170, doi:10.1016/j.ijhydene.2014.10.003.

41. González-Cortés, A. Electrochemical Impedance Spectroscopy. Agric. Food Electroanal. 2015, 381-419, doi:10.1002/9781118684030.ch14.

42. Bandarenka, A.S. Exploring the interfaces between metal electrodes and aqueous electrolytes with electrochemical impedance spectroscopy. Analyst 2013, 138, 5540-5554, doi:10.1039/c3an00791j.

43. Bertoluzzi, L.; Bisquert, J. Equivalent circuit of electrons and holes in thin semiconductor films for photoelectrochemical water splitting applications. J. Phys. Chem. Lett. 2012, 3, 2517-2522, doi:10.1021/jz3010909.

44. Levinas, R.; Tsyntsaru, N.; Lelis, M.; Cesiulis, H. Synthesis, electrochemical impedance spectroscopy study and photoelectrochemical behaviour of asdeposited and annealed $\mathrm{WO}_{3}$ films. Electrochim. Acta 2017, 225, 29-38, doi:10.1016/j.electacta.2016.12.112.

45. Bertoluzzi, L.; Lopez-Varo, P.; Jiménez Tejada, J.A.; Bisquert, J. Charge transfer processes at the semiconductor/electrolyte interface for solar fuel production: Insight from impedance spectroscopy. J. Mater. Chem. A 2016, 4, 2873-2879, doi:10.1039/c5ta03210e.

46. Krol, R. va de; Grätzel, M. Photoelectrochemical Hydrogen Production; Electronic Materials: Science \& Technology, 2012; ISBN 9781461413790.

47. Uosaki, K. Effects of the Helmholtz Layer Capacitance on the Potential Distribution at Semiconductor/Electrolyte Interface and the Linearity of the Mott-Schottky Plot. J. Electrochem. Soc. 1983, 130, 895-897, doi:10.1149/1.2119853.

48. Albery, W.J.; O'Shea, G.J.; Smith, A.L. Interpretation and use of Mott-Schottky plots at the semiconductor/electrolyte interface. J. Chem. Soc. - Faraday Trans. 1996, 92, 4083-4085, doi:10.1039/FT9969204083.

49. Zhang, Z.; Yates, J.T. Band bending in semiconductors: Chemical and physical consequences at surfaces and interfaces. Chem. Rev. 2012, 112, 5520-5551, doi:10.1021/cr3000626.

50. Dhingra, P.; Singh, P.; Rana, P.J.S.; Garg, A.; Kar, P. Hole-Transporting Materials for Perovskite-Sensitized Solar Cells. Energy Technol. 2016, 4, 891-938, doi:10.1002/ente.201500534.

51. Gelderman, K.; Lee, L.; Donne, S.W. Flat-band potential of a semiconductor: Using the Mott-Schottky equation. J. Chem. Educ. 2007, 84, 685-688, doi:10.1021/ed084p685. 
52. Jagtap, R.N.; Ambre, A.H. Overview literature on atomic force microscopy (AFM): Basics and its important applications for polymer characterization. Indian J. Eng. Mater. Sci. 2006, 13, 368-384.

53. Chung, K.H.; Kim, D.E. Fundamental investigation of micro wear rate using an atomic force microscope. Tribol. Lett. 2003, 15, 135-144, doi:10.1023/A:1024457132574.

54. Benmouna, F.; Dimitrova, T.D.; Johannsmann, D. Nanoscale Mapping of the Mechanical Properties of Polymer Surfaces by Means of AFM Noise Analysis: Spatially Resolved Fibrillation of Latex Films. Langmuir 2003, 19, 10247-10253, doi:10.1021/la034924m.

55. Goodman, D.; Kizhakkedathu, J.N.; Brooks, D.E. Molecular Weight and Polydispersity Estimation of Adsorbing Polymer Brushes by Atomic Force Microscopy. Langmuir 2004, 20, 3297-3303, doi:10.1021/la036164l.

56. Kang, J.; Beers, K.J. Synthesis and characterization of PCL-b-PEO-b-PCL-based nanostructured and porous hydrogels. Biomacromolecules 2006, 7, 453-458, doi:10.1021/bm050637g.

57. Gelbert, M.; Biesalski, M.; Rühe, J.; Johannsmann, D. Collapse of polyelectrolyte brushes probed by noise analysis of a scanning force microscope cantilever. Langmuir 2000, 16, 5774-5784, doi:10.1021/la991664t.

58. Skoog, D.A.; Holler, F.J.; Crouch, S.R. Principios de análisis fundamental; 6th ed.; Cengage learning, 2008; ISBN 9786074813906.

59. Berlett, B.S.; Levine, R.L.; Stadtman, E.R. Use of isosbestic point wavelength shifts to estimate the fraction of a precursor that is converted to a given product. Anal. Biochem. 2000, 287, 329-333, doi:10.1006/abio.2000.4876.

60. Tajeddine, L.; Nemmaoui, M.; Mountacer, H.; Dahchour, A.; Sarakha, M. Photodegradation of fenamiphos on the surface of clays and soils. Environ. Chem. Lett. 2010, 8, 123-128, doi:10.1007/s10311-008-0198-2.

61. Wu, N.; Clausen, A.M. Fundamental and practical aspects of ultrahigh pressure liquid chromatography for fast separations. J. Sep. Sci. 2007, 30, 1167-1182, doi:10.1002/jssc.200700026.

62. Bos, S.J.; Van Leeuwen, S.M.; Karst, U. From fundamentals to applications: Recent developments in atmospheric pressure photoionization mass spectrometry. Anal. Bioanal. Chem. 2006, 384, 85-99, doi:10.1007/s00216-005-0046-1.

63. Thurman, E.M.; Ferrer, I.; Barceló, D. Choosing between atmospheric pressure chemical ionization and electrospray ionization interfaces for the HPLC/MS analysis of pesticides. Anal. Chem. 2001, 73, 5441-5449, doi:10.1021/ac010506f. 
64. Cech, N.B.; Enke, C.G. Practical implications of some recent studies in electrospray ionization fundamentals. Mass Spectrom. Rev. 2001, 20, 362-387, doi:10.1002/mas.10008.

65. Henion, J.; Rule, G. Sample Preparation for LC/MS/MS: Anal. Chem. News Featur. 1998. 



\section{Capítulo 4}

\section{Análisis y discusión de resultados}





\section{Capítulo 4. Análisis y discusión de resultados}

El objetivo de este apartado de la Tesis es analizar cada uno de los datos obtenidos, tanto individuamente como en su conjunto, con el fin de obtener una conclusión clara en cada uno de los objetivos parciales de la presente Tesis. En este capítulo, se tratarán y comentarán datos de tres partes bien diferenciadas. En la primera parte se analizarán los resultados obtenidos durante la caracterización de las diferentes nanoestructuras obtenidas al realizar los ensayos propuestos en el diseño de experimentos. En la segunda parte se compararán y se comentarán los resultados obtenidos al realizar el análisis del diseño de experimentos con el programa Statgraphics Centurion. Y finalmente, se realizará un estudio del proceso de degradación de los 4 pesticidas organofosforados elegidos mediante la técnica de fotoelectrocatálisis analizándose tanto el transcurso de la degradación como sus posibles intermedios. 

1. Caracterización de las nanoestructuras de $\mathrm{WO}_{3}$ 



\section{Caracterización de las nanoestructuras de $\mathrm{WO}_{3}$.}

Con el fin de optimizar la síntesis de nanoestructuras de $\mathrm{WO}_{3}$ se realizó un diseño de experimentos. Como se ha mencionado en el capítulo 3.1, se ha utilizado un diseño $3^{3}$ en el que los factores a variar han sido el ácido utilizado en el electrolito, la temperatura y la atmósfera en el proceso de post-anodizado. A su vez, cada factor se ha variado en tres niveles siendo los experimentos realizados los que se muestran en la Tabla 4.1.

Tabla 4.1. Experimentos realizados variando: tipo de ácido, temperatura y atmósfera de calentamiento.

\begin{tabular}{|c|c|c|}
\hline Ácido & Temperatura & Atmósfera \\
\hline \multirow{9}{*}{$\mathrm{H}_{2} \mathrm{SO}_{4}$} & \multirow{3}{*}{$400^{\circ} \mathrm{C}$} & Aire \\
\hline & & $\mathrm{N}_{2}$ \\
\hline & & $\mathrm{Ar}$ \\
\hline & \multirow{3}{*}{$500^{\circ} \mathrm{C}$} & Aire \\
\hline & & $\mathrm{N}_{2}$ \\
\hline & & $\mathrm{Ar}$ \\
\hline & \multirow{3}{*}{$600^{\circ} \mathrm{C}$} & Aire \\
\hline & & $\mathrm{N}_{2}$ \\
\hline & & $\mathrm{Ar}$ \\
\hline \multirow{9}{*}{$\mathrm{CH}_{4} \mathrm{O}_{3} \mathrm{~S}$} & \multirow{3}{*}{$400^{\circ} \mathrm{C}$} & Aire \\
\hline & & $\mathrm{N}_{2}$ \\
\hline & & $\mathrm{Ar}$ \\
\hline & \multirow{3}{*}{$500^{\circ} \mathrm{C}$} & Aire \\
\hline & & $\mathrm{N}_{2}$ \\
\hline & & $\mathrm{Ar}$ \\
\hline & \multirow{3}{*}{$600^{\circ} \mathrm{C}$} & Aire \\
\hline & & $\mathrm{N}_{2}$ \\
\hline & & $\mathrm{Ar}$ \\
\hline
\end{tabular}


Tabla 4.1. Experimentos realizados variando: tipo de ácido, temperatura y atmósfera de calentamiento (continuación).

\begin{tabular}{|c|c|c|}
\hline \multirow{4}{*}{$400^{\circ} \mathrm{C}$} & Aire \\
\cline { 3 - 3 } & & $\mathrm{N}_{2}$ \\
\cline { 3 - 3 } & & $\mathrm{Ar}$ \\
\cline { 3 - 3 } & \multirow{3}{*}{$500^{\circ} \mathrm{C}$} & Aire \\
\cline { 3 - 3 } & & $\mathrm{N}_{2}$ \\
\cline { 3 - 3 } & & $\mathrm{Ar}$ \\
\cline { 3 - 3 } & \multirow{3}{*}{$600^{\circ} \mathrm{C}$} & $\mathrm{Aire}$ \\
\cline { 3 - 3 } & & $\mathrm{N}_{2}$ \\
\cline { 3 - 3 } & & $\mathrm{Ar}$ \\
\hline
\end{tabular}

\subsection{Transitorio de densidad de corriente.}

En primer lugar, se va a analizar el transitorio de corriente obtenido al anodizar con los diferentes ácidos elegidos $\left(\mathrm{H}_{2} \mathrm{SO}_{4}, \mathrm{CH}_{4} \mathrm{O}_{3} \mathrm{~S}\right.$ y $\left.\mathrm{HNO}_{3}\right)$ ya que se trata de los primeros datos que se obtienen al sintetizar las nanoestructuras y nos dan una idea de cómo se está produciendo el proceso de anodizado, cuantas fases se pueden distinguir o incluso, si hay alguna anomalía durante la síntesis. Estos transitorios de corriente se ven modificados solo en el caso de variar el ácido empleado ya que los otros dos factores del diseño de experimentos se modifican en el proceso de post-anodizado, y, por tanto, las modificaciones se verán en los resultados obtenidos del resto de técnicas empleadas para caracterizar las nanoestructuras.

El anodizado electroquímico es el proceso mediante el cual se modifica la superficie de un material. En esta técnica se crea una capa que protege al material a través del óxido protector de éste. Esta capa protectora se origina mediante procedimientos electroquímicos dotando de una mayor resistencia y durabilidad al material escogido. Este proceso ha despertado mucho interés ya que cuenta con una gran variedad de aplicaciones como son los tradicionales recubrimientos decorativos y de protección, y más novedosas, las aplicaciones en nanotecnología [1]. 
Las propiedades del metal base que se quiera someter a anodizado son de gran relevancia ya que de ellas dependen en gran medida las condiciones experimentales que se adoptarán en el proceso. Durante el anodizado, el wolframio que es el metal base que se utiliza en este estudio, actúa como ánodo, mientras que otro metal químicamente estable como es el platino en este caso, actúa como cátodo.

El potencial aplicado, la temperatura y la naturaleza del electrolito utilizado son los factores más condicionantes en las propiedades y características tanto físicas, morfológicas como estructurales. Además, la velocidad de crecimiento de la película de óxido que se deposita sobre la superficie también es muy dependiente de esos factores. Las películas de óxido que se forman en la superficie pueden ser de dos tipos principalmente: tipo compacta o tipo porosa. La capa tipo compacta se forma en soluciones neutras ( $\mathrm{pH}$ entre 5 y 7) en donde el óxido anódico permanece prácticamente insoluble. Estas películas son extremadamente delgadas y dieléctricamente compactas. En cambio, las películas porosas se generan en electrolitos muy ácidos como es el $\mathrm{H}_{2} \mathrm{SO}_{4}$, con un pH bastante inferior al utilizado en la formación de capas compactas. El anodizado electroquímico en medio sulfúrico es el más conocido y utilizado ya que resulta un método económico y fácil de llevar a cabo además de proporcionar buenos resultados [2]. En la Figura 4.1 se muestra un esquema de estas películas.

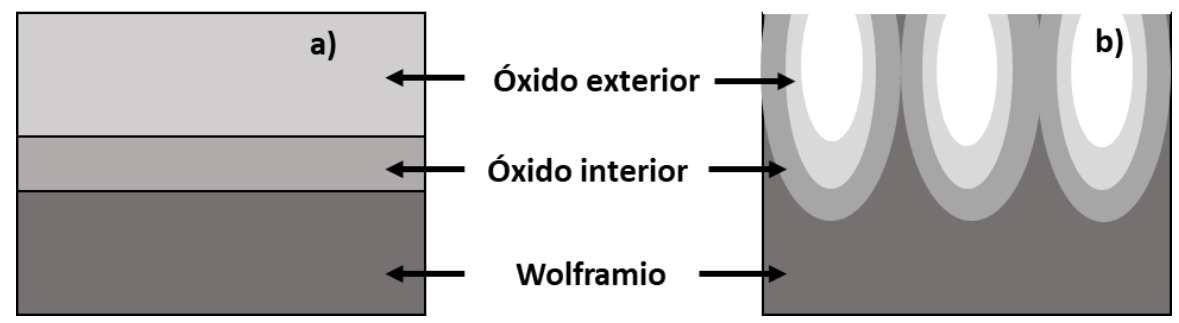

Figura 4.1. a) Película compacta, b) Película porosa.

Ambas películas están formadas por una capa de óxido interior que se encuentra contiguo a la interfase óxido-metal y otra de óxido exterior que se encuentra contigua a la interfase óxido-electrolito.

El anodizado electroquímico que se llevó a cabo en este estudio se realizó bajo las siguientes condiciones: $50{ }^{\circ} \mathrm{C}$, velocidad de giro del electrodo de $375 \mathrm{rpm}, 20 \mathrm{~V} \mathrm{y}$ durante 4 horas, siendo el electrolito el parámetro variable. Los ácidos empleados 
fueron los siguientes: $1.5 \mathrm{M}$ de $\mathrm{H}_{2} \mathrm{SO}_{4}+0.05 \mathrm{M}$ de $\mathrm{H}_{2} \mathrm{O}_{2}, 1.5 \mathrm{M}$ de $\mathrm{CH}_{4} \mathrm{O}_{3} \mathrm{~S}+0.05 \mathrm{M}$ de $\mathrm{H}_{2} \mathrm{O}_{2}$ y $1.5 \mathrm{M}$ de $\mathrm{HNO}_{3}+0.05 \mathrm{M}$ de $\mathrm{H}_{2} \mathrm{O}_{2}$. Mientras se realizaba el anodizado se registraron los datos de densidad de corriente correspondientes a cada instante de tiempo. Estos registros se pueden usar para analizar el comportamiento del electrodo en la disolución. Además, como la densidad de corriente se puede relacionar de manera directa con la cinética de los procesos electroquímicos llevados a cabo en la superficie del electrodo, estos resultados son muy útiles porque proporcionan información sobre las características del proceso de formación de las nanoestructuras [3].

En la Figura 4.2, se representan los cambios en la densidad de corriente registrada durante la formación del óxido de wolframio sobre la superficie del electrodo para cada uno de los tres ácidos seleccionados. A pesar de utilizar tres ácidos diferentes con la formación de sus respectivos aniones, las curvas difieren poco entre ellas ya que, salvo pequeñas diferencias, como son el valor máximo alcanzado o la pendiente de la misma, su forma es muy similar. En ellas se observan tres regiones claramente diferenciadas. A continuación, se explican los procesos que se llevan a cabo en cada región, con sus respectivas reacciones químicas o electroquímicas. 


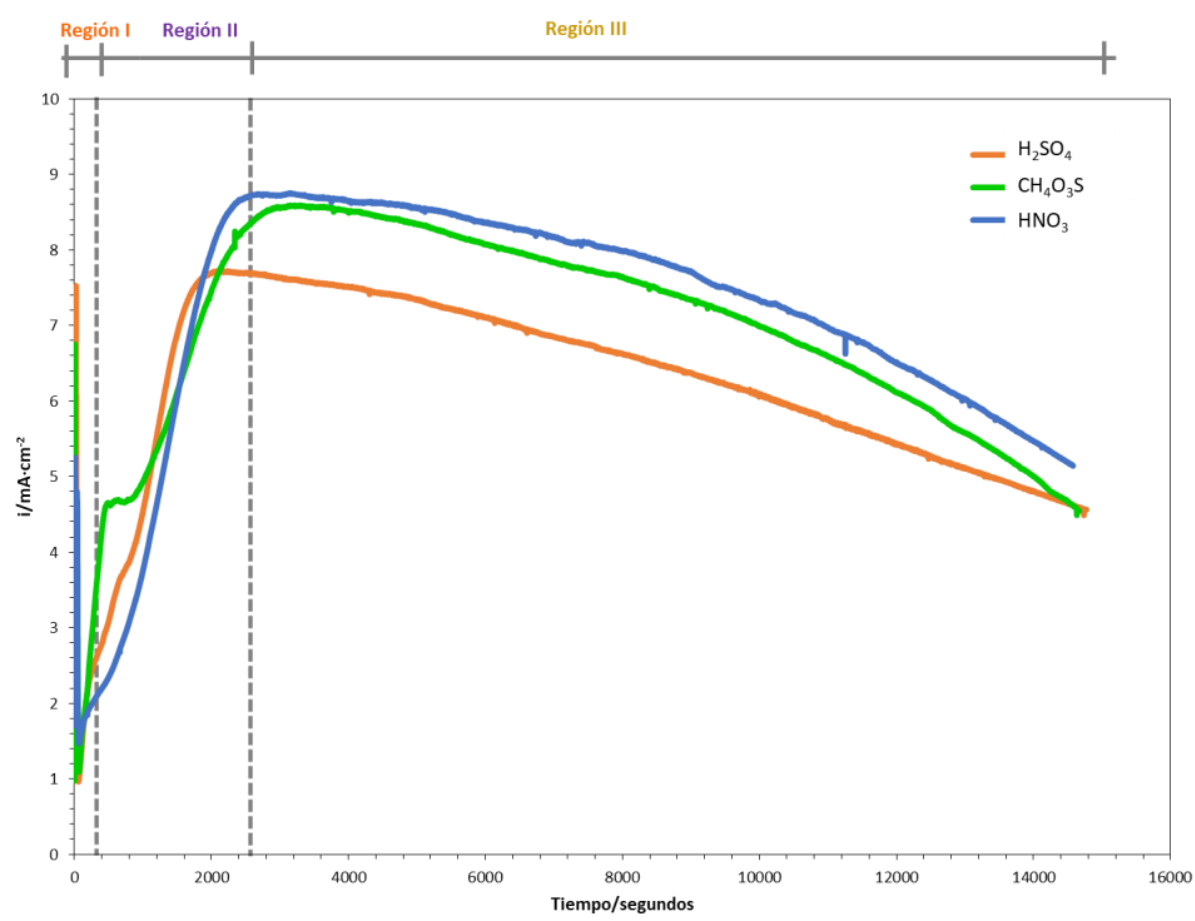

Figura 4.2. Registros de la densidad de corriente frente al tiempo, durante el anodizado electroquímico del wolframio a $20 \mathrm{~V}$ durante 4 horas con los 3 ácidos diferentes.

Justo después de empezar a aplicar los $20 \mathrm{~V}$, en esta gráfica se observa un descenso de la densidad de corriente, que va desde $7 \mathrm{~mA} \cdot \mathrm{cm}^{2}$ hasta $1 \mathrm{~mA} \cdot \mathrm{cm}^{2}$, que es causado por la formación de una capa compacta de $\mathrm{WO}_{3}$ en la superficie expuesta de la muestra a anodizar (Región I). Al haber cada vez menos superficie expuesta de wolframio, bloqueada por la película de $\mathrm{WO}_{3}$ que presenta una mayor resistencia y dificulta el paso de la corriente eléctrica, la densidad de corriente disminuye. Esta formación de $\mathrm{WO}_{3}$ está regida por la siguiente ecuación $[4,5]$ :

$$
W+3 \mathrm{H}_{2} \mathrm{O} \rightarrow \mathrm{WO}_{3}+6 \mathrm{H}^{+}+6 e^{-}
$$

El segundo tramo de los gráficos de la Figura 4.2 (Región II) se corresponde a un aumento de la densidad de corriente que es debido a la disminución de la resistencia al paso de la corriente por la disolución de la capa de óxido de 
wolframio formada en el tramo anterior. Esta disolución hace que la superficie de la muestra de wolframio vuelva a ser expuesta en mayor cantidad y por ello la densidad de corriente aumenta.

La disolución es debida a la acción de $\mathrm{H}^{+}$como se muestra en la ecuación $4.2 \mathrm{y}$, principalmente, debido al efecto del $\mathrm{H}_{2} \mathrm{O}_{2}$. El grupo peroxo $\left(\mathrm{O}_{2}{ }^{2-}\right)$ es un conocido ligando bidentado para especies de wolframio, sustituyendo el ligando $\mathrm{O}_{2}$ en el ion wolframato $[6,7]$.

$$
\mathrm{WO}_{3}+2 \mathrm{H}^{+} \rightarrow \mathrm{WO}_{2}^{2+}+\mathrm{H}_{2} \mathrm{O}
$$

El peróxido de hidrógeno reacciona con wolframatos y $W_{3}$ para formar peroxowolframatos y ácidos peroxowolfrámicos. En soluciones ácidas, el peroxowolframato prevalente es el dinuclear $\mathrm{W}_{2} \mathrm{O}_{11}{ }^{2-}$. Este compuesto resulta de la disolución de $\mathrm{WO}_{3}$ por la acción del $\mathrm{H}_{2} \mathrm{O}_{2}$ a través de la siguiente ecuación $[4,8,9]$ :

$$
2 \mathrm{WO}_{3}+4 \mathrm{H}_{2} \mathrm{O}_{2} \rightarrow\left[\mathrm{W}_{2} \mathrm{O}_{11}\right]^{2-}+2 \mathrm{H}^{+}+3 \mathrm{H}_{2} \mathrm{O}
$$

El complejo $\left[\mathrm{W}_{2} \mathrm{O}_{11}\right]^{2-}$ también se puede obtener por reacción directa entre el sustrato de wolframio y el peróxido de hidrógeno, según la siguiente ecuación:

$$
2 \mathrm{~W}+10 \mathrm{H}_{2} \mathrm{O}_{2} \rightarrow\left[\mathrm{W}_{2} \mathrm{O}_{11}\right]^{2-}+2 \mathrm{H}^{+}+9 \mathrm{H}_{2} \mathrm{O}
$$

Después de alcanzar un valor máximo, las densidades de corriente disminuyeron nuevamente, dando lugar a la Región III, debido a la precipitación de ácidos wolfrámicos $\left(\mathrm{WO}_{3} \cdot \mathrm{H}_{2} \mathrm{O}\right.$ y $\left.\mathrm{WO}_{3} \cdot 2 \mathrm{H}_{2} \mathrm{O}\right)$ a partir de peroxowolframatos en forma de nanoestructuras $[8,10,11]$, tal y como se verá más adelante.

Esta precipitación tiene lugar cuando se alcanzaron las condiciones de sobresaturación. Además, dado que los peroxowolframatos son termodinámicamente inestables, se descomponen lentamente. El complejo $\mathrm{W}_{2} \mathrm{O}_{11}{ }^{2-}$ puede descomponerse en $\mathrm{WO}_{3}$ sólido, de acuerdo con [12-14]:

$$
\left[\mathrm{W}_{2} \mathrm{O}_{11}\right]^{2-}+2 \mathrm{H}^{+} \rightarrow 2 \mathrm{WO}_{3}+2 \mathrm{O}_{2}+\mathrm{H}_{2} \mathrm{O}
$$


A partir de este primer análisis de los registros de densidad de corriente frente al tiempo no se puede deducir qué ácido será el óptimo en la síntesis ya que la forma es prácticamente igual, lo que nos indica que las nanoestructuras se están obteniendo de una manera similar. No obstante, con el resto de caracterizaciones se podrá comprobar las diferencias en la morfología, en la topología, en la estructura cristalina y en las propiedades fotoelectrocatalíticas de las nanoestructuras.

Una vez explicado el mecanismo de formación de la capa de óxido de wolframio se analizarán los resultados obtenidos de la caracterización morfológica de la superficie mediante microscopia FE-SEM.

\subsection{Caracterización morfológica de la superficie mediante microscopía FE-SEM.}

Mediante el uso del microscopio electrónico de barrido de alta resolución de emisión de campo (FE-SEM) se han caracterizado morfológicamente las nanoestructuras obtenidas en la superficie del electrodo. El FE-SEM se trata de una herramienta muy ventajosa para obtener imágenes de superficies sobre todo en el área de los nanomateriales. La calidad de imagen que ofrece es superior a la del SEM debido a que el haz de electrones originado es aproximadamente 1000 veces menor.

\subsubsection{Nanoestructuras sintetizadas con $\mathrm{H}_{2} \mathrm{SO}_{4}$.}

A continuación, en las Figuras $4.3,4.4$ y 4.5 se muestran las imágenes obtenidas en el FE-SEM de las nanoestructuras depositadas en la superficie del electrodo de wolframio en las siguientes condiciones: a una temperatura de $50{ }^{\circ} \mathrm{C}$, a $375 \mathrm{rpm}$, con un potencial aplicado de $20 \mathrm{~V}$, durante 4 horas en un electrolito con una concentración $1.5 \mathrm{M} \mathrm{H}_{2} \mathrm{SO}_{4}$ y $0.05 \mathrm{M}$ de $\mathrm{H}_{2} \mathrm{O}_{2}$ y calentadas a diferentes temperaturas $\left(400{ }^{\circ} \mathrm{C}, 500{ }^{\circ} \mathrm{C}\right.$ y $600^{\circ} \mathrm{C}$ ) y en diferentes atmósferas (aire, nitrógeno y argón). El hecho de que las nanoestructuras sintetizadas presentaran una estructura amorfa, hacía necesario este calentamiento posterior para transformarla en una estructura cristalina con el fin de utilizarlas posteriormente como fotocatalizadores. 
La morfología que se observa en las siguientes figuras está relacionada con el transitorio de densidad de corriente registrado durante el anodizado (Figura 4.2), el cual definía el comportamiento característico de la formación de estas nanoestructuras.

A grandes rasgos, en todos los casos se observa que se trata de nanoplaquetas muy pequeñas en forma de nanofilamentos formando una especie de capa esponjosa. Estas nanoestructuras agregadas forman agrupaciones en forma de conos o "montañas" como se observa en todas las imágenes FE-SEM a 1000 aumentos. Tras analizar el transitorio de densidad de corriente y las imágenes obtenidas del FE-SEM, y compararlos bibliográficamente con otros estudios, el mecanismo de formación de las nanoestructuras es un mecanismo de precipitación de ácido wolfrámico $\left(\mathrm{WO}_{3} \cdot \times \mathrm{H}_{2} \mathrm{O}\right)$ debido a la presencia de $\mathrm{H}_{2} \mathrm{O}_{2}$ en el electrolito, a diferencia de lo que ocurre si no se añade $\mathrm{H}_{2} \mathrm{O}_{2}$, cuyo mecanismo de formación ralentiza la descomposición de peroxowolframatos a la forma $\mathrm{WO}_{3}$ deshidratada $[3,15]$.

Además, el tamaño tan pequeño de las nanoestructuras, está relacionado con la tendencia del ligando bidentado $\mathrm{O}_{2}{ }^{2-}$ para formar enlaces más fuertes con wolframio que el monodentado $\mathrm{O}^{2-}$. Este hecho da como resultado una ralentización de la velocidad de descomposición o precipitación de peroxowolframatos, impidiendo el crecimiento de las nanoestructuras, por lo que su tamaño disminuye [16-18]. 

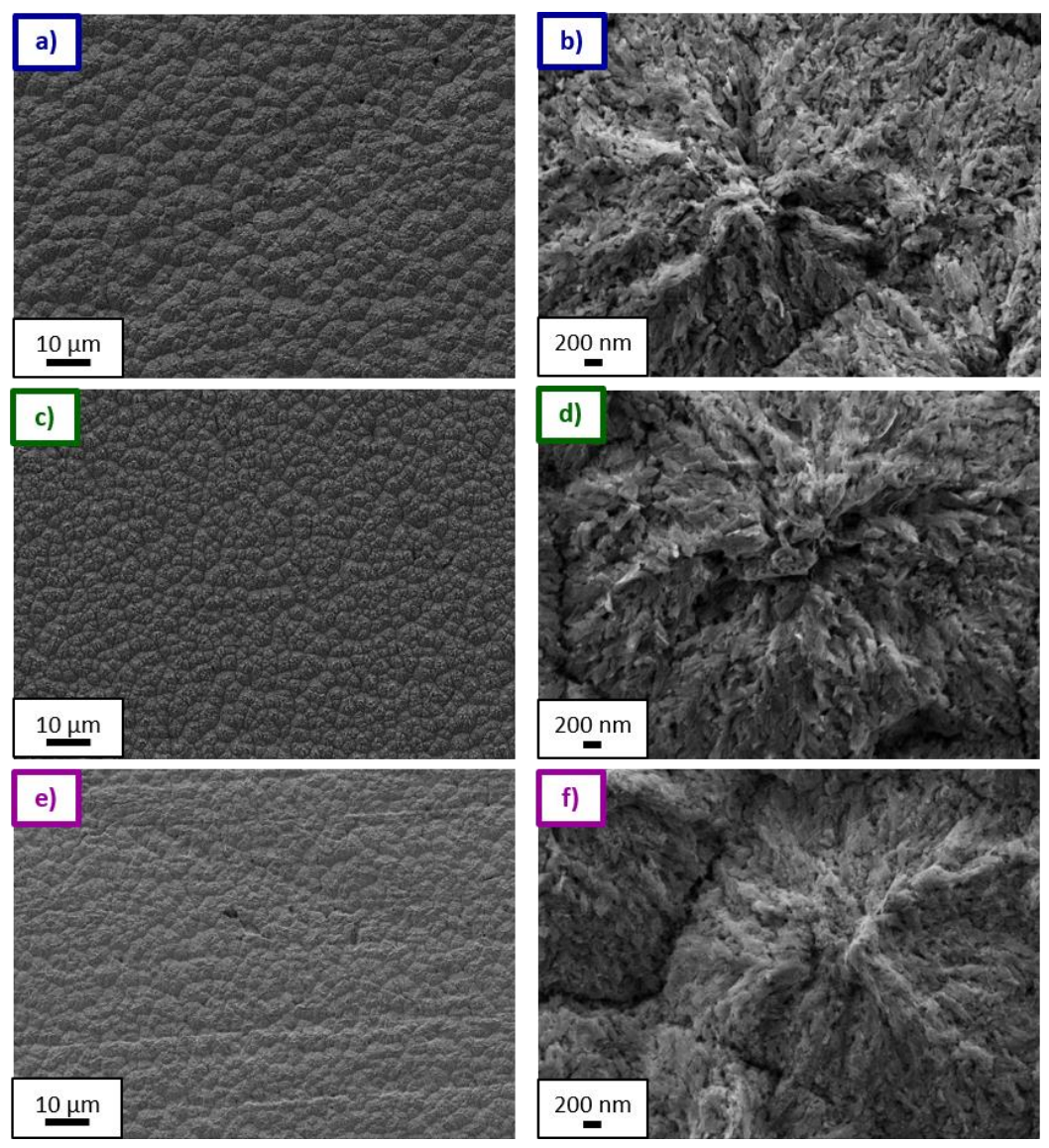

Figura 4.3. Imágenes FE-SEM de las nanoestructuras de óxido de wolframio tras el anodizado electroquímico con $\mathrm{H}_{2} \mathrm{SO}_{4}$ y su posterior calentamiento a $400{ }^{\circ} \mathrm{C}$ en a) aire a 1000 aumentos, b) aire a 20000 aumentos, c) $N_{2}$ a 1000 aumentos, d) $N_{2}$ a 20000 aumentos, e) Ar a 1000 aumentos, f) Ar a 20000 aumentos.

Al analizar las imágenes a 1000 aumentos de la Figura 4.3, es decir, de las muestras calentadas a $400{ }^{\circ} \mathrm{C}$, se puede ver como las nanoestructuras calentadas en aire y nitrógeno tienen las agrupaciones en montañas más definidas, que en el caso de las muestras calentadas en argón. Además, en las imágenes a más aumentos (20000 aumentos), se pueden observar unas nanoestructuras más definidas en el caso de calentar en aire, seguidas de las de calentadas en nitrógeno, siendo las calentadas en argón las que presentan una menor definición. 

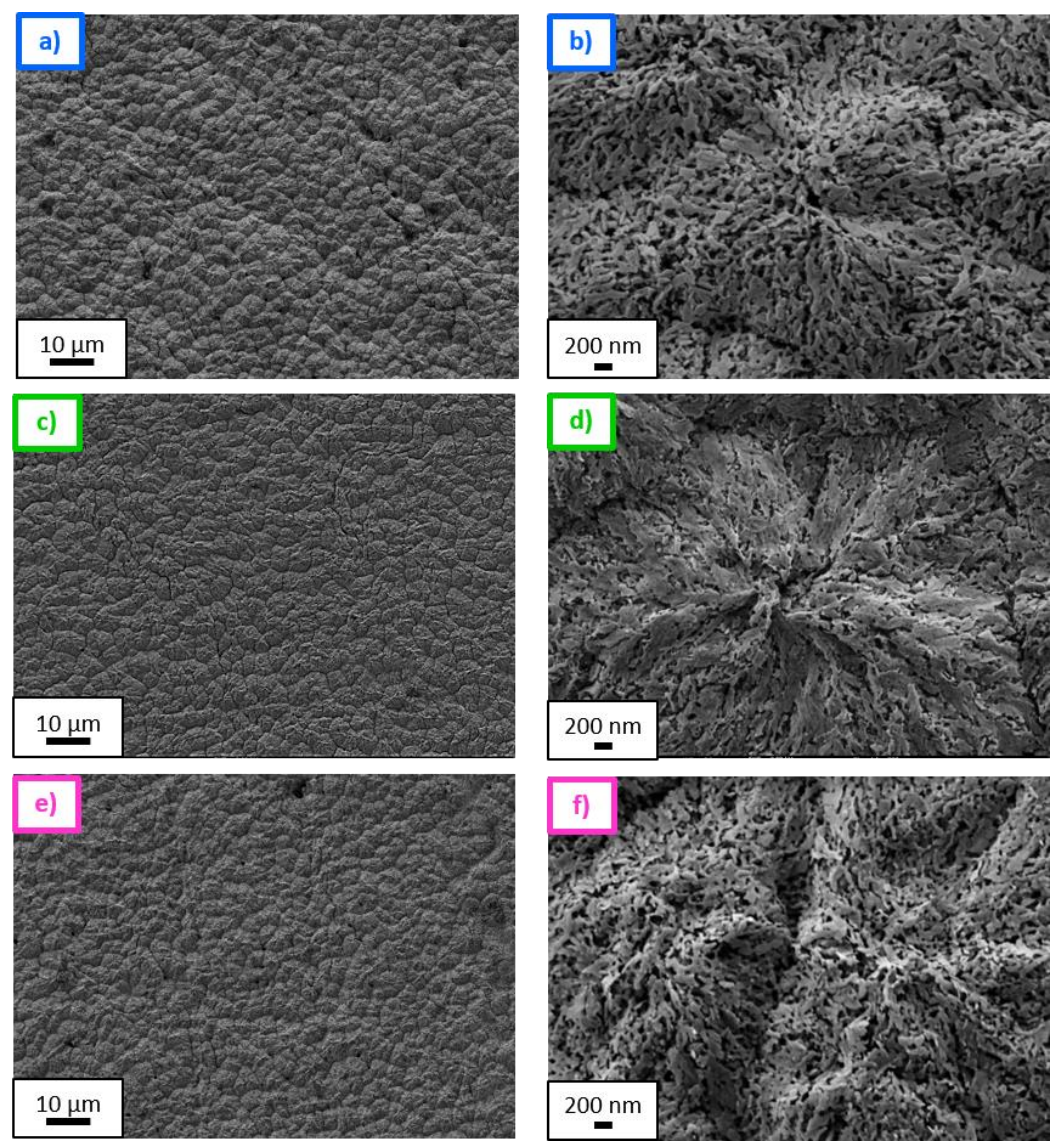

Figura 4.4. Imágenes FE-SEM de las nanoestructuras de óxido de wolframio tras el anodizado electroquímico con $\mathrm{H}_{2} \mathrm{SO}_{4}$ y su posterior calentamiento a $500{ }^{\circ} \mathrm{C}$ en a) aire a 1000 aumentos, b) aire a 20000 aumentos, c) $N_{2}$ a 1000 aumentos, d) $N_{2}$ a 20000 aumentos, e) Ar a 1000 aumentos, f) Ar a 20000 aumentos.

En la Figura 4.4 se muestran las imágenes FE-SEM de las nanoestructuras sintetizadas en $\mathrm{H}_{2} \mathrm{SO}_{4}$ y calentadas a $500{ }^{\circ} \mathrm{C}$ en las diferentes atmósferas. En ella se puede observar cómo nuevamente, en atmósferas de aire y nitrógeno, las nanoestructuras están más definidas que las calentadas en atmósfera de argón, ya que éstas últimas están agregadas de manera que se asemejan más a una estructura tipo capa compacta que nanoestructuras. No obstante, si se comparan con las calentadas a $400{ }^{\circ} \mathrm{C}$, se puede ver una mayor definición de las 
nanoestructuras en las tres atmósferas al aumentar la temperatura de calentamiento.
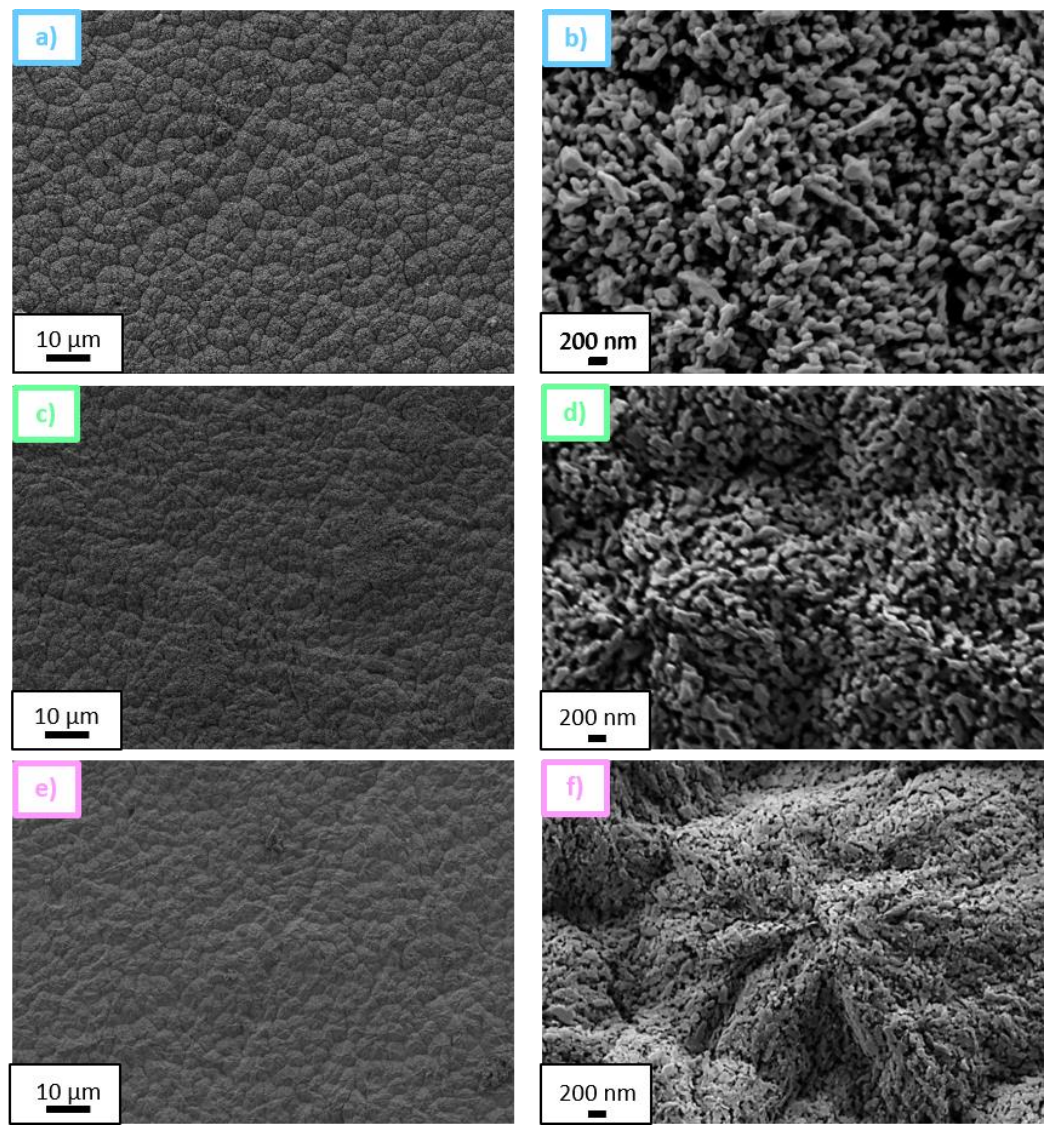

Figura 4.5. Imágenes FE-SEM de las nanoestructuras de óxido de wolframio tras el anodizado electroquímico con $\mathrm{H}_{2} \mathrm{SO}_{4}$ y su posterior calentamiento a $600{ }^{\circ} \mathrm{C}$ en a) aire a 1000 aumentos, b) aire a 20000 aumentos, c) $N_{2}$ a 1000 aumentos, d) $N_{2}$ a 20000 aumentos, e) Ar a 1000 aumentos, f) Ar a 20000 aumentos.

Finalmente, al analizar la Figura 4.5 en donde se muestran las nanoestructuras calentadas a $600{ }^{\circ} \mathrm{C}$, se puede concluir que la tendencia observada en las temperaturas anteriores se vuelve a cumplir, es decir, las nanoestructuras calentadas en aire y nitrógeno presentan una morfología mucho más definida. Pero además, al calentar a $600{ }^{\circ} \mathrm{C}$ se ve un cambio más significativo en cuanto a la 
morfología de las nanoestructuras, ya que a esta temperatura las nanoesturcturas están menos apelmazadas existiendo mayor porosidad entre ellas.

Como conclusión, se puede observar que la morfología de estas nanoestructuras se definió mucho más a medida que aumentaba la temperatura de calentamiento. De hecho, a $400{ }^{\circ} \mathrm{C}$ e independientemente de la atmósfera del tratamiento térmico, se obtuvo una morfología de nanocapas con tamaños muy pequeños, que se transformó progresivamente en nanohilos a temperaturas más altas.

De hecho, a $600{ }^{\circ} \mathrm{C}$, se puede observar una clara morfología de la matriz de nanorod. De acuerdo con la bibliografía $[9,19]$, este tipo de nanoestructura ofrece una transferencia eficiente de electrones. La transformación de las nanoestructuras mal definidas a nanohilos claramente definidos con temperatura de calentamiento creciente puede estar relacionada con un mayor grado de deshidratación de las nanoestructuras.

Con respecto a la influencia de la atmósfera de calentamiento en la morfología y el tamaño de las nanoestructuras $\mathrm{WO}_{3}$, se consiguen nanoestructuras con morfologías más definidas en atmósferas oxidantes, como es el aire, que en atmósferas no oxidantes, como es el Ar.

Esto se observa principalmente, en las muestras calentadas a $600{ }^{\circ} \mathrm{C}$ en argon (Figura $4.5 \mathrm{f}$ ), en donde no se observaron nanohilos. En cambio, se obtuvieron nanoplacas o nanopartículas muy pequeñas y deformadas. Esta morfología podría evitar que las cargas fotogeneradas se separen de manera eficiente, reduciendo así el rendimiento fotoelectroquímico de las nanoestructuras.

Por tanto, para el uso del $\mathrm{H}_{2} \mathrm{SO}_{4}$, una mayor temperatura favorece la definición de las nanoestructuras, presentando la morfología deseada de nanofilamentos tanto en atmósfera de aire como de $\mathrm{N}_{2}$. Estas nuevas conformaciones de las nanoestructuras pueden ser beneficiosas para aplicaciones energéticas, ya que pueden presentar buenas propiedades fotocatalíticas debido a la naturaleza de las nanoestructuras de $\mathrm{WO}_{3}$, además de presentar una mejora del transporte electrónico que proporciona la estructura de nanohilos sintetizados directamente sobre el sustrato metálico $[6,20,21]$.

\subsubsection{Nanoestructuras sintetizadas con $\mathrm{CH}_{4} \mathrm{O}_{3} \mathrm{~S}$.}

Una vez analizada la morfología de las nanoestructuras obtenidas con $\mathrm{H}_{2} \mathrm{SO}_{4}$, se va a estudiar la morfología de las nanoestructuras sintetizadas con $\mathrm{CH}_{4} \mathrm{O}_{3} \mathrm{~S}$ y 
calentadas a las mismas temperaturas y atmósferas que en el caso anterior. En las Figuras 4.6, 4.7 y 4.8 se muestran las imágenes FE-SEM correspondientes a las nanoestructuras calentadas a $400{ }^{\circ} \mathrm{C}, 500^{\circ} \mathrm{C}$ y $600^{\circ} \mathrm{C}$ respectivamente.
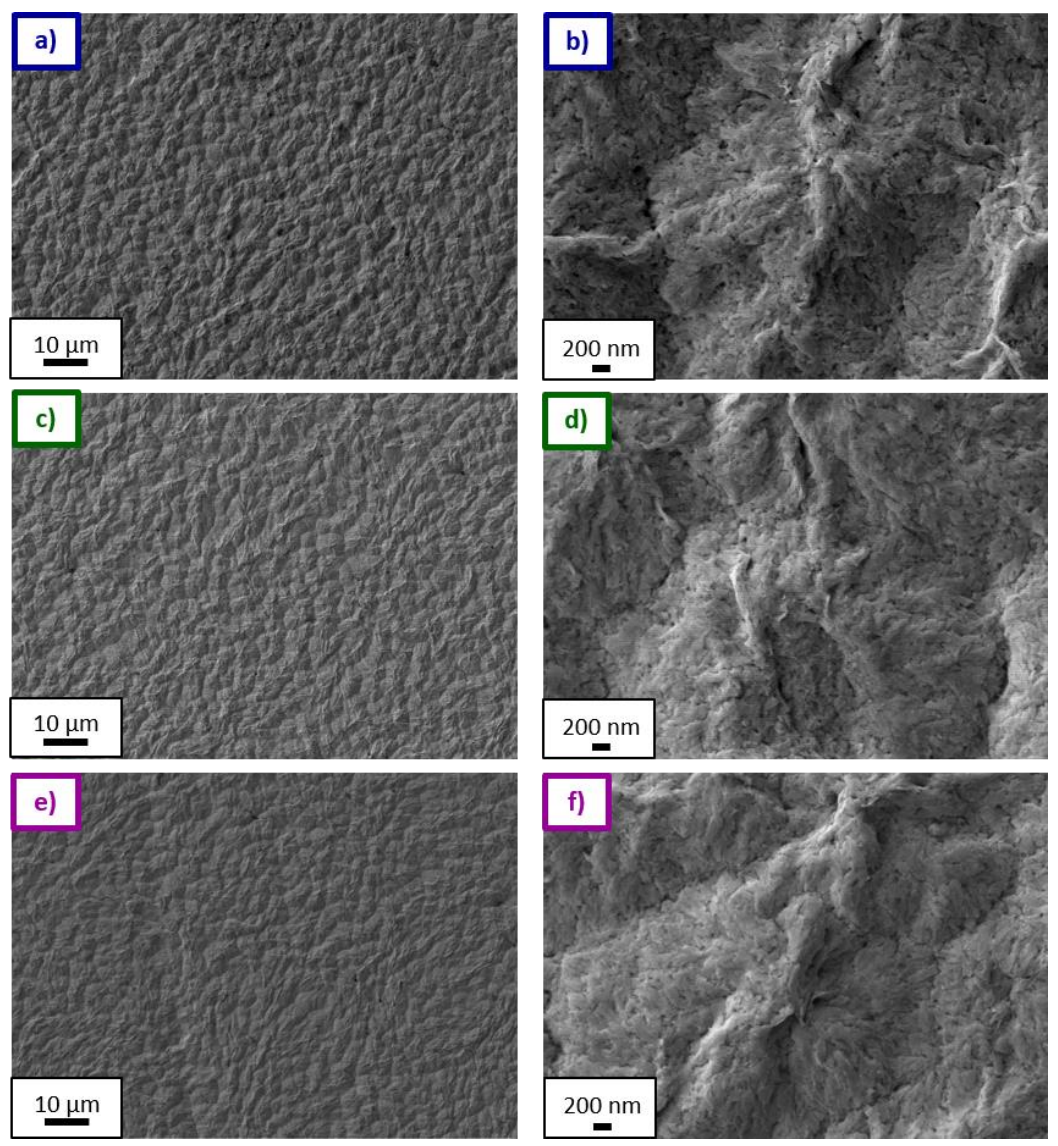

Figura 4.6. Imágenes FE-SEM de las nanoestructuras de óxido de wolframio tras el anodizado electroquímico con $\mathrm{CH}_{4} \mathrm{O}_{3} \mathrm{~S}$ y su posterior calentamiento a $400^{\circ} \mathrm{C}$ en a) aire a 1000 aumentos, b) aire a 20000 aumentos, c) $N_{2}$ a 1000 aumentos, d) $N_{2}$ a 20000 aumentos, e) Ar a 1000 aumentos, f) Ar a 20000 aumentos. 

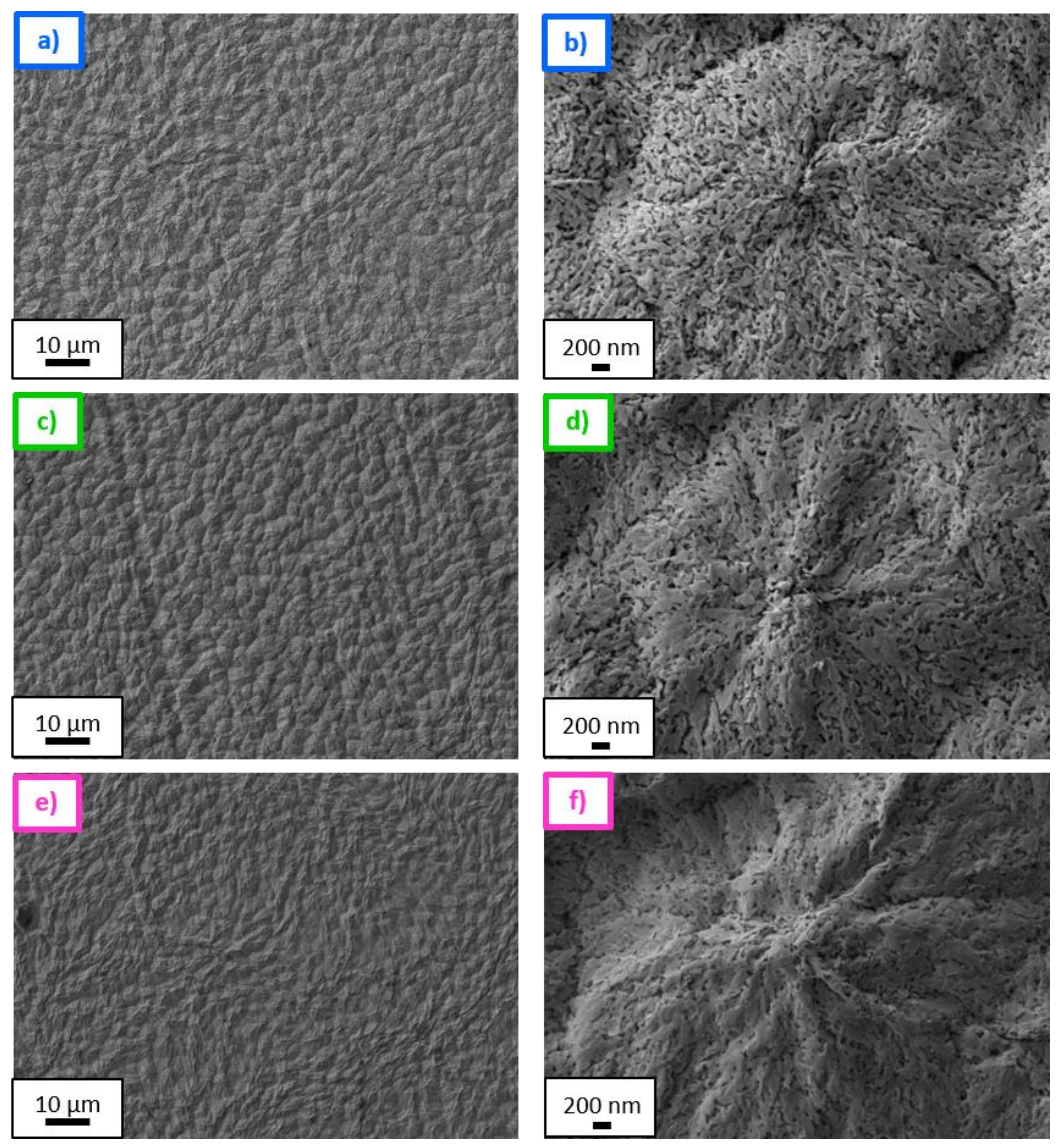

Figura 4.7. Imágenes FE-SEM de las nanoestructuras de óxido de wolframio tras el anodizado electroquímico con $\mathrm{CH}_{4} \mathrm{O}_{3} \mathrm{~S}$ y su posterior calentamiento a $500^{\circ} \mathrm{C}$ en a) aire a 1000 aumentos, b) aire a 20000 aumentos, c) $N_{2}$ a 1000 aumentos, d) $N_{2}$ a 20000 aumentos, e) Ar a 1000 aumentos, f) Ar a 20000 aumentos. 

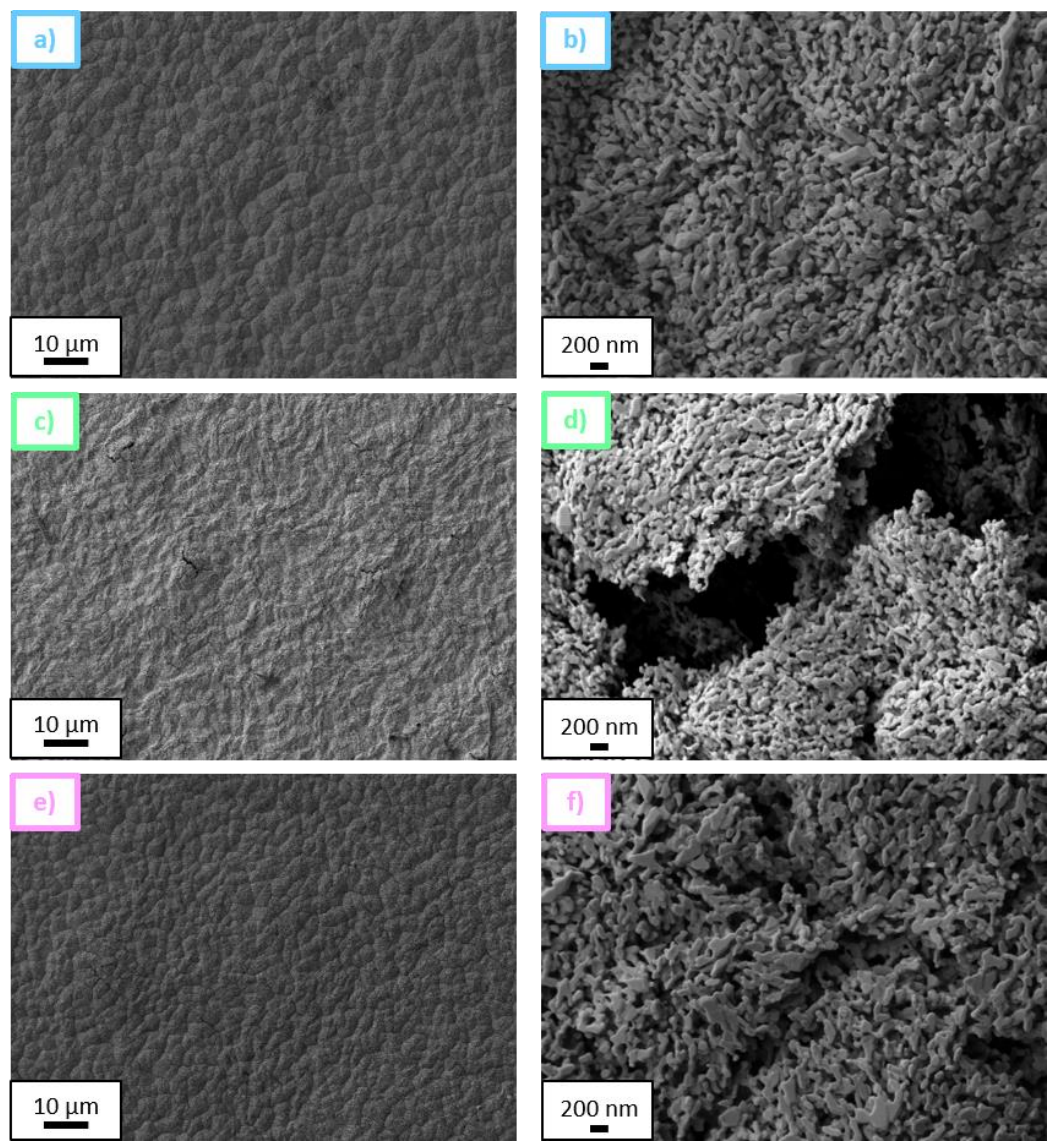

Figura 4.8. Imágenes FE-SEM de las nanoestructuras de óxido de wolframio tras el anodizado electroquímico con $\mathrm{CH}_{4} \mathrm{O}_{3} \mathrm{~S}$ y su posterior calentamiento a $600^{\circ} \mathrm{C}$ en a) aire a 1000 aumentos, b) aire a 20000 aumentos, c) $N_{2}$ a 1000 aumentos, d) $N_{2}$ a 20000 aumentos, e) Ar a 1000 aumentos, f) Ar a 20000 aumentos.

Con el uso de $\mathrm{CH}_{4} \mathrm{O}_{3} \mathrm{~S}$ como electrolito se obtienen nanoestructuras con una morfología de nanohilos o nanohojas diminutos en la superficie de los electrodos, formando una especie de capa esponjosa en todos los casos. Estas nanoestructuras con un tamaño tan pequeño y la forma en que se agregan pueden estar relacionadas con la predisposición del ligando bidentado $\mathrm{O}_{2}{ }^{2-}$ para establecer enlaces muy fuertes con el wolframio, lo que dificulta el crecimiento de las nanoestructuras durante la anodizado, como se ha mencionado anteriormente $[18,22,23]$. Sin embargo, la morfología de las nanoestructuras en este caso son nanohilos más compactos y más uniformes en atmósfera de aire que en el caso de usar $\mathrm{H}_{2} \mathrm{SO}_{4}$ como electrolito. Si se comparan los nanohilos obtenidos en $\mathrm{H}_{2} \mathrm{SO}_{4} \mathrm{Y}$ 
con la obtenida en $\mathrm{CH}_{4} \mathrm{O}_{3} \mathrm{~S}$ (Figura 4.5 y Figura 4.8 respectivamente), en el primer caso los nanohilos se organizan en forma de montañas en lugar de formar una capa más uniforme y sin alteraciones como en el caso del $\mathrm{CH}_{4} \mathrm{O}_{3} \mathrm{~S}$. La formación de esta capa más uniforme, sin la presencia de zonas libres de nanoestructuras, da como resultado densidades de corriente más altas $[10,24]$ y, por lo tanto, esa nanoestructura podría ser más eficaz a la hora de degradar pesticidas que los nanohilos obtenidos en $\mathrm{H}_{2} \mathrm{SO}_{4}$.

Este fenómeno es debido a la elevada área superficial que presentan las nanoestructuras obtenidas con $\mathrm{CH}_{4} \mathrm{O}_{3} \mathrm{~S}$, lo que permite captar de forma efectiva la luz solar y generar pares electrón-hueco. Al presentar una capa más uniforme permite que los huecos fotogenerados puedan llegar con mayor facilidad al electrolito. Además, los electrones viajan hasta el sustrato metálico con mayor facilidad debido a la poca presencia de espacios entre las nanoestructuras y haciendo que el recorrido presente menos impedimentos [25]. Por tanto, la alta probabilidad de recombinación se ve reducida haciendo que los huecos $\left(\mathrm{h}^{+}\right)$ lleguen a la interfase nanoestructura-electrolito para oxidar al medio, mientras que los electrones $\left(\mathrm{e}^{-}\right)$pasan al sustrato metálico, para circular por el circuito eléctrico hasta el cátodo en donde se producirá la reducción del medio [26-28].

En cuanto al efecto de la temperatura de calentamiento al usar $\mathrm{CH}_{4} \mathrm{O}_{3} \mathrm{~S}$ como electrolito se puede observar que conforme se aumenta la temperatura del proceso de post-anodizado, las nanoestructuras quedan más definidas, observándose la misma tendencia que en el caso de utilizar $\mathrm{H}_{2} \mathrm{SO}_{4}$ como electrolito.

Al analizar el efecto de la atmósfera de calentamiento, se puede concluir lo mismo que al analizar las nanoestructuras obtenidas con $\mathrm{H}_{2} \mathrm{SO}_{4}$, es decir, que en atmósfera oxidante las nanoestructuras están mucho más definidas que en atmósferas como argón. No obstante, en este caso se observa que al utilizar una atmósfera diferente del aire a temperaturas elevadas, se originan grietas en la superficie [12,29]. Estas grietas pueden ser debidas a una gran tensión ejercida entre las nanoestructuras ya que al producirse una gran deshidratación la red cristalina no puede soportar las tensiones de unión entre ellas, haciendo que esa red se rompa y provoque grietas en la capa de nanoestructuras obtenida. Estas grietas disminuirán el área superficial de las muestras y, por tanto, empeorarán su comportamiento fotoelectrocatalítico evaluado más adelante. Finalmente, al analizar las nanoestructuras obtenidas al calentarlas con atmósfera de Ar, se 
observa que en este caso no presentan morfología de nanohilo sino que vuelven a aparecer morfología de nanoplaqueta menos eficiente que los nanohilos.

\subsubsection{Nanoestructuras sintetizadas con $\mathrm{HNO}_{3}$.}

Finalmente, en las Figuras 4.9, 4.10 y 4.11 se muestran las imágenes FE-SEM de las nanoestructuras sintetizadas con el último ácido utilizado, que corresponde con el $\mathrm{HNO}_{3}$, y calentadas a $400{ }^{\circ} \mathrm{C}, 500^{\circ} \mathrm{C}$ y $600{ }^{\circ} \mathrm{C}$ respectivamente.
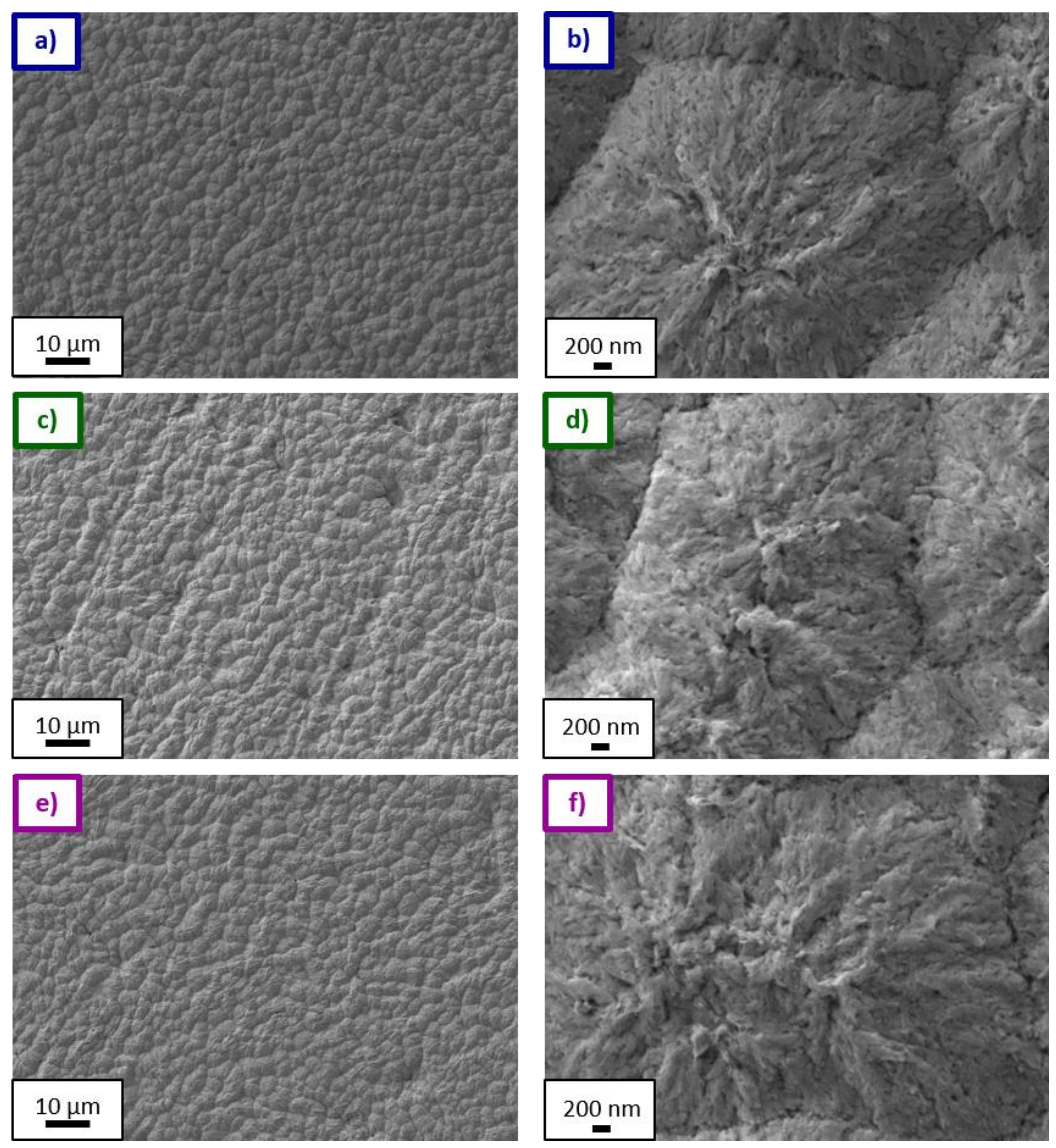

Figura 4.9. Imágenes FE-SEM de las nanoestructuras de óxido de wolframio tras el anodizado electroquímico con $\mathrm{HNO}_{3}$ y su posterior calentamiento a $400{ }^{\circ} \mathrm{C}$ en a) aire a 1000 aumentos, b) aire a 20000 aumentos, c) $N_{2}$ a 1000 aumentos, d) $N_{2}$ a 20000 aumentos, e) Ar a 1000 aumentos, f) Ar a 20000 aumentos. 

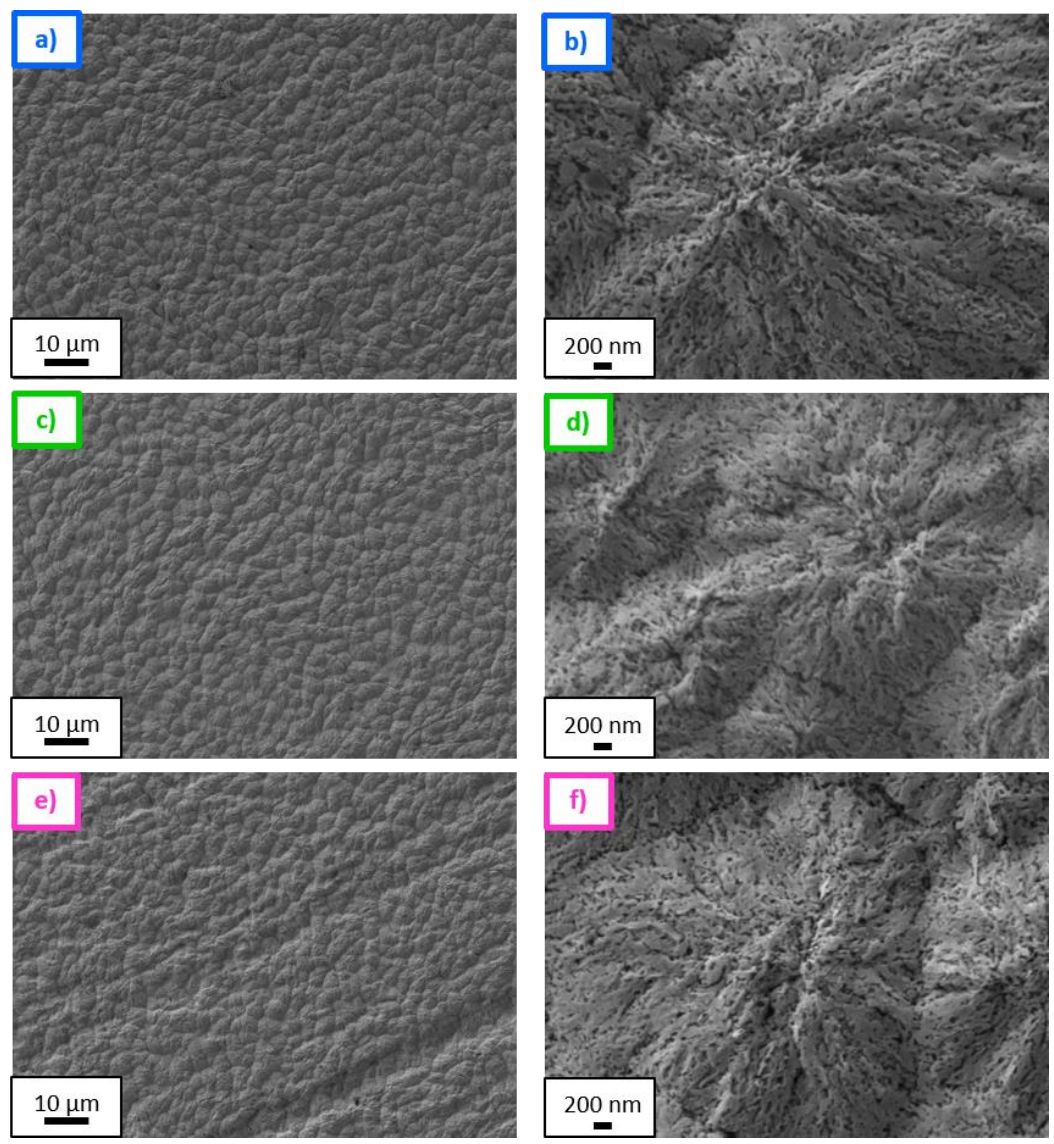

Figura 4.10. Imágenes FE-SEM de las nanoestructuras de óxido de wolframio tras el anodizado electroquímico con $\mathrm{HNO}_{3}$ y su posterior calentamiento a $500{ }^{\circ} \mathrm{C}$ en a) aire a 1000 aumentos, b) aire a 20000 aumentos, c) $N_{2}$ a 1000 aumentos, d) $N_{2}$ a 20000 aumentos, e) Ar a 1000 aumentos, f) Ar a 20000 aumentos. 

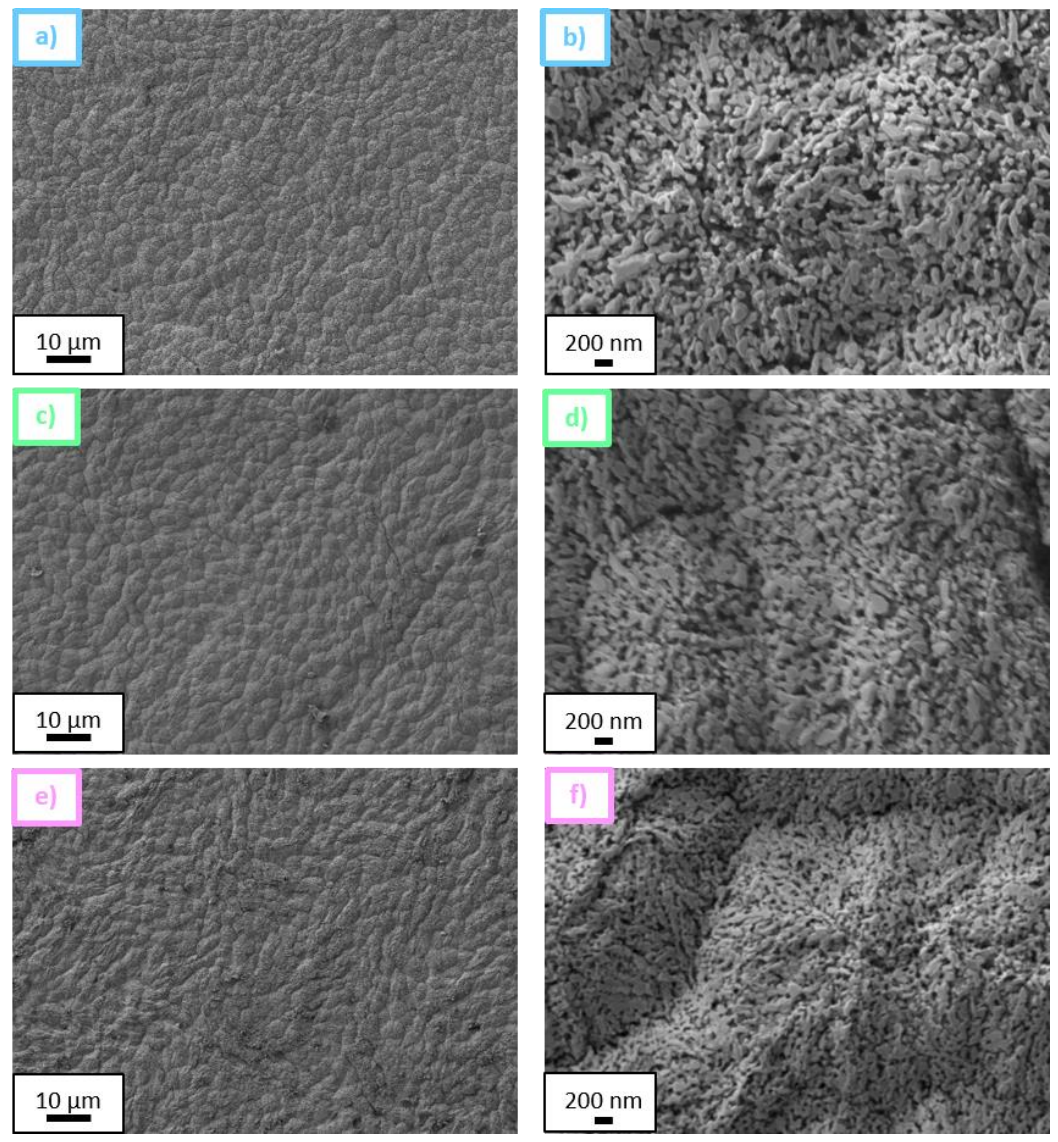

Figura 4.11. Imágenes FE-SEM de las nanoestructuras de óxido de wolframio tras el anodizado electroquímico con $\mathrm{HNO}_{3}$ y su posterior calentamiento a $600^{\circ} \mathrm{C}$ en a) aire a 1000 aumentos, b) aire a 20000 aumentos, c) $N_{2}$ a 1000 aumentos, d) $N_{2}$ a 20000 aumentos, e) Ar a 1000 aumentos, f) Ar a 20000 aumentos.

Los resultados morfológicos obtenidos al utilizar $\mathrm{HNO}_{3}$ en el electrolito son nanoestructuras semejantes a las obtenidas con $\mathrm{H}_{2} \mathrm{SO}_{4}$ en donde las nanoestructuras están agrupadas en forma de montañas o conos y sin la presencia de grietas en las nanoestructuras obtenidas a altas temperaturas por lo que se esperan resultados electroquímicos similares a los obtenidos con $\mathrm{H}_{2} \mathrm{SO}_{4}$. Asimismo, en las imágenes se puede observar que las muestras son más compactas que en el caso de utilizar $\mathrm{CH}_{4} \mathrm{O}_{3} \mathrm{~S}$, lo que conllevará una menor porosidad y a unas peores propiedades fotoelectroquímicas. Esto es debido a que al utilizar un electrolito que contiene nitrógeno, éste es introducido en la 
estructura produciendo un tamaño de grano más pequeño y una peor calidad de la estructura cristalina [30]. Además, estas nanoestructuras tienen un grosor mayor, lo que puede verse como una desventaja en cuanto al comportamiento fotoelectroquímico de las muestras, ya que pueden dificultar la difusión de los electrones, y favorecer así, la recombinación de los pares electrón-hueco. No obstante, la morfología que se obtuvo fue mucho más desordenada, apareciendo nanohilos en forma de pequeños aglomerados.

En cuanto a la temperatura y atmósfera de calentamiento, se observa que, con un aumento de la temperatura, nuevamente las nanoestructuras están más definidas. En cambio, las nanoestructuras calentadas en nitrógeno y argón no presentan los nanohilos deseados, presentando una morfología de nanoplaquetas, menos eficientes fotocatalíticamente hablando [14,31]. Estas nanoplaquetas hacen que la luz no tenga fácil acceso a las nanoestructuras, y no se obtengan los beneficios de la geometría cilíndrica de los nanohilos. Con todo esto, las propiedades fotoelectroquímicas de las nanoestructuras se verían empeoradas con respecto a la morfología obtenida al anodizar con $\mathrm{CH}_{4} \mathrm{O}_{3} \mathrm{~S}$ como electrolito.

\subsection{Caracterización de la estructura cristalina de las nanoestructuras mediante Microscopía Láser Confocal Raman.}

Para analizar la composición y la estructura cristalina de las nanoestructuras de óxido de wolframio que se han formado en la superficie del electrodo tras el anodizado electroquímico, se ha utilizado un Microscopio de Barrido Láser Confocal dotado de espectroscopía Raman.

En la Figura 4.12 se muestra el espectro Raman obtenido al estudiar una muestra de $\mathrm{WO}_{3}$ anodizada en medio $\mathrm{H}_{2} \mathrm{SO}_{4}$ antes de someterla al tratamiento térmico durante 4 horas. Con esto se pretende analizar las diferencias en la estructura de las muestras antes y después del anodizado, y por tanto, lo importante que es el proceso de post-anodizado para la aplicación de las nanoestructuras como fotocatalizadores.

Observando el espectro de la muestra sin calentar se pueden distinguir cuatro picos más diferenciados. El primero de ellos, que se sitúa en un desplazamiento Raman de $150 \mathrm{~cm}^{-1}$ hasta $280 \mathrm{~cm}^{-1}$ aproximadamente, el segundo de ellos se sitúa en un desplazamiento Raman de $600 \mathrm{~cm}^{-1}$ a $750 \mathrm{~cm}^{-1}$ aproximadamente, el tercero 
se sitúa en un desplazamiento Raman alrededor de $760-900 \mathrm{~cm}^{-1}$, y finalmente, el cuarto, se trata de un pequeño pico situado a aproximadamente $960 \mathrm{~cm}^{-1}[4,32]$.

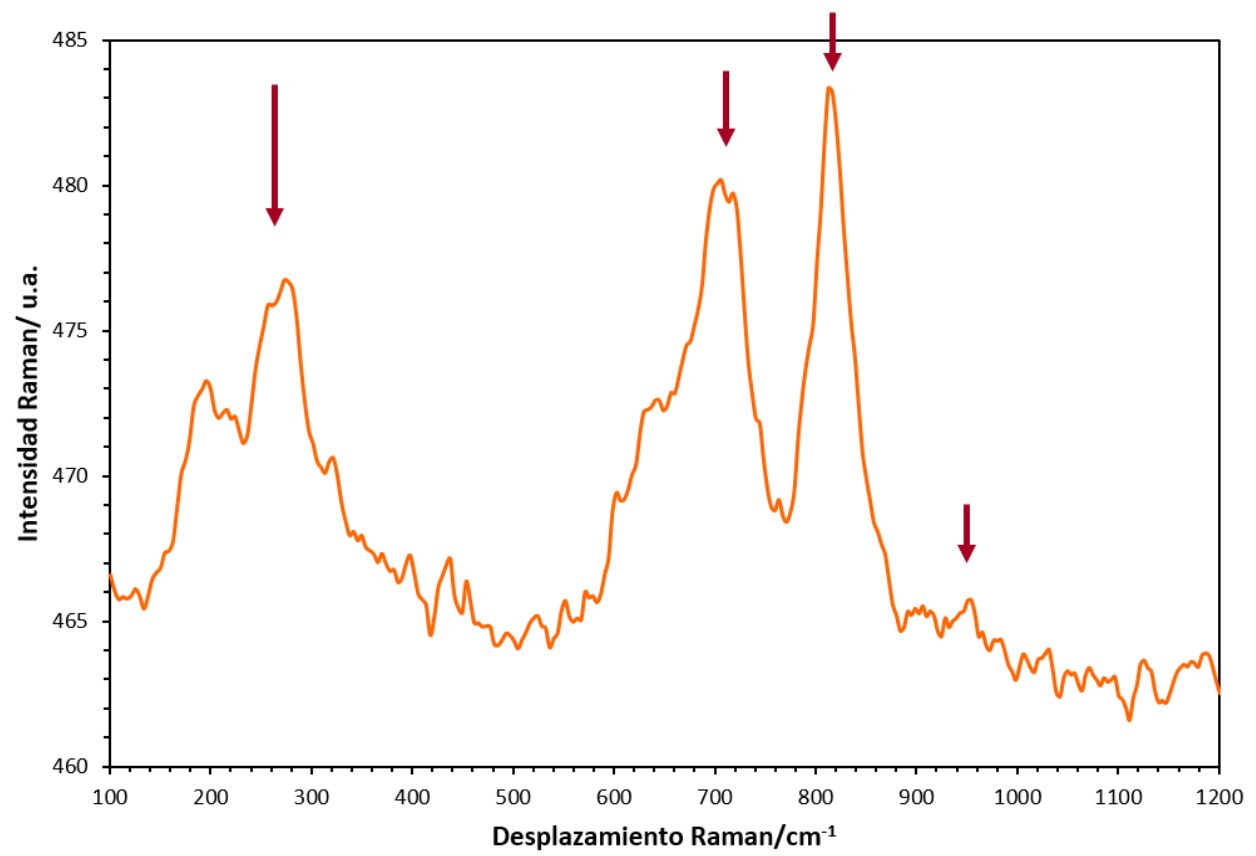

Figura 4.12. Espectro Raman de las nanoestructuras de óxido de wolframio tras el anodizado electroquímico con $\mathrm{H}_{2} \mathrm{SO}_{4}$, sin tratamiento térmico.

El primer pico $\left(270 \mathrm{~cm}^{-1}\right)$ se asocia a la presencia de especies hidratadas tales como $\mathrm{WO}_{3} \cdot \mathrm{H}_{2} \mathrm{O}$ además de estar asociado con la vibración antisimétrica de la extensión de los enlaces (W-O-W) de dichas especies. También es característico de la vibración debida a la flexión de los enlaces (O-W-O) en el $\mathrm{WO}_{3}$ amorfo $[33,34]$.

El segundo pico más característico es el pico ancho centrado a $660-690 \mathrm{~cm}^{-1} \mathrm{y}$ surge debido a la vibración del estiramiento simétrico de los enlaces (O-W-O) en el $\mathrm{WO}_{3}$ hidratado $[12,35,36]$.

No obstante, el pico observado a $816 \mathrm{~cm}^{-1}$ en las muestras anodizadas es otro pico característico de las nanoestructuras de $\mathrm{WO}_{3}$, pero en este caso se asocia a la 
presencia de formas cristalinas de $\mathrm{WO}_{3}$, aunque también se ha asociado con el modo de estiramiento de los enlaces $\mathrm{O}-\mathrm{W}-\mathrm{O}$ de muestras hidratadas.

Además, el pico que se observa a aproximadamente $960 \mathrm{~cm}^{-1}$, aunque de manera menos pronunciada que los anteriores, también ha sido considerado como un marcador de estructuras amorfas e hidratadas $\mathrm{WO}_{3} \cdot \mathrm{xH}_{2} \mathrm{O}[32,37,38]$.

Con estas asociaciones se puede concluir que las nanoestructuras sintetizadas mediante anodizado electroquímico antes de someterlas a un tratamiento térmico son parcialmente cristalinas, ya que presentan varios indicadores que demuestran la presencia de una estructura amorfa, y poseen cierto grado de hidratación. Este nivel de hidratación de las nanoestructuras es el resultado de la inestabilidad termodinámica de los peroxowolframatos [39-41], que se descomponen en $\mathrm{WO}_{3}$ deshidratado (como se muestra en la ecuación 4.5). Por lo tanto, la descomposición de peroxowolframatos desempeñó un importante papel en el modo de formación de las nanoestructuras de $\mathrm{WO}_{3}$.

Una vez analizadas las muestras antes de someterlas a tratamiento térmico y concluida la necesidad de éste para poder obtener nanoestructuras totalmente cristalinas y deshidratadas, se van a analizar los espectros obtenidos de las nanoestructuras sintetizadas con $\mathrm{H}_{2} \mathrm{SO}_{4}$ como electrolito y calentadas en las diferentes temperaturas y atmósferas comentadas con anterioridad.

Los espectros Raman de las muestras de $\mathrm{WO}_{3}$ calentadas en atmósfera de aire a diferentes temperaturas están representados en la Figura 4.13, los obtenidos de las muestras calentadas en atmósfera de nitrógeno están representados en la Figura 4.14, y finalmente, los espectros de las muestras calentadas en atmósfera de argón están representados en la Figura 4.15. 


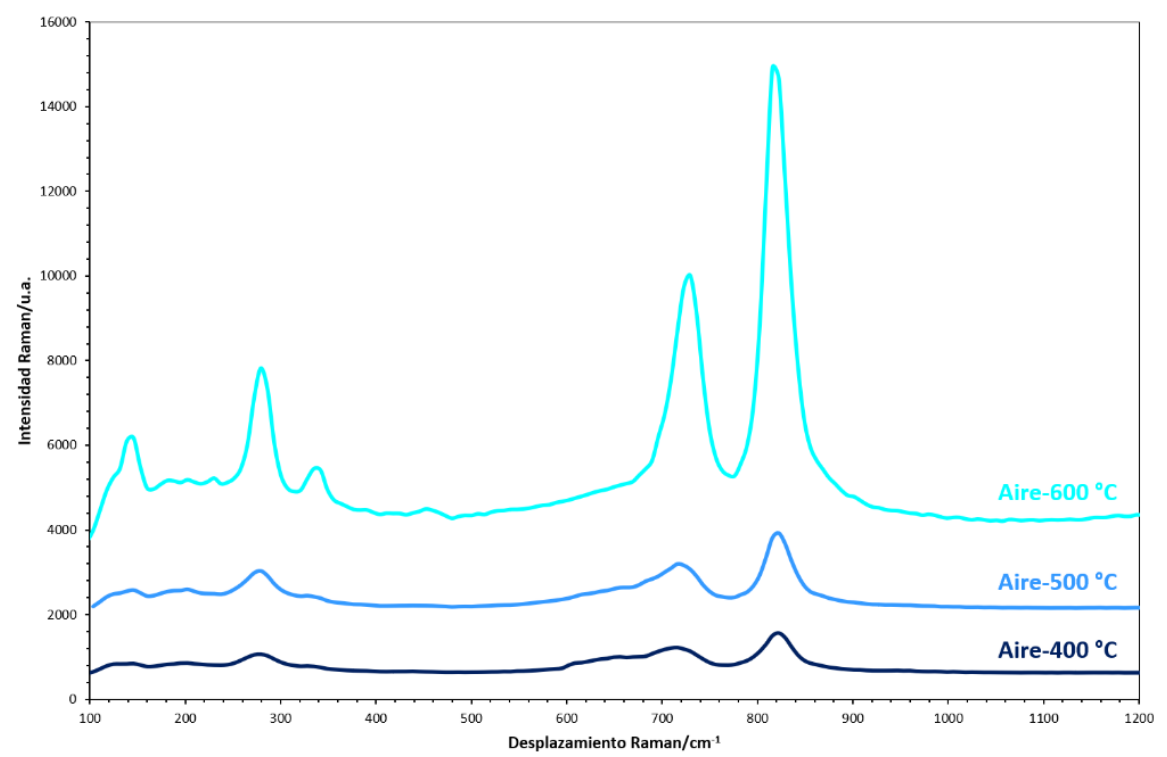

Figura 4.13. Espectros Raman obtenidos para las muestras sintetizadas por anodizado electroquímico en medio $\mathrm{H}_{2} \mathrm{SO}_{4}$, y calentadas a diferentes temperaturas y en atmósfera de aire.

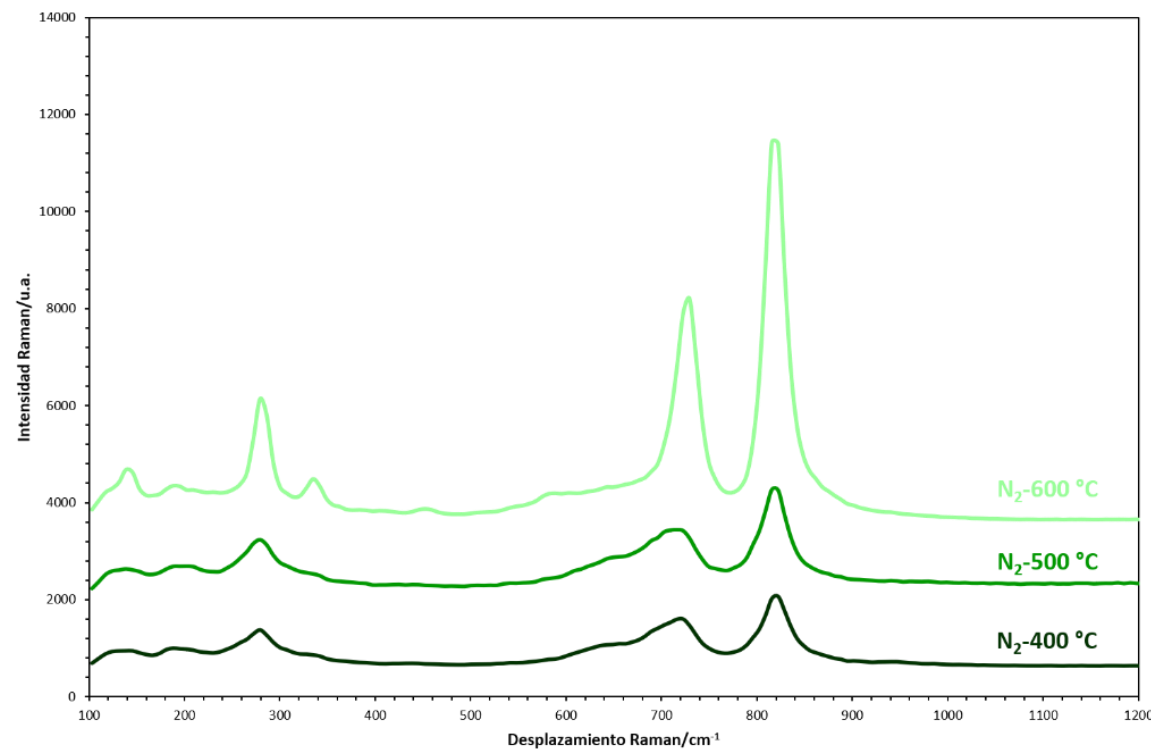

Figura 4.14. Espectros Raman obtenidos para las muestras sintetizadas por anodizado electroquímico en medio $\mathrm{H}_{2} \mathrm{SO}_{4}$, y calentadas a diferentes temperaturas y en atmósfera de nitrógeno. 


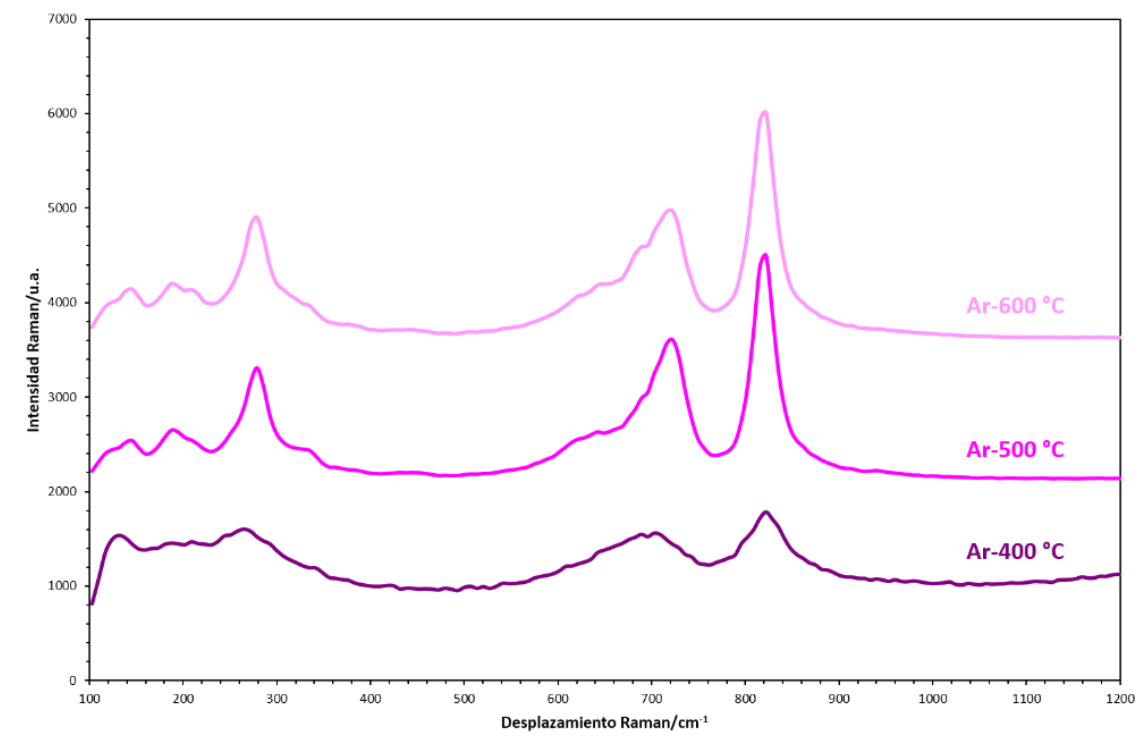

Figura 4.15. Espectros Raman obtenidos para las muestras sintetizadas por anodizado electroquímico en medio $\mathrm{H}_{2} \mathrm{SO}_{4}$, y calentadas a diferentes temperaturas y en atmósfera de argón.

La forma de todos los espectros es similar, independientemente de las condiciones de calentamiento. Los picos característicos del $\mathrm{WO}_{3}$ cristalino se observan en todos los casos en mayor o menor medida a $125 \mathrm{~cm}^{-1}, 195 \mathrm{~cm}^{-1}, 275$ $\mathrm{cm}^{-1}, 715 \mathrm{~cm}^{-1}$ y $822 \mathrm{~cm}^{-1}$. Además, otro cambio común en todos los casos es la división de la banda ancha entre 200 y $270 \mathrm{~cm}^{-1}$, presente en las muestras antes de someterlas al tratamiento térmico, que se convirtió en tres picos separados después del tratamiento térmico [42]. Estos picos fueron consecuencia de la vibración de la flexión de los enlaces (O-W-O) cristalinos (tanto monoclínicos como ortorrómbicos) del $\mathrm{WO}_{3}[43,44]$.

Sin embargo, hay algunas diferencias. A $400{ }^{\circ} \mathrm{C}$, se puede discernir un hombro a alrededor de $650 \mathrm{~cm}^{-1}$, que se ha asociado habitualmente con $\mathrm{WO}_{3}$ hidratado y amorfo $\left(\mathrm{WO}_{3} \cdot \mathrm{xH}_{2} \mathrm{O}\right)[3,45]$. Estas bandas desaparecieron cuando la temperatura de calentamiento aumentó en las atmósferas de aire y $\mathrm{N}_{2}$ (Figura 4.13 y Figura 4.14), lo que indica un mayor grado de deshidratación y cristalinidad de las nanoestructuras tratadas en esas condiciones. En cambio, en atmósfera de argón, se puede ver el hombro en todas la temperaturas de calentamiento. Además, a 
$600{ }^{\circ} \mathrm{C}$ para atmósferas de aire y $\mathrm{N}_{2}$, tanto el pico centrado a $275 \mathrm{~cm}^{-1}$ como el centrado en $820 \mathrm{~cm}^{-1}$ se hizo mucho más evidente. Estos picos se han relacionado con el $\mathrm{WO}_{3}$ cristalino, lo que confirma una mayor cristalinidad de las muestras calentadas a $600{ }^{\circ} \mathrm{C}$ en atmósferas de aire y $\mathrm{N}_{2}[6,46]$.

Por otro lado, los espectros de las muestras tratadas en atmósfera de Ar (Figura 4.15) no mostraron la misma tendencia que las muestras calentadas en otras atmósferas. En este caso, los picos característicos de estructuras cristalinas son más pronunciados y definidos en las muestras calentadas a $500{ }^{\circ} \mathrm{C}$, por lo tanto, se puede concluir que la tendencia observada en las otras atmósferas, en donde la cristalinidad aumentaba con la temperatura, no es la que se sigue en este caso, ya que las nanoestructuras calentadas a $600{ }^{\circ} \mathrm{C}$ tienen una menor cristalinidad que las calentadas a $500^{\circ} \mathrm{C}$.

Todos los cambios descritos anteriormente son debidos principalmente a la desorción de las moléculas de agua presentes en las nanoestructuras de wolframio. Este tipo de espectros son los típicos en cristales monoclínicos de $\mathrm{WO}_{3}$. Por tanto, a mayor temperatura de deshidratación, se observa una mayor intensidad y definición de los picos, dando lugar a nanoestructuras con una estructura cristalina monoclínica $[41,47,48]$.

Con el fin de poder ver mejor la comparación entre las atmósferas empleadas en el tratamiento térmico de deshidratación de las nanoestructuras sintetizadas en medio $\mathrm{H}_{2} \mathrm{SO}_{4}$, y concluir en cuál se produce una mayor deshidratación, se ha representado en la Figura 4.16 los espectros superpuestos a la temperatura a la que las nanoestructuras son más cristalinas $\left(600^{\circ} \mathrm{C}\right)$. 


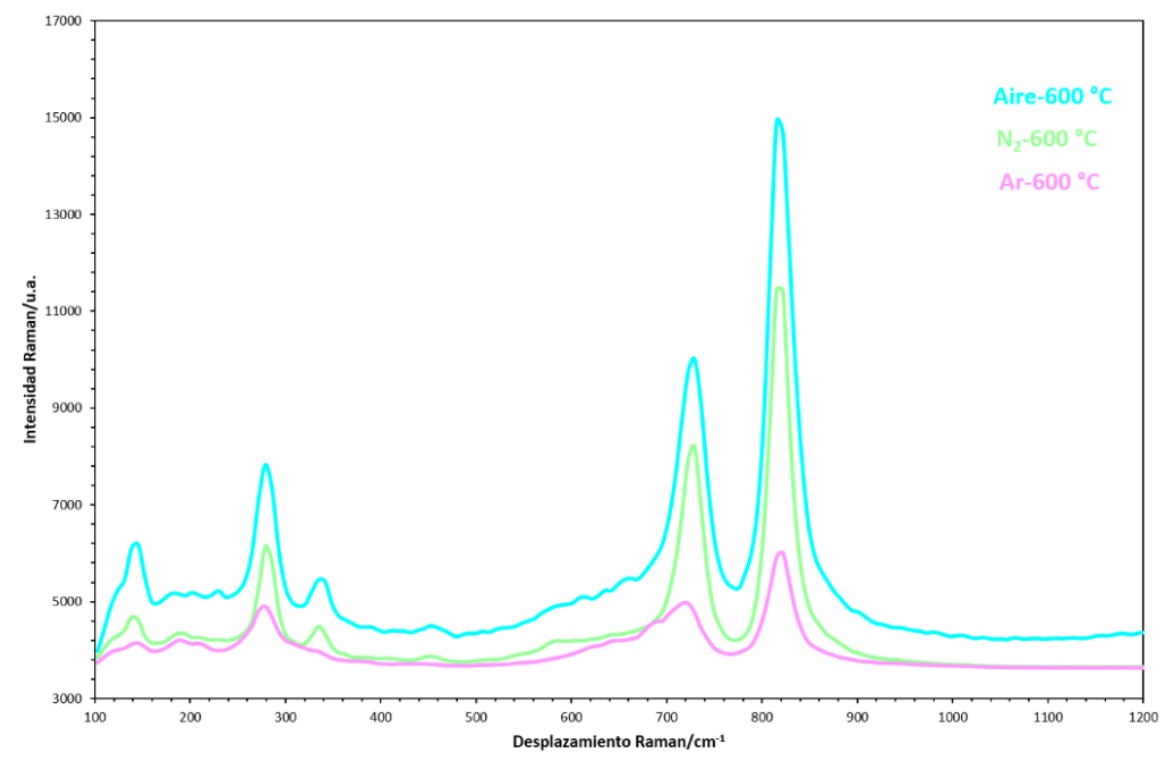

Figura 4.16. Espectros Raman obtenidos para las nanoestructuras de $\mathrm{WO}_{3}$ sintetizadas por anodizado electroquímico en medio $\mathrm{H}_{2} \mathrm{SO}_{4}$, calentadas a diferentes atmósferas y a $600{ }^{\circ} \mathrm{C}$.

Por tanto, comparando todos los espectros obtenidos con $\mathrm{H}_{2} \mathrm{SO}_{4}$, se puede concluir que las muestras calentadas a $600{ }^{\circ} \mathrm{C}$ y en atmósfera de aire presentan una estructura más cristalina y con mayor grado de deshidratación ya que los picos que se observan son los característicos de este tipo de estructura.

Finalmente, esta conclusión es respaldada por los resultados mostrados en las imágenes del FE-SEM, en donde se podían observar unas nanoestructuras más definidas además de presentar la forma deseada de nanohilos en el caso de utilizar una atmósfera de aire a una temperatura de $600^{\circ} \mathrm{C}$.

Una vez analizadas todas las muestras anodizadas con $\mathrm{H}_{2} \mathrm{SO}_{4}$, se analizarán las obtenidas con $\mathrm{CH}_{4} \mathrm{O}_{3} \mathrm{~S}$ y $\mathrm{HNO}_{3}$, pero en estos casos solo se mostrarán los datos obtenidos en atmósfera de aire, ya que se ha comprobado en los resultados obtenidos en FE-SEM que con esas condiciones de calentamiento se obtenían unas nanoestructuras más definidas.

En la Figura 4.17, se muestra el espectro Raman de las nanoestructuras obtenidas con $\mathrm{CH}_{4} \mathrm{O}_{3} \mathrm{~S}$ y calentadas en aire a las tres temperaturas elegidas para el diseño de 
experimentos, mientras que en la Figura 4.18 se muestra el espectro de las nanoestructuras obtenidas con $\mathrm{HNO}_{3}$.

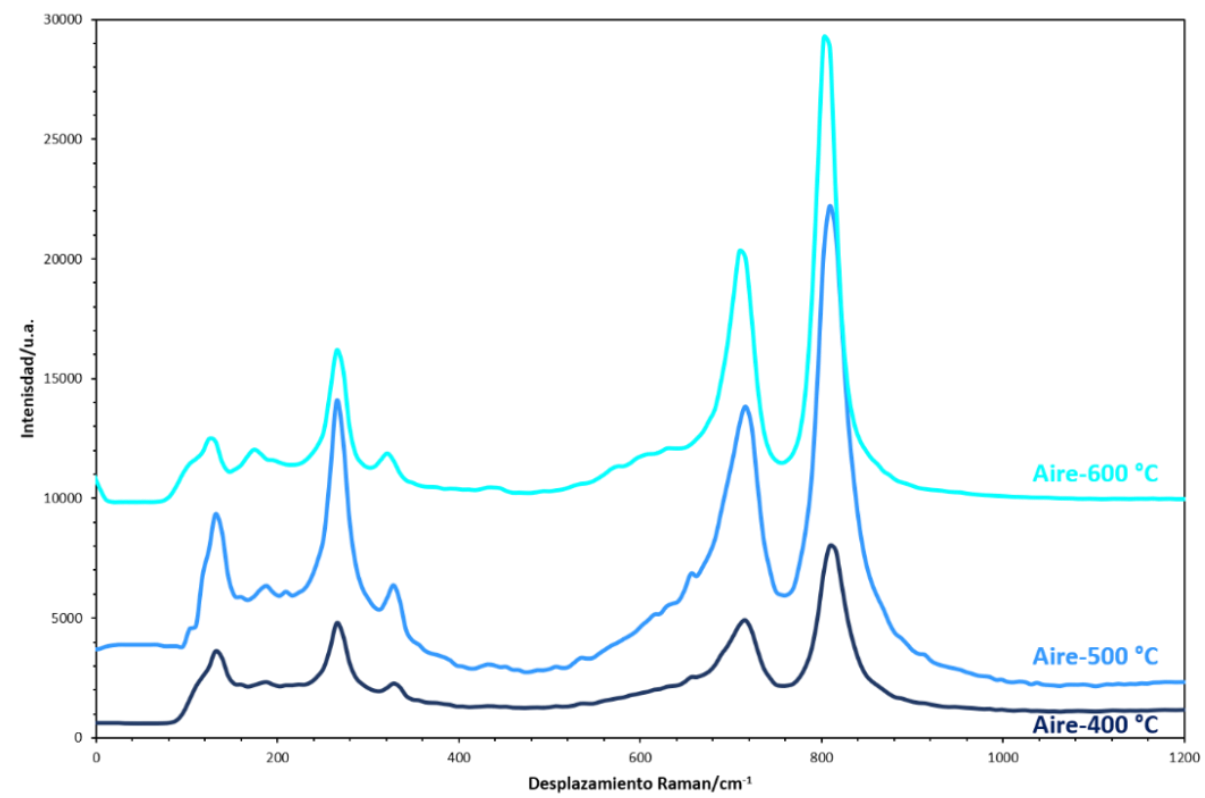

Figura 4.17. Espectros Raman obtenidos para las muestras sintetizadas por anodizado electroquímico con $\mathrm{CH}_{4} \mathrm{O}_{3} \mathrm{~S}$, calentadas a diferentes temperaturas. 


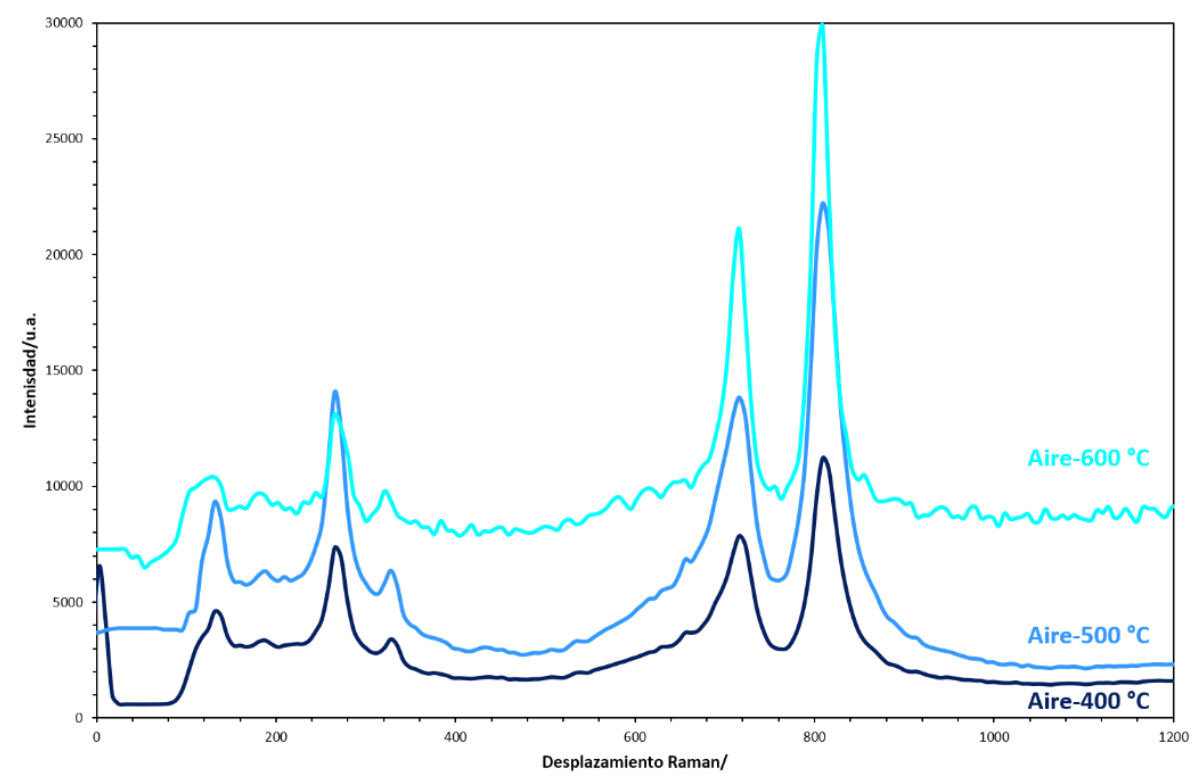

Figura 4.18. Espectros Raman obtenidos para las muestras sintetizadas por anodizado electroquímico con $\mathrm{HNO}_{3}$, calentadas a diferentes temperaturas.

En ambas figuras se observa que vuelven a estar los picos característicos de nanoestructuras de $\mathrm{WO}_{3}$ cristalinas, como son los que aparecen a $125 \mathrm{~cm}^{-1}, 275$ $\mathrm{cm}^{-1}, 325 \mathrm{~cm}^{-1}, 700 \mathrm{~cm}^{-1}$ y $825 \mathrm{~cm}^{-1}$ que se producen por la vibración de la flexión de los enlaces $(\mathrm{O}-\mathrm{W}-\mathrm{O})$ cristalinos del $\mathrm{WO}_{3}$. Por tanto, se puede afirmar nuevamente que al someterse a tratamiento térmico desaparecen los picos o bandas característicos de estructuras amorfas o hidratadas para dar lugar a nanoestructuras cristalinas.

Finalmente, en la Figura 4.19 se muestra el espectro Raman de las nanoestructuras obtenidas con los diferentes ácidos y calentadas en aire a $600{ }^{\circ} \mathrm{C}$ para comprobar que en los tres casos las muestras presentan una estructura cristalina que proporciona a las nanoestructuras una propiedades fotoquímicas mejoradas. 


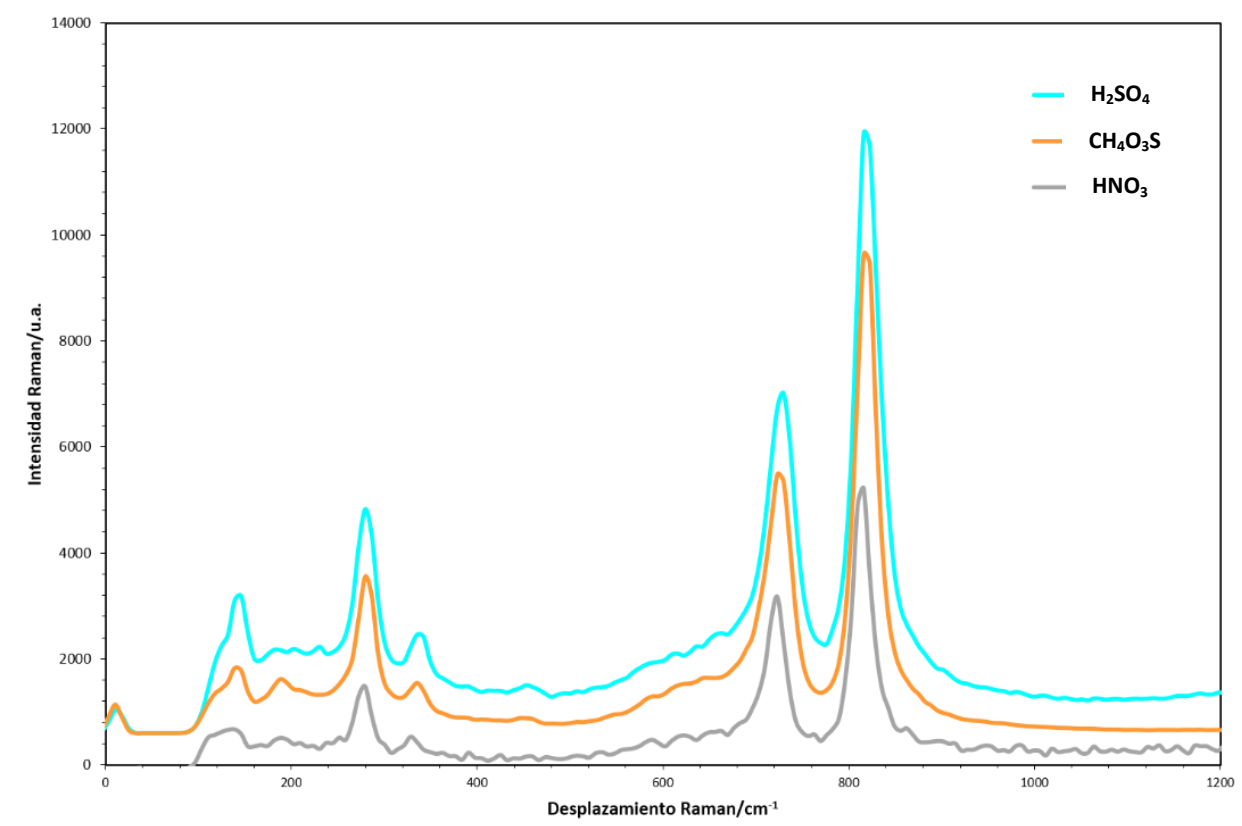

Figura 4.19. Espectros Raman obtenidos para las muestras sintetizadas por anodizado electroquímico con los diferentes ácidos, calentadas a $600^{\circ} \mathrm{C}$ en aire.

Al comparar el espectro obtenido con los diferentes ácidos, se puede ver como la muestra sintetizada con $\mathrm{H}_{2} \mathrm{SO}_{4}$ y $\mathrm{CH}_{4} \mathrm{O}_{3} \mathrm{~S}$ presenta una intensidad y definición de picos muy similar ya que, si se tiene en cuenta que la línea base de la muestra anodizado con $\mathrm{H}_{2} \mathrm{SO}_{4}$ está por encima de la de la muestra anodizada con $\mathrm{CH}_{4} \mathrm{O}_{3} \mathrm{~S}$, los picos prácticamente coincidirían, indicando que presentan una cristalinidad muy parecida entre ellas. Sin embargo, al comparar estos picos con los obtenidos en medio $\mathrm{HNO}_{3}$, se observa que esta última muestra tiene menor intensidad de pico dando lugar a muestras con menor grado de cristalinidad.

\subsection{Caracterización topográfica mediante Microscopía de fuerza atómica (AFM).}

La microscopía de fuerza atómica (AFM) es una de las herramientas más utilizadas para obtener imágenes y analizar estructuras a escala nanométrica. La AFM se ha utilizado para obtener información sobre la topografía de la superficie de las muestras. La morfología de la superficie y la rugosidad de las estructuras se han examinado utilizando el modo AC a temperatura ambiente y con un cantilever de 
silicio (con una frecuencia de resonancia de aproximadamente $240 \mathrm{kHz}$ ) y la rugosidad de la media cuadrática se calculó con el software de AFM Project Five en imágenes de tamaño de escaneo de $5 \mu \mathrm{m} \times 5 \mu \mathrm{m}$. Las imágenes AFM de las nanoestructuras obtenidas con $\mathrm{H}_{2} \mathrm{SO}_{4}$ y calentadas en aire a $400{ }^{\circ} \mathrm{C}$ se muestran en la Figura 4.20a), en la $4.20 \mathrm{~b}$ ) calentadas a $500{ }^{\circ} \mathrm{C}$ y en la $4.20 \mathrm{c}$ ) calentadas a $600{ }^{\circ} \mathrm{C}$. Las obtenidas con $\mathrm{CH}_{4} \mathrm{O}_{3} \mathrm{~S}$ y calentadas en aire a $400{ }^{\circ} \mathrm{C}$ se muestran en la Figura 4.21a), en la $4.21 \mathrm{~b}$ ) se muestran las calentadas a $500{ }^{\circ} \mathrm{C}$ y en la $4.21 \mathrm{c}$ ) las calentadas a $600{ }^{\circ} \mathrm{C}$. Finalmente, las sintetizadas con $\mathrm{HNO}_{3}$ y calentadas en aire a $400{ }^{\circ} \mathrm{C}$ se muestran en la Figura $4.22 \mathrm{a}$ ), en la $4.22 \mathrm{~b}$ ) las calentadas a $500{ }^{\circ} \mathrm{C}$ y la $4.22 \mathrm{c}$ ) las calentadas a $600^{\circ} \mathrm{C}$.

Como se puede ver en estas imágenes, las muestras están formadas por nanogranos esféricos del orden de $400 \mathrm{~nm}$ en el caso de las obtenidas con $\mathrm{H}_{2} \mathrm{SO}_{4} \mathrm{Y}$ $\mathrm{CH}_{4} \mathrm{O}_{3} \mathrm{~S}$, y del orden de $800 \mathrm{~nm}$ las obtenidas con $\mathrm{HNO}_{3}$, todos ellos haciendo buen contacto entre sí. Las micrografías también muestran una estructura altamente porosa con conglomerados de granos. Las películas de óxido de wolframio sintetizadas con $\mathrm{CH}_{4} \mathrm{O}_{3} \mathrm{~S}$ son más porosas que las películas obtenidas con $\mathrm{HNO}_{3}$, pero similares a las de $\mathrm{H}_{2} \mathrm{SO}_{4}$. Este tipo de estructura se considera esencial para el funcionamiento eficiente de los materiales fotoelectroquímicos, ya que exhibe una buena transferencia de carga y por tanto, una gran conductividad eléctrica $[49,50]$.

En las nanoestructuras obtenidas con $\mathrm{H}_{2} \mathrm{SO}_{4}$ y $\mathrm{CH}_{4} \mathrm{O}_{3} \mathrm{~S}$ se puede ver un gran crecimiento de los nanogranos (picos blanquecinos) de forma aglomerada dando como resultado una mayor porosidad, mientras que en las obtenidas con $\mathrm{HNO}_{3}$ son mucho menos pronunciados, dando lugar a una menor rugosidad. Los valores promedio de rugosidad de las películas de $\mathrm{WO}_{3}$ calentadas a diferentes temperaturas se muestran en las Figuras $4.20,4.21$ y 4.22 con la abreviatura de $\mathrm{S}_{\mathrm{a}}$. El valor promedio de rugosidad de las películas aumenta con el aumento de la temperatura de calentamiento, pudiendo deberse a la aglomeración de los microcristales a temperaturas más altas [51-53]. La mejora de la morfología de la superficie y el crecimiento gradual con más centros de nucleación se debe a una energía térmica relativamente más alta. Además, una morfología de superficie más rugosa es útil para la adsorción de compuestos orgánicos, y, por tanto, es útil para mejorar la degradación fotoelectrocatalítica [54-56] debido a una mayor área superficial. 
Como conclusión, la muestra que presenta una mayor rugosidad y porosidad es la sintetizada con $\mathrm{CH}_{4} \mathrm{O}_{3} \mathrm{~S}$ y calentada en aire a $600{ }^{\circ} \mathrm{C}$, siendo la que presentaría una mejor actividad fotocatalítica, como se había predicho al analizar las imágenes FE-SEM.
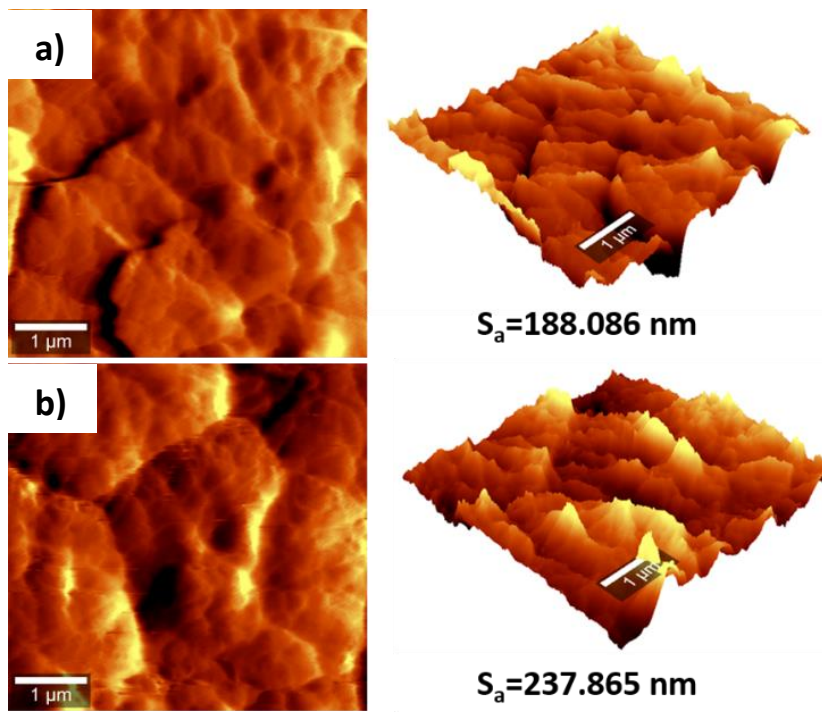

$\mathrm{S}_{\mathrm{a}}=188.086 \mathrm{~nm}$
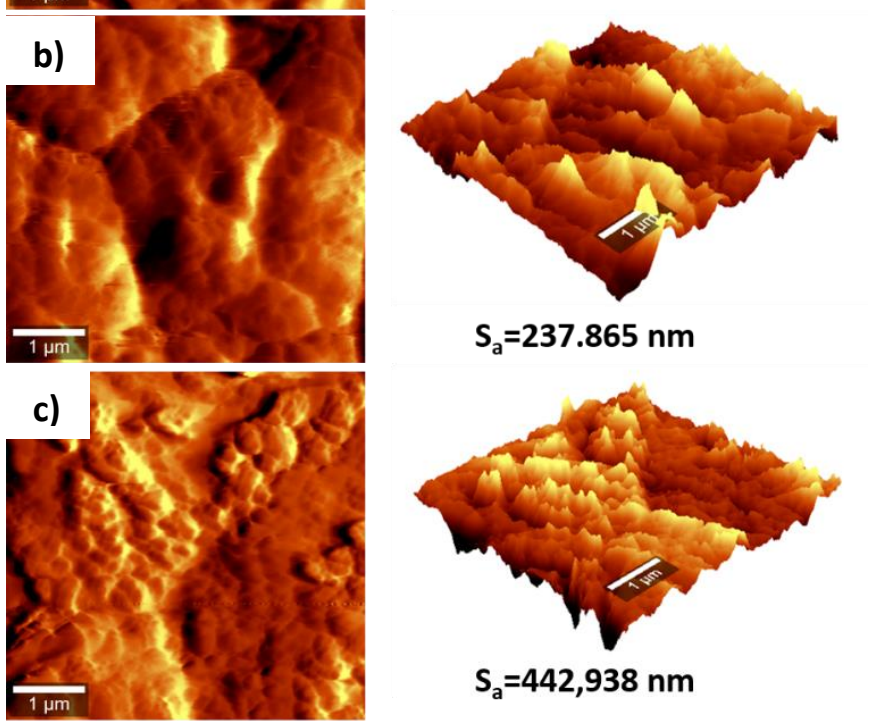

$S_{a}=442,938 \mathrm{~nm}$

Figura 4.20. Imágenes AFM en dos y tres dimensiones de las nanoestructuras obtenidas con $\mathrm{H}_{2} \mathrm{SO}_{4}$ y calentadas en aire a a) $400^{\circ} \mathrm{C}$, b) $500^{\circ} \mathrm{C}$ y c) $600{ }^{\circ} \mathrm{C}$. 

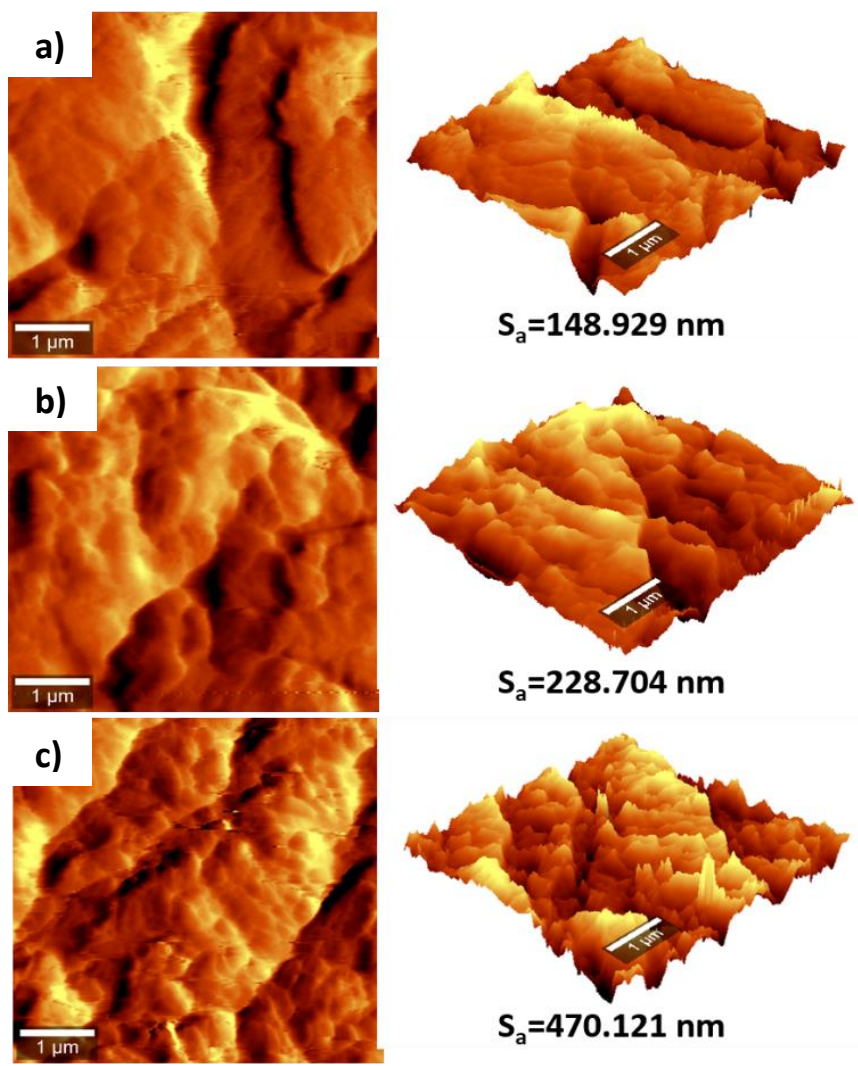

Figura 4.21. Imágenes AFM en dos y tres dimensiones de las nanoestructuras obtenidas con $\mathrm{CH}_{4} \mathrm{O}_{3} \mathrm{~S}$ y calentadas en aire a a) $400^{\circ} \mathrm{C}$, b) $500^{\circ} \mathrm{C}$ y c) $600^{\circ} \mathrm{C}$. 

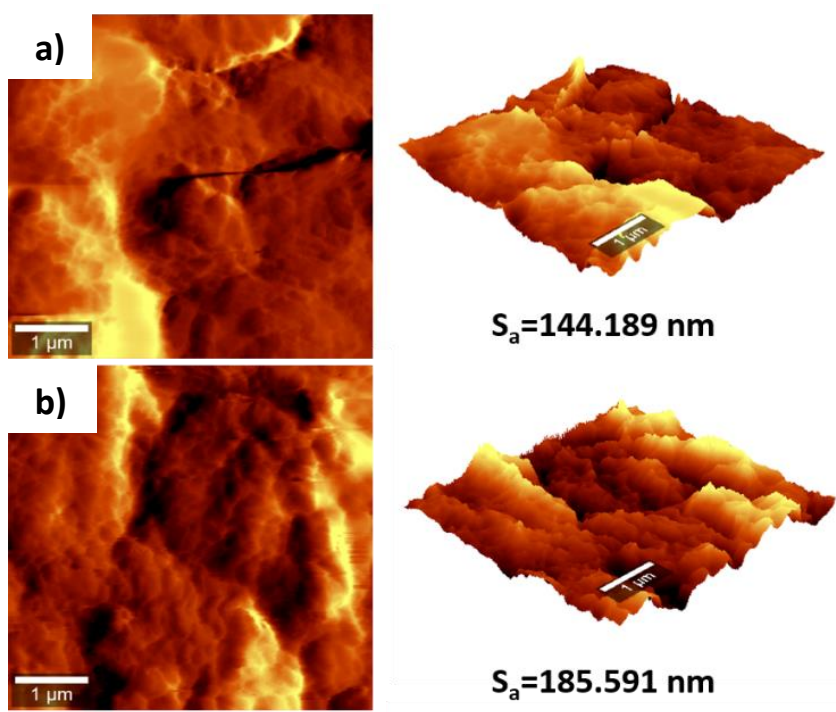

$$
S_{a}=144.189 \mathrm{~nm}
$$
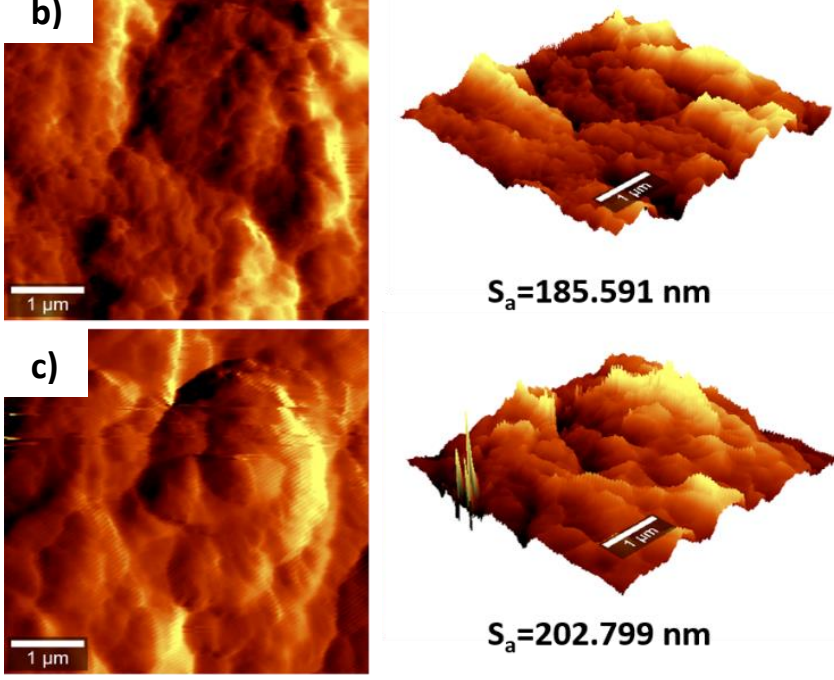

$$
\mathrm{S}_{\mathrm{a}}=185.591 \mathrm{~nm}
$$

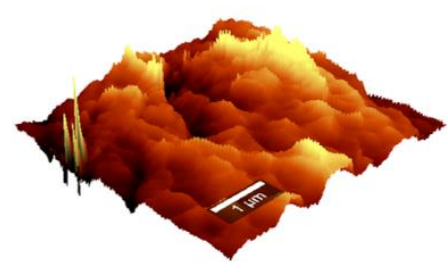

$$
S_{a}=202.799 \mathrm{~nm}
$$

Figura 4.22. Imágenes AFM en dos y tres dimensiones de las nanoestructuras obtenidas con $\mathrm{HNO}_{3}$ y calentadas en aire a a) $400^{\circ} \mathrm{C}$, b) $500^{\circ} \mathrm{C}$ y c) $600^{\circ} \mathrm{C}$.

\subsection{Caracterización superficial de las nanoestructuras mediante Espectroscopía} Fotoelectrónica de Rayos X (XPS).

Con el fin de obtener información cualitativa y cuantitativa de todos los elementos presentes en las nanoestructuras, se ha realizado un análisis de Espectroscopía Fotoelectrónica de Rayos $\mathrm{X}$ (XPS) de las tres muestras sintetizadas con los tres diferentes electrolitos $\left(\mathrm{H}_{2} \mathrm{SO}_{4}, \mathrm{CH}_{4} \mathrm{O}_{3} \mathrm{~S}\right.$ y $\left.\mathrm{HNO}_{3}\right)$ y posteriormente calentadas en aire a $600^{\circ} \mathrm{C}$ ya que eran las condiciones de calentamiento óptimas. En esta técnica se realiza un análisis de los estados electrónicos del núcleo y de la valencia (electrones de enlace) que proporciona información sobre la naturaleza química de las muestras. El fenómeno fundamental que subyace al XPS es el 
efecto fotoeléctrico que describe la expulsión de electrones de una superficie cuando los fotones inciden sobre ella. La energía cinética (o energía de enlace) del electrón expulsado es característica de cada elemento y su estado químico. En la Figura 4.23 se muestra el espectro XPS completo de las tres muestras analizadas.

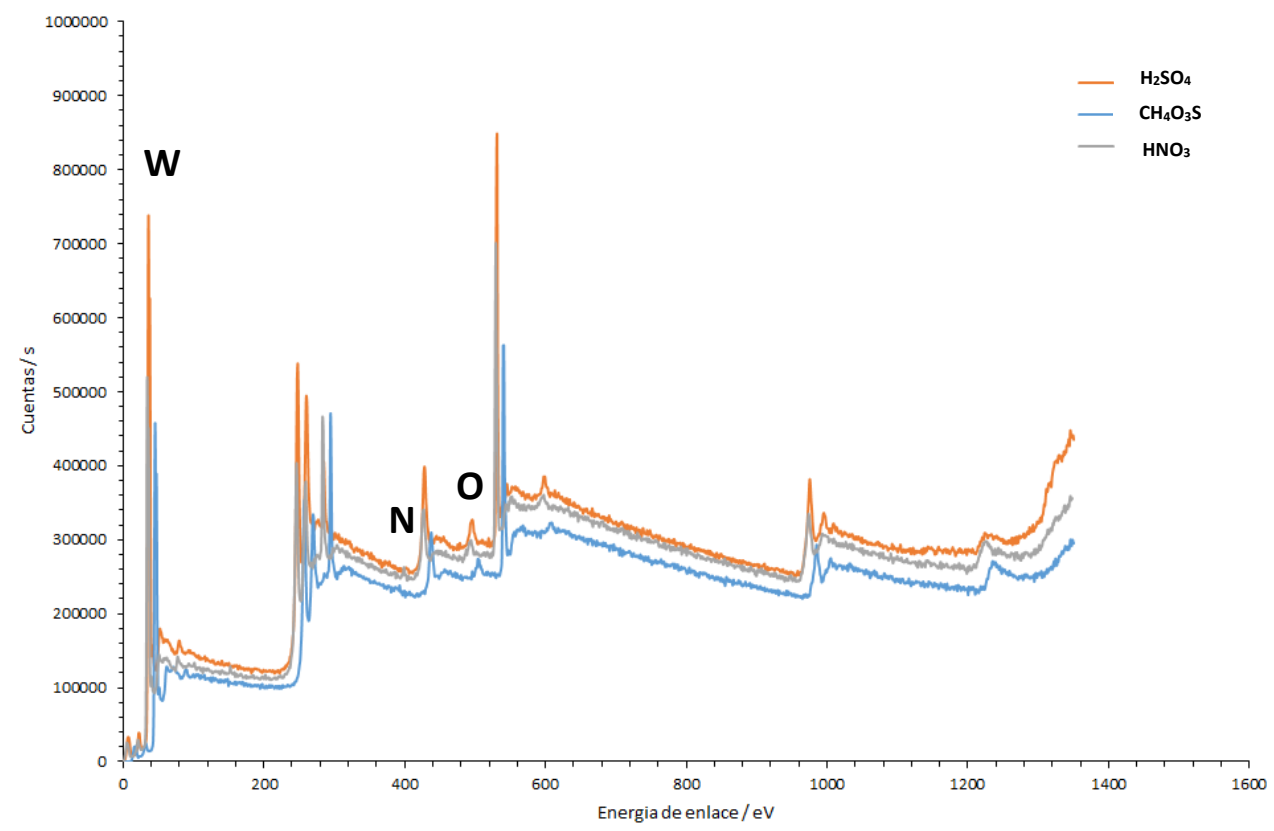

Figura 4.23. Espectro XPS de las muestras sintetizadas con $\mathrm{H}_{2} \mathrm{SO}_{4}, \mathrm{CH}_{4} \mathrm{O}_{3} \mathrm{~S}$ y $\mathrm{HNO}_{3}$.

Aunque en el espectro de la Figura 4.23 parece que el contenido de estos elementos es similar, los espectros de alta resolución revelan que existe una gran diferencia entre los estados de valencia de estos elementos y esto puede influir en sus actividades fotocatalíticas. Con los datos obtenidos del análisis se puede afirmar que los elementos que hay presentes en las nanoestructuras son wolframio, oxígeno y nitrógeno. A continuación, se va a realizar una comparación cuantitativa de estos elementos en las tres muestras analizadas.

\subsubsection{Wolframio.}

El primer elemento detectado en el espectro XPS de las tres muestras ha sido el wolframio. En las Figuras 4.24, 4.25 y 4.26 se muestran los espectros XPS de los picos asociados al wolframio de las muestras sintetizadas con $\mathrm{H}_{2} \mathrm{SO}_{4}, \mathrm{CH}_{4} \mathrm{O}_{3} \mathrm{~S}$ y $\mathrm{HNO}_{3}$ respectivamente. En los tres casos se pueden observar dos picos 
principales, como son el $\mathrm{W}_{4} \mathrm{f}_{7 / 2}$ y el $\mathrm{W}_{4} \mathrm{f}_{5 / 2}$ (en color negro). Además, estos picos se pueden deconvular con el fin de obtener picos independientes que se asocian a estados del wolframio diferentes. En este caso, se va a realizar la deconvolución del pico $\mathrm{WHf}_{7 / 2}$, ya que es la que se realiza según la bibliografía. Al realizar la deconvolución del $W^{4} f_{7 / 2}$ se observan tres picos asociados al $W$. Los picos aparecen en $34.6 \mathrm{eV}\left(\mathrm{W}_{4} \mathrm{f}_{7 / 2} \mathrm{Scan} A\right.$, de color azul en los tres gráficos), $35.5 \mathrm{eV}$ $\left(\mathrm{W}_{4} \mathrm{f}_{7 / 2} \mathrm{Scan} \mathrm{B}\right.$, de color naranja en los tres gráficos) y $36.4 \mathrm{eV}\left(\mathrm{W} 4 \mathrm{f}_{7 / 2} \mathrm{Scan} \mathrm{C}\right.$, de color verde en los tres gráficos). El pico asociado a la generación de fotoelectrones emitidos por átomos de $\mathrm{W}$ con estado de oxidación $+6\left(\mathrm{WO}_{3}\right)$, es decir, cuando se tiene óxido de wolframio estequiométrico, es el segundo pico $\left(\mathrm{W}_{4} \mathrm{f}_{7 / 2} \mathrm{Scan} B\right)$, que aparece a $35.5 \mathrm{eV}$ [57]. En cambio, el primer y tercer pico, están asociados a vacantes o defectos en las nanoestructuras. El primero de ellos ( $W 4 f_{7 / 2}$ Scan $\left.A\right)$ hace referencia a los fotoelectrones emitidos por los átomos de wolframio cerca de las vacantes de oxígeno, donde el estado de oxidación de $W$ es menor que +6 (subestequiométrico $\left.\mathrm{WO}_{3-\mathrm{x}}\right)$. Finalmente, el tercer pico $\left(\mathrm{W}_{4} \mathrm{f}_{7 / 2} \mathrm{Scan} \mathrm{C}\right)$, está asociado a variaciones locales en la energía del nivel de vacío $\left(E_{\mathrm{vl}}\right)$ causada por defectos superficiales.

Tras analizar los tres gráficos conjuntamente se puede observar que el pico asociado al $\mathrm{W}^{+6}\left(\mathrm{~W}^{4} \mathrm{f}_{7 / 2} \mathrm{Scan} \mathrm{B}\right)$, y por tanto al óxido de wolframio estequimétrico, presenta mayor intensidad y mayor área en el caso de la muestra sintetizada con $\mathrm{H}_{2} \mathrm{SO}_{4}$, seguido de la muestra anodizada con $\mathrm{HNO}_{3}$, y finalmente, los que menor intensidad presentan son los de la muestra sintetizada con $\mathrm{CH}_{4} \mathrm{O}_{3} \mathrm{~S}$. Este resultado es coherente ya que cuanto menor sea la intensidad de los picos, menor es la cantidad de $\mathrm{W}^{+6}$, y por tanto, mayor cantidad de óxido de wolframio no estequimetrico $\left(\mathrm{WO}_{3-\mathrm{x}}\right)$ se encontrará, dando como resultado mayor cantidad de vacantes en la estructura.

Además, este resultado se confirma al analizar los datos obtenidos del pico asociado a las vacantes de oxígeno ( $\left(\mathrm{W}^{4} \mathrm{f}_{7 / 2} \mathrm{Scan} \mathrm{A}\right)$, ya que el pico que presenta mayor intensidad es el de la muestra obtenida con $\mathrm{CH}_{4} \mathrm{O}_{3} \mathrm{~S}$, seguido del de la muestra sintetizada con $\mathrm{HNO}_{3}$ y finalmente el que presenta menor intensidad es el obtenido con $\mathrm{H}_{2} \mathrm{SO}_{4}$. Por tanto, analizando ambos picos se puede afirmar que la muestra que presenta mayor cantidad de vacantes de oxígeno es la sintetizada con $\mathrm{CH}_{4} \mathrm{O}_{3} \mathrm{~S}$.

Finalmente, si se analiza el pico asociado a defectos superficiales ( $\mathrm{W}^{4} \mathrm{f}_{7 / 2}$ Scan C), se puede concluir que la muestra que presenta mayor densidad de defectos 
superficiales es la sintetizada con $\mathrm{HNO}_{3}$, seguida de la muestra sintetizada con $\mathrm{H}_{2} \mathrm{SO}_{4}$, y finalmente la que menos densidad de defectos superficiales presenta es la obtenida con $\mathrm{CH}_{4} \mathrm{O}_{3} \mathrm{~S}$. Este resultado se puede asociar a la incorporación del nitrógeno presente en el electrolito, dando como resultado nanoestructuras dopadas con nitrógeno. Además, este efecto también se verá reflejado en los picos asociados al oxígeno.

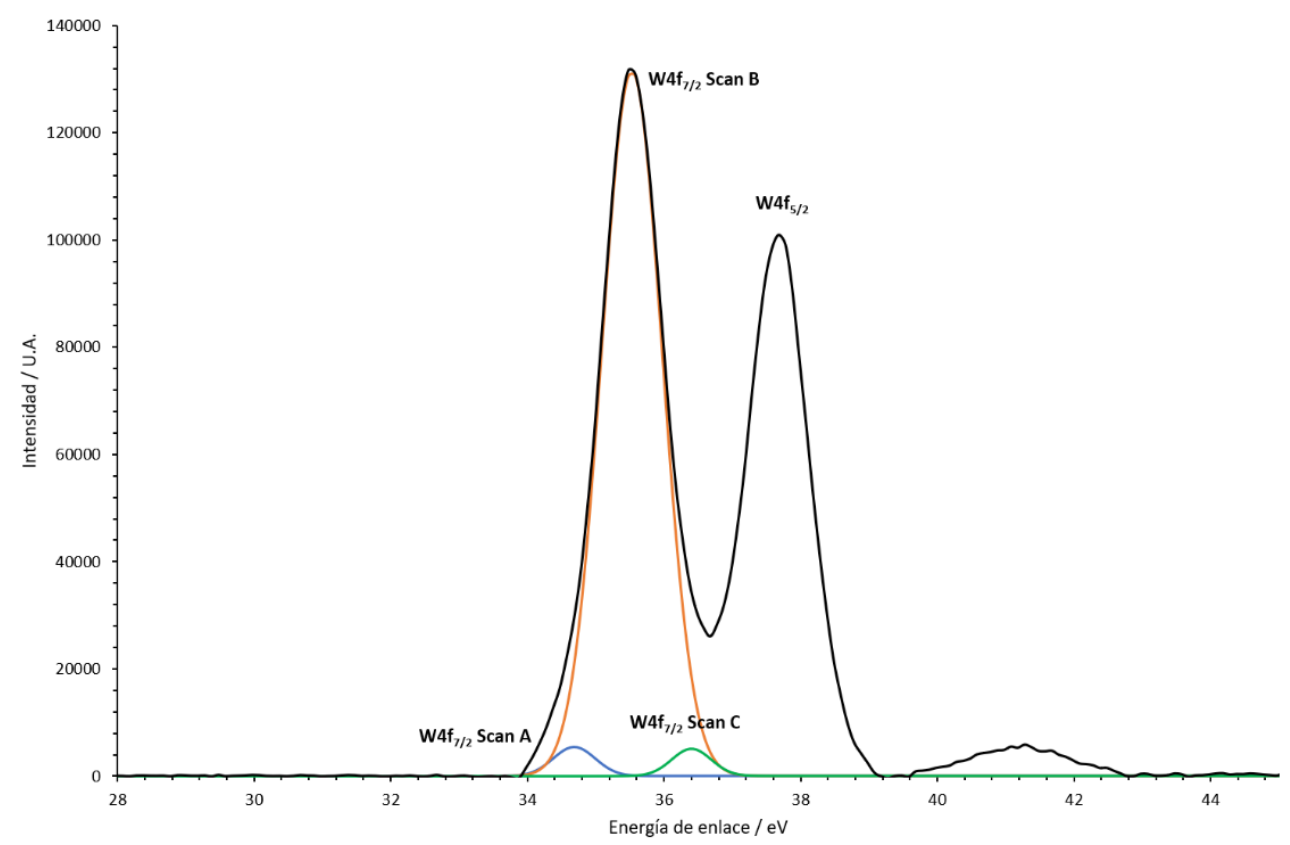

Figura 4.24. Espectros XPS de alta resolución de pico W4f de las muestras sintetizadas con $\mathrm{H}_{2} \mathrm{SO}_{4}$. 


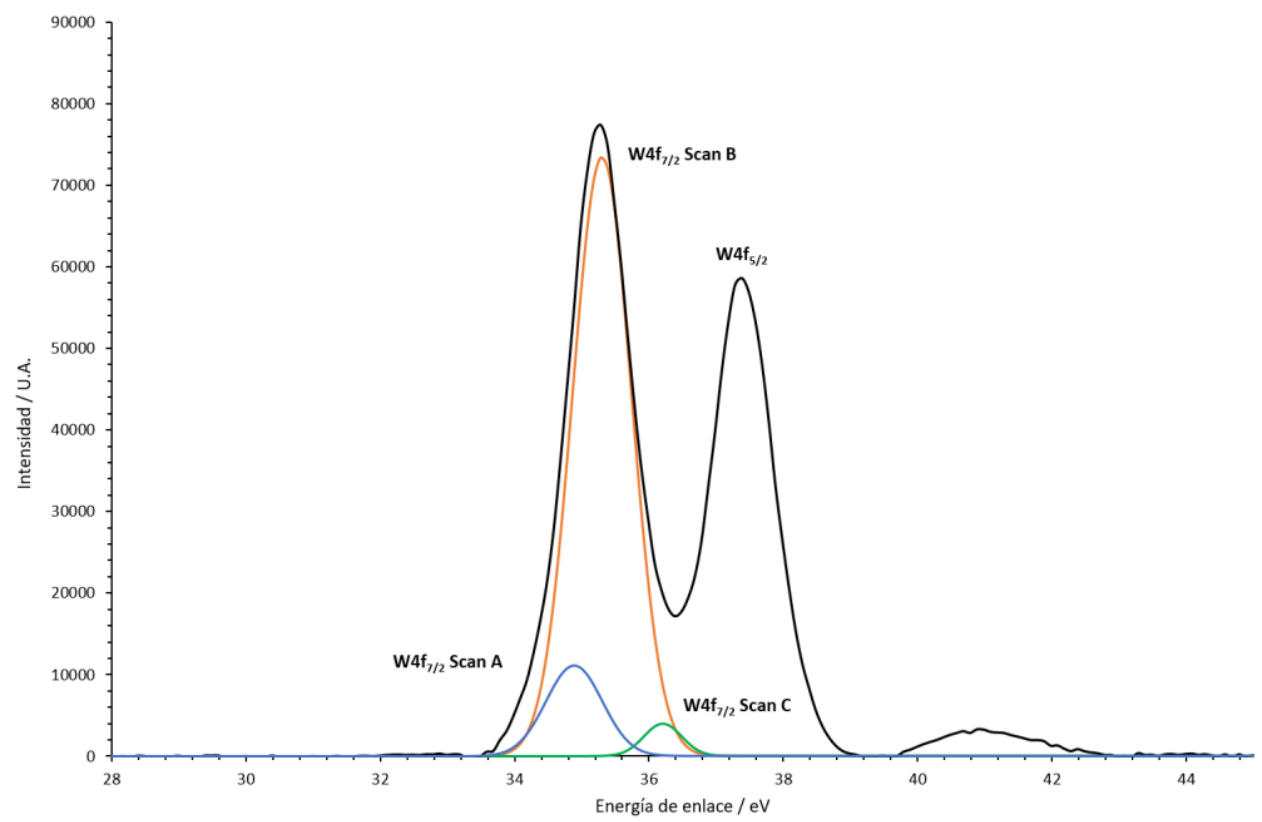

Figura 4.25. Espectros XPS de alta resolución de pico W4f de las muestras sintetizadas con $\mathrm{CH}_{4} \mathrm{O}_{3} \mathrm{~S}$.

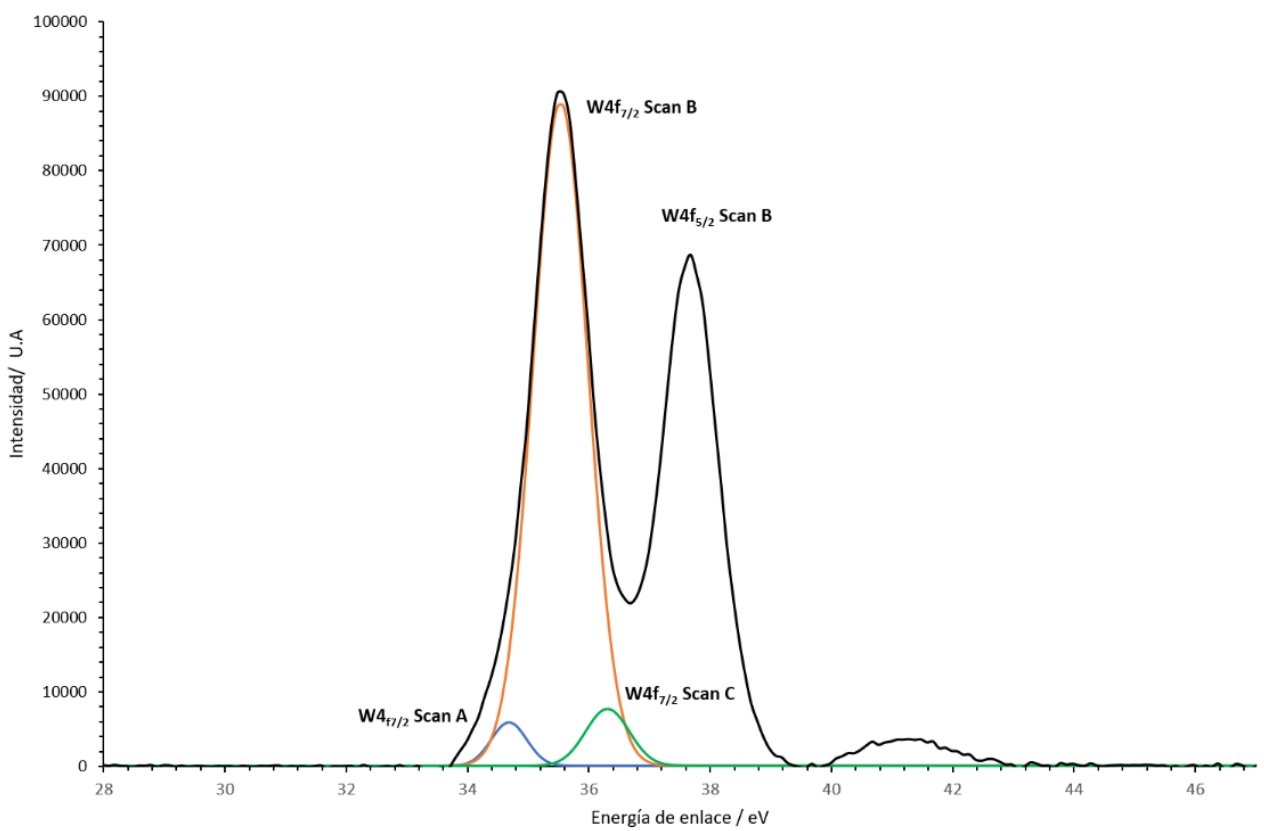

Figura 4.26. Espectros XPS de alta resolución de pico W4f de las muestras sintetizadas con $\mathrm{HNO}_{3}$. 
En la Tabla 4.2 se muestra el área normalizada del pico $W_{4 f_{7 / 2}}$ de las tres muestras, en donde se comprueba que el pico $W 4_{f / 2}$ Scan $B$ de la muestra anodizada en $\mathrm{CH}_{4} \mathrm{O}_{3} \mathrm{~S}$ presenta menor área y por tanto, menor cantidad de $\mathrm{W}$ en estado de oxidación +6 , dando como resultado mayor cantidad de vacantes en su estructura.

Tabla 4.2. Área del pico de $\mathrm{W}_{4} \mathrm{f}_{7 / 2}$ en el espectro XPS de alta resolucion en las tres muestras.

\begin{tabular}{|c|c|c|c|}
\cline { 2 - 4 } \multicolumn{1}{c|}{} & $\mathbf{H}_{2} \mathbf{S O}_{4}$ & $\mathbf{C H}_{4} \mathbf{O}_{3} \mathbf{S}$ & $\mathbf{H N O}_{3}$ \\
\hline $\mathbf{W} 4_{\mathrm{f} / 2}$ Scan A & 4191.9 & 11614.32 & 4350.6 \\
\hline $\mathbf{W} 4_{\mathrm{f} / 2}$ Scan B & 145013.7 & 80561.7 & 100958.3 \\
\hline $\mathbf{W} 4_{\mathrm{f} / 2}$ Scan C & 3672.14 & 2786.55 & 6960.88 \\
\hline
\end{tabular}

\subsubsection{Oxígeno}

Otro elemento detectado en el análisis XPS de las tres muestras ha sido el oxígeno. En las Figuras $4.27,4.28$ y 4.29 se muestran los resultados de la deconvolución (descomposición en tres picos) de la línea O1s para las muestras de óxido de wolframio sintetizadas con $\mathrm{H}_{2} \mathrm{SO}_{4}, \mathrm{CH}_{4} \mathrm{O}_{3} \mathrm{~S}$ y $\mathrm{HNO}_{3}$. En los tres casos la forma del espectro es similar, apareciendo tres picos claramente diferenciados.

El pico que aparece a una energía de enlace de $529.92 \mathrm{eV}$ (O1s Scan A) corresponde a los átomos de oxígeno $\mathrm{O}^{2-}$ en la red, sin embargo, los picos que aparecen a una energía de enlace de 531.5 (O1s Scan B) y 532.9 eV (O1s Scan C) están relacionados con defectos en las nanoestructuras. El primero de ellos se asocia a grupos hidroxilo $(-\mathrm{OH})$ presentes en la superficie de las muestras, mientras que el segundo de ellos está relacionado con las especies adsorbidas y con los átomos de oxígeno en estado 0 ;' es decir, vacantes de oxígeno $[58,59]$.

El aumento del contenido de grupos - $\mathrm{OH}$ en la superficie de los óxidos de wolframio no estequiométricos puede explicarse debido a la posibilidad de relleno de vacantes de oxígeno por el grupo - $\mathrm{OH}$. En ese caso, el catión $\mathrm{W}^{5+}$ debe estar en el centro del octaedro de cinco iones $\mathrm{O}^{2-}$ y un anión $\mathrm{OH}^{-}$. La fórmula de dicho compuesto no estequiométrico se puede escribir como:

$$
\mathrm{W}_{\mathrm{x}}^{5+} \mathrm{W}_{1-\mathrm{x}}^{6+} \mathrm{O}_{3-\mathrm{x}}(\mathrm{OH})_{\mathrm{x}}
$$

donde $x$ son los grupos hidroxilo que llenaron las vacantes de oxígeno en la red.

Además, según estudios realizados por Shpak [58], se muestra un vínculo directo entre la actividad catalítica y electroquímica de los compuestos con grupos 
hidroxilo, dando lugar a mejores comportamientos catalíticos cuanta mayor cantidad de grupos hidroxilo se detecte.

Una vez explicado a que corresponde cada pico, se van a analizar los espectros de las tres muestras estudiadas.

El pico asociado a los átomos de oxígeno $\mathrm{O}^{2-}$ en la red (329.92 eV, O1s Scan A) es mayor en la muestra sintetizada con $\mathrm{H}_{2} \mathrm{SO}_{4}$, seguida de la muestra sintetizada con $\mathrm{HNO}_{3}$, y finalmente, la que presenta un pico menor es la sintetizada con $\mathrm{CH}_{4} \mathrm{O}_{3} \mathrm{~S}$, indicando que es la que presenta más vacantes de oxígeno, ya que presenta menor densidad de átomos de oxígeno $\mathrm{O}^{2-}$ en la red. Además, el área obtenida de cada pico se muestra en la Tabla 4.3, observándose la tendencia explicada, en donde la muestra sintetizada con $\mathrm{H}_{2} \mathrm{SO}_{4}$ es la que presenta mayor área.

Además, si se analizan los dos picos restantes se puede concluir que la muestra sintetizada con $\mathrm{CH}_{4} \mathrm{O}_{3} \mathrm{~S}$ presenta mayor cantidad de vacantes de oxígeno ya que el pico asociado a estas vacantes (O1s Scan C) es mayor que el del resto de muestras. Finalmente, al comparar el segundo pico (O1s Scan B) se puede observar que el que presenta mayor área (como se observa en la Tabla 4.3) e intensidad es el obtenido con la muestra sintetizada con $\mathrm{HNO}_{3}$ indicando que posee mayor cantidad de grupo - $\mathrm{OH}$ en la superficie y por tanto mayor defectos superficiales, como se había predicho al analizar el pico del wolframio $\mathrm{W}_{4 \mathrm{f}} \mathrm{f/2}$ Scan C. La segunda muestra con mayor intensidad en este pico es la sintetizada con $\mathrm{CH}_{4} \mathrm{O}_{3} \mathrm{~S}$ siendo la que menor área presenta la sintetizada con $\mathrm{H}_{2} \mathrm{SO}_{4}$. 


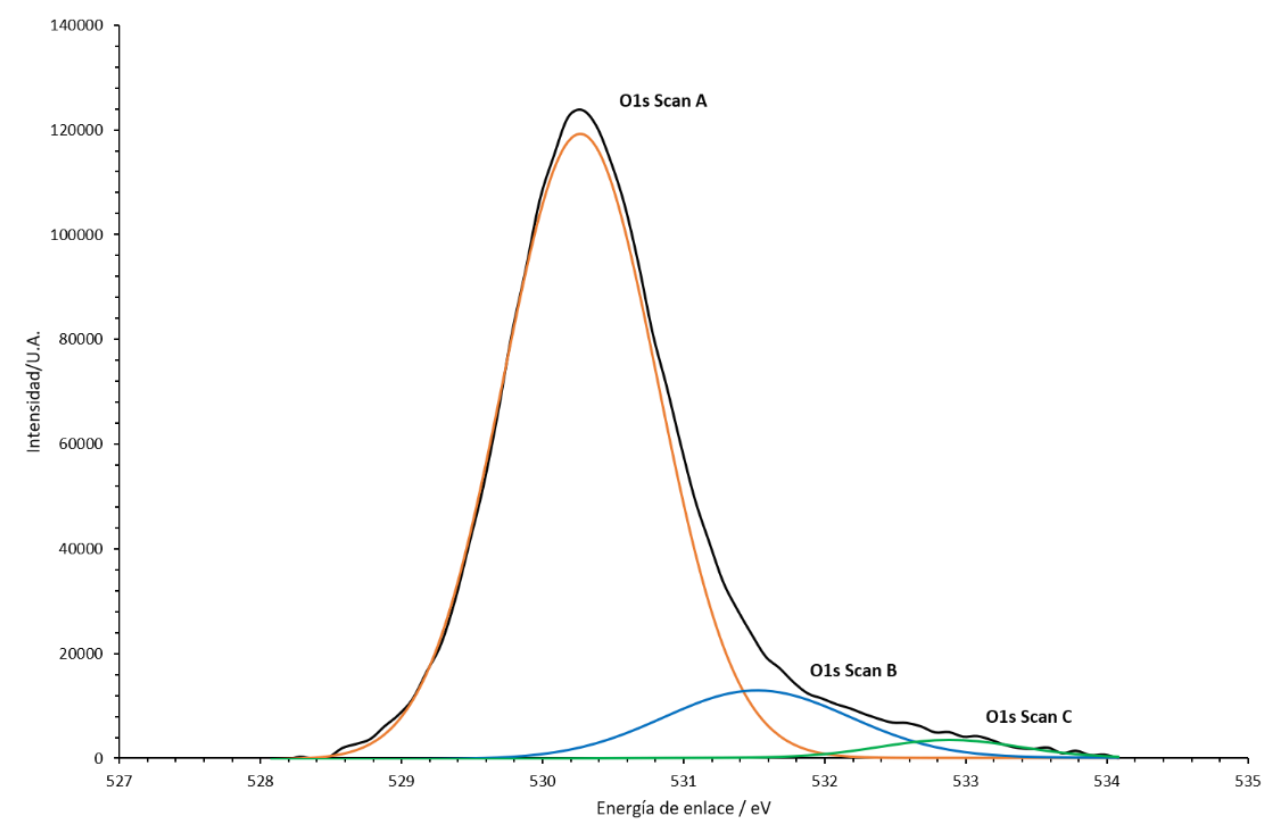

Figura 4.27. Espectros XPS de alta resolución de pico O1s de las muestras sintetizadas con $\mathrm{H}_{2} \mathrm{SO}_{4}$.

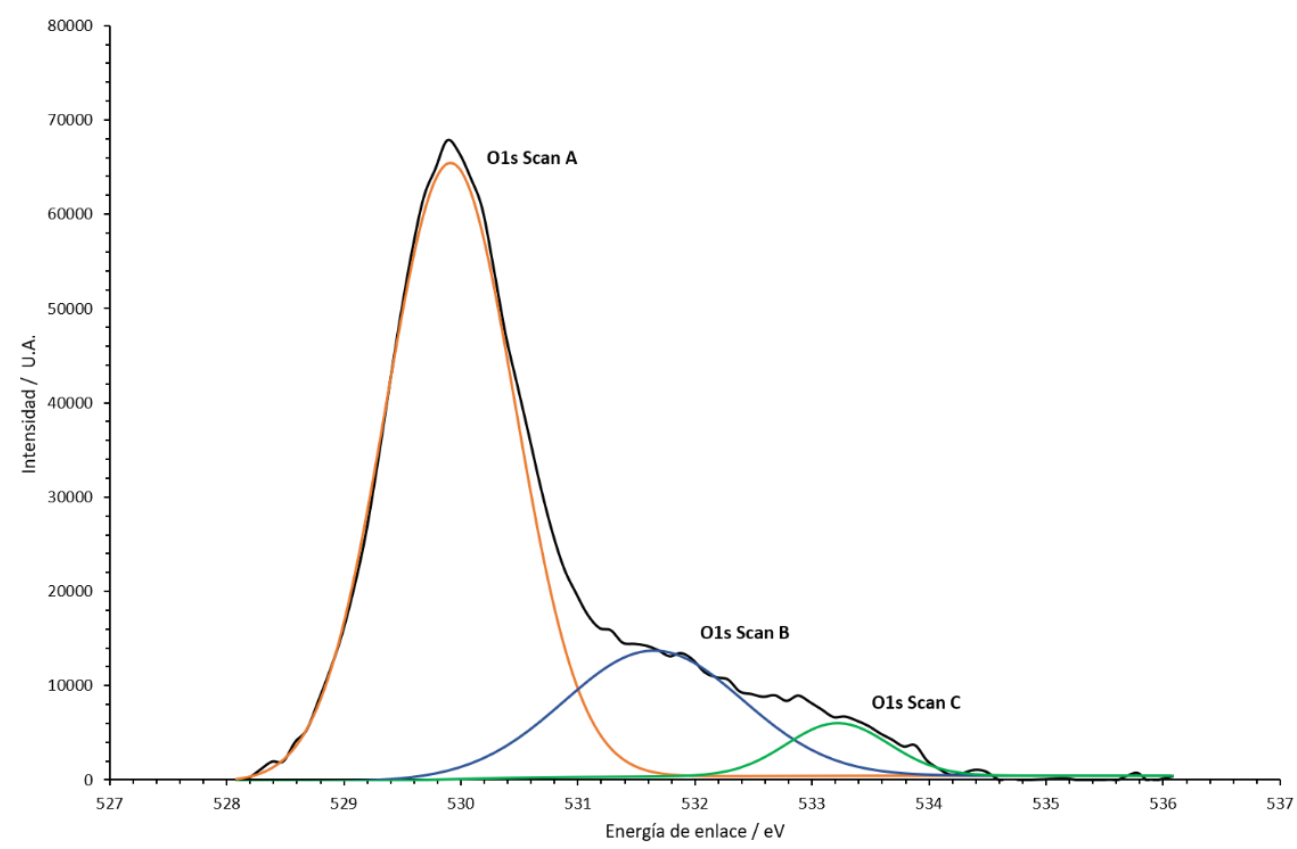

Figura 4.28. Espectros XPS de alta resolución de pico 01s de las muestras sintetizadas con $\mathrm{CH}_{4} \mathrm{O}_{3} \mathrm{~S}$. 


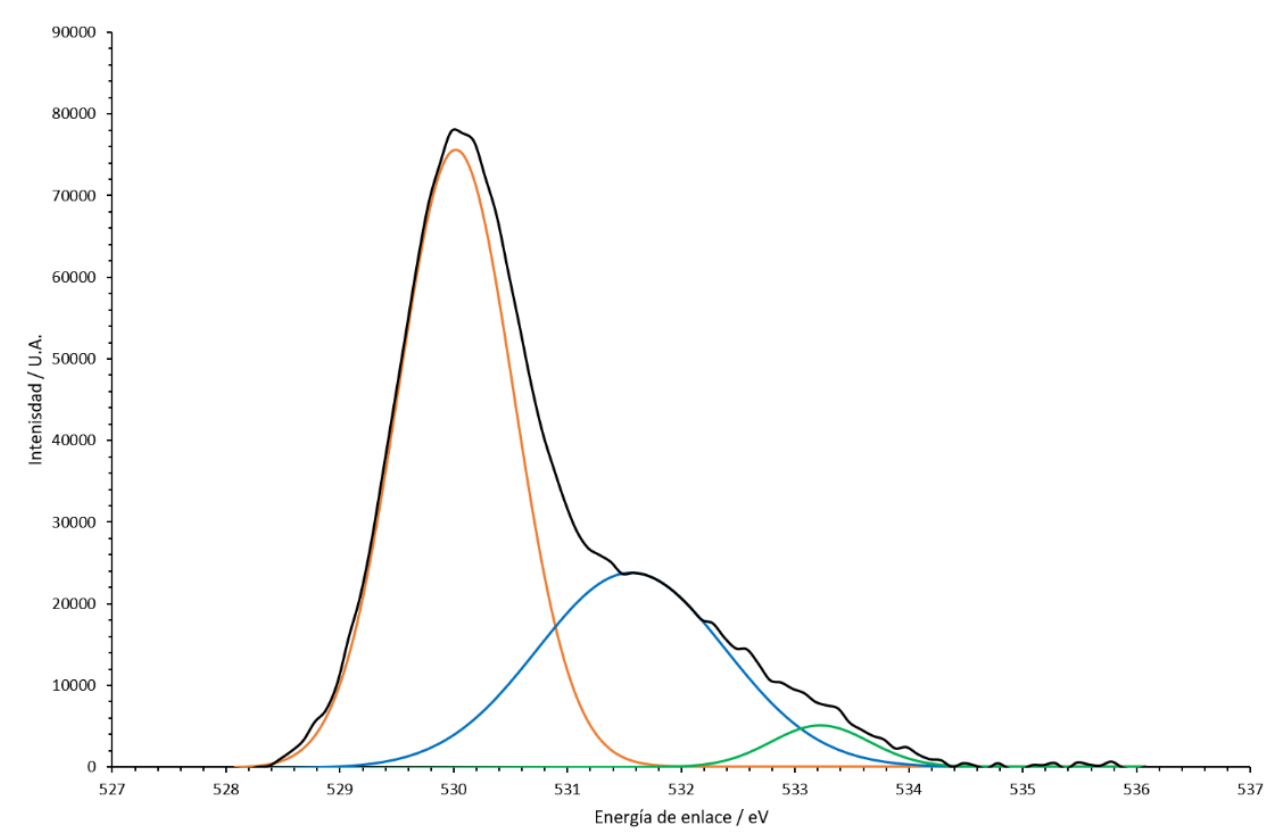

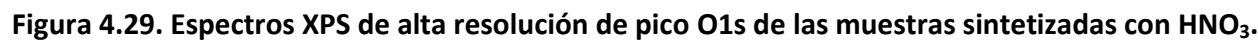

Tabla 4.3. Área del pico de oxígeno en el espectro XPS de alta resolucion en las tres muestras.

\begin{tabular}{|l|c|c|c|}
\cline { 2 - 4 } \multicolumn{1}{c|}{} & $\mathrm{H}_{2} \mathrm{SO}_{4}$ & $\mathrm{CH}_{4} \mathrm{O}_{3} \mathrm{~S}$ & $\mathrm{HNO}_{3}$ \\
\hline O1s Scan A & 163474.8 & 90606.55 & 96487.06 \\
\hline O1s Scan B & 21193.75 & 25527.14 & 49338.46 \\
\hline O1s Scan C & 4164.747 & 6130.371 & 5493.497 \\
\hline
\end{tabular}

\subsubsection{Nitrógeno}

El tercer y último elemento identificado en el análisis XPS ha sido el nitrógeno, pero a diferencia de los otros dos elementos, solo se ha detectado en las muestras sintetizadas con $\mathrm{CH}_{4} \mathrm{O}_{3} \mathrm{~S}$ y $\mathrm{HNO}_{3}$. En las Figuras 4.30 y 4.31 se muestran resultados de la deconvolución (descomposición en tres picos) de la línea N1s para las muestras de óxido de wolframio sintetizadas con $\mathrm{CH}_{4} \mathrm{O}_{3} \mathrm{~S}$ y $\mathrm{HNO}_{3}$.

Teóricamente el espectro asociado al nitrógeno N1s se separa en tres picos diferentes, pero en el caso de la muestra sintetizada con $\mathrm{CH}_{4} \mathrm{O}_{3} \mathrm{~S}$ solo aparece el primero, mientras que en el espectro de la muestra sintetizada con $\mathrm{HNO}_{3}$ aparecen el primero y el segundo, siendo el tercero prácticamente despreciable. 
El primer pico aparece alrededor de $399.4 \mathrm{eV}$ y el segundo a $401.7 \mathrm{eV}$. Ambos picos indican la presencia de nitrógeno en las nanoestructuras, pero de forma diferente. Si bien el pico en $399.4 \mathrm{eV}$ corresponde al nitrógeno unido al óxido de wolframio, indicando la presencia de nitrógeno en las películas, el segundo pico centrado en $401.7 \mathrm{eV}$ corresponde con compuestos nitrogenados adsorbido en la superficie y al nitrógeno atrapado en las capas superficiales $[23,30]$.

Analizando los espectros obtenidos para ambas muestras se puede concluir que las nanoestructuras que presentan mayor concentración de nitrógeno son las obtenidas con $\mathrm{HNO}_{3}$, seguidas de las obtenidas con $\mathrm{CH}_{4} \mathrm{O}_{3} \mathrm{~S}$, y finalmente las obtenidas con $\mathrm{H}_{2} \mathrm{SO}_{4}$, que no presentan nitrógeno en la estructura. Esto es debido principalmente al efecto del electrolito usado en la síntesis de las nanoestructuras ya que al anodizar con $\mathrm{HNO}_{3}$ se incorpora nitrógeno en la red formando W-O-N. Además, que la segunda muestra que presenta más contenido en nitrógeno sea la sintetizada con $\mathrm{CH}_{4} \mathrm{O}_{3} \mathrm{~S}$ es lógico ya que es la muestra que presenta mayor cantidad de defectos (como se ha visto anteriormente) y hace que el nitrógeno presente en la atmósfera (al someter las muestras al tratamiento térmico con aire) tenga más facilidad para incorporarse en la red que en el caso de la muestra sintetizada con $\mathrm{H}_{2} \mathrm{SO}_{4}$, que presenta menor cantidad de defectos.

Además, que el segundo pico solo aparezca en el espectro de la muestra sintetizada con $\mathrm{HNO}_{3}$ es coherente ya que el $\mathrm{N}$ adsorbido sobre la superficie se debe principalmente al electrolito utilizado, que contiene nitrógeno, y por eso, en las otras dos muestras no aparece este pico, ya que el electrolito utilizado en su síntesis no contiene nitrógeno como elemento. 


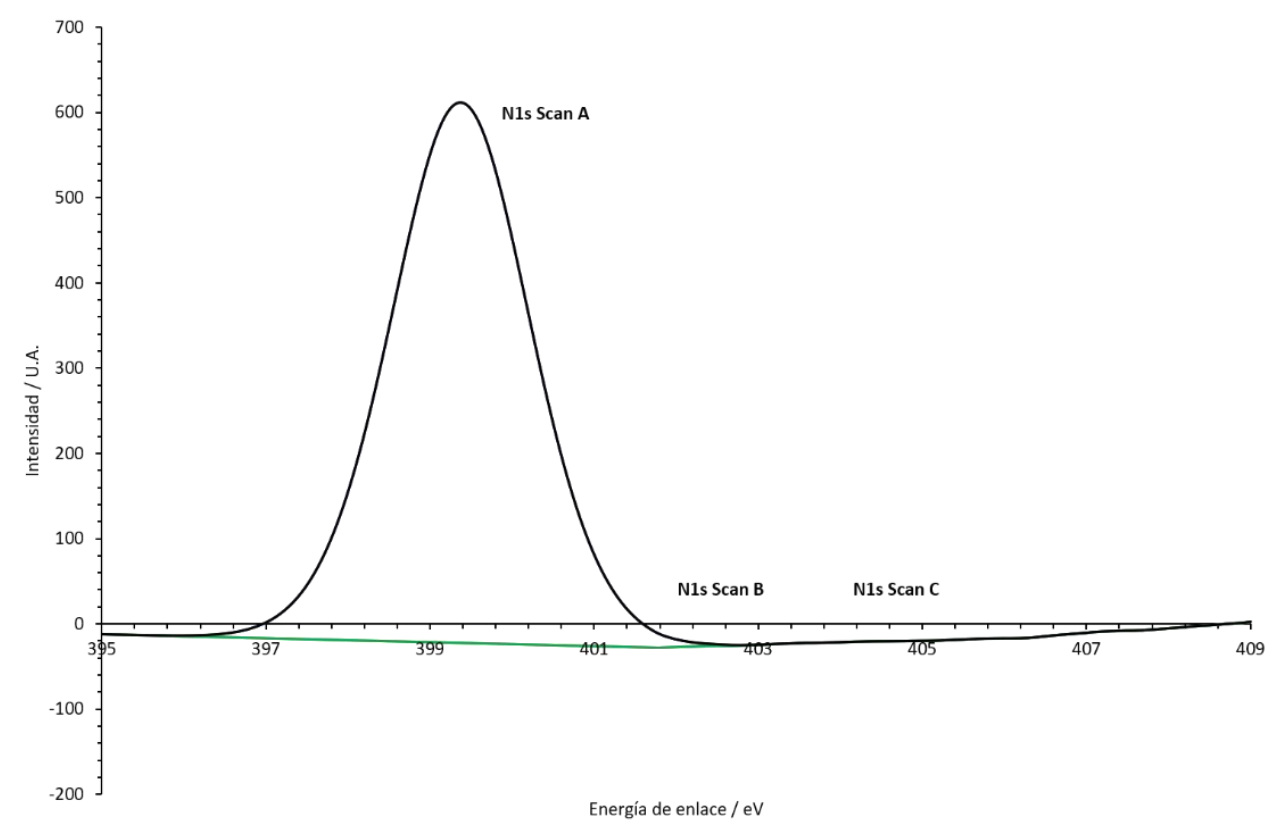

Figura 4.30. Espectros XPS de alta resolución de pico $\mathrm{N} 1 \mathrm{~s}$ de las muestras sintetizadas con $\mathrm{CH}_{4} \mathrm{O}_{3} \mathrm{~S}$.

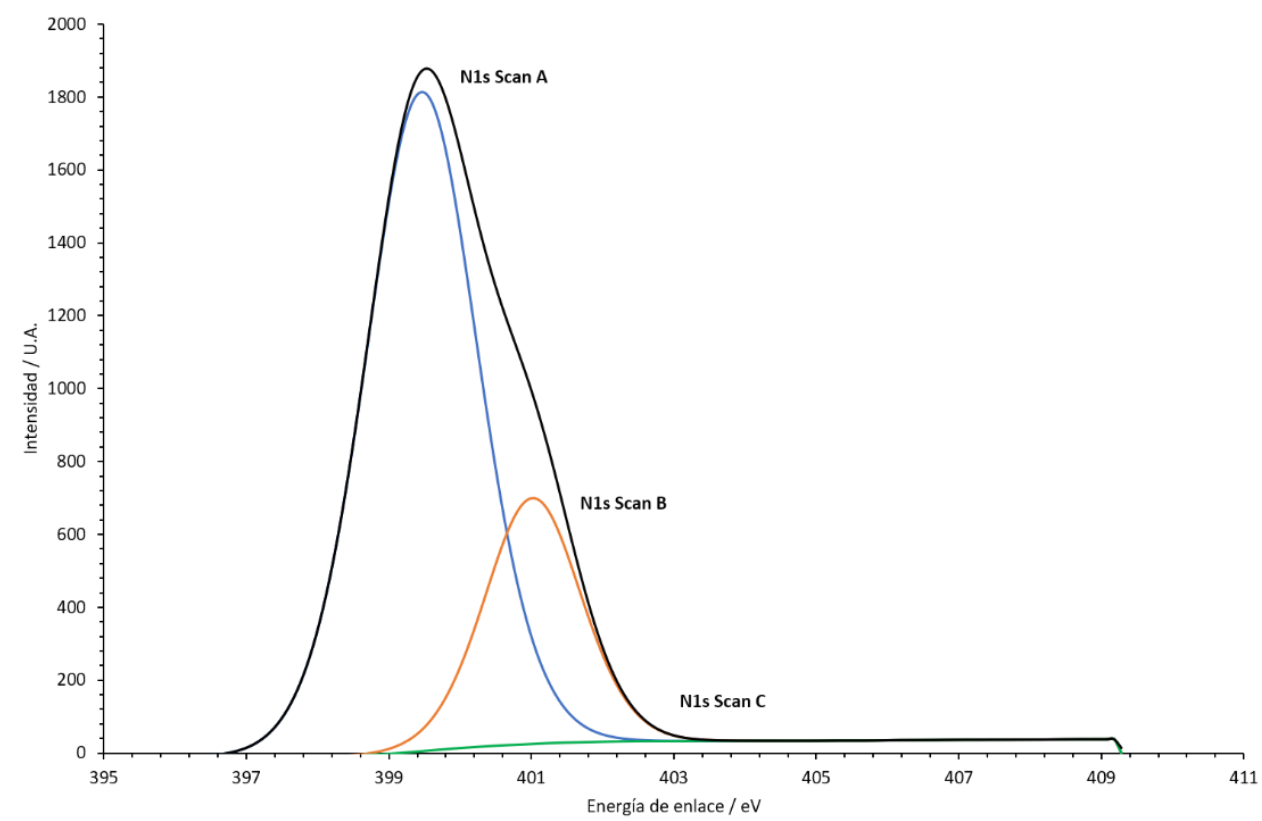

Figura 4.31. Espectros XPS de alta resolución de pico $\mathrm{N} 1 s$ de las muestras sintetizadas con $\mathrm{HNO}_{3}$. 
Tabla 4.4. Área del pico de nitrógeno en el espectro XPS de alta resolucion en las tres muestras.

\begin{tabular}{|c|c|c|c|}
\cline { 2 - 4 } \multicolumn{1}{c|}{} & $\mathrm{H}_{2} \mathrm{SO}_{4}$ & $\mathrm{CH}_{4} \mathrm{O}_{3} \mathrm{~S}$ & $\mathrm{HNO}_{3}$ \\
\hline N1s Scan A & 0 & 11.37 & 30.33 \\
\hline N1s Scan B & 0 & 0 & 9.74 \\
\hline N1s Scan C & 0 & 0 & 0 \\
\hline
\end{tabular}

\subsection{Caracterización fotoelectroquímica de las nanoestructuras mediante espectroscopía de impedancia electroquímica (PEIS).}

Una vez analizada tanto la morfología como la estructura cristalina de todas las muestras sintetizadas, se va a realizar una caracterización fotoelectroquímica a partir de la técnica explicada anteriormente en el capítulo 3.3.4 conocida como espectroscopía de impedancia electroquímica. A partir de sus resultados se podrá concluir qué muestra presenta un mejor comportamiento fotoelectroquímico, $y$, por tanto, cual actúa mejor como fotocatalizador.

\subsubsection{Nanoestructuras de $\mathrm{WO}_{3}$ sintetizadas en medio $\mathrm{H}_{2} \mathrm{SO}_{4}$.}

Antes de realizar los ensayos de espectroscopía de impedancia electroquímica, se han realizado ensayos de estabilidad con el fin de evaluar el comportamiento de las nanoestructuras frente a procesos fotoelectroquímicos. Para ello, se empleó una disolución $0.1 \mathrm{M}$ de $\mathrm{H}_{2} \mathrm{SO}_{4}$, una celda electroquímica con tres electrodos (el de trabajo, el de referencia y el contraelectrodo), un potencial externo de $1 \mathrm{~V}_{\mathrm{Ag} / \mathrm{AgCl}}$ y luz solar simulada durante 30 minutos de estabilización, ya que estas condiciones eran las idóneas en los ensayos fotoelectroquímicos según otros estudios bibliográficos [60].

En la Figura 4.32 a) se muestra la densidad de fotocorriente $\left(\mathrm{i}_{\mathrm{ph}}\right)$ registrada de las nanoestructuras obtenidas mediante anodizado electroquímico en medio $\mathrm{H}_{2} \mathrm{SO}_{4}$ Y calentadas en aire tanto a $400{ }^{\circ} \mathrm{C}, 500{ }^{\circ} \mathrm{C}$ como $600{ }^{\circ} \mathrm{C}$, en la $4.32 \mathrm{~b}$ ) la densidad de fotocorriente obtenida al calentar las nanoestructuras en atmósfera de nitrógeno, en la $4.32 \mathrm{c}$ ) en el caso de calentarse en atmósfera de argón y finalmente, en la 4.32 d) se muestra el valor final (tras pasar 30 minutos) de esta densidad de 
fotocorriente en todos los casos para poder comparar mejor los resultados obtenidos. Esta densidad de fotocorriente registrada se asocia con el rendimiento fotoelectroquímico que experimentan las nanoestructuras al ser iluminadas mediante luz solar. Se puede ver que los valores de $i_{\text {ph }}$ aumentaron, en general, al aumentar la temperatura de calentamiento para todas las atmósferas, excepto para la muestra calentada en argón a $600{ }^{\circ} \mathrm{C}$. La mejora del rendimiento fotoelectrocatalítico con la temperatura de calentamiento se debe a una mayor cristalinidad de las muestras, como se mostró en los resultados obtenidos mediante la microscopía Raman donde se observó que con un aumento de la temperatura se obtenía una mejor cristalinidad $[24,32,40]$. La influencia de la atmósfera del proceso de post-anodizado en el rendimiento fotoelectrocatalítico también es importante ya que la morfología de nanohilo obtenida en las atmósferas de aire y nitrógeno está asociada con un mejor transporte electrónico a través de las nanoestructuras de $\mathrm{WO}_{3}[18,61,62]$. En cambio, en atmósfera de argón la morfología que presentan son nanoplaquetas que no favorecen tanto este transporte, y por ello, el valor de densidad de fotocorriente es menor. Por tanto, según la Figura 4.32, el mejor rendimiento fotoelectroquímico correspondió a la nanoestructura calentada a $600{ }^{\circ} \mathrm{C}$ en una atmósfera de aire, además de presentar una gran estabilidad en el tiempo ya que su gráfica es la más constante durante todo el ensayo. 

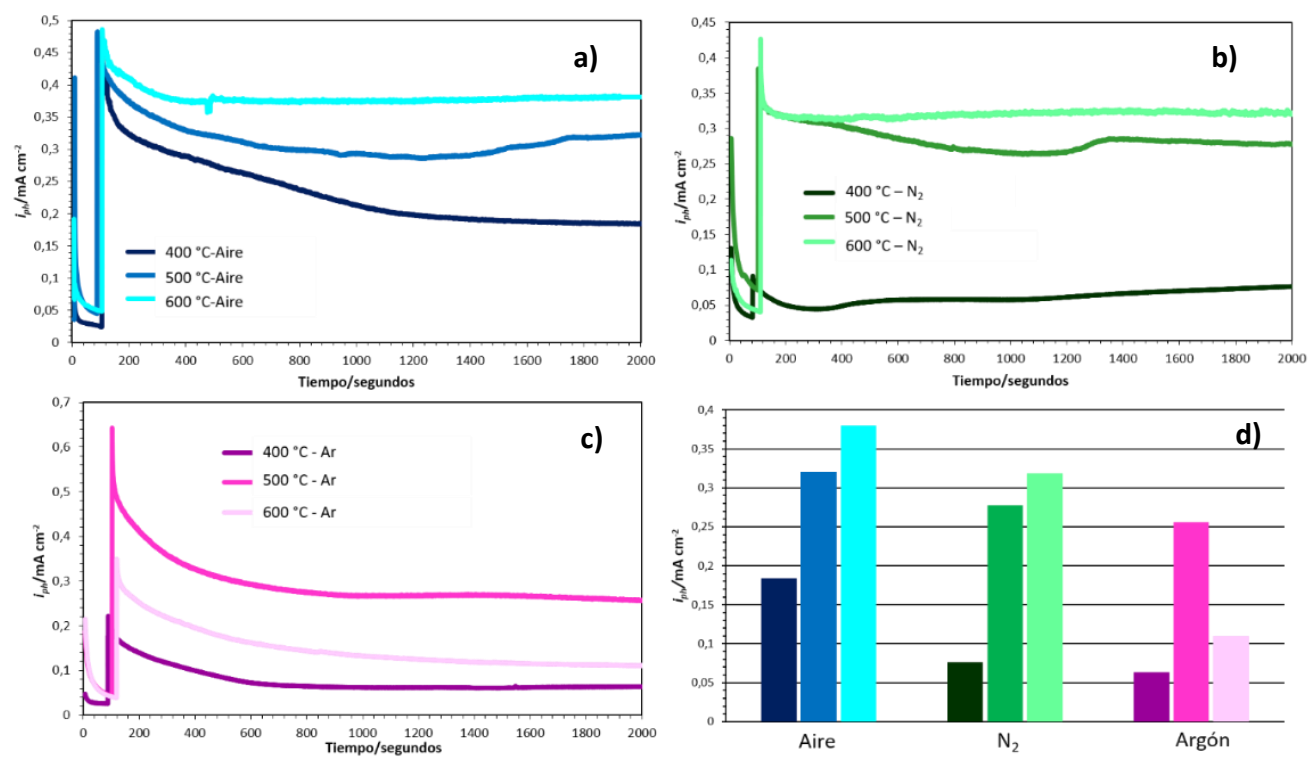

Figura 4.32. Densidad de corriente registrada durante $30 \mathrm{~min}$ con las nanoestructuras obtenidas mediante anodizado electroquímico en medio $\mathrm{H}_{2} \mathrm{SO}_{4}$ y calentadas en a) aire, b) $\mathrm{N}_{2}$, c) Ar y d) resumen de todos los casos.

Una vez realizados los ensayos de estabilidad, se han realizado los ensayos de espectroscopía de impedancia electroquímica. Estos ensayos se han llevado a cabo en el mismo medio y con la misma configuración que los ensayos de estabilidad.

Con la técnica de PEIS se obtienen tres tipos de gráficos que revelan una gran información sobre las propiedades fotoelectroquímicas del material y sobre el mecanismo de generación de fotocorriente en las nanoestructuras de $\mathrm{WO}_{3}$, y la influencia de las condiciones de calentamiento en los diferentes fenómenos electroquímicos y fotoelectroquímicos que tienen lugar en las nanoestructuras semiconductoras irradiadas.

En la Figura 4.33 se muestra el primer gráfico obtenido mediante los ensayos PEIS de las muestras sintetizadas con $\mathrm{H}_{2} \mathrm{SO}_{4}$ en todas las condiciones de calentamiento comentadas anteriormente. Este gráfico es el conocido como diagrama de Nyquist. La Figura 4.33 a) muestra el diagrama de Nyquist de las muestras calentadas en aire tanto a $400^{\circ} \mathrm{C}, 500^{\circ} \mathrm{C}$ como $600^{\circ} \mathrm{C}$, en la $4.33 \mathrm{~b}$ ) el diagrama al calentar las nanoestructuras en atmósfera de nitrógeno y finalmente en la $4.33 \mathrm{c}$ ) al calentarse en atmósfera de argón. 

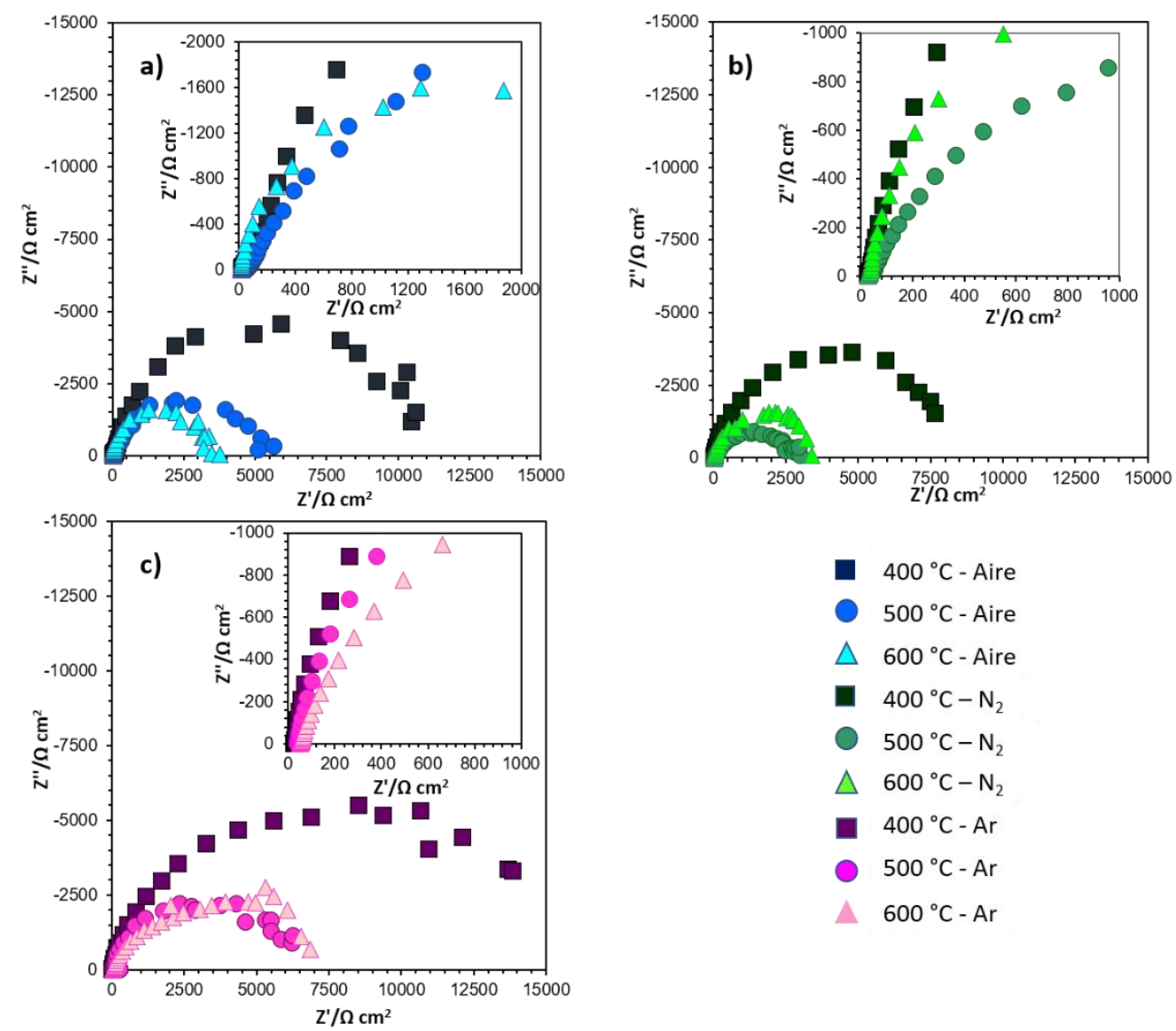

- $400{ }^{\circ} \mathrm{C}$ - Aire

- $500{ }^{\circ} \mathrm{C}$ - Aire

$\triangle 600^{\circ} \mathrm{C}$ - Aire

- $400^{\circ} \mathrm{C}-\mathrm{N}_{2}$

- $500^{\circ} \mathrm{C}-\mathrm{N}_{2}$

$\triangle 600^{\circ} \mathrm{C}-\mathrm{N}_{2}$

- $400^{\circ} \mathrm{C}-\mathrm{Ar}$

- $500^{\circ} \mathrm{C}-\mathrm{Ar}$

$600{ }^{\circ} \mathrm{C}-\mathrm{Ar}$

Figura 4.33. Diagramas experimentales de Nyquist en condiciones de iluminación de las nanoestructuras formadas tras el anodizado electroquímico en $\mathrm{H}_{2} \mathrm{SO}_{4}$ como electrolito y calentadas a diferentes temperaturas en atmósferas de a) Aire, b) $\mathrm{N}_{2}$, c) Ar.

A primera vista, solo es perceptible un semicírculo en los diagramas de Nyquist. Sin embargo, a altas frecuencias también se puede observar un semicírculo muy pequeño.

En los diagramas de Nyquist, el semicírculo de alta amplitud obtenido a frecuencias intermedias y bajas disminuyó, en general, con el aumento de las temperaturas de calentamiento para todas las atmósferas. Cuando se trabaja con semiconductores nanoestructurados bajo condiciones de iluminación, este semicírculo generalmente se ha asociado en la bibliografía con la transferencia de carga de los huecos desde la banda de valencia o los estados superficiales al electrolito, donde pueden oxidar al medio para formar especies tales como oxígeno gaseoso, radicales hidroxilo, materia orgánica oxidada, etc $[21,61,63]$. Por 
lo tanto, el semicírculo de baja frecuencia relacionado con la transferencia de carga de huecos dominó la respuesta de impedancia de todas las muestras. Por lo tanto, la disminución de los valores de impedancia al aumentar las temperaturas de calentamiento indica una mejor respuesta fotoelectroquímica de las nanoestructuras tratadas a $600{ }^{\circ} \mathrm{C}$ en atmósferas de aire y de $\mathrm{N}_{2}$. Sin embargo, en la atmósfera de $\mathrm{Ar}$, a pesar de que el semicírculo tiene una amplitud similar para las muestras calentadas a $500{ }^{\circ} \mathrm{C}$ y $600{ }^{\circ} \mathrm{C}$, la respuesta fotoelectroquímica fue menor a $600{ }^{\circ} \mathrm{C}$. Esto es debido a la menor cristalinidad de las muestras, ya que en el espectro Raman se pudo comprobar que a $500{ }^{\circ} \mathrm{C}$ los picos característicos de estructuras cristalinas estaban más definidos que en el caso de las muestras calentadas a $600{ }^{\circ} \mathrm{C}$. Por tanto, las conclusiones obtenidas a partir de los diagramas de Nyquist son consistentes con las respuestas de densidad de fotocorriente observadas anteriormente.

Los otros dos gráficos que se obtienen al realizar los ensayos de PEIS son el diagrama de Bode-fase, en donde se representa el ángulo de fase frente a la frecuencia en escala logarítmica, y el de Bode-módulo, en donde se representa el módulo de la impedancia frente a la frecuencia en escala logarítmica también. 

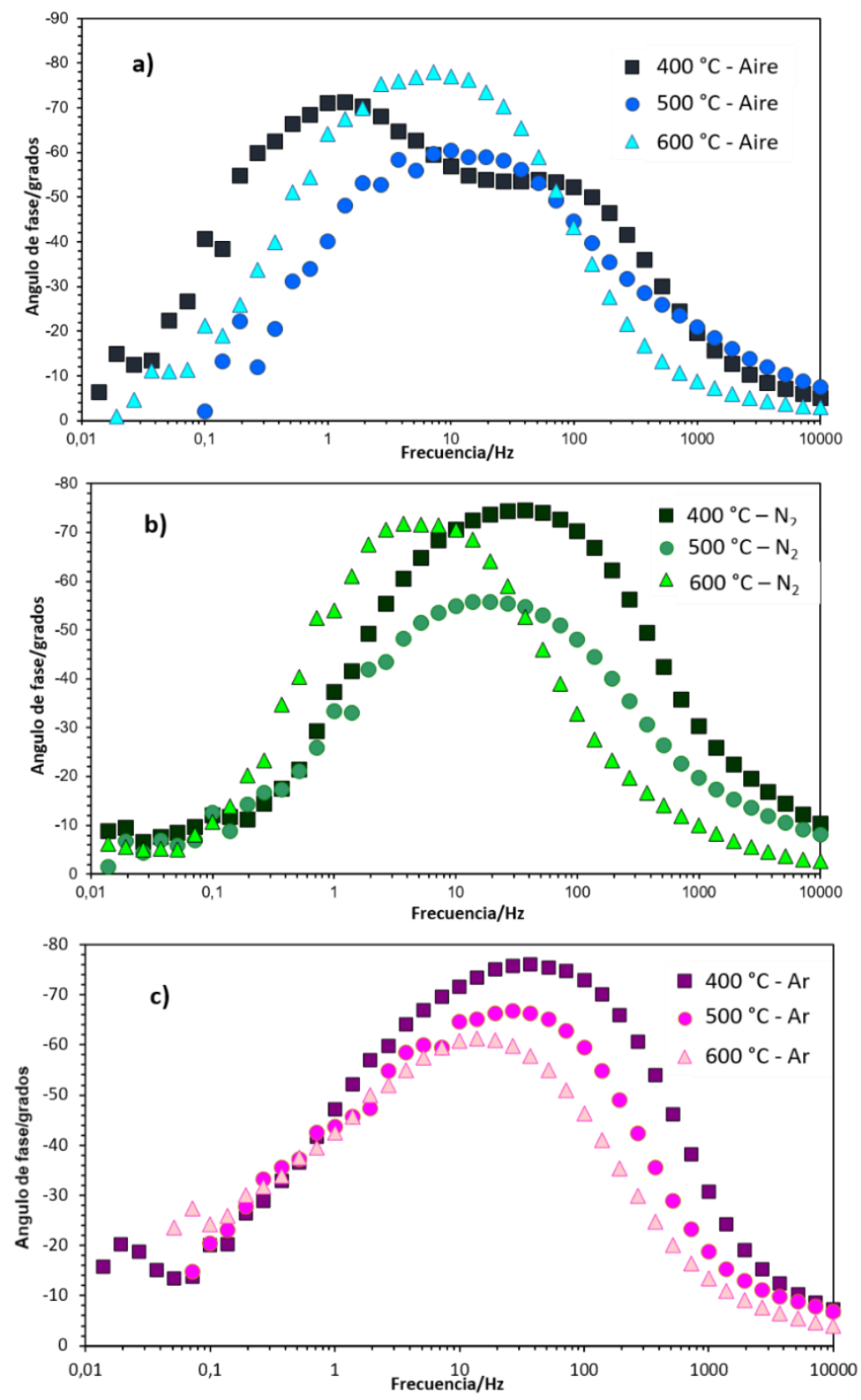

Figura 4.34. Diagramas experimentales de Bode-fase de las nanoestructuras formadas tras el anodizado electroquímico en $\mathrm{H}_{2} \mathrm{SO}_{4}$ como electrolito y calentadas a diferentes temperaturas en atmósferas de a) aire, b) $\mathrm{N}_{2}$, c) Ar. 

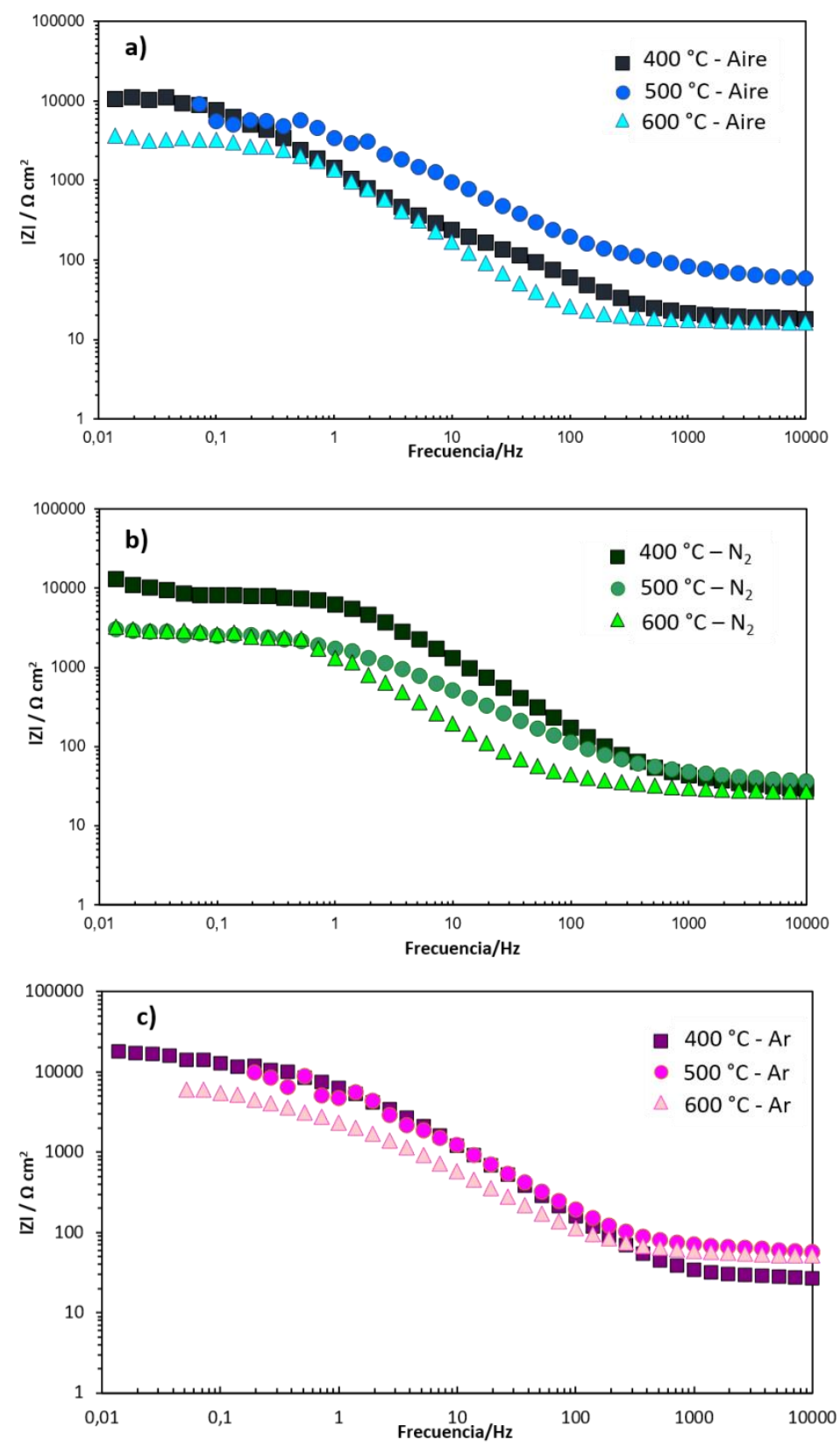

Figura 4.35. Diagramas experimentales de Bode-módulo de las nanoestructuras formadas tras el anodizado electroquímico en $\mathrm{H}_{2} \mathrm{SO}_{4}$ como electrolito y calentadas a diferentes temperaturas en atmósferas de a) aire, b) $\mathrm{N}_{2}$, c) Ar. 
En primer lugar, se pudieron distinguir claramente dos picos en el diagrama experimental de Bode-fase (Figura 4.34) para la muestra calentada en aire a 400 ${ }^{\circ} \mathrm{C}$, y se evidenció un pico ancho en el resto de las gráficas de Bode, lo que probablemente indica la superposición de dos picos individuales. Esto indica la presencia de dos constantes de tiempo en el circuito eléctrico equivalente utilizado para ajustar los datos obtenidos [64,65] (mostrado en la Figura 4.36). En un circuito en el que solo hay resistencias (R) y condensadores (CPE), la constante de tiempo hace referencia al producto entre $R$ y CPE. Cada constante de tiempo (par R-CPE) describe un fenómeno que aparece en un intervalo determinado del espectro de frecuencias.

En cuanto al diagrama de Bode-módulo se puede observar que las tres muestras calentadas a $600{ }^{\circ} \mathrm{C}$, independientemente de la atmósfera utilizada, tienen un valor del módulo de la impedancia menor que las muestras calentadas a temperaturas menores. Cuando se comparan las atmósferas, se puede comprobar que tanto en aire como en nitrógeno el módulo de la impedancia es menor que en el caso del argón. Esto quiere decir que las nanoestructuras calentadas a $600{ }^{\circ} \mathrm{C}$ y en atmósfera de aire y nitrógeno presentan una menor resistencia a la transferencia de carga $\left(R_{t c}\right)$, ya que el valor del módulo de la impedancia es directamente proporcional a esta resistencia (como se ha explicado en el capítulo 3.3.3. de la metodología experimental), siendo su relación la siguiente:

$$
|Z|=R_{S}+R_{t c}
$$

Una vez analizados los resultados de los tres gráficos, se ajustaron los datos obtenidos de los ensayos de PEIS a un circuito equivalente para poder obtener a partir de él los valores numéricos de las resistencias de los procesos. El circuito propuesto en este caso es el que se muestra en la Figura 4.36, en el que se encuentra un elemento resistivo $\left(R_{s}\right)$ y dos grupos $R-C P E$ en paralelo ya que a partir de los diagramas de Bode se concluyó que se necesitarían dos constantes de tiempo en el circuito eléctrico equivalente [26,61]. El significado del elemento resistivo $R_{s}$ hace referencia a la resistencia que opone el electrolito, la $R_{1}$ hace referencia a la resistencia a la recombinación de los pares electrón-hueco y finalmente la $R_{2}$ corresponde a la resistencia a la transferencia de carga en la interfase electrodo-electrolito. Además, se han utilizado elementos de fase constante (CPE) en lugar de condensadores para tener en cuenta la no idealidad del sistema [66-68]. 


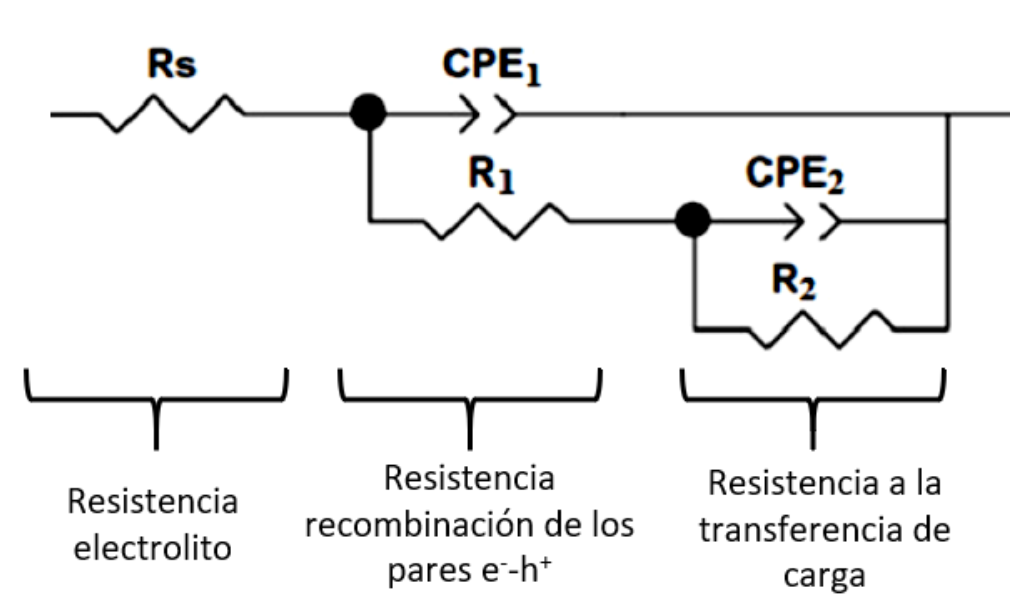

Figura 4.36. Circuito eléctrico equivalente utilizado para ajustar los datos experimentales de PEIS al modelo teórico propuesto.

Los valores de las resistencias que conforman el circuito equivalente se muestran en la Tabla 4.5 para todas las muestras. El valor de $R_{s}$ en todos los casos está entre 20 y $30 \Omega \mathrm{cm}^{2}$, valor característico del $\mathrm{H}_{2} \mathrm{SO}_{4} 0.1 \mathrm{M}[66,69]$ y los valores de $\mathrm{R}_{1}$ son en todos los casos mucho más bajos que los de $R_{2}$, como era de esperar según bibliografía [17]. Además, al comparar los valores de $R_{1}$ entre sí, se puede ver una tendencia al alza con la temperatura, y unos valores mayores en el caso de utilizar aire como atmósfera de calentamiento. Esto indica que las nanoestructuras obtenidas en aire a mayor temperatura presentan una mayor resistencia a la recombinación de pares electrón- hueco y por tanto tendrán una mayor eficiencia fotocatalítica. Por otra parte, los valores de $\mathrm{R}_{2}$ disminuyen con el aumento de la temperatura de calentamiento, lo que indica una mayor transferencia de carga de los huecos desde la nanoestructura al electrolito. Esta tendencia también fue observada en bibliografía $[24,70]$. En el caso de la muestra calentada en una atmósfera de argón a $600^{\circ} \mathrm{C}$, se puede ver que el valor de $\mathrm{R}_{2}$ fue superior al valor obtenido con la muestra calentada a $500{ }^{\circ} \mathrm{C}$. Este hecho puede estar relacionado con la cristalinidad de las nanoestructuras explicadas anteriormente, ya que, a $600{ }^{\circ} \mathrm{C}$ en $\mathrm{Ar}$, se obtuvieron nanoestructuras con un menor grado de cristalinidad, lo que aumentó la resistencia de transferencia de carga de los huecos desde la nanoestructura al electrolito. Finalmente, al presentar un valor de $\chi^{2}$ del orden de $10^{-3}$ indica que se ha producido un buen ajuste de los datos al circuito equivalente elegido [63]. 
Por tanto, las condiciones de calentamiento que favorecen un mejor transporte de carga y una menor recombinación de pares electrón-hueco son a $600{ }^{\circ} \mathrm{C}$ y en atmósfera de aire. Estos resultados pueden asociarse directamente con el mayor grado de cristalinidad de esta nanoestructura, que mejoró los fenómenos interfaciales electroquímicos y fotoelectroquímicos.

Tabla 4.5. Valores medios de las resistencias, obtenidos tras el ajuste de los datos experimentales de EIS al circuito eléctrico equivalente, de las nanoestructuras sintetizadas con $\mathrm{H}_{2} \mathrm{SO}_{4}$ como electrolito.

\begin{tabular}{|c|c|c|c|c|c|}
\hline \multicolumn{2}{|c|}{ Condiciones } & $R_{s}\left(\Omega \mathrm{cm}^{2}\right)$ & $R_{1}\left(\Omega \mathrm{cm}^{2}\right)$ & $R_{2}\left(k \Omega \mathrm{cm}^{2}\right)$ & $\chi^{2}\left(\times 10^{-3}\right)$ \\
\hline \multirow{3}{*}{ Aire } & $400^{\circ} \mathrm{C}$ & $29 \pm 3$ & $19.4 \pm 11$ & $11.8 \pm 1.6$ & 6.1 \\
\hline & $500^{\circ} \mathrm{C}$ & $44 \pm 9$ & $28.6 \pm 26$ & $7.6 \pm 1.3$ & 6.8 \\
\hline & $600^{\circ} \mathrm{C}$ & $28 \pm 6$ & $31 \pm 7$ & $3.0 \pm 0.9$ & 8.6 \\
\hline \multirow{3}{*}{$\mathbf{N}_{2}$} & $400^{\circ} \mathrm{C}$ & $27 \pm 6$ & $5 \pm 1$ & $10.1 \pm 4.0$ & 3.3 \\
\hline & $500^{\circ} \mathrm{C}$ & $32 \pm 2$ & $22 \pm 5$ & $2.7 \pm 0.3$ & 4.7 \\
\hline & $600^{\circ} \mathrm{C}$ & $27 \pm 3$ & $28.6 \pm 9$ & $2.9 \pm 0.4$ & 6.6 \\
\hline \multirow{3}{*}{$\mathrm{Ar}$} & $400^{\circ} \mathrm{C}$ & $37 \pm 8$ & $16 \pm 2$ & $14.9 \pm 0.8$ & 7.3 \\
\hline & $500^{\circ} \mathrm{C}$ & $27 \pm 1$ & $32 \pm 9$ & $9.1 \pm 0.1$ & 5.5 \\
\hline & $600^{\circ} \mathrm{C}$ & $22 \pm 4$ & $21 \pm 3$ & $9.6 \pm 3.7$ & 6.1 \\
\hline
\end{tabular}

\subsubsection{Nanoestructuras de $\mathrm{WO}_{3}$ sintetizadas en medio $\mathrm{CH}_{4} \mathrm{O}_{3} \mathrm{~S}$.}

Una vez analizados los datos obtenidos mediante PEIS de las muestras sintetizadas con $\mathrm{H}_{2} \mathrm{SO}_{4}$ y calentadas a todas las condiciones explicadas anteriormente, se van a analizar los datos obtenidos al realizar los ensayos PEIS a las muestras obtenidas con $\mathrm{CH}_{4} \mathrm{O}_{3} \mathrm{~S}$.

En la Figura 4.37, están representadas las densidades de corriente registradas durante 30 min al aplicar $1 \mathrm{~V}_{\mathrm{Ag} / \mathrm{AgCl}}$, luz solar simulada y en $0.1 \mathrm{M}$ de $\mathrm{H}_{2} \mathrm{SO}_{4}$ como medio electrolítico con el fin de estudiar el rendimiento fotoelectroquímico de las nanoestructuras de óxido de wolframio y su estabilidad fotoelectroquímica. 

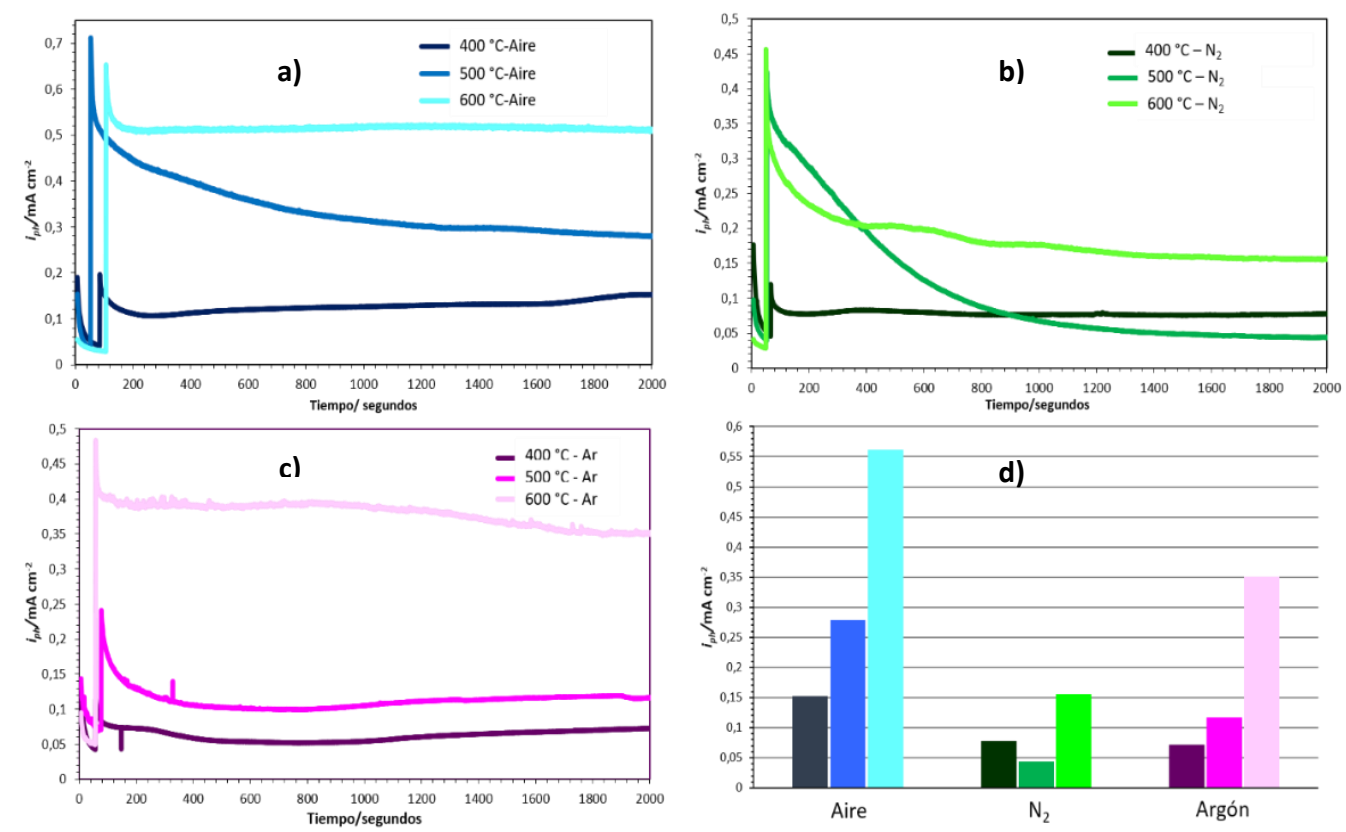

Figura 4.37. Densidad de corriente registrada durante $30 \mathrm{~min}$ con las nanoestructuras obtenidas con $\mathrm{CH}_{4} \mathrm{O}_{3} \mathrm{~S}$ y calentadas en a) aire, b) $\mathrm{N}_{2}$, c) Ar y d) resumen de todos los casos.

En este caso, también se observa una tendencia con respecto a la temperatura en la que con un aumento de ésta el registro de densidad de fotocorriente es mayor. No obstante, las nanoestructuras obtenidas en una atmósfera de nitrógeno no se parecen tanto a las obtenidas en aire como ocurría al utilizar $\mathrm{H}_{2} \mathrm{SO}_{4}$ como electrolito. En este caso, al utilizar una atmósfera de nitrógeno los resultados son más parecidos a los obtenidos al utilizar una atmósfera de argón. Esto puede ser debido a la morfología que presentan las nanoestructuras en las imágenes obtenidas en el FE-SEM, en donde se observa que en atmósferas no oxidantes aparecen grietas entre las nanoestructuras calentadas a altas temperaturas, por tanto, la densidad de fotocorriente registrada es mucho menor. Además, estas nanoestructuras también muestran una mayor densidad de fotocorriente cuando se calentaron a $600^{\circ} \mathrm{C}$ en atmósfera de aire, pero en este caso se obtienen valores más altos, dando como resultado unas nanoestructuras con mejores propiedades fotoelectroquímicas. 
En la Figura 4.38 se muestran los diagramas de Nyquist de las nanoestructuras obtenidas con $\mathrm{CH}_{4} \mathrm{O}_{3} \mathrm{~S}$ y calentadas en las diferentes condiciones de calentamiento. Se puede observar que las nanoestructuras obtenidas en aire a $600{ }^{\circ} \mathrm{C}$ muestran una amplitud del semicírculo mucho menor que en el resto de los casos. Esto indica que la resistencia a la transferencia de carga en estas muestras es mucho menor y por tanto el transporte de los electrones y los huecos hasta el electrolito se produce con mayor facilidad $[69,71,72]$, confirmándose así las conclusiones obtenidas al analizar los datos del resto de ensayos. Estos resultados se deben principalmente a que la morfología de la muestra era en forma de nanohilo, lo que mejora el transporte del electrón y la difusión de los huecos, y, por tanto, mejora las propiedades fotoelectroquímicas de la nanoestructura.
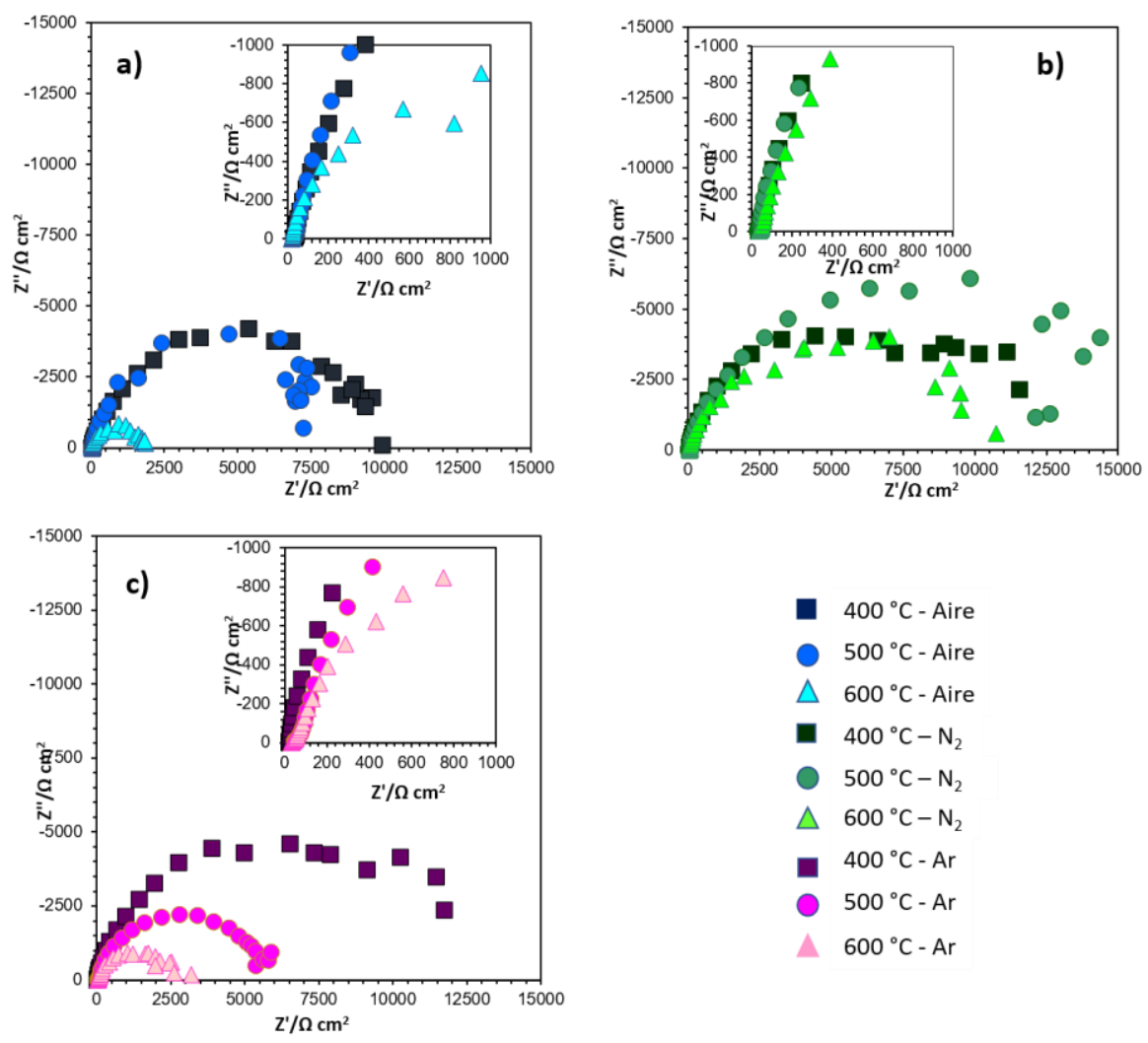

Figura 4.38. Diagramas experimentales de Nyquist de las nanoestructuras formadas tras el anodizado electroquímico en $\mathrm{CH}_{4} \mathrm{O}_{3} \mathrm{~S}$ como electrolito y calentadas a diferentes temperaturas en atmósferas de a) aire, b) $\mathrm{N}_{2}$, c) Ar. 
En las siguientes Figuras, la Figura 4.39 y la Figura 4.40, están representados los diagramas de Bode-fase y Bode-módulo respectivamente.
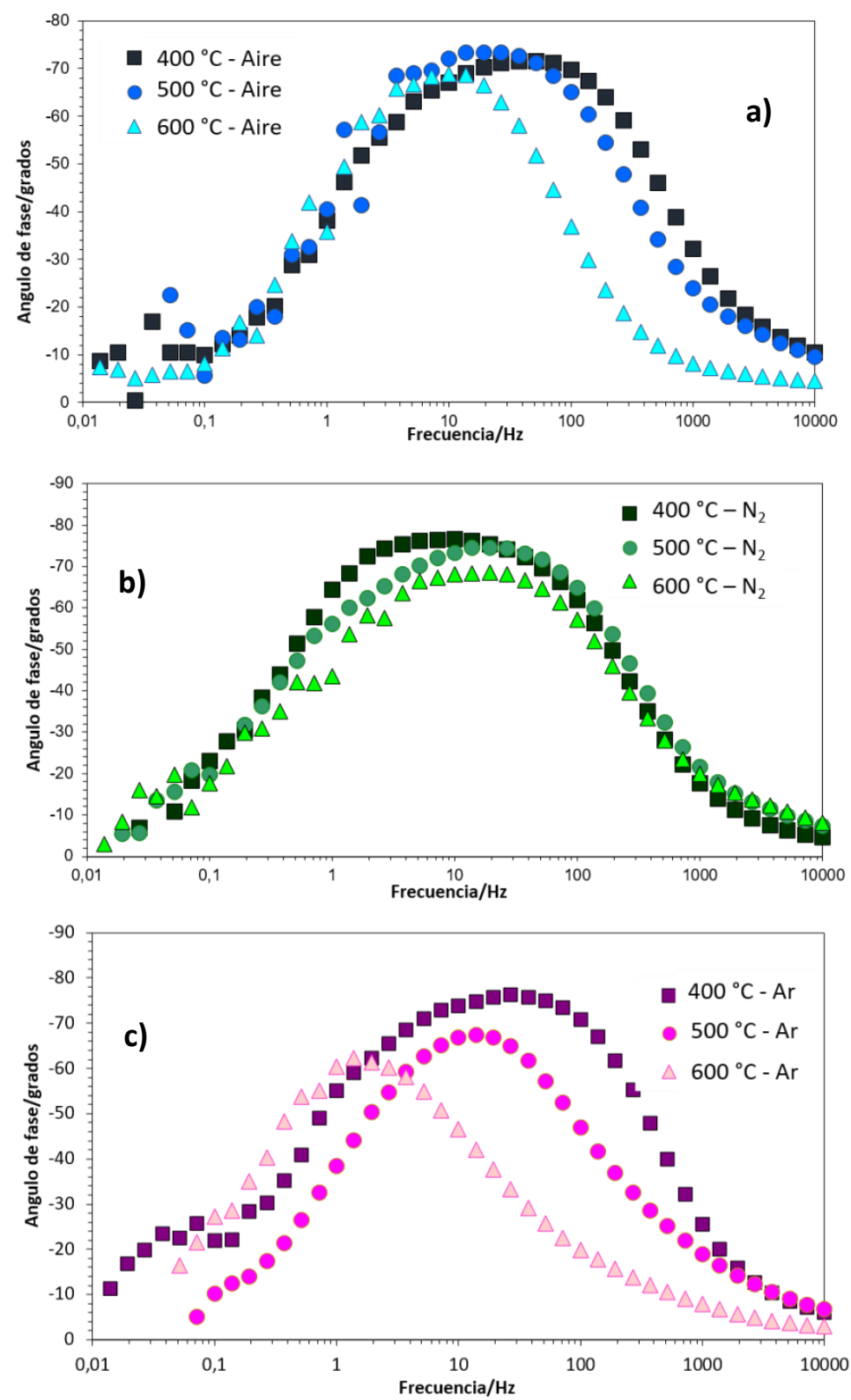

Figura 4.39. Diagramas experimentales de Bode-fase de las nanoestructuras formadas tras el anodizado electroquímico en $\mathrm{CH}_{4} \mathrm{O}_{3} \mathrm{~S}$ como electrolito y calentadas a diferentes temperaturas en atmósferas de a) aire, b) $\mathrm{N}_{2}$, c) Ar. 

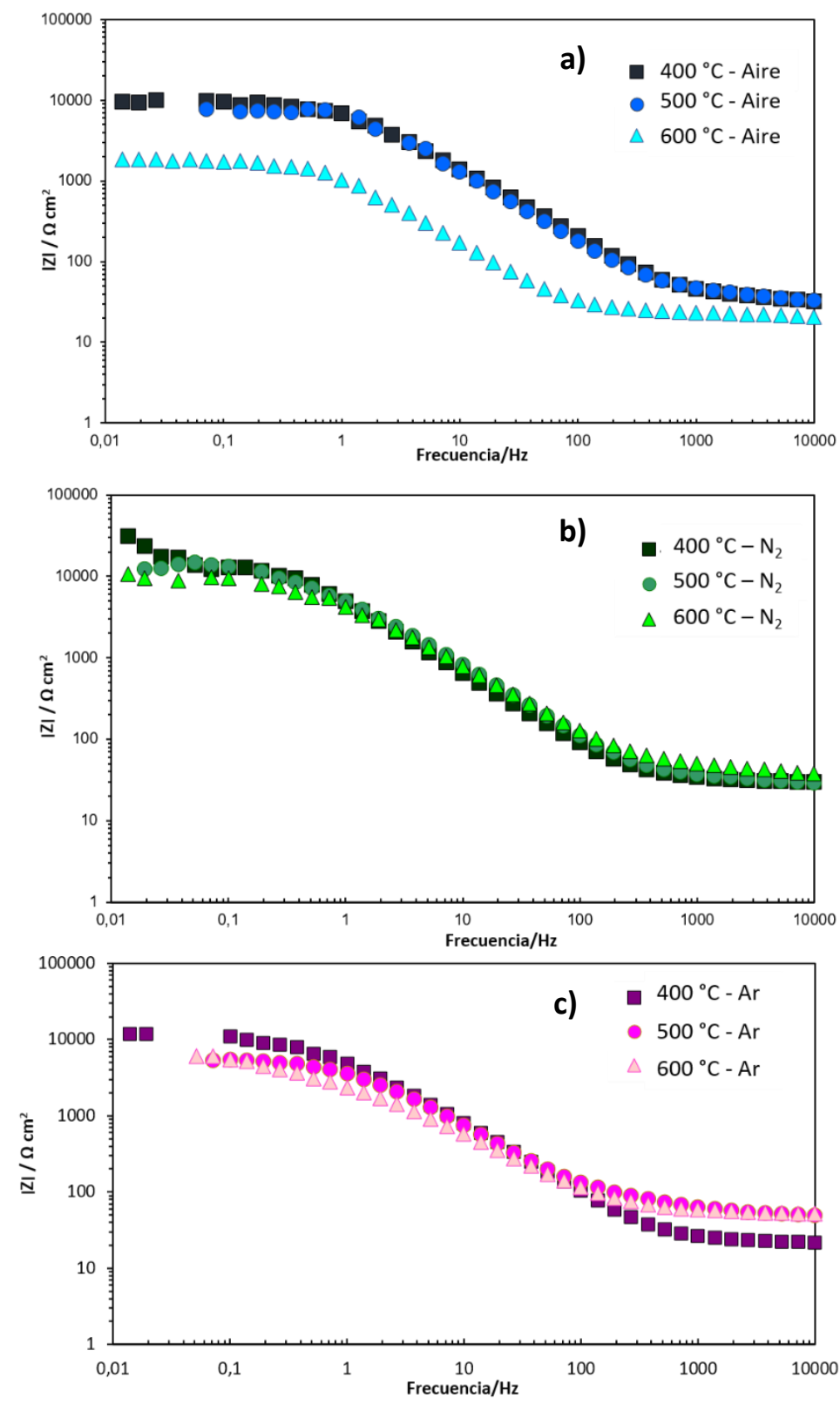

Figura 4.40. Diagramas experimentales de Bode-módulo de las nanoestructuras formadas tras el anodizado electroquímico en $\mathrm{CH}_{4} \mathrm{O}_{3} \mathrm{~S}$ como electrolito y calentadas a diferentes temperaturas en atmósferas de a) aire, b) $\mathrm{N}_{2}$, c) Ar. 
El gráfico de Bode-fase (Figura 4.39) vuelve a mostrar un solo pico ancho, indicando la posibilidad de ser el resultado de dos picos más estrechos superpuestos. Esto quiere decir que existen dos constantes de tiempo en todas las muestras $[63,73,74]$, y por tanto el circuito eléctrico equivalente empleado para ajustar los datos es el mismo que en el caso de las nanoestructuras obtenidas con $\mathrm{H}_{2} \mathrm{SO}_{4}$ como electrolito. Una de las constantes de tiempo se asocia a la resistencia de la transferencia de carga, mientras que la otra constante se asocian a la tendencia a recombinación existente en la interfase electrodo/electrolito $[61,75]$.

Observando el diagrama de Bode-módulo (Figura 4.40) se puede observar que la resistencia asociada al electrolito (impedancia a altas frecuencias) era similar independientemente de las condiciones de anodizado, ya que depende del electrolito empleado, y en todos los ensayos se utilizó el mismo $\left(0.1 \mathrm{M} \mathrm{H}_{2} \mathrm{SO}_{4}\right)$. Además, en el caso de las nanoestructuras calentadas a $600{ }^{\circ} \mathrm{C}$ en aire se obtiene una curva con menos pendiente, es decir, con un valor del módulo de la impedancia menor y, por tanto, una menor resistencia a la transferencia de carga.

Una vez ajustados los datos al circuito equivalente mostrado en la Figura 4.36, se han obtenido los datos característicos de las nanoestructuras obtenidas con $\mathrm{CH}_{4} \mathrm{O}_{3} \mathrm{~S}$ en todas las condiciones de post-anodizado ensayadas y que se muestran el Tabla 4.6.

Tabla 4.6. Valores medios de las resistencias, obtenidos tras el ajuste de los datos experimentales de EIS al circuito eléctrico equivalente, de las nanoestructuras sintetizadas con $\mathrm{CH}_{4} \mathrm{O}_{3} \mathrm{~S}$ como electrolito.

\begin{tabular}{|c|c|c|c|c|c|}
\hline \multicolumn{2}{|c|}{ Condiciones } & $\mathrm{Rs}_{\mathrm{s}}\left(\Omega \mathrm{cm}^{2}\right)$ & $R_{1}\left(\Omega \mathrm{cm}^{2}\right)$ & $R_{2}\left(k \Omega \mathrm{cm}^{2}\right)$ & $\chi^{2}\left(\times 10^{-3}\right)$ \\
\hline \multirow{3}{*}{ Aire } & $400^{\circ} \mathrm{C}$ & $36 \pm 10$ & $38 \pm 15$ & $10.5 \pm 11$ & 6.8 \\
\hline & $500^{\circ} \mathrm{C}$ & $30 \pm 0.7$ & $24 \pm 6$ & $7.1 \pm 1.4$ & 7.2 \\
\hline & $600^{\circ} \mathrm{C}$ & $37 \pm 6$ & $42 \pm 7$ & $1.7 \pm 0.3$ & 4.8 \\
\hline \multirow{3}{*}{$\mathbf{N}_{2}$} & $400^{\circ} \mathrm{C}$ & $31 \pm 2$ & $20 \pm 8$ & $15 \pm 3.3$ & 8 \\
\hline & $500^{\circ} \mathrm{C}$ & $28 \pm 1.5$ & $28 \pm 5$ & $13.7 \pm 4$ & 8.4 \\
\hline & $600^{\circ} \mathrm{C}$ & $38 \pm 4$ & $33 \pm 8$ & $10.7 \pm 3.9$ & 6.2 \\
\hline \multirow{3}{*}{$\mathrm{Ar}$} & $400^{\circ} \mathrm{C}$ & $24 \pm 2$ & $11 \pm 9$ & $14.6 \pm 6$ & 11 \\
\hline & $500^{\circ} \mathrm{C}$ & $35 \pm 5$ & $28 \pm 7$ & $7.3 \pm 1.9$ & 2.5 \\
\hline & $600^{\circ} \mathrm{C}$ & $31 \pm 4$ & $30 \pm 4$ & $2.9 \pm 1.8$ & 5.9 \\
\hline
\end{tabular}


Al analizar los datos mostrados en la Tabla 4.6 se observa que el valor de $\chi^{2}$ obtenido fue del orden de $10^{-3}$ en todos los casos, indicando que se ha conseguido un buen ajuste de los datos experimentales al circuito planteado [61]. Los valores de $R_{S}$ vuelven a situarse en torno al valor esperado de $30 \Omega \mathrm{cm}^{2}$. Las muestras siguen una tendencia similar a las obtenidas con ácido sulfúrico ya que con un aumento de la temperatura la resistencia a la transferencia de carga $\left(R_{2}\right)$ disminuye. Además, si comparamos los resultados obtenidos en las diferentes atmósferas, también se obtienen un mejor resultado con las nanoestructuras obtenidas en aire. Sin embargo, los valores en este caso de las resistencias son más bajos si los comparamos con los de las muestras obtenidas con $\mathrm{H}_{2} \mathrm{SO}_{4}$.

Por tanto, comparando todos los resultados obtenidos del ensayo PEIS se puede concluir que las nanoestructuras obtenidas anodizando en medio $\mathrm{CH}_{4} \mathrm{O}_{3} \mathrm{~S}$ y calentadas a $600{ }^{\circ} \mathrm{C}$ en atmósfera de aire son las que presentan una mayor respuesta de fotocorriente y mejores propiedades fotoelectroquímicas, ya que el valor de resistencia a la transferencia de carga es menor incluso comparando con las nanoestructuras obtenidas anodizando en medio $\mathrm{H}_{2} \mathrm{SO}_{4}$.

\subsubsection{Nanoestructuras de $\mathrm{WO}_{3}$ sintetizadas en medio $\mathrm{HNO}_{3}$.}

Finalmente, se analizan los resultados obtenidos de los ensayos PEIS realizados a las nanoestructuras obtenidas anodizando con $\mathrm{HNO}_{3}$ como electrolito.

En la Figura 4.41 se muestran los registros de densidad de corriente obtenidos durante 30 min con las muestras sintetizadas en medio $\mathrm{HNO}_{3}$ cuando se aplica 1 $\mathrm{V}_{\mathrm{Ag} / \mathrm{AgCl}}$, luz solar simulada y en $0.1 \mathrm{M}$ de $\mathrm{H}_{2} \mathrm{SO}_{4}$ como medio electrolítico. En la Figura 4.41 a) se muestra la densidad de corriente obtenida de las muestras calentadas en aire tanto a $400{ }^{\circ} \mathrm{C}, 500{ }^{\circ} \mathrm{C}$ como $600{ }^{\circ} \mathrm{C}$, en la $4.41 \mathrm{~b}$ ) la densidad de corriente obtenida al calentar las nanoestructuras en atmósfera de nitrógeno, en la $4.41 \mathrm{c}$ ) en el caso de calentarse en atmósfera de argón y finalmente, en la 4.41 d) se muestra el valor final de la densidad de corriente en todos los casos para confrontar con mayor facilidad los resultados obtenidos. 

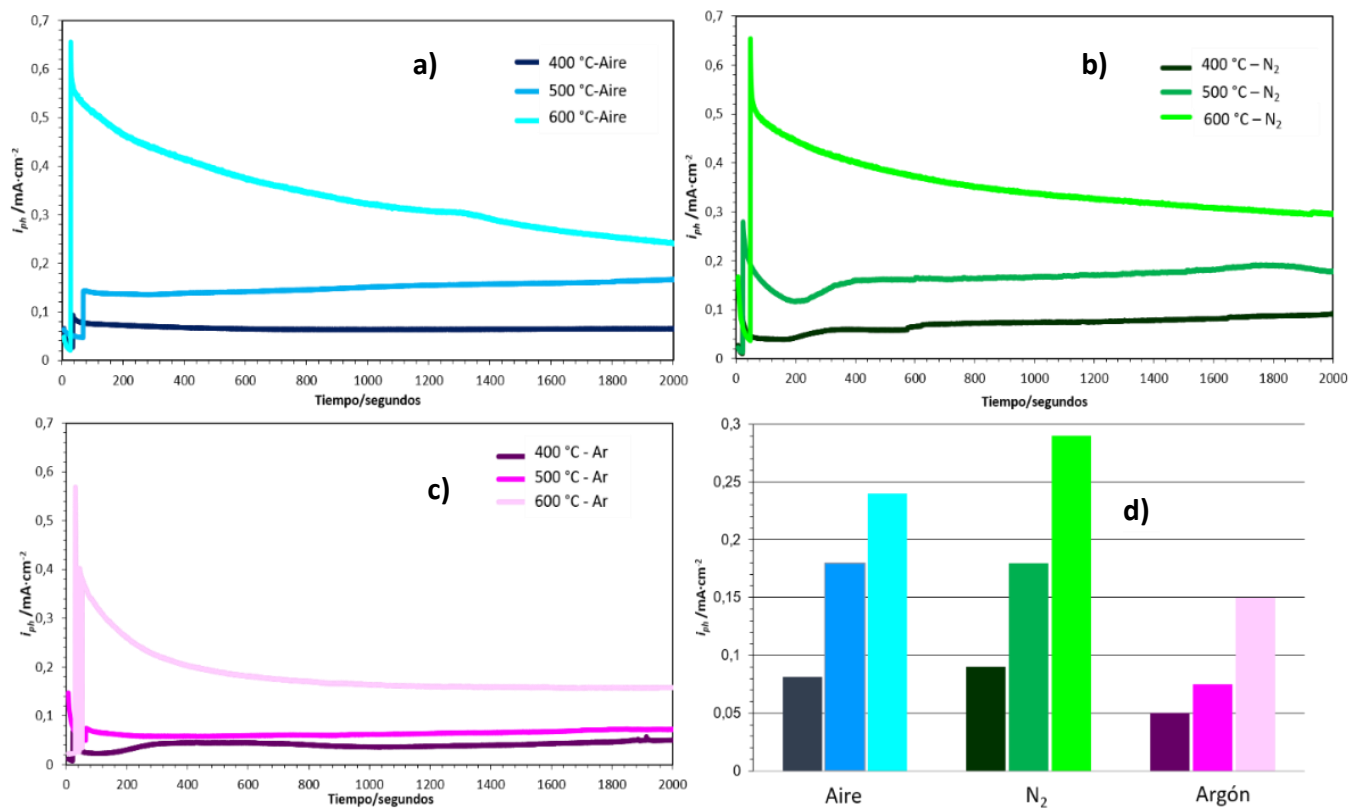

Figura 4.41. Densidad de corriente registrada durante $30 \mathrm{~min}$ con las nanoestructuras obtenidas con $\mathrm{HNO}_{3}$ y calentadas en a) aire, b) $\mathrm{N}_{2}$, c) Ar y d) resumen de todos los casos.

Nuevamente, se observa un aumento de la densidad de fotocorriente con el aumento de la temperatura de calentamiento en todas las atmósferas. No obstante, al utilizar $\mathrm{HNO}_{3}$ como electrolito de anodizado, se han obtenido unas nanoestructuras con mejor respuesta fotoelectroquímica con atmósfera de nitrógeno, aunque la diferencia con la atmósfera de aire no es muy significativa. En atmósfera de argón vuelven a experimentar una menor densidad de fotocorriente, dando a entender que poseen peores propiedades fotoelectroquímicas.

A continuación, en la Figura 4.42, se muestran los diagramas de Nyquist obtenidos de las muestras sintetizadas con $\mathrm{HNO}_{3}$. 

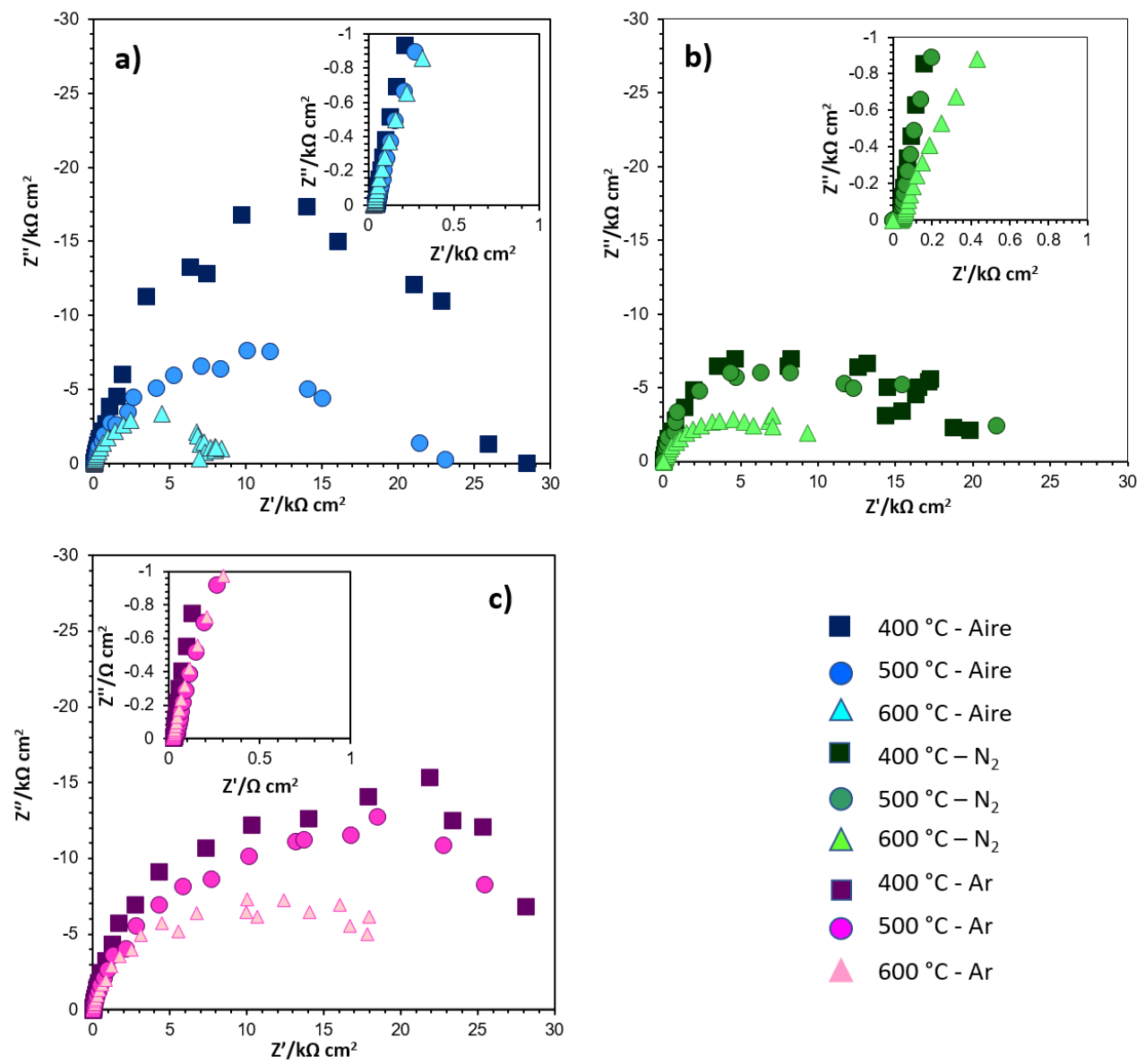

Figura 4.42. Diagramas experimentales de Nyquist de las nanoestructuras formadas tras el anodizado electroquímico en $\mathrm{HNO}_{3}$ como electrolito y calentadas a diferentes temperaturas en atmósferas de a) aire, b) $\mathbf{N}_{2}$, c) Ar.

En este caso, las impedancias de las muestras sintetizadas con $\mathrm{HNO}_{3}$ son más altas. Esto es debido, por una parte, a que la morfología obtenida tiende a ser en forma de nanoplaqueta en vez de nanohilo además de ser menos definida que en los casos anteriores $[21,65,69]$. Por tanto, el acceso de la luz se ve dificultado y no se consiguió una mejora ni en el transporte de los electrones ni en la difusión de los huecos. Todo ello hizo que las impedancias fueran mayores en el caso de las nanoestructuras obtenidas al anodizar las muestras con $\mathrm{HNO}_{3}$ como electrolito que en con el resto de ácidos. No obstante, concuerda el resultado obtenido en el 
diagrama de Nyquist con las densidades de fotocorriente registradas ya que las nanoestructuras calentadas en $\mathrm{N}_{2}$ a $600{ }^{\circ} \mathrm{C}$ fueron las que registraron una mayor densidad de fotocorriente y una amplitud del semicírculo menor, indicando que presenta una menor resistencia a la transferencia de carga.

En la Figura 4.43 y en la Figura 4.44 se muestran los diagramas de Bode-fase y Bode-módulo respectivamente. 

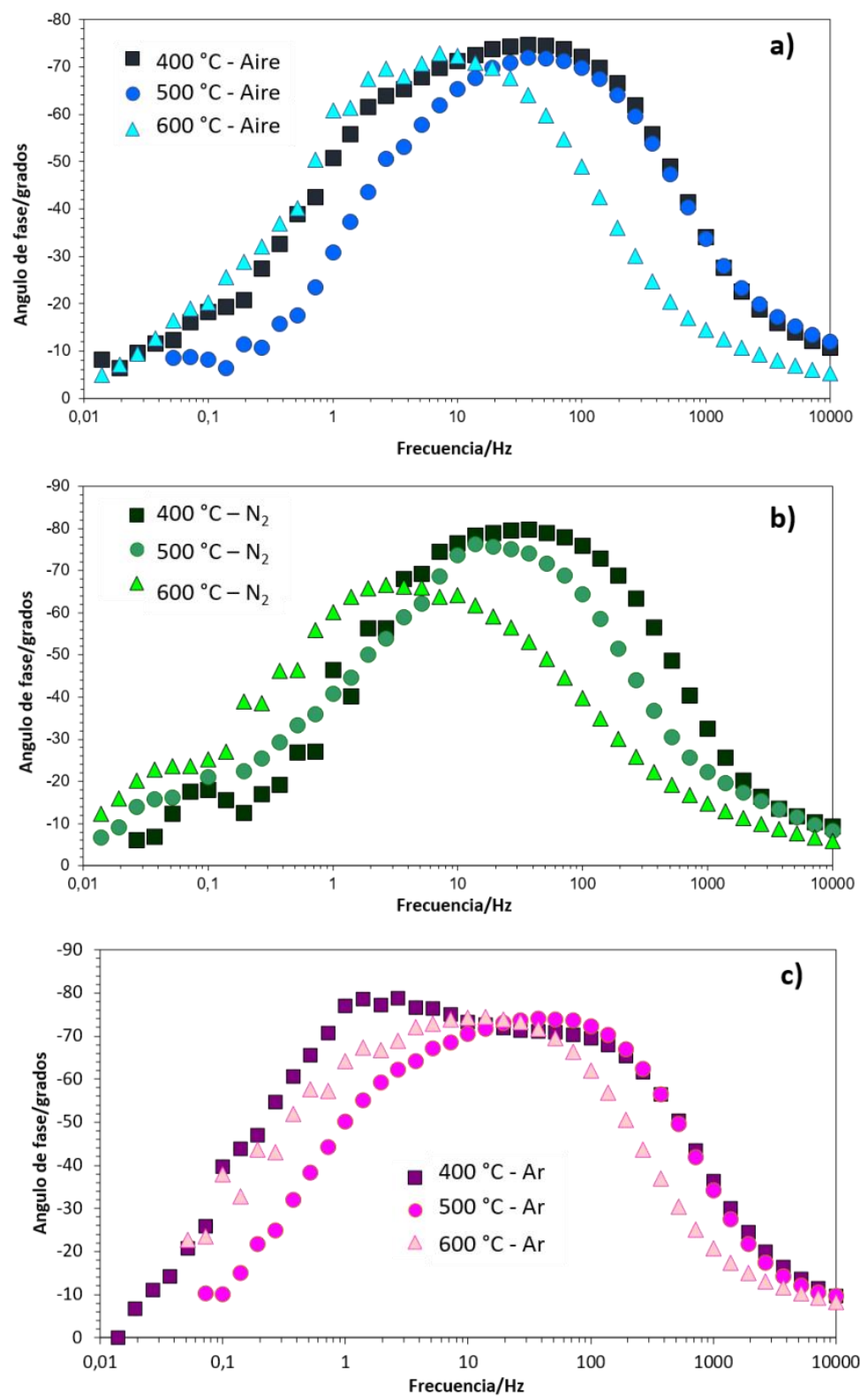

Figura 4.43. Diagramas experimentales de Bode-fase de las nanoestructuras formadas tras el anodizado electroquímico en $\mathrm{HNO}_{3}$ como electrolito y calentadas a diferentes temperaturas en atmósferas de a) aire, b) $\mathrm{N}_{2}$, c) Ar. 

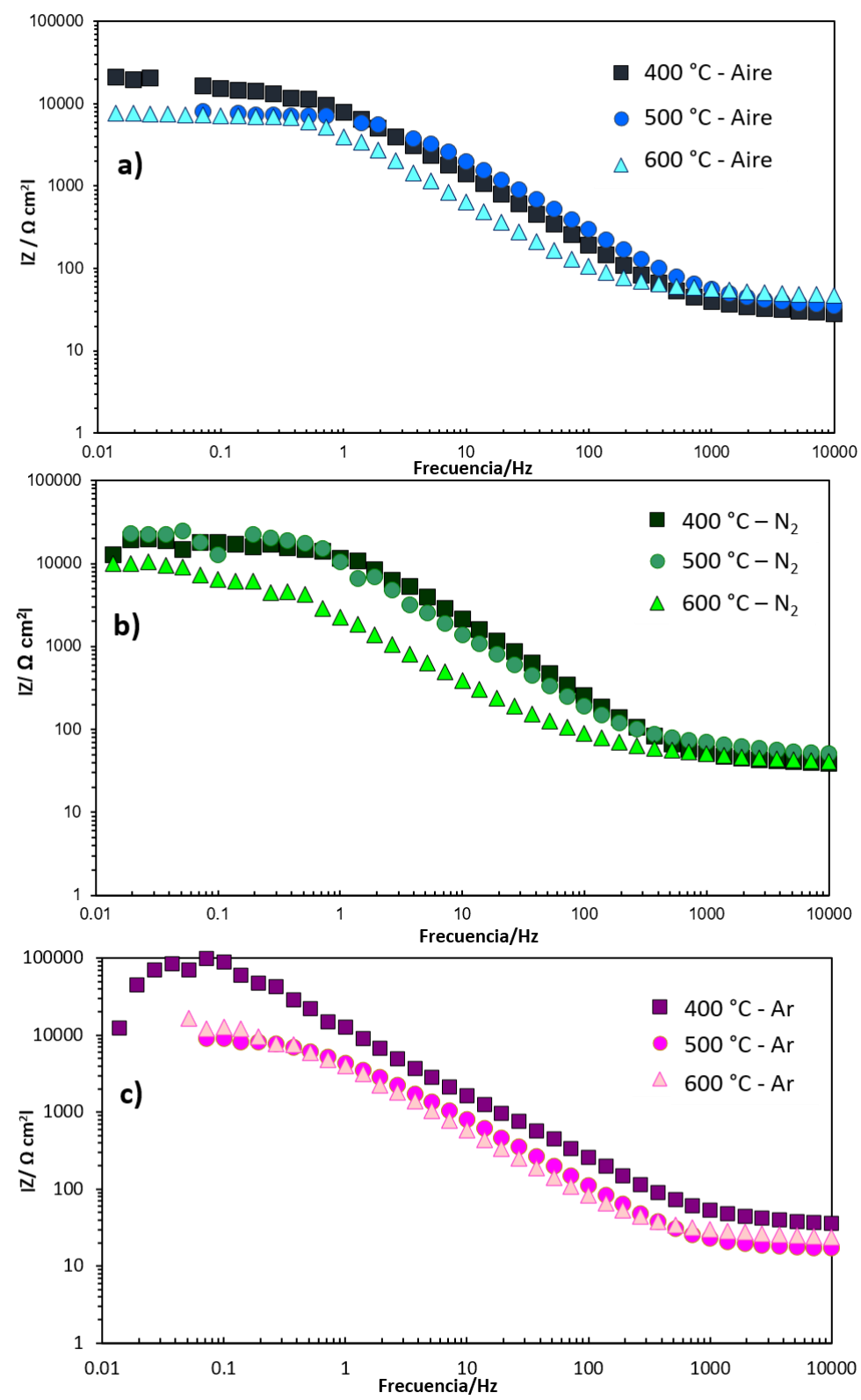

Figura 4.44. Diagramas experimentales de Bode-módulo de las nanoestructuras formadas tras el anodizado electroquímico en $\mathrm{HNO}_{3}$ como electrolito y calentadas a diferentes temperaturas en atmósferas de a) aire, b) $N_{2}$, c) Ar. 
Por una parte, del gráfico de Bode-fase (Figura 4.43), se puede concluir de nuevo que existen dos constantes de tiempo ya que se observa una superposición de dos picos, dando como resultado un solo pico de gran anchura. Por consiguiente, el circuito eléctrico equivalente utilizado para ajustar los datos experimentales es el mostrado en la Figura 4.36, utilizado también en los dos casos anteriores formado por una resistencia asociada al electrolito $\left(R_{s}\right)$ y dos grupos R-CPE en paralelo asociados a resistencia a la transferencia de carga y a la recombinación de los pares electrón- hueco.

Por otra parte, del gráfico de Bode-módulo (Figura 4.44) se puede apreciar que la resistencia asociada al electrolito es prácticamente la misma en todos los casos, ya que el electrolito utilizado fue el mismo en todos los ensayos $\left(0.1 \mathrm{M} \mathrm{H}_{2} \mathrm{SO}_{4}\right)$ $[66,76]$. Además, se vuelve a confirmar que las nanoestructuras calentadas con $\mathrm{N}_{2}$ a $600{ }^{\circ} \mathrm{C}$ presentan menor resistencia a la transferencia de carga ya que el valor del módulo de la impedancia es ligeramente menor que en atmósfera de argón, aunque similar a los datos obtenidos con aire.

Finalmente, los resultados obtenidos del ajuste de los datos al circuito eléctrico equivalente se muestran en la Tabla 4.7. En esta tabla se observa que el valor de $R_{2}$ vuelve a ser mucho mayor que el de $R_{1}$ ya que la resistencia que opone el material asociada a la recombinación de pares electrón-hueco es mucho menor que la resistencia asociada a la transferencia de carga entre las nanoestructuras y el electrolito.

Se puede comprobar en la Tabla 4.7, que en general los valores más bajos de $R_{2}$ fueron los obtenidos para las nanoestructuras calentadas en atmósfera de nitrógeno y a $600{ }^{\circ} \mathrm{C}$, aunque muy seguido de los valores obtenidos con las nanoestructuras calentadas con aire a $600{ }^{\circ} \mathrm{C}$. Esto se debe a la mayor facilidad que muestra la capa de nanoestructuras al paso de corriente eléctrica, lo que afecta positivamente al comportamiento fotoelectroquímico de las muestras. Además, el valor de $R_{1}$ es mayor también en el caso de las muestras calentadas con $\mathrm{N}_{2}$ a $600{ }^{\circ} \mathrm{C}$, indicando que estas condiciones de calentamiento en este caso son las óptimas ya que cuanto mayor es el valor de $R_{1}$ más se reduce la probabilidad de recombinación de los pares electrón-hueco. 
Tabla 4.7. Valores medios de las resistencias, obtenidos tras el ajuste de los datos experimentales de EIS al circuito eléctrico equivalente, de las nanoestructuras sintetizadas con $\mathrm{HNO}_{3}$ como electrolito.

\begin{tabular}{|c|c|c|c|c|c|}
\hline \multicolumn{2}{|c|}{ Condiciones } & $R_{s}\left(\Omega \mathrm{cm}^{2}\right)$ & $R_{1}\left(\Omega \mathrm{cm}^{2}\right)$ & $R_{2}\left(k \Omega \mathrm{cm}^{2}\right)$ & $x^{2}\left(\times 10^{-3}\right)$ \\
\hline \multirow{3}{*}{ Aire } & $400^{\circ} \mathrm{C}$ & $31 \pm 10$ & $11 \pm 0.8$ & $25 \pm 8.5$ & 5.3 \\
\hline & $500^{\circ} \mathrm{C}$ & $29.2 \pm 1.7$ & $28.4 \pm 2$ & $21.3 \pm 9$ & 3.3 \\
\hline & $600^{\circ} \mathrm{C}$ & $20.3 \pm 4$ & $25 \pm 7$ & $9.2 \pm 6$ & 8 \\
\hline \multirow{3}{*}{$\mathbf{N}_{2}$} & $400^{\circ} \mathrm{C}$ & $24.9 \pm 6$ & $9.9 \pm 3$ & $15 \pm 4.8$ & 7.6 \\
\hline & $500^{\circ} \mathrm{C}$ & $29 \pm 9$ & $32 \pm 5$ & $24.3 \pm 7$ & 15 \\
\hline & $600^{\circ} \mathrm{C}$ & $38 \pm 0.9$ & $46.5 \pm 9$ & $8.6 \pm 0.9$ & 4.9 \\
\hline \multirow{3}{*}{$\mathrm{Ar}$} & $400^{\circ} \mathrm{C}$ & $30 \pm 7$ & $9.57 \pm 2$ & $56.5 \pm 6$ & 1.7 \\
\hline & $500^{\circ} \mathrm{C}$ & $27 \pm 9$ & $18 \pm 4$ & $28.12 \pm 5.2$ & 3 \\
\hline & $600^{\circ} \mathrm{C}$ & $26.6 \pm 4$ & $23 \pm 9$ & $20.5 \pm 10$ & 4.3 \\
\hline
\end{tabular}

Como conclusión de este apartado se puede afirmar que al comparar la muestra obtenida en aire a $600{ }^{\circ} \mathrm{C}$ de los tres ácidos se observa que los valores de resistencia a la transferencia de carga $\left(R_{2}\right)$ en el caso del ácido metanosulfónico son más bajos y los de la resistencia a la recombinación de pares electrón-hueco $\left(R_{1}\right)$ más altos, por lo tanto, tendría un mejor comportamiento fotoelectroquímico que las nanoestructuras obtenidas con los otros ácidos. Estos resultados podrían estar relacionados con la morfología que presentan las nanoestructuras ya que tienen un mayor contacto entre ellas, mejorando la transferencia interfacial electroquímica y fotoelectroquímica, y con su cristalinidad, ya que cuanto más cristalinas sean mejor comportamiento como fotocatalizador tendrán. Los resultados de la densidad de fotocorriente y PEIS indican que las nanoestructuras obtenidas con $\mathrm{CH}_{4} \mathrm{O}_{3} \mathrm{~S}$ tienen la mayor eficiencia de separación de los portadores de carga fotogenerada, así como el transporte electrónico más rápido entre el electrolito y las nanoestructuras. Por tanto, las muestras anodizadas en medio $\mathrm{CH}_{4} \mathrm{O}_{3} \mathrm{~S}$ y sometidas al tratamiento térmico de $600^{\circ} \mathrm{C}$ y en atmósfera de aire parecen ser las más adecuadas para ser empleadas como fotocatalizador en aplicaciones fotoelectroquímicas. 


\subsection{Análisis de Mott-Schottky.}

Con los datos obtenidos de los ensayos de PEIS también se puede determinar la densidad de los dopantes en un semiconductor, mediante la ecuación de MottSchottky para semiconductores de tipo $\mathrm{n}[77,78]$, como es el caso del $\mathrm{WO}_{3}$ :

$$
\frac{1}{C^{2}}=\frac{1}{C_{H}^{2}}+\frac{2}{\varepsilon_{r} \varepsilon_{0} e N_{D}}\left(E-E_{F B}-\frac{k T}{e}\right)
$$

donde $\mathrm{C}$ es la capacitancia interfacial total medida, $\mathrm{C}_{\mathrm{H}}$ es la capacitancia de la capa de Helmholtz, $\varepsilon_{r}$ es la constante dieléctrica del semiconductor (50 para nanoestructuras de $\left.\mathrm{WO}_{3}\right), \varepsilon_{0}$ es la constante de permisividad a vacío $\left(8.85 \cdot 10^{-14}\right.$ $\left.\mathrm{F} \cdot \mathrm{cm}^{-1}\right)$, e es la carga del electrón $\left(1.60 \cdot 10^{-19} \mathrm{C}\right), \mathrm{N}_{\mathrm{D}}$ es la densidad de donantes en el semiconductor, $\mathrm{E}$ es el potencial aplicado, $\mathrm{E}_{\mathrm{FB}}$ es el potencial de banda plana, $k$ es el constante de Boltzmann $\left(1.38 \cdot 10^{-23} \mathrm{~J} \cdot \mathrm{K}^{-1}\right)$ y $T$ es la temperatura absoluta $[79,80]$.

De acuerdo con la ecuación (4.8), si se representa $1 / C^{2}$ frente al E se debe obtener una región lineal con pendiente positiva (para semiconductores de tipo $\mathrm{n}$ ), a partir de la cual se puede obtener el valor de $N_{D}$, mientras que de las ordenadas en el origen se obtienen los valores del potencial de banda plana, $\mathrm{E}_{\mathrm{FB}}$, en cada una de las muestras $[23,81,82]$.

\subsubsection{Nanoestructuras sintetizadas en medio $\mathrm{H}_{2} \mathrm{SO}_{4}$.}

Las gráficas de Mott-Schottky se muestran en la Figura 4.45 a) para las nanoestructuras obtenidas en aire, la 4.45 b) para las nanoestructuras obtenidas en nitrógeno y la 4.45 c) para las obtenidas en argón. 

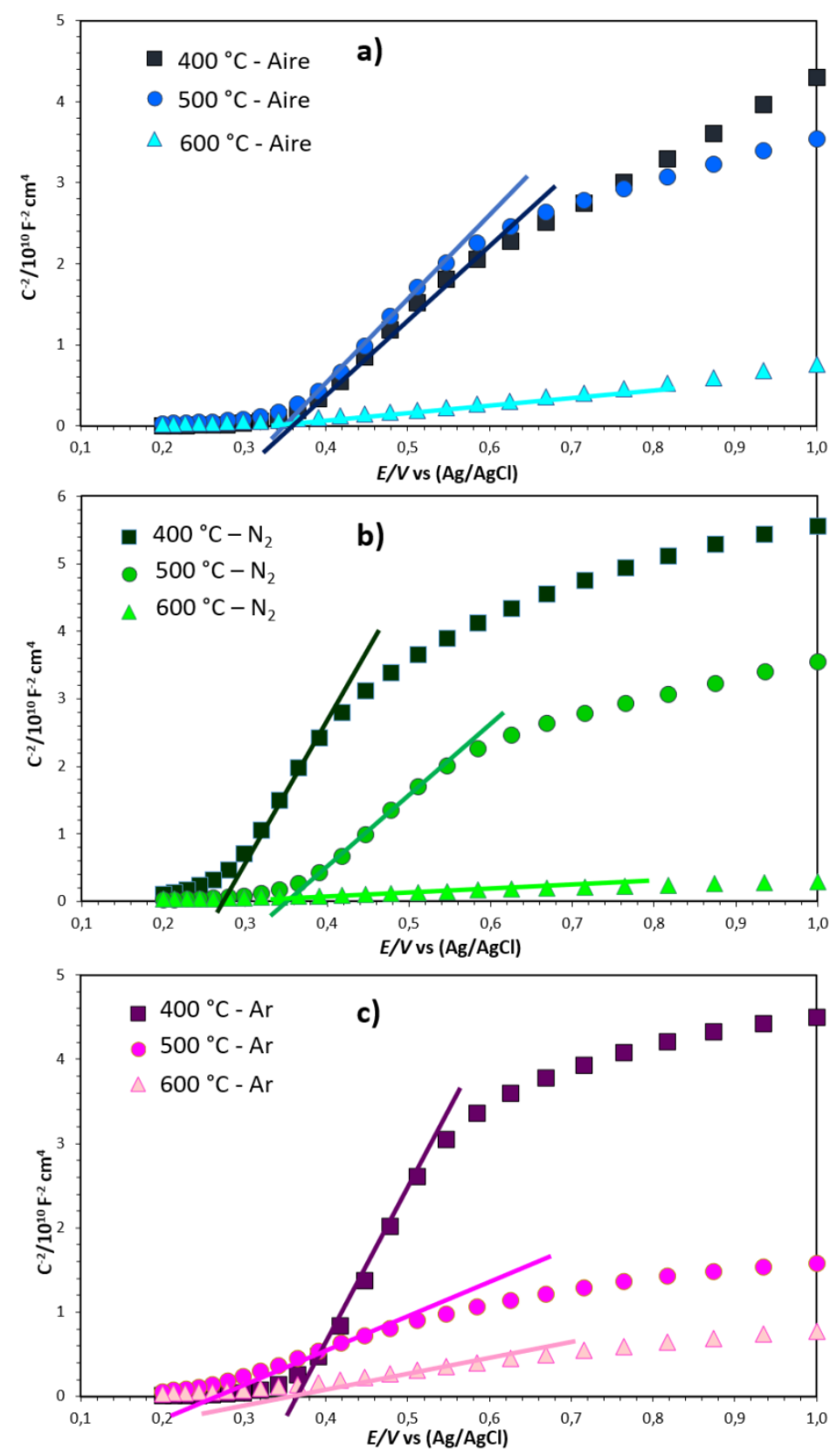

Figura 4.45. Gráficos Mott-Schottky realizados bajo iluminación solar simulada, de las nanoestructuras sintetizadas por anodizado electroquímico en medio $\mathrm{H}_{2} \mathrm{SO}_{4}$ como electrolito y calentadas en a) aire a diferentes temperaturas, b) $\mathrm{N}_{2}$ a diferentes temperaturas y c) $\mathrm{Ar}$ a diferentes temperaturas. 
En todos los casos, se puede observar una región lineal con pendiente positiva. Esta región está relacionada con la presencia de especies donantes dentro de la estructura cristalina de $\mathrm{WO}_{3}$, como son las especies intersticiales $\mathrm{W}^{6+} \mathrm{o}$ las vacantes de oxígeno [83,84]. Para muestras calentadas en atmósferas de $\mathrm{N}_{2}$ y $\mathrm{Ar}$, además, se puede observar claramente otra región lineal con una pendiente mucho más baja a potenciales altos, especialmente para muestras calentadas a $400{ }^{\circ} \mathrm{C}$. La presencia de esta región lineal a altos potenciales en las gráficas de Mott-Schottky puede atribuirse a estados electrónicos de nivel profundo cerca de la superficie, que son potencialmente dependientes $y$, por tanto, pueden cargarse o descargarse, o a un factor geométrico desconocido. La naturaleza de estos estados electrónicos no está identificada, aunque su relación con atmósferas no oxidantes durante el calentamiento es evidente $[83,85,86]$.

En todos los casos se han obtenido valores de $1 / \mathrm{C}^{2}$ más bajos (valores de capacitancia más altos) y pendientes más bajas al aumentar la temperatura de calentamiento, independientemente de la atmósfera utilizada. Los resultados de la densidad de los donantes se presentan en la Tabla 4.8. Se puede ver que los valores de $N_{D}$ en las muestras calentadas a $400{ }^{\circ} \mathrm{C}$ y $500{ }^{\circ} \mathrm{C}$ son similares, aunque ligeramente más altas a $500{ }^{\circ} \mathrm{C}$. Sin embargo, a $600{ }^{\circ} \mathrm{C}$, estos valores aumentaron significativamente para todas las muestras, especialmente para el calentamiento en la atmósfera de aire. Este hecho se debe a la morfología de las nanoestructuras que con el aumento de la temperatura se ve más definida y en forma de nanohilo en vez de nanoplaquetas, dando como resultado una mayor densidad de donantes. Además, en la Tabla 4.8 se muestran valores de densidad de donantes del orden de $10^{-19} \mathrm{~cm}^{-3}$, siendo dicho orden el requerido para las nanoestructuras de óxido de wolframio según la bibliografía $[85,87]$. En general, existe una correlación entre altas densidades de fotocorriente, bajas resistencias de transferencia de carga $\left(R_{2}\right)$ y altas densidades de donantes $\left(N_{D}\right)$. Esta relación es razonable, ya que una alta densidad de especies de donantes daría como resultado una mayor movilidad de electrones y huecos dentro de las nanoestructuras de $\mathrm{WO}_{3}$, reduciendo así las resistencias de transferencia de carga y mejorando el rendimiento fotoelectroquímico de los fotoánodos. 
Tabla 4.8. Valores medios de $N_{D}$ y $E_{F B}$, de las nanoestructuras sintetizadas por anodizado electroquímico en medio $\mathrm{H}_{2} \mathrm{SO}_{4}$ y calentadas a diferentes temperaturas y atmósferas.

\begin{tabular}{|c|c|cc|}
\hline Atmósfera & $\mathbf{T} /{ }^{\circ} \mathbf{C}$ & $N_{D}\left(\times 10^{19}\right) / \mathbf{c m}^{-3}$ & $\mathrm{E}_{\mathrm{FB}} / \mathbf{V}$ \\
\hline \multirow{3}{*}{ Aire } & 400 & $2.6 \pm 0.3$ & 0.360 \\
\cline { 2 - 4 } & 500 & $2.9 \pm 0.5$ & 0.326 \\
\cline { 2 - 4 } & 600 & $45.8 \pm 8.6$ & 0.330 \\
\hline \multirow{3}{*}{$\mathrm{N}_{2}$} & 400 & $4.7 \pm 2.7$ & 0.324 \\
\cline { 2 - 4 } & 500 & $5.2 \pm 1.5$ & 0.332 \\
\cline { 2 - 4 } & 600 & $20.4 \pm 27.7$ & 0.372 \\
\hline \multirow{3}{*}{$\mathrm{Ar}$} & 400 & $3.3 \pm 1.6$ & 0.396 \\
\cline { 2 - 4 } & 500 & $4.5 \pm 3.6$ & 0.337 \\
\cline { 2 - 4 } & 600 & $16.1 \pm 7.0$ & 0.344 \\
\hline
\end{tabular}

En cuanto al potencial de banda plana, en la Tabla 4.8 se muestran unos valores alrededor de $0.3 \mathrm{~V}$ (vs. $\mathrm{Ag} / \mathrm{AgCl}$ ) sin ver una influencia de la atmósfera de calentamiento utilizada. Este valor de alrededor de 0.35 era el esperado ya que es el característico de las nanoestructuras de $\mathrm{WO}_{3}$ según los valores encontrados en bibliografía $[60,88]$.

La muestra calentada a $600{ }^{\circ} \mathrm{C}$ y en una atmósfera de aire ha experimentado los valores más altos de densidad de defectos, mostrando un buen comportamiento fotoelectroquímico. Este fotoánodo es, por lo tanto, adecuado para usarse como fotocatalizador de alta eficiencia en muchas aplicaciones ambientales $y$ energéticas.

\subsubsection{Nanoestructuras sintetizadas en medio $\mathrm{CH}_{4} \mathrm{O}_{3} \mathrm{~S}$.}

En la Figura 4.46 se muestran los gráficos de Mott-Schottky obtenidos con las nanoestructuras sintetizadas con $\mathrm{CH}_{4} \mathrm{O}_{3} \mathrm{~S}$ y calentadas en diferentes atmósferas y temperaturas. Concretamente, en la Figura 4.46 a) se muestran los gráficos de las nanoestructuras obtenidas en aire, la 4.46 b) de las nanoestructuras obtenidas en nitrógeno y la 4.46 c) de las obtenidas en argón. 

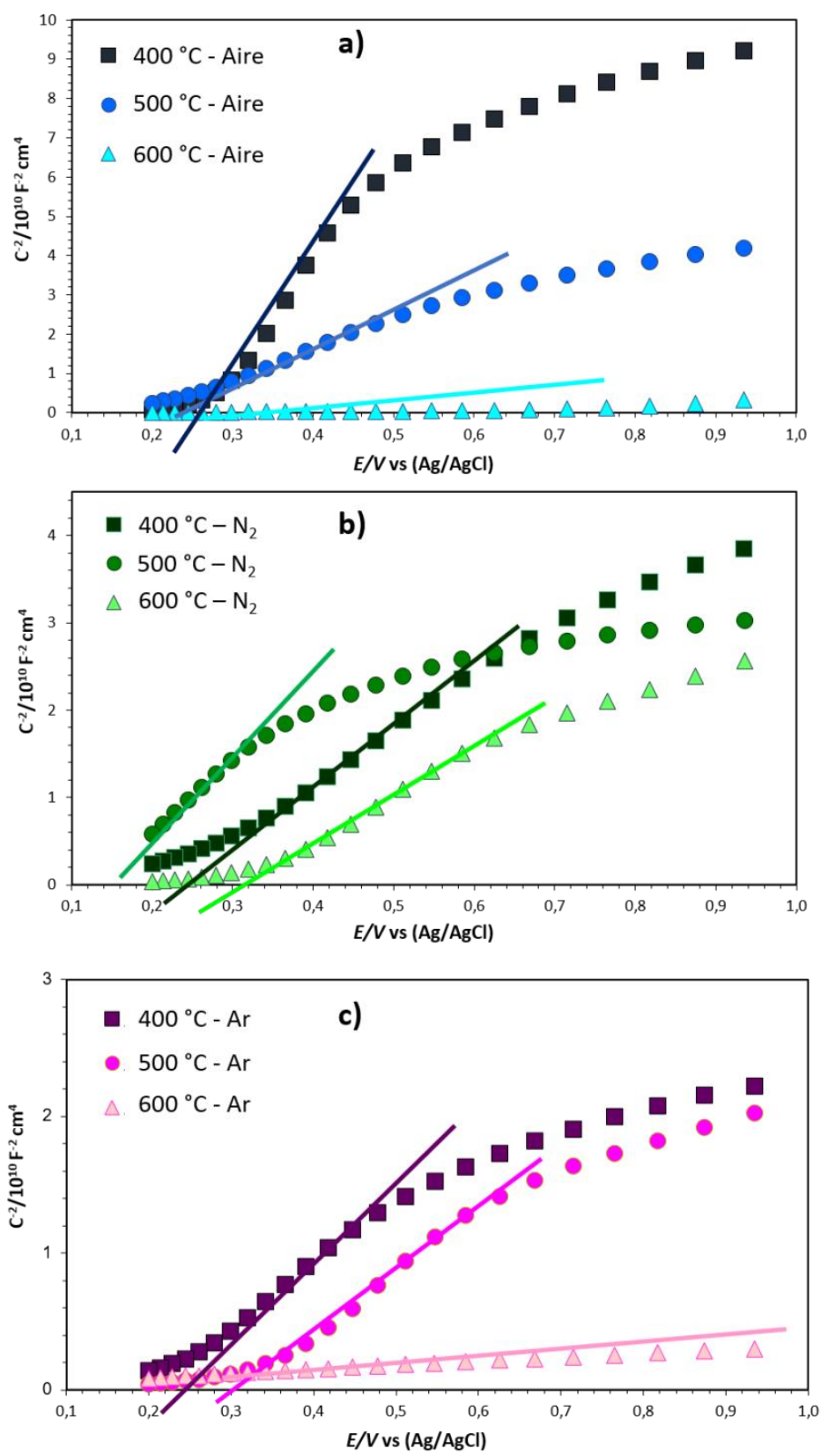

Figura 4.46. Gráficos Mott-Schottky realizados bajo iluminación solar simulada, de las nanoestructuras sintetizadas por anodizado electroquímico en medio $\mathrm{CH}_{4} \mathrm{O}_{3} \mathrm{~S}$ como electrolito y calentadas en a) aire a diferentes temperaturas, b) $\mathrm{N}_{2}$ a diferentes temperaturas y c) $\mathrm{Ar}$ a diferentes temperaturas. 
Nuevamente, en estos gráficos se puede observar que la parte lineal de las curvas posee una pendiente positiva, característica de semiconductor de tipo n, como es el caso del $\mathrm{WO}_{3}$. Además, existe una relación inversa entre la pendiente de la zona lineal y el número de defectos ya que cuanto mayor es la pendiente, menor es el número de defectos de las nanoestructuras $[79,89,90]$. Observando la Figura 4.46, se puede concluir que, en general, con un aumento de la temperatura la pendiente de la zona lineal disminuye, dando como resultado un mayor número de defectos. No obstante, existe una excepción como es en la atmósfera de $\mathrm{N}_{2}$ que las muestras que experimentan un peor comportamiento son las calentadas a $500{ }^{\circ} \mathrm{C}$, rompiendo la tendencia descrita. Esto concuerda con los resultados vistos anteriormente en los ensayos de espectroscopía de impedancia electroquímica, en donde estas muestras presentaban una menor densidad de fotocorriente y una mayor resistencia a la transferencia de carga, por tanto, se esperaba que el valor de $\mathrm{N}_{\mathrm{D}}$ fuese peor que el de la muestra calentada a $400{ }^{\circ} \mathrm{C}$ en $\mathrm{N}_{2}$. Como conclusión, según la Figura 4.46 , las nanoestructuras calentadas en aire a $600^{\circ} \mathrm{C}$ tenían mayor número de defectos que aquellas calentadas en el resto de atmósferas y temperaturas. Esto es debido a que se favorece la formación de pares electrónhueco fotogenerados $y$, por tanto, aumenta el número de defectos en la nanoestructura.

En la Tabla 4.9 se muestran los valores obtenidos de $\mathrm{N}_{\mathrm{D}}$ extraídos de la pendiente en todos los casos para las muestras sintetizadas en medio $\mathrm{CH}_{4} \mathrm{O}_{3} \mathrm{~S}$.

Tabla 4.9. Valores medios de $N_{D}$ y $E_{F B}$, de las nanoestructuras sintetizadas por anodizado electroquímico en medio $\mathrm{CH}_{4} \mathrm{O}_{3} \mathrm{~S}$ y calentadas a diferentes temperaturas y atmósferas.

\begin{tabular}{|c|c|cc|}
\hline Atmósfera & $\mathrm{T} /{ }^{\circ} \mathrm{C}$ & $N_{D}\left(\times 10^{19}\right) / \mathrm{cm}^{-3}$ & $\mathrm{E}_{\mathrm{FB}} / \mathrm{V}$ \\
\hline \multirow{3}{*}{ Aire } & 400 & $1.9 \pm 0.3$ & 0.278 \\
\cline { 2 - 4 } & 500 & $4 \pm 0.57$ & 0.343 \\
\cline { 2 - 4 } & 600 & $52.4 \pm 6.5$ & 0.356 \\
\hline \multirow{3}{*}{$\mathrm{N}_{2}$} & 400 & $3.6 \pm 4.4$ & 0.220 \\
\cline { 2 - 4 } & 500 & $1.62 \pm 1.3$ & 0.355 \\
\cline { 2 - 4 } & 600 & $6.6 \pm 0.9$ & 0.186 \\
\hline \multirow{3}{*}{$\operatorname{Ar}$} & 400 & $4.7 \pm 4.8$ & 0.202 \\
\cline { 2 - 4 } & 500 & $5.64 \pm 2.1$ & 0.312 \\
\cline { 2 - 4 } & 600 & $6.16 \pm 3.9$ & 0.237 \\
\hline
\end{tabular}


A partir de los valores que se muestran en la Tabla 4.9 se puede confirmar que las nanoestructuras calentadas a $600{ }^{\circ} \mathrm{C}$ en aire son las que presentan un mayor número de defectos, como se había predicho al analizar los gráficos de la Figura 4.46. Por el contrario, las nanoestructuras que menor número de defectos presentan son las calentadas a $400{ }^{\circ} \mathrm{C}$ en atmósferas de aire y argón, y las calentadas a $500{ }^{\circ} \mathrm{C}$ en atmósfera de $\mathrm{N}_{2}$. Todos los valores obtenidos de $\mathrm{N}_{\mathrm{D}}$ eran del orden de $10^{19} \mathrm{~cm}^{-3}$, siendo el valor esperado y más apropiado para el caso de nanoestructuras que posteriormente se quieran utilizar como fotocatalizadores, de acuerdo con la bibliografía [91-93]. En cuanto a los valores de $E_{F B}$ se sitúan en torno a $0.3 \mathrm{~V}$, valor característico del $\mathrm{WO}_{3}$, por tanto, se puede concluir que ni la temperatura ni la atmósfera de calentamiento influyen en ese valor.

\subsubsection{Nanoestructuras sintetizadas en medio $\mathrm{HNO}_{3}$.}

Una vez analizados los datos de las muestras sintetizadas con $\mathrm{CH}_{4} \mathrm{O}_{3} \mathrm{~S}$, se evaluarán finalmente los obtenidos con las muestras obtenidas con el último ácido probado, el $\mathrm{HNO}_{3}$. En la Figura 4.47, se muestran los gráficos de MottSchokky, en donde la Figura 4.47 a) vuelve a mostrar los gráficos de las nanoestructuras obtenidas en aire, la 4.47 b) de las nanoestructuras obtenidas en nitrógeno y la 4.47 c) de las obtenidas en argón. 

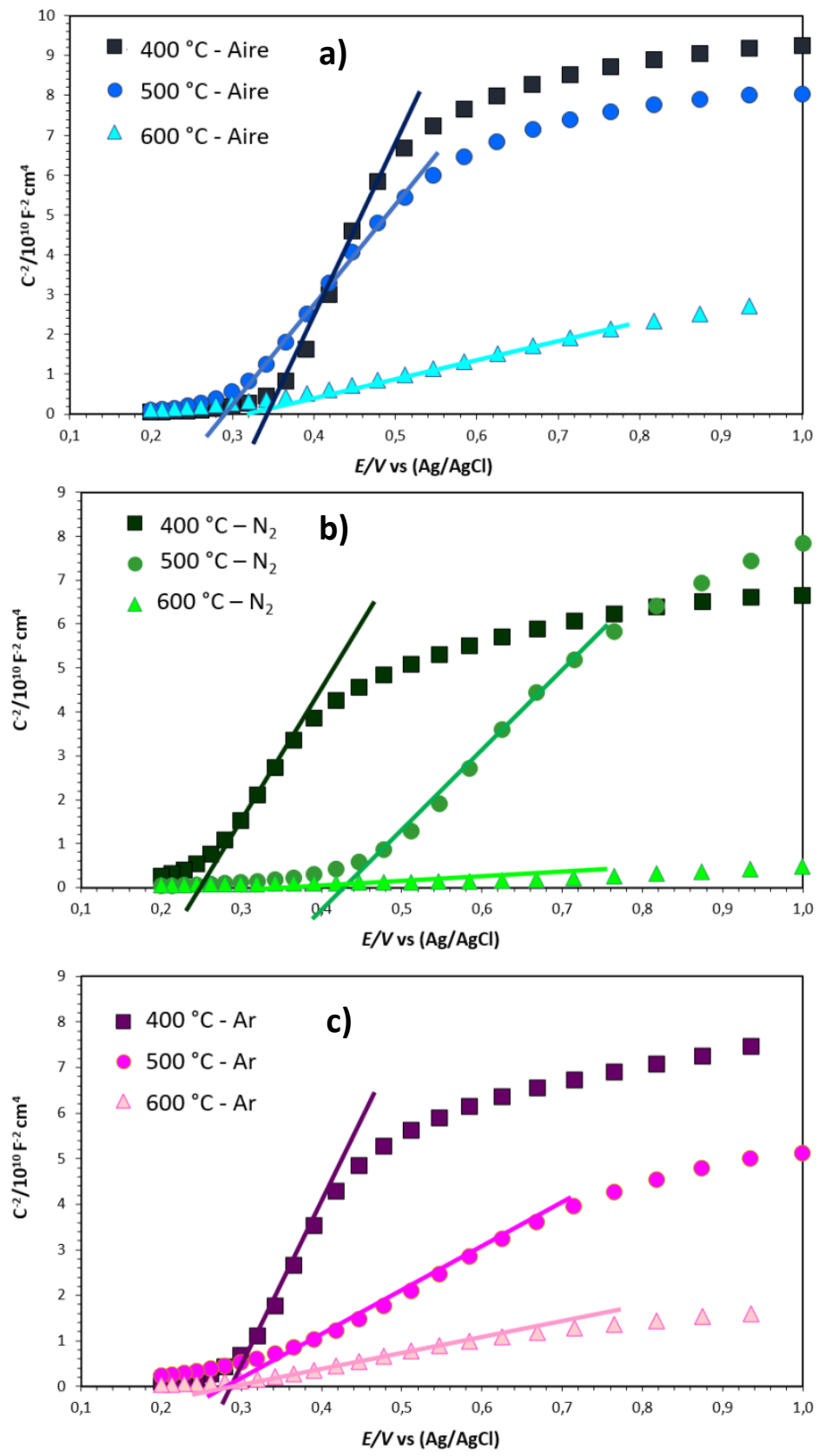

Figura 4.47. Gráficos Mott-Schottky realizados bajo iluminación solar simulada, de las nanoestructuras sintetizadas por anodizado electroquímico en medio $\mathrm{HNO}_{3}$ como electrolito y calentadas en a) aire a diferentes temperaturas, b) $\mathrm{N}_{2}$ a diferentes temperaturas y c) $\mathrm{Ar}$ a diferentes temperaturas. 
Nuevamente, como la pendiente es positiva, se puede afirmar que el semiconductor es de tipo n. Además, como en los anteriores casos, el valor de $N_{D}$ se obtiene de la pendiente, mientras que el valor de $\mathrm{E}_{\mathrm{FB}}$ se obtiene de la ordenada en el origen $[91,94,95]$.

En la Figura 4.47, se puede observar que también disminuye la pendiente con un aumento de la temperatura, como ocurre en los dos casos anteriores. No obstante, todas las muestras sintetizadas en medio $\mathrm{HNO}_{3}$ presentan pendientes más altas, lo que indica que dichas muestras no tenían elevada conductividad eléctrica $[94,96]$. Por tanto, se puede predecir que, en general, presentarán los valores de No más bajos, si se compara con las nanoestructuras obtenidas con los otros dos ácidos. En la Tabla 4.10, se muestran los datos de $N_{D}$ obtenidos a partir de las pendientes.

Tabla 4.10. Valores medios de $N_{D}$ y $E_{F B}$, de las nanoestructuras sintetizadas por anodizado electroquímico en medio $\mathrm{HNO}_{3}$ y calentadas a diferentes temperaturas y atmósferas.

\begin{tabular}{|c|c|c|c|}
\hline Atmósfera & $\mathrm{T} /{ }^{\circ} \mathrm{C}$ & $N_{D}\left(\times 10^{19}\right) / \mathrm{cm}^{-3}$ & $E_{F B} / V$ \\
\hline \multirow{3}{*}{ Aire } & 400 & $1.7 \pm 1.5$ & 0.351 \\
\hline & 500 & $2.05 \pm 0.42$ & 0.326 \\
\hline & 600 & $6.51 \pm 0.21$ & 0.306 \\
\hline \multirow{3}{*}{$\mathrm{N}_{2}$} & 400 & $4.6 \pm 3.6$ & 0.252 \\
\hline & 500 & $5.43 \pm 0.22$ & 0.364 \\
\hline & 600 & $20.3 \pm 10.6$ & 0.339 \\
\hline \multirow{3}{*}{$\mathrm{Ar}$} & 400 & $4.21 \pm 5.7$ & 0.211 \\
\hline & 500 & $10 \pm 2.3$ & 0.330 \\
\hline & 600 & $8.7 \pm 2.9$ & 0.214 \\
\hline
\end{tabular}

En la Tabla 4.10 se puede observar que nuevamente las muestras calentadas a $400{ }^{\circ} \mathrm{C}$ presentan un valor menor de $\mathrm{N}_{\mathrm{D}}$ que el resto, independientemente de la atmósfera utilizada. Por el contrario, las muestras calentadas a $600{ }^{\circ} \mathrm{C}$ son las que presentan los valores de $N_{D}$ más altos, siendo la muestra calentada en $\mathrm{N}_{2}$ la que mayor valor presenta. No obstante, como era de esperar debido a las altas pendientes que se observan en la Figura 4.47, estos valores de $N_{D}$ son más bajos que los obtenidos con los ácidos anteriores. Este resultado concuerda con los 
obtenidos tras analizar las técnicas anteriores a excepción de los resultados obtenidos con XPS, ya que en esa técnica se llegaba a la conclusión de que las nanoestructuras obtenidas con $\mathrm{HNO}_{3}$ presentan mayor número de vacantes que las obtenidas con $\mathrm{H}_{2} \mathrm{SO}_{4}$. No obstante, al utilizar $\mathrm{HNO}_{3}$ como electrolito, según el análisis XPS se consigue dopar la red estructural con nitrógeno, haciendo, según la bibliografía [30], que la red esté sometida a grandes tensiones y dificulte el movimiento de cargas, produciendo una menor conductividad eléctrica. Por tanto, en el análisis Mott- Schottky el valor obtenido de $N_{D}$ es más bajo de lo esperado debido a la baja conductividad eléctrica de las nanoestructuras.

Es importante resaltar que el valor de $\mathrm{N}_{\mathrm{D}}$, ha de ser elevado para que haya buena conductividad eléctrica $y$, por tanto, las nanoestructuras tengan un buen comportamiento fotoelectroquímico, aunque si fuera demasiado elevado puede facilitar la recombinación de los pares electrón-hueco, dando como resultado un rendimiento fotoelectroquímico más bajo $[94,97]$. En este caso, el valor obtenido en todas las muestras es el adecuado para que las nanoestructuras actúen como fotocatalizadores, ya que está en torno a $10^{-19} \mathrm{~cm}^{-3}$. En cuanto al valor de $E_{F B}$ vuelve a encontrarse alrededor de $0.3 \mathrm{~V}$, por lo que a las nanoestructuras de óxido de wolframio sintetizadas en medio $\mathrm{HNO}_{3}$ no les afecta el posterior tratamiento de calentamiento en las diferentes temperaturas y atmósferas.

Como conclusión de este apartado, se puede afirmar que, después de analizar todos los datos obtenidos de las muestras anodizadas con los 3 diferentes ácidos $\left(\mathrm{H}_{2} \mathrm{SO}_{4}, \mathrm{CH}_{4} \mathrm{O}_{3} \mathrm{~S}\right.$ y $\left.\mathrm{HNO}_{3}\right)$, y posteriormente calentadas a las diferentes temperaturas $\left(400{ }^{\circ} \mathrm{C}, 500{ }^{\circ} \mathrm{C}\right.$ y $600{ }^{\circ} \mathrm{C}$ ) y atmósferas (aire, $\mathrm{N}_{2}$ y Ar), las nanoestructuras obtenidas mediante $\mathrm{CH}_{4} \mathrm{O}_{3} \mathrm{~S}$ y calentadas a $600{ }^{\circ} \mathrm{C}$ en atmósfera de aire son las que presentan un mayor número de defectos. Esto se ha visto tanto en el gráfico de Mott-Schokky, en donde mostraba la menor pendiente, como en el valor obtenido de dicha pendiente que expresa la cantidad de defectos en las nanoestructuras. Por tanto, se puede concluir que estas nanoestructuras son las óptimas para utilizarlas como fotocatalizadores ya que son las que mejor conducen la electricidad. Esta conclusión respalda todos los resultados obtenidos en los análisis de las propiedades fotoelectroquímicas a través de los ensayos PEIS, los análisis morfológicos a través de las imágenes FESEM y AFM y los análisis de la estructura cristalina con la Microscopía de Láser Confocal Raman y XPS en los que también se concluía que estas nanoestructuras eran las que mejores propiedades presentaban. 
2. Diseño de experimentos (DDE) 



\section{Diseño de experimentos (DDE).}

\subsection{Diseño factorial $3^{3}$.}

Para evaluar las condiciones óptimas que dieran la mejor respuesta se realizó un análisis de varianza (ANOVA) y un análisis de superficie de respuesta en el que se evalúa el efecto de la variación de dos de los tres factores en la respuesta registrada. Los tres factores elegidos fueron el ácido empleado en el electrolito, la temperatura y la atmósfera de calentamiento en el proceso de post-anodizado. Como se ha mencionado anteriormente, los ácidos empleados fueron $\mathrm{H}_{2} \mathrm{SO}_{4}$, $\mathrm{CH}_{4} \mathrm{O}_{3} \mathrm{~S}$ y $\mathrm{HNO}_{3}$, la temperatura empleada fue $400{ }^{\circ} \mathrm{C}, 500{ }^{\circ} \mathrm{C}$ y $600{ }^{\circ} \mathrm{C}$ y las atmósferas que se probaron fueron en aire, $\mathrm{N}_{2}$ y Ar. Como variable respuesta para poder optimizar las nanoestructuras de $\mathrm{WO}_{3}$ se tomó la densidad de fotocorriente registrada durante los 30 minutos del ensayo de estabilización realizado antes de los ensayos de PEIS. En la Tabla 4.11 se muestran todos estos parámetros.

Tabla 4.11. Rango de variables y niveles del diseño de experimentos.

\begin{tabular}{|c|c|c|c|c|}
\hline \multirow{2}{*}{ Factores } & \multirow{2}{*}{ Variables } & \multicolumn{3}{|c|}{ Niveles de los factores } \\
\cline { 3 - 5 } & & $\mathbf{1}$ & $\mathbf{2}$ & $\mathbf{3}$ \\
\hline A & Ácido electrolito & $\mathrm{H}_{2} \mathrm{SO}_{4}$ & $\mathrm{CH}_{4} \mathrm{O}_{3} \mathrm{~S}$ & $\mathrm{HNO}_{3}$ \\
\hline B & Atmósfera & Aire & $\mathrm{N}_{2}$ & $\mathrm{Ar}$ \\
\hline C & Temperatura & $400{ }^{\circ} \mathrm{C}$ & $500^{\circ} \mathrm{C}$ & $600^{\circ} \mathrm{C}$ \\
\hline
\end{tabular}

Al realizar un diseño de experimentos $3^{3}$, el número total de experimentos para estudiar el efecto de los tres parámetros (ácido electrolito, temperatura y atmósfera) que se debían realizar eran 27 , pero con el fin de obtener más grados de libertad y que el análisis sea más robusto, se duplicaron los ensayos y se realizaron finalmente 54. En la Tabla 4.12 se muestran los ensayos realizados junto con el valor medio de la variable respuesta registrada. 
Tabla 4.12. Diseño factorial completo utilizado para la optimización de las nanoestructuras de $\mathrm{WO}_{3}$.

\begin{tabular}{|c|c|c|c|}
\hline Factor $\mathrm{A}$ & Factor B & Factor C & Variable Respuesta \\
\hline $\begin{array}{c}\text { Ácido } \\
\text { electrolito }\end{array}$ & Atmósfera & $\begin{array}{c}\text { Temperatura } \\
\left({ }^{\circ} \mathrm{C}\right)\end{array}$ & $\begin{array}{c}\text { Densidad fotocorriente } \\
(\mathrm{mA} \mathrm{cm})\end{array}$ \\
\hline 1 & 1 & 400 & 0.184 \\
\hline 1 & 2 & 400 & 0.076 \\
\hline 1 & 3 & 400 & 0.064 \\
\hline 1 & 1 & 500 & 0.320 \\
\hline 1 & 2 & 500 & 0.277 \\
\hline 1 & 3 & 500 & 0.256 \\
\hline 1 & 1 & 600 & 0.380 \\
\hline 1 & 2 & 600 & 0.319 \\
\hline 1 & 3 & 600 & 0.110 \\
\hline 2 & 1 & 400 & 0.152 \\
\hline 2 & 2 & 400 & 0.077 \\
\hline 2 & 3 & 400 & 0.072 \\
\hline 2 & 1 & 500 & 0.279 \\
\hline 2 & 2 & 500 & 0.044 \\
\hline 2 & 3 & 500 & 0.117 \\
\hline 2 & 1 & 600 & 0.562 \\
\hline 2 & 2 & 600 & 0.156 \\
\hline 2 & 3 & 600 & 0.351 \\
\hline 3 & 1 & 400 & 0.082 \\
\hline 3 & 2 & 400 & 0.090 \\
\hline 3 & 3 & 400 & 0.050 \\
\hline 3 & 1 & 500 & 0.180 \\
\hline 3 & 2 & 500 & 0.180 \\
\hline 3 & 3 & 500 & 0.075 \\
\hline 3 & 1 & 600 & 0.240 \\
\hline 3 & 2 & 600 & 0.290 \\
\hline 3 & 3 & 600 & 0.150 \\
\hline
\end{tabular}


Al introducir estos datos en el software StatGraphics se han obtenido los resultados mostrados a continuación.

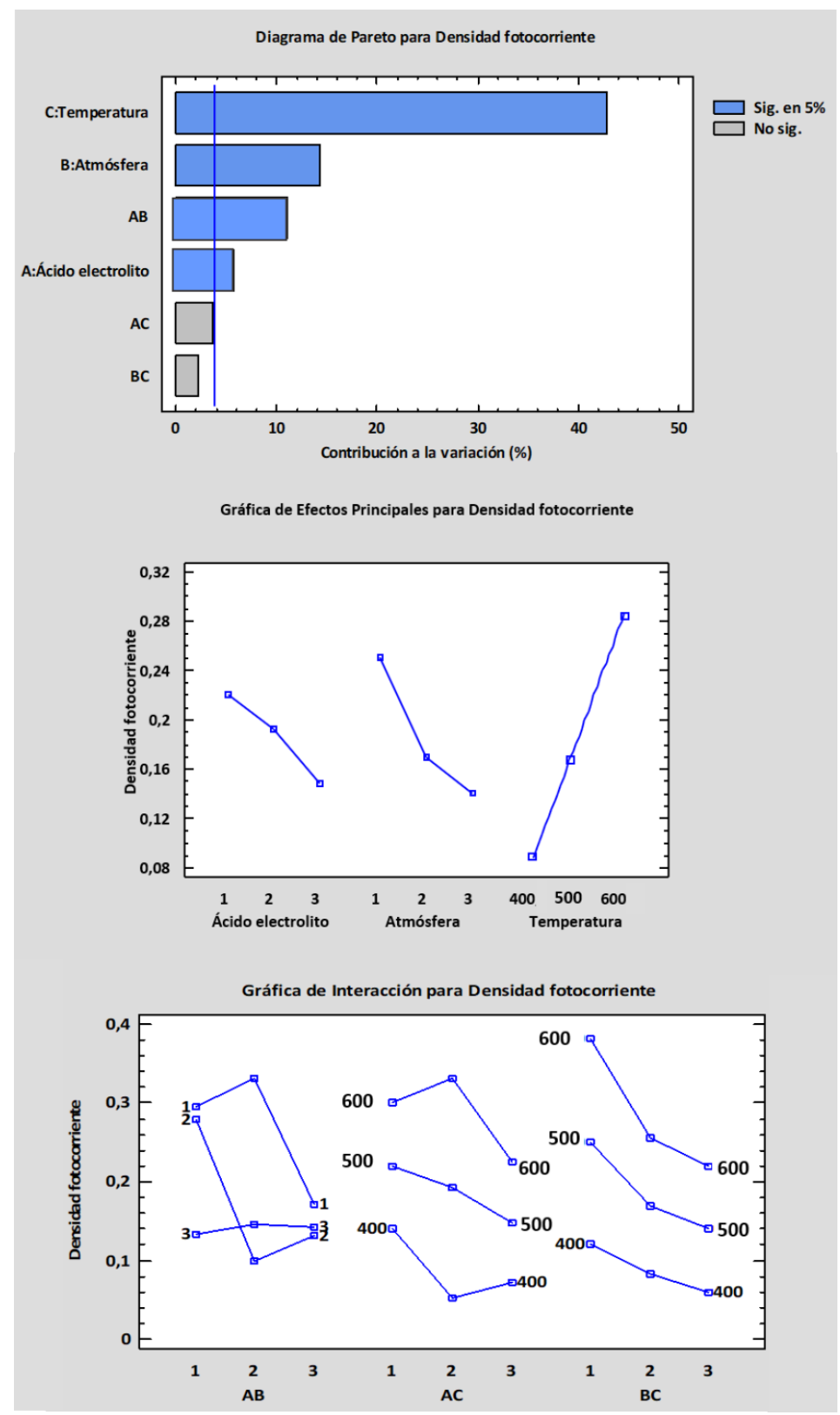

Figura 4.48. a) Diagrama de Pareto, b) gráfico de efectos principales y c) gráfico de interacción entre los factores. 
En la Figura 4.48, se muestran el diagrama de Pareto y los gráficos de efectos principales como de las interacciones entre los factores. El gráfico de Pareto estandarizado puede ser utilizado para determinar rápidamente qué efectos son los más importantes. La longitud de cada barra es proporcional al valor del estadístico obtenido para cada efecto. Las barras que sobrepasan la línea vertical son estadísticamente significativas al nivel de confianza escogido, situado por defecto al $5 \%[98,99]$. En este caso, el factor con un efecto más significativo es la temperatura. El Gráfico de efectos principales muestra cómo cada factor afecta al valor de la densidad de fotocorriente. Las líneas indican los cambios estimados en la densidad de fotocorriente cuando cada factor pasa de su nivel bajo a su nivel alto, con todos los otros factores constantes en un valor medio entre sus valores altos y bajos [100]. Se puede observar que, como ya se ha predicho con el Diagrama de Pareto, el factor de temperatura tiene una mayor influencia en el valor de la densidad de fotocorriente ya que existe una mayor variación de la respuesta, situándose el valor deseado en una temperatura de $600{ }^{\circ} \mathrm{C}$ ya que es el valor que maximiza esta respuesta. En cuanto a la atmósfera, su efecto es menor, pero también se puede concluir que, en una atmósfera de aire, la respuesta también se maximiza. Todo esto concuerda con lo concluido en todos los estudios anteriores al emplear diferentes técnicas de caracterización, pero cuando se analiza el factor del ácido del electrolito, según la Figura 4.48 b), se podría concluir que el ácido que maximiza la densidad de fotocorriente sería el $\mathrm{H}_{2} \mathrm{SO}_{4}$, pero esto no es lo que se ha observado en resultados obtenidos a partir de las técnicas de caracterización anteriores. Esto ocurre porque, como se ha explicado anteriormente, al analizar el efecto de un factor individualmente, se mantienen el resto constantes en su nivel medio, es decir, en este caso sería a $500{ }^{\circ} \mathrm{C}$ y en atmósfera de $\mathrm{N}_{2}$. En esas condiciones el ácido que presenta una mayor densidad de fotocorriente es el $\mathrm{H}_{2} \mathrm{SO}_{4}$, como se muestra en el gráfico. Por tanto, es muy importante evaluar también el gráfico de interacciones entre los factores (Figura 4.48 c), ya que muchas veces debido a las interacciones entre ellos los resultados obtenidos al analizar cada factor individuamente no se corresponden con los esperados.

Al analizar el gráfico de interacción se puede observar cómo hay una fuerte y significativa interacción entre los factores A (ácido) y B (atmósfera), ya que las líneas son todo lo contrario a paralelas entre sí. En este caso se puede observar 
cómo efectivamente con el $\mathrm{CH}_{4} \mathrm{O}_{3} \mathrm{~S}$ y en aire se obtiene el mejor resultado de densidad de fotocorriente. Esto es debido a que la atmósfera empleada en el calentamiento de las nanoestructuras y el ácido empleado en la síntesis interaccionan y dan resultados diferentes a los esperados si solo se tuvieran en cuenta los efectos principales de los factores.

\subsection{Estudio de superficie de respuesta (RSM) mediante Box-Behnken (BBD).}

Con el fin de comprobar los resultados obtenidos en el diseño factorial realizado en el apartado 4.2.1., se ha hecho un estudio de superficie de respuesta (RSM). Se trata de una colección de métodos estadísticos y matemáticos que se pueden utilizar para estudiar el efecto de varios factores a diferentes niveles y su influencia entre sí. Por lo tanto, RSM es una técnica de experimentación eficiente bien conocida que se aplica en una amplia gama de campos con el fin de producir productos de alta calidad o para analizar problemas de ingeniería de una manera más estable y económica. El objetivo principal de esta técnica es optimizar la superficie de respuesta que está influenciada por varios parámetros del proceso. También cuantifica la relación entre los parámetros de entrada controlables y las superficies de respuesta obtenidas. Los dos diseños más comunes utilizados en RSM son el Diseño Central Compuesto (CCD) y el diseño Box-Behnken (BBD). El BBD se considera una opción eficiente en RSM y una alternativa ideal al CCD $[98,101]$.

El diseño Box-Behnken es un método útil para desarrollar modelos de superficie de respuesta de segundo orden, basado en la construcción de diseños de bloques incompletos equilibrados que requieren al menos tres niveles para cada factor. En el BBD, el nivel de uno de los factores se fija en el nivel central, mientras que se aplican combinaciones de todos los niveles de los dos factores restantes $[101,102]$. La Tabla 4.13 muestra el diseño de Box-Behnken de los tres factores mencionados anteriormente. 
Tabla 4.13. Experimentos realizados en el diseño Box-Behnken.

\begin{tabular}{|c|c|c|c|c|}
\hline & Factor A & Factor B & Factor C & Variable Respuesta \\
\hline BLOQUE & $\begin{array}{c}\text { Ácido } \\
\text { electrolito }\end{array}$ & Atmósfera & $\begin{array}{c}\text { Temperatura } \\
\left({ }^{\circ} \mathrm{C}\right)\end{array}$ & $\begin{array}{l}\text { Densidad fotocorriente } \\
\qquad\left(\mathrm{mA} \cdot \mathrm{cm}^{-2}\right)\end{array}$ \\
\hline 1 & 1 & 1 & 500 & 0.32 \\
\hline 1 & 3 & 1 & 500 & 0.1795 \\
\hline 1 & 1 & 3 & 500 & 0.256 \\
\hline 1 & 3 & 3 & 500 & 0.075 \\
\hline 1 & 1 & 2 & 400 & 0.0763 \\
\hline 1 & 3 & 2 & 400 & 0.09 \\
\hline 1 & 1 & 2 & 600 & 0.319 \\
\hline 1 & 3 & 2 & 600 & 0.29 \\
\hline 1 & 2 & 1 & 400 & 0.152 \\
\hline 1 & 2 & 3 & 400 & 0.0724 \\
\hline 1 & 2 & 1 & 600 & 0.562 \\
\hline 1 & 2 & 3 & 600 & 0.351 \\
\hline 1 & 2 & 2 & 500 & 0.0438 \\
\hline 1 & 2 & 2 & 500 & 0.0443 \\
\hline 1 & 2 & 2 & 500 & 0.0425 \\
\hline 2 & 1 & 1 & 500 & 0.329 \\
\hline 2 & 3 & 1 & 500 & 0.179 \\
\hline 2 & 1 & 3 & 500 & 0.252 \\
\hline 2 & 3 & 3 & 500 & 0.076 \\
\hline 2 & 1 & 2 & 400 & 0.0743 \\
\hline 2 & 3 & 2 & 400 & 0.095 \\
\hline 2 & 1 & 2 & 600 & 0.311 \\
\hline 2 & 3 & 2 & 600 & 0.26 \\
\hline 2 & 2 & 1 & 400 & 0.147 \\
\hline 2 & 2 & 3 & 400 & 0.0729 \\
\hline 2 & 2 & 1 & 600 & 0.557 \\
\hline 2 & 2 & 3 & 600 & 0.359 \\
\hline 2 & 2 & 2 & 500 & 0.048 \\
\hline 2 & 2 & 2 & 500 & 0.045 \\
\hline 2 & 2 & 2 & 500 & 0.0432 \\
\hline
\end{tabular}


El diseño de Box-Behnken es rotable o casi rotable de segundo orden. La rotabilidad es importante para que el modelo de segundo orden proporcione buenas predicciones en toda la región de interés. En la Figura 4.49 se muestra una representación gráfica de un diseño de tres factores utilizando dos tipos de análisis diferentes.
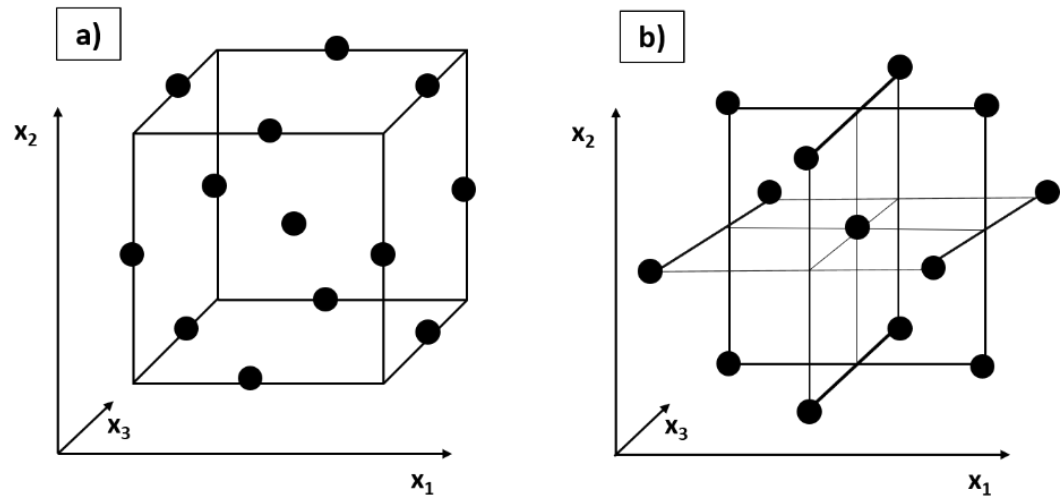

Figura. 4.49. a) La representación para BBD consiste en el punto central y el punto medio de los bordes; b) Tres diseños factoriales entrelazados $2^{2}$ y un punto central.

El número de experimentos $(\mathrm{N})$ necesarios para el desarrollo de BBD se define como $\mathrm{N}=2 \mathrm{k}(\mathrm{k}-1)+\mathrm{C}_{0}$ (donde $\mathrm{k}$ es el número de factores y $\mathrm{C}_{0}$ es el número de puntos centrales). Para la comparación de BBD, la ecuación utilizada para el número de experimentos en el caso de un diseño compuesto central es $\mathrm{N}=2 \mathrm{k}+$ $2 \mathrm{k}+\mathrm{C}_{0}$. Según la bibliografía BBD es más eficiente que otros diseños de superficie de respuesta como $C C D$, ya que se evitan condiciones extremas de experimentos y supone un menor coste experimental si se consideran dos o tres factores [100].

El análisis de varianza (ANOVA) se muestra en la Tabla 4.14, en donde se observa el p-valor de cada factor e interacción, concluyéndose que los realmente significativos, y por tanto, a tener en cuenta en el diseño son los que presentan un valor-p menor a 0.05 . Si los valores-p son mayores que 0.100 , indica que los términos del modelo son insignificantes [98]. En este caso, al presentar un valor-p menor al 0,05 los tres factores, así como la interacción entre el factor A y B, es decir, entre el ácido del electrolito y la atmósfera de calentamiento, todos ellos se han de tener en cuenta en el estudio estadístico. 
Tabla 4.14. Tabla ANOVA para el modelo cuadrático de superficie de respuesta en la optimización de las nanoestructuras $\mathrm{WO}_{3}$.

\begin{tabular}{|c|c|c|c|c|c|}
\hline Fuente & $\begin{array}{c}\text { Suma de } \\
\text { Cuadrados }\end{array}$ & GL & $\begin{array}{c}\text { Cuadrado } \\
\text { Medio }\end{array}$ & Razón-F & Valor-P \\
\hline $\begin{array}{c}\text { A:Ácido } \\
\text { electrolito }\end{array}$ & 0.0300242 & 1 & 0.0300242 & 8.76 & 0.00320 \\
\hline B:Atmósfera & 0.0518928 & 1 & 0.0518928 & 22.23 & 0.0002 \\
\hline C:Temperatura & 0.310555 & 1 & 0.310555 & 133.03 & 0.0000 \\
\hline AA & 0.00882354 & 1 & 0.00882354 & 3.78 & 0.0668 \\
\hline AB & 0.000552781 & 1 & 0.000552781 & 12.86 & 0.00021 \\
\hline AC & 0.00163592 & 1 & 0.00163592 & 0.70 & 0.4129 \\
\hline BB & 0.12342 & 1 & 0.12342 & 52.87 & 0.0000 \\
\hline BC & 0.00814726 & 1 & 0.00814726 & 3.49 & 0.0772 \\
\hline CC & 0.0900321 & 1 & 0.0900321 & 38.57 & 0.0000 \\
\hline bloques & 0.0000215053 & 1 & 0.0000215053 & 0.01 & 0.9245 \\
\hline Error total & 0.0443555 & 19 & 0.0023345 & & \\
\hline Total (corr.) & 0.647867 & 29 & & & \\
\hline
\end{tabular}

En la Tabla 4.15 se muestran los valores de $\mathrm{R}^{2}$. El estadístico R-Cuadrado indica que el modelo, así ajustado, explica el $93.15 \%$ de la variabilidad en la Densidad de fotocorriente. El estadístico R-cuadrado ajustado, que es más adecuado para comparar modelos con diferente número de variables independientes, es $89.55 \%$. El error estándar del estimado muestra que la desviación estándar de los residuos es 0.048 . El error medio absoluto (MAE) de 0.031 es el valor promedio de los residuos. El estadístico de Durbin-Watson (DW) prueba los residuos para determinar si hay alguna correlación significativa basada en el orden en que se presentan los datos en el archivo. Puesto que el valor-P es mayor que $5 \%$, no hay indicación de autocorrelación serial en los residuos con un nivel de significancia del $5 \%$. 
Tabla 4.15. Valores característicos del análisis ANOVA.

\begin{tabular}{|c|c|}
\hline R-cuadrada & $93.15 \%$ \\
\hline $\begin{array}{c}\text { R-cuadrada } \\
\text { (ajustada por g.I.) }\end{array}$ & $89.55 \%$ \\
\hline $\begin{array}{c}\text { Error estándar del } \\
\text { est. }\end{array}$ & 0.048 \\
\hline $\begin{array}{c}\text { Error absoluto medio } \\
\text { Estadístico Durbin- } \\
\text { Watson }\end{array}$ & $\begin{array}{c}2.97972 \\
(\mathrm{P}=0.9865)\end{array}$ \\
\hline
\end{tabular}

Otra forma de estudiar el efecto de los factores sobre la densidad de fotocorriente registrada, son los gráficos de superficie de respuesta tridimensional.

La Figura 4.50 a) muestra el gráfico de superficie de respuesta tridimensional para el ácido del electrolito y la atmósfera frente a la densidad de fotocorriente registrada en cada caso cuando la temperatura es de $600{ }^{\circ} \mathrm{C}$, ya que es la temperatura a la cual se consiguen mejores resultados, según se ha visto en las otras gráficas. El gráfico muestra que con la atmósfera en valor 1, es decir, atmósfera de aire, la densidad de fotocorriente es la máxima hasta llegar al valor óptimo de ésta que se da cuando el ácido del electrolito se sitúa entre 1 y 2 , es decir, cuando se utiliza $\mathrm{CH}_{4} \mathrm{O}_{3} \mathrm{~S} \circ \mathrm{H}_{2} \mathrm{SO}_{4}$. El valor mínimo se alcanza cuando la atmósfera y el electrolito valen 2, es decir, en atmósfera de $\mathrm{N}_{2}$ y $\mathrm{CH}_{4} \mathrm{O}_{3} \mathrm{~S}$, formando un valle en la gráfica. Con la formación de este valle se muestra la interacción que hay entre ambos factores, dando como resultado valores de la variable respuesta diferentes a los esperados si se analizasen los efectos de los factores simples.

La Figura 4.50 b) muestra el gráfico de superficie de respuesta tridimensional para la atmósfera y la temperatura frente a la densidad de fotocorriente registrada en cada caso cuando el ácido del electrolito utilizado es $\mathrm{CH}_{4} \mathrm{O}_{3} \mathrm{~S}$ ya que con él se consigue el resultado óptimo. Con el aumento de la temperatura, se observa un aumento en la densidad de fotocorriente debido a una mayor deshidratación de las nanoestructuras. Además, el valor de la variable respuesta más alto se dio cuando la atmósfera tomaba el valor 1, es decir, en aire, como se había observado 
en la Figura 4.50 a), ya que una atmósfera oxidante favorece la formación de nanoestructuras en forma de nanohilos. Finalmente, los peores resultados se han dado cuando la atmósfera toma valores de 2 y 3 ( $\mathrm{N}_{2}$ y Ar respectivamente) y a temperaturas iguales o menores a $500^{\circ} \mathrm{C}$.

La Figura 4.50 c) muestra el gráfico de superficie de respuesta tridimensional para el ácido del electrolito y la temperatura frente a la densidad de fotocorriente cuando la atmósfera utilizada es aire, ya que es la atmósfera óptima como se ha visto en resultados anteriores. Se observa nuevamente que a mayor temperatura la densidad de corriente también aumenta, alcanzándose los valores máximos cuando el ácido del electrolito es $\mathrm{CH}_{4} \mathrm{O}_{3} \mathrm{~S}$ o $\mathrm{H}_{2} \mathrm{SO}_{4}$, como se observó en la Figura 4.50 a). 


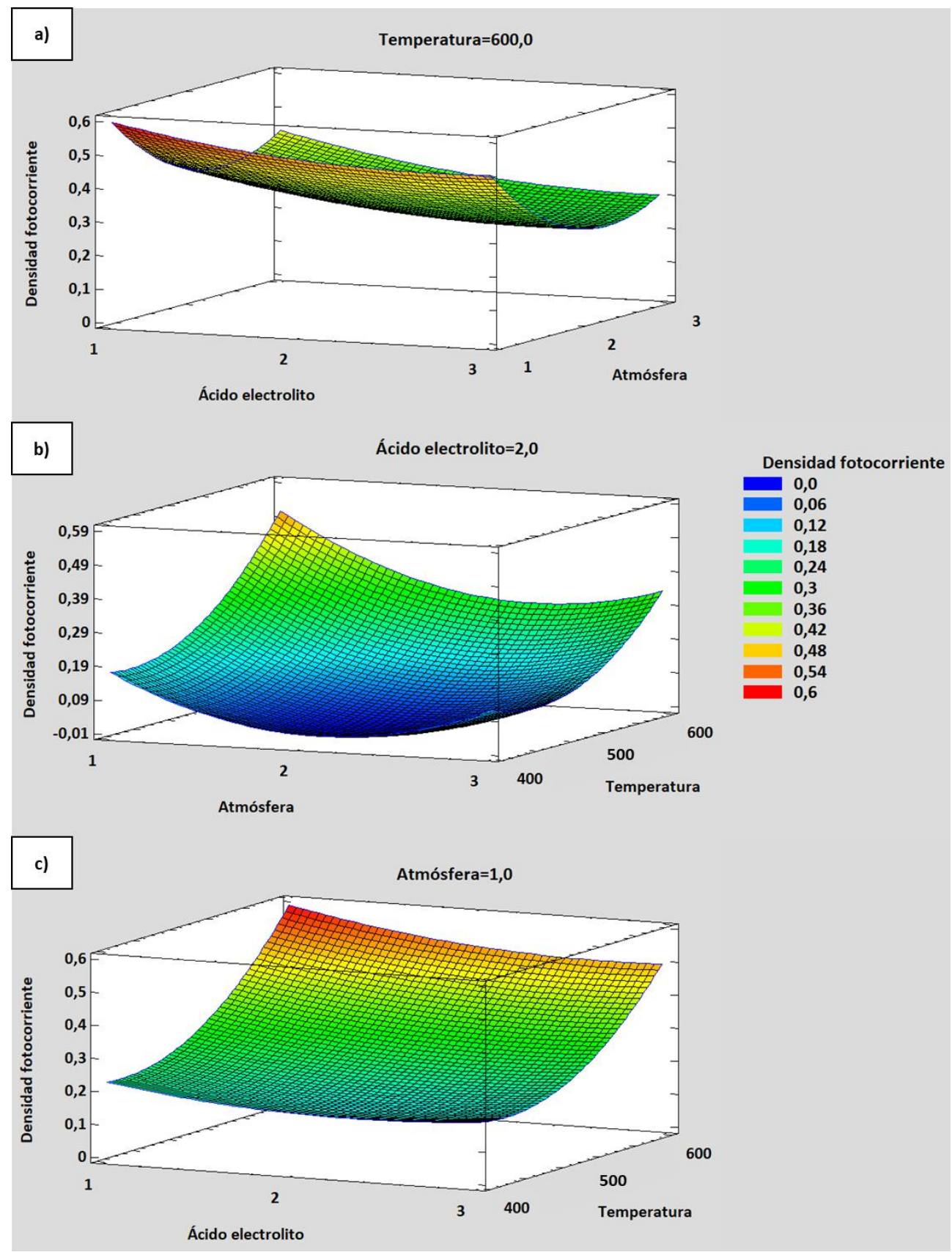

Figura 4.50. Gráficos de superficie de respuesta tridimensional en donde los factores variables son a) ácido electrolito y atmósfera, b) atmósfera y temperatura y c) ácido electrolito y temperatura. 
Por tanto, los valores óptimos de los factores ensayados al analizar los gráficos de RSM se muestran en la Tabla 4.16. La respuesta de densidad de fotocorriente en estas condiciones fue de $0.562 \mathrm{~mA} \cdot \mathrm{cm}^{-2}$.

Tabla 4.16. Valores óptimos de los tres factores.

\begin{tabular}{|c|c|}
\hline Factores & Valor óptimo \\
\hline Ácido electrolito & $\mathrm{CH}_{4} \mathrm{O}_{3} \mathrm{~S}$ \\
\hline Atmósfera & Aire \\
\hline Temperatura & $600^{\circ} \mathrm{C}$ \\
\hline
\end{tabular}


3. Degradación fotoelectrocatalítica de pesticidas organofosforados 



\section{Degradación fotoelectrocatalítica de pesticidas organofosforados.}

La tercera y última parte de la Tesis consistió en degradar cuatro pesticidas organofosforados mediante la técnica de oxidación avanzada conocida como fotoelectrocatálisis con el fin de obtener compuestos más pequeños e inocuos, ya que estos pesticidas son muy tóxicos para los seres vivos, así como persistentes y perjudiciales en el medioambiente.

Esta degradación se llevó a cabo según se ha explicado en el capítulo 3.4, en donde mediante el uso del potenciostato y el simulador solar se aplicaron las condiciones necesarias para llevar a cabo la degradación fotoelectroquímica de los pesticidas.

\subsection{Diazinón}

El primer pesticida organofosforado elegido para degradar fue el diazinón. A continuación, se muestran los resultados obtenidos mediante la técnica de UV-Vis y UHPLC-MS-Q-TOF.

\subsubsection{Espectroscopía UV-Vis}

En primer lugar, mediante espectroscopía Ultravioleta-Visible, se siguió el transcurso de la degradación fotoelectroquímica del diazinón, con el fin de controlar el proceso, así como poder corregir a tiempo cualquier problema surgido durante el ensayo.

Se registró el espectro UV-Vis de 4 patrones de diazinón a diferentes concentraciones ( $1 \mathrm{ppm}, 5 \mathrm{ppm}, 10 \mathrm{ppm}$ y $20 \mathrm{ppm}$ ), con el fin de analizar la evolución del espectro asociado al diazinón con la concentración. En la Figura 4.51 se muestra este espectro UV-Vis característico del diazinón, en donde se observa un pico a $250 \mathrm{~nm}$ aproximadamente y una banda a $330 \mathrm{~nm}$. El pico a $250 \mathrm{~nm}$ se ha asociado, según bibliografía [103], con el anillo aromático característico de diazinón. Este pico está relacionado con la excitación de un electrón desde un orbital de enlace $\pi$ a un orbital $\pi *$ antienlazante [104] y normalmente se utiliza para seguir la degradación de este compuesto orgánico. Además, la banda observada a $330 \mathrm{~nm}$ se ha relacionado con la transición $n-\pi *$ que se refiere al átomo de azufre donde un electrón procedente de un orbital no enlazante es excitado a un orbital $\pi *$ antienlazante $[105,106]$. 


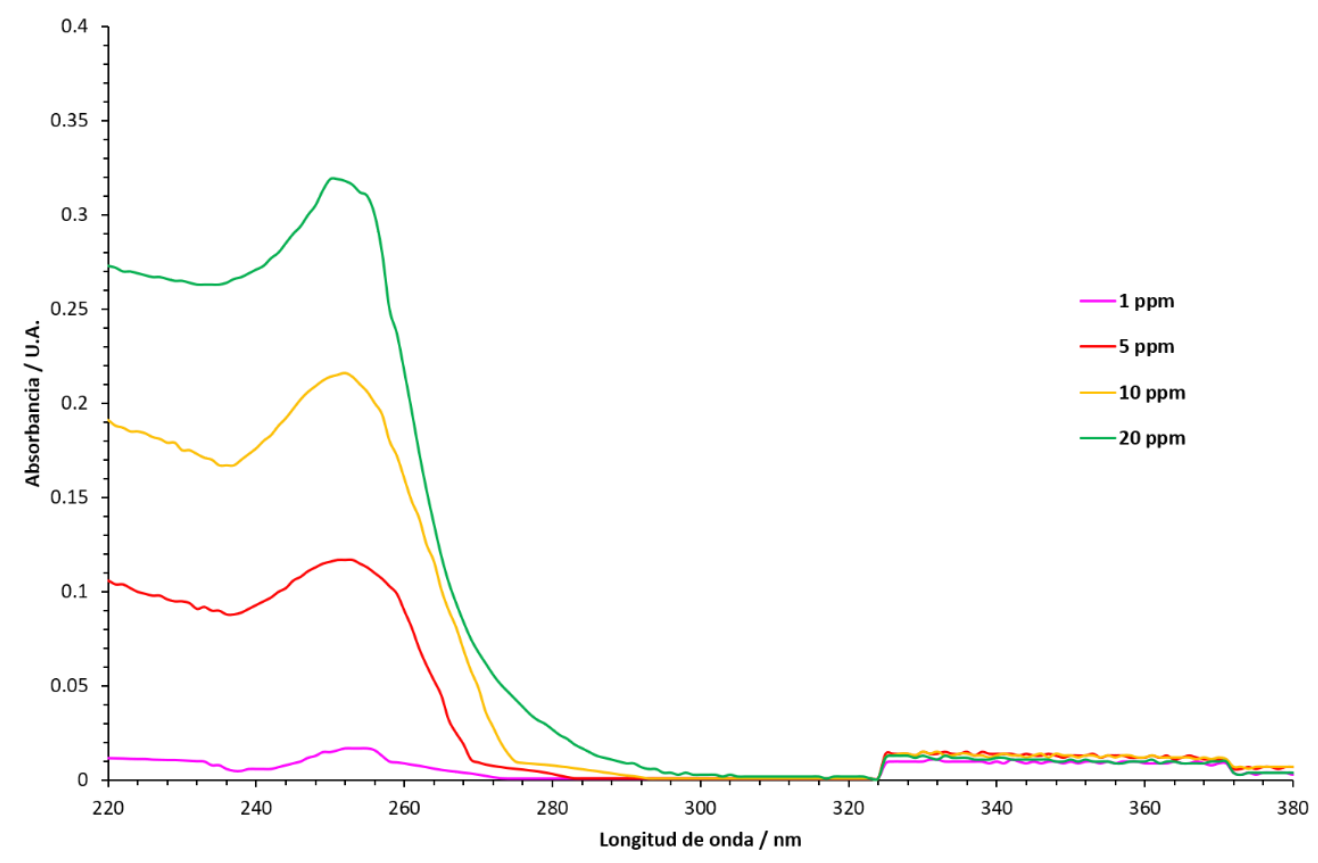

Figura 4.51. Espectro UV-vis de los patrones de diazinón.

La Figura 4.52 muestra la evolución con el tiempo del espectro de absorción UV de la disolución de diazinón de 20 ppm en $0.1 \mathrm{M} \mathrm{H}_{2} \mathrm{SO}_{4}$ después de irradiación con luz solar simulada y con la aplicación de un potencial constante de $1 \mathrm{~V}$. La banda a $250 \mathrm{~nm}$ disminuyó progresivamente con el tiempo hasta $270 \mathrm{~min}$, donde se mantuvo prácticamente constante. Sin embargo, surgió un nuevo pico con el tiempo a $230 \mathrm{~nm}$, que corresponde a la formación de intermedios de degradación, aunque esta banda disminuyó ligeramente al final del ensayo. Este intermedio de degradación puede ser una molécula más pequeña debido a la ruptura del pesticida a través del enlace etanotiol o enlace fosforamidato [105], lo que da como resultado una molécula más pequeña y menos polar, o la incorporación de grupos auxocromos como - $\mathrm{OH}$ y $-\mathrm{NH}_{2}$ en el anillo [107]. Ésta sería la razón por la que la banda aparece a la izquierda, en longitudes de onda más cortas, ya que tanto el enlace etanotiol como el fosforamidato actúan como auxocromos. 


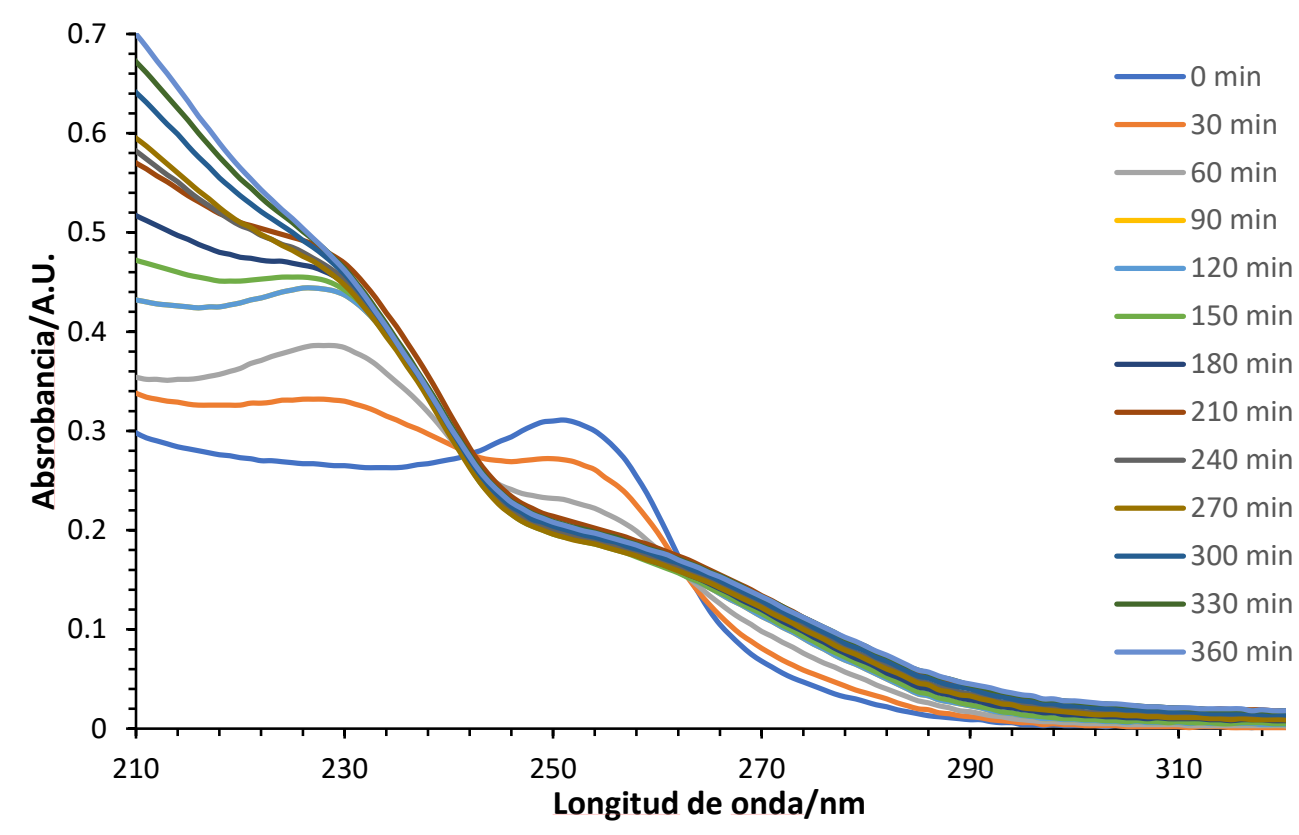

Figura 4.52. Espectros UV-Vis de diazinón cuando se utiliza la técnica PEC durante 6 h.

\subsubsection{Análisis HPLC-MS.}

Posteriormente, mediante medidas de HPLC-MS, se analizaron los patrones y las muestras de diazinón recogidas cada hora con el fin de analizar la concentración exacta de diazinón con el paso del tiempo, así como identificar los intermedios de degradación obtenidos durante el proceso fotoelectrocatalitico. En primer lugar, se evaluaron los patrones para obtener nuevamente la recta de calibrado (4.9) que se utilizará para calcular la concentración de diazinón en las muestras experimentales.

$$
\text { Área }=3310267.7854 \times \text { concentración }
$$

En la Figura 4.53 se muestra el cromatograma de Corriente lónica Total (TIC) de los patrones de diazinón a $1 \mathrm{ppm}, 5 \mathrm{ppm}, 10 \mathrm{ppm}$ y $20 \mathrm{ppm}$, una ampliación del pico para analizar mejor los resultados, y el espectro de masas correspondiente al pico.

En el espectro de masas esta representado el valor de la relación masa/carga $(\mathrm{m} / \mathrm{z})$ del compuesto asociado a ese pico. Ese valor de $\mathrm{m} / \mathrm{z}$ es la división de la masa atómica o molecular de un ion $\mathrm{m}$ por el número de cargas $\mathrm{z}$ que tiene el ion. 
Debido a que la mayoría de los iones en $M S$ tienen $\mathrm{z}=1$, el término $\mathrm{m} / \mathrm{z}$ a menudo se reduce al término más adecuado de masa.

No obstante, la mayor o menor capacidad que tendrá el analito para generar moléculas depende directamente del peso molecular $(m)$ y del carácter polar del mismo, o sea de su estructura química (tipo y número de grupos funcionales polares presentes). A mayor peso molecular y mayor número de grupos polares, mayor posibilidad de generar iones policargados $(z>1)$ y menor posibilidad de generar iones monocargados $(z=1)$. Además, la mayor o menor capacidad que tendrá el analito para generar iones cargados positivamente (cationes) o negativamente (aniones) depende en primer lugar del tipo de grupos polares presentes en su estructura y en segundo lugar de las características del medio $(\mathrm{pH}$, presencia de sales) y del solvente de la solución original (caracter prótico del solvente, polaridad, constante dieleléctrica, etc.). 

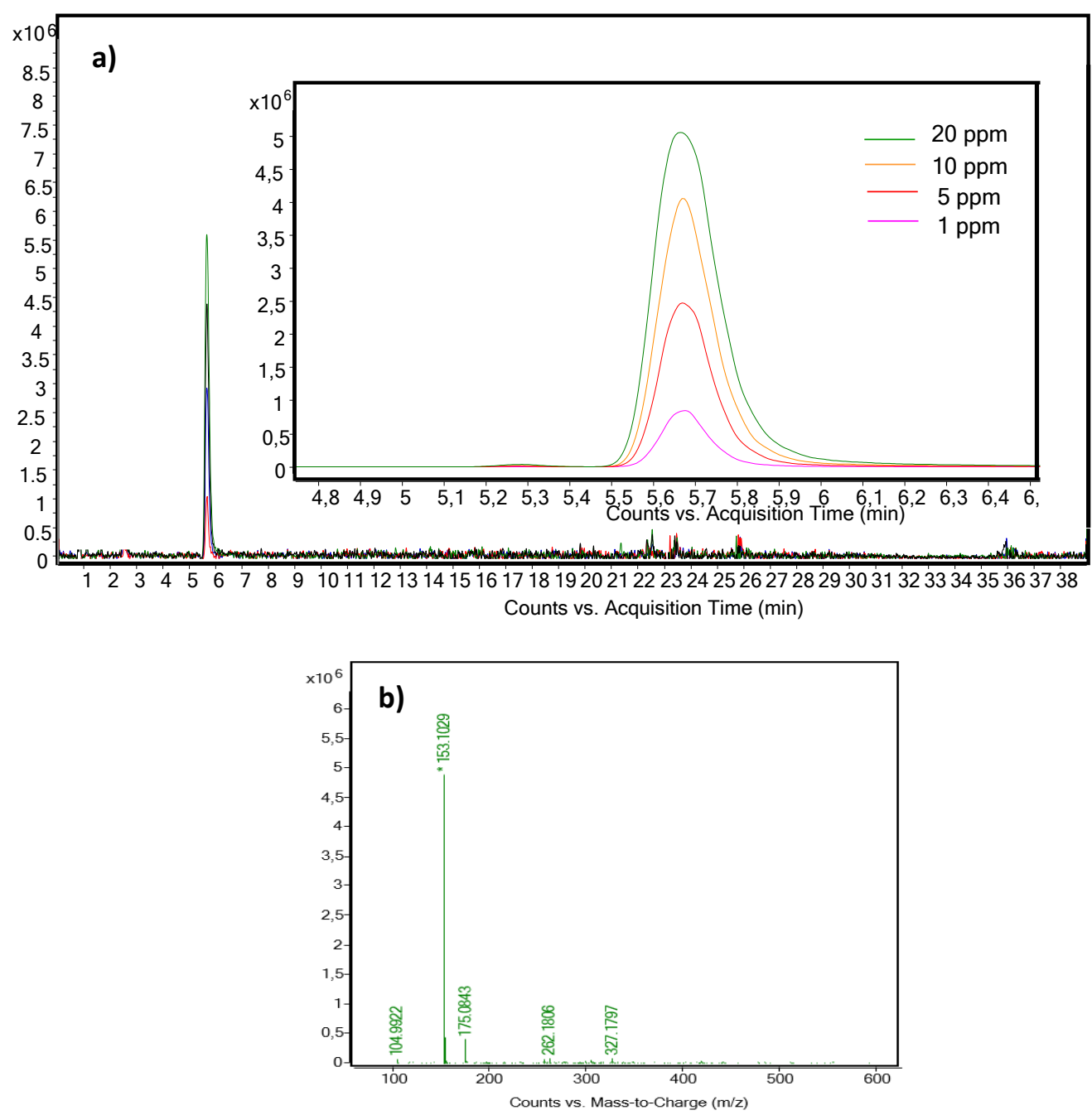

Figura 4.53. a) Cromatograma TIC de los patrones de diazinón. Ampliación del pico, b) espectro de masas asociado a ese pico.

Sin embargo, si se observa el valor $\mathrm{m} / \mathrm{z}$ del espectro, no corresponde al $\mathrm{m} / \mathrm{z}$ del diazinón (cuyo valor de $\mathrm{m} / \mathrm{z}$ es 305.108 ), ya que el $\mathrm{m} / \mathrm{z}$ obtenido es 153.1029 . Este valor corresponde al producto 2-isopropil-6-metilpirimidin-4-ol (IMP) [108]. Esto es debido a la hidrólisis de diazinón cuando entra en contacto con un medio ácido [109] para dar IMP (2) y O, O-dimetilfosforotioato (DETP) (3), según estudios realizados por Doreen Churchill [105]. En la Figura 4.54 se muestra este proceso de hidrólisis. 
<smiles>CCOP(=S)(OCC)Oc1cc(C)nc(C(C)C)n1</smiles>

1

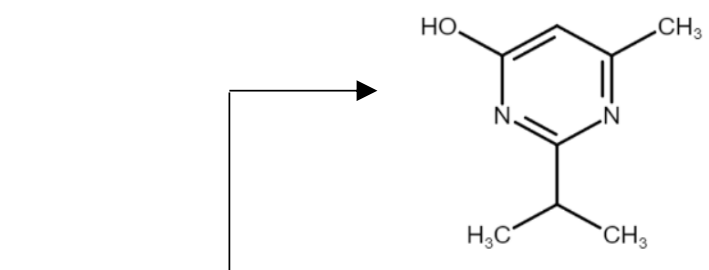

2<smiles>COP(O)(=S)OC</smiles>

Figura 4.54. Hidrólisis del diazinón en condiciones ácidas.

Esta reacción se debe principalmente a que a un pH bajo el ataque sobre el carbono aromático y/o el fósforo podría volverse más favorecido que el ataque al carbono alifático, lo contrario a lo que se esperaría en el caso de tener un medio más básico [106]. Por lo tanto, en medios ácidos, ocurre una multiplicidad de sitios de protonación, como se muestra en la Figura 4.55.

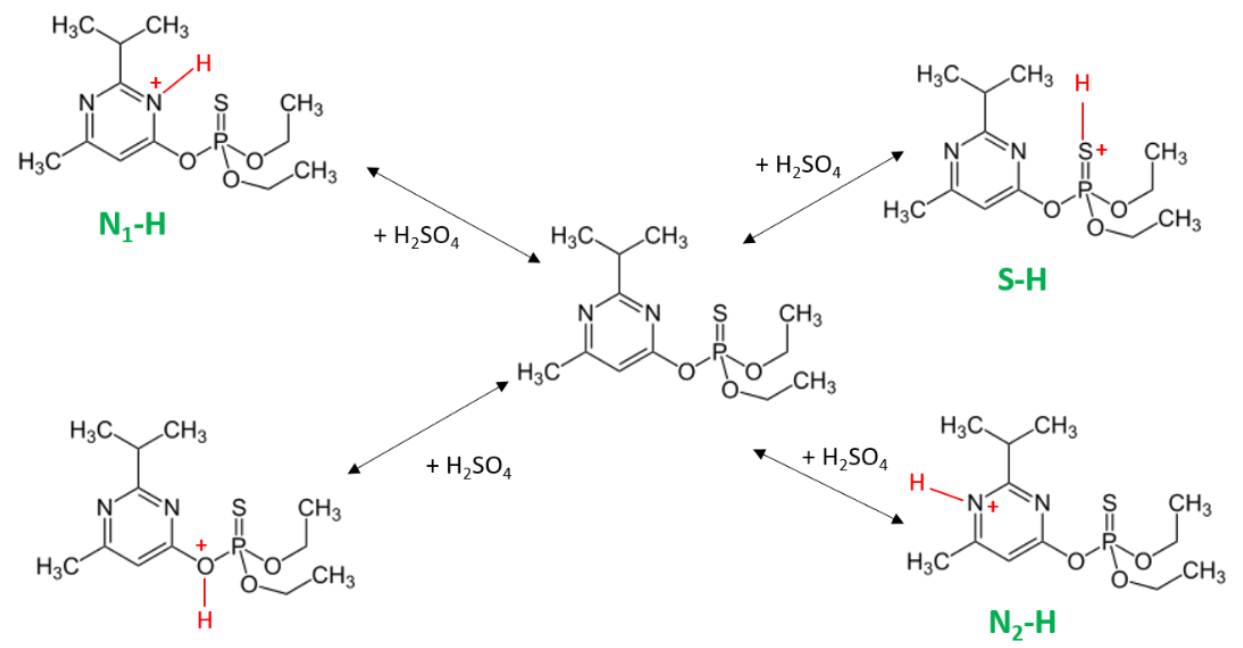

O-H

Figura 4.55. Vías de protonación del diazinón. 
La protonación del diazinón sobre el oxígeno del grupo alcoxi, dando lugar a O-H, mejoraría la reacción proporcionando un grupo saliente más reactivo. Alternativamente, la protonación del nitrógeno del anillo del diazinón para dar $\mathrm{N}_{1}$ $\mathrm{H} \circ \mathrm{N}_{2}-\mathrm{H}$ también produciría un mejor grupo saliente y por lo tanto podría potenciar la posterior reacción de degradación. La protonación en $\mathrm{P}=\mathrm{S}$ para dar $\mathrm{S}-\mathrm{H}$ aumentaría la electrofilicidad de $\mathrm{P}$, mejorando el ataque de los nucleófilos al fósforo. Por tanto, la hidrólisis en medios ácidos podría deberse a cualquiera de estas protonaciones o mediante la interacción de varias simultáneamente $[109,110]$. En conclusión, cuando el diazinón se encuentra en contacto con $\mathrm{H}_{2} \mathrm{SO}_{4}$, se hidroliza rápidamente para dar IMP y DETP, por lo que el pico observado en la Figura 4.53 corresponde a IMP en lugar de diazinón.

A modo de comprobación, en la Figura 4.56 se muestra la diferencia entre el pico de diazinón a 20 ppm con y sin medio ácido, así como el espectro de masas correspondiente al diazinón. En ella se observa una gran diferencia en la intensidad del pico, confirmando que cuando el pesticida entra en contacto con el $\mathrm{H}_{2} \mathrm{SO}_{4}$ sufre el proceso de hidrólisis y se degrada para dar IMP y DETP. 

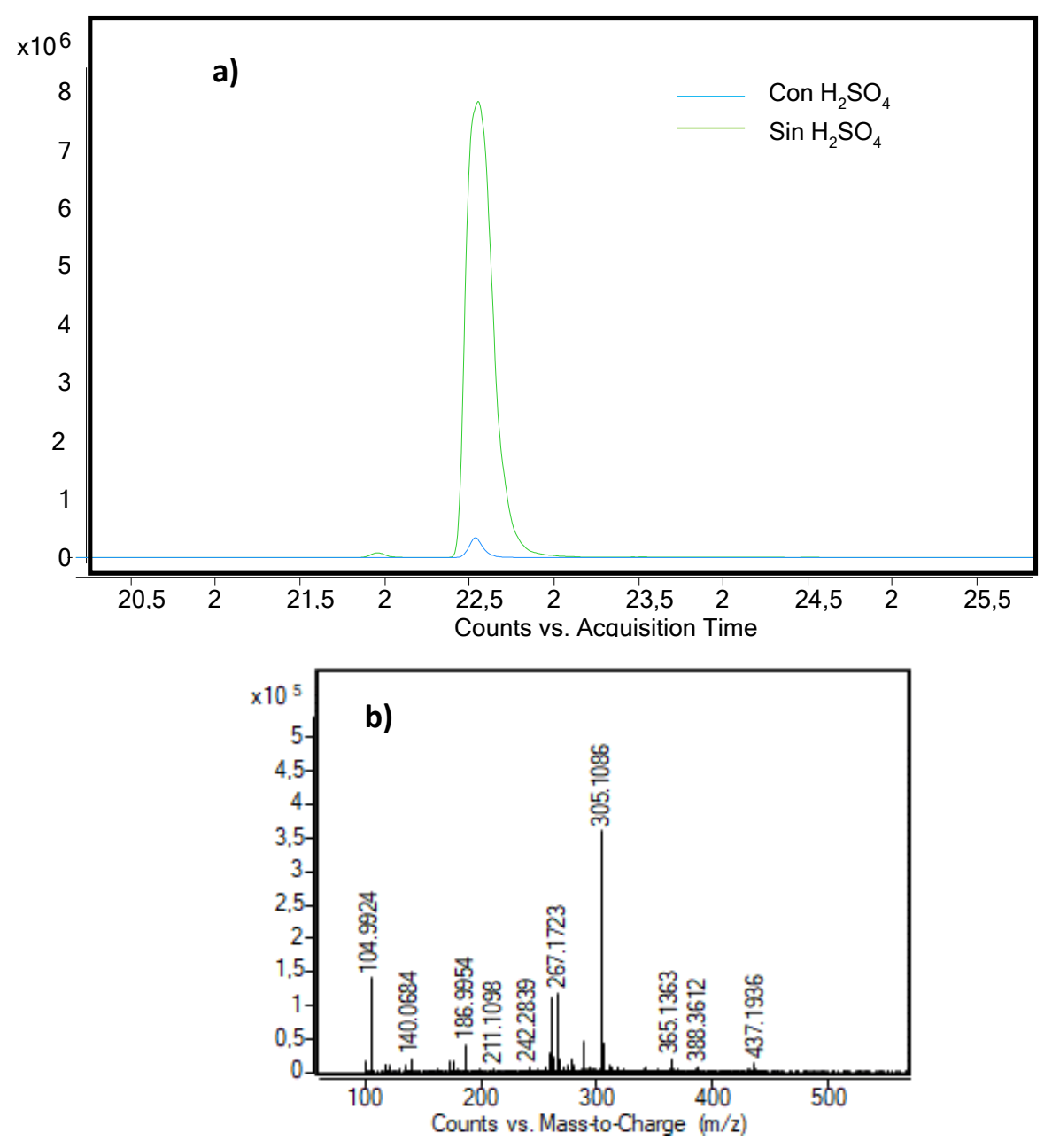

Figura 4.56. a) Cromatograma del diazinón con y $\sin \mathrm{H}_{2} \mathrm{SO}_{4}$ y b) espectro de masas del cromatograma.

La Figura 4.57 muestra los cromatogramas TIC de diazinón y sus intermedios registrados en diferentes tiempos de reacción. En la ampliacion del pico de seguimiento se puede observar que, tras $24 \mathrm{~h}$ de degradación, la concentración del pesticida es de 2 ppm aproximadamente. La concentración de IMP presente 
en todas las muestras se puede calcular a partir de la recta de calibrado (ec.4.9). La Tabla 4.17 muestra la concentración de IMP en cada muestra.

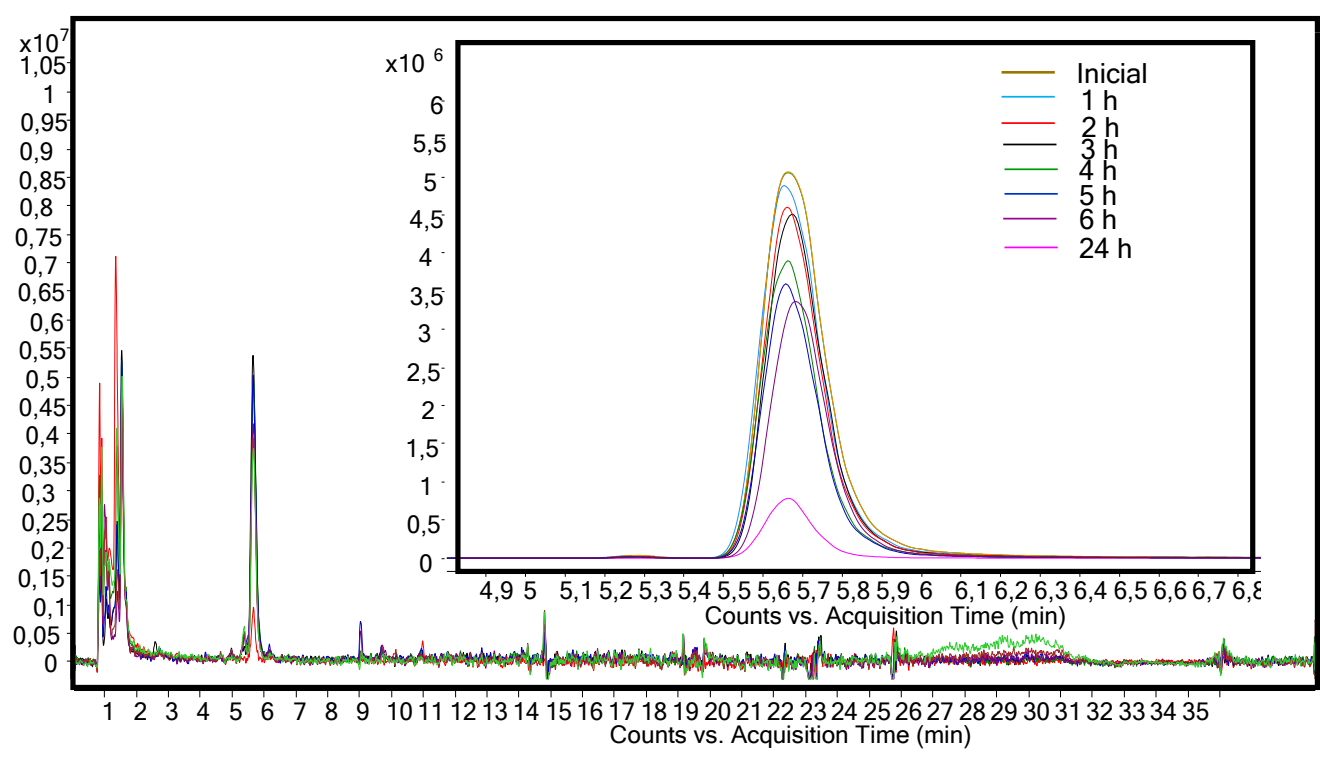

Figura 4.57. Cromatograma TIC de todas las muestras degradadas. El recuadro muestra una ampliación del pico principal.

Tabla 4.17. Concentración de IMP en cada muestra degradada.

\begin{tabular}{|c|c|c|}
\cline { 2 - 3 } \multicolumn{1}{c|}{} & $\begin{array}{c}\text { Área } \\
\text { (cuentas) }\end{array}$ & $\begin{array}{c}\text { Concentración } \\
\text { (ppm) }\end{array}$ \\
\hline $\mathbf{1 h}$ & 54680909.9 & 16.5 \\
\hline $\mathbf{2 h}$ & 48509678.5 & 14.6 \\
\hline $\mathbf{3 h}$ & 45618361.2 & 13.7 \\
\hline $\mathbf{4 h}$ & 40668829 & 12.2 \\
\hline $\mathbf{5 h}$ & 36600076.9 & 11.1 \\
\hline $\mathbf{6 h}$ & 35095441.8 & 10.6 \\
\hline $\mathbf{2 4 h}$ & 6980753.64 & 2.1 \\
\hline
\end{tabular}

Una vez determinada la concentración de cada muestra, se va a determinar el orden de la cinética de degradación del diazinón. La cinética de degradación expresa el cambio de la concentración de un reactante o producto en función del 
tiempo. Las unidades en las que se expresa la cinética de reacción son generalmente moles por litro por segundo, para las reacciones en solución, y moles por centímetros cúbico por segundo para los procesos en fase gaseosa. En cambio, la velocidad de reacción es proporcional a las concentraciones de los reactantes elevadas a una potencia, por lo que es conveniente hablar de orden de reacción, en vez de velocidad o cinética de degradación.

Pero si en una reacción hay exceso de uno de los reactantes, de forma tal que su concentración no cambia apreciablemente a medida que transcurre el tiempo, la investigación cinética no revelará dependencia alguna de rapidez respecto a la concentración de esa sustancia. El resultado es un orden diferente al real llamado pseudo orden [111].

En este caso, se puede aproximar a una cinética de degradación de pseudo-primer orden ya que teniendo en cuenta los reactivos que están presentes en el proceso (el diazinón y los radicales $\cdot \mathrm{OH}$ ) la concentración de éstos últimos es prácticamente constante. Como se ha mencionado anteriormente, en una cinética de este tipo, la velocidad de reacción es directamente proporcional a la concentración de una única especie $A$ y es independiente de las concentraciones de todas las demás.

Las reacciones de pseudo primer orden son reacciones de segundo orden del tipo: $\mathrm{A}+\mathrm{B} \rightarrow \mathrm{P}$. Es importante comentar que uno de los reactantes tiene una concentración tan grande comparada con el otro que durante la reacción prácticamente no presenta cambio alguno en su concentración, por lo tanto, la cinética original de segundo orden toma la forma de una de primer orden [112].

Para aproximar los datos a una cinética de primer orden se sigue la siguiente ecuación:

$$
\mathrm{dC} / \mathrm{dt}=-\mathrm{k}^{\prime} \mathrm{C}_{\mathrm{A}}
$$

Agrupando los términos queda la ecuación de la siguiente manera:

$$
\int \mathrm{dC} / \mathrm{C}_{\mathrm{A}}=-\mathrm{k}^{\prime} \int \mathrm{dt}
$$

Finalmente, integrando ambas partes resulta la siguiente ecuación:

$$
\ln \mathrm{C} / \mathrm{C}_{0}=-\mathrm{k}^{\prime} \mathrm{t}
$$


Por tanto, se ha representado en primer lugar el logaritmo del cociente de la concentración a un tiempo entre la concentración inicial $\left(\ln \left(C / C_{0}\right)\right)$ frente al tiempo. Esta gráfica se muestra en la Figura 4.58, en donde se observa una recta con un $\mathrm{R}^{2}$ de 0,991 , por tanto se puede asumir que la cinética es de pseudoprimer orden cuya ecuación es:

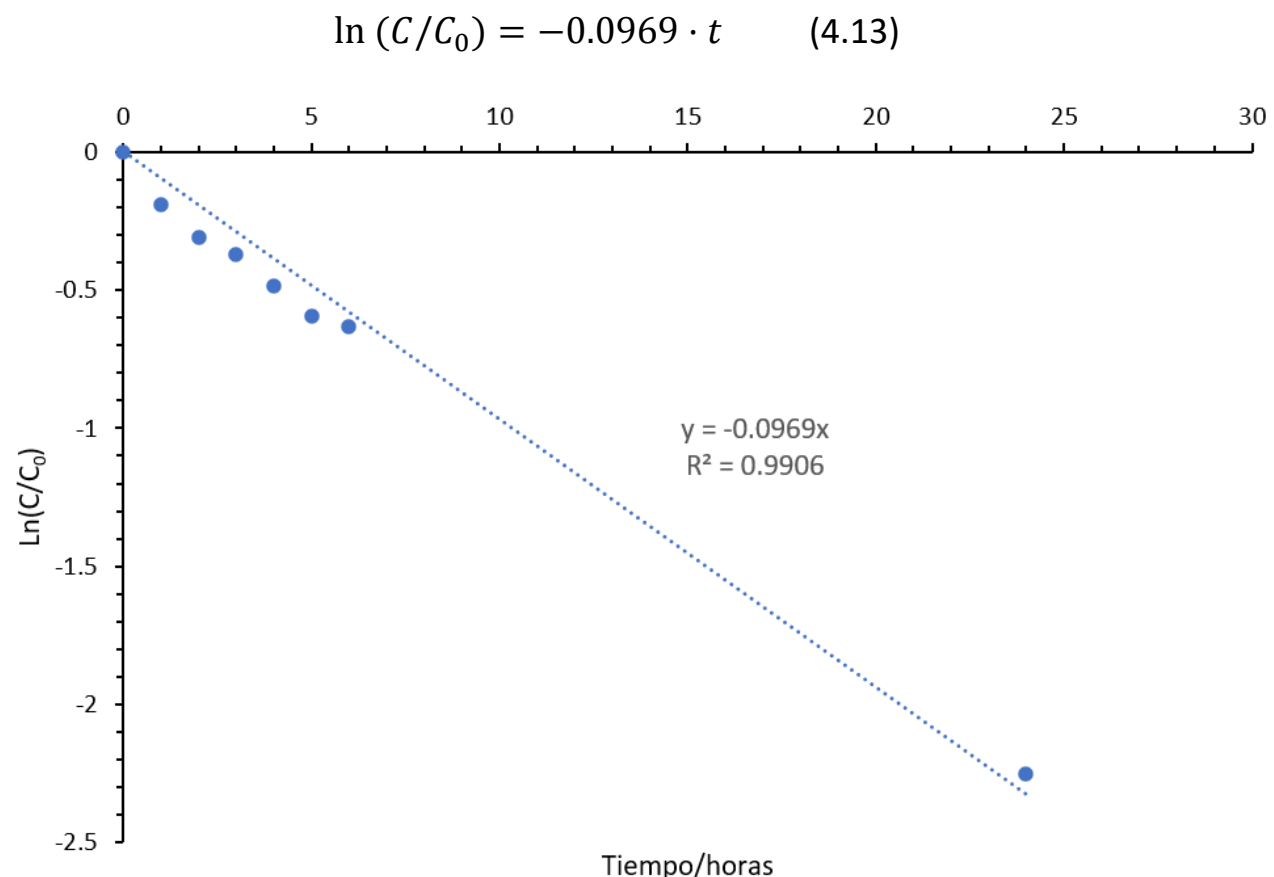

Figura 4.58. Ajuste cinética pseudo-primer orden.

A partir del cromatograma de la Figura 4.57, se han identificado intermedios de degradación gracias a bibliografía, así como a la identificación de picos presentes en dicho cromatograma. Los intermediarios encontrados gracias a otros estudios que analizaron posibles intermedios del pesticida son 2-isopropanol-6metilpirimidin-4-ol (4) [107] y 1-hidroxiisopropil diazoxon (6) [108,109], mostrados en el cromatograma EIC de la Figura 4.59 y la Figura 4.60 respectivamente, y cuyos valores de $\mathrm{m} / \mathrm{z}$ son 169.09 y 305.126 respectivamente. En ambos casos, la concentración del intermedio aumenta a medida que avanza el tiempo de degradación, sin embargo, en el caso del 2-isopropanol-6metilpirimidin-4-ol, este compuesto prácticamente desaparece después de 24 
horas. Esto puede deberse a que una vez que se forma el intermedio, se ha degradado en moléculas más pequeñas.
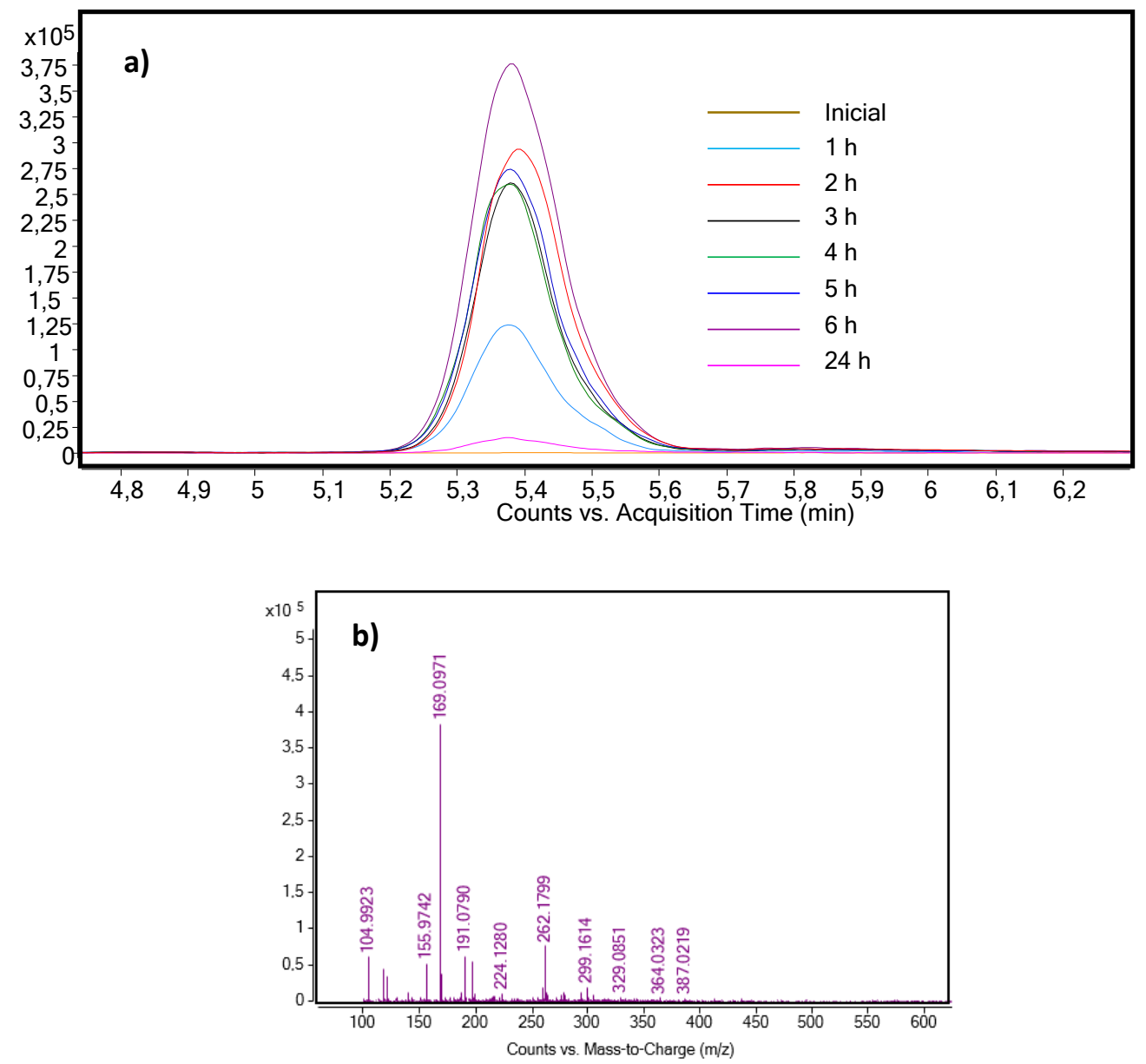

Figura 4.59. a) Cromatograma de ion exacto (EIC) de 2-isopropanol-6-metilpirimidin-4-ol y b) espectro de masas del compuesto. 

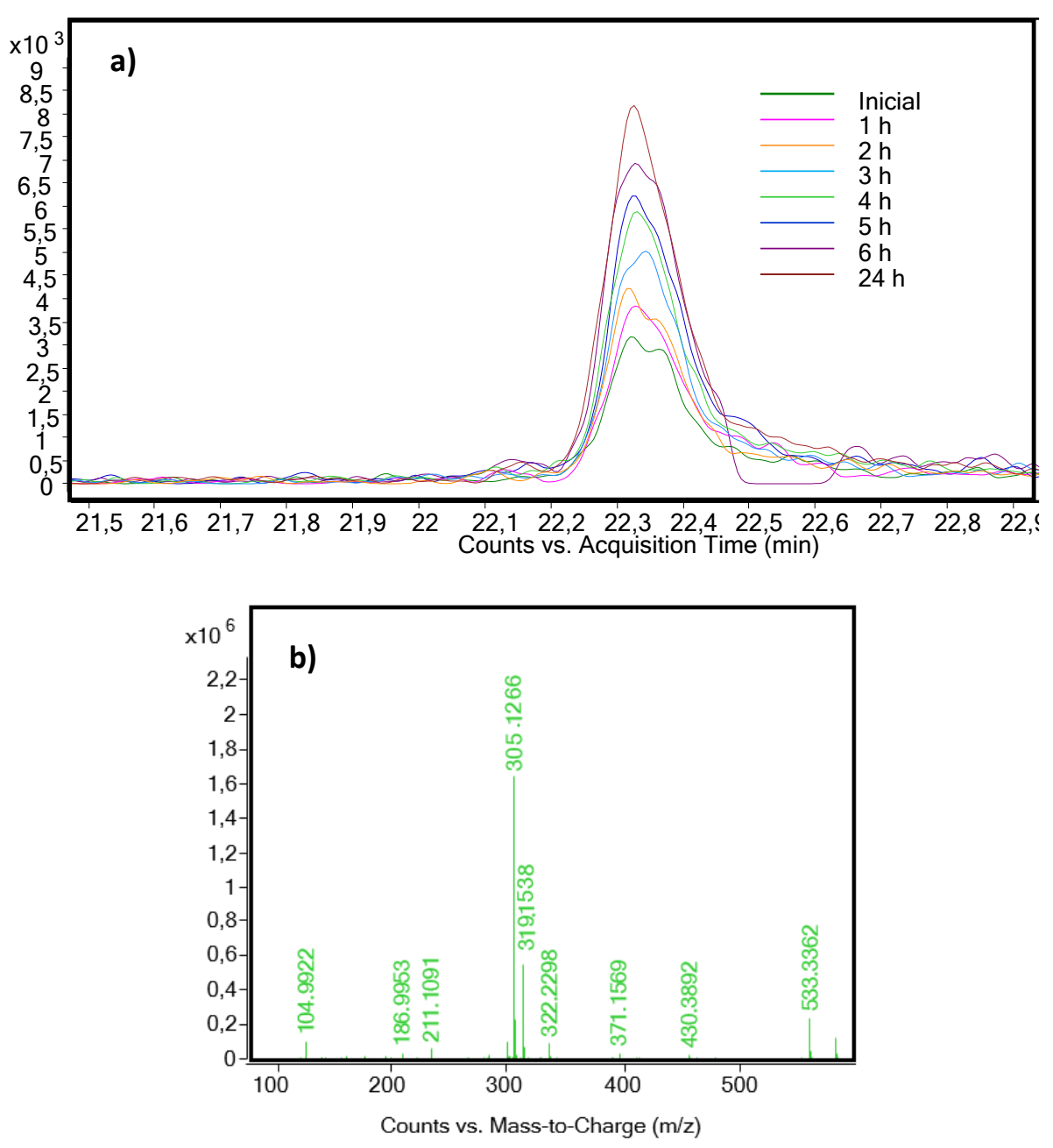

Figura 4.60. a) Cromatograma EIC de 1-hidroxiisopropil diazoxon y b) espectro de masas del compuesto.

Además, a partir de los picos presentes en el cromatograma TIC de degradación, se identificaron dos nuevos intermedios, como los productos 5 y 7 (2-hydroxy-N((2E,3Z)-4-hydroxybut-3-en-2-ylidene)acetimidamida y N-((2E,3Z)-4-hydroxybut-3en-2-ylidene)acetimidamida, respectivamente), que se muestran en la Figura 4.64. El cromatograma de cada uno de ellos se muestra en las Figuras 4.61 y 4.62 
respectivamente, siendo el valor de m/z 144.982 y 155.046 respectvamente. Nuevamente, la concentración del compuesto 5 aumenta con el tiempo, mientras que el compuesto 7 alcanza su valor máximo después de 1 hora y posteriormente se degrada hasta obtener aproximadamente una tercera parte de la concentración máxima [113].
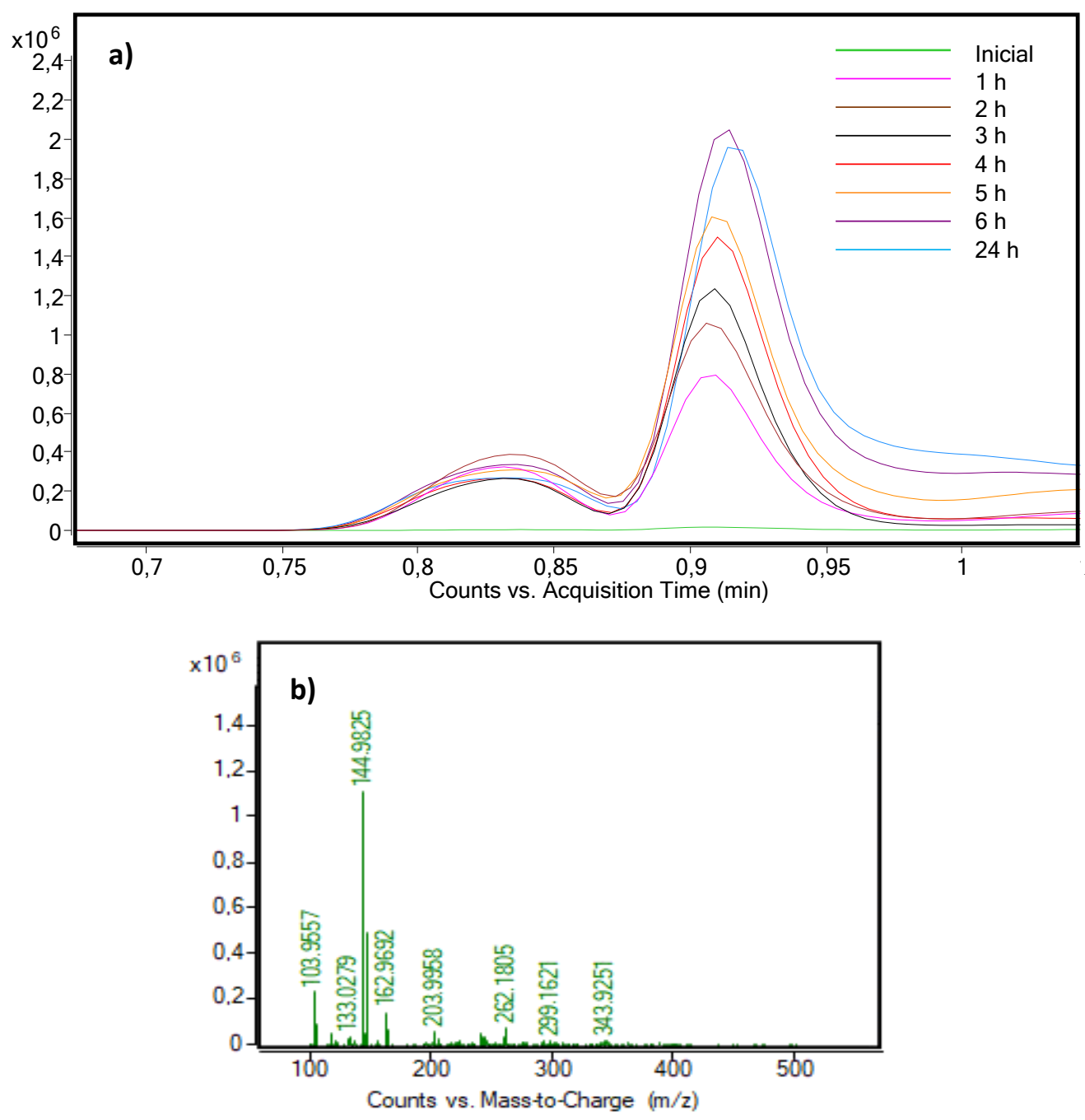

Figura 4.61. a) Cromatograma EIC del producto de degradación número 5 y b) espectro de masas del compuesto. 

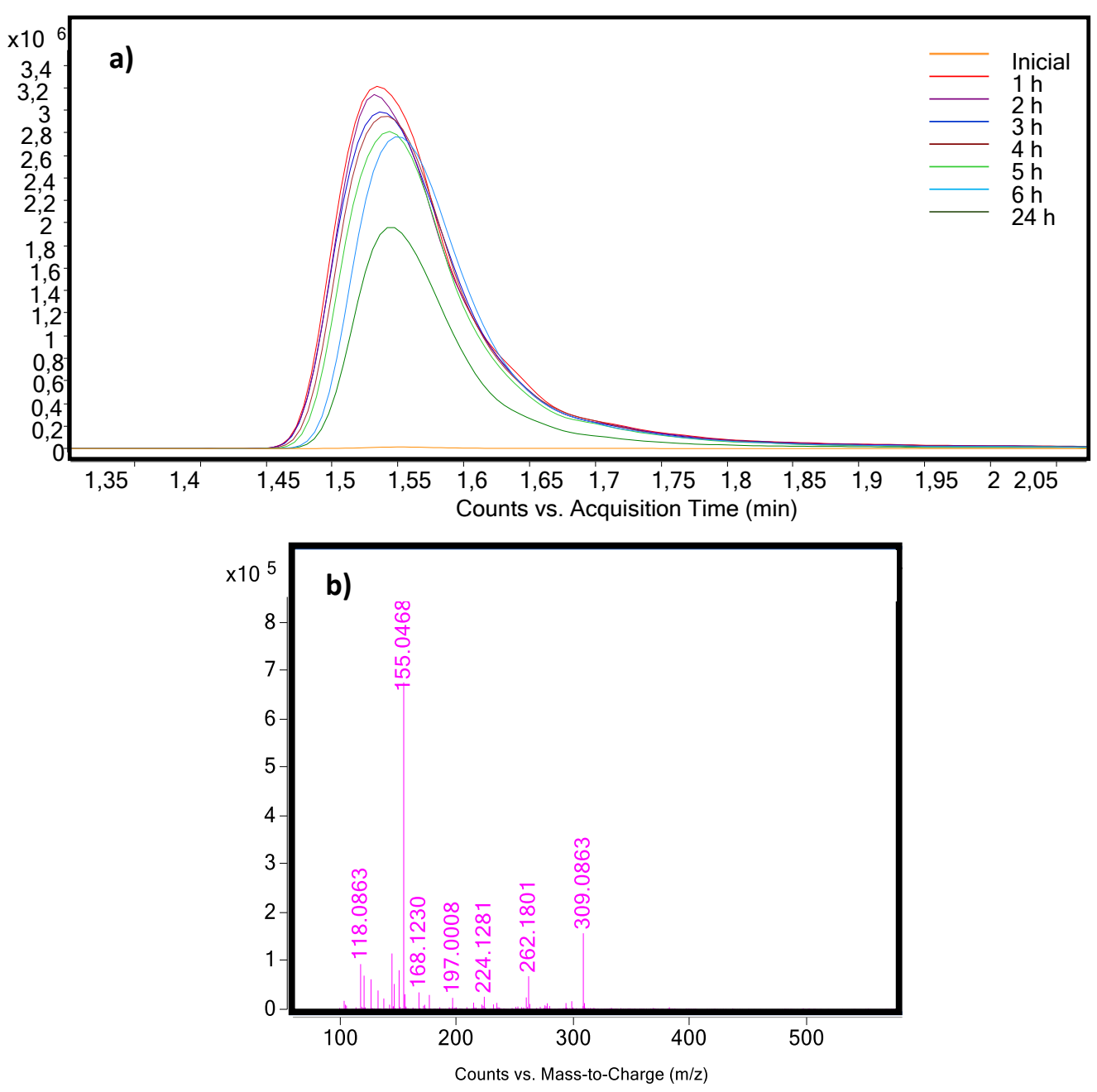

Figura 4.62. a) Cromatograma EIC del producto de degradación número 7 y b) espectro de masas del compuesto.

Los intermedios 6 y 7 son el producto de la degradación del diazinón que permanece en la solución no hidrolizada. Con el fin de demostrar que el diazinón no se hidroliza completamente cuando entra en contacto con el $\mathrm{H}_{2} \mathrm{SO}_{4}$, en la Figura 4.63a se muestra el cromatograma EIC del diazinón presente en los 
patrones y en la Figura 4.63b se muestra el cromatograma de todas las muestras degradadas, en donde se puede comprobar como el diazinón tras una hora de degradación ha desaparecido completamente $[114,115]$.

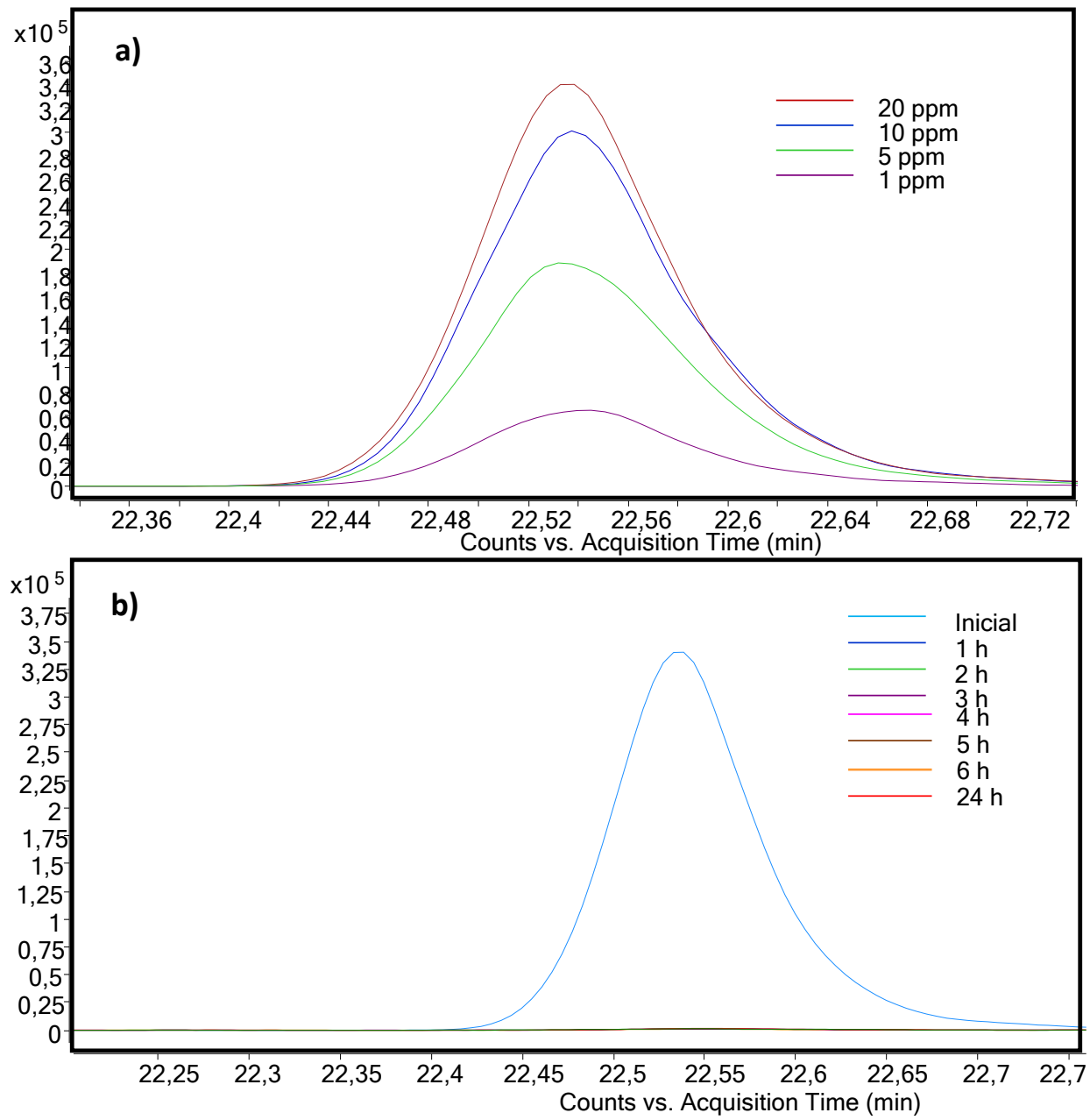

Figura 4.63. a) Cromatograma EIC de los patrones de diazinón y b) Cromatograma EIC de diazinón para las muestras degradadas. 
Por lo tanto, de acuerdo con los intermedios identificados, la ruta de degradación del diazinón propuesta se muestra en la Figura 4.64.

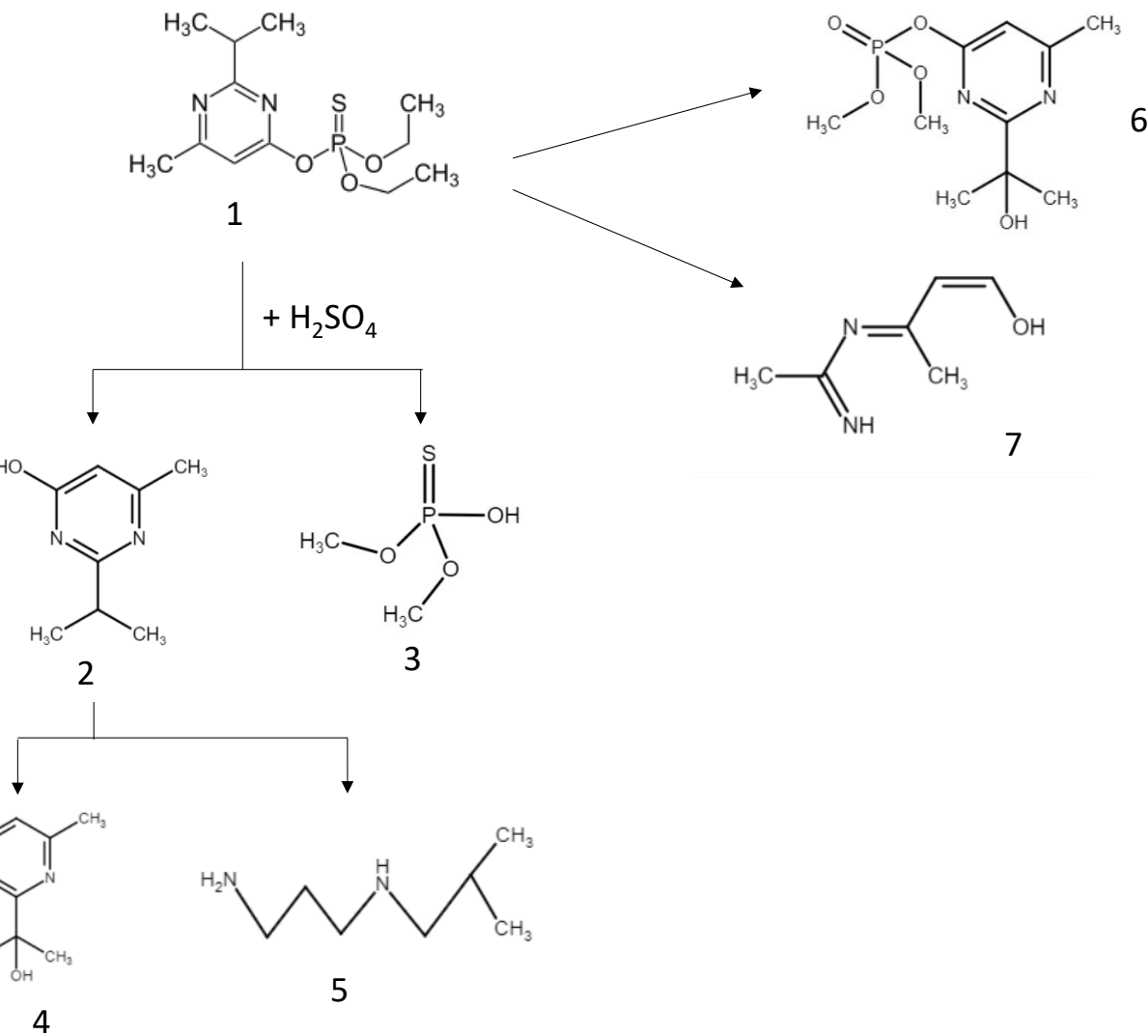

Figura 4.64. Ruta de degradación propuesta del diazinón mediante PEC.

Finalmente, a modo de resumen, se muestra en la Tabla 4.18 los intermedios identificados, así como su $\mathrm{m} / \mathrm{z}$ y su tiempo de retención. 
Tabla 4.18. Tabla resumen de los compuestos intermedios identificados con su $\mathrm{m} / \mathrm{z}$ y tiempo de retención.

\begin{tabular}{c|cccc}
$\begin{array}{c}\text { Número } \\
\text { de } \\
\text { compuesto }\end{array}$ & Compuesto & $\begin{array}{c}\text { Fórmula } \\
\text { molecular }\end{array}$ & $\begin{array}{c}\text { Tiempo de } \\
\text { retención (s) }\end{array}$ & Valor m/z \\
\hline $\mathbf{2}$ & IMP & $\mathrm{C}_{8} \mathrm{H}_{13} \mathrm{~N}_{2} \mathrm{O}$ & 5.68 & 153.1029 \\
$\mathbf{4}$ & $\begin{array}{c}\text { 2-isopropanol-6- } \\
\text { methylpyrimidin-4-ol } \\
\mathbf{5}\end{array}$ & $\begin{array}{c}\mathrm{C}_{8} \mathrm{H}_{13} \mathrm{~N}_{2} \mathrm{O}_{2} \\
\text { 2-hydroxy-N-((2E,3Z)- }\end{array}$ & 5.38 & 169.097 \\
$\mathbf{4 - h y d r o x y b u t - 3 - e n - 2 -}$ & $\mathrm{C}_{5} \mathrm{H}_{8} \mathrm{~N}_{2} \mathrm{O}_{3}$ & 0.92 & 144.982 \\
$\mathbf{6}$ & $\begin{array}{c}\text { ylidene)acetimidamida } \\
\text { 1-hydroxyisopropyl } \\
\text { diazoxon }\end{array}$ & $\mathrm{C}_{12} \mathrm{H}_{22} \mathrm{~N}_{2} \mathrm{O}_{5} \mathrm{P}$ & 22.32 & 305.12 \\
$\mathbf{7}$ & $\begin{array}{c}\mathrm{N} \text {-((2E,3Z)-4- } \\
\text { hydroxybut-3-en-2- } \\
\text { ylidene)acetimidamida }\end{array}$ & $\mathrm{C}_{6} \mathrm{H}_{10} \mathrm{~N}_{2} \mathrm{O}$ & 1.55 & 155.046 \\
& & & &
\end{tabular}

\subsection{Clorfenvinfos.}

El segundo pesticida organofosforado elegido para degradar fue el clorfenvinfos. A continuación, se muestran los resultados obtenidos de la degradación fotoelectrocatalítica mediante la técnica de UV-Vis y HPLC-MS.

\subsubsection{Espectroscopía UV-Vis}

En todos los ensayos de degradación del clorfenvinfos llevados a cabo se utilizó el equipo de espectroscopía Ultravioleta-Visible con el fin de obtener la información necesaria para controlar dicho proceso.

En primer lugar, se prepararon patrones con diferentes concentraciones de clorfenvinfos para analizar su espectro UV-Vis y ver como varía con la concentración. En la Figura 4.65 se muestra el espectro obtenido mediante 
espectroscopía Ultravioleta-Visible para 4 concentraciones diferentes de clorfenvinfos.

Se eligieron concentraciones patrón 1 ppm, 5 ppm, 10 ppm y 20 ppm, ya que la concentración inicial de la muestra era 20 ppm.

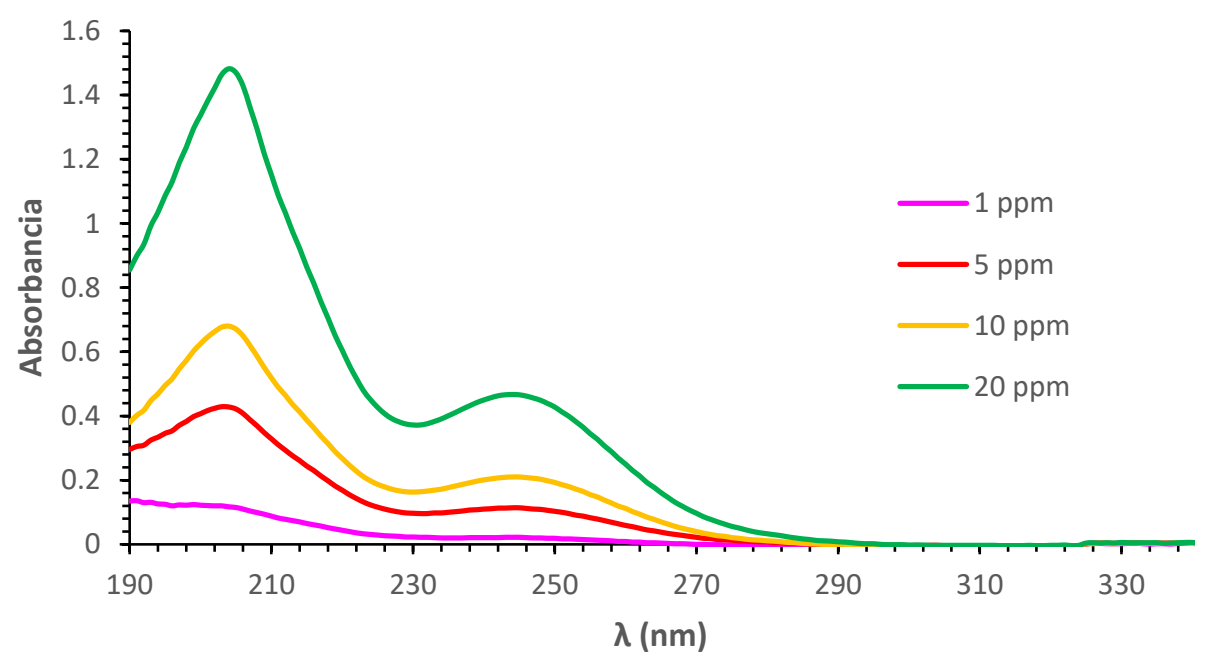

Figura 4.65. Espectro UV-vis de los patrones de clorfenvinfos.

La banda entre 230 y $270 \mathrm{~nm}$ en el espectro UV se asigna a la transición $\pi \rightarrow \pi *$ característica del anillo aromático presente en la molécula de clorfenvinfos, en donde $\lambda_{\max }$ está a $248 \mathrm{~nm}$. No obstante, existe otro pico entre 190 y $225 \mathrm{~nm}$, aunque en este caso en la bibliografía no se asocia al anillo aromático ni a ningún otro compuesto, por tanto, se seguirá la disminución del pico a $248 \mathrm{~nm}$ como se referencia en la bibliografía $[93,116]$.

En la Figura 4.66 se representa el espectro UV-Vis del clorfenvifos durante el proceso de degradación. Se observan dos picos claramente diferenciados, pero con un comportamiento ante la degradación diferente, ya que el primero (que aparece a $200 \mathrm{~nm}$ ), no solo disminuye, sino que también se desplaza levemente hacia longitudes de onda menores, mientras que el segundo pico (aparece a 248 $\mathrm{nm}$ ) simplemente disminuye con el aumento del tiempo de degradación. 
Se observa que conforme se aumenta el tiempo de degradación, el pico asociado al anillo aromático disminuye ya que la absorbancia a esa longitud de onda (245 $\mathrm{nm}$ ) cada vez es menor y, por tanto, la concentración del pesticida también lo es. De esta manera queda comprobado que el proceso de degradación seguía una tendencia esperada.

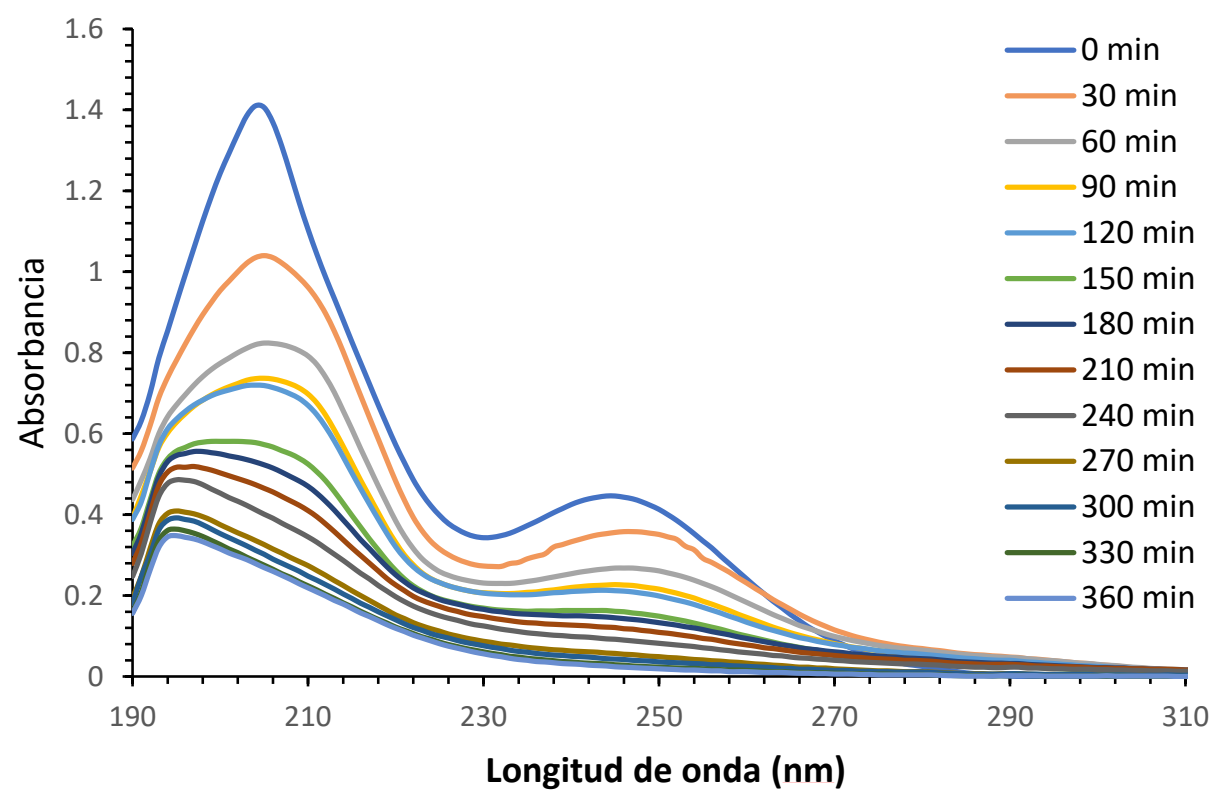

Figura 4.66. Espectros UV-Vis de clorfenvinfos cuando se utiliza la técnica PEC durante 6 h.

\subsubsection{UHPLC-MS/Q-TOF.}

Una vez analizados los datos obtenidos mediante UV-Vis, se van a analizar los cromatogramas obtenidos mediante UHPLC-MS de todas las muestras degradadas, así como de los patrones de clorfenvinfos preparados con las siguientes concentraciones: 1 ppm, 5 ppm, 10 ppm y 20 ppm.

En primer lugar, se ha obtenido el cromatograma EIC (exact ion chromatogram) de los patrones de clorfenvifos (Figura 4.67 a)) con el fin de poder hallar una recta de calibrado en la que esté representada la absorbancia en función de la concentración, y así poder calcular la concentración de clorfenvinfos en las muestras degradadas. Además, en la Figura 4.67 b) se muestra el espectro de masas, para confirmar que el pico corresponde con el compuesto a degradar, es decir que el valor de $\mathrm{m} / \mathrm{z}$ es el asociado al pesticida ( $\mathrm{m} / \mathrm{z}=358.9772$ ) [117]. 


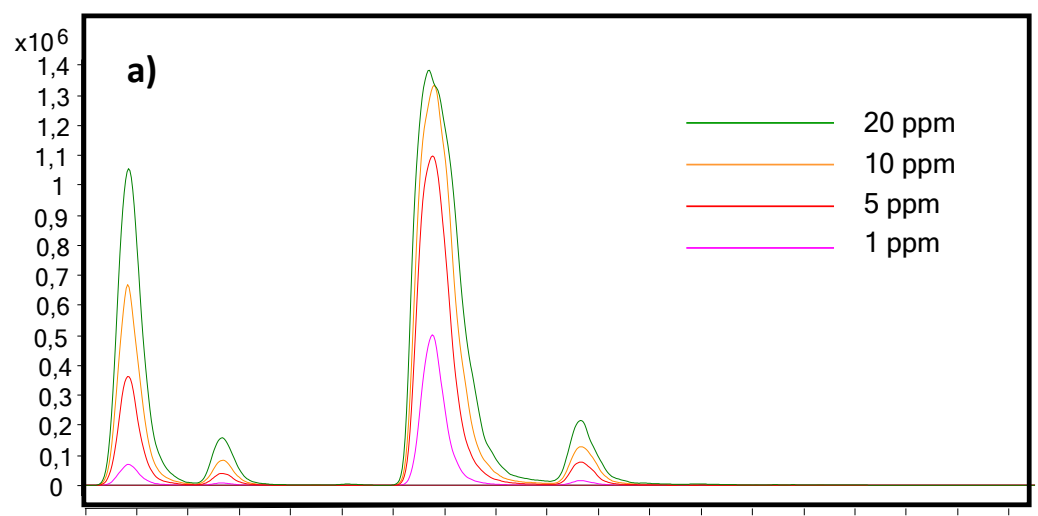

$20,2 \quad 20,420,620,82121,221,4 \quad 21,621,82222,2 \quad 22,422,6 \quad 22,823 \quad 23,2$ 23,423,6

Counts vs. Acquisition Time (min)

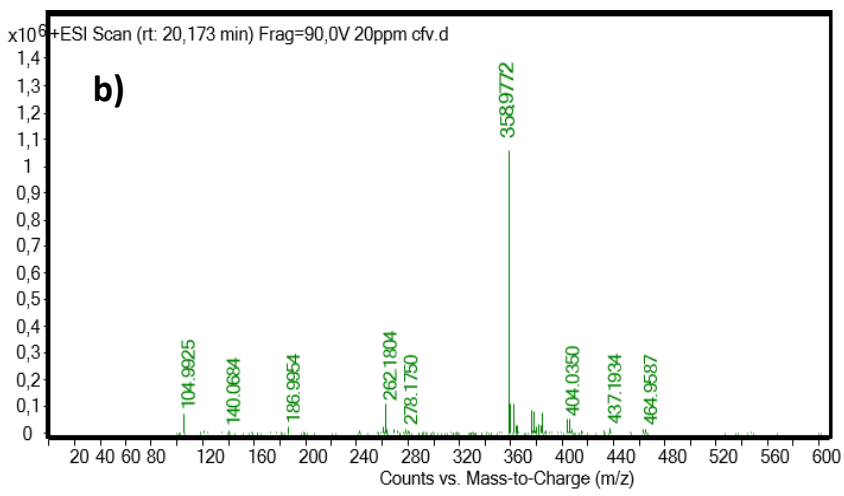

Figura 4.67. a) Cromatograma EIC de los patrones de diazinón y b) espectro de masas del compuesto.

Observando la Figura 4.67a, se puede comprobar como aparecen 4 picos. Los dos primeros corresponden a un enantiómero, mientras que los dos últimos corresponden al otro enantiómero de la molécula ( $E$ y $Z$ respectivamente).

Por tanto, se ha hallado una recta de calibrado para cada uno de los enantiómeros de la molécula. La primera recta corresponde al enantiómero que aparece a un tiempo de retención de 20.2 min y la segunda al enantiómero que aparece a 21.4 min. Así, se podrá seguir la degradación de cada uno de los enantiómeros identificados. 


$$
\begin{aligned}
& \text { Area }(\text { cuentas })=366555.02 \times \text { concentracion } \\
& \text { Area }(\text { cuentas })=1290695.1 \times \text { concentracion }
\end{aligned}
$$

En la Figura 4.68, se muestra el cromatograma TIC de las muestras degradadas, así como una ampliación de los picos asociados al clorfenvinfos. Esta degradación se ha realizado durante 24 horas, como el pesticida anterior, para poder obtener posteriormente una ruta de degradación completa.

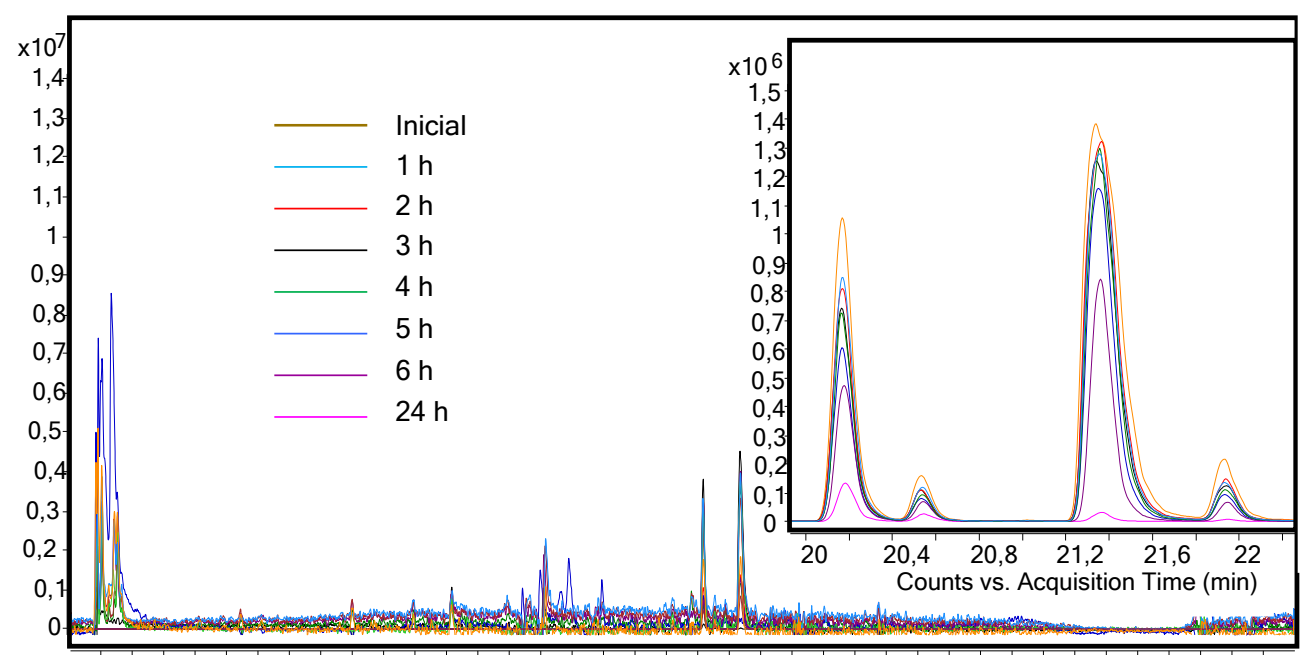

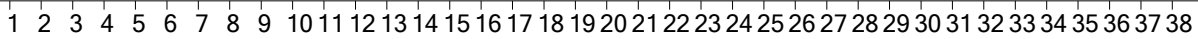
Counts vs. Acquisition Time (min)

Figura 4.68. Cromatograma TIC de todas las muestras degradadas. El recuadro muestra una ampliación del pico principal.

En ella se puede observar como la concentración de clorfenvinfos disminuye con el paso del tiempo hasta prácticamente desaparecer tras 24 horas de ensayo. En la Tabla 4.19 se muestra la concentración de cada uno de los enantiómeros del pesticida en las diferentes muestras analizadas. 
Tabla 4.19. Concentración de clorfenvinfos en cada muestra degradada.

\begin{tabular}{|c|c|c|c|c|}
\cline { 2 - 5 } \multicolumn{1}{c|}{} & Área Pico 1 & $\begin{array}{c}\text { Concentración } \\
\text { Pico 1 } \mathbf{( p p m )}\end{array}$ & Área Pico 2 & $\begin{array}{c}\text { Concentración } \\
\text { Pico 2 (ppm) }\end{array}$ \\
\hline $\mathbf{1 h}$ & 5265392.73 & 14.36 & 13959456.24 & 11.81 \\
\hline $\mathbf{2 h}$ & 5037167.08 & 13.74 & 13146945 & 10.18 \\
\hline $\mathbf{3 h}$ & 4682438.64 & 12.77 & 12860103.59 & 9.96 \\
\hline $\mathbf{4 h}$ & 4223297.95 & 11.52 & 11986513.59 & 9.28 \\
\hline $\mathbf{5 h}$ & 3598339.29 & 9.81 & 10340218.04 & 7.01 \\
\hline $\mathbf{6 h}$ & 2742050.91 & 7.48 & 5954599.91 & 4.61 \\
\hline $\mathbf{2 4 h}$ & 695310.93 & 1.89 & 193730.56 & 0.15 \\
\hline
\end{tabular}

Se puede comprobar cómo tras pasar 24 horas de degradación, la concentración del primer enantiómero disminuyó hasta aproximadamente 1 ppm, mientras que el segundo enantiómero prácticamente desapareció ya que su concentración era prácticamente nula.

Además, con las concentraciones obtenidas se ha podido hallar la cinética de degradación, es decir, la velocidad con la que se degrada el pesticida. En la Figura 4.69, se muestra la linealización de los datos relacionados con el primer pico, según una cinética de pseudo-primer orden, en donde en el eje $Y$ se representa el logaritmo del cociente entre la concentración a un tiempo t y la concentración inicial frente al tiempo. El ajuste obtenido es adecuado ya que la $\mathrm{R}^{2}$ obtenida es superior al 0.99, por tanto, se puede afirmar que la cinética de degradación del clorfenvinfos también es de pseudo-primer orden. La ecuación de la recta obtenida es la que se muestra en la ecuación 4.16.

$$
\ln \left(C / C_{0}\right)=-0.1225 \cdot t
$$




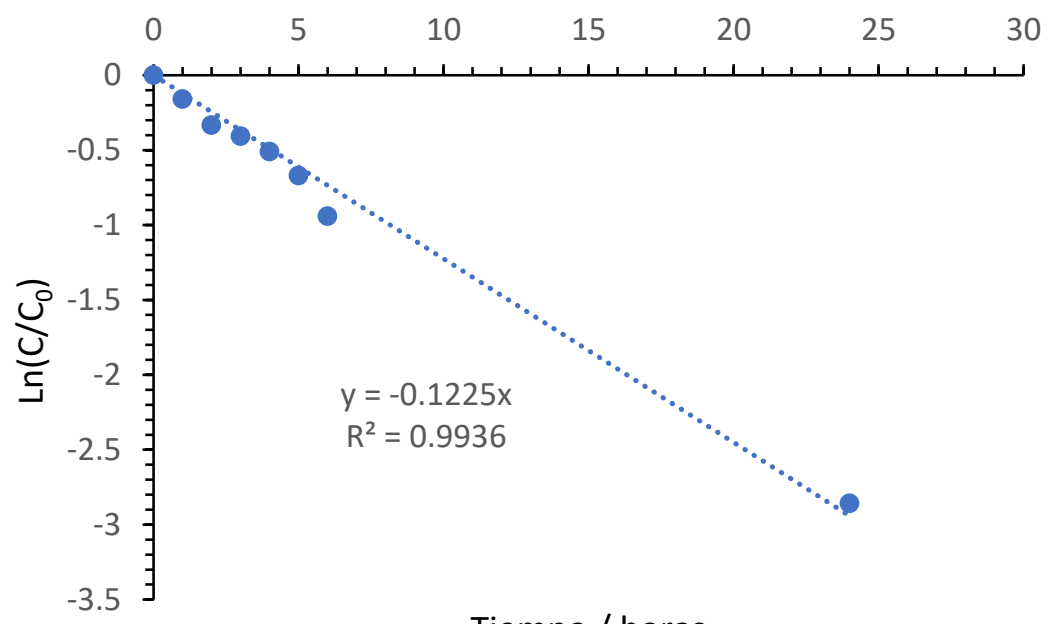

Tiempo / horas

Figura 4.69. Ajuste cinética pseudo-primer orden.

Además, en la Figura 4.70 se muestra la linealización de los datos obtenidos con el segundo pico (que corresponde al enantiómero Z). Debido al buen ajuste se puede concluir que también sigue una cinética de degradación de pseudo-primer orden, cuya ecuación es la siguiente:

$$
\ln \left(C / C_{0}\right)=-0.202 \cdot t
$$




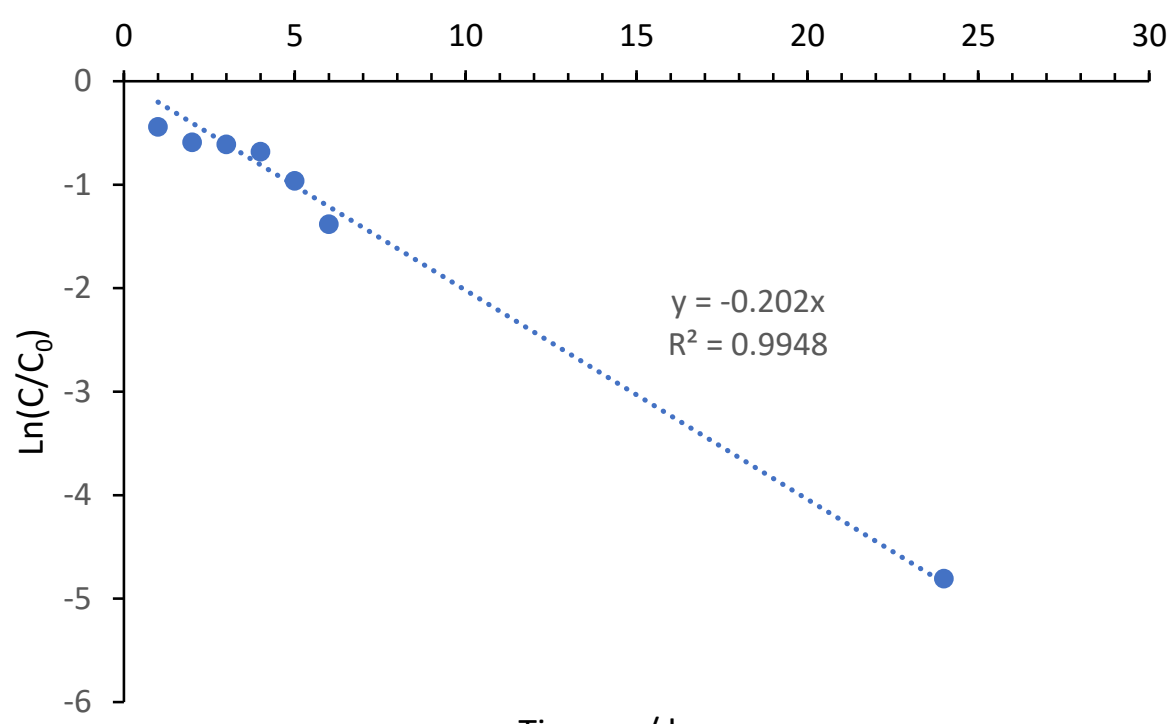

Tiempo / horas

Figura 4.70. Ajuste cinética pseudo-primer orden segundo pico.

Una vez analizado el orden de la cinética de degradación del pesticida, se han identificado posibles intermedios de degradación durante los ensayos. Estos intermedios han sido identificados mediante la bibliografía y analizando el valor de $\mathrm{m} / \mathrm{z}$ de los picos obtenidos en el cromatograma de la Figura 4.68.

Por tanto, según la bibliografía, se han detectado 4 intermedios de degradación, mientras que al analizar los picos obtenidos se han identificado 5 intermedios más.

El primer intermedio identificado con bibliografía ha sido el 2,4-ácido diclorobenzoico-metiléster, cuyo valor de $\mathrm{m} / \mathrm{z}$ es 203.97 y su estructura molecular es la representada en la Figura 4.80 con el número 1. Su cromatograma está representado el Figura 4.71, en donde se puede observar como a un tiempo de retención de $0.88 \mathrm{~min}$ aparece el pico asociado a ese compuesto [118]. Si se comparan las diferentes disoluciones analizadas, se puede concluir que su concentración va aumentando hasta llegar a su máximo a las 5 horas. A partir de ese momento, la concentración de este intermedio va disminuyendo hasta alcanzar prácticamente la mitad de su concentración máxima tras 24 horas. 

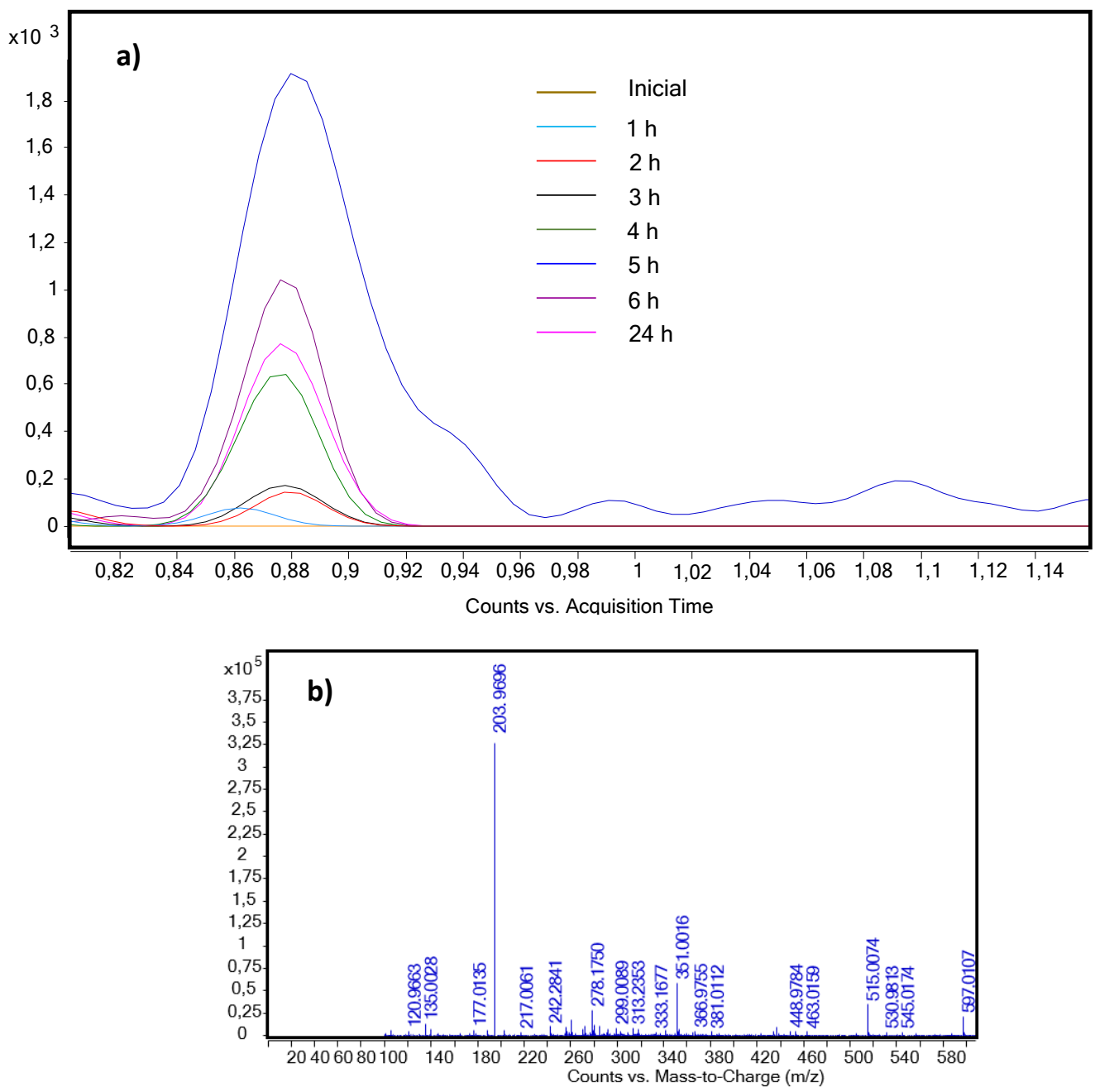

Figura 4.71. a) Cromatograma EIC del producto de degradación número 1 y b) espectro de masas del compuesto.

El siguiente intermedio identificado ha sido el 2,4-ácido diclorobenzoico (número 2 en la Figura 4.80). Al analizar el valor de $\mathrm{m} / \mathrm{z}$ de este pico, ésta ha sido la molécula que se ha obtenido como posible compuesto. Su valor de $\mathrm{m} / \mathrm{z}$ es 189.958 y el tiempo de retención al que ha aparecido ha sido a 1 min [119]. En la Figura 4.72, se muestra su cromatograma con el paso del tiempo, así como el espectro de masas asociado a este compuesto. En él se puede observar como con 
el paso del tiempo su concentración va aumentando hasta llegar a un máximo tras pasar 24 horas.
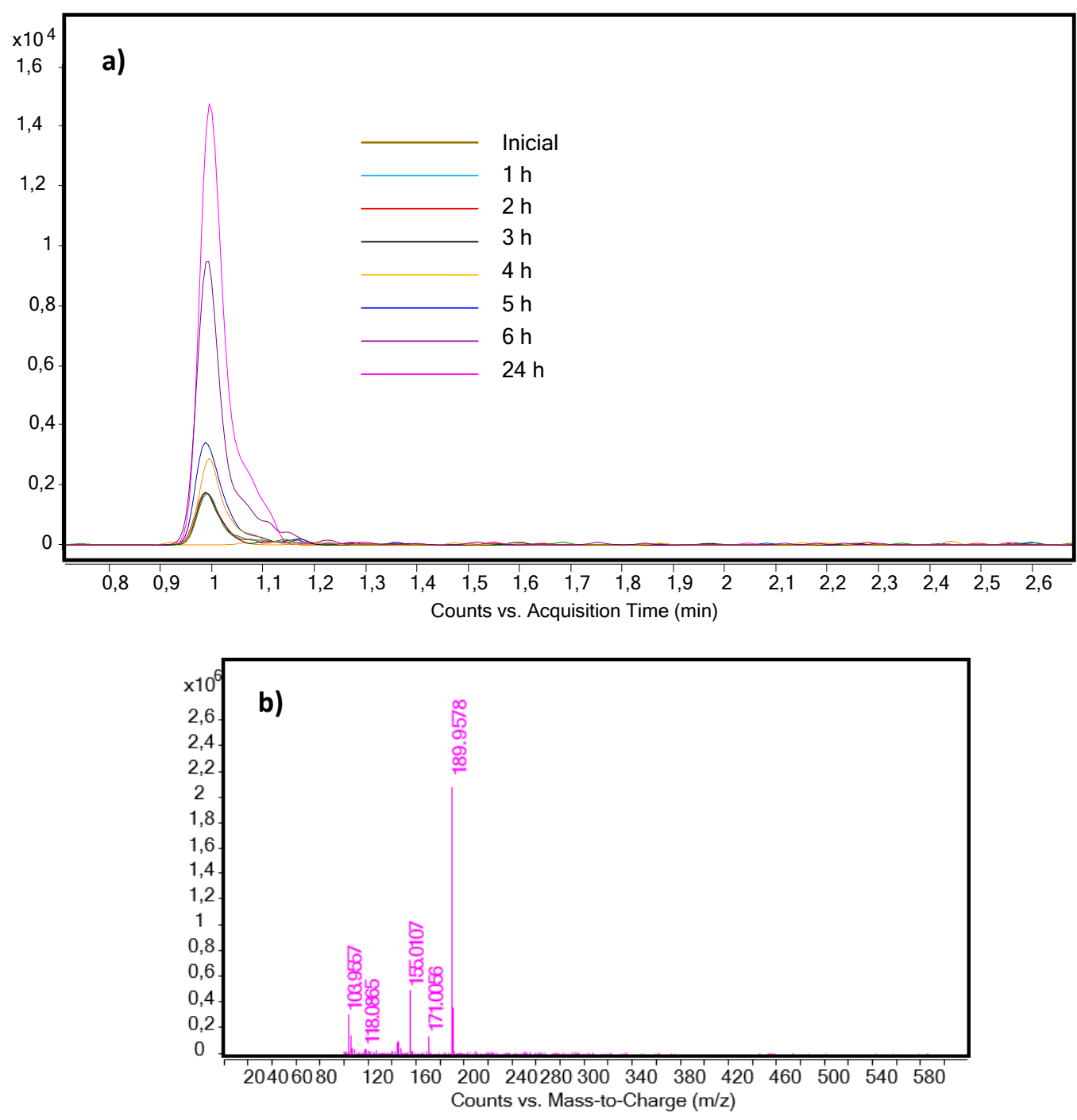

Figura 4.72. a) Cromatograma EIC del producto de degradación número 2 y b) espectro de masas del compuesto. 
El siguiente compuesto identificado en el cromatograma ha sido el 1-cloropropano-1,2,3-triol. Este intermedio tiene un valor de $\mathrm{m} / \mathrm{z}$ de 127.0157 y su estructura química está representada en la Figura 4.80 con el número 3 [120]. En la Figura 4.73, se muestra su cromatograma con el paso del tiempo junto con su correspondiente espectro de masas. De él se puede concluir que su concentración va aumentando durante el ensayo hasta alcanzar tras 24 horas su valor máximo.
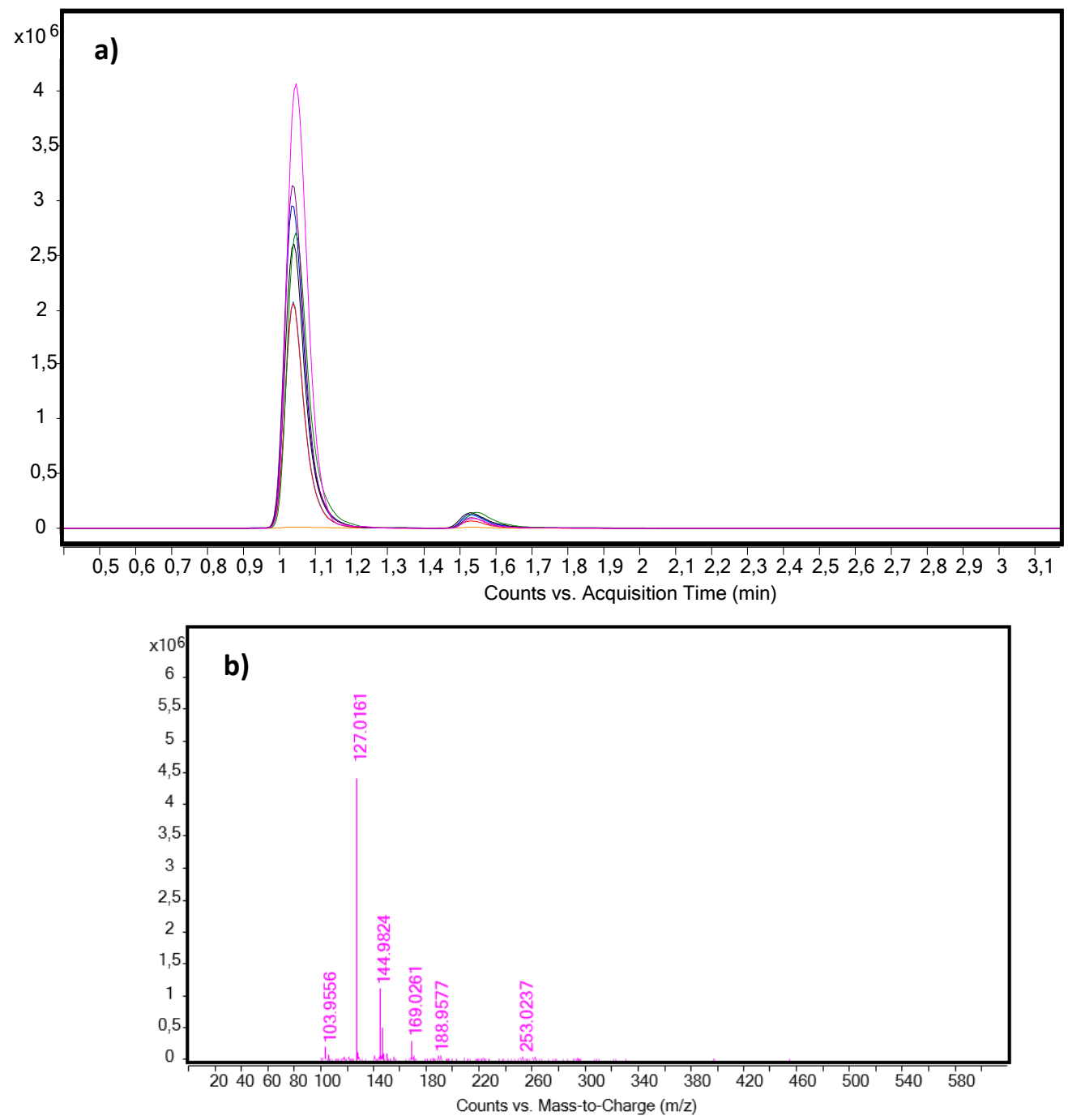

Figura 4.73. a) Cromatograma EIC del producto de degradación número 3 y b) espectro de masas del compuesto. 
El cuarto intermedio identificado ha sido el 4-ácido hidroxybenzoico. La estructura química está representada en la Figura 4.80 con el número 4 y su valor de $\mathrm{m} / \mathrm{z}$ es 136.94 [121]. En la Figura 4.74 se puede ver como la formación de este compuesto alcanza su máxima concentración tras 4 horas de ensayo, para acabar desapareciendo casi por completo y dar lugar a otros compuestos diferentes.
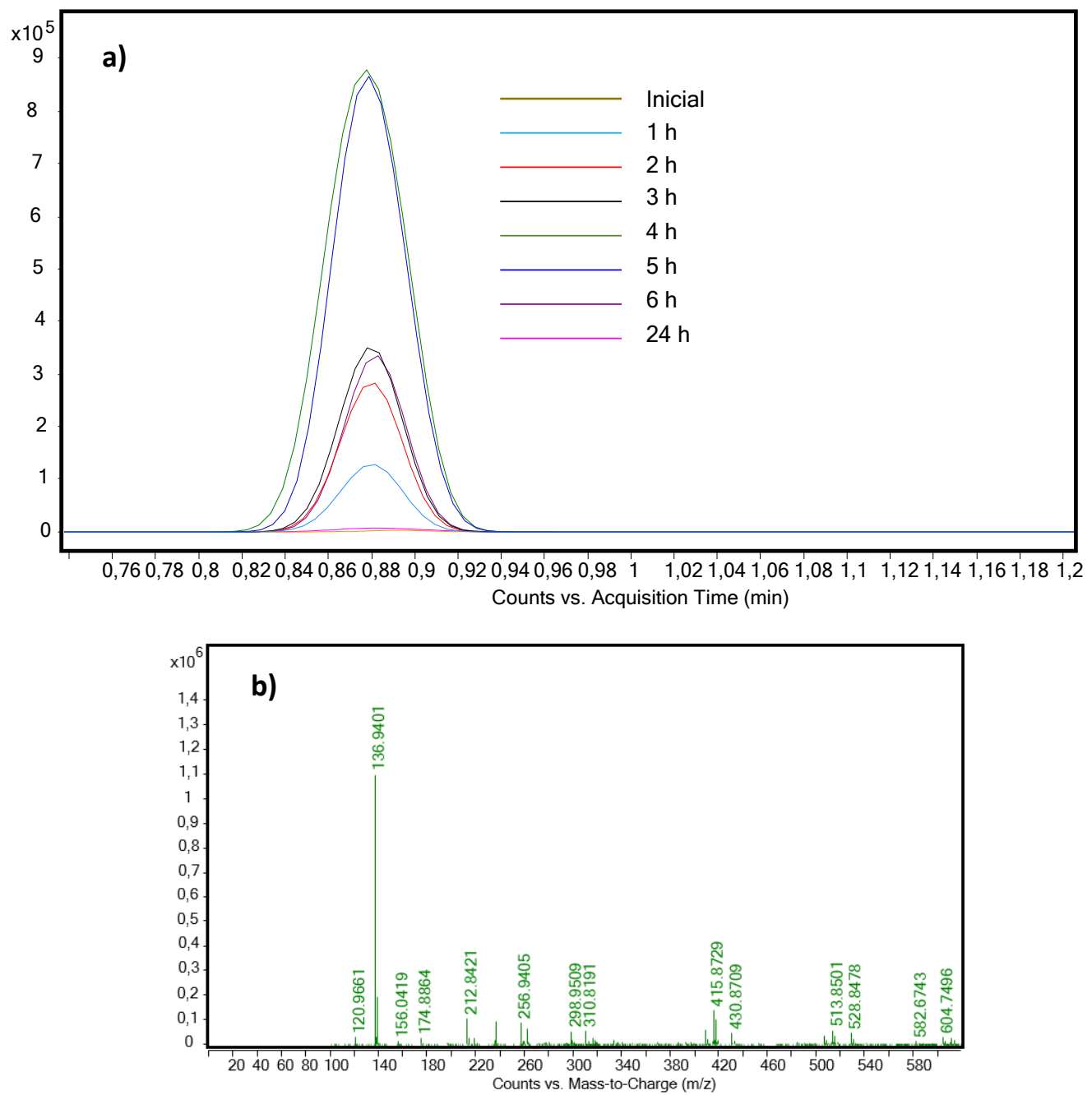

Figura 4.74. a) Cromatograma EIC del producto de degradación número 4 y b) espectro de masas del compuesto. 
El siguiente compuesto que se ha identificado en el cromatograma ha sido el ácido dicarboxílico. Este intermedio tiene un valor de $\mathrm{m} / \mathrm{z}$ de 116.011 y su estructura química es la que está representada con el número 5 en la Figura 4.80 Este compuesto puede obtenerse debido a la apertura de anillo y su posterior rotura de la cadena [122]. Analizando el cromatograma de este compuesto, mostrado en la Figura 4.75, se puede concluir que ocurre lo mismo que con el tercer compuesto identificado, es decir, su concentración va aumentando hasta alcanzar su máximo tras 24 horas de ensayo.
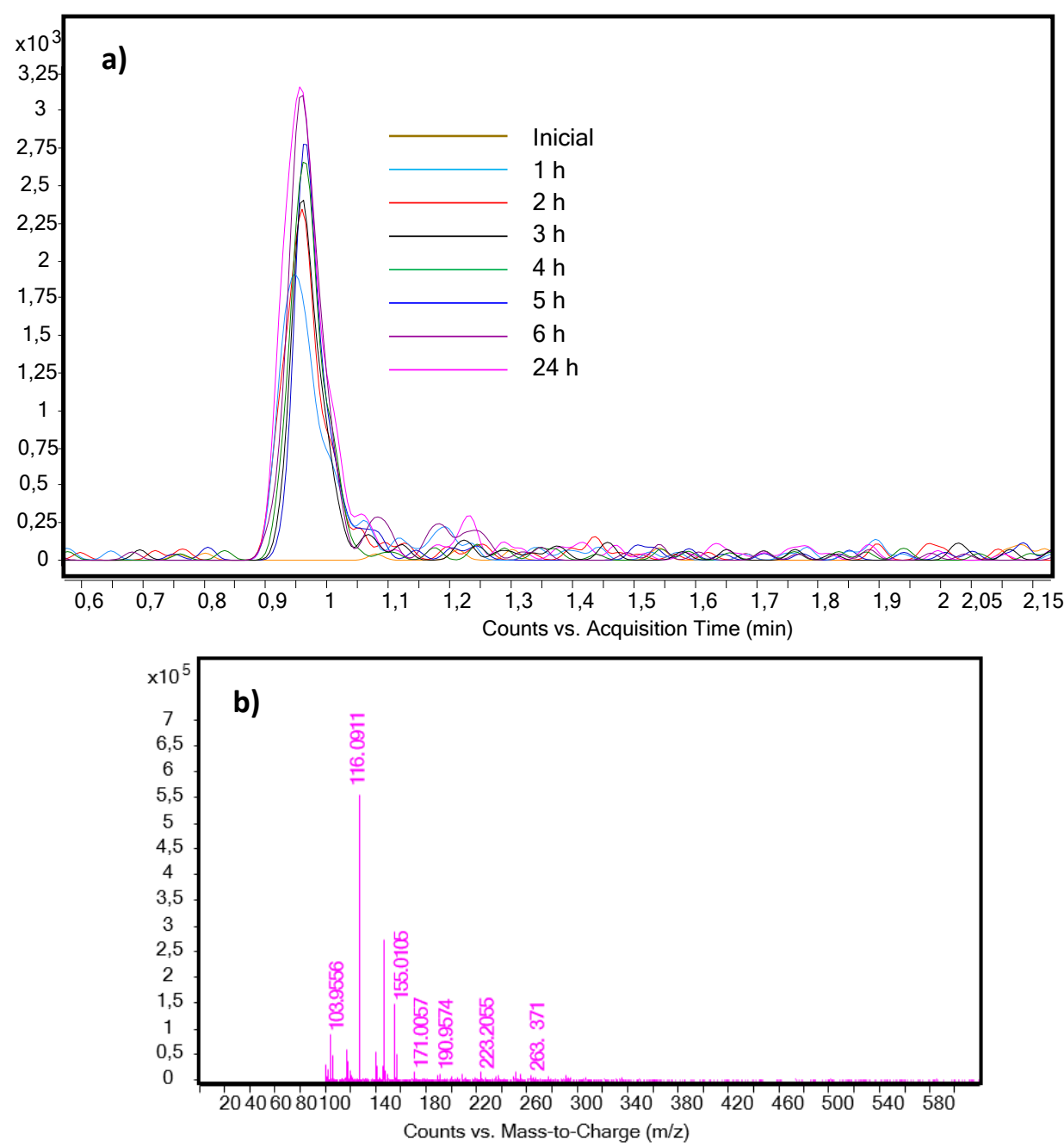

Figura 4.75. a) Cromatograma EIC del producto de degradación número 5 y b) espectro de masas del compuesto. 
El sexto compuesto reconocido ha sido el trietilfosfato, cuyo valor de $\mathrm{m} / \mathrm{z}$ es 182.069 y su estructura molecular es la representada en la Figura 4.80 con el número 6 [123,124]. En la Figura 4.76 está representado el cromatograma EIC del pesticida junto con su espectro de masas. A partir de él se puede concluir que con el paso del tiempo la concentración de este intermedio va aumentando hasta llegar a un máximo a las 5 horas, y, a partir de ese momento su concentración empieza a disminuir debido a su posible degradación, dando como resultado moléculas más pequeñas.
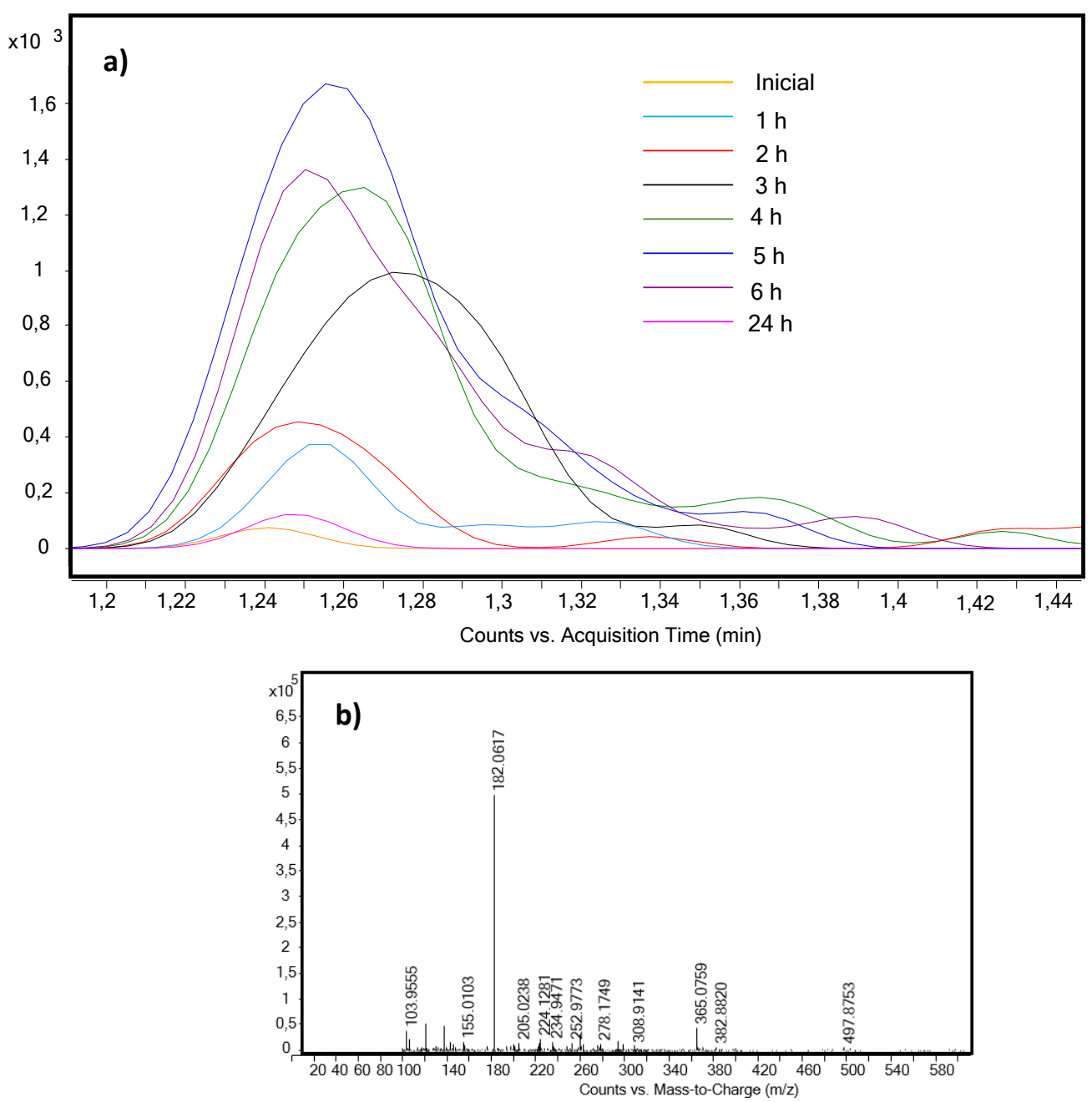

Figura 4.76. a) Cromatograma EIC del producto de degradación número 6 y b) espectro de masas del compuesto. 
Los últimos tres compuestos identificados han sido el etildimetilfosfato, 4butoxymetil-2-metoxy-fenol y el 1-octen-1,2-diol. La estructura química de cada uno de ellos está representada en la Figura 4.80 con los números 7,8 y 9 respetivamente, mientras que el valor de $\mathrm{m} / \mathrm{z}$ de cada compuesto se muestra en el espectro de masas de las Figuras $4.77,4.78$ y 4.79 respectivamente $[125,126]$.

Si se analiza el cromatograma del intermedio 7 (etildimetilfosfato) se puede confirmar que la concentración de este compuesto va aumentando con el paso del tiempo hasta las 3 horas de ensayo, momento a partir del cual empieza a disminuir su concentración debido a su degradación en otros productos.

Lo mismo ocurre con el compuesto número 8 , cuyo valor de $\mathrm{m} / \mathrm{z}$ es 210.11 y su cromatograma queda representado en la Figura 4.78 [127,128]. En él se puede observar cómo tras 4 horas de ensayo, se alcanza su valor máximo de concentración, pero al acabar el proceso de degradación, es decir, tras 24 horas, desaparece totalmente para dar lugar a moléculas más pequeñas.

Y finalmente, el cromatograma del compuesto número 9 se muestra en la Figura 4.79, cuyo valor de $\mathrm{m} / \mathrm{z}$ es 144.98 . En este caso, la concentración de este intermedio de degradación va aumentando con el paso del tiempo hasta alcanzar su máximo tras 24 horas. Este compuesto se ha podido originar debido a una apertura del anillo aromático característico del clorfenvinfos. 

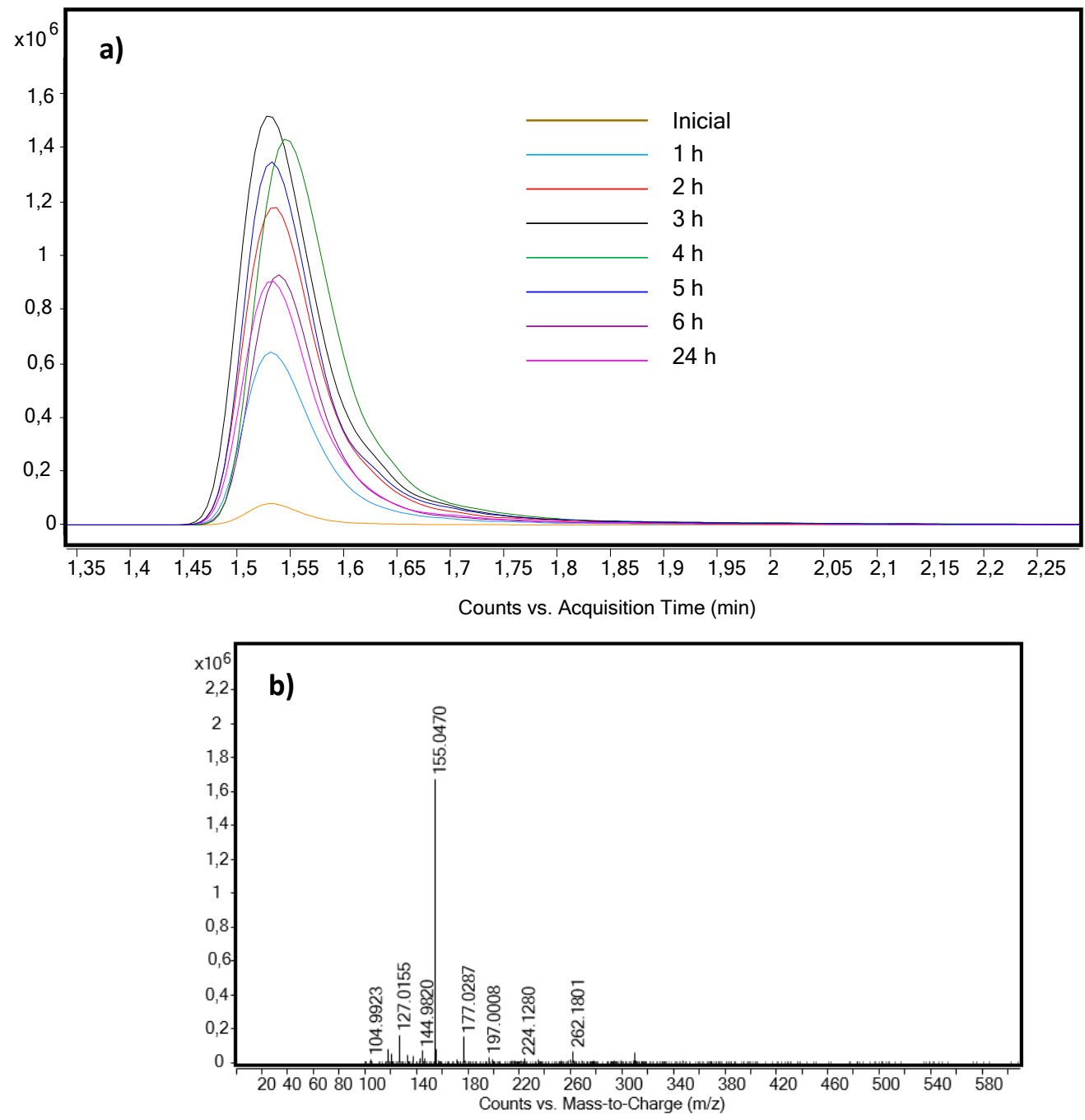

Figura 4.77. a) Cromatograma EIC del producto de degradación número 7 y b) espectro de masas del compuesto. 

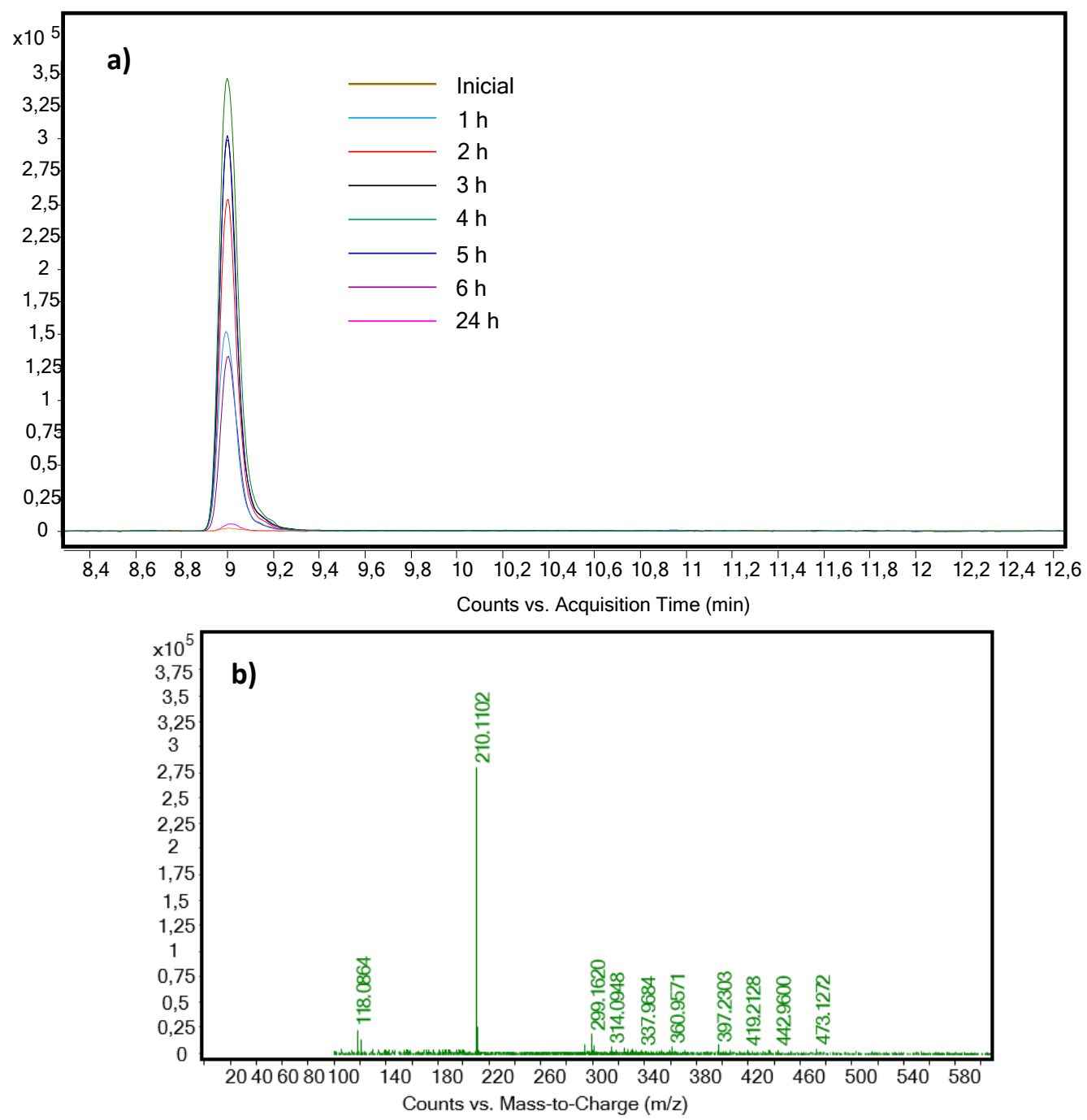

Figura 4.78. a) Cromatograma EIC del producto de degradación número 8 y b) espectro de masas del compuesto. 

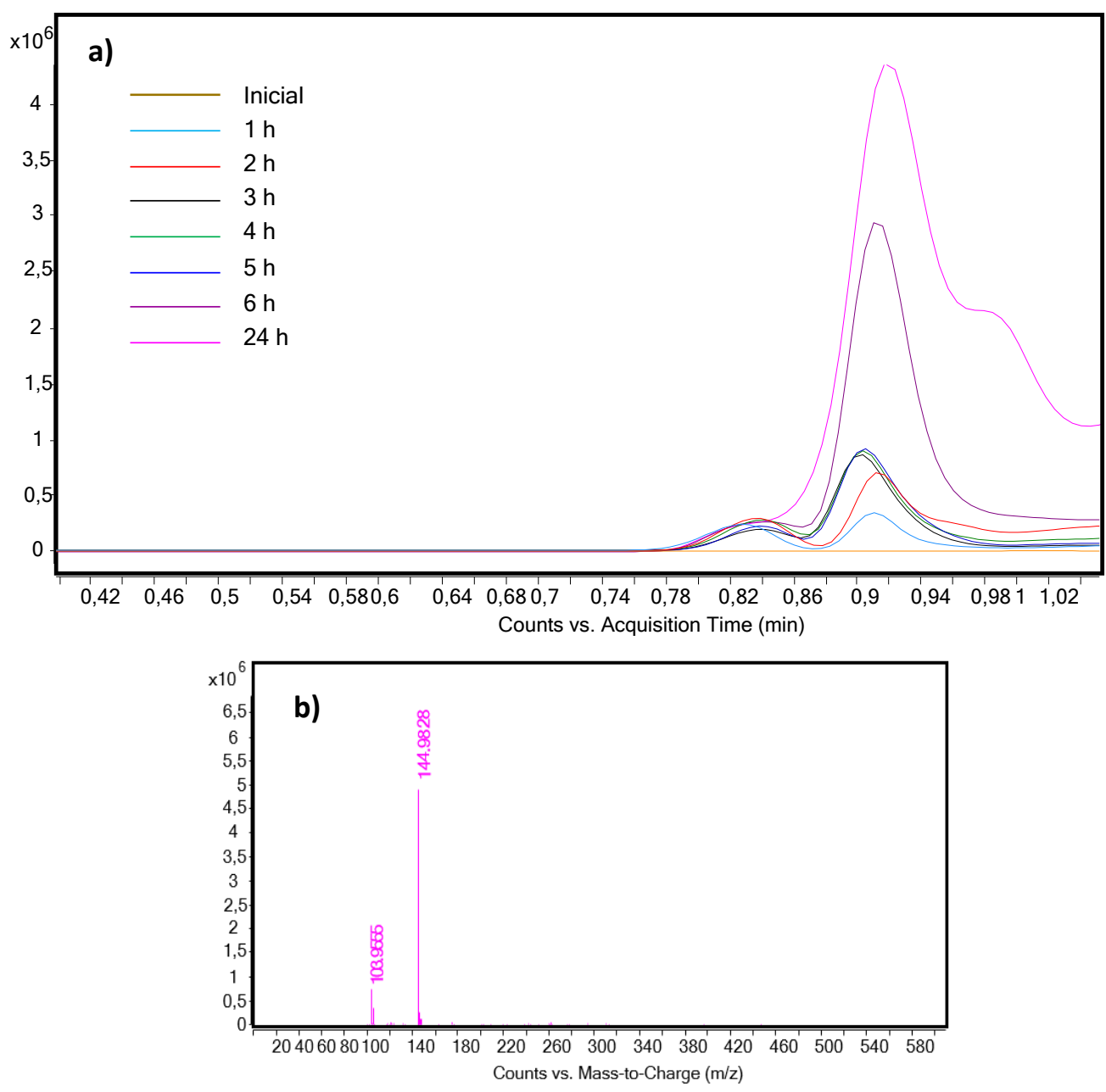

Figura 4.79. a) Cromatograma EIC del producto de degradación número 9 y b) espectro de masas del compuesto.

Por tanto, en la Figura 4.80 se muestra la ruta de degradación propuesta del clorfenvinfos tras 24 horas de ensayo. En ella se puede ver como el pesticida se degrada para dar tres rutas diferentes. Por un lado, la molécula se rompe para dar el grupo fosfato (molécula 6) y la parte el anillo aromático (molécula 1) característico del clorfenvinfos. Estos dos compuestos con el paso del tiempo se van degradando también para dar moléculas más pequeñas. Finalmente, la 
tercera ruta de degradación del pesticida ha sido la rotura de la molécula de clorfenvinfos por el enlace con el fosforo, pero en este caso, dando lugar a un compuesto sin cloros y con cadenas alifáticas más largas. Ambas rutas acaban con la apertura del anillo aromático.

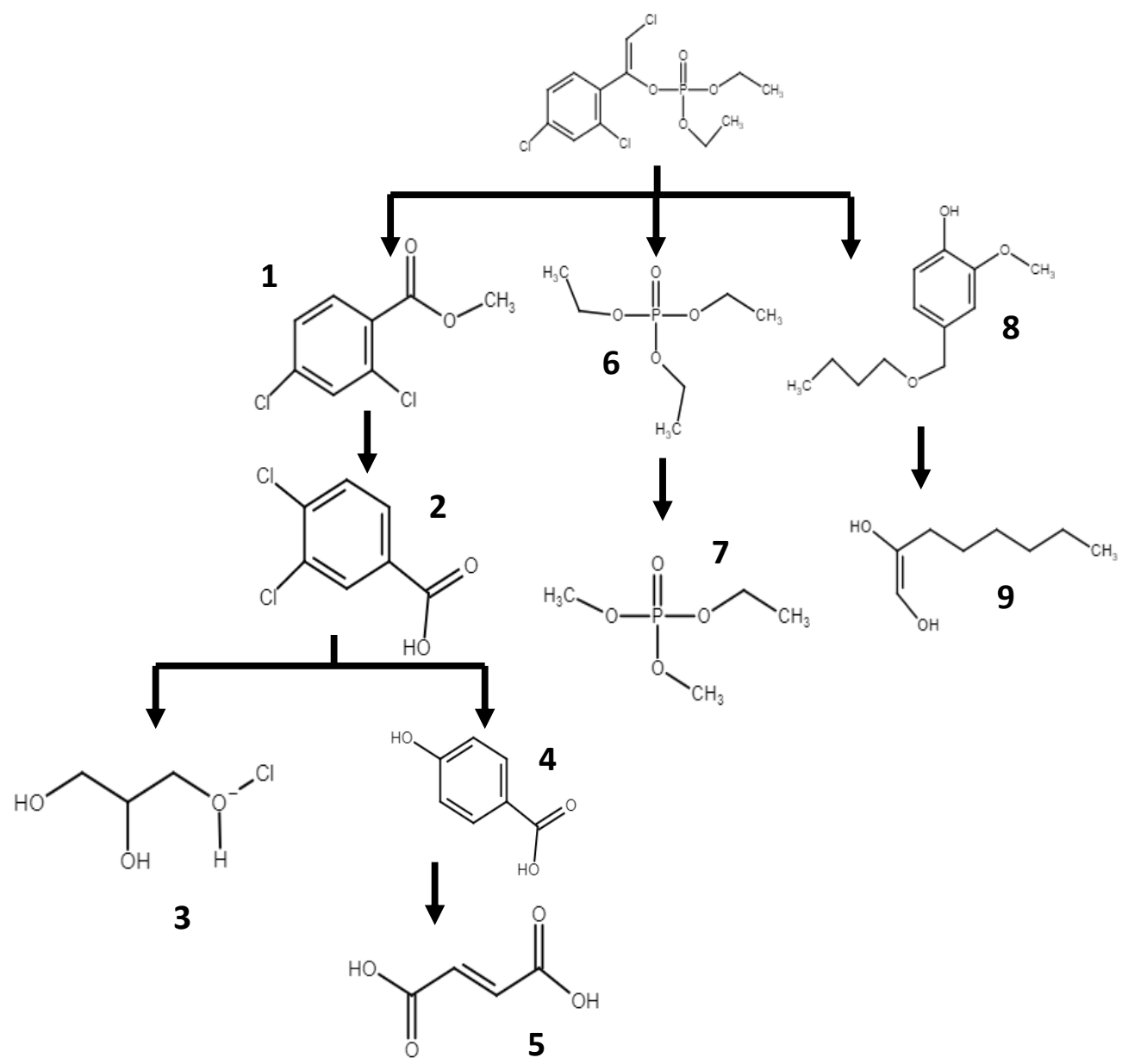

Figura 4.80. Ruta de degradación propuesta del clorfenvinfos mediante PEC. 
A modo de resumen, en la Tabla 4.20 se muestra la formula molecular de cada compuesto, así como el tiempo de retención y el valor de $\mathrm{m} / \mathrm{z}$ asociado a cada intermedio.

Tabla 4.20. Tabla resumen de los compuestos intermedios identificados con su $\mathrm{m} / \mathrm{z}$ y tiempo de retención.

\begin{tabular}{|c|c|c|c|c|}
\hline $\begin{array}{l}\text { Número de } \\
\text { compuesto }\end{array}$ & Compuesto & $\begin{array}{l}\text { Formula } \\
\text { molecular }\end{array}$ & $\begin{array}{l}\text { Tiempo de } \\
\text { retención (s) }\end{array}$ & Valor $\mathrm{m} / \mathrm{z}$ \\
\hline 1 & $\begin{array}{l}\text { 2,4-ácido } \\
\text { diclorobenzoico- } \\
\text { metiléster }\end{array}$ & $\mathrm{C}_{8} \mathrm{H}_{8} \mathrm{O}_{2} \mathrm{Cl}_{2}$ & 0.87 & 203.97 \\
\hline 2 & $\begin{array}{c}\text { 2,4-ácido } \\
\text { diclorobenzoico }\end{array}$ & $\mathrm{C}_{7} \mathrm{H}_{4} \mathrm{O}_{2} \mathrm{Cl}_{2}$ & 1 & 189.958 \\
\hline 3 & $\begin{array}{c}\text { 1-cloro-propano- } \\
\text { 1,2,3-triol }\end{array}$ & $\mathrm{C}_{4} \mathrm{H}_{9} \mathrm{O}_{3} \mathrm{Cl}$ & 1.04 & 127.0157 \\
\hline 4 & $\begin{array}{c}\text { 4-ácido } \\
\text { hidroxybenzoico }\end{array}$ & $\mathrm{C}_{7} \mathrm{H}_{6} \mathrm{O}_{3}$ & 0.88 & 136.9402 \\
\hline 5 & $\begin{array}{c}\text { Ácido } \\
\text { dicarboxílico }\end{array}$ & $\mathrm{C}_{4} \mathrm{H}_{4} \mathrm{O}_{4}$ & 0.95 & 116.011 \\
\hline 6 & Trietilfosfato & $\mathrm{C}_{5} \mathrm{H}_{13} \mathrm{O}_{4} \mathrm{P}$ & 1.26 & 182.069 \\
\hline 7 & Etildimetilfosfato & $\mathrm{C}_{4} \mathrm{H}_{11} \mathrm{O}_{4} \mathrm{P}$ & 1.55 & 155.047 \\
\hline 8 & $\begin{array}{c}\text { 4-butoxymetil-2- } \\
\text { metoxy-fenol }\end{array}$ & $\mathrm{C}_{12} \mathrm{H}_{18} \mathrm{O}_{3}$ & 9 & 210.11 \\
\hline 9 & 1-octen-1,2-diol & $\mathrm{C}_{8} \mathrm{H}_{16} \mathrm{O}_{2}$ & 1.37 & 144.98 \\
\hline
\end{tabular}

\subsection{Fosmet}

El tercer pesticida organofosforado elegido para degradar fotoelectroquímicamente ha sido el fosmet. De nuevo, mediante espectroscopía 
UV-Vis y HPLC-MS se ha seguido el transcurso de la degradación, así como se ha podido identificar posibles compuestos intermedios para proponer finalmente una ruta de degradación para el fosmet.

\subsubsection{Espectroscopía UV-Vis.}

En primer lugar, se analizaron 4 patrones de fosmet con las siguientes concentraciones: 1 ppm, 5 ppm, 10 ppm y 20 ppm, siendo su espectro UV-Vis el que se muestra en la Figura 4.81.

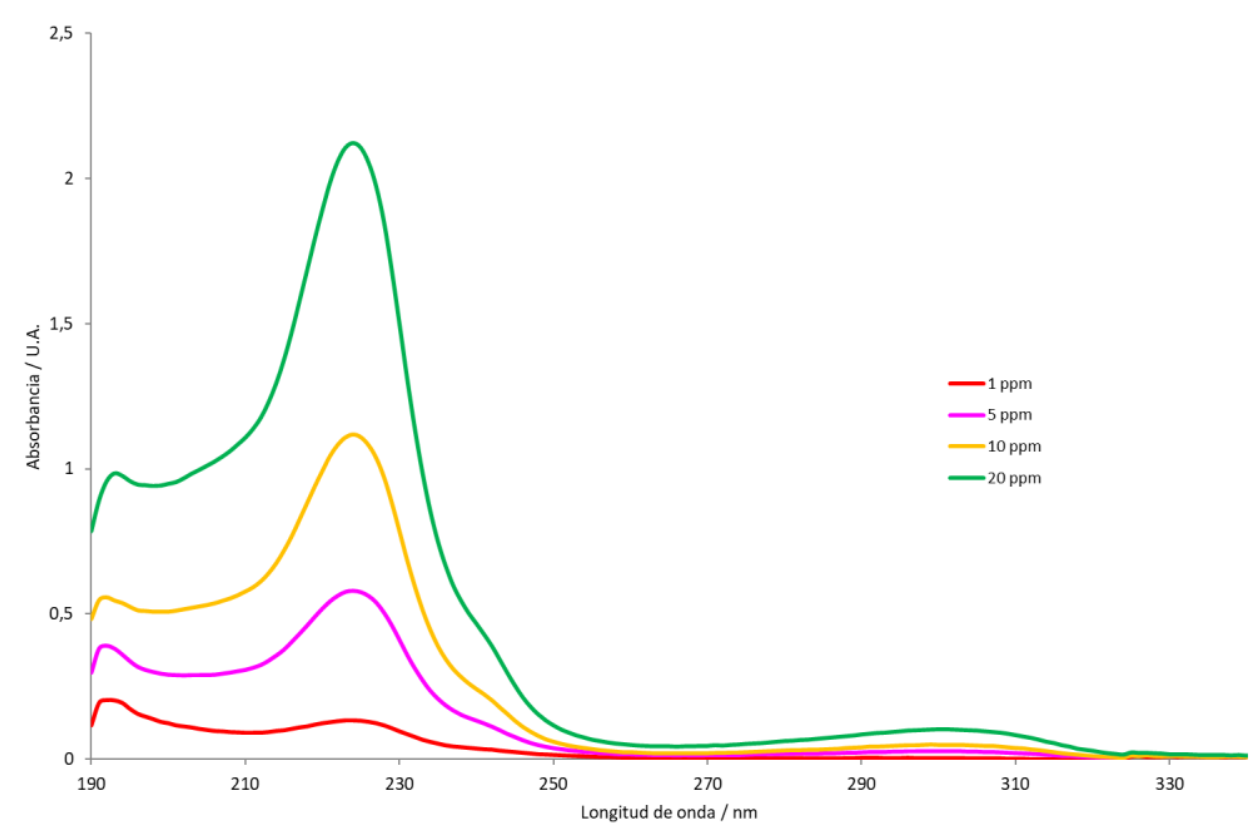

Figura 4.81. Espectro UV-Vis de los patrones de fosmet.

A continuación, el espectro UV-Vis asociado al fosmet, y registrado durante la degradación fotoelectrocatalítica, se muestra en la Figura 4.82. El espectro característico del fosmet presenta una banda a $220 \mathrm{~nm}$, que corresponde con la transición $\pi / \pi^{*}$ donde el electrón de un orbital enlazante se excita hasta un orbital anti-enlazante $\pi^{*}$, y un hombro a $200 \mathrm{~nm}$. La banda que aparece a $220 \mathrm{~nm}$, que es la que se asocia al anillo aromático del fosmet, va disminuyendo con el paso del tiempo, mientras que el hombro que aparece a $200 \mathrm{~nm}$ va aumentando 
con el tiempo de degradación, indicando que el pesticida se va degradando mientras que van apareciendo compuestos intermedios más pequeños $[129,130]$.

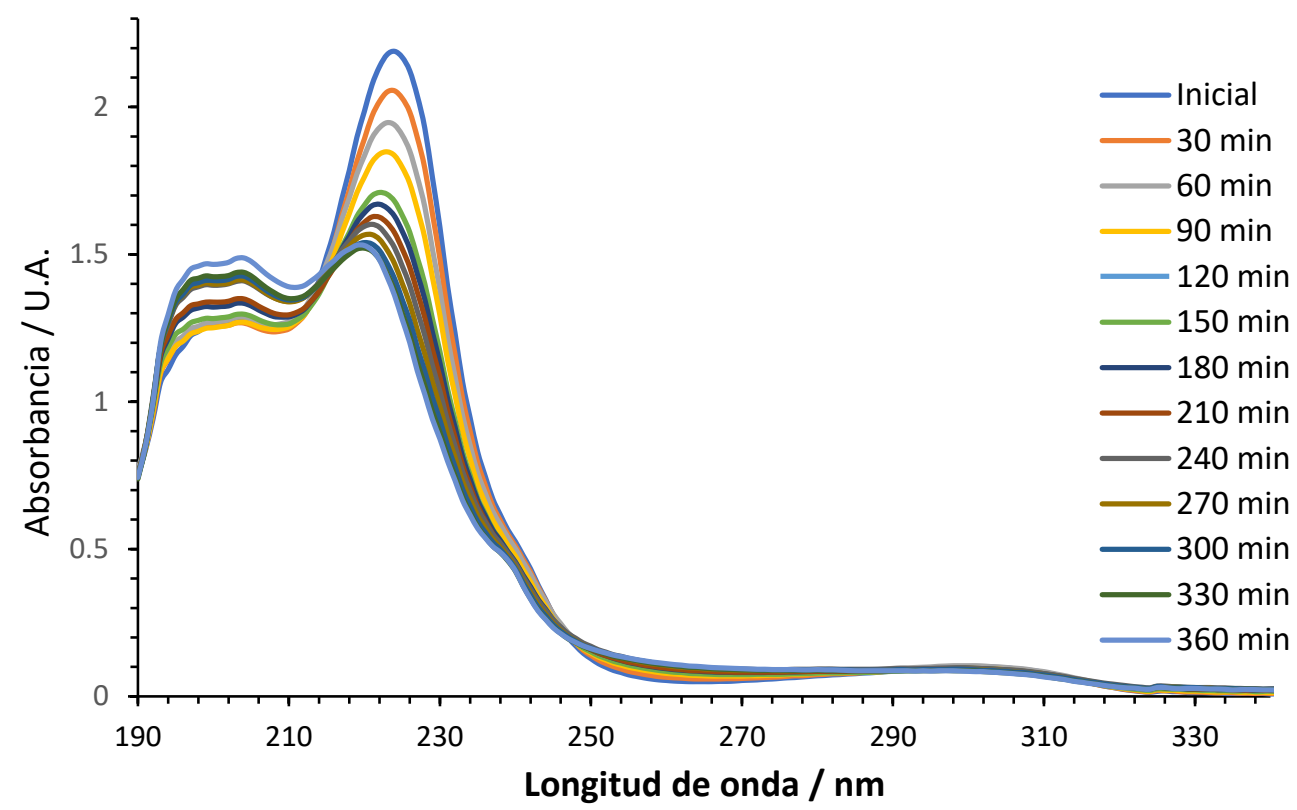

Figura 4.82. Espectros UV-Vis de fosmet cuando se utiliza la técnica PEC durante $6 \mathrm{~h}$.

Por tanto, analizando el espectro de la Figura 4.82, se puede concluir que la degradación siguió la tendencia esperada, en donde la banda usada para seguir la degradación del fosmet va disminuyendo, mientras que va aumentando el pico asociado a compuestos intermedios más pequeños producto de la degradación del fosmet.

\subsubsection{UHPLC-MS/Q-TOF}

Una vez se realizó la degradación del fosmet durante 24 horas, se analizaron todas las muestras mediante UHPLC-MS/Q-TOF para poder hallar la concentración exacta de fosmet así como identificar los intermedios producidos tras 24 de degradación fotoelectrocatalitica con el uso de nanoestructuras de $\mathrm{WO}_{3}$ como fotocatalizador.

Para poder hallar la concentración de fosmet en cada muestra degradada, se estudiaron nuevamente los 4 patrones que se analizaron mediante UV-Vis. En la 
Figura 4.83 se muestra el cromatograma EIC de estos patrones en donde se observa que a un tiempo de retención de $18.6 \mathrm{~min}$ aparece el pico asociado al fosmet. Este pico se asocia con el pesticida gracias al valor de $\mathrm{m} / \mathrm{z}$, ya que el valor del fosmet es 318 y en el espectro de masas que aparece en la Figura $4.83 \mathrm{~b}$ ) presenta el mismo valor [131].
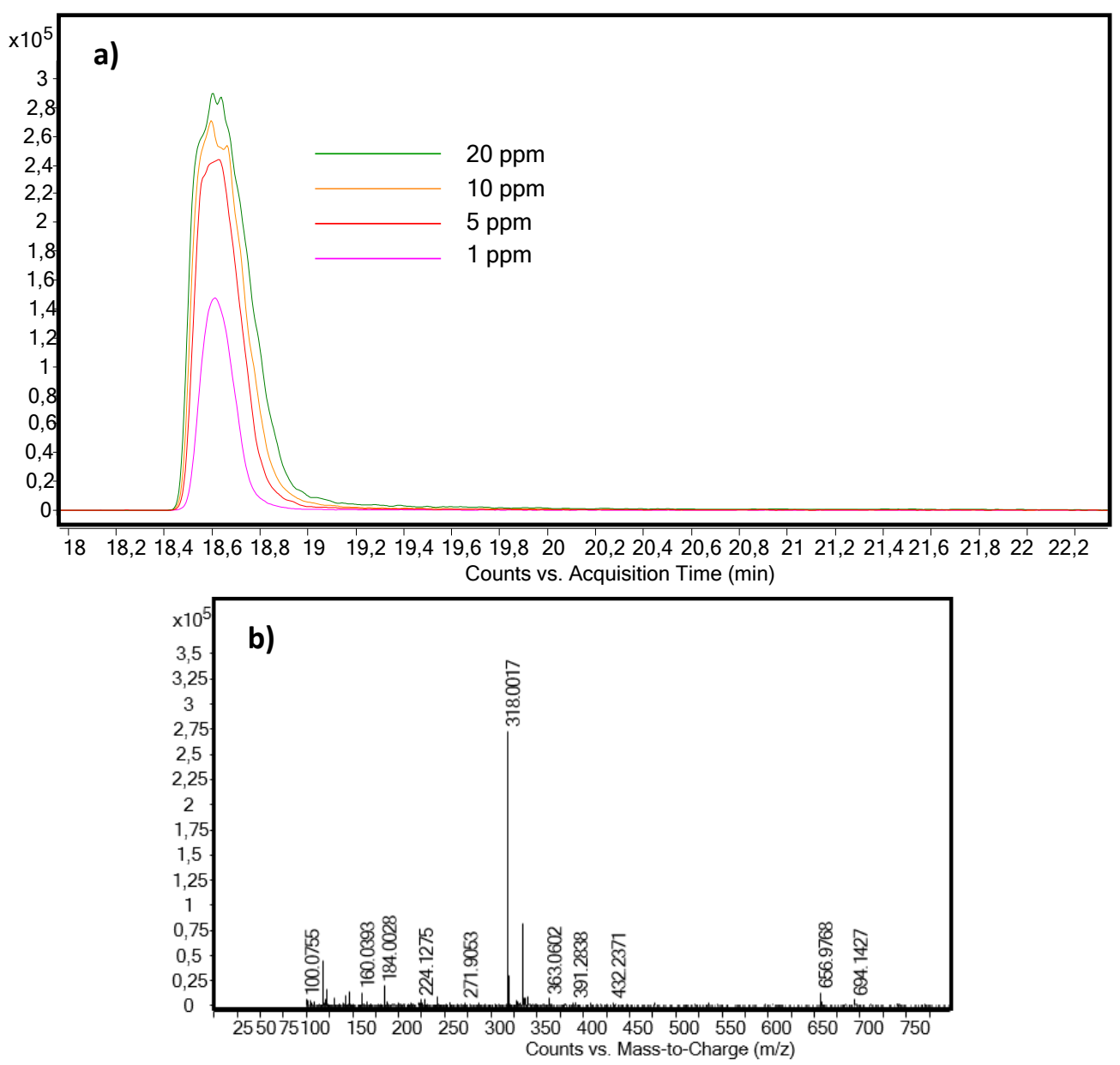

Figura 4.83. a) Cromatograma EIC de los patrones de fosmet y b) espectro de masas del compuesto. 
A partir de este cromatograma y de las áreas obtenidas de cada patrón, se ha hallado la recta de calibrado para obtener la concentración exacta de fosmet en cada muestra. En la Figura 4.84 se muestra la linealización de los datos obtenidos junto con la ecuación que relaciona el área obtenida con la concentración. Además, se puede comprobar que se ha obtenido un buen ajuste ya que el valor de $R^{2}$ es superior a 0.99 .

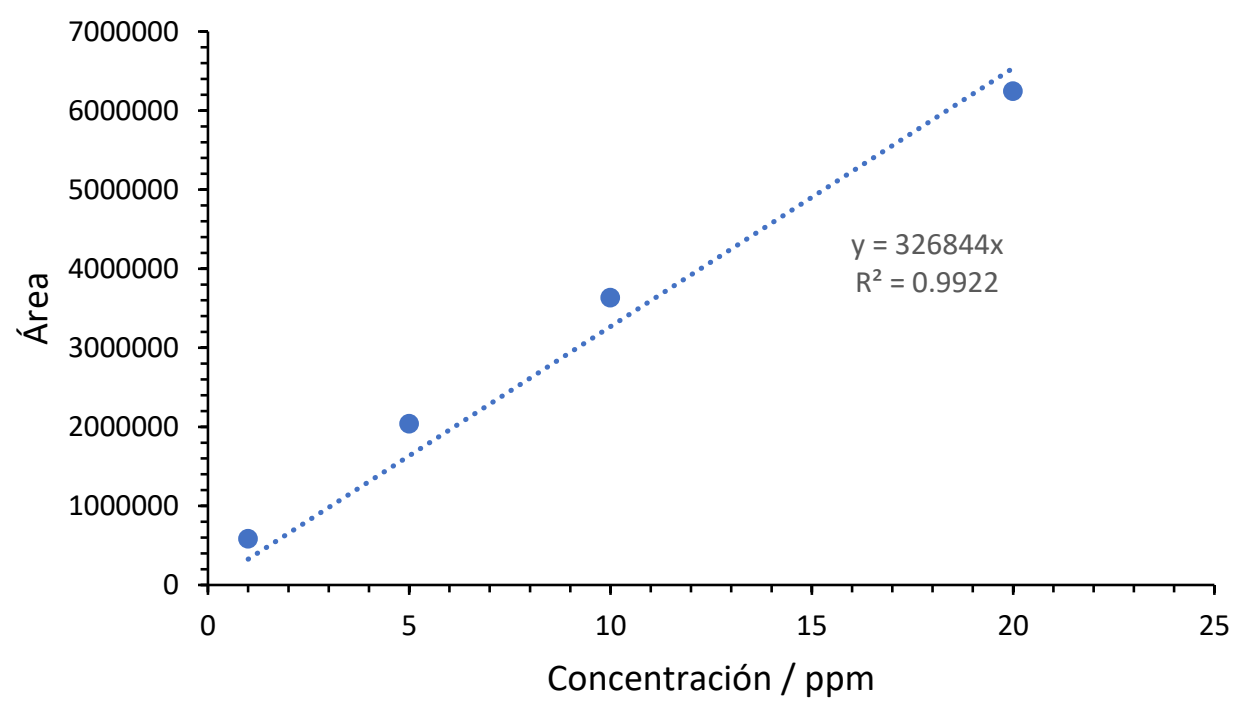

Figura 4.84. Recta de calibrado de los patrones de fosmet mediante UHPLC-MS.

En la Figura 4.85 a) se muestra el cromatograma EIC de las muestras degradadas junto con el espectro de masas asociado a ese pico (Figura 4.85 b)), y que corresponde al fosmet. En él se observa cómo tras 24 horas de degradación no queda prácticamente nada de fosmet, produciendo una degradación total del pesticida. 

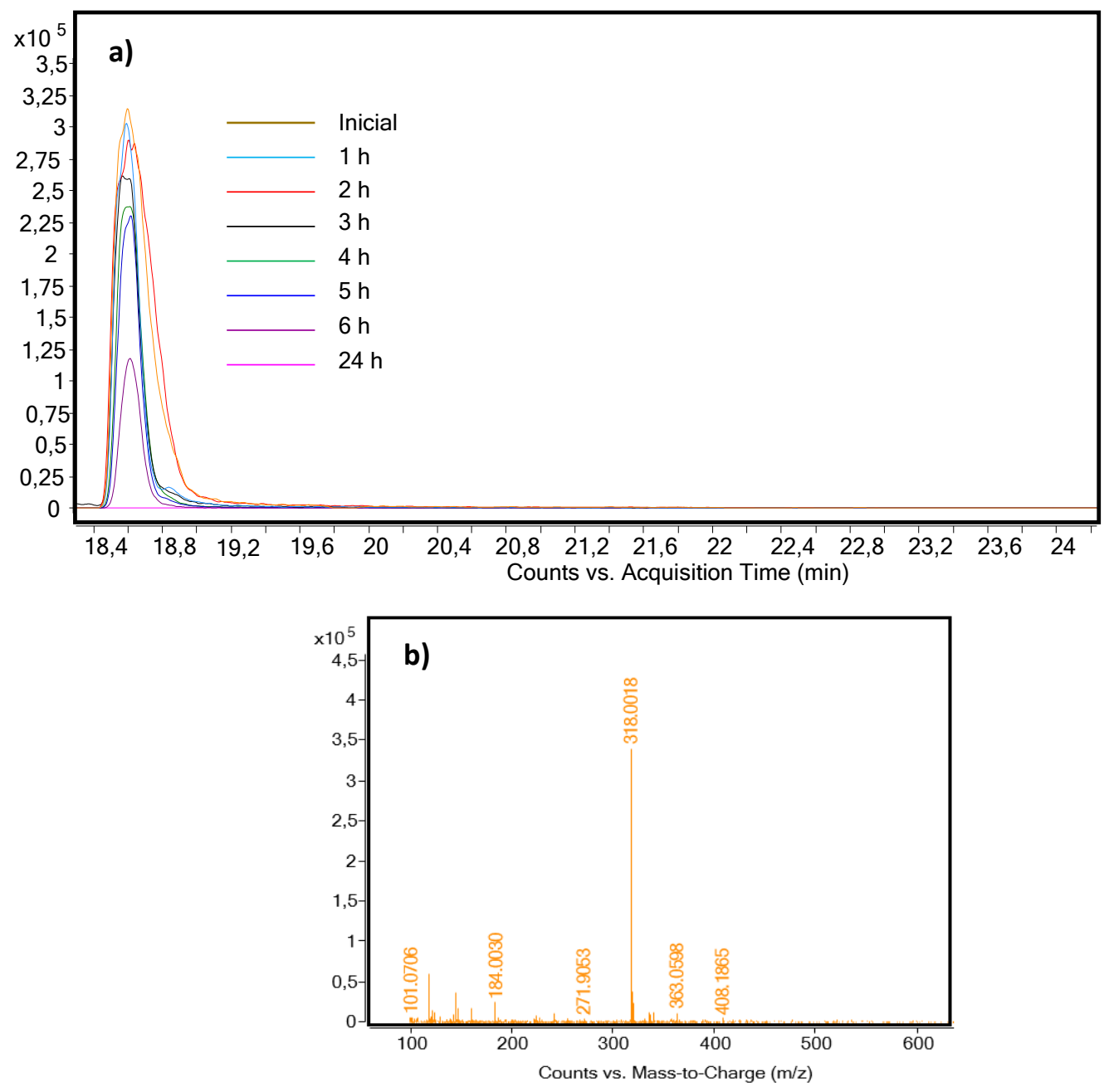

Figura 4.85. a) Cromatograma EIC de todas las muestras degradadas de fosmet y b) espectro de masas del compuesto.

En la Tabla 4.21 se muestra la concentración de fosmet en cada una de las disoluciones, hallada a partir de la recta de calibrado mostrada en la Figura 4.84, en donde se comprueba que tras 24 horas de degradación la concentración de fosmet es prácticamente nula. 
Tabla 4.21. Concentración de fosmet en cada muestra degradada.

\begin{tabular}{|c|c|c|}
\cline { 2 - 3 } \multicolumn{1}{c|}{} & $\begin{array}{c}\text { Área } \\
\text { (cuentas) }\end{array}$ & Concentración/ ppm \\
\hline $\mathbf{0}$ & 6242460.05 & 19.55 \\
\hline $\mathbf{1}$ & 4587684.49 & 14.37 \\
\hline $\mathbf{2}$ & 3540926.89 & 11.09 \\
\hline $\mathbf{3}$ & 2536377.09 & 7.95 \\
\hline $\mathbf{4}$ & 1583506.65 & 4.96 \\
\hline $\mathbf{5}$ & 1199270.97 & 3.76 \\
\hline $\mathbf{6}$ & 499695 & 1.57 \\
\hline $\mathbf{2 4}$ & 10.5 & 0 \\
\hline
\end{tabular}

Según la Figura 4.86, la cinética de degradación de este pesticida vuelve a ajustarse a una cinética de pseudo-primer orden, ya que se ha representado el logaritmo neperiano del cociente entre la concentración a un tiempo t y la concentración inicial, frente al tiempo, y se ha obtenido un buen ajuste.

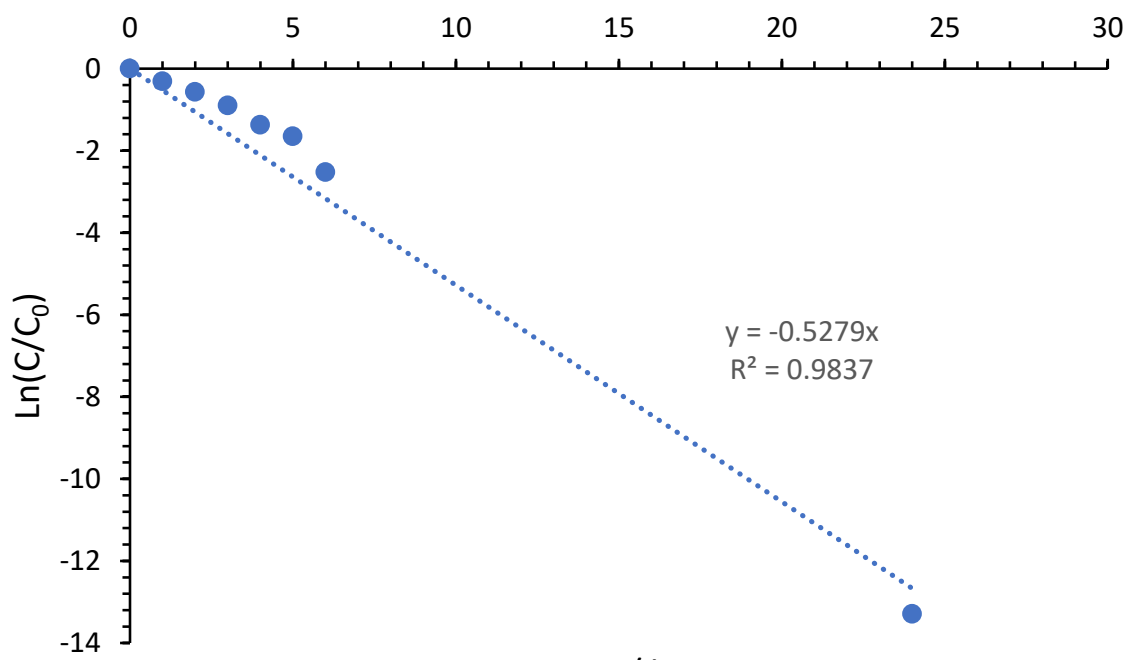

Tiempo / horas

Figura 4.86. Ajuste cinética pseudo-primer orden. 
Una vez analizados los datos relacionados con el fosmet, a continuación se presentan los resultados relacionados con los intermedios de degradación identificados.

En primer lugar, se ha identificado el compuesto conocido como Fosmet-oxon, en donde el azufre del fosmet unido al fosforo con un doble enlace es substituido por oxígeno, y cuya m/z es 320.05 (Figura 4.87 b)). Su estructura molecular se muestra en la Figura 4.93 con el número 1 [132]. En la Figura 4.93 a), está representado el cromatograma de este compuesto, en donde se observa que alcanza su concentración máxima tras 6 horas de degradación y tras 24 horas acaba desapareciendo totalmente para dar nuevos productos de degradación. 

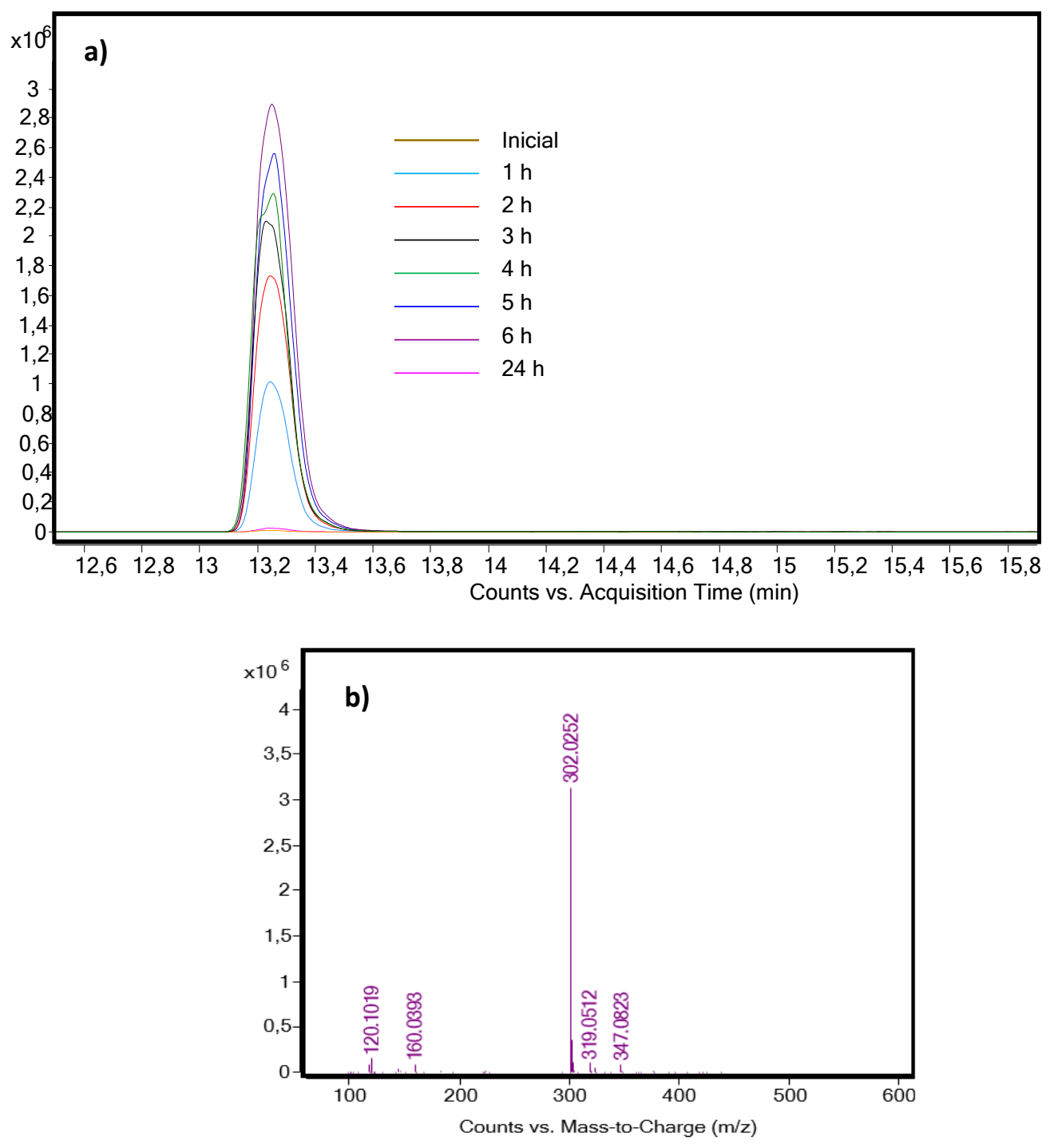

Figura 4.87. a) Cromatograma EIC del producto de degradación número 1 y b) espectro de masas del compuesto.

El siguiente compuesto hallado ha sido el conocido como NHidroxymetilphthalimida. Este compuesto tiene un valor de $\mathrm{m} / \mathrm{z}$ de 178.05 y su estructura química está representada en la Figura 4.93 con el número 2 [133]. Además, en la siguiente Figura se muestra su cromatograma en todas las muestras degradadas. De él se puede concluir que su concentración va 
aumentando con el paso del tiempo, aunque a medida que avanzaba el tiempo el aumento era menor.
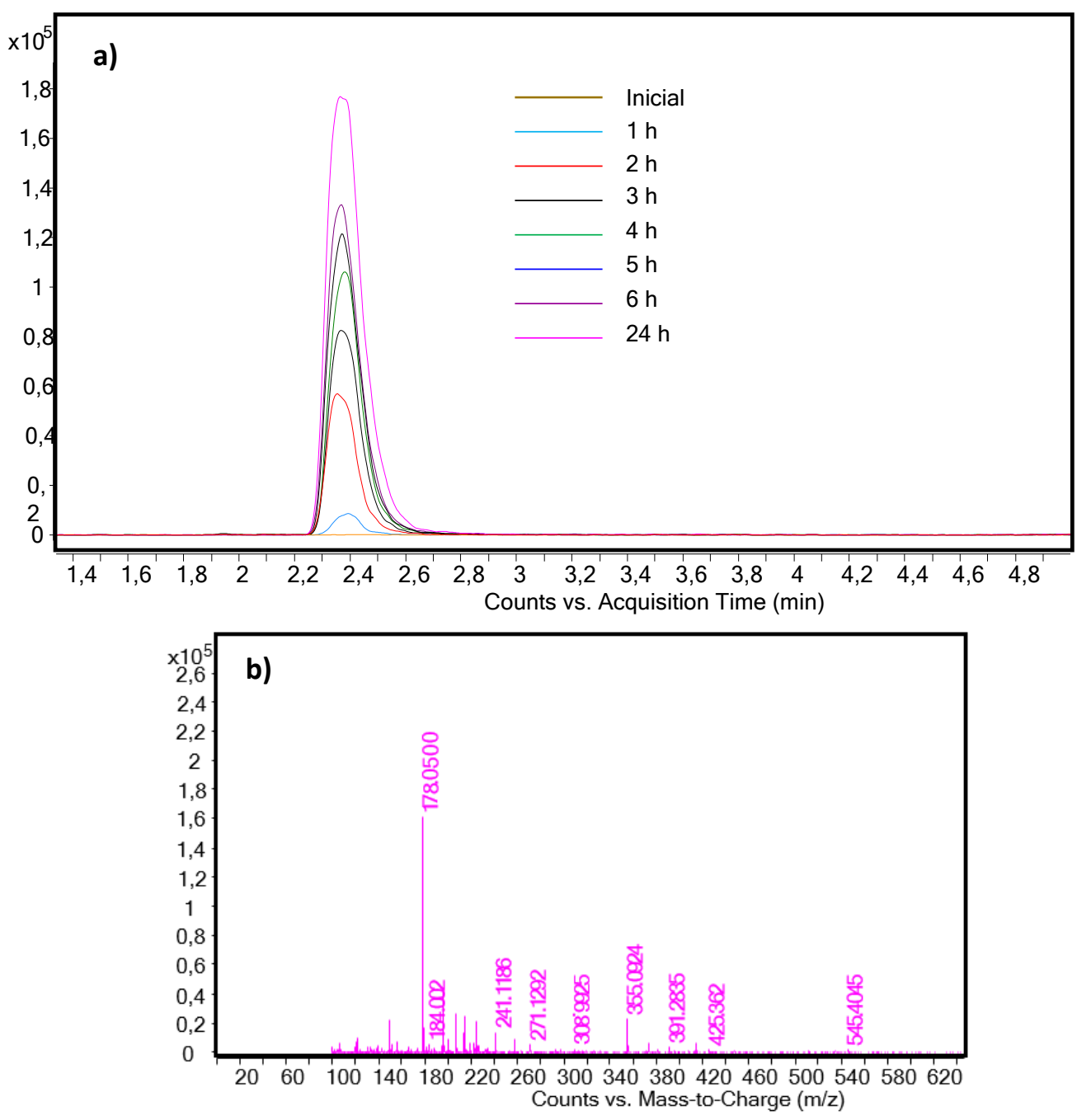

Figura 4.88. a) Cromatograma EIC del producto de degradación número 2 y b) espectro de masas del compuesto.

El tercer intermedio identificado ha sido el $\mathrm{N}$-Metilphthalimida. Este intermedio posee un valor de $\mathrm{m} / \mathrm{z}$ de 162.05 siendo su estructura química la representada en la Figura 4.93 con el número 3 [134]. En este caso, se alcanza un máximo de concentración tras 6 horas de ensayo, momento a partir del cual su concentración disminuye considerablemente para dar lugar a nuevos compuestos más 
pequeños. El cromatograma correspondiente al intermedio número 3 está representado en la Figura 4.89 a) y su espectro de masas en la Figura 4.89 b).
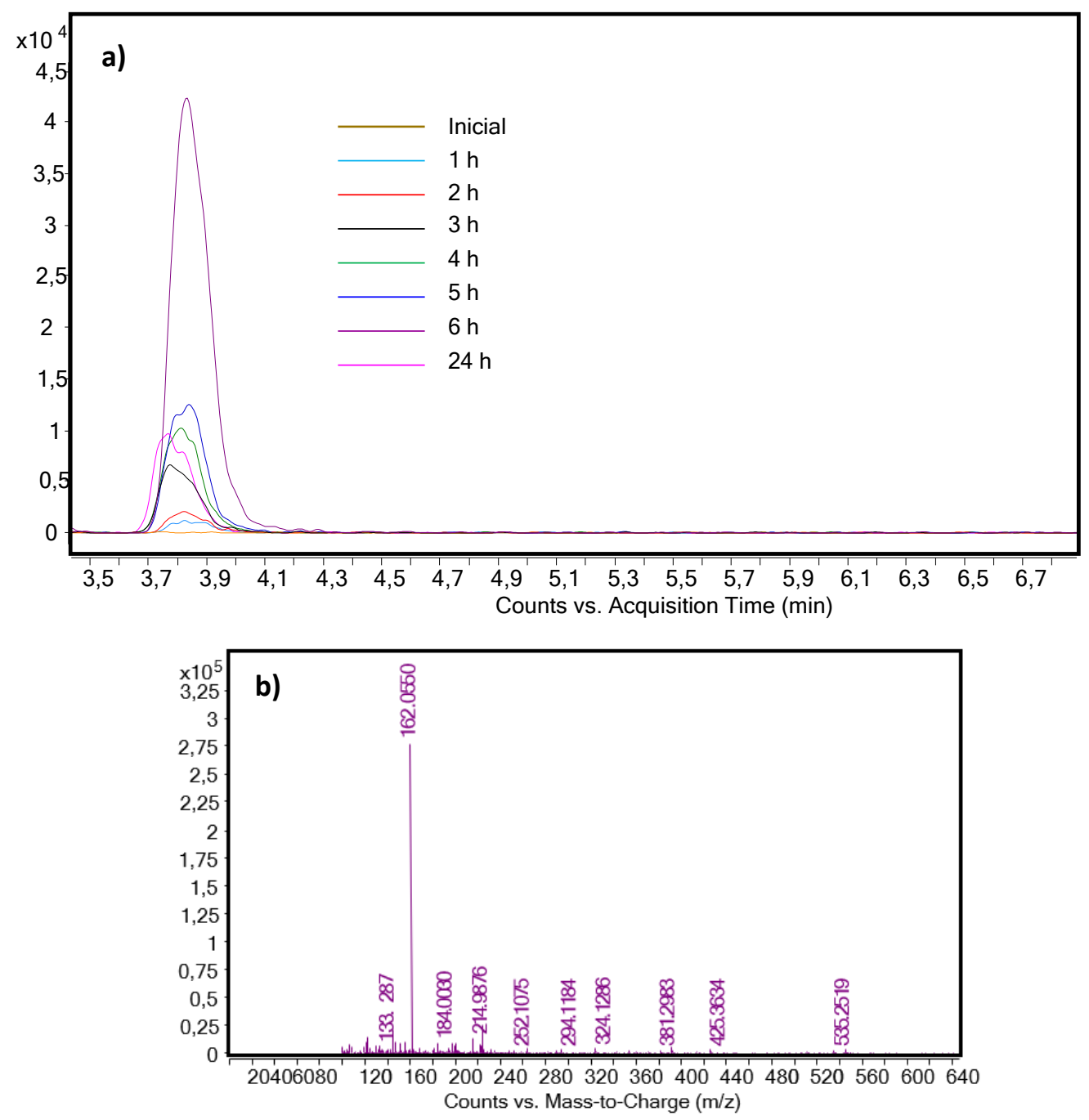

Figura 4.89. a) Cromatograma EIC del producto de degradación número 3 y b) espectro de masas del compuesto.

El cuarto intermedio corresponde con el Ciclohexil(metil)amina. Este intermedio posee una $\mathrm{m} / \mathrm{z}$ de 113 y la estructura química queda representada en la Figura 4.93 con el número 4 [135]. Si se observa el cromatograma asociado a este 
compuesto (Figura 4.90) se puede ver como con el paso del tiempo aumenta su concentración hasta llegar a su máximo tras las 24 horas de ensayo.
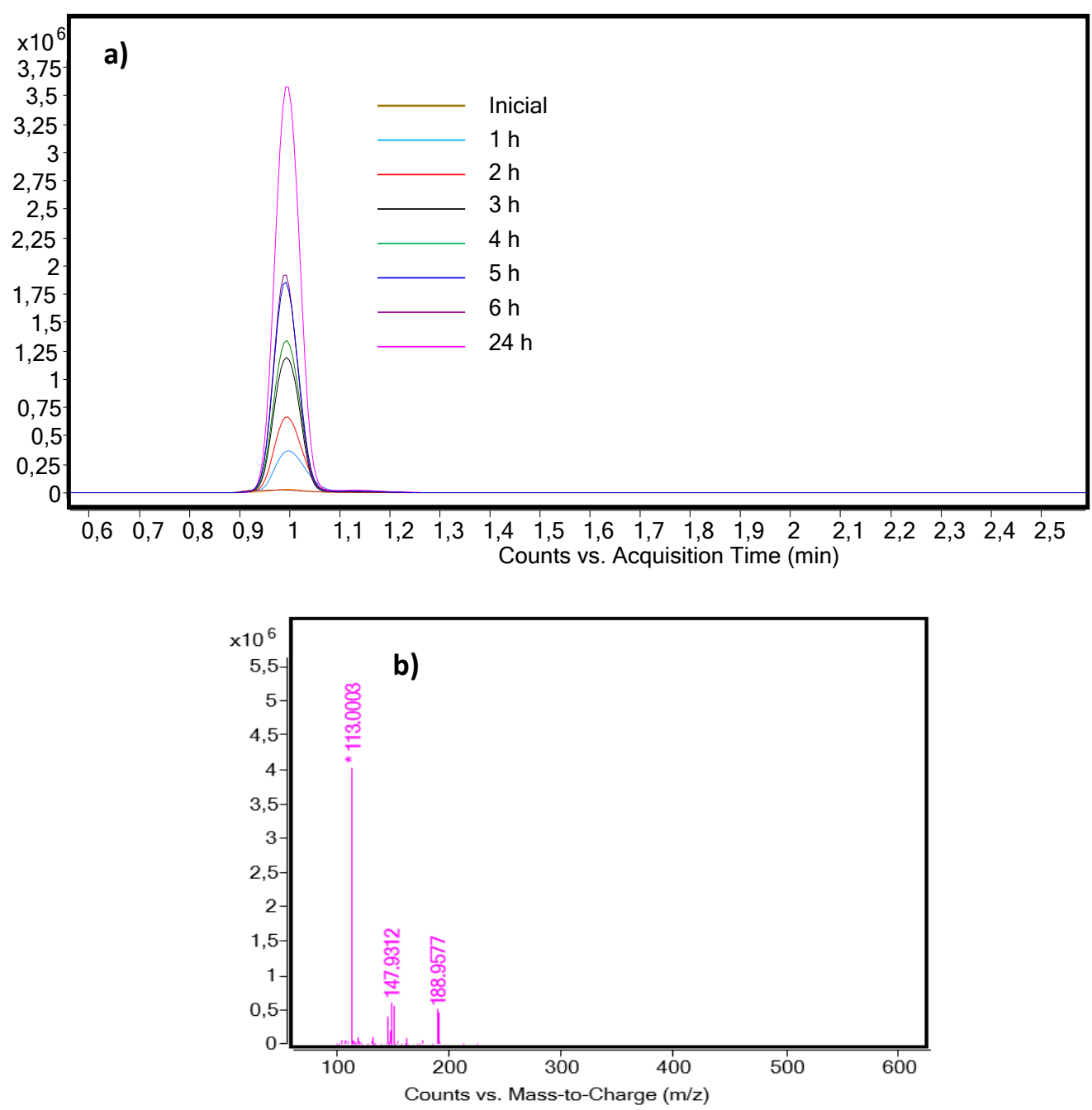

Figura 4.90. a) Cromatograma EIC del producto de degradación número 4 y b) espectro de masas del compuesto.

El quinto compuesto identificado ha sido el ácido phthalamico. La estructura química de este compuesto queda de nuevo detallada en la Figura 4.93 pero en este caso con el número 5, y su valor de $\mathrm{m} / \mathrm{z}$ es de 166.05 [136]. Este compuesto sigue el mismo comportamiento que el anterior, es decir, va aumentando su 
concentración con el paso del tiempo, hasta alcanzar su máximo al finalizar el ensayo (este comportamiento se muestra en el cromatograma de la Figura 4.91).
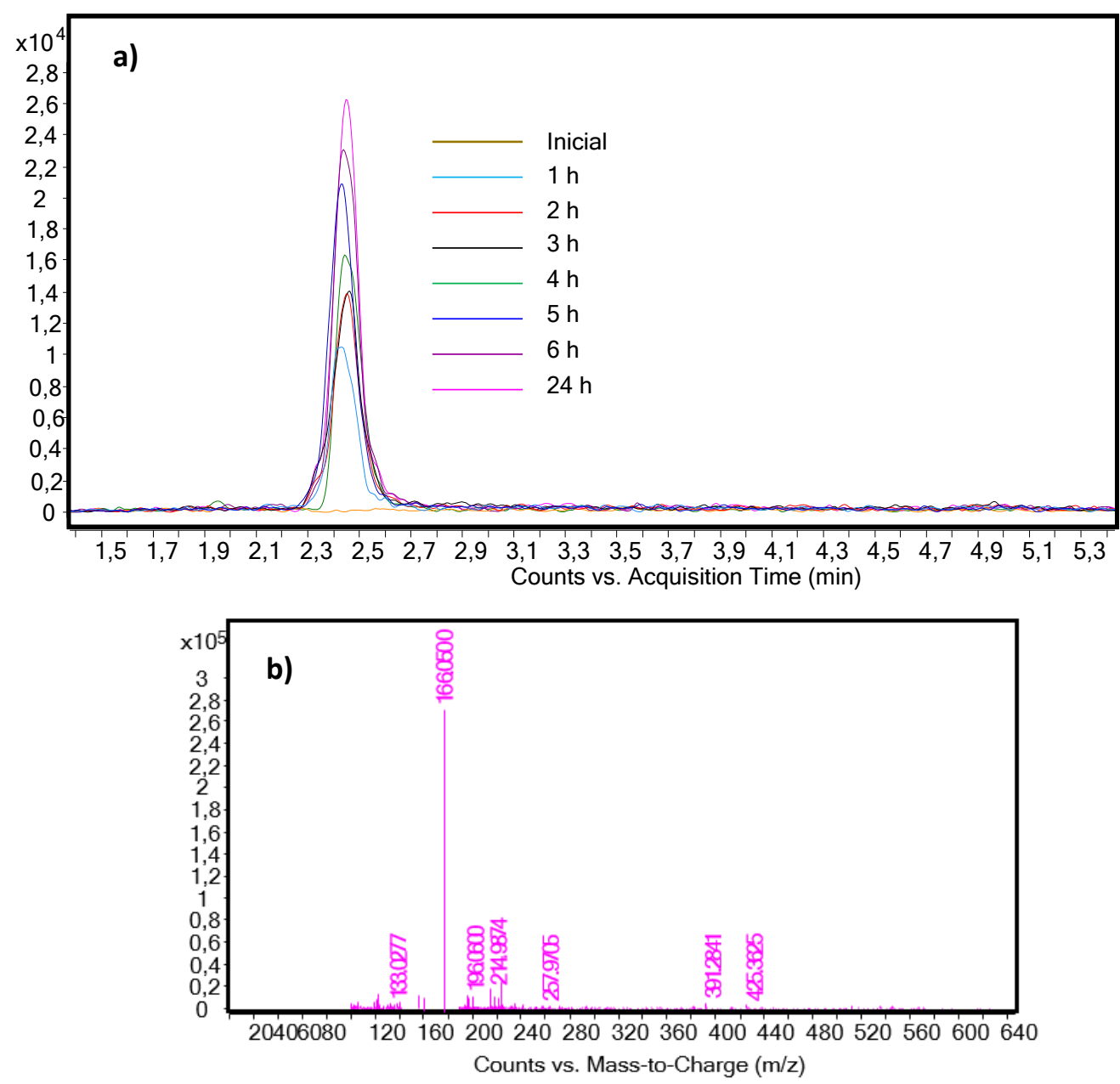

Figura 4.91. a) Cromatograma EIC del producto de degradación número 5 y b) espectro de masas del compuesto.

Y finalmente, el ultimo compuesto identificado ha sido el Dimetiltriptamina. Este compuesto tiene un valor de $\mathrm{m} / \mathrm{z}$ de 188.13 cuya estructura química está 
representada en la Figura 4.93 con el número $6[115,137,138]$. En este caso, este compuesto alcanza su máximo de concentración tras 5 horas de ensayo, momento a partir del cual, empieza a degradarse para dar otros productos diferentes, como se muestra en el cromatograma de la Figura 4.92.
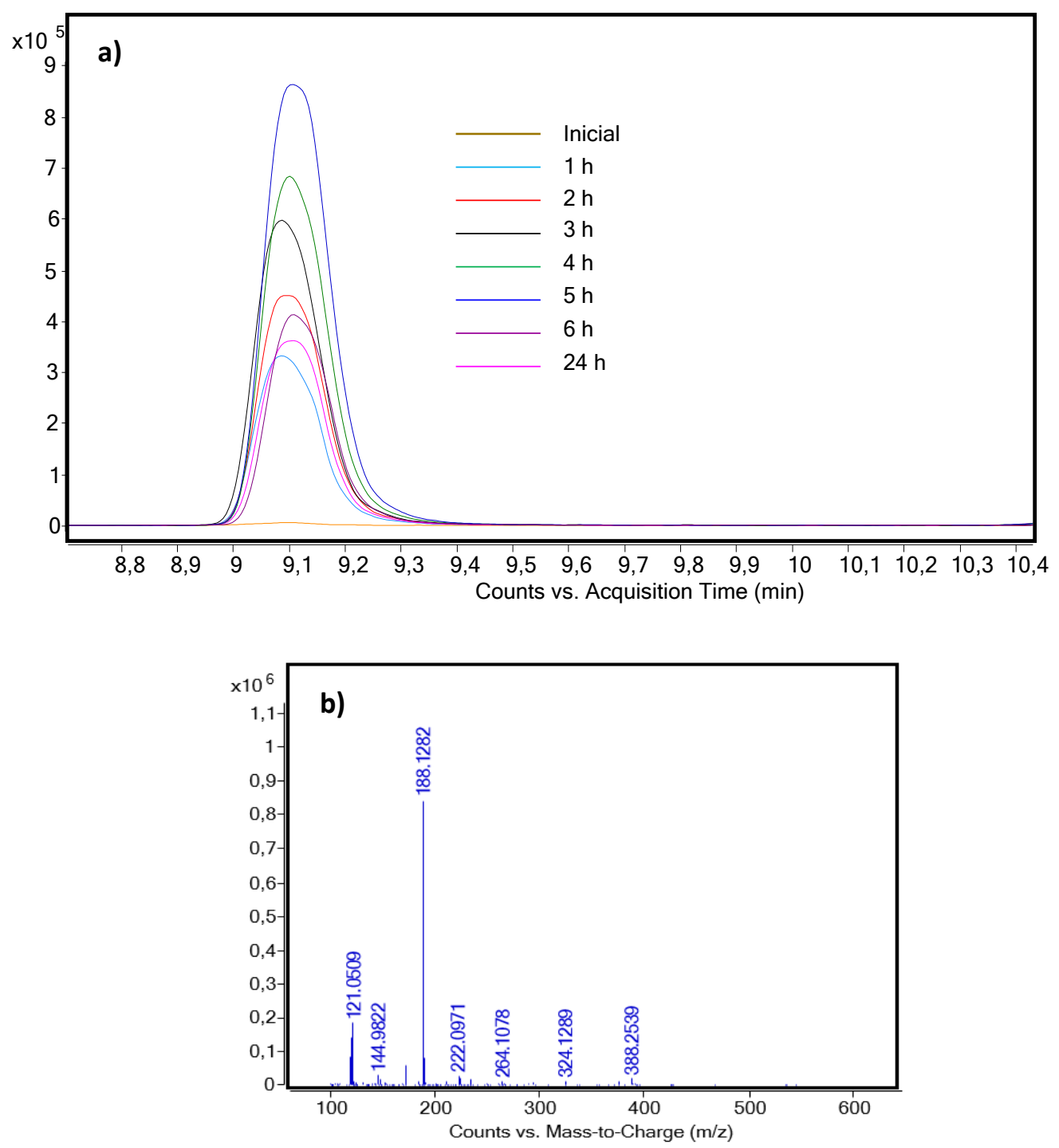

Figura 4.92. a) Cromatograma EIC del producto de degradación número 6 y b) espectro de masas del compuesto. 
Por tanto, una vez comentados todos los intermedios identificados, así como su comportamiento durante el ensayo de degradación, se propone la siguiente ruta de degradación del fosmet, mostrada en la Figura 4.93. En ella se observa como en primer lugar ocurre una desulfuración oxidativa en donde se substituye el azufre por un oxígeno. Este compuesto se degrada para dar el compuesto número 2 , en donde se ha roto la molécula por el enlace con el fosforo y además se ha substituido el azufre por otro oxígeno. Este compuesto puede degradarse para dar como resultado el compuesto número 3, en donde el nuevo compuesto se ha desprendido de un $\mathrm{OH}$. $\mathrm{Y}$ finalmente, ese compuesto se degrada en dos posibles intermedios (compuesto 4 y 5).

Además de esta ruta principal de degradación, también se ha identificado otro intermedio de degradación (compuesto 6) que sería un producto directo de la degradación del fosmet para posteriormente degradarse en moléculas más pequeñas.

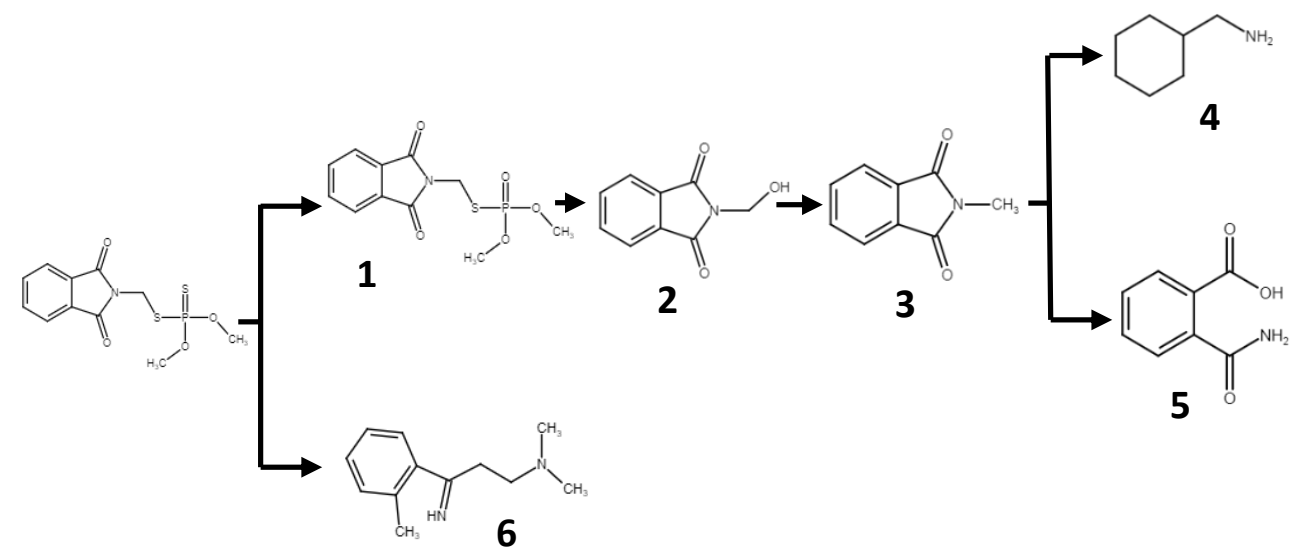

Figura 4.93. Ruta de degradación propuesta del fosmet mediante PEC.

A modo de resumen, en la Tabla 4.22, se muestra la formula molecular, el tiempo de retención y el valor de $\mathrm{m} / \mathrm{z}$ asociado a cada intermedio identificado. 
Tabla 4.22. Tabla resumen de los compuestos intermedios identificados con su $\mathrm{m} / \mathrm{z}$ y tiempo de retención.

\begin{tabular}{c|cccc}
$\begin{array}{c}\text { Número } \\
\text { de } \\
\text { compuesto }\end{array}$ & Compuesto & $\begin{array}{c}\text { Formula } \\
\text { molecular }\end{array}$ & $\begin{array}{c}\text { Tiempo de } \\
\text { retención (s) }\end{array}$ & Valor $\mathbf{m} / \mathbf{z}$ \\
\hline $\mathbf{1}$ & Fosmet-oxon & $\mathrm{C}_{11} \mathrm{H}_{12} \mathrm{O}_{5} \mathrm{NPS}$ & 13.25 & 302.025 \\
$\mathbf{2}$ & N-Hidroxymetilphthalimida & $\mathrm{C}_{9} \mathrm{H}_{7} \mathrm{NO}_{3}$ & 2.4 & 178.05 \\
$\mathbf{3}$ & N-Metilphthalimida & $\mathrm{C}_{9} \mathrm{H}_{7} \mathrm{NO}_{2}$ & 3.85 & 162.055 \\
$\mathbf{4}$ & Ciclohexil(metil)amina & $\mathrm{C}_{7} \mathrm{H}_{16} \mathrm{~N}$ & 1 & 113 \\
$\mathbf{5}$ & Ácido phthalamico & $\mathrm{C}_{8} \mathrm{H}_{7} \mathrm{NO}_{3}$ & 2.1 & 166.05 \\
$\mathbf{6}$ & Dimetiltriptamina & $\mathrm{C}_{10} \mathrm{H}_{16} \mathrm{~N}_{2}$ & 9.1 & 188.13
\end{tabular}

\subsection{Fenamifos}

Por último, el cuarto pesticida elegido para degradar fotoelectrocatalíticamente ha sido el fenamifos.

\subsubsection{Espectroscopía UV-Vis.}

Al igual que con los tres pesticidas anteriores, mediante espectroscopía Ultravioleta-Visible, se ha seguido la degradación fotoelectrocatalitica del fenamifos. En primer lugar, se ha registrado el espectro UV-Vis del fenamifos a 4 concentraciones diferentes con el fin de evaluar la forma de su espectro, así como la influencia con su concentración. Estos espectros se muestran en la Figura 4.94.

Se pueden ver dos bandas bien definidas, una a $249 \mathrm{~nm}$ y un hombro a $290 \mathrm{~nm}$. La banda a $249 \mathrm{~nm}$ se asocia con el anillo aromático característico del fenamifos en donde ocurre la transición $\pi / \pi^{*}$. En esta transicion un electrón del orbital $\pi$ se excita hasta el correspondiente orbital anti-enlazante $\pi^{*}$. Esta banda se usa 
normalmente para seguir la degradación de este pesticida mientras que el hombro corresponde a la transición $n-\pi^{*}$ asociado al átomo de azufre donde un electrón de un orbital no enlazante se excita hasta un orbital anti-enlazante $\pi^{*}$ $[103,116]$.

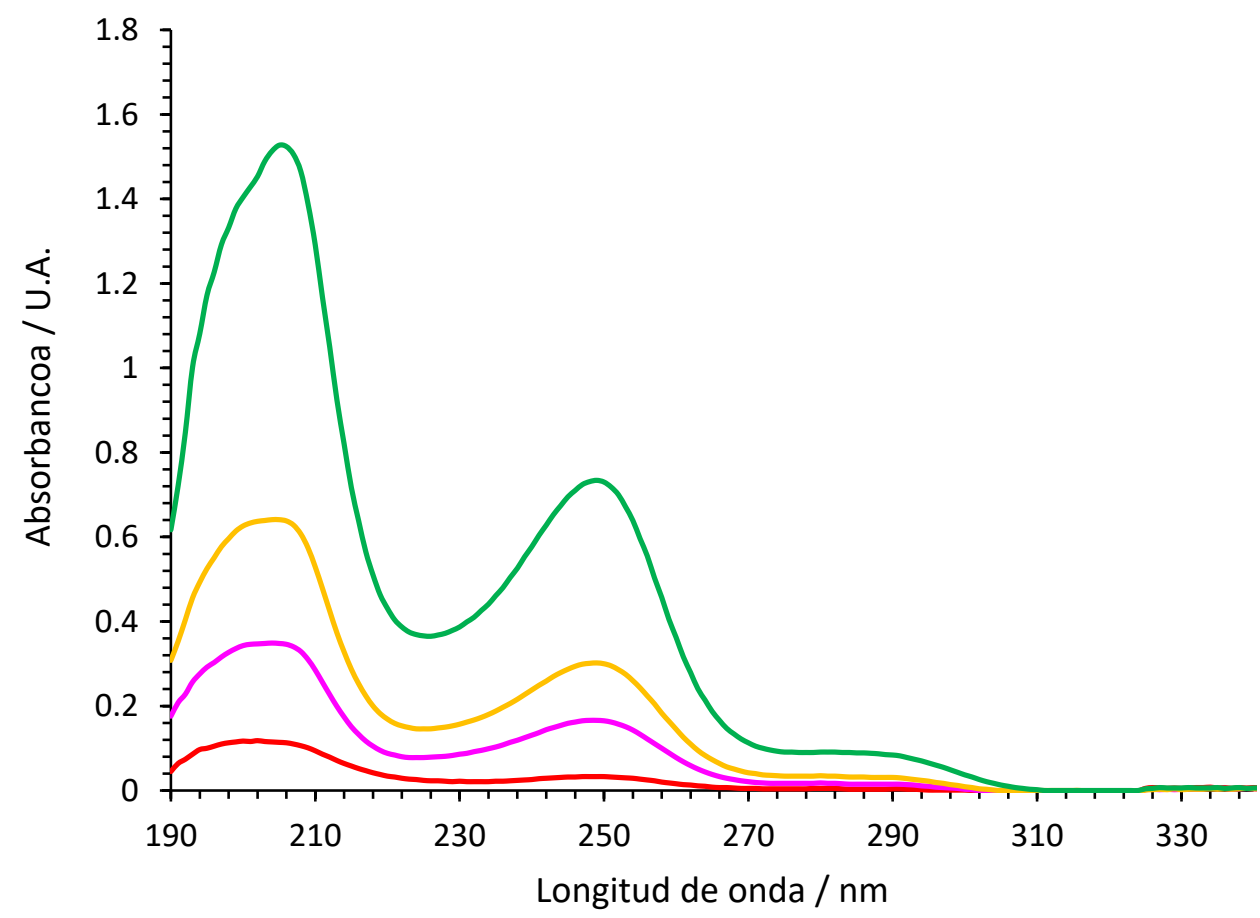

Figura 4.94. Espectro UV-Vis de los patrones de fenamifos.

En la Figura 4.95, se muestra la evolución de los espectros UV-Vis del pesticida durante las $6 \mathrm{~h}$ de degradación (la muestra se tomó cada media hora). Como puede verse, la banda a $249 \mathrm{~nm}$ y el pequeño hombro registrado a $290 \mathrm{~nm}$ disminuyen con el tiempo hasta prácticamente desaparecer. Sin embargo, a 229 $\mathrm{nm}$ se observa que con el paso del tiempo aparece una nueva banda, que corresponde a intermedios de degradación que se estan formando, aunque esta banda disminuye ligeramente con el tiempo al final del ensayo. Estos intermedios de degradación pueden corresponder a una descomposición de la molécula de 
fenamifos a través del enlace etanotiol o el enlace fosforamidato, resultando en una molécula más pequeña y menos polar. Esta sería la razón por la que el pico aparece a la izquierda, en longitudes de onda más cortas, ya que tanto el enlace etanotiol como el fosforamidato actúan como auxocromos. Los auxocromos son los grupos funcionales unidos a los cromóforos (son la parte de la molécula responsable para impartir color o los grupos funcionales que contienen múltiples enlaces capaces de absorber radiación por encima de $200 \mathrm{~nm}$ debido a la transiciones $\pi / \pi^{*}$ y $n-\pi^{*}$ ) que modifican su capacidad para absorber luz, alterando la longitud de onda o la intensidad de absorción hacia longitudes de onda más largas. Por tanto, la banda intermedia aparece en longitudes de onda más bajas que la banda principal de fenamifos, ya que este intermedio ha perdido los auxocromos (uno o ambos de los auxocromos) que confieren ese aumento en la longitud de onda registrada [139].

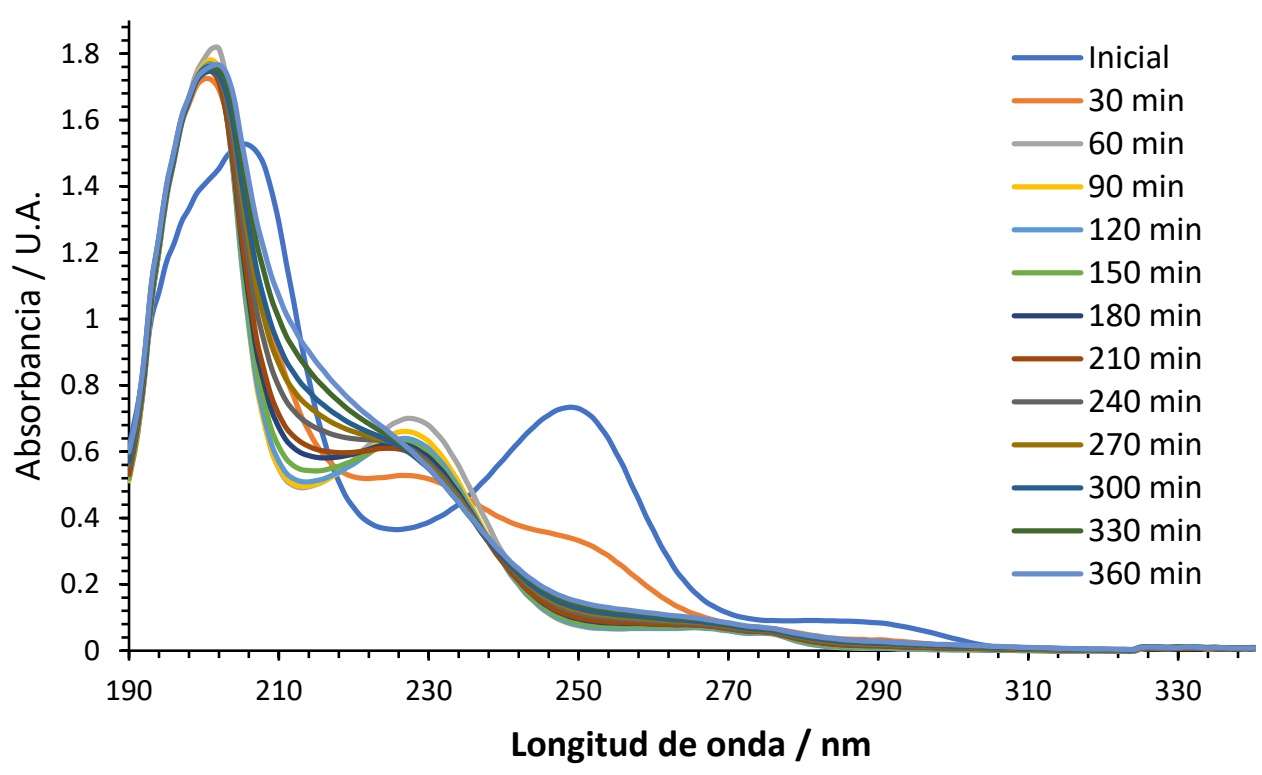

Figura 4.95. Espectros UV-Vis de fenamifos cuando se utiliza la técnica PEC durante $6 \mathrm{~h}$.

\subsubsection{UHPLC-MS}

Con los resultados del UV-Vis analizados se van a estudiar los resultados obtenidos mediante UHPLC-MS, para hallar la concentración exacta de fenamifos 
en cada muestra, así como los posibles intermedios de degradación que se han producido durante las 24 horas de ensayo.

Para ello, se analizaron 4 patrones con la misma concentración que los patrones analizados mediante UV-Vis para hallar la recta de calibrado correspondiente y poder relacionar el valor del área obtenida en cada muestra con la concentración de fenamifos. En la Figura 4.96 se muestra el cromatograma EIC del fenamifos. El pico asociado a este pesticida tiene un valor de $\mathrm{m} / \mathrm{z}$ de 304.01 y aparece a un tiempo de retención de 12.5 min [140].
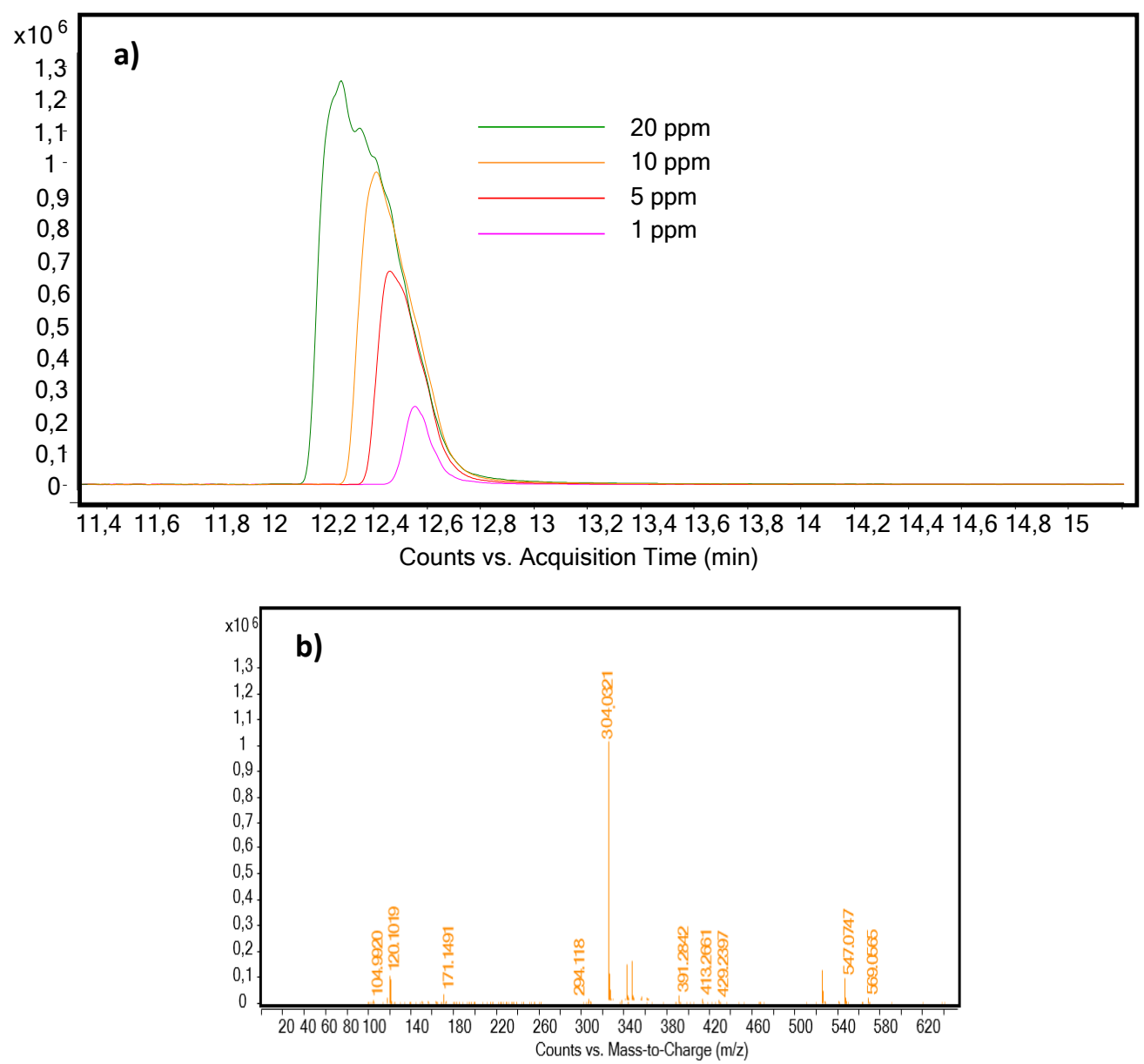

Figura 4.96. a) Cromatograma EIC de los patrones de fenamifos y b) espectro de masas del compuesto.

En la Figura 4.97 se representa el área obtenida en función de cada concentración de pesticida, así como la recta de calibrado asociada a este pesticida. 


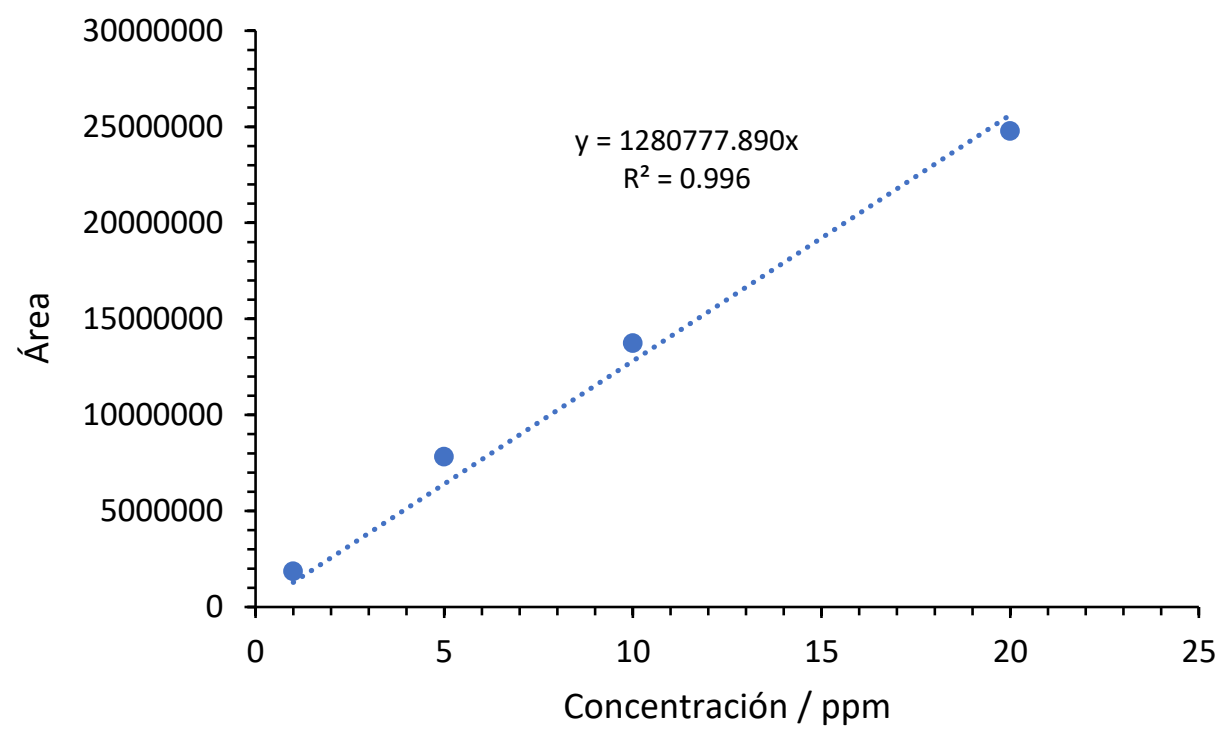

Figura 4.97. Recta de calibrado de los patrones de fenamifos mediante HPLC-MS.

El cromatograma EIC asociado al fenamifos de todas las muestras degradadas, así como el espectro de masas está representado en la Figura 4.98. En él se ve como tras dos horas de degradación la concentración de pesticida es prácticamente nula. Pero para hallar la concentración exacta de fenamifos en cada muestra se ha utilizado la recta de calibrado hallada anteriormente y se han obtenido las concentraciones que se muestran en la Tabla 4.23. 

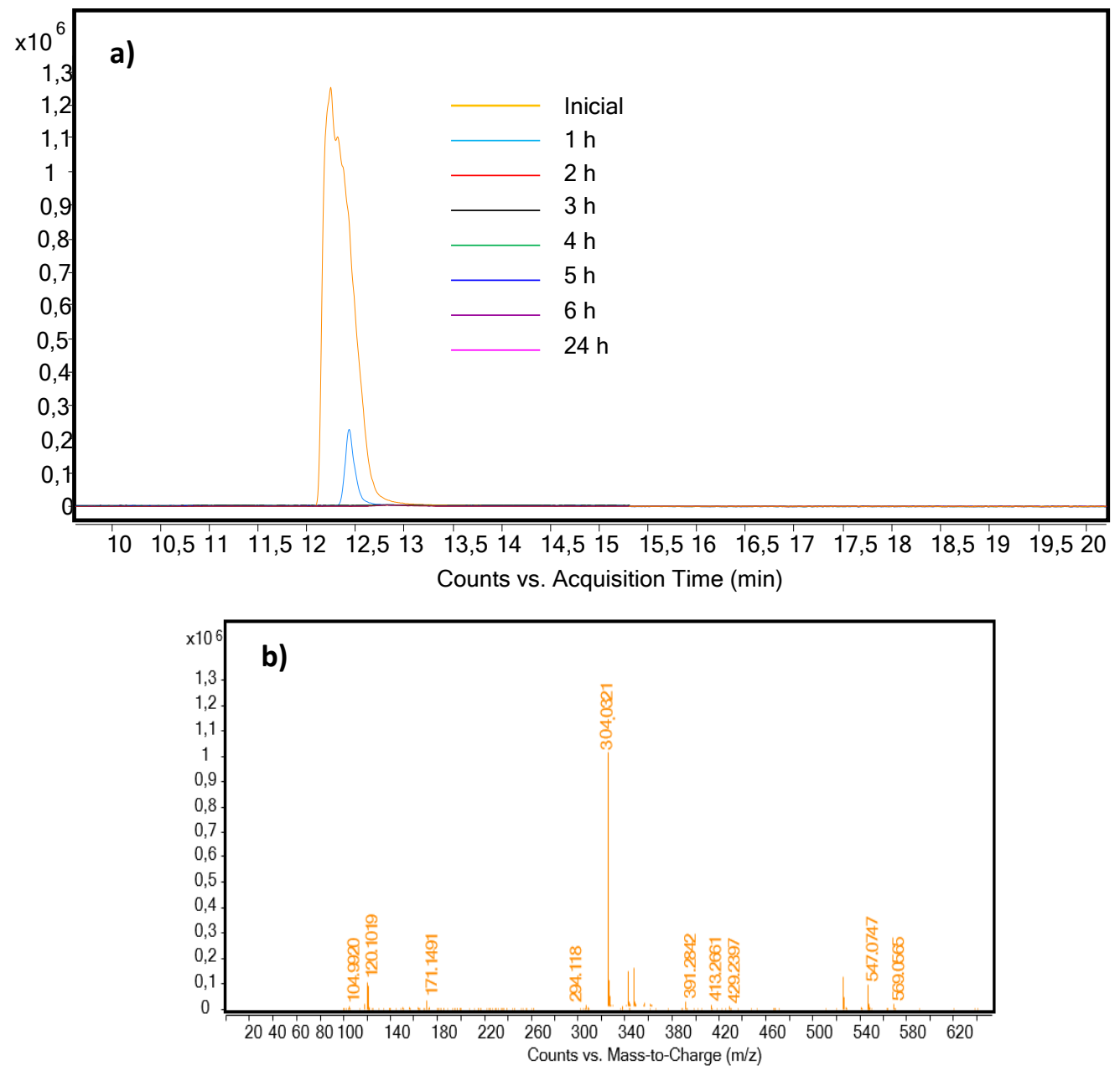

Figura 4.98. a) Cromatograma EIC de todas las muestras degradadas de fenamifos y b) espectro de masas del compuesto. 
Tabla 4.23. Concentración de fenamifos en cada muestra degradada.

\begin{tabular}{|c|c|c|}
\cline { 2 - 3 } \multicolumn{1}{c|}{} & $\begin{array}{c}\text { Área } \\
\text { (cuentas) }\end{array}$ & Concentración/ppm \\
\hline $\mathbf{0}$ & 24774548.1 & 19.34 \\
\hline $\mathbf{1 ~ h}$ & 3691487.39 & 2.88 \\
\hline $\mathbf{2} \mathbf{~ h}$ & 1369919.35 & 1.07 \\
\hline $\mathbf{3 ~ h}$ & 706272.27 & 0.55 \\
\hline $\mathbf{4} \mathbf{~ h}$ & 355661.18 & 0.27 \\
\hline $\mathbf{5} \mathbf{~ h}$ & 191351.81 & 0.14 \\
\hline $\mathbf{6} \mathbf{~ h}$ & 97792.98 & 0.07 \\
\hline $\mathbf{2 4} \mathbf{~ h}$ & 0.46 & 0 \\
\hline
\end{tabular}

Los datos obtenidos se aproximan a una cinética de pseudo-primer orden, como ocurre con los tres pesticidas anteriores, cuya representación se muestra en la Figura 4.99. En esta gráfica se observa como los datos se ajustan a una línea, por tanto, se puede asumir que la cinética de degradación sí que corresponde a una cinética de pseudo-primer orden.

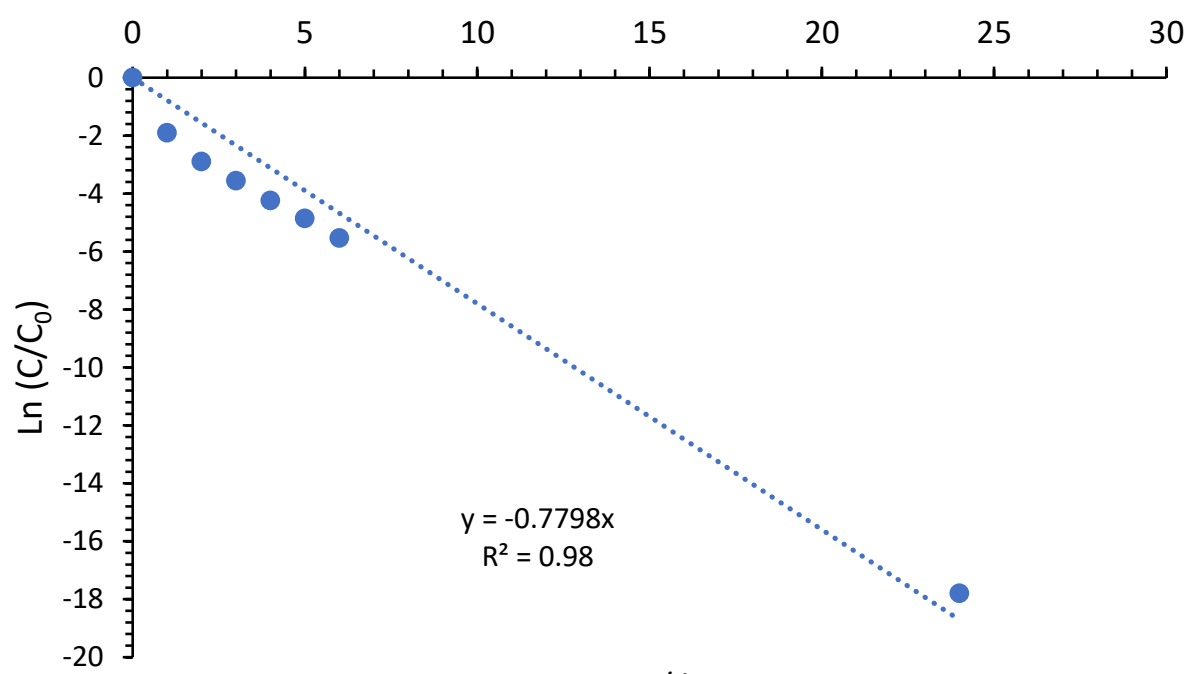

Tiempo / horas

Figura 4.99. Ajuste cinética pseudo-primer orden. 
Una vez analizados los datos relativos al fenamifos, se van a identificar los posibles intermedios de degradación producidos durante 24 horas.

El primer intermedio identificado es el conocido como Fenamifos sulfóxido. Este intermedio consiste en la unión de un oxigeno con un doble enlace al azufre de la molecula. El valor de $\mathrm{m} / \mathrm{z}$ de este compuesto es de 320 y su estructura química está representada en la Figura 4.106 con el número 1 [141]. Además, en la Figura 4.100 a), se muestra el cromatograma asociado a este compuesto, mientras que en la Figura 4.100 b) se muestra el espectro de masas asociado a ese pico. Se puede concluir que tras dos horas de degradación se alcanza la concentración máxima, y a partir de ese momento, va disminuyendo hasta alcanzar aproximadamente un tercio de esta concentración máxima, para dar otros compuestos diferentes de degradación. 

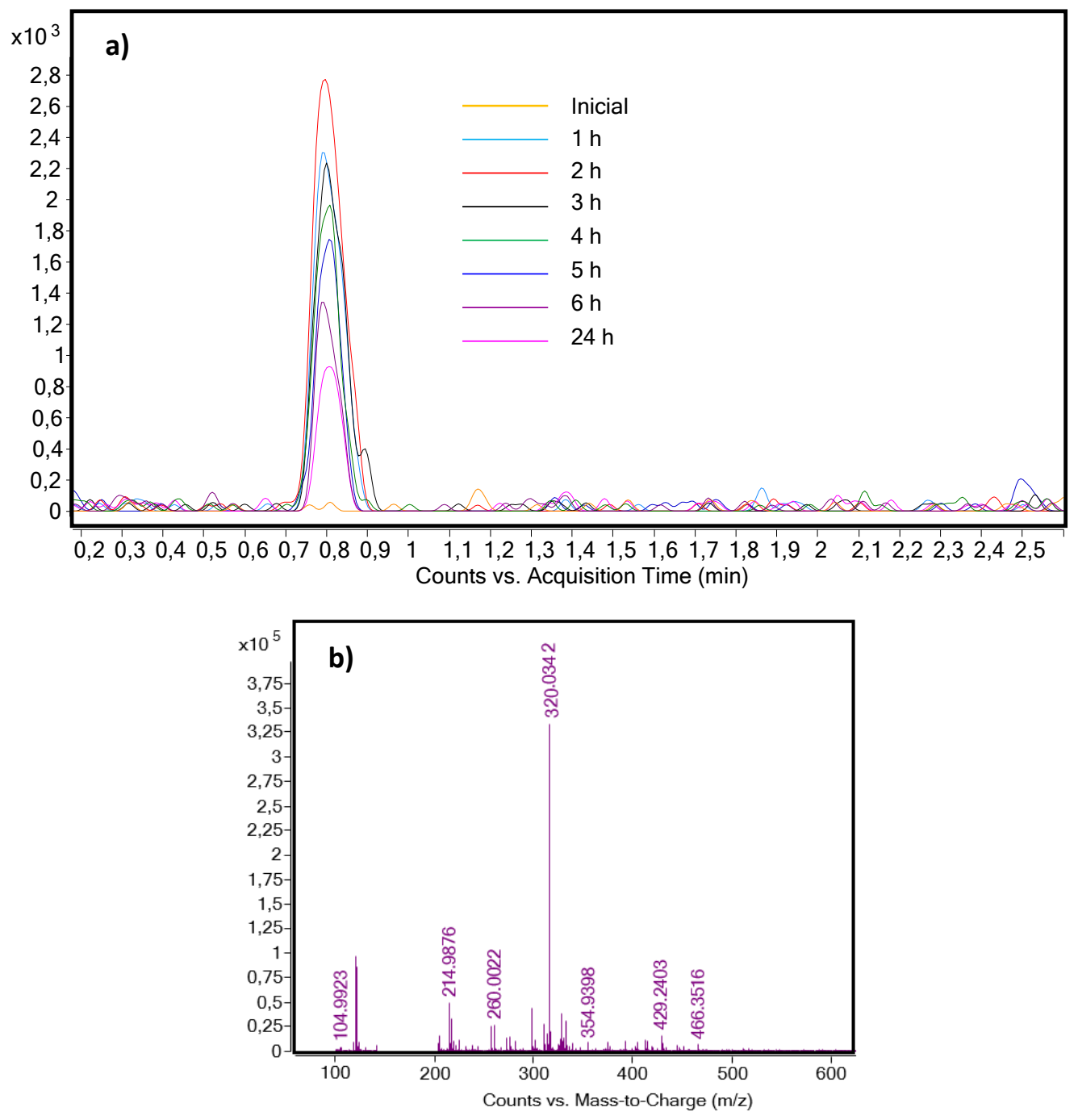

Figura 4.100. a) Cromatograma EIC del producto de degradación número 1 y b) espectro de masas del compuesto.

El segundo compuesto identificado ha sido el Fenamifos sulfona, el cual presenta dos dobles enlaces en el azufre con oxígeno. El valor de $\mathrm{m} / \mathrm{z}$ asociado a este intermedio es 336.1 y su estructura química está representada en la Figura 4.106 con el número 2 [134]. Analizando el cromatograma de la Figura 4.101, se puede observar que hasta las 2 horas de degradación no empieza a formarse este intermedio y alcanza su máximo de concentración tras 6 horas, momento a partir del cual se empieza a degradar para dar otros compuestos diferentes. 

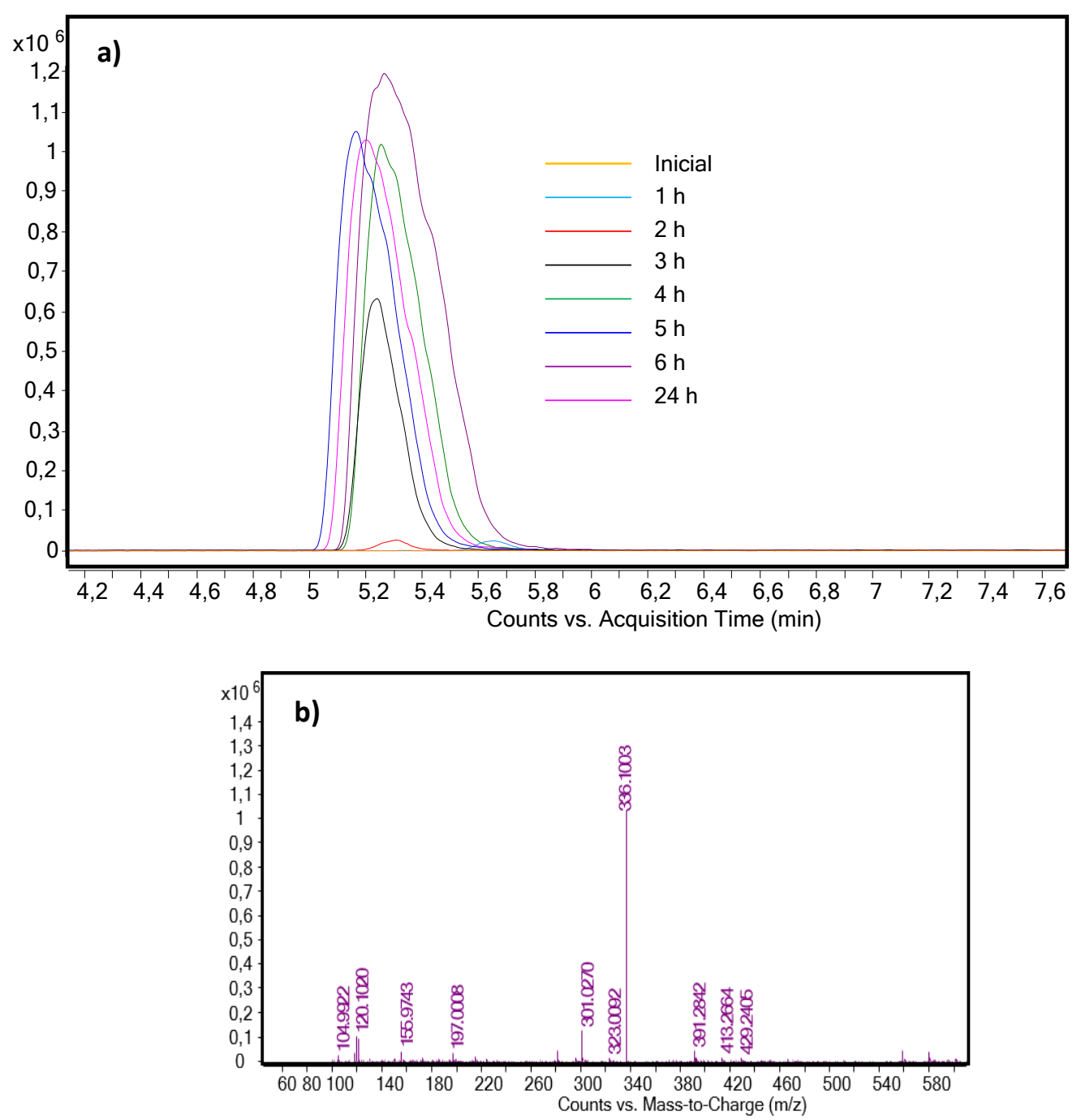

Figura 4.101. a) Cromatograma EIC del producto de degradación número 2 y b) espectro de masas del compuesto.

El tercer intermedio identificado ha sido el Fenamifos sulfóxido fenol. Este compuesto es el resultado de la rotura del fenamifos sulfóxido por el enlace P-O, siendo su valor de $\mathrm{m} / \mathrm{z}$ de 170.04 y su estructura química la representada en la Figura 4.106 con el número 3 [142]. Si se analiza el cromatograma EIC asociado a este compuesto y representado en la Figura 4.102, se puede ver como con el paso del tiempo su concentración va aumentando hasta alcanzar su máximo tras 24 horas. 

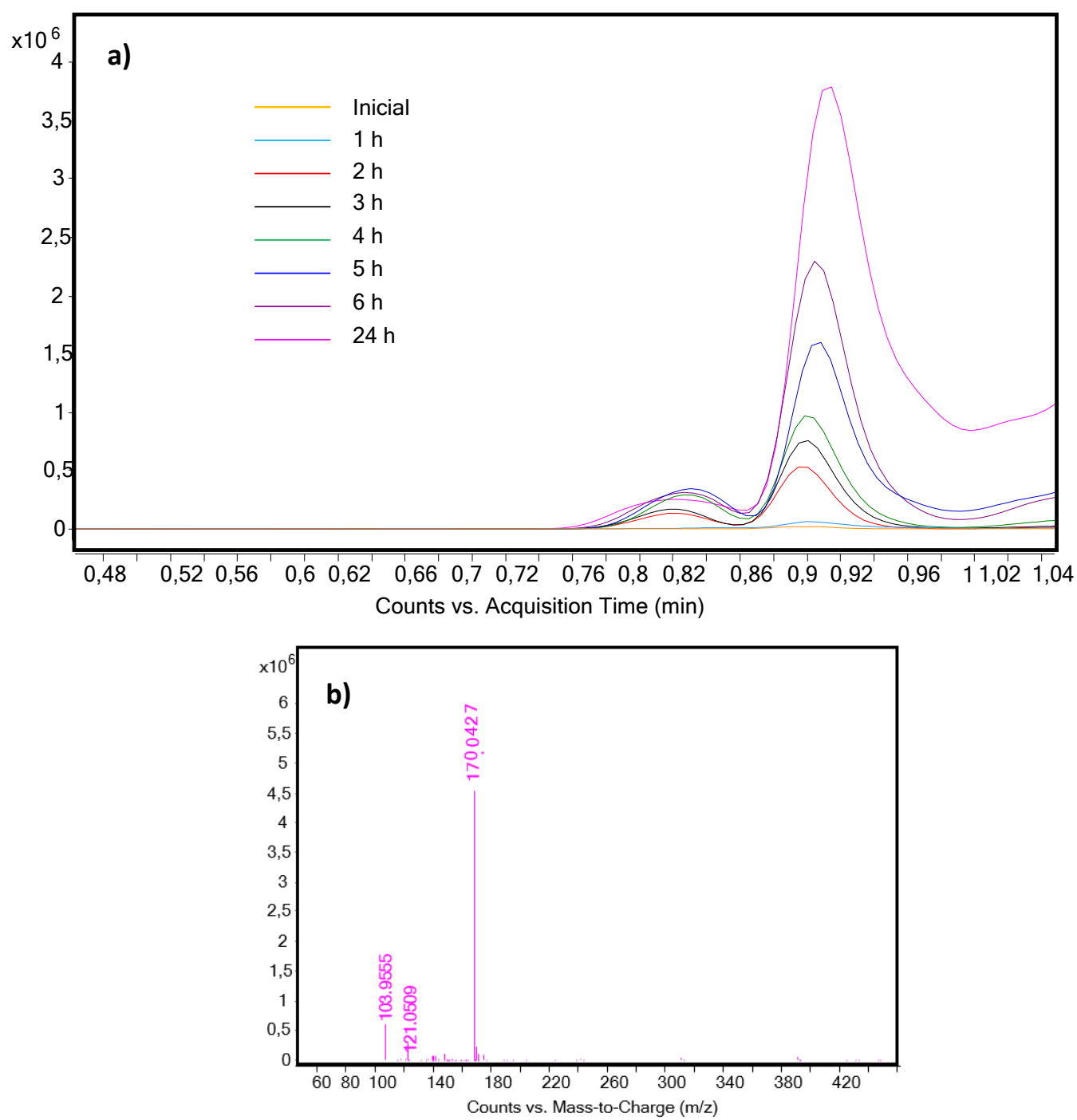

Figura 4.102. a) Cromatograma EIC del producto de degradación número 3 y b) espectro de masas del compuesto.

El cuarto pesticida identificado ha sido el Fenamifos sulfona fenol. Este compuesto es el producido debido a la rotura del enlace P-O del Fenamifos sulfona para dar como resultado un compuesto con solamente la parte del anillo aromático. Su valor de $\mathrm{m} / \mathrm{z}$ está representado en el espectro de masas de la Figura 4.103 y su estructura química en la Figura 4.106 con el número 4 [143]. Si se 
observa el cromatograma asociado a este compuesto se puede concluir que con el paso del tiempo su concentración va aumentando, lo mismo que ocurre con el intermedio anterior.

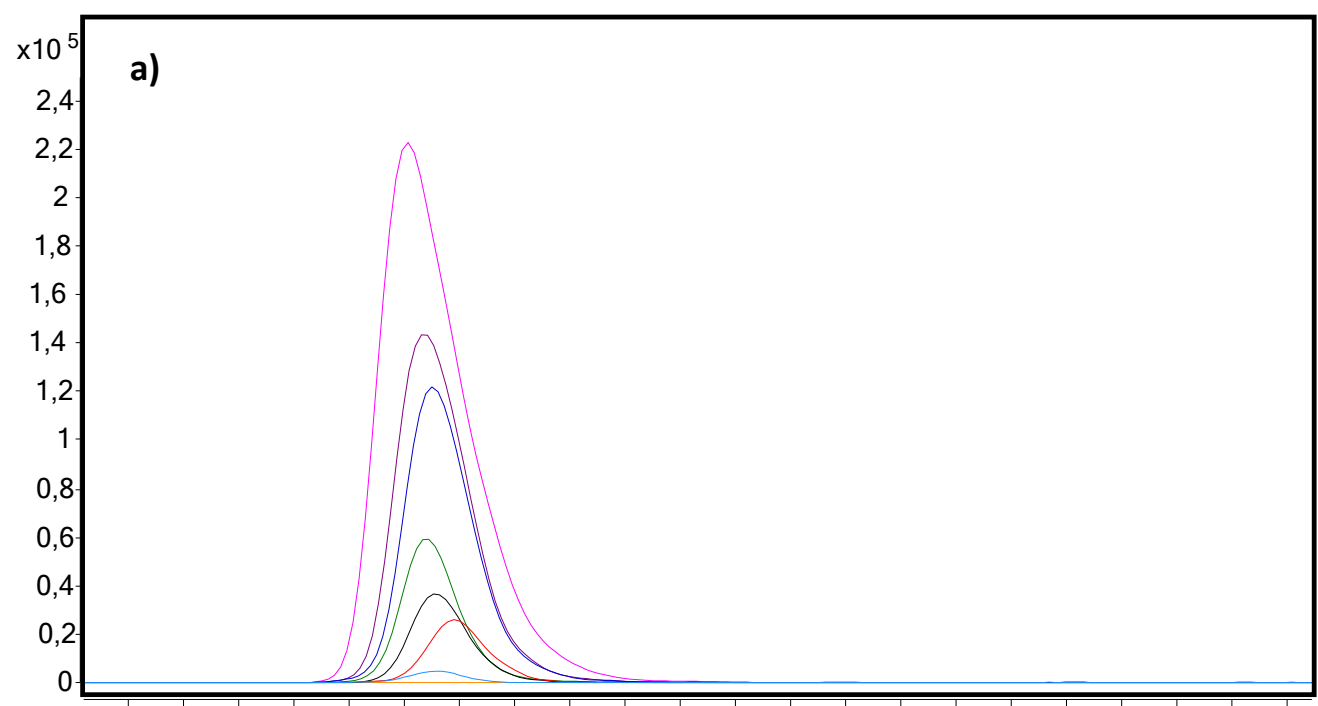

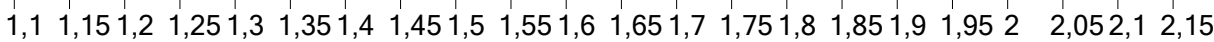
Counts vs. Acquisition Time (min)

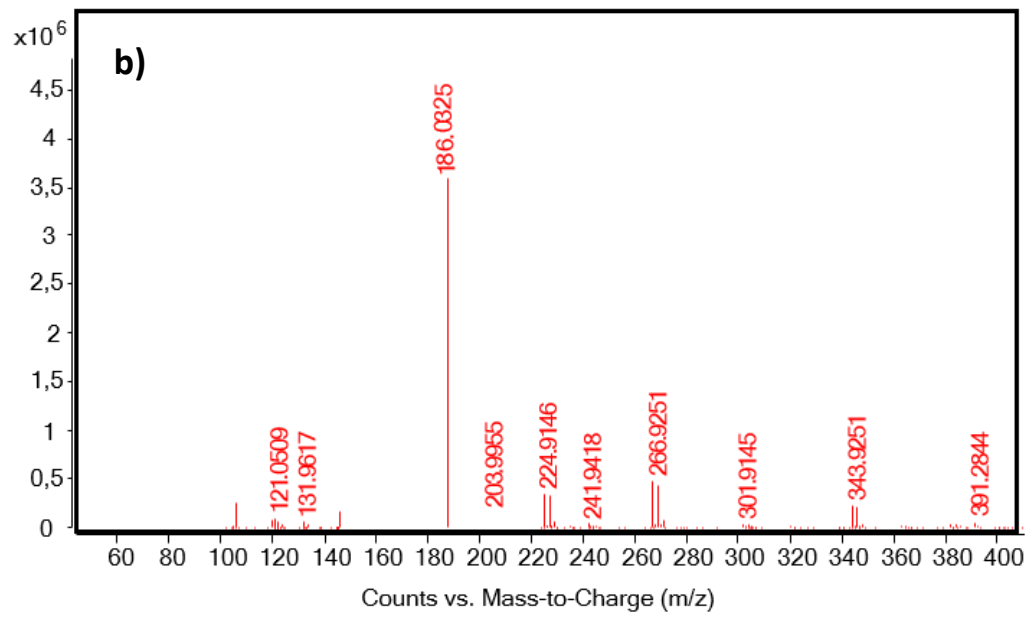

Figura 4.103. a) Cromatograma EIC del producto de degradación número 4 y b) espectro de masas del compuesto.

Finalmente, los últimos dos intermedios identificados han sido los representado en la Figura 4.106 con el número 5 (cuyo nombre es Ethyl hydrogen isopropyl 
phosphoramidate) y 6 (cuyo nombre es 4-methyl-5-(methylthio)benzene-1,2-diol), siendo su valor de $\mathrm{m} / \mathrm{z} 168.01$ y 171 respectivamente [144,145]. El cromatograma de ambos intermedios está representado en la Figura 4.104 y 4.105 respectivamente. Además, la concentración de ambos productos es menor que la de los intermedios anteriores ya que el orden del eje $Y$ del cromatograma es de $10^{3}$ mientras que el de los otros es de $10^{6}$. No obstante, ambos compuestos van aumentando su concentración con el paso del tiempo.
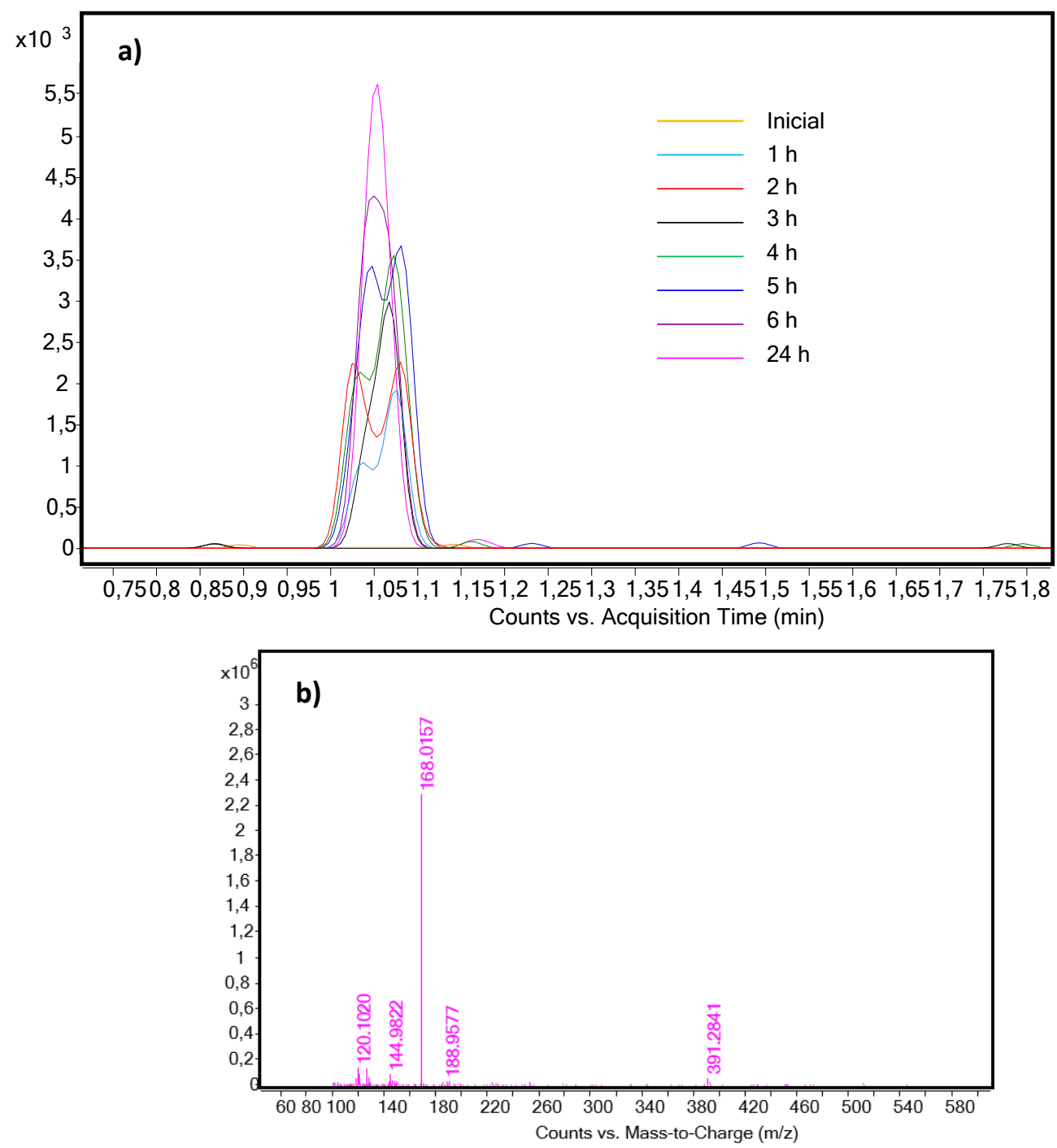

Figura 4.104. a) Cromatograma EIC del producto de degradación número 5 y b) espectro de masas del compuesto. 

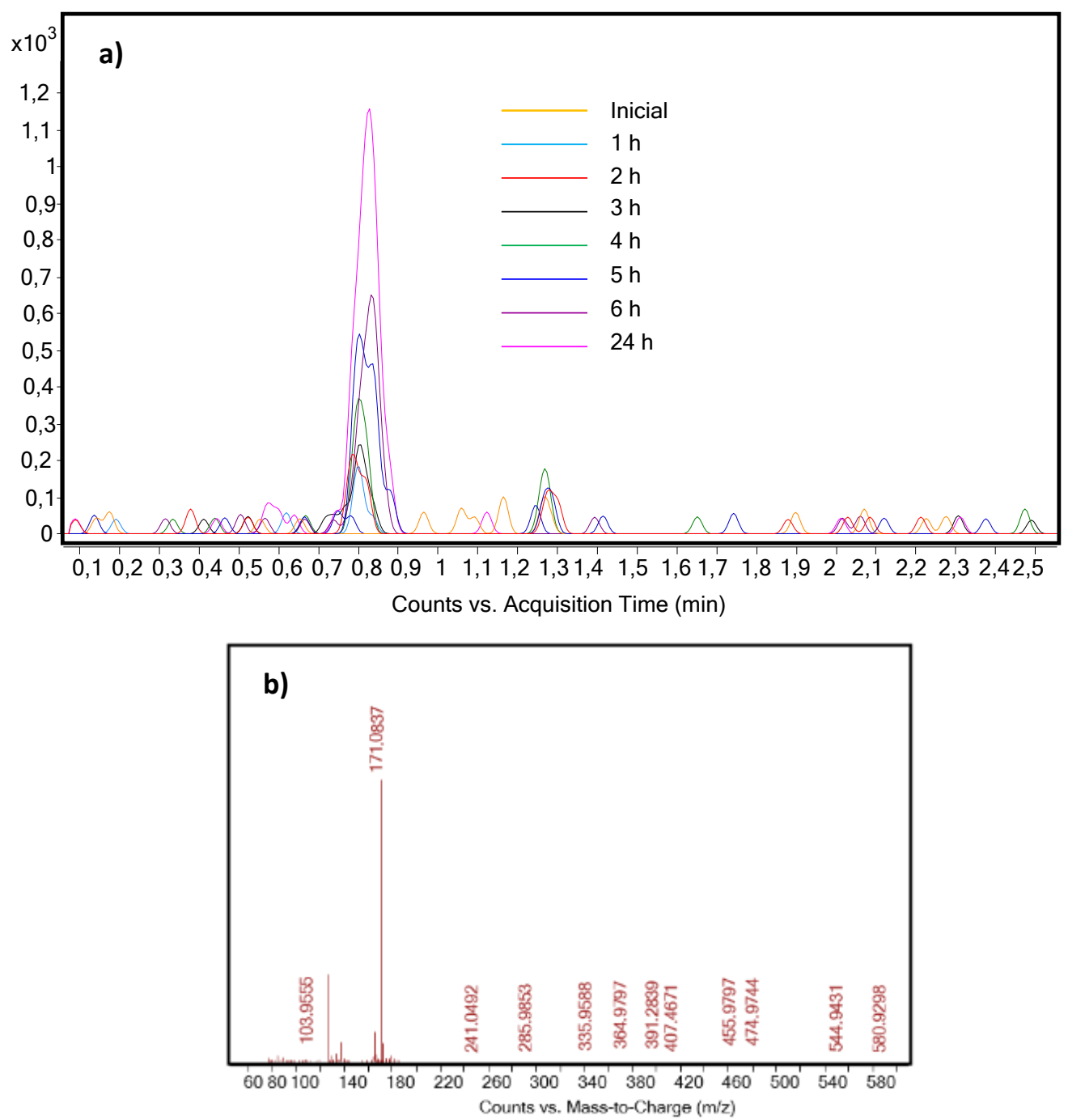

Figura 4.105. a) Cromatograma EIC del producto de degradación número 6 y b) espectro de masas del compuesto.

Finalmente, en la Figura 4.106 se muestra la ruta de degradación propuesta para el fenamifos después de analizar los datos obtenidos mediante UHPLC-MS. 

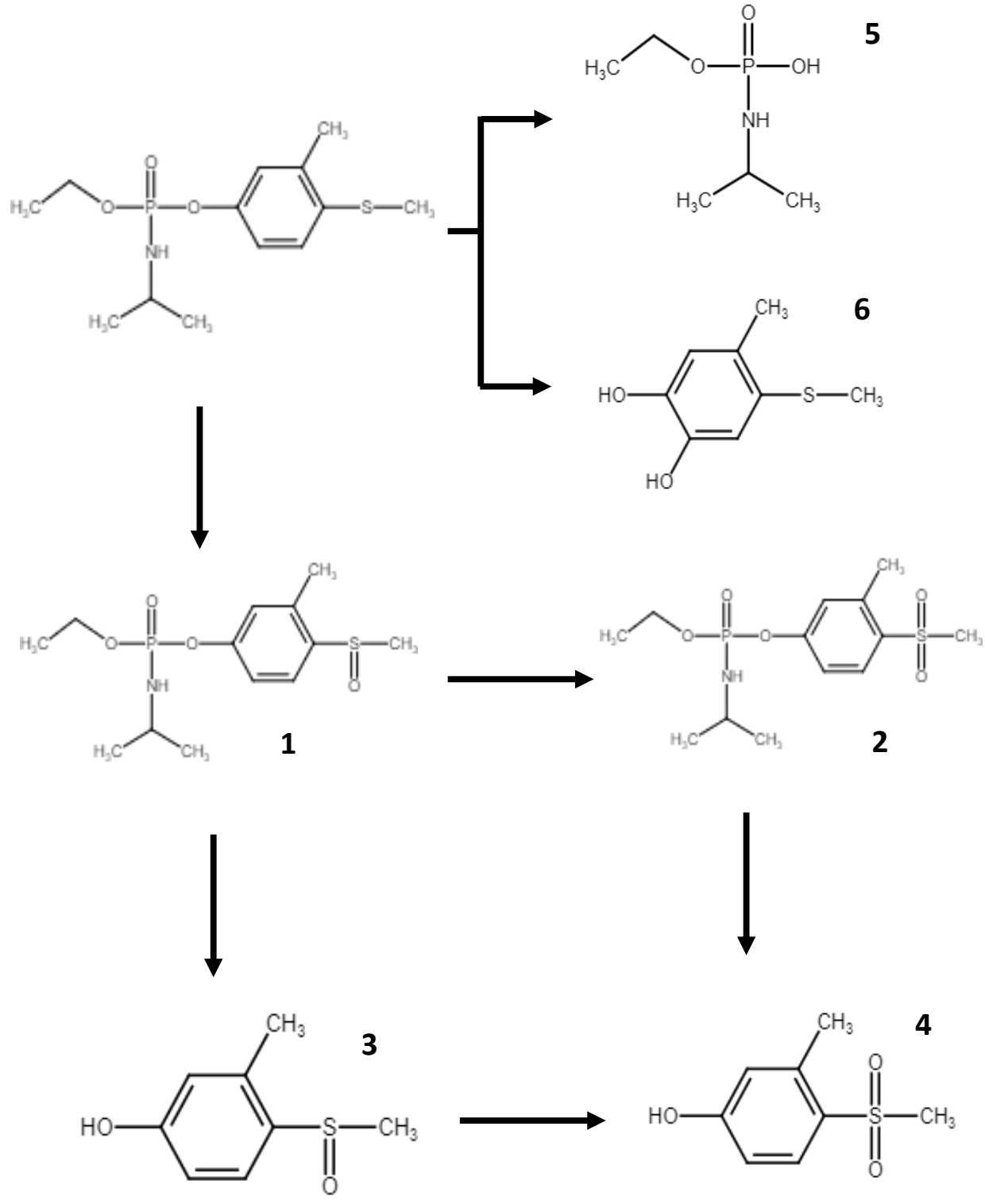

Figura 4.106. Ruta de degradación propuesta del fenamifos mediante PEC. 
Esta ruta tiene dos vías principales de degradación. La primera de ellas es la formación del compuesto Fenamifos sulfóxido para posteriormente degradarse y dar tanto Fenamifos sulfóxido fenol como Fenamifos sulfona. Una vez producidos estos compuestos intermedios se degradan para dar finalmente Fenamifos sulfona fenol.

La segunda ruta de degradación es la formada por la rotura de la molécula por el enlace P-O para dar dos moléculas diferentes, una de ellas que contiene el anillo aromático y la otra la que contiene el fosforo con el resto de oxígenos.

A modo de resumen, en la Tabla 4.24 se muestra la fórmula molecular, el tiempo de retención y el valor de $\mathrm{m} / \mathrm{z}$ de cada compuesto intermedio identificado.

Tabla 4.24. Tabla resumen de los compuestos intermedios identificados con su $\mathrm{m} / \mathrm{z}$ y tiempo de retención.

\begin{tabular}{|c|c|c|c|c|}
\hline $\begin{array}{l}\text { Número de } \\
\text { compuesto }\end{array}$ & Compuesto & $\begin{array}{l}\text { Formula } \\
\text { molecular }\end{array}$ & $\begin{array}{c}\text { Tiempo de } \\
\text { retención (s) }\end{array}$ & Valor $\mathrm{m} / \mathrm{z}$ \\
\hline 1 & Fenamifos sulfoxido & $\mathrm{C}_{13} \mathrm{H}_{22} \mathrm{NO}_{4} \mathrm{PS}$ & 0.8 & 302.025 \\
\hline 2 & Fenamifos sulfona & $\mathrm{C}_{13} \mathrm{H}_{22} \mathrm{NO}_{5} \mathrm{PS}$ & 5.3 & 336.10 \\
\hline 3 & $\begin{array}{l}\text { Fenamifos sulfoxido } \\
\text { fenol }\end{array}$ & $\mathrm{C}_{8} \mathrm{H}_{10} \mathrm{SO}_{2}$ & 0.92 & 170.04 \\
\hline 4 & $\begin{array}{l}\text { Fenamifos sulfona } \\
\text { fenol }\end{array}$ & $\mathrm{C}_{8} \mathrm{H}_{10} \mathrm{SO}_{3}$ & 1.4 & 186.03 \\
\hline 5 & $\begin{array}{l}\text { Ethyl hydrogen } \\
\text { isopropyl } \\
\text { phosphoramidate }\end{array}$ & $\mathrm{C}_{5} \mathrm{H}_{14} \mathrm{O}_{3} \mathrm{PN}$ & 1.05 & 168 \\
\hline 6 & $\begin{array}{c}\text { 4-methyl-5- } \\
\text { (methylthio)benzene- } \\
\text { 1,2-diol }\end{array}$ & $\mathrm{C}_{8} \mathrm{H}_{10} \mathrm{O}_{2} \mathrm{~S}$ & 0.85 & 171 \\
\hline
\end{tabular}


Una vez analizados todos los resultados obtenidos de la degradación fotoelectrocatalítica de los 4 pesticidas organofosforados, y comentados los mecanismos de degradación propuestos, se observa que tienen en común los siguientes aspectos:

- Los pesticidas que contienen azufre enlazado al fosforo sufren en primer lugar la oxidación de éste para ser sustituido por oxígenos. Este hecho se observa en el diazinón y en el fosmet.

- Una vez el fosforo está unido a oxígenos, el siguiente paso que ocurre en los cuatro pesticidas es la rotura de la molécula para dar, por una parte, el fósforo con sus cadenas alifáticas y por otra, el fragmento aromático con sus ramificaciones.

- Finalmente, la parte de los anillos aromáticos acaba degradándose en todos los casos para dar moléculas lineales más sencillas.

\section{Referencias.}

1. Sánchez Botero, L.M. Síntesis y caracterización de nanoestructuras porosas de aluminio anodizado, Trabajo Final de Máster, Facultad de Ciencias Exactas y Naturales, Universidad Nacional De Colombia, 2009.

2. De Tacconi, N.R.; Chenthamarakshan, C.R.; Yogeeswaran, G.; Watcharenwong, A.; De Zoysa, R.S.; Basit, N.A.; Rajeshwar, K. Nanoporous $\mathrm{TiO}_{2}$ and $\mathrm{WO}_{3}$ films by anodization of titanium and tungsten substrates: Influence of process variables on morphology and photoelectrochemical response. J. Phys. Chem. B 2006, 110, 25347-25355, doi:10.1021/jp064527v.

3. Fernández-Domene, R.M.; Sánchez-Tovar, R.; Lucas-Granados, B.; García-Antón, J. Improvement in photocatalytic activity of stable $\mathrm{WO}_{3}$ nanoplatelet globular clusters arranged in a tree-like fashion: Influence of rotation velocity during anodization. Appl. Catal. B Environ. 2016, 189, 266-282, doi:10.1016/j.apcatb.2016.02.065.

4. Fernández-Domene, R.M.; Sánchez-Tovar, R.; Lucas-Granados, B.; RosellóMárquez, G.; García-Antón, J. A simple method to fabricate high-performance nanostructured $\mathrm{WO}_{3}$ photocatalysts with adjusted morphology in the presence of complexing agents. Mater. Des. 2017, 116, 160-170, doi:10.1016/j.matdes.2016.12.016. 
5. Lord, H.L.; Zhan, W.; Pawliszyn, J. Fundamentals and applications of needle trap devices. Anal. Chim. Acta 2010, 677, 3-18, doi:10.1016/B978-0-12-3813732.00056-9.

6. Li, W.; Li, J.; Wang, X.; Luo, S.; Xiao, J.; Chen, Q. Visible light photoelectrochemical responsiveness of self-organized nanoporous $\mathrm{WO}_{3}$ films. Electrochim. Acta 2010, 56, 620-625, doi:10.1016/j.electacta.2010.06.025.

7. Lassner, E.; Schubert, W.-D. Properties, chemistry, technology of the element, alloys, and chemical compounds; Plenum, 1999; ISBN 0306450534.

8. Tsuchiya, H.; Macak, J.M.; Sieber, I.; Taveira, L.; Ghicov, A.; Sirotna, K.; Schmuki, P. Self-organized porous $\mathrm{WO}_{3}$ formed in NaF electrolytes. Electrochem. commun. 2005, 7, 295-298, doi:10.1016/j.elecom.2005.01.003.

9. Fernández-Domene, R.M.; Sánchez-Tovar, R.; Segura-Sanchís, E.; García-Antón, J. Novel tree-like $\mathrm{WO}_{3}$ nanoplatelets with very high surface area synthesized by anodization under controlled hydrodynamic conditions. Chem. Eng. J. 2016, 286, 59-67, doi:10.1016/j.cej.2015.10.069.

10. Widenkvist, E.; Quinlan, R.A.; Holloway, B.C.; Grennberg, H.; Jansson, U. Synthesis of nanostructured tungsten oxide thin films. Cryst. Growth Des. 2008, 8, 37503753, doi:10.1021/cg800383c.

11. Sánchez Martínez, D.; Torres Guerra, L.; Zarazúa Morín, M.; Gómez Solís, C. Influencia del método de síntesis sobre la morfología y propiedades fotocatalíticas del $\mathrm{WO}_{3}$. Cienc. UANL 2015, 18, 40-47.

12. Wang, C.K.; Lin, C.K.; Wu, C.L.; Wang, S.C.; Huang, J.L. Synthesis and characterization of electrochromic plate-like tungsten oxide films by acidic treatment of electrochemical anodized tungsten. Electrochim. Acta 2013, 112, 2431, doi:10.1016/j.electacta.2013.07.204.

13. Paola, A. Di; Quarto, F. Di; Sunseri, C. Anodic oxide films on tungsten-I. The influence of anodizing parameters on charging curves and film composition. Corros. Sci. 1980, 20, 1067-1078, doi:10.1016/0010-938X(80)90085-2.

14. Ng, C.; Ye, C.; Ng, Y.H.; Amal, R. Flower-shaped tungsten oxide with inorganic fullerene-like structure: Synthesis and characterization. Cryst. Growth Des. 2010, 10, 3794-3801, doi:10.1021/cg100625m.

15. Lai, C.W.; Sreekantan, S. Fabrication of $\mathrm{WO}_{3}$ nanostructures by anodization method for visible-light driven water splitting and photodegradation of methyl orange. Mater. Sci. Semicond. Process. 2013, 16, 303-310, doi:10.1016/j.mssp.2012.10.007.

16. Ng, C.J.W. Synthesis of tungsten oxide for solar energy conversion and water 
splitting applications. PhD Sch. Chem. Eng. Univ. New South Wales 2012, 5-10.

17. Dias, P.; Lopes, T.; Meda, L.; Andrade, L.; Mendes, A. Photoelectrochemical water splitting using $\mathrm{WO}_{3}$ photoanodes: The substrate and temperature roles. Phys. Chem. Chem. Phys. 2016, 18, 5232-5243, doi:10.1039/c5cp06851g.

18. Ou, J.Z.; Ahmad, M.Z.; Latham, K.; Kalantar-Zadeh, K.; Sberveglieri, G.; Wlodarski, $W$. Synthesis of the nanostructured $\mathrm{WO}_{3}$ via anodization at elevated temperature for $\mathrm{H} 2$ sensing applications. Procedia Eng. 2011, 25, 247-251, doi:10.1016/j.proeng.2011.12.061.

19. Wang, C.; Sun, R.; Li, X.; Sun, Y.; Sun, P.; Liu, F.; Lu, G. Hierarchical flower-like $\mathrm{WO}_{3}$ nanostructures and their gas sensing properties. Sensors Actuators, B Chem. 2014, 204, 224-230, doi:10.1016/j.snb.2014.07.083.

20. Sadek, A.; Zheng, H.; Breedon, M.; Bansal, V.; Bhargava, S.K.; Latham, K.; Zhu, J.; $\mathrm{Yu}$, L.; $\mathrm{Hu}, \mathrm{Z}$.; Spizzirri, P.G.; et al. High-temperature anodized $\mathrm{WO}_{3}$ nanoplatelet films for photosensitive devices. Langmuir 2009, 25, 9545-9551, doi:10.1021/la901944x.

21. Zeng, Q.; Li, J.; Bai, J.; Li, X.; Xia, L.; Zhou, B. Preparation of vertically aligned $\mathrm{WO}_{3}$ nanoplate array films based on peroxotungstate reduction reaction and their excellent photoelectrocatalytic performance. Appl. Catal. B Environ. 2017, 202, 388-396, doi:10.1016/j.apcatb.2016.09.045.

22. Eftekhari, A.; Babu, V.J.; Ramakrishna, S. Photoelectrode nanomaterials for photoelectrochemical water splitting. Int. J. Hydrogen Energy 2017, 42, 1107811109, doi:10.1016/j.ijhydene.2017.03.029.

23. Liu, Y.; Li, Y.; Li, W.; Han, S.; Liu, C. Photoelectrochemical properties and photocatalytic activity of nitrogen-doped nanoporous $\mathrm{WO}_{3}$ photoelectrodes under visible light. Appl. Surf. Sci. 2012, 258, 5038-5045, doi:10.1016/j.apsusc.2012.01.080.

24. Zhu, T.; Nan, M.; Wen, Y.; Chan, E. Electrochemically synthesized tungsten trioxide nanostructures for photoelectrochemical water splitting : Influence of heat treatment on physicochemical properties, photocurrent densities. Colloids Surfaces A Physicochem. Eng. Asp. 2015, 484, 297-303, doi:10.1016/j.colsurfa.2015.08.016.

25. Naseri, N. Photoresponse enhancing in nanostructured $\mathrm{WO}_{3}$ films by slight change in heating ambient. J. Alloys Compd. 2017, 693, 871-875, doi:10.1016/j.jallcom.2016.09.275.

26. Chai, Y.; Tam, C.W.; Beh, K.P.; Yam, F.K.; Hassan, Z. Effects of thermal treatment on the anodic growth of tungsten oxide films. Thin Solid Films 2015, 588, 44-49, doi:10.1016/j.tsf.2015.04.033. 
27. Hong, S.J.; Jun, H.; Borse, P.H.; Lee, J.S. Size effects of $\mathrm{WO}_{3}$ nanocrystals for photooxidation of water in particulate suspension and photoelectrochemical film systems. Int. J. Hydrogen Energy 2009, 34, 3234-3242, doi:10.1016/j.ijhydene.2009.02.006.

28. Ma, Z.; Linnenberg, O.; Rokicinska, A.; Kustrowski, P.; Slabon, A. Augmenting the photocurrent of $\mathrm{CuWO}_{4}$ photoanodes by heat treatment in the nitrogen atmosphere. J. Phys. Chem. C 2018, 122, 19281-19288, doi:10.1021/acs.jpcc.8b02828.

29. Syrek, K.; Zaraska, L.; Zych, M.; Sulka, G.D. The effect of anodization conditions on the morphology of porous tungsten oxide layers formed in aqueous solution. J. Electroanal. Chem. 2018, 829, 106-115, doi:10.1016/j.jelechem.2018.09.054.

30. Vemuri, R.S.; Noor-A-Alam, M.; Gullapalli, S.K.; Engelhard, M.H.; Ramana, C. V. Nitrogen-incorporation induced changes in the microstructure of nanocrystalline $\mathrm{WO}_{3}$ thin films. Thin Solid Films 2011, 520, 1446-1450, doi:10.1016/j.tsf.2011.08.080.

31. Fan, X.; Gao, B.; Wang, T.; Huang, X.; Gong, H.; Xue, H.; Guo, H.; Song, L.; Xia, W.; $\mathrm{He}$, J. Layered double hydroxide modified $\mathrm{WO}_{3}$ nanorod arrays for enhanced photoelectrochemical water splitting. Appl. Catal. A Gen. 2016, 528, 52-58, doi:10.1016/j.apcata.2016.09.014.

32. Pecquenard, B.; Lecacheux, H.; Livage, J.; Julien, C. Orthorhombic $\mathrm{WO}_{3}$ formed via a Ti-stabilized WO3.1/3H2O phase. J. Solid State Chem. 1998, 135, 159-168, doi:10.1006/jssc.1997.7618.

33. Bittencourt, C.; Landers, R.; Llobet, E.; Correig, X.; Calderer, J. The role of oxygen partial pressure and annealing temperature on the formation of $\mathrm{W}=\mathrm{O}$ bonds in thin $\mathrm{WO}_{3}$ films. Semicond. Sci. Technol. 2002, 17, 522-525, doi:10.1088/0268$1242 / 17 / 6 / 304$.

34. Ou, J.Z.; Rani, R.A.; Balendhran, S.; Zoolfakar, A.S.; Field, M.R.; Zhuiykov, S.; O'Mullane, A.P.; Kalantar-Zadeh, K. Anodic formation of a thick three-dimensional nanoporous $\mathrm{WO}_{3}$ film and its photocatalytic property. Electrochem. commun. 2013, 27, 128-132, doi:10.1016/j.elecom.2012.11.009.

35. Sánchez-Tovar, R.; Fernández-Domene, R.M.; García-García, D.M.; García-Antón, J. Enhancement of photoelectrochemical activity for water splitting by controlling hydrodynamic conditions on titanium anodization. J. Power Sources 2015, 286, 224-231, doi:10.1016/j.jpowsour.2015.03.174.

36. Souza-Filho, A.G.; Freire, V.N.; Sasaki, J.M.; Mendes Filho, J.; Julião, J.F.; Gomes, U.U. Coexistence of triclinic and monoclinic phases in $\mathrm{WO}_{3}$ ceramics. J. Raman Spectrosc. 2000, 31, 451-454, doi:10.1002/1097-4555(200006)31:6<451::AIDJRS528>3.0.CO;2-K. 
37. Santato, C.; Odziemkowski, M.; Ulmann, M.; Augustynski, J. Crystallographically oriented mesoporous $\mathrm{WO}_{3}$ films: Synthesis, characterization, and applications. J. Am. Chem. Soc. 2001, 123, 10639-10649, doi:10.1021/ja011315x.

38. Ha, J.H.; Muralidharan, P.; Kim, D.K. Hydrothermal synthesis and characterization of self-assembled $\mathrm{h}-\mathrm{WO}_{3}$ nanowires/nanorods using EDTA salts. J. Alloys Compd. 2009, 475, 446-451, doi:10.1016/j.jallcom.2008.07.048.

39. Amano, F.; Tian, M.; Ohtani, B.; Chen, A. Photoelectrochemical properties of tungsten trioxide thin film electrodes prepared from facet-controlled rectangular platelets. J. Solid State Electrochem. 2012, 16, 1965-1973, doi:10.1007/s10008011-1586-2.

40. Song, H.; Li, Y.; Lou, Z.; Xiao, M.; Hu, L.; Ye, Z.; Zhu, L. Synthesis of Fe-doped $\mathrm{WO}_{3}$ nanostructures with high visible-light-driven photocatalytic activities. Appl. Catal. B Environ. 2015, 166-167, 112-120, doi:10.1016/j.apcatb.2014.11.020.

41. Lee, S.H.; Cheong, H.M.; Tracy, C.E.; Mascarenhas, A.; Benson, D.K.; Deb, S.K. Raman spectroscopic studies of electrochromic a-WO $\mathrm{WO}_{3}$. Electrochim. Acta 1999, 44, 3111-3115, doi:10.1016/S0013-4686(99)00027-4.

42. Ex, C.; Juan, S.; Km, M.; Claudio, S.; Manuel, S.; Av, U. Obtaining of films of tungsten trioxide $\left(\mathrm{WO}_{3}\right)$ by resistive heating of a tungsten filament. Superf. y vacio 2008, 21, 12-17.

43. Muthu Karuppasamy, K.; Subrahmanyam, A. Results on the electrochromic and photocatalytic properties of vanadium doped tungsten oxide thin films prepared by reactive dc magnetron sputtering technique. J. Phys. D. Appl. Phys. 2008, 41, doi:10.1088/0022-3727/41/3/035302.

44. Ou, J.Z.; Yaacob, M.H.; Campbell, J.L.; Breedon, M.; Kalantar-Zadeh, K.; Wlodarski, W. $\mathrm{H}_{2}$ sensing performance of optical fiber coated with nano-platelet $\mathrm{WO}_{3}$ film. Sensors Actuators, B Chem. 2012, 166-167, 1-6, doi:10.1016/j.snb.2011.01.033.

45. A. Rougier, F. Portemer, A. Quede, M.E.M. Characterization of pulsed laser deposited $\mathrm{WO}_{3}$ thin films for electrochromic devices. Appl. Surf. Sci. 1999, 1-9.

46. Lu, Z.; Kanan, S.M.; Tripp, C.P. Synthesis of high surface area monoclinic $\mathrm{WO}_{3}$ particles using organic ligands and emulsion based methods. J. Mater. Chem. 2002, 12, 983-989, doi:10.1039/b107993j.

47. Boulova, M.; Lucazeau, G. Crystallite Nanosize Effect on the Structural Transitions of $\mathrm{WO}_{3}$ Studied by Raman Spectroscopy. J. Solid State Chem. 2002, 167, 425-434, doi:10.1006/jssc.2002.9649.

48. Kalantar-Zadeh, K.; Vijayaraghavan, A.; Ham, M.H.; Zheng, H.; Breedon, M.; Strano, M.S. Synthesis of atomically thin WO3 sheets from hydrated tungsten trioxide. 
Chem. Mater. 2010, 22, 5660-5666, doi:10.1021/cm1019603.

49. Hepel, M.; Hazelton, S. Photoelectrocatalytic degradation of diazo dyes on nanostructured $\mathrm{WO}_{3}$ electrodes. Electrochim. Acta 2005, 50, 5278-5291, doi:10.1016/j.electacta.2005.03.067.

50. Ponzoni, A.; Comini, E.; Ferroni, M.; Sberveglieri, G. Nanostructured $\mathrm{WO}_{3}$ deposited by modified thermal evaporation for gas-sensing applications. Thin Solid Films 2005, 490, 81-85, doi:10.1016/j.tsf.2005.04.031.

51. Badilescu, S.; Ashrit, P. V. Study of sol-gel prepared nanostructured $\mathrm{WO}_{3}$ thin films and composites for electrochromic applications. Solid State lonics 2003, 158, 187197, doi:10.1016/S0167-2738(02)00764-6.

52. Lethy, K.J.; Beena, D.; Vinod Kumar, R.; Mahadevan Pillai, V.P.; Ganesan, V.; Sathe, V. Structural, optical and morphological studies on laser ablated nanostructured $\mathrm{WO}_{3}$ thin films. Appl. Surf. Sci. 2008, 254, 2369-2376, doi:10.1016/j.apsusc.2007.09.068.

53. Hunge, Y.M.; Mahadik, M.A.; Kumbhar, S.S.; Mohite, V.S.; Rajpure, K.Y.; Deshpande, N.G.; Moholkar, A. V.; Bhosale, C.H. Visible light catalysis of methyl orange using nanostructured $\mathrm{WO}_{3}$ thin films. Ceram. Int. 2016, 42, 789-798, doi:10.1016/j.ceramint.2015.08.178.

54. Wolcott, A.; Kuykendall, T.R.; Chen, W.; Chen, S.; Zhang, J.Z. Synthesis and characterization of ultrathin $\mathrm{WO}_{3}$ nanodisks utilizing long-chain Poly(ethylene glycol). J. Phys. Chem. B 2006, 110, 25288-25296, doi:10.1021/jp064777b.

55. Mechler, Á.; Kopniczky, J.; Kokavecz, J.; Hoel, A.; Granqvist, C.G.; Heszler, P. Anomalies in nanostructure size measurements by AFM. Phys. Rev. B - Condens. Matter Mater. Phys. 2005, 72, 1-6, doi:10.1103/PhysRevB.72.125407.

56. Urbańczyk, M.; Maciak, E.; Gut, K.; Pustelny, T.; Jakubik, W. Layered thin film nanostructures of $\mathrm{Pd} / \mathrm{WO}_{3-\mathrm{x}}$ as resistance gas sensors. Bull. Polish Acad. Sci. Tech. Sci. 2011, 59, 401-407, doi:10.2478/v10175-011-0048-4.

57. Navío, C.; Vallejos, S.; Stoycheva, T.; Llobet, E.; Correig, X.; Snyders, R.; Blackman, C.; Umek, P.; Ke, X.; Van Tendeloo, G.; et al. Gold clusters on $\mathrm{WO}_{3}$ nanoneedles grown via AACVD: XPS and TEM studies. Mater. Chem. Phys. 2012, 134, 809-813, doi:10.1016/j.matchemphys.2012.03.073.

58. Shpak, A.P.; Korduban, A.M.; Medvedskij, M.M.; Kandyba, V.O. XPS studies of active elements surface of gas sensors based on $\mathrm{WO}_{3-\mathrm{x}}$ nanoparticles. J. Electron Spectros. Relat. Phenomena 2007, 156-158, 172-175, doi:10.1016/j.elspec.2006.12.059.

59. Wang, L.; Xu, X.; Wu, S.; Cao, F. Nonstoichiometric tungsten oxide residing in a 3D 
nitrogen doped carbon matrix, a composite photocatalyst for oxygen vacancy induced VOC degradation and $\mathrm{H}_{2}$ production. Catal. Sci. Technol. 2018, 8, 13661374, doi:10.1039/c7cy02572f.

60. Roselló-Márquez, G.; Fernández-Domene, R.M.; Sánchez-Tovar, R.; García-Antón, $\mathrm{J}$. Influence of annealing conditions on the photoelectrocatalytic performance of $\mathrm{WO}_{3}$ nanostructures. Sep. Purif. Technol. 2020, 238, 116417, doi:10.1016/j.seppur.2019.116417.

61. Bertoluzzi, L.; Bisquert, J. Equivalent circuit of electrons and holes in thin semiconductor films for photoelectrochemical water splitting applications. J. Phys. Chem. Lett. 2012, 3, 2517-2522, doi:10.1021/jz3010909.

62. Klahr, B.; Gimenez, S.; Fabregat-Santiago, F.; Hamann, T.; Bisquert, J. Water oxidation at hematite photoelectrodes: The role of surface states. J. Am. Chem. Soc. 2012, 134, 4294-4302, doi:10.1021/ja210755h.

63. Bertoluzzi, L.; Lopez-Varo, P.; Jiménez Tejada, J.A.; Bisquert, J. Charge transfer processes at the semiconductor/electrolyte interface for solar fuel production: Insight from impedance spectroscopy. J. Mater. Chem. A 2016, 4, 2873-2879, doi:10.1039/c5ta03210e.

64. Leng, W.H.; Zhang, Z.; Zhang, J.Q.; Cao, C.N. Investigation of the kinetics of a $\mathrm{TiO}_{2}$ photoelectrocatalytic reaction involving charge transfer and recombination through surface states by electrochemical impedance spectroscopy. J. Phys. Chem. B 2005, 109, 15008-15023, doi:10.1021/jp051821z.

65. Kim, Y.O.; Yu, S.H.; Ahn, K.S.; Lee, S.K.; Kang, S.H. Enhancing the photoresponse of electrodeposited $\mathrm{WO}_{3}$ film: Structure and thickness effect. J. Electroanal. Chem. 2015, 752, 25-32, doi:10.1016/j.jelechem.2015.05.031.

66. Mi, Q.; Coridan, R.H.; Brunschwig, B.S.; Gray, H.B.; Lewis, N.S. Photoelectrochemical oxidation of anions by $\mathrm{WO}_{3}$ in aqueous and nonaqueous electrolytes. Energy Environ. Sci. 2013, 6, 2646-2653, doi:10.1039/c3ee40712h.

67. Zhu, T.; Chong, M.N.; Phuan, Y.W.; Chan, E.S. Electrochemically synthesized tungsten trioxide nanostructures for photoelectrochemical water splitting: Influence of heat treatment on physicochemical properties, photocurrent densities and electron shuttling. Colloids Surfaces A Physicochem. Eng. Asp. 2015, 484, 297-303, doi:10.1016/j.colsurfa.2015.08.016.

68. Li, L.; Zhao, X.; Pan, D.; Li, G. Nanotube array-like $\mathrm{WO}_{3} / \mathrm{W}$ photoanode fabricated by electrochemical anodization for photoelectrocatalytic overall water splitting. Cuihua Xuebao/Chinese J. Catal. 2017, 38, 2132-2140, doi:10.1016/S18722067(17)62948-6.

69. Levinas, R.; Tsyntsaru, N.; Lelis, M.; Cesiulis, H. Synthesis, electrochemical 
impedance spectroscopy study and photoelectrochemical behaviour of asdeposited and annealed $\mathrm{WO}_{3}$ films. Electrochim. Acta 2017, 225, 29-38, doi:10.1016/j.electacta.2016.12.112.

70. Whitman, S.R.; Raja, K.S. Formation and electrochemical characterization of anodic $\mathrm{ZrO}_{2}-\mathrm{WO}_{3}$ mixed oxide nanotubular arrays. Appl. Surf. Sci. 2014, 303, 406418, doi:10.1016/j.apsusc.2014.03.016.

71. Cristino, V.; Caramori, S.; Argazzi, R.; Meda, L.; Marra, G.L.; Bignozzi, C.A. Efficient photoelectrochemical water splitting by anodically grown $\mathrm{WO}_{3}$ electrodes. Langmuir 2011, 27, 7276-7284, doi:10.1021/la200595x.

72. Brug, G.J.; van den Eeden, A.L.G.; Sluyters-Rehbach, M.; Sluyters, J.H. The analysis of electrode impedances complicated by the presence of a constant phase element. J. Electroanal. Chem. 1984, 176, 275-295, doi:10.1016/S00220728(84)80324-1.

73. Hirschorn, B.; Orazem, M.E.; Tribollet, B.; Vivier, V.; Frateur, I.; Musiani, M. Determination of effective capacitance and film thickness from constant-phaseelement parameters. Electrochim. Acta 2010, 55, 6218-6227, doi:10.1016/j.electacta.2009.10.065.

74. Prabhu, S.; Cindrella, L.; Kwon, O.J.; Mohanraju, K. Photoelectrochemical and photocatalytic activity of $\mathrm{TiO}_{2}-\mathrm{WO}_{3}$ heterostructures boosted by mutual interaction. Mater. Sci. Semicond. Process. 2018, 88, 10-19, doi:10.1016/j.mssp.2018.07.028.

75. Yang, J.; Li, W.; Li, J.; Sun, D.; Chen, Q. Hydrothermal synthesis and photoelectrochemical properties of vertically aligned tungsten trioxide (hydrate) plate-like arrays fabricated directly on FTO substrates. J. Mater. Chem. 2012, 22, 17744-17752, doi:10.1039/c2jm33199c.

76. Cristino, V.; Marinello, S.; Molinari, A.; Caramori, S.; Carli, S.; Boaretto, R.; Argazzi, R.; Meda, L.; Bignozzi, C.A. Some aspects of the charge transfer dynamics in nanostructured $\mathrm{WO}_{3}$ films. J. Mater. Chem. A 2016, 4, 2995-3006, doi:10.1039/c5ta06887h.

77. Bonham, D.B. A Mathematical Model for the Influence of Deep-Level Electronic States on Photoelectrochemical Impedance Spectroscopy. J. Electrochem. Soc. 1992, 139, 127-137, doi:10.1149/1.2069156.

78. Yagi, M.; Maruyama, S.; Sone, K.; Nagai, K.; Norimatsu, T. Preparation and photoelectrocatalytic activity of a nano-structured $\mathrm{WO}_{3}$ platelet film. J. Solid State Chem. 2008, 181, 175-182, doi:10.1016/j.jssc.2007.11.018.

79. Weinhardt, L.; Blum, M.; Bär, M.; Heske, C.; Cole, B.; Marsen, B.; Miller, E.L. Electronic surface level positions of $\mathrm{WO}_{3}$ thin films for photoelectrochemical 
hydrogen production. J. Phys. Chem. C 2008, 112, 3078-3082, doi:10.1021/jp7100286.

80. Bonham, D.B. A Mathematical Model for the Influence of Deep-Level Electronic States on Photoelectrochemical Impedance Spectroscopy. J. Electrochem. Soc. 1992, 139, 127, doi:10.1149/1.2069156.

81. Siuzdak, K.; Szkoda, M.; Sawczak, M.; Lisowska-Oleksiak, A.; Karczewski, J.; Ryl, J. Enhanced photoelectrochemical and photocatalytic performance of iodine-doped titania nanotube arrays. RSC Adv. 2015, 5, 50379-50391, doi:10.1039/c5ra08407e.

82. Liu, Y.; Li, Y.; Li, W.; Han, S.; Liu, C. Applied Surface Science Photoelectrochemical properties and photocatalytic activity of nitrogen-doped nanoporous $\mathrm{WO}_{3}$ photoelectrodes under visible light. 2012, 258, 5038-5045, doi:10.1016/j.apsusc.2012.01.080.

83. Ahmadi, E.; Yan, C.; Abdul, K.; Lockman, Z. Preparation of anodic nanoporous $\mathrm{WO}_{3}$ film using oxalic acid as electrolyte. J. Alloys Compd. 2017, 704, 518-527, doi:10.1016/j.jallcom.2017.02.123.

84. Li, W.; Li, J.; Wang, X.; Ma, J.; Chen, Q. Photoelectrochemical and physical properties of $\mathrm{WO}_{3}$ films obtained by the polymeric precursor method. Int. J. Hydrogen Energy 2010, 35, 13137-13145, doi:10.1016/j.ijhydene.2010.09.011.

85. Krishnan Rajeshwar Fundamentals of Semiconductor Electrochemistry and Photoelectrochemistry. Encycl. Electrochem. 2002, doi:10.1002/9783527610426.bard060001.

86. Li, W.; Da, P.; Zhang, Y.; Wang, Y.; Lin, X.; Gong, X.; Zheng, G. WO $\mathrm{W}_{3}$ nanoflakes for enhanced photoelectrochemical conversion. ACS Nano 2014, 8, 11770-11777, doi:10.1021/nn5053684.

87. Hill, M.D.; Egdell, R.G.; Henrich, V.E.; Campagnoli, G.; Gustinetti, A. Bulk and surface electron states in $\mathrm{WO}_{3}$ and tungsten bronzes. 1983.

88. Zheng, H.; Ou, J.Z.; Strano, M.S.; Kaner, R.B.; Mitchell, A.; Kalantar-Zadeh, K. Nanostructured tungsten oxide - Properties, synthesis, and applications. Adv. Funct. Mater. 2011, 21, 2175-2196, doi:10.1002/adfm.201002477.

89. Zhu, J.; Li, W.; Li, J.; Li, Y.; Hu, H.; Yang, Y. Photoelectrochemical activity of $\mathrm{NiWO}_{4}$ $/ \mathrm{WO}_{3}$ heterojunction photoanode under visible light irradiation. Electrochim. Acta 2013, 112, 191-198, doi:10.1016/j.electacta.2013.08.146.

90. Irie, H.; Watanabe, Y.; Hashimoto, K. Nitrogen-concentration dependence on photocatalytic activity of $\mathrm{TiO}_{2}$-xNx powders. J. Phys. Chem. B 2003, 107, 54835486, doi:10.1021/jp030133h.

91. Uosaki, K. Effects of the Helmholtz Layer Capacitance on the Potential Distribution 
at Semiconductor/Electrolyte Interface and the Linearity of the Mott-Schottky Plot. J. Electrochem. Soc. 1983, 130, 895-897, doi:10.1149/1.2119853.

92. Bockris, J.O.M.; Uosaki, K.; Kita, H. Interfacial electron transfer as a significant step in photoelectrochemical reactions on some semiconductors. J. Appl. Phys. 1981, 52, 808-810, doi:10.1063/1.328847.

93. Roselló-Márquez, G.; Fernández-Domene, R.M.; Sánchez-Tovar, R.; García-Antón, $\mathrm{J}$. Influence of annealing conditions on the photoelectrocatalytic performance of $\mathrm{WO}_{3}$ nanostructures. Sep. Purif. Technol. 2020, 238, 116417, doi:10.1016/j.seppur.2019.116417.

94. Beranek, R. (Photo)electrochemical methods for the determination of the band edge positions of $\mathrm{TiO}_{2}$-based nanomaterials. Adv. Phys. Chem. 2011, 2011, 80-83, doi:10.1155/2011/786759.

95. Fernández-Domene, R.M.; Blasco-Tamarit, E.; García-García, D.M.; García-Antón, J. Passive and transpassive behaviour of Alloy 31 in a heavy brine $\mathrm{LiBr}$ solution. Electrochim. Acta 2013, 95, 1-11, doi:10.1016/j.electacta.2013.02.024.

96. Wang, D.; Zhang, X.; Sun, P.; Lu, S.; Wang, L.; Wang, C.; Liu, Y. Photoelectrochemical water splitting with rutile $\mathrm{TiO}_{2}$ nanowires array: Synergistic effect of hydrogen treatment and surface modification with anatase nanoparticles. Electrochim. Acta 2014, 130, 290-295, doi:10.1016/j.electacta.2014.03.024.

97. Wang, G.; Ling, Y.; Wang, H.; Yang, X.; Wang, C.; Zhang, J.Z.; Li, Y. Hydrogentreated $\mathrm{WO}_{3}$ nanoflakes show enhanced photostability. Energy Environ. Sci. 2012, 5, 6180-6187, doi:10.1039/c2ee03158b.

98. Montgomery, D.C. Design and Analysis of Experiments Eighth Edition; 2012; Vol. 2; ISBN 9781118146927.

99. Cordero García, A. Eficiencia fotocatalítica solar del $\mathrm{WO}_{3} / \mathrm{TIO}_{2-\mathrm{a}}(\mathrm{a}=\mathrm{n}, \mathrm{c})$ en la degradación de diclofenaco en medio acuoso., Universitat de les Illes Balears, 2018.

100. Gutiérrez Pulido, Humberto; de la Vara Salazar, R. Análisis y diseño de experimentos; McGrawHill, 2008; ISBN 9789701065266.

101. Kuehl, R.O. Design of Experiments: Statistical Principles of Research Design and Analysis; 2001; Vol. 43; ISBN 0534368344.

102. Singla, J. Studies on the photoelectrocatalysis induced degradation of pharmaceutical drug using fabricated $\mathrm{TiO}_{2}$ electrode., School of Energy and Environment Thapar University.

103. Tajeddine, L.; Nemmaoui, M.; Mountacer, H.; Dahchour, A.; Sarakha, M. Photodegradation of fenamiphos on the surface of clays and soils. Environ. Chem. 
Lett. 2010, 8, 123-128, doi:10.1007/s10311-008-0198-2.

104. Shemer, H.; Linden, K.G. Degradation and by-product formation of diazinón in water during UV and UV/ $\mathrm{H}_{2} \mathrm{O}_{2}$ treatment. J. Hazard. Mater. 2006, 136, 553-559, doi:10.1016/j.jhazmat.2005.12.028.

105. Churchill, D.; Dust, J.M.; Buncel, E. Concerted rate-limiting proton transfer to sulfur with nucleophilic attack at phosphorus - A new proposed mechanism for hydrolytic decomposition of the $\mathrm{P}=\mathrm{S}$ pesticide, Diazinón, in moderately acidic sulfuric acid media. Can. J. Chem. 2007, 85, 421-431, doi:10.1139/V07-049.

106. Bavcon, M.; Trebše, P.; Zupančič-Kralj, L. Investigations of the determination and transformations of diazinón and malathion under environmental conditions using gas chromatography coupled with a flame ionisation detector. Chemosphere 2003, 50, 595-601, doi:10.1016/S0045-6535(02)00643-4.

107. Mahdavi, V.; Hamidi, H.; Es-haghi, A.; Ghassempour, A. Elucidation of diazinón metabolites in rice plants by liquid chromatography ion-trap mass spectrometry. Int. J. Environ. Anal. Chem. 2018, 98, 1342-1351, doi:10.1080/03067319.2018.1554102.

108. Perez-Lainez, M.D.; Corona-Torres, T.; Del Rosario Garcia-Mateos, M.; Winkler, R.; Barrientos-Priego, A.F.; Nieto-Angel, R.; Aguilar-Rincon, V.H.; Garcia-Velazquez, J.A. Metabolomic study of volatile compounds in the pigmented fruit from Mexico crataegus genotypes. J. Appl. Bot. Food Qual. 2019, 92, 15-23, doi:10.5073/JABFQ.2019.092.003.

109. Kouloumbos, V.N.; Tsipi, D.F.; Hiskia, A.E.; Nikolic, D.; Van Breemen, R.B. Identification of photocatalytic degradation products of diazinón in $\mathrm{TiO}_{2}$ aqueous suspensions using GC/MS/MS and LC/MS with quadrupole time-of-flight mass spectrometry. J. Am. Soc. Mass Spectrom. 2003, 14, 803-817, doi:10.1016/S10440305(03)00333-7.

110. Um, I.H.; Chun, S.M.; Bae, S.K. Effect of changing electrophilic center from carbonyl to sulfonyl group on electrophilicity. Bull. Korean Chem. Soc. 2005, 26, 457-460, doi:10.5012/bkcs.2005.26.3.457.

111. Mitsika, E.E.; Christophoridis, C.; Fytianos, K. Fenton and Fenton-like oxidation of pesticide acetamiprid in water samples: Kinetic study of the degradation and optimization using response surface methodology. Chemosphere 2013, 93, 18181825, doi:10.1016/j.chemosphere.2013.06.033.

112. Chelme-Ayala, P.; El-Din, M.G.; Smith, D.W. Kinetics and mechanism of the degradation of two pesticides in aqueous solutions by ozonation. Chemosphere 2010, 78, 557-562, doi:10.1016/j.chemosphere.2009.11.014.

113. Díaz, R.; Ibáñez, M.; Sancho, J. V.; Hernández, F. Target and non-target screening 
strategies for organic contaminants, residues and illicit substances in food, environmental and human biological samples by UHPLC-QTOF-MS. Anal. Methods 2012, 4, 196-209, doi:10.1039/c1ay05385j.

114. Maldonado, M.I.; Malato, S.; Pérez-Estrada, L.A.; Gernjak, W.; Oller, I.; Doménech, X.; Peral, J. Partial degradation of five pesticides and an industrial pollutant by ozonation in a pilot-plant scale reactor. J. Hazard. Mater. 2006, 138, 363-369, doi:10.1016/j.jhazmat.2006.05.058.

115. Ibáñez, M.; Sancho, J. V.; Pozo, Ó.J.; Hernández, F. Use of liquid chromatography quadrupole time-of-flight mass spectrometry in the elucidation of transformation products and metabolites of pesticides. Diazinón as a case study. Anal. Bioanal. Chem. 2006, 384, 448-457, doi:10.1007/s00216-005-0167-6.

116. Sogorb, M.A.; Monroy-Noyola, A.; Vilanova, E. The importance of stereospecific hydrolysis in the risk assessment of phosphoramidate insecticides. Rev. Toxicol. 2002, 19, 61-67.

117. Robles-Molina, J.; Lara-Ortega, F.J.; Gilbert-López, B.; García-Reyes, J.F.; MolinaDíaz, A. Multi-residue method for the determination of over 400 priority and emerging pollutants in water and wastewater by solid-phase extraction and liquid chromatography-time-of-flight mass spectrometry. J. Chromatogr. A 2014, 1350, 30-43, doi:10.1016/j.chroma.2014.05.003.

118. Masiá, A.; Ibáñez, M.; Blasco, C.; Sancho, J. V.; Picó, Y.; Hernández, F. Combined use of liquid chromatography triple quadrupole mass spectrometry and liquid chromatography quadrupole time-of-flight mass spectrometry in systematic screening of pesticides and other contaminants in water samples. Anal. Chim. Acta 2013, 761, 117-127, doi:10.1016/j.aca.2012.11.032.

119. Pérez-Ortega, P.; Lara-Ortega, F.J.; García-Reyes, J.F.; Beneito-Cambra, M.; GilbertLópez, B.; Martos, N.R.; Molina-Díaz, A. Determination of Over 350 Multiclass Pesticides in Jams by Ultra-High Performance Liquid Chromatography Time-ofFlight Mass Spectrometry (UHPLC-TOFMS). Food Anal. Methods 2016, 9, 19391957, doi:10.1007/s12161-015-0369-2.

120. Nikolaus Klamerth, Wolfgang Gernjak, Sixto Malatob, Ana Aguera, B.L. PhotoFenton decomposition of chlorfenvinphos: Determination of reaction pathway. Water Res. 2009, 43, 441-449.

121. Portóles, T.; Ibáñez, M.; Sancho, J. V.; López, F.J.; Hernández, F. Combined use of GC-TOF MS and UHPLC-(Q)TOF MS to investigate the presence of nontarget pollutants and their metabolites in a case of honeybee poisoning. J. Agric. Food Chem. 2009, 57, 4079-4090, doi:10.1021/jf900099u.

122. Luan, J.; Ma, K.; Wang, S.; Hu, Z.; Li, Y.; Pan, B. Research on Photocatalytic Degradation Pathway and Degradation Mechanisms of Organics. Curr. Org. Chem. 
2010, 14, 645-682, doi:10.2174/138527210790963403.

123. Oniszczuk, A.; Widelska, G.; Wójtowicz, A.; Oniszczuk, T.; Wojtunik-Kulesza, K.; Dib, A.; Matwijczuk, A. Content of phenolic compounds and antioxidant activity of new gluten-free pasta with the addition of chestnut flour. Molecules 2019, 24, doi:10.3390/molecules24142623.

124. Couchman, L.; Slaughter, J.A.; Coombes, G.; Johnston, A.; Ogoti, E.; Holt, D.W. The Smell of Death: An Unusual Case of Poisoning with the Organophosphorus Pesticide Chlorfenvinphos. Ther. Drug Monit. 2019, 41, 250-252, doi:10.1097/FTD.0000000000000584.

125. Grüschow, S.; Buchholz, T.J.; Seufert, W.; Dordick, J.S.; Sherman, D.H. Substrate Profile Analysis and ACP-Mediated Acyl Transfer in Streptomyces coelicolor Type III PKS Supporting Information. 2007.

126. Hollosi, L.; Bromirski, M.; Godula, M. Pesticide residues screening analysis in tea and honey using a Q Exactive Focus High-Resolution Mass Spectrometer Authors.

127. Kraft, V.; Weber, W.; Streipert, B.; Wagner, R.; Schultz, C.; Winter, M.; Nowak, S. Qualitative and quantitative investigation of organophosphates in an electrochemically and thermally treated lithium hexafluorophosphate-based lithium ion battery electrolyte by a developed liquid chromatography-tandem quadrupole mass spectrometry method. RSC Adv. 2015, 6, 8-17, doi:10.1039/c5ra23624j.

128. Bojanowska-Czajka, A.; Gałęzowska, A.; Marty, J.L.; Trojanowicz, M. Decomposition of pesticide chlorfenvinphos in aqueous solutions by gammairradiation. J. Radioanal. Nucl. Chem. 2010, 285, 215-221, doi:10.1007/s10967010-0567-8.

129. Sogorb, M.A.; Monroy-Noyola, A.; Vilanova, E. Importancia de la hidrolisis estereoespecifica en la evaluacion de riesgos toxicos de insecticidas fosforamidatos. Rev. Toxicol. 2002, 19, 61-67.

130. Fernández-Domene, R.M.; Sánchez-Tovar, R.; Lucas-Granados, B.; Muñoz-Portero, M.J.; García-Antón, J. Elimination of pesticide atrazine by photoelectrocatalysis using a photoanode based on $\mathrm{WO}_{3}$ nanosheets. Chem. Eng. J. 2018, 350, 11141124, doi:10.1016/j.cej.2018.06.015.

131. Rajski, Ł.; Lozano, A.; Uclés, A.; Ferrer, C.; Fernández-Alba, A.R. Determination of pesticide residues in high oil vegetal commodities by using various multi-residue methods and clean-ups followed by liquid chromatography tandem mass spectrometry. J. Chromatogr. A 2013, 1304, 109-120, doi:10.1016/j.chroma.2013.06.070.

132. Vázquez, P.P.; Lozano, A.; Uclés, S.; Ramos, M.M.G.; Fernández-Alba, A.R. A 
sensitive and efficient method for routine pesticide multiresidue analysis in bee pollen samples using gas and liquid chromatography coupled to tandem mass spectrometry. J. Chromatogr. A 2015, 1426, 161-173, doi:10.1016/j.chroma.2015.11.081.

133. Dias, J. V.; Cutillas, V.; Lozano, A.; Pizzutti, I.R.; Fernández-Alba, A.R. Determination of pesticides in edible oils by liquid chromatography-tandem mass spectrometry employing new generation materials for dispersive solid phase extraction cleanup. J. Chromatogr. A 2016, 1462, 8-18, doi:10.1016/j.chroma.2016.07.072.

134. He, Z.; Xu, Y.; Wang, L.; Peng, Y.; Luo, M.; Cheng, H.; Liu, X. Wide-scope screening and quantification of 50 pesticides in wine by liquid chromatography/quadrupole time-of-flight mass spectrometry combined with liquid chromatography/quadrupole linear ion trap mass spectrometry. Food Chem. 2016, 196, 1248-1255, doi:10.1016/j.foodchem.2015.10.042.

135. Arsand, J.B.; Hoff, R.B.; Jank, L.; Dallegrave, A.; Galeazzi, C.; Barreto, F.; Pizzolato, T.M. Wide-Scope Determination of Pharmaceuticals and Pesticides in Water Samples: Qualitative and Confirmatory Screening Method Using LC-qTOF-MS. Water. Air. Soil Pollut. 2018, 229, doi:10.1007/s11270-018-4036-2.

136. Fillâtre, Y.; Gray, F.X.; Roy, C. Pesticides in essential oils: Occurrence and concentration in organic and conventional orange essential oils from eleven geographical origins. Anal. Chim. Acta 2017, 992, 55-66, doi:10.1016/j.aca.2017.08.039.

137. Rahman, A.J.; Sharma, D.; Kumar, D.; Pathak, M.; Singh, A.; Kumar, V.; Chawla, R.; Ojha, H. Spectroscopic and molecular modelling study of binding mechanism of bovine serum albumin with phosmet. Spectrochim. Acta-Part A Mol. Biomol. Spectrosc. 2021, 244, 118803, doi:10.1016/j.saa.2020.118803.

138. Hernández, F.; Grimalt, S.; Pozo, Ó.J.; Sancho, J. V. Use of ultra-high-pressure liquid chromatography-quadrupole time-of-flight MS to discover the presence of pesticide metabolites in food samples. J. Sep. Sci. 2009, 32, 2245-2261, doi:10.1002/jssc.200900093.

139. Roselló-Márquez, G.; Fernández-Domene, R.M.; Sánchez-Tovar, R.; García-Antón, J. Photoelectrocatalyzed degradation of organophosphorus pesticide fenamiphos using $\mathrm{WO}_{3}$ nanorods as photoanode. Chemosphere 2020, 246, 1-9, doi:10.1016/j.chemosphere.2019.125677.

140. Li, J.X.; Li, X.Y.; Chang, Q.Y.; Li, Y.; Jin, L.H.; Pang, G.F.; Fan, C.L. Screening of 439 pesticide residues in fruits and vegetables by gas chromatography-quadrupoletime-of-flight mass spectrometry based on TOF accurate mass database and QTOF spectrum library. J. AOAC Int. 2018, 101, 1631-1638, doi:10.5740/jaoacint.170105. 
141. Gao, L.; Qin, D.; Huang, X.; Wu, S.; Chen, Z.; Tang, S.; Wang, P. Determination of pesticides and Pharmaceuticals from Fish Cultivation Water by parallel solid-phase extraction (SPE) and liquid chromatography-quadrupole time-of-flight mass spectrometry (LC-QTOF-MS). Anal. Lett. 2019, 52, 983-997, doi:10.1080/00032719.2018.1509076.

142. Mountacer, H.; Nemmaoui, S.M.; Rafqah, S.; Voyard, G.; Sarakha, M. TiO 2 Photocatalysis of the Organophosphorus Fenamiphos: Insight into the Degradation Mechanism . ISRN Environ. Chem. 2013, 2013, 1-8, doi:10.1155/2013/319178.

143. Molina, C.; Honing, M.; Barceló, D. Determination of Organophosphorus Pesticides in Water by Solid-Phase Extraction Followed by Liquid Chromatography/High-Flow Pneumatically Assisted Electrospray Mass Spectrometry. Anal. Chem. 1994, 66, 4444-4449, doi:10.1021/ac00096a009.

144. Cai, X.; Xiong, W.; Xia, T.; Chen, J. Probing the stereochemistry of successive sulfoxidation of the insecticide fenamiphos in soils. Environ. Sci. Technol. 2014, 48, 11277-11285, doi:10.1021/es502834v.

145. Mattern, G.C.; Parker, G.D.; Green, D.L.; Yeutter, G.L. Determination of Phenol Sulfone, Phenol Sulfoxide, and Phenol Sulfonic Acid Metabolites of Fenamiphos in Soil by Liquid Chromatography. J. AOAC Int. 1995, 78, 1286-1293, doi:10.1093/jaoac/78.5.1286. 


\section{Capítulo 5}

\section{Conclusiones finales/Final conclusions}



1. Conclusiones finales de la caracterización de las nanoestructuras de $\mathrm{WO}_{3}$.

- Tras estudiar los resultados obtenidos con las nanoestructuras sintetizadas con $\mathrm{H}_{2} \mathrm{SO}_{4}$, se puede concluir lo siguiente:

- Las nanoestructruas presentan una morfología en forma de nanofilamentos formando una especie de capa esponjosa. Estas nanoestructuras agregadas forman agrupaciones en forma de conos o "montañas". En aire y nitrógeno las agrupaciones en montañas están más definidas, que en el caso de las muestras calentadas en argón. Además, la morfología de estas nanoestructuras se definió mucho más a medida que aumentaba la temperatura de calentamiento. El aumento de la definición de estas nanoestructuras con la temperatura de calentamiento creciente puede estar relacionada con un mayor grado de deshidratación de las nanoestructuras.

- Los espectros Raman obtenidos de las muestras tratadas con aire y $\mathbf{N}_{2}$ presentan picos más definidos, lo que indica un mayor grado de deshidratación y cristalinidad de las nanoestructuras tratadas en esas condiciones. Además, a mayor temperatura de calentamiento, se observa una mayor intensidad y definición de los picos, dando lugar a nanoestructuras con una estructura cristalina monoclínica.

- En las imágenes obtenidas mediante AFM con $\mathrm{H}_{2} \mathrm{SO}_{4}$ se puede ver un gran crecimiento de los nanogranos (picos blanquecinos) de forma aglomerada dando como resultado una gran porosidad.

- Tras estudiar los resultados de XPS se concluyó que las muestras sintetizadas en $\mathrm{H}_{2} \mathrm{SO}_{4}$ presentan menor número de vacantes que las obtenidas con $\mathrm{CH}_{4} \mathrm{O}_{3} \mathrm{~S}$ y $\mathrm{HNO}_{3}$, además de no encontrarse presencia de nitrógeno en la estructura. 
- A partir de los ensayos fotoelectroquimicos se concluye que existe una mejora del rendimiento fotoelectrocatalítico con la temperatura de calentamiento debido a una mayor cristalinidad de las muestras. Además, la influencia de la atmósfera del proceso de post-anodizado también es importante ya que la morfología de nanohilo obtenida en las atmósferas de aire y nitrógeno está asociada con un mejor transporte electrónico a través de las nanoestructuras de $\mathrm{WO}_{3}$ que la obtenida con Ar.

- Finalmente, al analizar los resultados obtenidos en el análisis de Mott-Schottky se concluye que la muestra calentada a $600{ }^{\circ} \mathrm{C}$ y en una atmósfera de aire ha experimentado los valores más altos de densidad de defectos.

- Por tanto, se puede concluir que las condiciones óptimas del tratamiento térmico son $600{ }^{\circ} \mathrm{C} y$ en atmósfera de aire.

- En el caso de las nanoestructuras obtenidas con $\mathrm{CH}_{4} \mathrm{O}_{3} \mathrm{~S}$, las conclusiones obtenidas tras su caracterización fueron las siguientes:

- Al analizar las imágenes obtenidas del FE-SEM, se obtienen nanoestructuras con una morfología de nanohilos o nanohojas diminutos en la superficie de los electrodos, formando una especie de capa esponjosa en todos los casos. Sin embargo, en este caso son nanohilos más compactos y más uniformes en atmósfera de aire que en el caso de usar $\mathrm{H}_{2} \mathrm{SO}_{4}$ como electrolito.

- Con los espectros Raman estudiados se puede concluir que el grado de cristalinidad de las muestras sintetizadas aumenta con la temperatura siendo similar al obtenido en las nanoestructuras sintetizadas con $\mathrm{H}_{2} \mathrm{SO}_{4}$. 
- En las imágenes obtenidas mediante AFM, se pudo comprobar la porosidad de las nanoestructuras, resultando un comportamiento similar a las obtenidas con $\mathrm{H}_{2} \mathrm{SO}_{4}$.

- Mediante XPS se pudo comprobar que las nanoestructuras obtenidas con este electrolito eran las que mayor densidad de vacantes tenían ya que los picos de los espectros asociados a ellas eran los que mayor intensidad mostraban.

- En los análisis fotoelectroquímicos, las muestras que presentan una mayor respuesta de fotocorriente y mejores propiedades fotoelectroquímicas son las calentadas nuevamente en aire a $\mathbf{6 0 0}$ ${ }^{\circ} \mathrm{C}$, ya que el valor de resistencia a la transferencia de carga es menor incluso comparando con las nanoestructuras obtenidas anodizando en medio $\mathrm{H}_{2} \mathrm{SO}_{4}$.

- Con los resultados de Mott-Schottky se puede confirmar que las nanoestructuras calentadas a $600{ }^{\circ} \mathrm{C}$ en aire son las que presentan un mayor número de defectos, siendo éste aun mayor que el valor obtenido en el caso de $\mathrm{H}_{2} \mathrm{SO}_{4}$.

- Finalmente, tras analizar los resultados obtenidos con las nanoestructuras sintetizadas con $\mathrm{HNO}_{3}$, se puede concluir lo siguiente:

- Al analizar las imágenes obtenidas del FE-SEM, se observa una morfología semejante a las obtenidas con $\mathrm{H}_{2} \mathrm{SO}_{4}$ en donde las nanoestructuras están agrupadas en forma de montañas o conos, pero siendo mucho más desordenadas y apareciendo nanohilos en forma de pequeños aglomerados.

- Con los espectros Raman se puede concluir que el grado de cristalinidad de las muestras sintetizadas es menor que en los casos anteriores ya que se observan picos de menor intensidad. 
- En las imágenes obtenidas mediante AFM, se pudo comprobar la porosidad de las nanoestructuras, siendo mucho menor el valor que en el caso de las nanoestructuras obtenidas con $\mathrm{H}_{2} \mathrm{SO}_{4} \mathrm{Y}$ $\mathrm{CH}_{4} \mathrm{O}_{3} \mathrm{~S}$, debido a la morfología más compacta que presentan.

- En el análisis XPS se pudo comprobar que las nanoestructuras obtenidas con $\mathrm{HNO}_{3}$ eran las que presentaban una densidad de vacantes intermedia. Además, se pudo comprobar como gracias al nitrógeno presente en el electrolito se consiguió dopar las nanoestructuras, ya que el pico asociado a este elemento se encontró en los espectros obtenidos.

- Tras los estudios fotoelectroquímicos, las muestras sintetizadas con $\mathrm{HNO}_{3}$, presenta una menor respuesta de fotocorriente si se compara con las obtenidas en el resto de electrolitos. No obstante, las nanoestructuras que muestran mejores propiedades fotoelectrocatalíticas son las calentadas a $600{ }^{\circ} \mathrm{C}$ en atmosfera de aire aunque en este caso son muy similares a las obtenidas en atmósfera de nitrógeno.

- Con los ensayos de Mott-Schottky se puede confirmar que las nanoestructuras calentadas a $600{ }^{\circ} \mathrm{C}$ en aire son las que presentan un mayor número de defectos. Sin embargo, las sintetizadas en $\mathrm{HNO}_{3}$ son las que menos densidad de defectos presentan si se comparan con el resto de electrolitos.

Por tanto, de acuerdo con los resultados obtenidos en los tres electrolitos empleados y mediante el DISEÑO DE EXPERIMENTOS $3^{3}$, se ha determinado que las condiciones más adecuadas en la síntesis de nanoestructuras de $\mathrm{WO}_{3}$ son:

- Electrolito de $\mathrm{CH}_{4} \mathrm{O}_{3} \mathrm{~S}$ durante el proceso de anodizado.

- Atmósfera de aire y $600{ }^{\circ} \mathrm{C}$ en el proceso de tratamiento térmico del post-anodizado. 


\section{Conclusiones finales de la degradación fotoelectrocatalítica.}

Con el uso de las nanoestructuras optimizadas se realizó la degradación de los 4 pesticidas, obteniéndose las siguientes conclusiones:

- Degradación del diazinón.

- Tras 24 horas de ensayo, se consiguió degradar el diazinon un $90 \%$, es decir, se consiguió disminuir la concentración de 20 ppm a 2 ppm aproximadamente.

- Esta degradación se ajustó a una cinética de pseudo-primer orden y los intermedios identificados fueron los siguientes:

- IMP.

- 2-isopropanol-6-methylpyrimidin-4-ol.

- 2-hydroxy-N-((2E,3Z)-4-hydroxybut-3-en-

2ylidene)acetimidamida.

- 1-hydroxyisopropyl diazoxon.

- $\quad \mathrm{N}-((2 \mathrm{E}, 3 \mathrm{ZZ})-4-h y d r o x y b u t-3-e n-2-y l i d e n e)$ acetimidamida.

- Degradación del fosmet.

- En el caso del segundo pesticida degradado, fosmet, la degradación conseguida fue del $\mathbf{1 0 0 \%}$, es decir, se eliminó completamente el pesticida tras 24 horas de degradación.

- Esta degradación se ajustó nuevamente a una cinética de pseudoprimer orden y los intermedios identificados fueron los siguientes:

- Fosmet-oxon.

- N-Hidroxymetilphthalimida.

- N-Metilphthalimida.

- Cyclohexyl(methyl) amina.

- Ácido Phthalamico.

- Dimethyltryptamina 
- Degradación del clorfenvinfos.

- El clorfenvinfos fue el tercer pesticida elegido para degradar consiguiéndose una degradación del $\mathbf{9 5 \%}$, es decir, la concentración final de pesticida fue de $1 \mathrm{ppm}$ aproximadamente tras 24 horas de degradación.

- La cinética a la que se aproximó la degradación de este pesticida fue una cinética de pseudo-primer orden, siendo sus intermedios de degradación los que se muestran a continuación:

- Ácido 2,4- Dichlorobenzoic-metilester.

- Ácido 2,4- Dichlorobenzoico.

- 1-Cloro-propan-1,2,3-triol.

- Ácido 4- Hidroxybenzoico.

- Ácido Dicarboxilic.

- Trietil fosfato.

- Etildimetil fosfato.

- 4-butoxymetil-2-metoxy-fenol.

- 1-octen-1,2-diol.

- Degradación del fenamifos.

- Finalmente, el ultimo pesticidas degradado fue el fenamifos Al igual que el fosmet, se consiguió degradarlo al $100 \%$, pero en este caso la degradación completa se consiguió mucho antes, concretamente a la hora de ensayo.

- Esta degradación se ajustó a una cinética de pseudo-primer orden y los intermedios identificados fueron los siguientes:

- Fenamifos sulfoxido.

- Fenamifos sulfona.

- Fenamifos sulfoxido fenol.

- Fenamifos sulfona fenol. 
- Ethyl hydrogen isopropyl fosforamidato.

- 4-metil-5-(metilthio)benzeno-1,2-diol.

\section{Final conclusions of the characterization of $\mathrm{WO}_{3}$ nanostructures.}

- After studying the results obtained with nanostructures synthesized in $\mathrm{H}_{2} \mathrm{SO}_{4}$, it can be concluded the following:

- Nanostructures have a morphology in the form of nanofilaments forming a kind of spongy layer. These aggregated nanostructures form clusters in the form of cones or "mountains". In air and nitrogen atmospheres, mountain clusters are more well-defined than in the case of argon annealed samples. Furthermore, the morphology of these nanostructures became much more defined as the annealing temperature increased. Increasing the definition of these nanostructures with increasing annealing temperature may be related to a higher degree of dehydration of the nanostructures.

- The Raman spectra obtained for samples treated with air and $\mathbf{N}_{\mathbf{2}}$ show more defined peaks, which indicates a greater degree of dehydration and crystallinity of the nanostructures treated under these conditions. Furthermore, the higher the annealing temperature, the greater the intensity and definition of the peaks, giving rise to nanostructures with a monoclinic crystalline structure.

- In the images obtained by AFM in $\mathrm{H}_{2} \mathrm{SO}_{4}$, a large growth of nanograins (whitish peaks) can be seen in an agglomerated form, resulting in high porosity. 
- After studying the XPS results, it was concluded that samples synthesized in $\mathrm{H}_{2} \mathrm{SO}_{4}$ have fewer vacancies than those obtained in $\mathrm{CH}_{4} \mathrm{O}_{3} \mathrm{~S}$ and $\mathrm{HNO}_{3}$, in addition to not finding the presence of nitrogen in the structure.

- From the photoelectrochemical tests it is concluded that there is an improvement in the photoelectrocatalytic performance with increasing annealing temperatures due to a greater crystallinity of the samples. Furthermore, the influence of the atmosphere of the post-anodization process is also important since the nanowire morphology obtained in the air and nitrogen atmospheres is associated with a better electronic transport through the $\mathrm{WO}_{3}$ nanostructures than that obtained with $\mathrm{Ar}$.

- Finally, when analyzing the results obtained in the Mott-Schottky analysis, it is concluded that the sample annealed at $600^{\circ} \mathrm{C}$ and in an air atmosphere has experienced the highest values of defect density.

- Therefore, it can be concluded that the optimal conditions for heat treatment are $600{ }^{\circ} \mathrm{C}$ and in an air atmosphere.

- In case of the nanostructures obtained in $\mathrm{CH}_{4} \mathrm{O}_{3} \mathrm{~S}$, the conclusions obtained after their characterization were the following:

- When analyzing the images obtained from FE-SEM, nanostructures are obtained with a morphology of tiny nanowires or nanofilms on the surface of the electrodes, forming a kind of spongy layer in all cases. However, in this case nanowires are more compact and more uniform in an air atmosphere than in the case of using $\mathrm{H}_{2} \mathrm{SO}_{4}$ as electrolyte. 
- With the studied Raman spectra, it can be concluded that the degree of crystallinity of the synthesized samples increases with temperature, being similar to that obtained in the nanostructures synthesized in $\mathrm{H}_{2} \mathrm{SO}_{4}$.

- In the images obtained by AFM, it was possible to verify the porosity of the nanostructures, resulting in a similar behavior to those obtained in $\mathrm{H}_{2} \mathrm{SO}_{4}$.

- Trough XPS technique it was possible to verify that the nanostructures obtained with this electrolyte were those with the highest density of vacancies, since the peaks of the spectra associated with them were those that showed the highest intensity.

- In photoelectrochemical analyses, the samples that present a greater photocurrent response and better photoelectrochemical properties are again those heated in air at $600{ }^{\circ} \mathrm{C}$, since the value of charge transfer resistance is lower even when compared with the nanostructures obtained by anodization in $\mathrm{H}_{2} \mathrm{SO}_{4}$ medium.

- With the Mott-Schottky results, it can be confirmed that the nanostructures annealed at $600{ }^{\circ} \mathrm{C}$ in air are the ones that present a greater number of defects, the value being even higher than in the case of those obtained in $\mathrm{H}_{2} \mathrm{SO}_{4}$.

- Finally, after analyzing the results obtained with nanostructures synthesized in $\mathrm{HNO}_{3}$, it can be concluded the following:

- When analyzing the images obtained from FE-SEM, a morphology similar to those obtained in $\mathrm{H}_{2} \mathrm{SO}_{4}$ is observed where the nanostructures are grouped in the form of mountains or cones, but being much more disordered and nanowires appear in the form of small agglomerates. 
- With the Raman spectra, it can be concluded that the degree of crystallinity of the synthesized samples is lower than in the previous cases since peaks of less intensity are observed.

- In the images obtained by AFM, the porosity of the nanostructures could be verified, the value being much lower than in the case of the nanostructures obtained in $\mathrm{H}_{2} \mathrm{SO}_{4}$ and $\mathrm{CH}_{4} \mathrm{O}_{3} \mathrm{~S}$, due to the more compact morphology they present.

- In the XPS analysis it was possible to verify that the nanostructures obtained in $\mathrm{HNO}_{3}$ were those with an intermediate vacancy density. In addition, in the analysis it was possible to verify how thanks to the nitrogen present in the electrolyte, the nanostructures were doped, since the peak associated with this element was found in the obtained spectra.

- After the photoelectrochemical studies, the samples synthesized in $\mathrm{HNO}_{3}$ present a lower photocurrent response when compared to those obtained in the rest of the electrolytes. However, the nanostructures that show the best photoelectrocatalytic properties are those annealed at $600{ }^{\circ} \mathrm{C}$ in an air atmosphere, although in this case they are very similar to those obtained in nitrogen atmosphere.

- With the Mott-Schottky tests, it can be confirmed that the nanostructures annealed at $600{ }^{\circ} \mathrm{C}$ in air are those with the highest number of defects. However, those synthesized in $\mathrm{HNO}_{3}$ have the lowest density of defects when compared to the rest of electrolytes.

Therefore, according to the results obtained in the three electrolytes used and through the DESIGN OF EXPERIMENTS $3^{3}$, it has been determined that the most suitable conditions in the synthesis of $\mathrm{WO}_{3}$ nanostructures are: 
- $\mathrm{CH}_{4} \mathrm{O}_{3} \mathrm{~S}$ electrolyte during the anodization process.

- Air atmosphere and $600{ }^{\circ} \mathrm{C}$ in the post-anodization annealing treatment.

\section{Final conclusions of the photoelectrocatalytic degradation.}

With use of the optimized nanostructures, the degradation of the 4 pesticides was carried out, obtaining the following conclusions:

- Degradation of diazinon.

- After 24 hours of testing, it was possible to degrade the diazinon by $\mathbf{9 0 \%}$, that is, it was possible to reduce the concentration from $20 \mathrm{ppm}$ to approximately $2 \mathrm{ppm}$.

- This degradation was adjusted to pseudo-first order kinetics and the intermediates identified were the following:

- IMP.

- 2-isopropanol-6-methylpyrimidin-4-ol.

- 2-hydroxy-N - ((2E, 3Z) -4-hydroxybut-3-en-2ylidene) acetimidamide.

- 1-hydroxyisopropyl diazoxon.

- $\mathrm{N}-((2 \mathrm{E}, 3 \mathrm{Z})$-4-hydroxybut-3-en-2-ylidene) acetimidamide.

- Degradation of phosmet.

- In the case of the second pesticide, fosmet, the degradation achieved was $100 \%$, that is, the pesticide was completely eliminated after 24 hours of degradation.

- This degradation was again adjusted to pseudo-first order kinetics and the intermediates identified were the following:

- Phosmethoxon.

- N-Hydroxymethylphthalimide.

- N-Methylphthalimide. 
- Cyclohexyl (methyl) amine.

- Phthalamic acid.

- Dimethyltryptamine

- Degradation of chlorfenvinphos.

- Chlorfenvinphos was the third pesticide chosen to degrade, achieving a degradation of $\mathbf{9 5 \%}$, so, the final concentration of pesticide was approximately $1 \mathrm{ppm}$ after 24 hours of degradation.

- The degradation kinetics of this pesticide was a pseudo-first order kinetics, and its degradation intermediates identified are those shown below:

- 2,4-Dichlorobenzoic-methyl ester acid.

- 2,4-Dichlorobenzoic acid.

- 1-Chloro-propan-1,2,3-triol.

- 4-Hydroxybenzoic Acid.

- Dicarboxilic acid.

- Triethyl phosphate.

- Ethyl dimethyl phosphate.

- 4-butoxymethyl-2-methoxy-phenol.

- 1-octen-1,2-diol.

- Degradation of fenamiphos.

- Finally, the last pesticide degraded was fenamiphos. Like phosmet, it was degraded to $100 \%$, but in this case complete degradation was achieved much earlier, specifically at one hour of testing.

- This degradation was adjusted to pseudo-first order kinetics and the intermediates identified were the following:

- Fenamiphos sulfoxide. 
- Phenamiphos sulfone.

- Phenamiphos sulfoxide phenol.

- Phenamiphos sulfone phenol.

- Ethyl hydrogen isopropyl phosphoramidate.

- 4-methyl-5- (methylthio) benzene-1,2-diol. 


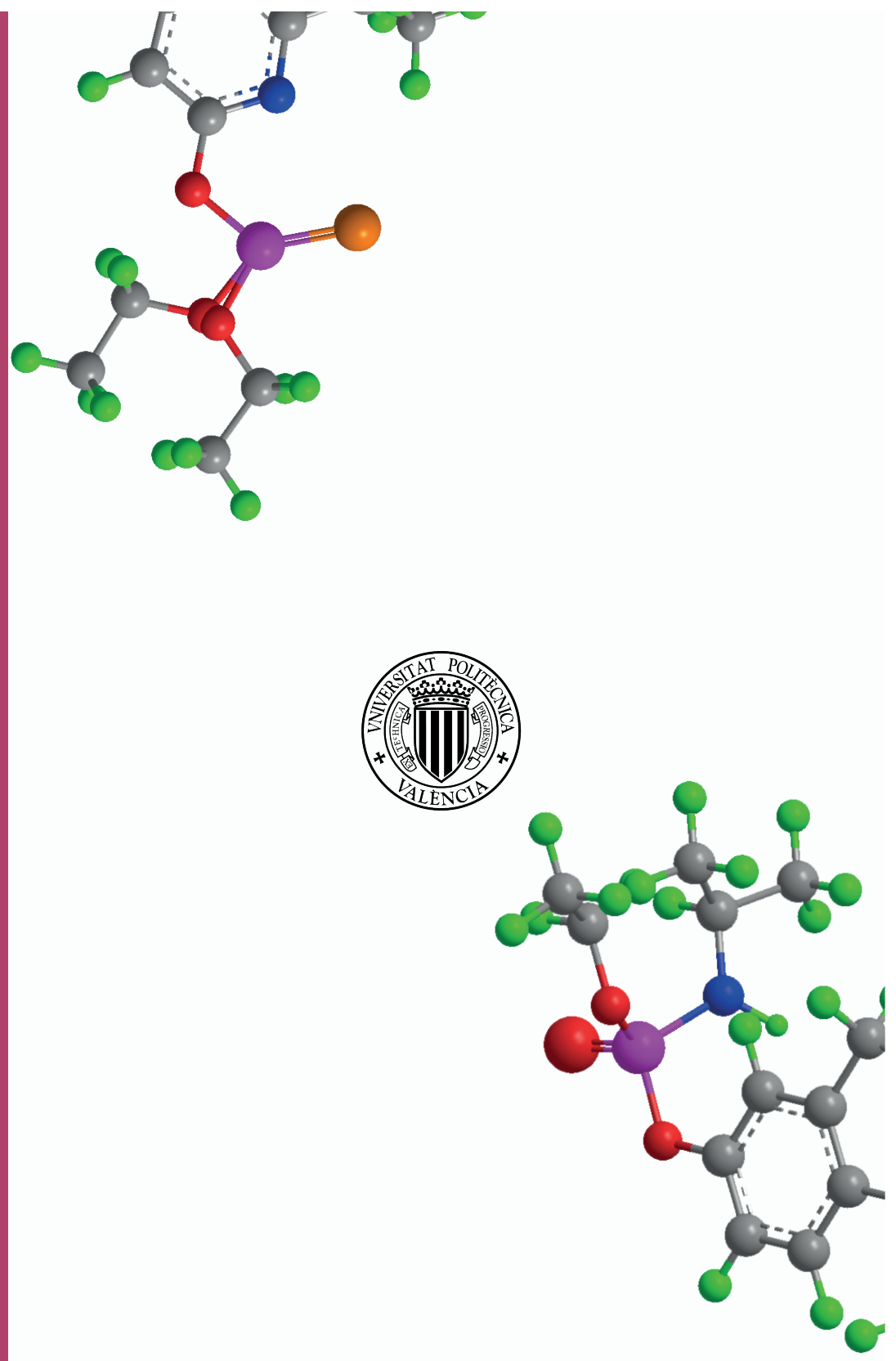